\title{
Padrões de Dificuldades Relacionadas com o Aprendizado de Programação
}

\author{
Yorah Bosse
}

\author{
TESE APRESENTADA AO \\ InstituTo DE MATEMÁTICA E EsTATÍSTICA \\ dA Universidade de SÃo Paulo \\ PARA OBTENÇÃO DO TÍTULO DE \\ DOUTORA EM CIÊNCIAS
}

Programa: Ciência da Computação

Orientador: Prof. Dr. Marco Aurélio Gerosa

Durante o desenvolvimento deste trabalho o autor recebeu auxílio financeiro do Programa de Doutorado Sanduíche no Exterior - CAPES - Processo PDSE - 88881.135066/2016-01.

São Paulo

15 de Junho de 2020 



\title{
Padrões de Dificuldades Relacionadas com o Aprendizado de Programação
}

\author{
Yorah Bosse
}

Esta versão da tese contém as correções e alterações sugeridas pela Comissão Julgadora durante a defesa da versão original do trabalho, realizada em 15 de Junho de 2020.

Uma cópia da versão original está disponível no Instituto de Matemática e Estatística da Universidade de São Paulo.

Comissão Julgadora:

- Prof. Dr. Marco Aurélio Gerosa (orientador) - IME-USP

- Profa. Dra. Ellen Francine Barbosa - ICMC-USP

- Prof. Dr. Fabio Kon - IME-USP

- Prof. Dr. Ricardo Edgard Caceffo - UNICAMP

- Prof. Dr. Roberto Almeida Bittencourt - UEFS 
Autorizo a reprodução e divulgação total ou parcial deste trabalho, por qualquer meio convencional ou eletrônico, para fins de estudo e pesquisa, desde que citada a fonte.

BOSSE, Y. Padrões de Dificuldades Relacionadas com o Aprendizado de Programação. 2020. 270f. Tese (Doutorado) - Instituto de Matemática e Estatística, Universidade de São Paulo, São Paulo, 2020. 
Aos meus pais,

Anita e Horst,

e aos meus filhos,

Paula e Thiago. 



\section{Agradecimentos}

Foram cinco anos de pesquisa, numa jornada levada com dedicação, passando por muitos desafios, aprendizado e amadurecimento. Quem possibilitou essa experiência foi meu orientador, Marco Aurélio Gerosa. Gostaria primeiramente de agradecê-lo por me receber na USP, permitindo que eu passasse por tudo isso. Um pesquisador respeitado com o qual tive a oportunidade de trabalhar e de receber orientações para desenvolver esta pesquisa. Muito obrigada!

Gostaria de agradecer também ao professor David F. Redmiles, por me receber na Universidade da Califórnia (UCI) e pacientemente me ensinar muito sobre pesquisa. Suas orientações, sugestões e revisões foram fundamentais para meu desenvolvimento. Agradeço muitíssimo ao professor Fabio Kon, por ter acompanhado meu trabalho desde o início do meu doutorado, suas sugestões ajudaram muito no andamento da tese. Igor S. Wiese e Marco Aurélio Graciotto Silva, agradeço pelo suporte dado na orientação durante os últimos meses do desenvolvimento da tese. Ao professor Leônidas de Oliveira Brandão que me deu a oportunidade de trabalhar com alunos com muita dificuldade e me forneceu dados importantíssimos para análise. Sem esses dados, não seria possível alcançar alguns dos resultados apresentados. Ao Nelson Posse Lago que sempre estava pronto para ajuda quando necessário, seja em revisões de texto ou para resolver problemas técnicos. A ajuda de vocês todos foi fundamental para alcançar meus objetivos.

Ao começar o doutorado, meu orientador falou que um dos resultados mais importantes de um doutorado são as amizades que fizemos durante esse período. Certíssimo ele. Hoje me sinto agraciada com pessoas maravilhosas na minha vida. Além dos já citados acima, que considero meus amigos, uma das primeiras foi a Renata Wassermann, excelente professora, pesquisadora, pessoa incrível e principalmente, uma excelente amiga. Jefferson O. Silva, quantas coisa fizemos juntos, quantas batalhas, quantas gargalhadas, choros, lamentações e comemorações, um verdadeiro amigo, suporte presente no meu dia a dia. Leonardo Souza Silva nos estudos dos artigos de inglês quando eu não entendia quase nada, além de todo estímulo para continuar na batalha. Ao Alfredo Goldman vel 
Lejbman, pelos valiosos conselhos e inúmeras conversas, sempre disposto a ajudar. Ao Cleidson de Souza por mostrar o caminho de como analisar os dados e conseguir chegar em alguns dos resultados alcançados. São tantas pessoas, cada um especial do seu jeito: Ana Paula O. dos Santos - amizade mais que especial; Renan Rodrigo Barbosa - com inúmeras ajudas e risadas gostosas para distrair; Débora Silva de Souza - minha profesora de inglês, amiga, conselheira e suporte na preparação e treinos para apresentações dos artigos no exterior; Bruno Chagas - um grande amigo e meu apoio em Irvine (CA-USA); Ivete Dalpiaz e Rita de Cassia dos Santos que me iluminavam e acalmavam com seus conselhos. Considero vocês todos amigos muito especiais para mim.

Aos colegas de jornada que fazem ou fizeram parte do grupo LAPESSC, do departamento de Ciência da Computação do IME e do campus de Ponta Porã da UFMS, entre eles: Igor Steinmacher, Mauricio Aniche, Gustavo Ansaldi, Kesia C. Ramires Neves, Marcia Queiroz, às secretárias da pós graduação de Ciência da Computação Lucileide R. G. Tadei e Katia Kiesshau, à secretária do departamento Ana Carla de Souza, e a tantos outros que direta ou indiretamente fizeram parte dessa jornada.

Agradeço também aos alunos e professores que carinhosamente atenderam aos pedidos e prontamente ajudaram com preenchimento de diários, entrevistas e respostas aos questionários de pesquisa, enfim, que nos forneceram dados para que essa pesquisa pudesse ser realizada. Sem vocês, nada disso seria possível.

Agradeço à UFMS pela afastamento concedido para que eu pudesse estudar e à CAPES, pelo auxílio financeiro do Programa de Doutorado Sanduíche no Exterior - CAPES Processo PDSE - 88881.135066/2016-01, que possibilitou a minha ida aos Estados Unidos, onde fiquei sob supervisão do prof. Dr. David Redmiles.

E, por último, porém os primeiros no meu coração, gostaria de agradecer aos meus filhos, meus tesouros, Paula e Thiago, que me apoiaram incondicionalmente, mesmo recebendo atenção reduzida durante boa parte desse período. Meus pais, Horst e Anita, que sempre me apoiaram e incentivaram, dando todo apoio e suporte necessário para que eu chegasse até aqui. Aos meus irmãos Duhnya e Douglas, e suas famílias, pelo apoio e incentivo para prosseguir nos estudos, ajudando sempre no que fosse necessário. Amo vocês demais!.

\section{Muito obrigada!}




\section{Resumo}

Yorah Bosse. Padrões de Dificuldades Relacionadas com o Aprendizado de Pro-

gramação. Tese (Doutorado). Instituto de Matemática e Estatística, Universidade de São

Paulo, São Paulo, 2020.

Aprender a programar é uma tarefa árdua. Muitos erros são cometidos durante o desenvolvimento de código e aprender com esses erros pode ajudar a evitá-los. Apesar da quantidade considerável de pesquisas sobre esse tema, os professores têm pouco suporte para entender as dificuldades dos alunos. Perante esse cenário, o principal objetivo desta tese é identificar padrões de dificuldades enfrentadas pelos alunos durante o aprendizado de programação. Para realização da pesquisa, trabalhamos com dados de estudantes e professores de disciplinas de introdução à programação de cursos de graduação da USP. A pesquisa foi elaborada em três fases: primeiramente, analisamos dados para avaliar as taxas de insucesso do ensino introdutório de programação na universidade; em seguida, verificamos com alunos, através de diários de estudos, e professores, através de entrevistas semiestruturadas, o que eles entendem como sendo os problemas no ensino e aprendizagem de programação; e, por último, buscamos nos códigos de exercícios desenvolvidos por alunos durante seus cursos evidências sobre as dificuldades encontradas. Com essa última fase, catalogamos os resultados e os validamos através de um questionário com professores brasileiros com experiência no ensino desse conteúdo. Os dados coletados foram examinados utilizando-se de análise quanti e qualitativa. A análise de 19.500 matrículas, nos possibilitou verificar que $\sim 30 \%$ dos alunos matriculados em disciplinas de introdução à programação, no período analisado, não foram aprovados, ou seja, 1.100 alunos por ano. Possibilitou ainda que fossem criadas listas das dificuldades citadas nos diários e entrevistas. Essas listas foram organizadas por conteúdo e por linguagem de programação (C e Python). Além disso, percebemos nesses dados ligações entre os conteúdos e, com isso, criamos um conjunto de conexões entre tópicos, mostrando a existência de pré-requisitos entre eles. Depois, analisando a evolução no desenvolvimento dos códigos dos estudantes, tivemos a oportunidade de identificar 139 tipos de equívocos cometidos utilizandose as linguagens $\mathrm{C}$ e Python. Os equívocos que eram recorrentes foram considerados antipadrões (soluções comuns, porém com consequências negativas) e agrupados em catálogos. No total, foram criados 3 catálogos: um com antipadrões encontrados nos códigos desenvolvidos em C (21 equívocos), outro em Python (11 equívocos) e o último com a intersecção dos dois, totalizando 9 antipadrões encontrados tanto em C como em Python. Os antipadrões e os catálogos foram avaliados através de uma pesquisa de questionário respondida por 43 professores. Em geral, os professores conheciam os antipadrões apresentados. Além do mais, eles consideraram os catálogos fáceis para usar ( 76\%) e úteis $(\sim 81 \%)$; 53\% mostraram ter intenção de usá-los regularmente nas suas aulas. Esperamos que os materiais gerados nesta tese possam ajudar professores no planejamento de suas aulas e pesquisadores a desenvolverem novas ferramentas e darem novos passos rumo ao aprimoramento do ensino e aprendizagem de programação.

Palavras-chave: CS1. Dificuldade. Antipadrões. Aprendizado de programação. C. Python. 



\begin{abstract}
Yorah Bosse. Patterns of Difficulties Related to Programming Learning. Thesis

(Doctorate). Institute of Mathematics and Statistics, University of São Paulo, São Paulo, 2020.
\end{abstract}

Learning to program is a complex and arduous task. Many mistakes are made during code development, and learning from those mistakes could be a way to avoid them. Despite the considerable amount of research on this topic, professors have support to understand students' difficulties. In this context, the main goal of this thesis is to identify patterns of difficulties faced by students while learning how to program. This research deals with data from students and instructors from introductory programming disciplines of undergraduate courses at USP. The research was developed in three phases: first, we analyzed data to assess the actual grades and failure rates of the university's introductory programming courses; then, we checked with students, through study diaries, and instructors, through semi-structured interviews, what they understand to be the problems in teaching and learning programming; and, lastly, we searched the exercise code developed by students during their courses for evidences of the difficulties encountered. Based on this last phase, we cataloged the results and validated them through a survey with Brazilian professors with experience in teaching this content. The collected data was examined using quantitative and qualitative analysis. The analysis of $\sim 19,500$ enrollments allowed us to verify that $\sim 30 \%$ of students enrolled in introductory programming courses, in the analyzed period, were not approved, i.e., $~ 1,100$ students per year. It also allowed the creation of lists of difficulties mentioned in the diaries and interviews. These lists were organized by content and programming language ( $\mathrm{C}$ and Python). We also observed in this data connections among topics, which enabled us to create a set of such connections, showing the existence of prerequisites between them. In addition, analyzing the evolution in the development of student code, we identified 139 types of mistakes made using $\mathrm{C}$ and Python. Recurring mistakes were considered antipatterns (common solutions, but with negative consequences) and grouped into catalogs. In total, 3 catalogs were created: one with antipatterns found in code developed in C (21 mistakes), another in Python (11) and the last with the intersection of the two, totaling 9 antipatterns found both in $\mathrm{C}$ and Python. The antipatterns and the catalogs were evaluated through a survey answered by 43 professors. In general, the respondents knew the antipatterns. In addition, they found the catalogs easy to use $(\sim 76 \%)$ and useful $(\sim 81 \%)$; 53\% have shown the intention to use them regularly in their classes. We hope that the results of this thesis help professors in planning their classes and researchers in developing new tools, taking new steps towards improving teaching and learning introductory programming courses.

Keywords: CS1. Misconceptions. Antipatterns. Programming learning. C. Python. 



\section{Lista de Figuras}

1.1 Metodologia de Pesquisa. . . . . . . . . . . . . . . . . . 4

3.1 (A) Percentual geral e (B) Dispersão temporal dos resultados obtidos nas disciplinas de introdução à programação na USP, no período de 2010-1 a

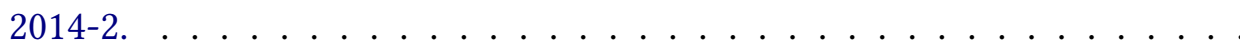

3.2 Percentual de vezes que alunos tiveram que cursar a disciplina de introdução à programação antes de obterem aprovação. . . . . . . . . . . . . . . .

3.3 Percentual de aprovações e reprovações/trancamentos nas disciplinas de introdução à programação na USP, de 2010 a 2014, por curso da área de computação. . . . . . . . . . . . . . . . . . . . .

3.4 Percentual de aprovações e reprovações por nota dos alunos que frequentaram uma das disciplinas do primeiro semestre da grade curricular dos cursos da área de computação dos campi de São Paulo (capital) - USP. . .

3.5 Percentual de Reprovações dos alunos que cursaram a disciplina pela primeira vez e geral, separados por cursos de Computação, dos demais cursos e visão completa da situação. . . . . . . . . . . . . . . . .

3.6 Percentual de vezes que os alunos de cursos de computação e demais áreas necessitam cursar a disciplina de introdução à programação para obterem aprovação na disciplina. . . . . . . . . . . . . . . . . . .

3.7 Médias das notas obtidas pelos alunos dos professores do IME-USP-SP, nas disciplinas de IP. . . . . . . . . . . . . . . . . . .

3.8 Percentuais de utilização das quatro linguagens citadas pelos professores do IME-USP-SP, nas disciplinas de introdução à programação entre 2010 e 2014.

4.1 Visão geral da metodologia usada. . . . . . . . . . . . . . . . . . . . 44

4.2 Diagrama apresentando uma lista de dificuldades por tópicos ensinados nas disciplinas de introdução à programação. . . . . . . . . . . . . . . . . 48

4.3 Visão geral das conexões encontradas entre os tópicos. . . . . . . . . . . 53 
4.4 O relacionamento entre o tópico Sintaxe da Linguagem de Programação (SLP) e os tópicos que precisam desse conhecimento. . . . . . . . . . .

4.5 Diagrama mostrando em quais tópicos as dificuldades aparecem devido à falta de conhecimento de Variável. . . . . . . . . . . . . . . . . . . . .

4.6 Diagrama mostrando em quais tópicos as dificuldades aparecem devido à falta de habilidade em Pensar em uma Solução. . . . . . . . . . . . . . . .

4.7 Diagrama mostrando as conexões existentes entre Pensamento Lógico e os demais tópicos. . . . . . . . . . . . . . . . . . . .

4.8 Diagrama mostrando em quais tópicos as dificuldades aparecem devido à falta de conhecimento de Vetor. . . . . . . . . . . . . . . . . . . .

4.9 Diagrama mostrando em quais tópicos as dificuldades aparecem devido à falta de conhecimento de Ponteiro. . . . . . . . . . . . . . . . . . . 57

4.10 Diagrama mostrando em quais tópicos as dificuldades aparecem devido à falta de conhecimento sobre Expressões. . . . . . . . . . . . . . .

4.11 Diagrama mostrando em quais tópicos as dificuldades aparecem devido à falta de conhecimento de Estruturas de Repetição. . . . . . . . . . . . . . 58

4.12 Diagrama mostrando em quais tópicos as dificuldades aparecem devido à falta de conhecimento sobre funcões de Entrada e Saída. . . . . . . . . . 58

4.13 A conexão existente entre o tópico Exercício e Pensando em uma Solução. 58

4.14 A conexão existente entre o tópico Funcionamento da Máquina e Pensando em uma Solução. . . . . . . . . . . . . . . . . . . . . . . 59

4.15 Conexões mostrando tópicos que influenciam o aprendizado de Funções. $\quad 60$

4.16 Dificuldades encontradas durante os estudos de programação. . . . . . . . 61

4.17 Dificuldades com C. . . . . . . . . . . . . . . . . . . . . 62

4.18 Dificuldades com Python. . . . . . . . . . . . . . . . 63

4.19 Dificuldades gerais. . . . . . . . . . . . . . . . . . . 63

5.1 Antipadrões em C, em Python e sua intersecção. . . . . . . . . . . . . . . 68

5.2 Visão Geral da metodologia de pesquisa usada nos E4 e E5. . . . . . . . . 68

5.3 Esboço detalhado da coleta de dados. . . . . . . . . . . . . . . . . . . 69

5.4 Esboço detalhado da análise dos dados. . . . . . . . . . . . . . . . . 70

5.5 Explicação da primeira parte da ficha dos antipadrões. . . . . . . . . . . . 71

5.6 Explicação da segunda parte da ficha dos antipadrões. . . . . . . . . . . . 71

5.7 Explicação da terceira parte da ficha dos antipadrões. . . . . . . . . . . . 72

5.8 Percentual por tópico dos equívocos encontrados em códigos desenvolvidos em C e Python. . . . . . . . . . . . . . . . . . . . . . . . . 73

5.9 Percentual de antipadrões em cada tipo de erro, por linguagem. . . . . . . 74 
5.10 Média de submissões necessárias para resolver cada tipo de erro, por linguagem, mostrando o intervalo de confiança $(95 \%)$. . . . . . . . . 74

5.11 Percentual de eventos não resolvidos pelo total geral de eventos, por tipo de erro na linguagem . . . . . . . . . . . . . . . 75

5.12 (A) Percentual de docentes por tempo de experiência e (B) Percentual de docentes por tempo de experiência em lecionar introdução à programação $(\mathrm{N}=43$ docentes). . . . . . . . . . . . . . . .

5.13 Percentual de respondentes que citou cada linguagem como sendo uma das utilizadas em suas aulas de introdução à programação $(\mathrm{N}=43$ respondentes). 84

5.14 Percentuais das respostas dadas à primeira pergunta feita sobre os antipadrões, investigando se o antipadrão já era conhecido pelo respondente $(\mathrm{N}$ $=43$ respondentes $) \ldots \ldots \ldots \ldots \ldots \ldots \ldots \ldots \ldots \ldots \ldots \ldots \ldots \ldots$

5.15 Resultados da avaliação dos catálogos quanto à utilidade, facilidade e intenção de uso. . . . . . . . . . . . . . . . . . . . . 89

A.1 Metodologia usada no acompanhamento de alunos com dificuldades. . . 104

A.2 Trechos de códigos com erros, desenvolvidos pelos alunos nas entrevistas. 106 



\section{Lista de Tabelas}

2.1 Modelo de apresentação de um padrão. Fonte: Adaptado de AlEXAnder et al. (1977) . . . . . . . . . . . . . . . . . . . . .

2.2 Síntese de alguns artigos que exploram as dificuldades em aprender a programar. ............................... 22

2.3 Síntese de alguns artigos que exploram as dificuldades em aprender a programar (continuação). . . . . . . . . . . . . . .

3.1 Subquestões de pesquisa do estudo de investigação das disciplinas da USP. $\quad 30$

3.2 Totais de disciplinas apresentadas por palavra de busca utilizada. . . . . . 31

3.3 Critérios de inclusão e exclusão das disciplinas apresentadas pelo Sistema Jupiter da USP. . . . . . . . . . . . . . . . . . . . . . . . . . 31

3.4 Disciplinas consideradas no Estudo 1 dessa tese. . . . . . . . . . . . . 33

3.5 Conteúdos ministrados na disciplina MAC2166 - Introdução à Programação. 33

3.6 Resultados por disciplina da Etapa 1. . . . . . . . . . . . . . . 34

3.7 Comparação entre disciplina de introdução à programação e cálculo, cursadas pela primeira vez e no mesmo ano e semestre, nos cursos da área de computação da USP. . . . . . . . . . . . . . . . . . . 36

3.8 Total de turmas, matrículas e média de alunos por turma, por ano, referente

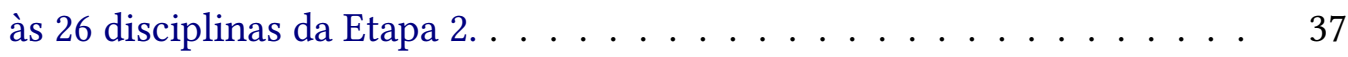

4.1 Tempo de Experiência e gênero dos 16 professores entrevistados. . . . . . 45

4.2 Faixa etária dos alunos e o número de vezes que frequentaram a disciplina. 46

4.3 Estratégias didáticas usadas para evitar ou minimizar as dificuldades enfrentadas pelos alunos ao estudarem programação. . . . . . . . . . . . 49

4.4 Dificuldades com o conteúdo, por linguagem, em ordem decrescente da mais para menos citada. . . . . . . . . . . . . . 62

4.5 Resultados finais das 12 turmas de introdução à programação participantes. 64

5.1 Enunciados reduzidos dos exercícios selecionados para análise. . . . . . . 71 
5.2 Resumo do Catálogo de Antipadrões em C . . . . . . . . . . . . . . . 76

5.3 Exemplos de códigos mostrando antipadrões que ocorreram somente ao ser usado o C . . . . . . . . . . . . . . . . . . . . . . 77

5.4 Resumo do Catálogo de Antipadrões em Python. . . . . . . . . . . . . . 78

5.5 Exemplos de códigos mostrando antipadrões que ocorreram somente com o uso da linguagem Python. . . . . . . . . . . . . . . . . . . . . 79

5.6 Resumo do Catálogo de Antipadrões em C e Python. . . . . . . . . . . . . 80

5.7 Exemplos de códigos mostrando antipadrões que ocorreram em ambas linguagens: $\mathrm{C}$ e Python. . . . . . . . . . . . . . . . . . . . . . . . . 81

5.8 Respostas dadas à primeira pergunta feita sobre os antipadrões, investigando se o antipadrão já era conhecido pelo respondente $(\mathrm{N}=43$ respondentes) . . . . . . . . . . . . . . . . . . . 85

5.9 Respostas dadas à segunda pergunta feita sobre os antipadrões, investigando sobre o que o respondente entendia ser o nível de dificuldade do aluno para resolver o antipadrão $(\mathrm{N}=43$ respondentes $) . \ldots . . . . . .886$

5.10 Média, mediana e moda da quantidade de submissões para resolver o antipadrão em comparação com a opinião dos professores em relação a dificuldade que o aluno tem nessa tarefa. . . . . . . . . . . . . . . . .

5.11 Respostas dadas à terceira pergunta feita sobre os antipadrões, investigando qual estratégia didática o respondente considera melhor para evitar o antipadrão com seus alunos. . . . . . . . . . . . . . . . 87

5.12 Comentários feitos sobre os antipadrões apresentados. . . . . . . . . 88

A.1 Erros de sintaxe encontrados nos códigos dos alunos do mini curso. . . . 107

A.2 Erros de semântica encontrados nos códigos dos alunos do mini curso. . 107 


\section{Sumário}

1 Introdução 1

1.1 Objetivo da Tese . . . . . . . . . . . . . . . . 2

1.2 Projeto e Métodos da Pesquisa . . . . . . . . . . . . . . . . . 3

1.2.1 Fase Preliminar: Motivação e Definição do Escopo . . . . . . . . 3

1.2.2 Fase 1: Identificação das Dificuldade com o Conteúdo . . . . . . . 5

1.2.3 Fase 2: Identificação de Antipadrões em Códigos de Aprendizes . 6

1.3 Escopo da Pesquisa . . . . . . . . . . . . . . . . . . . 6

1.4 Principais Contribuições . . . . . . . . . . . . . . . . 7

1.5 Outros Resultados . . . . . . . . . . . . . . . . . . . . 8

1.5.1 Artigos Publicados . . . . . . . . . . . . . . . 8

1.5.2 Orientação . . . . . . . . . . . . . . . . . . . 10

1.5.3 Financiamentos . . . . . . . . . . . . . . . . 10

1.5.4 Curso Ministrado . . . . . . . . . . . . . . . . . . 10

1.6 Organização da Tese . . . . . . . . . . . . . . . . . . . . . . . 11

2 Fundamentação Teórica e Trabalhos Relacionados 13

2.1 Fundamentação Teórica . . . . . . . . . . . . . . . . . . . . . . . . . . . 13

2.1.1 Aprender a Programar . . . . . . . . . . . . . . . . 13

2.1.2 Padrões e Antipadrões . . . . . . . . . . . . . . . . . . . . 15

2.2 Trabalhos Relacionados . . . . . . . . . . . . . . . . . . . 16

2.2.1 Dificuldades no Aprendizado de Como Programar . . . . . . . . . 18

2.2 .2 Dificuldades Gerais . . . . . . . . . . . . . . . . . . . . . 24

$2.2 .3 \quad$ Estratégias Didáticas . . . . . . . . . . . . . . . 25

2.3 Onde esta Tese se Encaixa _ . . . . . . . . . . . . . . . . . . 27

3 Situação das Disciplinas de Introdução à Programação: Um Estudo na USP 29

3.1 Contextualização . . . . . . . . . . . . . . . . . . . 29

3.2 Metodologia . . . . . . . . . . . . . . . . . 31

3.3 Disciplinas de Introdução à Programação . . . . . . . . . . . . . . . . . . 32 
3.4 Resultados da Etapa $1 \ldots \ldots$. . . . . . . . . . . . . . . . 34

3.5 Resultados da Etapa $2 \ldots \ldots$. . . . . . . . . . . . . . 37

3.6 Limitações e Ameaças à Validade . . . . . . . . . . . . . . . . . . . . . . . . . . . . . . . . . . . . . . . . . . .

3.7 Conhecimentos Adquiridos . . . . . . . . . . . . . . . . . 41

4 Dificuldades para Aprender a Programar no Ponto de Vista de Alunos e $\begin{array}{ll}\text { Professores } & 43\end{array}$

4.1 Metodologia Geral . . . . . . . . . . . . . . . . . . 44

4.1 .1 Coleta de Dados . . . . . . . . . . . . . . . 44

4.1 .2 Análise dos Dados . . . . . . . . . . . . . . 46

4.2 Dificuldades Quanto ao Conteúdo . . . . . . . . . . . . . . . . . . . . . . . . 47

$4.2 .1 \quad$ Estratégias Didáticas . . . . . . . . . . . . . . . . . . 49

4.2 .2 Validação . . . . . . . . . . . . . . . 52

4.3 Conexões entre Tópicos . . . . . . . . . . . . . . . . . 52

4.4 Dificuldades Por Linguagem . . . . . . . . . . . . . . . . . . 59

4.4.1 Dificuldades Gerais por Linguagem . . . . . . . . . . . . . 62

4.5 Turmas Envolvidas: Uma Análise Quanto ao Rendimento . . . . . . . . . 64

4.6 Limitações . . . . . . . . . . . . . . . . . . . . . . 65

4.7 Conhecimentos Adquiridos . . . . . . . . . . . . . . . 65

5 Antipadrões no Aprendizado de Programação $\quad 67$

5.1 Estudo 4 - Coleta e Análise de Códigos de Aprendizes para Identificação de Antipadrões . . . . . . . . . . . . . . . . . . . . . . . 67

5.1.1 Metodologia do Estudo $4 \ldots \ldots$. . . . . . . . . 68

Coleta de Dados . . . . . . . . . . . . . . . . 68

Análise dos Dados . . . . . . . . . . . . . . . 69

5.1.2 Resultados do Estudo 4: Antipadrões . . . . . . . . . . . . 72

Antipadrões em C . . . . . . . . . . . . . . . 75

Antipadrões em Python . . . . . . . . . . . 78

Antipadrões Ocorridos em C e em Python . . . . . . . . . . . 80

5.2 Estudo 5 - Estudo de Avaliação dos Antipadrões Identificados no E4 ‥ . 82

5.2.1 Metodologia do Estudo $5 \ldots \ldots \ldots 2$

5.2.2 Resultados do Estudo 5: Avaliação dos Catálogos de Antipadrões 83

Parte 1: Perfil dos Respondentes . . . . . . . . . . . . . . 83

Parte 2: Avaliação dos Antipadrões . . . . . . . . . . . . . 83

Parte 3: Avaliação dos Catálogos . . . . . . . . . . . . . . 89

5.3 Conhecimentos Adquiridos . . . . . . . . . . . . . . . . . . . 90 
6 Discussão $\quad 91$

6.1 Os Antipadrões e a Percepção Subjetiva das Dificuldades pelos Alunos 91

6.2 Os Antipadrões e a Percepção Subjetiva das Dificuldades pelos Professores 92

6.3 Impacto dos Antipadrões no Aprendizado de Programação . . . . . . . . 94

6.4 Utilidade dos Resultados . . . . . . . . . . . . . . . . . . . . . . . 95

6.4.1 Para Professores e Aprendizes de Programação . . . . . . . . . . 95

6.4.2 Para Pesquisadores . . . . . . . . . . . . . . . . . 96

7 Conclusões $\quad 99$

7.1 Sugestões de Trabalhos Futuros . . . . . . . . . . . . . . . . . . . . 101

\section{Apêndices}

A Acompanhamento de Alunos com Dificuldade 103

A.1 Metodologia . . . . . . . . . . . . . . . . . . . . 103

A.2 Resultados . . . . . . . . . . . . . . . . . . . 105

A.3 Conhecimentos Adquiridos . . . . . . . . . . . . . . . . . 107

$\begin{array}{lll}\text { B Lista de Equívocos } & 109\end{array}$

C Enunciados dos Exercícios Selecionados 113

$\begin{array}{ll}\text { D Sugestões de Soluções para Professores e Alunos } & 117\end{array}$

E Catálogo de Antipadrões em C 121

$\begin{array}{lll}\text { F Catálogo de Antipadrões em Python } & 167\end{array}$

G Catálogo de Antipadrões em C e Python 191

H Questionário de Validação dos Catálogos de Antipadrões 221

$\begin{array}{ll}\text { Referências } & 239\end{array}$ 



\section{Capítulo 1}

\section{Introdução}

Programação de computadores é uma disciplina tradicionalmente difícil para estudantes iniciantes (PEARs et al., 2007). As dificuldades contribuem para os altos índices de reprovações e desistências em disciplinas iniciais de programação apresentados na literatura (Bennedsen e Caspersen, 2019; Watson e Li, 2014). Segundo Beaubouef e Mason (2005), o índice de retenção nessas disciplinas é um problema bem conhecido, porém o resultado dos primeiros cursos de programação geralmente permanece decepcionante (RADENSKI, 2006; Webber e Possamai, 2009; Koscianski e Bini, 2009).

Um dos problemas encontrados é a quantidade de novos conceitos e práticas necessárias à proficiência em programação, dificultando o aprendizado dos recém-chegados à área (Cooper et al., 2003). Para a maioria dos alunos de disciplinas introdutórias de programação, os conceitos e habilidades requeridas para programar têm poucos paralelos com suas experiências prévias na educação básica. Como resultado frequente, observa-se um alto nível de evasão e o abandono precoce nesses cursos (Softex, 2009).

Fatores como capacidade e estilos cognitivos, motivação e atitude têm sido apontados como contribuintes para os altos índices de reprovação e evasão (RoBINs, 2010). A aprendizagem de programação requer conhecimentos, estratégias e modelos mentais específicos (RobIns et al., 2003) e exige capacidade de abstração, raciocínio lógico e o domínio de noções de sintaxe e semântica de linguagens. Demanda ainda a aquisição de conhecimentos, habilidades e competências próprias de algoritmos e linguagens de programação.

Além disso, são inúmeros os obstáculos enfrentados pelos alunos durante o aprendizado de programação. Dentre tantos problemas, alguns alunos não entendem os conceitos abordados na disciplina (Helminen e Malmi, 2010; Meerbaum-Salant et al., 2013; Piteira e C. Costa, 2013), outros dizem entender os conceitos, mas não sabem como utilizá-los na construção dos algoritmos (A. Gomes e A. Mendes, 2014; Menezes e Nobre, 2002). Pesquisas mostram também dificuldades no desenvolvimento de códigos (N. C. Brown e Altadmri, 2014; M. Gomes et al., 2015; Mhashi e Alakeel, 2013; Sevella et al., 2013; Piteira e C. Costa, 2013), porém são poucos estudos que fazem algum tipo de classificação dessas dificuldades (Hristova et al., 2003; Souza et al., 2018; CAceffo, Wolfman et al., 2016). Classificar ou organizar as dificuldades traz um ganho para as pesquisas da área, pois professores podem utilizá-las para mapear tópicos que necessitam ser mais trabalhados 
nas aulas, além de dar apoio para pesquisadores no desenvolvimento de novas ferramentas educacionais e metodologias de ensino.

Conhecer erros frequentemente cometidos em códigos, os antipadrões, também é importante para auxiliar alunos, professores e pesquisadores. Estudá-los é uma importante atividade de pesquisa (W. H. Brown et al., 1998). Não basta conhecer os padrões "bons" existentes nos sistemas bem sucedidos e sua inexistência em sistemas mal sucedidos. $\hat{E}$ importante mostrar a presença de antipadrões em sistemas mal sucedidos e sua ausência em sistemas bem sucedidos (W. H. Brown et al., 1998).

Assim, nesta tese, buscamos entender mais a fundo as dificuldades enfrentadas por estudantes durante o aprendizado de programação. Para isso, focamos em definir antipadrões cometidos por aprendizes em códigos desenvolvidos em C e Python, catalogando-os. Os motivos que nos levaram a escolher essas duas linguagens foram sua vasta utilização em cursos introdutórios de programação, estando entre as mais populares para este fim (SEvella et al., 2013; BeCKer, 2019). Algumas contribuições desta tese são: (1) antipadrões em C e Python (como surgiram, como foram resolvidos, tempo usado para resolvê-los, etc.); (2) sugestões de como os professores podem trabalhar os antipadrões em sala de aula com o intuito de evitá-los nos códigos de seus alunos; (3) sugestões para alunos de como estudá-los; e (4) lista de dificuldades por conteúdo enfrentadas pelos alunos para aprender a programar, classificadas das mais impactantes no aprendizado de programação para as menos, com o intuito de facilitar abordá-las durante as aulas.

Diferentemente dos trabalhos da literatura, esta tese analisou códigos obtidos em todas as tentativas de compilação e execução por parte dos aprendizes para cada exercício proposto, o que viabilizou o levantamento de dados experimentais quantificáveis e mais aprofundados que o possível através de outras técnicas. Eles permitem, por exemplo, a extração de estatísticas de frequência e tempo dispendido para solucionar cada equívoco. Os resultados foram utilizados para a criação de fichas de antipadrões, mais adequado à análise que as descrições textuais ou tabelas ad hoc comumente encontradas nos trabalhos sobre o tema. Tanto a técnica de coleta de dados quanto o formato de apresentação dos resultados podem ser utilizados de forma sistematizada em trabalhos futuros. O levantamento resultante ainda deu origem a uma discussão sobre as conexões entre os tópicos principais de aprendizado.

\subsection{Objetivo da Tese}

O objetivo desta tese é identificar padrões de dificuldades relacionadas ao aprendizado de programação. A principal questão de pesquisa investigada é:

\section{Quais são as dificuldades enfrentadas pelos estudantes durante o aprendizado de programação?}

Como guia, definimos cinco questões de pesquisa $(\mathrm{QP})$ específicas:

- QP1 - Qual é a taxa de insucesso (reprovação e desistência) típica nas disciplinas de introdução à programação? 
- QP2 - Quais são as dificuldades referentes ao aprendizado de programação na perspectiva de alunos e professores?

- QP3 - Como as dificuldades mudam conforme a linguagem de programação usada?

- QP4 - Quais antipadrões aparecem nos códigos desenvolvidos por aprendizes de programação?

- QP5 - Como professores/pesquisadores avaliam os resultados alcançados?

\subsection{Projeto e Métodos da Pesquisa}

Esta tese é o resultado da utilização de diversos métodos de pesquisa: entrevistas, diários, questionários (Surveys), análises quantitativas e qualitativas.

Organizamos a pesquisa em três fases: primeiramente, fizemos um levantamento inicial da situação do ensino de programação introdutória na Universidade de São Paulo (USP); em seguida, coletamos evidências com alunos e professores do que eles entendem como sendo os problemas no ensino e aprendizagem de programação; e, por último, buscamos nos códigos de exercícios desenvolvidos por alunos durante seus cursos o que acontece durante o aprendizado, catalogamos os resultados e os avaliamos com professores com experiência no ensino desse conteúdo.

A seguir, descrevemos cada uma dessas fases da metodologia de pesquisa apresentada na Figura 1.1.

\subsubsection{Fase Preliminar: Motivação e Definição do Escopo}

A Fase Preliminar serviu para respondermos à primeira questão de pesquisa (QP1) e é composta por dois estudos.

Estudo 1 (E1) - Muito se ouve dizer que alunos têm dificuldades de aprender a programar e que muitos deles não conseguem aprovação em disciplinas introdutórias de programação. Buscando evidências para tais afirmações realizando o E1. Esse estudo buscou responder a QP1 e, para isso, fizemos uma análise quantitativa de um banco de dados (BD) fornecido pela USP. Esse BD contém resultados alcançados pelos alunos nas diversas disciplinas de introdução à programação ministradas na universidade durante um período de 5 anos (2010 a 2014). Esse estudo foi realizado em duas etapas, sendo a primeira com análises voltadas para comparações entre os três cursos da área de computação - Sistemas de Informação, Ciência da Computação e Engenharia de Computação - e comparações entre disciplinas. A etapa 2 foi direcionada para análise e comparação entre alunos da área de computação e os demais. Os resultados da análise de 19.500 matrículas mostram uma taxa de insucesso de $\sim 30 \%$. Foi considerado insucesso toda matrícula que não gerou aprovação. Outra descoberta foi que a diferença percentual de insucesso dos alunos da área de computação, cursando pela primeira vez a disciplina, era 8,2\% menor que alunos de outras áreas. Vimos também que o uso das linguagens de programação C e Java no ensino introdutório de programação foi diminuindo ao longo dos anos e o de Python aumentando. Apenas 3\% das disciplinas utilizavam Python como linguagem em 2010 e, em 2014, esse 


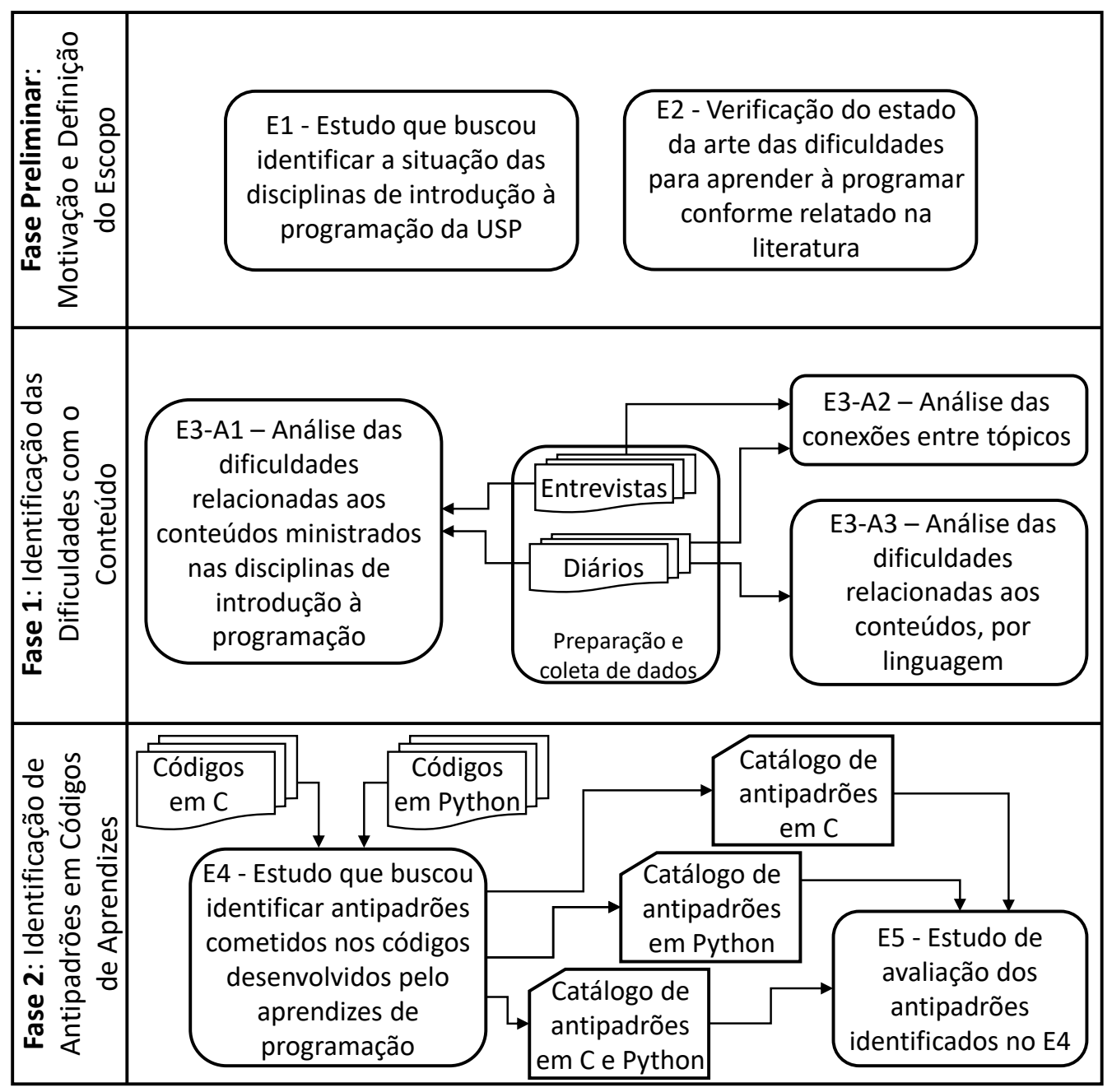

Figura 1.1: Metodologia de Pesquisa.

percentual aumentou para 40\%. No Capítulo 3 é apresentada uma descrição mais detalhada da metodologia utilizada e dos resultados alcançados.

Estudo 2 (E2) - O segundo estudo da Fase Preliminar foi um levantamento bibliográfico sobre as dificuldades enfrentadas pelos aprendizes de programação. Vimos que alguns estudos (GARner et al., 2005; BENnEdSEn e CASPERSEn, 2007) apresentam taxas de insucesso que corroboravam com os resultados alcançados no E1. Vimos também estudos que apresentam dificuldades relacionadas ao conteúdo (KRISTI, 2003; N. C. Brown e AltadmRI, 2014; Caceffo, Wolfman et al., 2016; A. Gomes e A. J. Mendes, 2007; Hristova et al., 2003; MHASHi e Alakeel, 2013), porém não detalhando os problemas encontrados em cada um deles. Hristova et al. (2003) classificaram os tipos de erros em três categorias: erros de sintaxe, de semântica e de lógica. Caceffo e colegas (CACEFfo, Wolfman et al., 2016) dividiram os equívocos pelos conceitos. Alguns estudos também trataram dificuldades não diretamente relacionadas ao conteúdo (Jenkins, 2002; A. Gomes e A. J. Mendes, 2007; A. Gomes e A. Mendes, 2014; Menezes e Nobre, 2002). Uma descrição mais detalhada do estado da arte está no Capítulo 2.

Após esses dois estudos, foi definido o escopo, o restante da pesquisa foi modelada e a 
Fase 1 foi iniciada.

\subsubsection{Fase 1: Identificação das Dificuldade com o Conteúdo}

A partir desta fase, começamos a interagir com alunos e professores para respondermos às QP2 e QP3. Essa fase é composta por um estudo no qual foram realizadas três análises com focos distintos.

Estudo 3 (E3) - O E3 trabalhou com dados gerados de duas fontes: diários e entrevistas. Os diários foram preenchidos por 110 alunos de cursos que não são da área de computação. O preenchimento se dava durante os estudos para as disciplinas de introdução à programação, relatando tudo o que ocorria, como dificuldades encontradas e soluções adotadas. O motivo da escolha pelos diários é que o método traz como benefício a possibilidade de examinar eventos e experiências na sua forma natural e expontânea (REIS, 1994). Bolger e colegas (Bolger et al., 2003) acrescentam que os diários encurtam o tempo entre o momento que a experiência ocorre e quando ela é relatada, diminuindo assim a perda de informações por esquecimento e aumentando a riqueza de detalhes (WHEELER e REIS, 1991). A outra fonte de dados é composta por entrevistas semiestruturadas realizadas com 16 professores do Instituto de Matemática e Estatística da USP (IME-USP) que já tinham lecionado a disciplina de Introdução à programação pelo menos uma vez. Nesse tipo de entrevista, as perguntas são abertas, não limitando o entrevistado nas respostas, dando assim a possibilidade de se obter riqueza de detalhes (Minayo, 2006; J. W. Creswell e J. D. Creswell, 2017). Para analisar os dados coletados, foram utilizadas técnicas da Teoria Fundamentada em Dados (Grounded Theory) para a análise qualitativa dos dados, conforme descrito por Strauss e Corbin (J. Corbin e STRauss, 2014). Mais detalhes da metodologia utilizada e dos resultados alcançados podem ser vistos no Capítulo 4. A seguir, uma breve descrição das análises realizadas neste estudo.

Antes de iniciar as análises do E3, um professor da USP, que estava lecionando a disciplina de introdução utilizando a linguagem $C$, ofereceu que fizessemos um acompanhamento de seus alunos que haviam sido reprovados e que precisariam realizar uma prova de recuperação (REC). Com esse estudo, foram verificadas algumas dificuldades com a sintaxe da linguagem usada, em entender o conteúdo e preferência por conteúdos específicos. Esse acompanhamento está descrito no Apêndice A.

Análise 3.1 (E3-A1) - Para esta análise foram utilizados dados dos diários e das entrevistas. O foco principal foi dado no que era relatado sobre cada conteúdo ministrado na disciplina de introdução à programação. Foram encontradas dificuldades em dez conteúdos, sendo que os três mais citados foram: Estruturas de Repetição (condição de parada e repetições encaixadas), Funções (passagem de parâmetro por referência e decomposição de problemas) e Matrizes (manipulação de índices). Além das dificuldades, catalogamos as dez estratégias didáticas mais citadas pelos professores. Professores as citavam e detalhavam como faziam para mitigar as dificuldades mencionadas. Os resultados desta análise podem ser vistos na Seção 4.2 .

Análise 3.2 (E3-A2) - Para se entender melhor a origem de algumas dificuldades, foram buscadas as conexões entre os tópicos necessários para aprender a programar, citadas nas entrevistas e diários. As conexões foram percebidas durante E3-A1, quando 
alunos e professores mencionavam problemas com determinados tópicos que não eram o foco naquele momento. As conexões mostram a influência que um aprendizado mal sucedido de um tópico pode ter no aprendizado de outro, conforme teoria do Momento de Aprendizagem (Learning Edge Momentum - LEM) de RoBins et al. (2003). Como exemplo dessas conexões, podemos dizer que foi visto que para aprender "Matrizes" é necessário saber "Estruturas de Repetição", que por sua vez requer conhecimentos sobre "Expressões" para montar as condições de parada, as quais precisam utilizar "Variáveis", e, para se utilizar tudo isso, é necessária a habilidade de "Pensar numa Solução", que por sua vez precisa de "Exercícios" bem formulados para se entender a tarefa solicitada. Várias outras conexões são apresentadas na Seção 4.3 .

Análise 3.3 (E3-A3) - Nessa análise buscamos identificar as dificuldades encontradas por linguagem de programação: $\mathrm{C}$ e Python. Para isso, foram utilizados os dados gerados pelos 110 diários. O motivo de excluirmos as entrevistas é a falta de comentários relacionados à linguagem Python feitos pelos professores. Os três conteúdos considerados mais difíceis pelos alunos que utilizavam $\mathrm{C}$ e Python foram os mesmos. Estruturas de Repetição ficaram em primeiro lugar em ambas linguagens, seguidos por Variáveis e Funções em Python e, em ordem inversa, em C (Seção 4.4).

\subsubsection{Fase 2: Identificação de Antipadrões em Códigos de Aprendizes}

Para a Fase 2, foram analisados códigos desenvolvidos por alunos cursando a disciplina de introdução à programação. Essa fase serviu para identificarmos, catalogarmos e validarmos os antipadrões encontrados nesses códigos, respondendo com isso às QP4 $\mathrm{e}$ QP5. A seguir, são apresentadas as descrições dos estudos dessa fase.

Estudo 4 (E4) - Os códigos foram coletados usando o plugin para o Moodle denominado Laboratório de Programação Virtual (VPL) (RodRíGuez-DEL-Pino et al., 2012). A cada compilação realizada pelos alunos uma cópia foi arquivada. Foi realizada análise qualitativa nos códigos em busca dos erros cometidos. Cada erro encontrado em três situações distintas foi considerado um antipadrão (W. H. Brown et al., 1998), ou seja, tratamos como antipadrões os erros encontrados em códigos de pelo menos três alunos distintos. Foram catalogados antipadrões cometidos em C, em Python e os que apareceram para ambas linguagens. Os resultados gerados pelas análises dos códigos são apresentados na Seção 5.1.2.

Estudo 5 (E5) - Os catálogos resultantes do E4 foram avaliados através de questionário (J. W. Creswell e J. D. CReswell, 2017) feito com professores que lecionam ou já lecionaram a disciplina de introdução à programação. Os resultados gerados pelas análises das respostas dadas nos questionários são apresentados na Seção 5.2.2.

\subsection{Escopo da Pesquisa}

Nesta seção, é apresentado o escopo da pesquisa e são definidos alguns termos usados na tese. Os estudos foram realizados utilizando-se disciplinas de introdução à programação ministradas em cursos de graduação. Essas disciplinas são normalmente oferecidas 
durante o primeiro ou segundo semestre dos cursos e, para muitos alunos, é o primeiro contato com programação. Na literatura, muitos autores se referem a essa disciplina como CS1 (Hertz, 2010), termo também usado em universidades americanas.

Um dos nossos interesses foi detectar dificuldades enfrentadas pelos alunos durante essa disciplina, ou seja, durante o aprendizado inicial de programação. Dificuldades ou problemas são considerados na nossa pesquisa como sendo todos os fatores que perturbam a aprendizagem. Segundo o Dicionário Houaiss, "dificuldade" é: (1) qualidade ou caráter do que é difícil; (2) aquilo que é difícil ou torna uma coisa difícil, custosa, penosa, árdua; (3) o que é difícil de entender e (4) o que impede, embaraça; estorvo, obstáculo. E a segunda palavra usada - 'problema' - é definida como sendo: (1) obstáculo, contratempo; (2) situação difícil, conflito.

Conteúdo é outro termo amplamente utilizado durante a pesquisa. Quando nos referimos a conteúdo, estamos falando da teoria apresentada para os alunos, como variáveis, estruturas de seleção e repetição, expressões aritméticas, relacionais e lógicas, entre outros. Quando necessário, os conteúdos considerados nos estudos são especificados na descrição da metodologia no início dos capítulos. Os conteúdos fazem parte dos tópicos.

Quando utilizamos o termo tópico, estamos nos referindo a algo mais amplo que o conteúdo ministrado. Tópicos englobam, além dos conteúdos mencionados acima, as linguagens de programação, o pensamento lógico, os enunciados dos exercícios, habilidade de pensar em uma solução, entre outros.

Ao gerarem os códigos, erros/equívocos são cometidos. Nesta tese, utilizamos a classificação de três tipos de erros/equívocos: de sintaxe, de semântica e de estilo. O Erro de Sintaxe é o que faz o código não executar, ou seja, o compilador ou interpretador da linguagem de programação detecta e avisa o desenvolvedor sobre a ocorrência desse erro. Erro de Semântica é aquele que faz com que o resultado apareça de forma errada/equivocada, ou seja, o código é executado mesmo com a presença do erro, porém o resultado gerado é diferente do esperado. E, por último, Erro de Estilo, não é detectado pelo compilador e não gera resultado errado, porém a sua prática pode levar o desenvolvedor a cometer outros erros. Um exemplo é a não indentação do código em C.

Erros, quando cometidos três ou mais vezes em situações distintas (W. H. Brown et al., 1998), são considerados antipadrões. Logo, quando usarmos o termo 'antipadrões', estamos nos referindo a algum erro cometido por pelo menos três alunos distintos. Segundo W. H. Brown et al. (1998), antipadrões são padrões "ruins", soluções comuns para problemas, porém que geram consequências negativas. Além disso, acrescentam que os antipadrões são normalmente gerados por desenvolvedores que não sabem fazer de uma forma melhor por falta de conhecimento ou experiência. A documentação dos antipadrões descreve a forma geral de cada um deles e como corrigí-los. (W. H. Brown et al., 1998).

\subsection{Principais Contribuições}

A partir dos resultados alcançados nos estudos experimentais, esta tese colabora com a literatura acrescentando as seguintes contribuições: 
- Catálogo de linguagem de padrão: foram gerados três catálogos, um com antipadrões encontrados nos códigos desenvolvidos em C, outro em Python outro com a interseção dos dois anteriores, ou seja, com os antipadrões vistos em códigos desenvolvidos em ambas linguagens. Além de informações necessárias para identificar de forma única cada antipadrão, apresentamos também estratégias para professores usarem nas suas aulas a fim de minimizar a ocorrência nos códigos de seus alunos e estratégias de estudo para alunos adotarem a fim de conhecerem e evitarem o antipadrão.

- Conjuntos de dificuldades por conteúdo ministrado na disciplina de introdução à programação: esses conjuntos são resultados das dificuldades reveladas por professores e estudantes, de forma geral e separadas por linguagem.

- Conexões entre os tópicos necessários para programar: são apresentadas as conexões entre os tópicos e suas influências na aprendizado de programação.

- Conjunto de estratégias de ensino: lista de estratégias usadas por professores em suas aulas e ligações delas com as dificuldades.

- Análise quantitativa sobre os resultados obtidos por alunos em disciplinas de Introdução à Programação: visão geral da situação em que se encontra o ensino de programação em uma grande universidade brasileira.

\subsection{Outros Resultados}

A seguir são apresentados resultados complementares gerados durante a realização desta pesquisa.

\subsubsection{Artigos Publicados}

Abaixo, listamos os artigos publicados durante este doutorado:

- Artigo 1. Bosse, Yorah; Gerosa, Marco A. Reprovações e Trancamentos nas Disciplinas de Introdução à Programação da Universidade de São Paulo: Um Estudo Preliminar. In: 23 WEI - Workshop sobre Educação em Computação. XXXV Congresso da Sociedade Brasileira de Computação (CSBC 2015), Recife, Pernambuco (Brasil), 2015 - 10pp.

- Artigo 2. Bosse, Yorah; Gerosa, Marco A. As Disciplinas de Introdução à Programação na USP: um Estudo Preliminar. In: I WAlgProg - Workshop de Ensino em Pensamento Computacional, Algoritmos e Programação. CBIE, Maceió, Alagoas (Brasil), 2015. 1389 - 9pp.

Os artigos 1 e 2 mostram os resultados da investigação realizada sobre os dados das disciplinas de introdução à programação ministradas na USP de 2010 a 2014 (Capítulo 3). No artigo 1, buscamos informações sobre reprovações e trancamentos de forma geral e por disciplina, quantidade de vezes que os estudantes precisaram cursar a disciplina até obterem aprovação, além da comparação entre os cursos da área de computação 
e das disciplinas de introdução à programação e cálculo. No artigo 2, o principal foco foi verificar as diferenças existentes entre alunos da área de computação e os demais, ao cursarem a disciplina de introdução à programação.

- Artigo 3. Brandão, Leônidas; Bosse, Yorah; Gerosa, Marco A. Visual Programming and Automatic Evaluation of Exercises: An Experience with a STEM Course. In: FIE - Frontiers in Education Conference, Erie, Pensilvânia (USA), 2016 - 9pp.

Nesse artigo é apresentado o resultado da experiência de se usar programação visual e avaliação automática de códigos desenvolvidos pelos alunos. Além disso, é mostrado o resultado da realização de um acompanhamento extra de alunos que não obtiveram aprovação (Apêndice A). Essa experiência foi realizada com alunos que não são da área de computação.

- Artigo 4. Bosse, Yorah; Gerosa, Marco A. Why is programming so difficult to learn?: Patterns of Difficulties Related to Programming Learning. In: 14th IDoESE - International Doctoral Symposium on Empirical Software Engineering and Measurement (ESEM 2016), ACM SIGSOFT Software Engineering Notes, Ciudad Real (Spain), 2016, 41 - 6pp.

Esse artigo apresenta o método proposto na tese e suas contribuições.

- Artigo 5. Bosse, Yorah; Gerosa, Marco A. Difficulties of Programming Learning from the Point of View of Students and Instructors. In: IEEE Latin America Transactions. Vol. 15, No. 11, Nov. 2017, 2191 - 9pp.

Esse artigo apresenta a análise dos dados colhidos através de diários preenchidos por alunos voluntários de seis turmas de introdução à programação e entrevistas com os professores que ministraram essas disciplinas (Capítulo 4).

- Artigo 6. Bosse, Yorah; Redmiles, David; Gerosa, Marco A. 2019. Pedagogical Content for Professors of Introductory Programming Courses. In Innovation and Technology in Computer Science Education (ITiCSE '19), July 15-17, 2019, Aberdeen, Scotland Uk. ACM, New York, NY, USA, 7 pp. doi.org/10.1145/3304221.3319776

Nesse artigo é apresentada uma parte dos resultados obtidos com a análise dos dados colhidos através de diários preenchidos por 110 alunos voluntários de 12 turmas de introdução à programação e entrevistas realizadas com 16 professores experientes em ministrar essa disciplina (Capítulo 4). O foco dado foi sobre o conhecimento pedagógico necessário para ensinar a programar. Segundo Council et al. (2000), o conhecimento pedagógico inclui três tipos de informações: (1) dificuldades enfrentadas pelos alunos; (2) caminhos típicos que os alunos precisam percorrer para entender o conteúdo; e (3) um conjunto de estratégias que os professores podem usar durantes suas aulas para evitar as dificuldades. Nesse artigo apresentamos o primeiro e o terceiro tipo de informação.

- Artigo 7. Bosse, Yorah; Redmiles, David; Gerosa, Marco A. 2019. Connections and Influences Among Topics of Learning How to Program. In: FIE - Frontiers in 
Education Conference, Cincinnati, Ohio (USA), 2019 - 8pp.

Esse artigo trata de conexões existentes entre os tópicos abordados nas disciplinas de introdução à programação e a influência que essas conexões têm no aprendizado (Capítulo 4). Dificuldades que estudantes têm em aprender determinados conteúdos podem estar ligadas a uma deficiência do não aprendizado de outro tópico.

\subsubsection{Orientação}

Trabalho de Conclusão de Curso (em andamento): Aluno: Abner de Amorim Bernal Moreno. Título: Ferramenta para visualização e análise de antipadroes. Trabalho de Conclusão de Curso iniciado no segundo semestre de 2019, com previsão de conclusão em 2020, na Universidade Federal de Mato Grosso do Sul, campus de Ponta Porã (UFMS-CPPP). Orientadores: Leonardo Souza Silva e Yorah Bosse.

Resumo: Além do compartilhamento de informações com professores e estudantes, o trabalho visa o desenvolvimento de uma ferramenta para visualização dos antipadrões encontrados, bem como a análise e a avaliação junto à comunidade científica.

\subsubsection{Financiamentos}

Foram dois os financiamentos relacionados a esta pesquisa aprovados durante o doutorado:

- Projeto de Pesquisa - Formação de Novos Programadores para a Internet do Futuro. FAPESP. N ${ }^{\circ}$ do processo: 2015/24331-1. Coordenador: Roberto Almeida Bittencourt.

- Doutorado Sanduíche - Programa de Doutorado Sanduíche no Exterior - CAPES - Processo PDSE - 88881.135066/2016-01. Local: Universidade da Califórnia - Irvine - USA. Supervisor: Prof. Dr. David F. Redmiles. Período: Agosto de 2017 a Julho de 2018.

\subsubsection{Curso Ministrado}

Introdução à Programação com Python: com o objetivo de ensinar programação de computadores utilizando a linguagem Python e com a justificativa do aumento da utilização da programação de computadores entre pessoas que não são da área de computação, foi oferecido um curso de verão de 30 horas, ministrado pela autora desta tese, nos laboratórios de computação do IME-USP. Período: de 16 a 27 de janeiro de 2017.

Foi usada a linguagem Python que, apesar de ser bastante poderosa e oferecer muitos recursos necessários em trabalhos complexos de programação, oferece também uma sintaxe simples para quem está aprendendo a programar. Foram usados recursos como prática intensiva de desenvolvimento de código nos computadores do laboratório usando o Moodle e o plugin de Laboratório Virtual de Programação (VPL), vídeos e exercícios do curso de Python desenvolvido pelo Prof. Dr. Fabio Kon e disponibilizado na plataforma Coursera, projeção de slides com os conteúdos e avaliação do aprendizado diário utilizando a ferramenta Kahoot! (Licorish et al., 2018; Dellos, 2015). 


\subsection{Organização da Tese}

O texto está dividido em sete capítulos. No Capítulo 2, apresentamos uma fundamentação teórica e uma visão geral do estado da arte sobre dificuldades em aprender a programar. No Capítulo 3, onde a QP1 da tese é respondida, apresentamos a metodologia usada e os resultados obtidos com a análise do banco de dados fornecido pela USP contendo dados referentes às 19.853 matrículas realizadas no período de 2010 a 2014 nas disciplinas de introdução à programação. No Capítulo 4, para responder as QP2 e QP3 da tese, apresentamos os resultados obtidos com a análise de diários preenchidos por alunos e entrevistas feitas com professores. As QP4 e QP5 são respondidas no Capítulo 5 , onde apresentamos os antipadrões encontrados em códigos desenvolvidos por alunos nas linguagens de programação $C$ e Python, além do retorno dado por professores através de um questionário de avaliação dos catálogos de antipadrões. No Capítulo 6 é feita uma discussão geral sobre os resultados dos estudos realizados. No Capítulo 7 concluímos esta tese e apresentamos sugestões de trabalhos futuros. 



\section{Capítulo 2}

\section{Fundamentação Teórica e Trabalhos Relacionados}

Este capítulo apresenta a fundamentação teórica e uma revisão da literatura sobre o ensino e aprendizagem de programação, em especial, dificuldades enfrentadas pelos alunos.

\subsection{Fundamentação Teórica}

Iremos tratar dois assuntos nesta seção. O primeiro é sobre as estruturas e conteúdos típicos de disciplinas de introdução à programação. Em seguida, iremos apresentar definições de padrões e antipadrões.

\subsubsection{Aprender a Programar}

Os alunos de programação, em todo o mundo, que estão escrevendo, executando e depurando códigos em cursos introdutórios passam por obstáculos frustantes (Drosos et al., 2017). Um desses obstáculos é a compreensão dos conceitos (KRISTI, 2003; GARNER et al., 2005; Milne e Rowe, 2002; Jenkins, 2002). Mesmo assim, muitas pessoas estão buscando aprender a programar por diferentes motivos (BERGSTRÖM e BLACKWELL, 2016) e para isso usam maneiras diversas, como com blocos de programação gráfica, texto ou ambos (WeIntrop, 2015; LEE, 2014; ICHINCo et al., 2014).

Preparar novas gerações de desenvolvedores profissionais e casuais é um grande desafio. Saber programar é uma habilidade que pode ajudar as pessoas a ganhar mais autonomia em sua vida cotidiana, por exemplo, modificando o comportamento de seus dispositivos para torná-los mais úteis para suas necessidades. Nesse contexto, é cada vez mais necessário estender a alfabetização em programação para além dos profissionais de informática (FISCHER e GIACCARDI, 2006). Muitos cursos de graduação de diversas áreas vêm introduzindo disciplinas introdutórias nas grades curriculares, conforme exposto na Seção 3.3 .

As abordagens usadas para ensinar a programar são as mais variadas e os paradigmas 
das linguagens de programação usadas para aprender essa prática também. BENNEDSEN e CASPERSEN (2007) e BeCKer (2019) verificaram que entre $43 \%$ e $49 \%$ dos cursos que participaram de suas pesquisas usavam linguagens orientadas a objetos, de $23 \%$ à $25 \%$ usavam imperativas/procedurais e entre $9 \%$ e $15 \%$ utilizavam funcionais, sendo esses três paradigmas os mais usados para ensinar programação. BENNEDSEN e CASPERSEN (2007) ainda acrescenta que $17 \%$ responderam "outros", informando que quase a totalidade destes usavam uma combinação de orientação a objetos com imperativas. Apesar dos públicos distintos das duas pesquisas, os resultados são bastante parecidos.

As linguagens de programação, independente do paradigma, são ferramentas usadas nas aulas para colocar em prática os conceitos estudados e ajudar a adquirir habilidades de programação, considerada essa uma tarefa difícil segundo BycKLING e SAJANIEMI (2006). Existem estudos que mostram formas de lecionar conceitos básicos da programação, como é o caso das variáveis, mostrando suas regras de uso em nível iniciante e formas de ensiná-las aos aprendizes (Byckling e Sajaniemi, 2006; Kuittinen e Sajaniemi, 2004).

Além das variáveis, vários outros conceitos são ensinados nas disciplinas introdutórias de programação HeRTz (2010), conforme pode ser verificado em livros que ensinam programação, como os de Harvey M. Deitel e Paul J Deitel (P. Deitel e H. Deitel, 2016; HARVEY et al., 2002; PAul e HARvey, 2012). Em resumo, utilizamos espaços na memória, denominados de variáveis, para armazenar valores necessários para um programa executar a tarefa que foi a ele destinada. Para colocar os valores nas variáveis, são usados conceitos como atribuição, onde o programador normalmente define o valor, ou através de função de entrada de dados, onde o usuário é solicitado a informar o valor que ele deseja que o programa processe. Quando se tem mais de um valor para armazenar em uma variável, são usadas variáveis estruturadas como as estruturas (structs), vetores e matrizes.

Mensagens e resultados gerados pelo programa são mostrados aos usuários do programa usando funções de saída de dados. Esses resultados muitas vezes são gerados por cálculos que usam operadores aritméticos nas suas fórmulas. São raras as vezes que os comandos são escritos de forma sequencial, de cima para baixo. Muitas vezes existe um desvio nesse fluxo, podendo ser condicional ou de repeticão. O desvio condicional executará uma vez um determinado conjunto de comandos, dependendo do resultado de uma condição. A estrutura de repetição executará um conjunto de comandos repetidamente conforme estipulado pela condição que a controla. Tanto a condição da estrutura de seleção quanto a da estrutura de repetição usam operadores relacionais e/ou lógicos.

A junção de todos comandos necessários para executar uma tarefa, pode fazer com que partes de códigos sejam repetidas ou que o programa ganhe proporções maiores. Com o objetivo de evitar a repetição de código e melhorar a organização, são criadas funções, que podem receber parâmetros (valores) para processar e podem retornar os resultados gerados para quem solicitou seus serviços. São muitos tipos de funções, cada uma com uma determinada finalidade, porém todas com o mesmo objetivo, conforme citado anteriormente. Algumas linguagens, como a linguagem $\mathrm{C}$, necessitam do uso de variáveis do tipo ponteiro para passar para as funções valores armazenados em variáveis como vetores, por exemplo. Os ponteiros têm outras finalidades além dessa, sendo a de passagem de parâmetro apenas um exemplo. Enfim, conhecer os conceitos e a forma de usá-los é importante para desenvolver programas destinados a resolver tarefas específicas. 


\subsubsection{Padrões e Antipadrões}

Cada padrão, segundo AlexAnder et al. (1977), "descreve um problema que ocorre repetidamente em nosso ambiente e, em seguida, descreve também o núcleo da solução para esse problema, de forma que você possa usar essa solução um milhão de vezes, sem que o problema ocorra novamente". Para Rising (1998), padrão é uma solução para um problema em um contexto. A Tabela 2.1 apresenta um modelo de como apresentar um padrão segundo AlEXANDER et al. (1977). A ideia para esse formato é dar clareza atendendo a dois propósitos: o de apresentar a conexão entre os padrões e o de apresentar o problema e a solução para que cada um possa julgá-lo por si só, sem perder a essência.

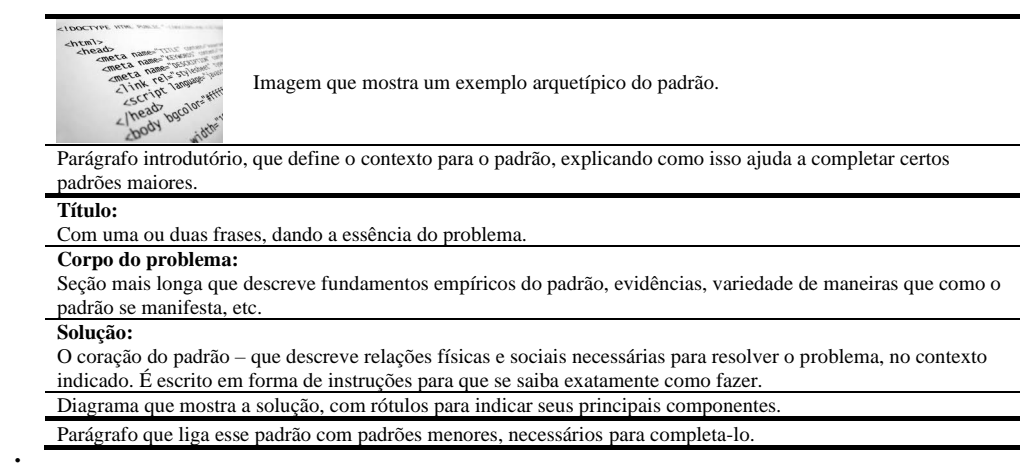

Tabela 2.1: Modelo de apresentação de um padrão. Fonte: Adaptado de ALEXANDER et al. (1977)

Um conjunto de padrões forma uma linguagem que pode ser usada na orientação da resolução de problemas (AleXANDer et al., 1977). Ambos, padrões e linguagem de padrões, ajudam os desenvolvedores, entre outras coisas, a evitar armadilhas que, tradicionalmente, teriam sido aprendidas apenas por uma experiência dispendiosa (MANOLESCU et al., 2006).

Antipadrão é outra definição importante para esta tese. Antipadrão é uma forma literária que descreve uma solução comum a um problema que gera consequências decididamente negativas (W. H. Brown et al., 1998). Para W. H. Brown et al. (1998), antipadrão é o resultado gerado por falta de conhecimento ou aplicação de um padrão bom em um contexto errado. Segundo W. H. Brown et al. (1998), o desenvolvimento de software pode ser entendido por três perspectivas:

1. Desenvolvedor: compreende problemas técnicos e soluções que são encontradas pelos programadores.

2. Arquiteto: identifica e resolve problemas na estrutura dos sistemas.

3. Gerente: aborda problemas comuns em processos de software e organizações de desenvolvimento.

Esta tese analisa os dados sob a perspectiva do "desenvolvedor".

Jim Coplien (apud W. H. Brown et al. (1998)) informa que o estudo de antipadrões é importante pois conhecer somente a presença de padrões "bons" em um sistema de sucesso não é o suficiente. É importante mostrar que existem certos padrões "ruins" (os antipadrões) em sistemas mal sucedidos e sua ausência em sistemas bem sucedidos. Muito 
importante ressaltar que, segundo W. H. BROWN et al. (1998), o equívoco só se torna padrão (antipadrão) se cometido pelo menos três vezes em situações distintas.

Alguns trabalhos na literatura apontam como objetivo a busca por antipadrões em diversos contextos e como exemplo citaremos os trabalhos de ABIDI et al. (2019) e BRADBURY e JALBERT (2009). ABIDi et al. (2019) buscaram e catalogaram seis antipadrões no uso de sistemas multilinguagem com o objetivo de ajudar a melhorar a qualidade deles. Esses antipadrões foram catalogados através da análise de sistemas de código aberto, documentação dos desenvolvedores, relatórios de bugs e especificações da linguagem de programação para extrair más práticas de uso dos sistemas multilíngues. Os antipadrões foram catalogados em forma de tópicos contendo: descrição do contexto, descrição do problema, má solução, consequências do antipadrão, antipadrões relacionados, exemplos, entre outras informações. BRADBURY e JALBERT (2009) buscaram antipadrões em programação concorrente com Java. Os 13 antipadrões foram identificados com base nos erros comuns que os programadores cometem ao desenvolver código concorrentes. Esses antipadrões foram catalogados um uma tabela contendo para cada um o nome do antipadrão, descrição do problema, do contexto e da solução.

Diferentemente do que é visto na catalogação de antipadrões apresentadas na literatura, as fichas de cada antipadrão nos três catálogos apresentados nesta tese (Apêndices E, F e G), são compostas por itens sugeridos na Tabela 2.1, com algumas informações a mais necessárias para identificar unicamente cada um deles e cada evento registrado, além de dados que podem gerar análises estatísticas e sugestões de uso para professores e alunos.

\subsection{Trabalhos Relacionados}

Aprender a programar é uma tarefa complexa (Mhashi e Alakeel, 2013) e árdua (KRISTI, 2003; BENNEDSEn e CASPERSEN, 2007; JENKIns, 2002; Robins et al., 2003) fazendo os estudantes enfrentarem dificuldades (MHASHI e AlAKEEL, 2013). Isso pode ser evidenciado pelos índices de reprovações e desistências (Kristi, 2003; BenNedsen e CASPERSEN, 2007; Bennedsen e CASPERSEn, 2019; GARner et al., 2005). GARner et al. (2005) divulgaram que o índice de reprovação em disciplinas de introdução à programação é de aproximadamente $30 \%$. Os resultados de BenNEDSEn e CASPERSEN (2007) não foram muito diferentes. Num questionário respondido por 67 instituições localizadas em 15 países, eles verificaram uma média de $33 \%$ de reprovações, desistências e trancamentos, quando turmas com mais alunos tinham maior peso e, $28 \%$ quando as turmas receberam todas o mesmo peso. Porém, eles não consideraram essas médias alarmantemente altas. Alguns anos depois, repetindo a pesquisa, BENNEDSEN e CASPERSEN (2019) verificaram que a média de reprovação que antes era de $33 \%$ (em 2007) passou para $28 \%$ (em 2018).

A falta de tempo é apontada como um dos fatores que podem ter influência nessas reprovações e desistências. Normalmente os cursos incluem a disciplina de introdução à programação em um dos seus primeiros semestres. Nesse período, os alunos estão passando por um momento de adaptação à vida na universidade (JENKINS, 2002) e ao ritmo de estudos. Ninguém aprende programação sem investir tempo de treinamento intensivo (A. Gomes e A. MENDES, 2014), pois o aprendizado é um processo lento e gradual de transformar o 
"novo em familiar" (Dijkstra et al., 1989). Giraffa e Mora (2013) obtiveram, de 83\% dos alunos que desistiram do curso, a afirmação que possuíam menos de 10 horas semanais para estudar e $74 \%$ deles declararam que esse foi um fator importante ou decisivo para o cancelamento da matrícula.

Segundo Mhashi e Alakeel (2013), alguns possíveis fatores relacionados com as dificuldades enfrentadas pelos alunos são: cursos mal projetados, falta de prática e de explicações/retornos sobre os exercícios, professores com habilidade insuficiente para organizar o material e falta de suporte da universidade. A falta de conhecimento de inglês também é citada como um dos fatores (Mhashi e Alakeel, 2013; M. Gomes et al., 2015). Para cursos noturnos, há também o fato de que muitos alunos trabalham durante dois turnos antes de irem estudar (GIrAFFA e MorA, 2013). Esses são apenas alguns fatores que levam alunos a não obterem sucesso, desistindo ou sendo reprovados, nas disciplinas de introdução à programação.

Alunos desistentes declaram ainda que melhores materiais e professores mais preparados ajudariam a fazê-los permanecer no curso (GIrAfFA e MorA, 2013). Conhecer esse cenário, com uma análise válida e confiável dos problemas enfrentados pelos alunos de programação, daria subsídios para aplicações potenciais (GARNER et al., 2005). Se entendermos o processo de aprendizado da primeira linguagem de programação, poderíamos criar ambientes de aprendizagem mais efetivos, ajustar melhor a quantidade e tipo de atenção dedicada aos vários tópicos nas aulas e laboratórios, além de podermos criar novos materiais didáticos (GARNER et al., 2005), diminuindo assim as dificuldades.

Para A. Gomes e A. Mendes (2014), é possível dividir as causas das dificuldades de muitos alunos em três categorias: estratégias de ensino, atitudes dos alunos/métodos de estudo e as dificuldades naturais da programação. QIAN e LEHMAN (2017) juntou através de uma revisão sistemática que os principais fatores que contribuem para as dificuldades dos alunos são: (1) complexidade da tarefa e carga cognitiva, (2) linguagem natural que pode interferir no entendimento dos comandos das linguagens de programação; (3) conhecimento prévio que o aluno tem sobre matemática; (4) modelos mentais imprecisos sobre a execução de código; (5) padrões e estratégias de programação inadequados; (6) recursos de linguagem e ambiente de programação e (7) instrução e conhecimento dos professores.

Utilizando-se de diversas metodologias, como questionários (MHASHI e AlakeEL, 2013; M. Gomes et al., 2015; Lahtinen et al., 2005; Milne e Rowe, 2002; Piteira e C. Costa, 2013), entrevistas (A. Gomes e A. Mendes, 2014), comentários descritivos (Jenkins, 2002; Giraffa e Mora, 2013), estudo de casos (Mhashi e Alakeel, 2013; Giraffa e Mora, 2013), observação (GARNER et al., 2005), exploratória quanto aos seus objetivos (M. GoMEs et al., 2015), entre outras, diversas pesquisas foram realizadas com o intuito de melhorar o processo de aprendizagem de programação. A seguir, são apresentados os resultados de algumas pesquisas e relatos feitos sobre dificuldades e outros tópicos relevantes para esta tese. 


\subsubsection{Dificuldades no Aprendizado de Como Programar}

Saber quais são as dificuldades enfrentadas pelos aprendizes de programação é de grande valia para orientar departamentos a organizarem melhor suas grades curriculares e professores a elaborarem suas aulas e materiais didáticos. Porém, os professores sentem dificuldades em detectar o que se passa com o aluno (SEvella et al., 2013) e, na literatura, não há dados suficientes para avaliar o conhecimento dos professores sobre os equívocos particulares dos alunos e seu impacto sobre a aprendizagem (SADLER et al., 2013).

Uma das conclusões da pesquisa realizada por N. C. BRown e Altadmri (2014) foi que o nível de experiência dos professores, medido em anos, não teve efeito sobre a frequência que os aprendizes cometiam os erros. Em sua pesquisa, usaram questionários com professores e códigos de alunos, desenvolvidos na linguagem de programação Java, comparando os resultados obtidos com cada técnica. Quanto à linguagem de programação, vale a pena ressaltar que as projetadas para uso profissional dificilmente são adequadas para iniciantes (A. Gomes e A. J. Mendes, 2007; Jenkins, 2002), já que possuem sintaxe muito complexa (A. Gomes e A. J. Mendes, 2007), como é o caso de Java, por exemplo. E, segundo TAN et al. (2009), aprender a sintaxe da linguagem de programação é um dos problemas enfrentados pelos alunos. GARNER et al. (2005) ficaram surpresos com a persistência, a frequência e a distribuição uniforme dos problemas relacionados aos detalhes sintáticos básicos.

Existem linguagens destinadas ao ensino, como o Pascal e LOGO, por exemplo, mas para Jenkins (2002), qualquer departamento que fosse usá-las seria objeto de ridículo. A maioria das universidades é obrigada a lecionar com uma linguagem que seja, no mínimo, próxima do que se está usando na indústria e raramente se escolhe a linguagem por razões pedagógicas (KRISTI, 2003). Apesar de os professores não considerarem a linguagem um dos aspectos mais importantes, a sintaxe para resolver pequenos problemas é considerada uma grande barreira. Com poucos detalhes sintáticos, Python, orientada a objeto, foi considerada uma linguagem simples (A. Gomes e A. Mendes, 2014; Becker, 2019) e que dentre as imperativas, C é a mais popular e a mais usada (SEvella et al., 2013).

Tanto com o objetivo de estudar as linguagens de programação utilizadas para ensinar a programar quanto com o objetivo direto ou indireto de melhorar o ensino e aprendizagem, várias pesquisas vêm sendo desenvolvidas (N. C. Brown e Altadmri, 2014; Kristi, 2003; Caceffo, Wolfman et al., 2016; A. Gomes e A. J. Mendes, 2007; Hristova et al., 2003; Mhashi e Alakeel, 2013; Becker e Quille, 2019). Em uma dessas pesquisas, Hristova et al. (2003) detectaram e categorizaram os erros pelo seu tipo. Os 20 erros detectados foram divididos em três categorias denominadas: erros de sintaxe, erros de semântica e erros de lógica. Os de sintaxe abordam erros que deixam o código incompreensível para o compilador, como erro de escrita de comando, pontuações, etc. Nessa categoria foram catalogados 13 erros, como: = versus ==; \& versus \&\& e | versus $\|$; e separadores errados na estrutura de repetição 'for'. A segunda categoria, de semântica, lida com o significado do código, com a ideia equivocada de como a linguagem interpreta certas instruções. Nela foi detectado apenas um erro relacionado com o conceito de classes. Os outros 6 erros ficaram na categoria de erros de lógica, que surgem de uma estratégia incorreta para a solução do problema. Essa última classificação não existe na classificação feita para os antipadrões gerados nesta tese (Seção 1.3). Segundo explicação dos autores, essa categoria inclui erros que tendem a surgir mais do pensamento equivocado do programador do que 
das peculiaridades da linguagem, embora alguns possam se manifestar por meio de sintaxe ou semântica imprópria. Nesta tese, os erros que seriam dessa categoria foram classificados como sendo de sintaxe, se foram detectados pelo compilador, ou de semântica, se geraram resultados errados.

Uma divisão baseada nos conceitos e não nos tipos de equívoco foi feita na pesquisa de Caceffo, Wolfman et al. (2016). Por meio de análise de códigos desenvolvidos em dois testes de uma disciplina de introdução à programação, ministrada em C, eles identificaram sete categorias de equívocos nos códigos desenvolvidos pelos alunos. Essas categorias agrupam tipos de equívocos semelhantes. Eles afirmam que, assim, há melhores oportunidades para a visualização de vínculos entre os equívocos. Nesse mesmo estudo, realizaram também entrevistas semiestruturadas com 5 professores. Nas entrevistas, notaram preocupações sobre a distinção entre equívocos cometidos pelo aprendizado errado dos conceitos e erros sintáticos da linguagem, o que os levaram a definir uma oitava categoria. As sete primeiras foram divididas pelos tipos de erros cometidos, sendo: 1 . Uso e escopo de parâmetro de função; 2. Variáveis, identificadores e escopo; 3. Recursão; 4. Iteração; 5. Estruturas; 6. Ponteiros (também chamados de apontadores) e 7. Expressões booleanas. Essa validação objetivava verificar se todos os erros foram identificados na análise e se os equívocos existentes nas listas são realmente equívocos. O grupo realizou também um estudo piloto. Esse estudo validou os equívocos encontrados e deu a oportunidade de encontrar alguns a mais, totalizando assim 33. Considerando que os códigos analisados são a versão final apresentada pelos alunos nos testes, os equívocos encontrados são os que os alunos não sabiam solucionar ou desconheciam sua existência. Outra forma de coleta de dados é necessária para se detectar os equívocos que os alunos cometem mas que de alguma forma conseguem resolver. Por esse motivo, buscamos nesta tese ter todas as versões elaboradas e compiladas pelo aluno, desde a primeira até a última, para que pudéssemos detectar equívocos existentes em todas elas.

Com o intuito de descrever com mais detalhes os equívocos encontrados e divulgados no artigo já citado, CACEFFO, FrAnÇA et al. (2017) publicaram um relatório técnico. Nesse relatório, cada equívoco foi colocado em uma ficha contendo as seguintes informações: código, nome, descrição, exemplo, fundamentação, consequências, detecção (onde e como o erro aparece) e melhoria (como prevenir). Integrantes desse grupo de pesquisa participaram também de uma pesquisa de Iniciação Científica (G. A. R. GAmA et al., 2018) na qual foram encontrados 28 equívocos hipotéticos em Python e da pesquisa de Souza et al. (2018), Caceffo, Frank-Bolton et al. (2019a) e Caceffo, Frank-Bolton et al. (2019b) com o mapeamento e documentação de possíveis equívocos que podem ser encontrados nos cursos CS1 com base na linguagem de programação JAVA.

Para M. Gomes et al. (2015), a grande maioria dos erros encontrados em C são erros de sintaxe, sendo de $49 \%$ a falta de tokens, como chaves e parênteses, e $8 \%$ quanto às terminações por aspas. Para a pesquisa usaram dois tipos de coleta de dados, o de coleta de códigos e o de aplicação de um questionários aos alunos. Com a análise dos dados coletados, o grupo identificou problemas como a falta de tokens (parênteses e chaves, por exemplo), sendo esse o erro mais comum encontrado nas compilações, com $49 \%$ dos casos e, em segundo lugar, a falta de declaração de variáveis, com $20 \%$. Além dos erros, foram analisados os 'warnings', que não são propriamente erros, mas mensagens de aviso emitidas pelo compilador. Essas mensagens podem ser alguma advertência de 
que algo poderá ser executado de forma incorreta. O warning mais comum, com $32 \%$, foi relacionado à leitura de strings e o segundo, com $28 \%$, foi a leitura de teclado (fgetc e fgets). Com 15\%, o terceiro warning mais encontrado foi o retorno de valor em funções do tipo 'void'. No questionário realizado com os alunos, a maior dificuldade citada foi encontrar erros nos códigos, sendo essa considerada uma importante habilidade segundo A. Gomes e A. J. Mendes (2007). Porém, estudos confirmam que achar erro (D'Souza et al., 2019), especialmente no seu próprio código (TAN et al., 2009), é uma dificuldade que os alunos enfrentam. Diferentemente dessa pesquisa, buscamos nesta tese deixar o aluno mais à vontade para mostrar as dificuldades sentidas durante o estudo/aprendizado de programação e para isso usamos os diários (Seção 4.1.1). Além disso, essa técnica faz o aluno comentar sobre as dificuldades no momento que elas ocorrem, buscando diminuir assim a perda de informações. E por fim, a pesquisa de M. Gomes et al. (2015) que foi realizada no Brasil, teve como uma de suas conclusões, a de que mesmo os erros sendo simples, existe dificuldade no entendimento da mensagem e, consequentemente, a resolução do problema. Isso se deve ao fato do idioma usado pelos compiladores ser normalmente o inglês.

Muitos programadores novatos acham difícil entender ponteiros e tipos de dados abstratos na linguagem C (Mhashi e Alakeel, 2013; Piteira e C. Costa, 2013). Segundo Mhashi e Alakeel (2013), os conceitos mais difíceis de programação são estruturas de repetição, recursão, listas, ponteiros, passagem de parâmetros, tipos abstratos de dados e o uso de bibliotecas. Passagem e retorno de parâmetro foi identificado por IzU e DiNH (2018) como o conteúdo com mais erros. Algumas dessas dificuldades também apareceram na pesquisa de Sevella et al. (2013). Sevella et al. (2013) identificaram confusão entre a sintaxe do 'for' e do 'while' na linguagem C; no uso de funções de entrada e saída de dados ('scanf' e 'printf', respectivamente); além de dificuldade com o uso de funções, fazendo os alunos desenvolvem programas sem que elas sejam usadas. A função de entrada de dados ('scanf') e demais funções, como as do tipo void, também estão entre as maiores incidências de erros para M. Gomes et al. (2015), além de leitura de strings. Ambas pesquisas, de Sevella et al. (2013) e de M. Gomes et al. (2015), realizaram coleta de códigos. Sevella et al. (2013) coletou os códigos com a captura de telas, porém não ficou claro no texto do artigo em quais momentos as telas eram capturadas. M. Gomes et al. (2015) coletou através da gravação de um arquivo de saída gerado a cada compilação e que continha os erros e warnings apresentados na compilação. Diferentemente dessas pesquisas, os códigos analisados nesta tese tiveram versões dos códigos a cada compilação, dando a possibilidade de recompilar durante a análise, caso necessário, além de registro do horário da submissão, resultados dos testes de execução, nota obtida, etc. Ainda na pesquisa de SEvella et al. (2013), os aprendizes mostraram também problemas com variáveis e com estruturas de seleção. Quanto às variáveis, eles esquecem de declará-las ou atribuem tipos errados a elas. Em relação às estruturas de seleção, o problema está no uso do 'switch', por exemplo, os aprendizes mostram dificuldade em criar a condição lógica, além de não entenderem seleções aninhadas. Não foi detectado, nessa pesquisa, dificuldade com entendimento de listas.

Porém, para os professores que participaram do questionário realizado por PiteirA e C. Costa (2013), listas estão entre os conteúdos considerados mais difíceis, além de ponteiros (considerado o mais difícil também pelos alunos), tipos de dados estruturados, manipulação de erros e parâmetros. Para os alunos, além dos citados acima, foi considerado 
difícil também o uso de bibliotecas da linguagem e tipos abstratos de dados. As opiniões divergem entre alunos e professores quanto às dificuldades em alguns conteúdos, como é o caso do uso de biblioteca que, ao contrário da opinião dos professores, foi considerado um dos mais difíceis pelos alunos. Além disso, os dados mostram que a opinião dos professores quanto às dificuldades encontradas pelos alunos nem sempre se confirma (N. C. Brown e Altadmri, 2014; Piteira e C. Costa, 2013). Por exemplo, foi visto, através das respostas dadas no questionário realizado na pesquisa de Piteira e C. Costa (2013), que os professores consideram variáveis um conceito difícil. Porém, na análise de exames resolvidos por alunos, durante a mesma pesquisa, o resultado foi o inverso. Esse fato pode estar relacionado a forma de coleta dos códigos analisados, que foi através de exames. Conforme mencionado anteriormente, essa forma de coleta pode deixar dificuldades passarem despercebidas por apresentarem apenas as versões finais, já corrigidas pelos aprendizes. As Tabelas 2.2 e 2.3 mostram uma síntese de alguns artigos que abordam dificuldades em aprender a programar.

A maioria das pesquisas citadas anteriormente utilizam ou analisaram dados gerados com o uso da linguagem de programação C, porém, muitas são as linguagens usadas para ensinar a programar, e Python está entre elas. Um estudo realizado por Becker (2019), na Irlanda, mostra que Python é a segunda linguagem mais usada no país para ensinar programação, perdendo apenas para Java. C ficou em quinto lugar. Eles ainda mostram que $\mathrm{C}++$, Java e $\mathrm{C}$ são as três linguagens consideradas mais difíceis para aprender, deixando Python em sexto lugar. Quanto aos benefícios que a linguagem traz para o ensino de programação, Python ficou em terceiro e $\mathrm{C}$ em quinto lugar.

Python é considerada mais simples que as demais (Lindstrom, 2005; Rufinus e KorTSARTS, 2006) e mais adequada como a primeira linguagem para aprender programação por refletir a maneira como as pessoas pensam e implementam código (WentworTH et al., 2015). Python minimiza as palavras reservadas e isso é importante para que os aprendizes possam se concentrar nos conceitos em vez de detalhes da linguagem (BogdANCHIKov et al., 2013; Rufinus e Kortsarts, 2006). Segundo Wainer e Xavier (2018), os resultados obtidos com estudantes usando Python foram melhores se comparados com os que estavam usando C. É importante analisar pesquisas realizadas com linguagens de programação diferentes pois podem apresentar outros tipos de dificuldades.

Quanto aos erros cometidos com o uso do Python, segundo Mannila et al. (2006), eles se originam de instruções incompletas ou da falta de dois pontos, usado no final das linhas dos comandos de seleção, repetição, entre outras. A pesquisa realizada por PIWEK e SAVAGE (2020), que codificou e analisou postagens feitas por alunos de introdução à programação em um fórum de ajuda online de Python, detectou que o principal desafio enfrentado pelo alunos é quanto à compreensão e ao uso de uma mistura de ambientes de programação (em particular, Python IDLE para programação offline e CodeRunner para testes de programação). Além disso, Piwek e SAVAGE (2020) mostraram que os tópicos considerados difíceis em Python incluem, entre outros, coleções, funções, mensagens de erro, iteração, saída de resultados, indentação, variáveis, importações e estruturas de selecão. Se compararmos esse resultado com os de outras pesquisas citadas anteriormente (M. Gomes et al., 2015; Piteira e C. Costa, 2013; Sevella et al., 2013), podemos observar que, independentemente da linguagem, algumas dificuldades se repetem. 


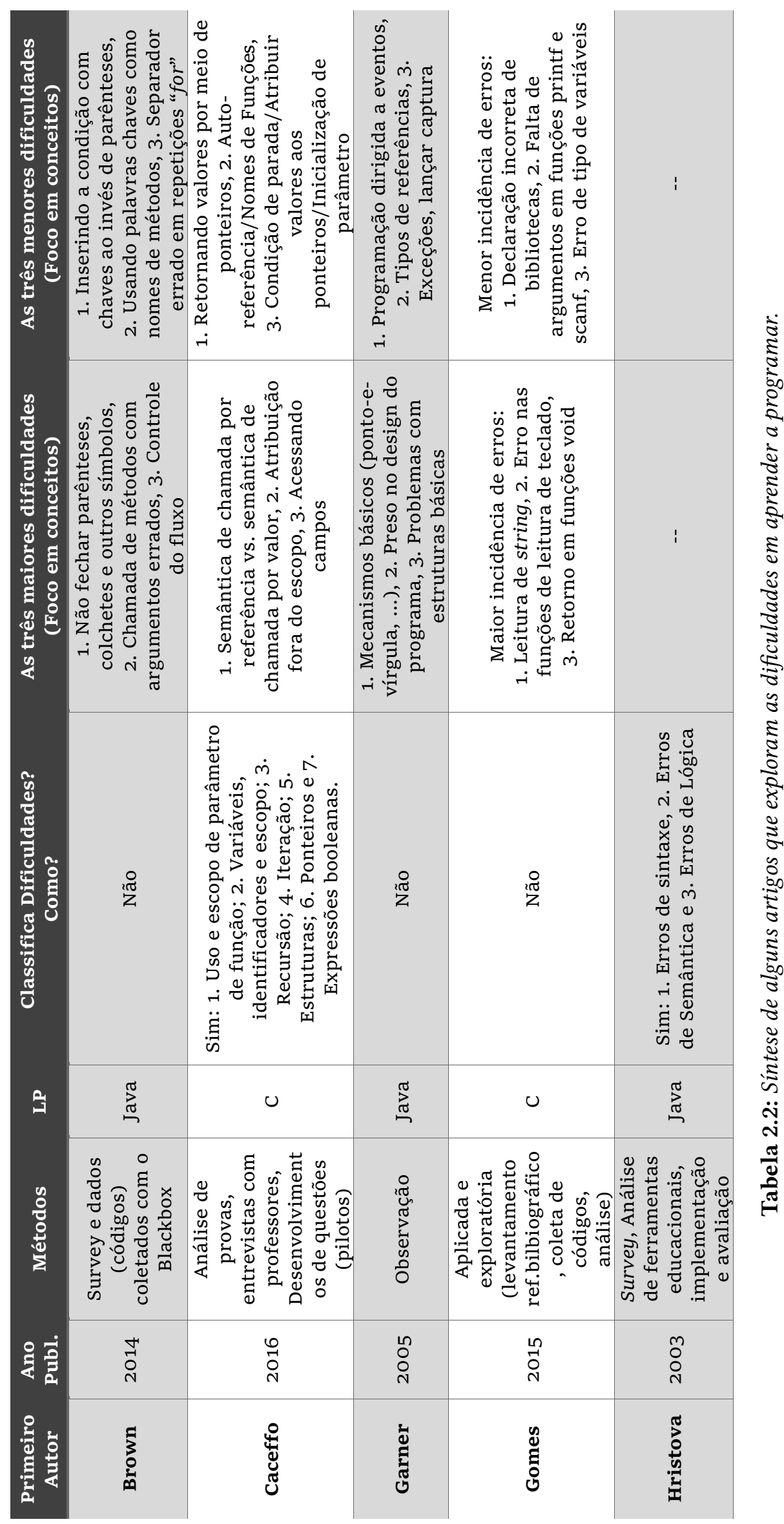




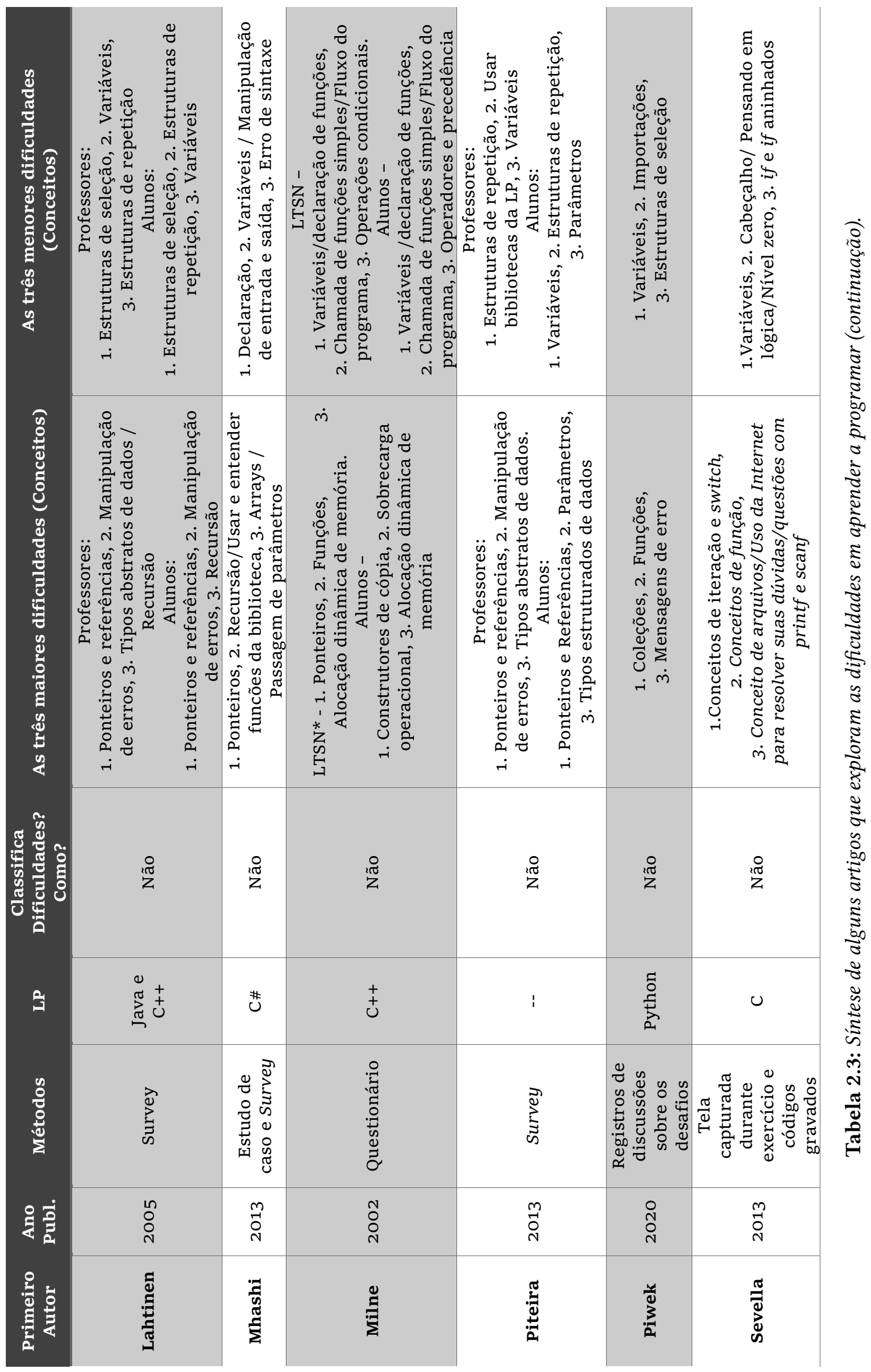


A linguagem utilizada nada mais é do que um meio pelo qual o objetivo principal deverá ser alcançado (JENKINS, 2002). Isso é difícil de ser entendido pelos alunos (JENKINS, 2002) e professores. Os professores estão mais concentrados em ensinar uma linguagem de programação e seus detalhes sintáticos do que em promover a resolução de problemas usando uma linguagem de programação (A. Gomes e A. J. Mendes, 2007). E, segundo OliVEIRA BRANDÃo et al. (2012), escrever a solução dos exercícios utilizando uma linguagem de programação já é uma experiência muito diferente das anteriormente vividas pelos aprendizes.

Mesmo que, na opinião de alunos desistentes, deveriam existir mais aulas de algoritmos e menos de programação utilizando linguagem (GIRAfFA e MorA, 2013), os professores consideram importante começar pela linguagem de programação em vez de pseudocódigo (A. Gomes e A. Mendes, 2014). Segundo a pesquisa realizada por A. Gomes e A. Mendes (2014), que entrevistaram professores de introdução à programação que usavam a linguagem C, a programação em papel é considerada muito artificial e os exercícios resolvidos com pseudocódigos devem ser traduzidos posteriormente, gerando dificuldades de relacionar e mapear os comandos do pseudocódigo para a linguagem. Porém, as dificuldades encontradas pelos alunos ao compilarem um código em $\mathrm{C}$, encontrando os erros apontados, tira a atenção da tarefa principal que é encontrar uma solução de algoritmo para o problema, podendo assim desmotivá-los durante o curso (Oliveira Brandão et al., 2012).

\subsubsection{Dificuldades Gerais}

Se estudantes tendem a adotar estilos de estudos errados ou estiverem desmotivados, eles irão considerar aprender a programar difícil (JENKINS, 2002) e existe a possibilidade de insucesso (Kristi, 2003). Porém, A. Gomes e A. Mendes (2014) acreditam que a maioria dos alunos são capazes de aprender se o professor oferece um apoio adequado, especialmente nos aspectos motivacionais. Ainda assim, há professores que não fazem nada para motiválos, pois consideram isso responsabilidade do próprio aluno (A. Gomes e A. Mendes, 2014).

São vários os obstáculos que um aprendiz de programação enfrenta e, para ter sucesso, segundo alguns professores, é necessário um ritmo intenso de estudos, sem o qual fica difícil aprender programação (GARNER et al., 2005). Outro obstáculo é que muitos alunos superestimam sua compreensão e nem sempre veem suas dificuldades completamente (Jenkins, 2002; Kristi, 2003; Mhashi e Alakeel, 2013). Eles não percebem suas dificuldades em entender questões relacionadas com a execução de um programa (KRISTI, 2003) e o que acontece na memória do computador durante essa execução (Milne e Rowe, 2002). Muitas vezes o problema não está no aprendizado do conceito e sua sintaxe, mas sim de como aplicá-lo apropriadamente em um programa (A. Gomes e A. Mendes, 2014; Kristi, 2003). Estudantes podem aprender muito bem, por exemplo, sobre ponteiros, mas ainda falham em usá-los apropriadamente (KRIsTi, 2003).

O nível de atenção necessário para cada estudante, dependendo da necessidade de direcionamento, também é importante. Alguns pesquisadores classificam os estudantes quanto a essa necessidade como "eficaz", que aprendem sem esforço excessivo e "ineficaz", que aprendem necessitando de muita supervisão (GARner et al., 2005; KRIsti, 2003). Porém, a atenção que o estudante necessita muitas vezes não acontece. Um dos motivos considera- 
dos são os tamanhos das turmas, o que resulta na inexistência de um monitoramento mais individualizado (A. Gomes e A. Mendes, 2014; Menezes e Nobre, 2002). De fato, turmas menores são uma sugestão de melhoria para os cursos vinda dos próprios alunos (GIRAFFA e Mora, 2013). Além disso, tarefas consideradas muito mais interessantes acabam não sendo aplicadas em turmas grandes. Turmas menores, com menos de 30 alunos, tendem a ter 13\% mais aprovação do que as maiores (BENNEDSEN e CASPERSEN, 2007).

A falta de maturidade geral dos estudantes também pode contribuir para que as dificuldades existam (A. Gomes e A. Mendes, 2014; Mhashi e Alakeel, 2013), além de outros tipos de imaturidade como a quase inexistência de capacidade de interpretação e análise, habilidades de discussão e pensamento crítico (A. Gomes e A. Mendes, 2014). Além dessas causas para a existência das dificuldades, outras também são citadas, como a falta de participação dos alunos, hesitando em perguntar durante as aulas quando têm dúvidas, a falta de conhecimento em inglês (Mhashi e Alakeel, 2013), a falta de pensamento computacional (WING, 2006) e a heterogeneidade das turmas quanto à disparidade de conhecimento e ritmo de aprendizagem (Menezes e Nobre, 2002).

Perante essas e outras dificuldades, as atitudes dos estudantes são importantes (GARNER et al., 2005) para seu sucesso. Perkins et al. (apud Soloway e Spohrer, 2013) classificam os estudantes de introdução à programação em dois tipos principais: os "stoppers" e os "movers". Os "stoppers" são os alunos que simplesmente param e abandonam perante situações problemáticas ou na falta de direcionamento claro. Em contrapartida, os "movers" continuam tentando, modificando seus códigos e usando efetivamente os retornos dados pelos erros cometidos, tendo potencial para resolver seus problemas e progredir. Em seguida eles citam os "tinkerers". Esses não conseguem entender seus códigos, tentam modificá-los, porém, assim como os "stoppers", não progridem muito nas suas tarefas. Algumas formas que estão sendo adotadas para lidar com tudo que foi exposto até aqui são apresentadas a seguir.

\subsubsection{Estratégias Didáticas}

A programação é um assunto muito complexo que requer esforço e uma abordagem especial na forma como é aprendido e ensinado (A. Gomes e A. J. Mendes, 2007). Aprender a programar é uma jornada que os alunos têm que fazer principalmente por eles mesmos, o professor deve ajudar pouco (A. Gomes e A. Mendes, 2014). Porém, a orientação e verificação do aprendizado são importantes pois, segundo RoBINs (2010), os estágios iniciais da aprendizagem de programação são críticos para o resultado do processo (teoria do Momento de Aprendizagem - Learning Edge Momentum - LEM), já que, uma vez estabelecido um momento negativo, é difícil superá-lo. Para eles, adquirir um conceito com sucesso torna o aprendizado de outro conceito estreitamente vinculado mais fácil (RoBINs, 2010). Por esse e outros motivos, o entendimento pedagógico e estratégias adotadas são importantes, sendo que o foco não deve ser apenas nos instrutores (JiménEZ e Villalobos, 2010), mas também nos estudantes e nos seus processos de aprendizagem (Alonso et al., 2010).

Para isso, muitos estudos usam o construtivismo, uma conhecida teoria da aprendizagem (VAn Gorp e Grissom, 2001). Segundo VAN Gorp e Grissom (2001), ao trabalhar com essa teoria de aprendizado, o foco está mais no aprendizado e nas experiências dos alunos. 
Os autores ainda acrescentam que as salas de aula construtivistas são frequentemente vistas como ambientes de solução de problemas manifestados por três C's: contexto, construção e colaboração. Alguns exemplos, apresentados na literatura, do uso da teoria do construtivismo são a "Pedagogia Contribuinte do Estudante", onde os alunos são encorajados a contribuir para a aprendizagem dos demais e também a valorizar as contribuições de outros (HAMER et al., 2008); e o estudo "Pedagogia para os laboratórios CS1" de LANG et al. (2006).

Porém, segundo (A. Gomes e A. J. Mendes, 2007), muitos alunos seguem métodos de estudos equivocados, não adequados para o aprendizado de programação. Os alunos usam metodologias de estudo não efetivas, como é o caso da estratégia de memorização, que é a leitura e visualização de exercícios resolvidos, mas que não é suficiente para aprender a programar (A. Gomes e A. Mendes, 2014). LAHtinen et al. (2005) afirmam que uma parte dos estudos deve ser a prática, para aprender fazendo. Além disso, MHAshi e Alakeel (2013) afirmam que uma abordagem usada para aumentar o conhecimento dos alunos e desenvolver suas habilidades é aumentar o número de exercícios, selecionando-os cuidadosamente e resolvendo-os posteriormente. Infelizmente, os alunos não se esforçam o suficiente para adquirir competências de programação (A. Gomes e A. J. Mendes, 2007). Mesmo assim, LAhtinen et al. (2005) mostram que os alunos consideram estudar sozinho mais útil do que as aulas e trabalhar sozinho mais útil do que sessões práticas e de exercícios.

A sessão de exercícios também foi considerada de pouca utilidade pela pesquisa realizada por Mhashi e Alakeel (2013) e estudar sozinho foi considerado menos útil do que estudar com amigos ou com a ajuda de alguém que conhece programação. Os alunos gostam de aprender de diversas maneiras (JENKIns, 2002) e o professor pode atuar como guia, mostrando as melhores práticas de organização e estudo, além de atuar no seu papel principal que é o de especialista no campo de ensino (A. Gomes e A. Mendes, 2014). O papel do professor fica mais difícil considerando que os estudantes em salas de aula de programação normalmente têm muitos níveis diferentes de experiências, dificultando projetar as aulas de forma que sejam desafiadoras e interessantes para todos (LAHTINEN et al., 2005). Muitos professores utilizam estratégias de motivação e consideram que a aproximação com os alunos, como "brincar" com eles e fazê-los sentir-se mais à vontade, é a melhor delas, seguida de jogos, competições ou desafios (A. Gomes e A. Mendes, 2014).

Mas é importante lembrar que tanto as aulas teóricas como as sessões práticas são importantes para entender os conceitos e aprender programação MHASHI e ALAKEEL (2013). é nas aulas práticas que os professores veem alunos que produzem programas sem indentação e sem comentários, por exemplo. Os alunos deixam essas tarefas para fazer "mais tarde", porém, somente são feitas se há pontuação para isso no método de avaliação adotado pelo professor (JENKIns, 2002). Inclusive, segundo Jenkins (2002), é a necessidade de avaliação que conduz o ritmo do curso. E, embora, a maioria dos professores defenda a avaliação contínua, eles geralmente não a praticam e só fazem um exame final (A. GomEs e A. Mendes, 2014).

O método de ensino tradicional não parece ser adequado para a necessidade de muitos estudantes, por diversas razões como: o ensino não é personalizado, as estratégias de 
ensino não dão suporte aos diversos estilos de aprendizado dos estudantes e são ensinados conceitos dinâmicos com material estático (A. Gomes e A. J. Mendes, 2007). Saindo do método tradicional, DEEK et al. (1998) criaram uma abordagem para cursos de programação com o objetivo de ajudar estudantes a aprenderem conceitos e seus usos. Nessa abordagem, as características da linguagem foram introduzidas aos alunos apenas no contexto de problemas específicos, pouco a pouco. Isso mostrou ter efeitos positivos nos resultados e na confiança dos alunos na programação. Outra abordagem foi o acréscimo no número dos exercícios, selecionando-os cuidadosamente e resolvendo-os posteriormente, contribuindo assim no aumento do conhecimento dos alunos e no desenvolvimento das suas habilidades (Mhashi e Alakeel, 2013).

A visualização é outra abordagem que foi usada no ensino de programação ao longo do tempo, sendo considerada benéfica na compreensão e aprendizado de conceitos abstratos e complexos (Mhashi e AlAKeel, 2013). Segundo pesquisa realizada por Lister et al. (2006), a visualização ajuda estudantes a entenderem e aprenderem os conceitos. Um exemplo é o sistema web de exercícios desenvolvido por ElENBOGEN et al. (2000), com um conjunto de exercícios web interativos para aprender vários recursos da linguagem $\mathrm{C}++$. Nesse sistema, os alunos podem modificar pequenos programas e verificar como o código se comporta.

\subsection{Onde esta Tese se Encaixa}

Muito está sendo feito para promover melhorias no ensino e aprendizado de programação. Isso mostra a preocupação da comunidade em melhorar o ensino e a aprendizagem de programação, mudando o atual cenário e consequentemente a atual taxa de insucessos dos cursos introdutórios de programação. Essa taxa é uma evidência da existência de dificuldades enfrentadas pelos aprendizes de programação. Para entender as dificuldades, estudos foram relatados na literatura mostrando o nível de dificuldades percebidas pelos alunos e professores nos diversos conteúdos abordados na disciplina.

Um conhecimento mais aprofundado de equívocos frequentemente cometidos pelos estudantes, os antipadrões, poderia ajudar a minimizar as dificuldades encontradas no ensino e estudo de como programar. Para a busca e catalogação dos antipadrões (Capítulo 5), esta tese se diferencia dos demais trabalhos citados anteriormente nos seguintes pontos:

Coleta: os códigos foram adquiridos de alunos que estavam resolvendo exercícios desenvolvidos para as aulas de introdução à programação. Cada vez que o programa era compilado, uma cópia do código era gravada. Esse tipo de captura dos códigos nos deu a possibilidade de identificar os próprios antipadrões, além de verificar, por exemplo, em que momento e situação o erro ocorreu e como o aluno o resolveu (se resolveu), possibilitando-nos saber, por exemplo, o tempo que o aprendiz levou para isso. Essa informação nos ajudou a verificar o impacto causado, dando-nos subsídios para gerar estatísticas de quantas submissões foram necessárias para os alunos resolverem cada antipadrão;

Alunos participantes: os alunos que desenvolveram os códigos analisados para o estudo 4 desta tese (Seção 1.2.3) eram alunos que já tinham frequentado essa disciplina 
no semestre anterior ao da captura dos códigos, porém tinham sido reprovados, caracterizando-os como alunos com dificuldades;

Eventos registrados nos catálogos: levando-se em consideração que é necessário ter pelo menos três ocorrências do equívoco para que possamos considerá-lo um antipadrão (W. H. BRown et al., 1998), são apresentados nos catálogos 3 ou 4 eventos encontrados, com os detalhes necessários para diferenciá-los uns dos outros;

Exemplos concretos dos equívocos ocorrendo e soluções adotadas: com o intuito de agregar valor ao trabalho, outro diferencial é o registro de cada evento com trecho de código desenvolvido por um aluno, mostrando o equívoco ocorrendo e outro trecho mostrando a solução encontrada (se existiu). Esses trechos de códigos poderiam dar subsídios para pesquisadores no desenvolvimento de sistemas, buscando automaticamente os equívocos cometidos em tempo real e dando retornos de como resolvê-los. Esses sistemas poderiam, inclusive, indicar más práticas de programação adotadas pelos alunos, classificadas nos catálogos como "Erro de Estilo";

Sugestões para Professores: não visto em outros trabalhos, esta tese apresenta sugestões para professores de como usar os catálogos nas suas aulas, mostrando meios de como apresentar os antipadrões para seus alunos com o intuito de evitá-los ou minimizar suas ocorrências;

Sugestões para Alunos: como acréscimo nas orientações de uso dos catálogos de antipadrões, esta tese tem também o diferencial de fornecer sugestões de como os alunos poderiam estudar os antipadrões.

Outro ponto que esta tese trabalhou foi a agregação de conjuntos de dificuldades por tópicos. Dessa forma, ao se trabalhar um determinado tópico, as dificuldades encontradas nele estariam agrupadas, podendo ajudar em decisões de onde aumentar o foco e escolha de exercícios mais adequados, por exemplo. Foram também apresentadas estratégias didáticas, porém, diferentemente de outros trabalhos, nós as vinculamos aos tópicos e/ou às dificuldades em que seu uso poderia se mostrar mais proveitoso.

Além disso, através de diários e entrevistas, buscamos evidências de conexões entre os tópicos abordados na disciplina. Essas conexões podem servir de subsídios aos professores na decisão da sequência em que os tópicos poderiam ser apresentados aos alunos, minimizando dificuldades, visto que RoBins et al. (2003) afirma, com sua teoria Learning Edge Momentum - LEM, que adquirir um conceito (tópico) com sucesso torna o aprendizado de outro conceito estreitamente vinculado mais fácil, enquanto falhar torna mais difícil o aprendizado. 


\section{Capítulo 3}

\section{Situação das Disciplinas de Introdução à Programação: Um Estudo na USP}

Objetivando verificar a situação da disciplinas da USP e buscando evidências de que alunos enfrentam dificuldades para obter aprovação, realizamos um estudo sobre um banco de dados anonimizado cedido pela Universidade de São Paulo - USP, com os dados das disciplinas de Introdução à Programação ministradas nos anos de 2010-1 a 2014-2. Os artigos 1 (Bosse e Gerosa, 2015b) e 2 (Bosse e Gerosa, 2015a) citados na Seção 1.5.1 apresentam alguns dos resultados obtidos. A questão de pesquisa abaixo norteou esse estudo:

\section{QP1 - Qual é a taxa de insucesso (reprovação e desistência) típica nas discipli-} nas de introdução à programação?

Os resultados do levantamento realizado mostraram que, em média, 30\% dos alunos matriculados nas disciplinas de introdução à programação foram reprovados ou trancaram matrícula, ou seja, mais de 1.100 alunos por ano não obtiveram sucesso durante o período analisado. Essa média foi calculada considerando todos os alunos matriculados nessas disciplinas na USP durante o período de 2010 à 2014. Além disso, alunos que não são da área da computação apresentaram 8,2 pontos percentuais a mais de insucesso do que os que são da área. Vimos também um crescimento na utilização da linguagem de programação Python, de 3\% em 2010 para 40\% em 2014. Esses e outros resultados são apresentados a seguir.

\subsection{Contextualização}

A grade curricular de diversos cursos das áreas de exatas, humanas e biológicas possui uma disciplina que ensina os conceitos básicos de programação. Muitos são os nomes atribuídos a ela, como Introdução à Programação e Introdução à Ciência da Computação, entre outros, mas sempre focando no mesmo objetivo, que é o ensino e aprendizagem de programação. Para treinar a aplicação dos conceitos passados em sala de aula, diversas 
linguagens de programação são usadas, tais como C, C++, Java, Python e VBA.

Entender os conceitos referentes à disciplina de introdução à programação é uma das fontes de dificuldades enfrentadas pelos alunos, levando a reprovações ou trancamentos na disciplina e até a desistências do curso (SAntos e H. A. X. Costa, 2006). São poucos os relatos sobre estudos que apresentam os percentuais de reprovações e desistências, ou até mesmo comparações dos resultados obtidos entre disciplinas. Um desses estudos foi realizado por BENNEDSEN e CASPERSEN (2007) com resultados de uma investigação realizada com universidades de vários países, mostrando que mais de $28 \%$ dos alunos matriculados nas disciplinas de introdução à programação não obtiveram sucesso, seja por desistência ou reprovação.

O estudo apresentado neste capítulo teve o intuito de trazer uma visão mais clara do cenário dessa disciplina na USP. Para isso, dividimos o estudo em duas etapas. A primeira etapa foi guiada por um conjunto de cinco subquestões de pesquisa e a segunda etapa por apenas uma, conforme apresentado na Tabela 3.1.

\begin{tabular}{c|l}
\hline \multicolumn{2}{c}{ Sub-Questões de Pesquisa da Etapa 1 } \\
\hline SQP1-E1 & $\begin{array}{l}\text { Qual o percentual de reprovações/trancamentos das disciplinas de introdução à } \\
\text { programação da USP? }\end{array}$ \\
\hline SQP2-E1 & Qual é a evolução temporal deste percentual? \\
\hline SQP3-E1 & $\begin{array}{l}\text { Quantas vezes o aluno frequenta a disciplina de introdução à programação antes de obter } \\
\text { aprovação? }\end{array}$ \\
\hline SQP4-E1 & Como se compara este percentual com outra disciplina do mesmo semestre? \\
\hline SQP5-E1 & $\begin{array}{l}\text { Como se mostra tal percentual analisando-se isoladamente as diversas disciplinas de } \\
\text { introduçãoà programação da USP? }\end{array}$ \\
\hline \multicolumn{2}{c}{ Sub-Questões de Pesquisa da Etapa 2 } \\
\hline \multicolumn{2}{|c}{} \\
\hline
\end{tabular}

Tabela 3.1: Subquestões de pesquisa do estudo de investigação das disciplinas da USP.

Com as respostas às questões da etapa 1, obtivemos uma visão geral dos resultados obtidos pelos alunos na disciplina de introdução à programação (SQP1-E1) e de como esses resultados se comportaram no decorrer dos anos (SQP2-E1). Buscamos saber ainda quantas vezes, em média, o aluno precisou frequentar a disciplina até obter aprovação (SQP5-E1). Outro aspecto analisado foi quanto a taxa de sucesso dessa disciplina comparada tanto com um conjunto de outras existentes no mesmo semestre do mesmo curso (SQP3-E1), quanto com uma disciplina específica (SQP4-E1). Foi escolhida a disciplina de Cálculo por também ser considerada uma disciplina na qual alunos enfrentam dificuldades e por existir em todos os cursos analisados. Na etapa 2, a questão de pesquisa nos fez analisar com mais detalhes as reprovações/trancamentos na disciplina (SQP1-E2), separando alunos que são da computação dos demais. 


\subsection{Metodologia}

Buscando responder a QP1 desta tese, foi feito um levantamento, que segundo J. W. Creswell e J. D. Creswell (2017), apresenta uma descrição quantitativa dos dados de uma determinada população. A população do presente estudo são os alunos das disciplinas de introdução à programação da USP que se matricularam no período de 2010-1 a 2014-2. A primeira tarefa realizada para obter os dados para análise foi escolher as disciplinas que iriam compor o estudo. As disciplinas foram selecionadas por meio de uma pesquisa no sistema acadêmico da universidade com as seguintes palavras chaves, usadas separadamente para cada busca: "programação", "algoritmos" e "computação". A Tabela 3.2 mostra a relação entre a quantidade de disciplinas apresentadas pelo sistema e a quantidade selecionada para a análise. Essa tarefa foi realizada manualmente e o conteúdo programático de cada disciplina foi analisado. As disciplinas foram escolhidas ou descartadas conforme os critérios de inclusão e exclusão apresentados na Tabela 3.3.

\begin{tabular}{c|c|c}
\hline $\begin{array}{c}\text { Palavra de } \\
\text { Busca }\end{array}$ & $\begin{array}{c}\text { Total de Disciplinas } \\
\text { Apresentadas }\end{array}$ & $\begin{array}{c}\text { Total de Disciplinas } \\
\text { Escolhidas }\end{array}$ \\
\hline Programação & 66 & 12 \\
\hline Algoritmos & 29 & O \\
\hline Computação & 112 & 19 \\
\hline Total & $\mathbf{2 0 7}$ & $\mathbf{3 1}$ \\
\hline
\end{tabular}

Tabela 3.2: Totais de disciplinas apresentadas por palavra de busca utilizada.

\begin{tabular}{cl}
\hline $\begin{array}{c}\text { Critérios } \\
\text { de }\end{array}$ & $\begin{array}{l}\text { Ter no seu programa pelo menos } 4 \text { dos seguintes assuntos: } \\
\Rightarrow \text { Conceitos de linguagens de programação, por exemplo: tipos de variáveis } \\
\text { Inclusão }\end{array}$ \\
$\begin{array}{c}\Rightarrow \text { Estruturas de programação: seleção e repetição } \\
\Rightarrow \text { Modularização de programas: funções e/ou procedimentos } \\
\Rightarrow \text { Utilização de alguma linguagem de programação }\end{array}$ \\
$\begin{array}{c}\text { Critério } \\
\text { de }\end{array}$ & $\begin{array}{l}\text { Tratar de uma comparação de paradigmas de programação como programação } \\
\text { funcional, procedural, orientada a objetos, entre outras. Estudando os } \\
\text { Exclusão }\end{array}$ \\
\hline
\end{tabular}

Tabela 3.3: Critérios de inclusão e exclusão das disciplinas apresentadas pelo Sistema fupiter da USP.

Na Etapa 1, das 31 disciplinas selecionadas apenas 29 foram consideradas (veja mais explicação sobre as disciplinas na Seção 3.3). Foram desconsideradas as de códigos SCC0222 e SCC0221 por não estarem ativas no período analisado. Para a Etapa 2, foram utilizados os dados de 26 das 31 disciplinas selecionadas. Para esta etapa foi usado um critério de exclusão a mais, que exclui disciplinas de laboratório ministradas paralelamente às disciplinas teóricas. Sendo assim, além das duas excluídas na etapa 1, desconsideramos ainda as de códigos SSC0102, SSC0601 e SSC0801. Essas três disciplinas, por serem disciplinas de laboratório, eram usadas para praticar os conceitos abordados nas disciplinas teóricas de introdução à programação do mesmo semestre. De fato, 96,3\% dos alunos cursaram as duas ao mesmo tempo. 
O banco de dados utilizado para este estudo, disponibilizado pela Pró-Reitoria de Graduação da USP, tinha os dados das matrículas realizadas em cada uma das 29 disciplinas, selecionadas para a Etapa 1, durante os 5 anos (2010-1 à 2014-2). Além disso, foram disponibilizados os históricos dos alunos que apareceram como matriculados. Os dados que compunham as matrículas são: código da disciplina, código da turma, ano, semestre, professor ministrante, código fictício do aluno, código do curso, tipo de ingresso (vestibular, transferência, ...), ano de ingresso, percentual de frequência, nota e resultado (aprovado, reprovado por nota, ...). Os históricos eram compostos pelo código do aluno, da disciplina e da turma, ano que cursou a disciplina, percentual de frequência, nota e resultado. Os resultados obtidos pelos alunos são apresentados levando-se em consideração notas e frequências. Na USP, em uma escala de 0 a 10, a média de aprovação direta é de 5,0 e 3,0 dá direito a fazer a prova de recuperação. Todos os alunos foram mantidos no anonimato, trocando suas identificações por números fictícios, necessários somente para cruzamentos dos dados.

\subsection{Disciplinas de Introdução à Programação}

Os estudos desta tese trabalharam com dados oriundos de alunos e professores de disciplinas de introdução à programação. Segundo Diretrizes Curriculares para Cursos da Área de Computação e Informática da SBC-2016, os currículos são compostos por quatro grandes áreas de formação: formação básica, tecnológica, complementar e humanística. A disciplina de introdução à programação faz parte da primeira grande área, "Formação Básica”.

Uma das áreas da "Formação Básica” é a 'Ciência da Computação', sendo considerada a área mais importante na composição dos currículos dos cursos de Computação e Informática; a 'Programação' é uma das suas sub áreas. Segundo essas diretrizes, essa sub área é voltada à solução de problemas e as linguagens de programação são usadas como ferramentas.

A disciplina que introduz habilidades de programação, aqui denominada de introdução à programação, está presente também na grade curricular de outros cursos da área de exatas e de alguns das áreas de humanas e biológicas. Para nosso estudo foram analisadas disciplinas de introdução à programação ministradas na USP, independente da área. Na Tabela 3.4 são apresentadas as 29 disciplinas utilizadas na Etapa 1 do Estudo, identificadas por suas respectivas siglas, nomes, instituto/escola/faculdade e total de matrículas existentes no período. Nessa Tabela, as três disciplinas excluídas na Etapa 2 do estudo estão marcadas com um “*”.

A Tabela 3.5 apresenta os conteúdos ministrados em uma das disciplinas, a qual foi utilizada para coletar os códigos analisados no estudo apresentado no Capítulo 5. Nas seções a seguir são apresentados os resultados alcançados com a análise dos dados gerados por essas disciplinas, conforme detalhado na Seção 3.2. 


\begin{tabular}{|c|c|c|c|c|}
\hline Cont. & $\begin{array}{l}\text { Código da } \\
\text { Disciplina }\end{array}$ & Nome da Disciplina & Instituto, Escola ou Faculdade & $\begin{array}{l}\text { Total } \\
\text { Matr. }\end{array}$ \\
\hline 1 & ACH2001 & Introdução à Programação & Escola de Artes, Ciências e Humanidades & 1239 \\
\hline 2 & LOB 1023 & Introdução à Programação de Computadores & Escola de Engenharia de Lorena & 787 \\
\hline 3 & 5910257 & Programação de Computadores & \multirow{3}{*}{$\begin{array}{c}\text { Faculdade de Filosofia, Ciências e Letras } \\
\text { de Ribeirão Preto }\end{array}$} & 109 \\
\hline 4 & 5950257 & Programação de Computadores & & 173 \\
\hline 5 & 5952010 & Introdução à Computação I & & 193 \\
\hline 6 & IBM1006 & Introdução à Computação I & Faculdade de Medicina de Ribeirão Preto & 394 \\
\hline 7 & ZAB0264 & Introdução à Computação & \multirow{2}{*}{$\begin{array}{l}\text { Faculdade de Zootecnia e Engenharia de } \\
\text { Alimentos }\end{array}$} & 491 \\
\hline 8 & ZAB1008 & Algoritmo e Programação de Computadores & & 310 \\
\hline 9 & BMM0580 & Introdução à Programação de Computadores & Instituto de Ciências Biomédicas & 37 \\
\hline 10 & SSC0101 & Introdução à Ciência de Computação I & \multirow{14}{*}{$\begin{array}{l}\text { Instituto de Ciências Matemáticas e de } \\
\text { Computação }\end{array}$} & 617 \\
\hline 11 & SSC0102* & Laboratório de Introdução à Ciência de Computação I & & 590 \\
\hline 12 & SCC0120 & Introdução à Ciência da Computação & & 1985 \\
\hline 13 & SCC0121 & Introdução à Programação & & 224 \\
\hline 14 & SCC0172 & Introdução à Programação para Biologia Molecular & & 233 \\
\hline 15 & SSC0301 & Introdução à Computação para Engenharia Ambienta & & 212 \\
\hline 16 & SSC0501 & Introdução à Ciência de Computação I & & 250 \\
\hline 17 & SSC0502 & Laboratório de Introdução à Ciência de Computação I & & 246 \\
\hline 18 & SSC0600 & Introdução à Ciência de Computação I & & 266 \\
\hline 19 & SSC0601* & Laboratório de Introdução à Ciência de Computação I & & 273 \\
\hline 20 & SSC0800 & Introdução à Ciência de Computação I & & 227 \\
\hline 21 & SSC0801* & Laboratório de Introdução à Ciência de Computação I & & 206 \\
\hline 22 & SME0230 & Introdução à Programação de Computadores & & 296 \\
\hline 23 & SME0330 & Introdução à Programação de Computadores & & 242 \\
\hline 24 & MAC0110 & Introdução à Computação & \multirow{5}{*}{ Instituto de Matemática e Estatística } & 2161 \\
\hline 25 & MAC0113 & Introdução à Computação para Ciências Humanas & & 1385 \\
\hline 26 & MAC0115 & Introdução à Computação para Ciências Exatas e Tecnologia & & 2159 \\
\hline 27 & MAC0119 & Introdução à Programação de Computadores & & 85 \\
\hline 28 & MAC2166 & Introdução à Computação & & 4448 \\
\hline 29 & BIO0454 & Introdução à Programação de Computadores para Biologia & Instituto de Biociências & 15 \\
\hline & & & & 19853 \\
\hline
\end{tabular}

*Disciplinas excluídas para as análises da Etapa 2.

Tabela 3.4: Disciplinas consideradas no Estudo 1 dessa tese.

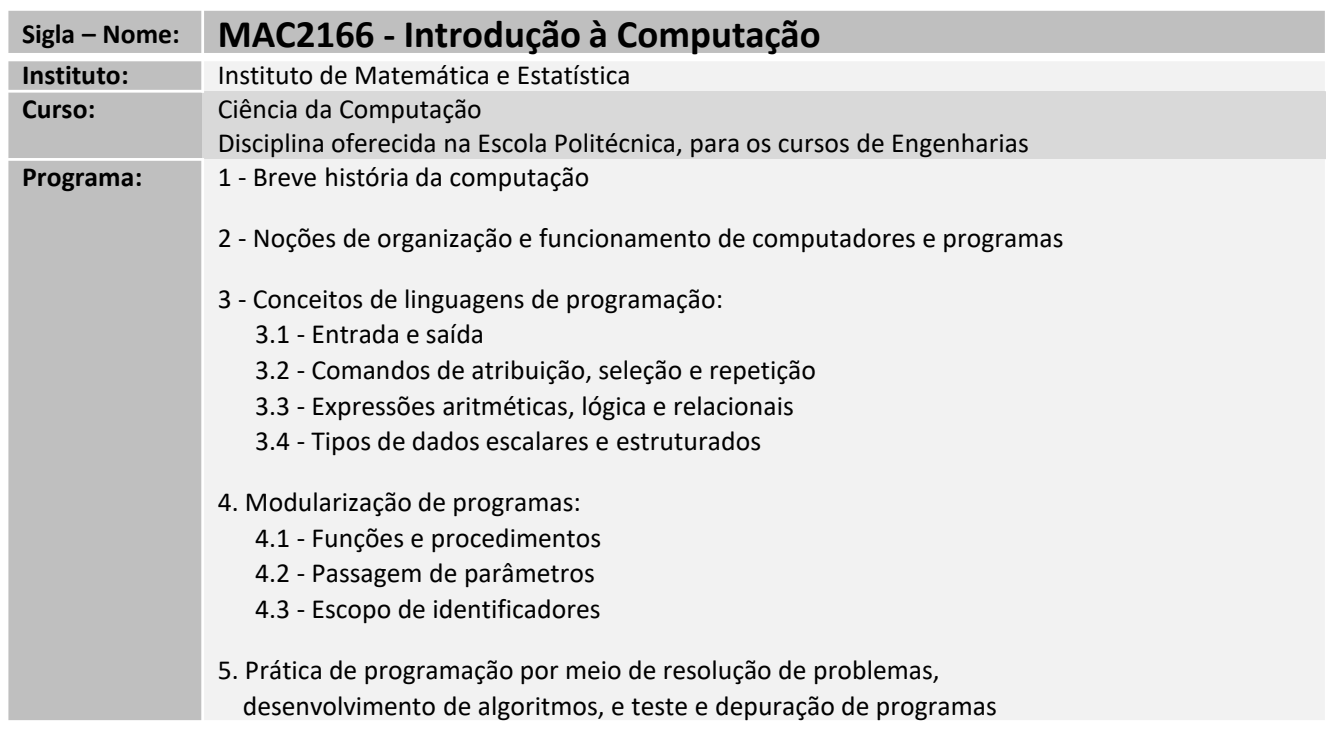

Tabela 3.5: Conteúdos ministrados na disciplina MAC2166 - Introdução à Programação. 


\subsection{Resultados da Etapa 1}

Nos cinco anos analisados na Etapa 1, ocorreram 20.948 matrículas em todas as 29 disciplinas juntas, das quais consideramos 19.859. As 1.095 matrículas desconsideradas são as que correspondem à situação "Não cadastrado", não sendo possível identificar se nessa situação o aluno foi ou não aprovado.

SQP1-E1 - Qual o percentual de reprovações/trancamentos das disciplinas de introdução à programação da USP? - Em primeira análise, verificamos que das 19.853 matrículas, 70,69\% resultaram em aprovação, 26,70\% em reprovação por nota e/ou frequência e $2,61 \%$ em trancamentos. Nessa análise foram considerados todos os alunos aprovados, antes ou depois da recuperação. Os dados dessa análise estão representados na Figura 3.1.A. Na Tabela 3.6 são apresentados os resultados por disciplina.

\begin{tabular}{|c|c|c|c|c|c|c|c|c|c|c|c|c|}
\hline N. & $\begin{array}{l}\text { Código } \\
\text { Disciplina }\end{array}$ & \begin{tabular}{|c|} 
Total \\
de \\
Matr.
\end{tabular} & Aprovados & $\%$ & $\begin{array}{c}\text { Reprovados } \\
\text { por Nota }\end{array}$ & $\%$ & \begin{tabular}{|c|} 
Reprovados \\
por \\
Frequência
\end{tabular} & $\%$ & \begin{tabular}{|c|} 
Reprovados \\
por Nota e \\
Freq.
\end{tabular} & $\%$ & Trancados & $\%$ \\
\hline 1 & $\mathrm{ACH} 2001$ & 1239 & 768 & $61.99 \%$ & 316 & $25.50 \%$ & 1 & $0.08 \%$ & 140 & $11.30 \%$ & 14 & $1.13 \%$ \\
\hline 2 & LOB1023 & 787 & 499 & $63.41 \%$ & 213 & $27.06 \%$ & 0 & $0.00 \%$ & 26 & $3.30 \%$ & 49 & $6.23 \%$ \\
\hline 3 & 5910257 & 109 & 64 & $58.72 \%$ & 38 & $34.86 \%$ & 0 & $0.00 \%$ & 6 & $5.50 \%$ & 1 & $0.92 \%$ \\
\hline 4 & 5950257 & 173 & 118 & $68.21 \%$ & 41 & $23.70 \%$ & 0 & $0.00 \%$ & 12 & $6.94 \%$ & 2 & $1.16 \%$ \\
\hline 5 & 5952010 & 193 & 73 & $37.82 \%$ & 78 & $40.41 \%$ & 0 & $0.00 \%$ & 34 & $17.62 \%$ & 8 & $4.15 \%$ \\
\hline 6 & IBM1006 & 394 & 163 & $41.37 \%$ & 173 & $43.91 \%$ & 0 & $0.00 \%$ & 41 & $10.41 \%$ & 17 & $4.31 \%$ \\
\hline 7 & ZAB0264 & 491 & 462 & $94.09 \%$ & 15 & $3.05 \%$ & 0 & $0.00 \%$ & 14 & $2.85 \%$ & 0 & $0.00 \%$ \\
\hline 8 & ZAB1008 & 310 & 225 & $72.58 \%$ & 57 & $18.39 \%$ & 0 & $0.00 \%$ & 23 & $7.42 \%$ & 5 & $1.61 \%$ \\
\hline 9 & BMM0580 & 37 & 32 & $86.49 \%$ & 5 & $13.51 \%$ & 0 & $0.00 \%$ & 0 & $0.00 \%$ & 0 & $0.00 \%$ \\
\hline 10 & SSC0101 & 617 & 452 & $73.26 \%$ & 130 & $21.07 \%$ & 1 & $0.16 \%$ & 30 & $4.86 \%$ & 4 & $0.65 \%$ \\
\hline 11 & SSC0102* & 590 & 506 & $85.76 \%$ & 39 & $6.61 \%$ & 1 & $0.17 \%$ & 42 & $7.12 \%$ & 2 & $0.34 \%$ \\
\hline 12 & SCC0120 & 1985 & 1699 & $85.59 \%$ & 207 & $10.43 \%$ & 3 & $0.15 \%$ & 74 & $3.73 \%$ & 2 & $0.10 \%$ \\
\hline 13 & SCC0121 & 224 & 136 & $60.71 \%$ & 59 & $26.34 \%$ & 0 & $0.00 \%$ & 25 & $11.16 \%$ & 4 & $1.79 \%$ \\
\hline 14 & SCC0172 & 233 & 172 & $73.82 \%$ & 27 & $11.59 \%$ & 2 & $0.86 \%$ & 24 & $10.30 \%$ & 8 & $3.43 \%$ \\
\hline 15 & SSC0301 & 212 & 184 & $86.79 \%$ & 19 & $8.96 \%$ & 1 & $0.47 \%$ & 2 & $0.94 \%$ & 6 & $2.83 \%$ \\
\hline 16 & SSC0501 & 250 & 159 & $63.60 \%$ & 61 & $24.40 \%$ & 1 & $0.40 \%$ & 28 & $11.20 \%$ & 1 & $0.40 \%$ \\
\hline 17 & SSC0502 & 246 & 180 & $73.17 \%$ & 27 & $10.98 \%$ & 2 & $0.81 \%$ & 37 & $15.04 \%$ & 0 & $0.00 \%$ \\
\hline 18 & SSC0600 & 266 & 233 & $87.59 \%$ & 23 & $8.65 \%$ & 0 & $0.00 \%$ & 8 & $3.01 \%$ & 2 & $0.75 \%$ \\
\hline 19 & SSC0601* & 273 & 255 & $93.41 \%$ & 7 & $2.56 \%$ & 2 & $0.73 \%$ & 8 & $2.93 \%$ & 1 & $0.37 \%$ \\
\hline 20 & SSC0800 & 227 & 98 & $43.17 \%$ & 87 & $38.33 \%$ & 0 & $0.00 \%$ & 39 & $17.18 \%$ & 3 & $1.32 \%$ \\
\hline 21 & SSC0801* & 206 & 131 & $63.59 \%$ & 29 & $14.08 \%$ & 0 & $0.00 \%$ & 43 & $20.87 \%$ & 3 & $1.46 \%$ \\
\hline 22 & SME0230 & 296 & 182 & $61.49 \%$ & 63 & $21.28 \%$ & 0 & $0.00 \%$ & 48 & $16.22 \%$ & 3 & $1.01 \%$ \\
\hline 23 & SME0330 & 242 & 165 & $68.18 \%$ & 50 & $20.66 \%$ & 0 & $0.00 \%$ & 19 & $7.85 \%$ & 8 & $3.31 \%$ \\
\hline 24 & MAC0110 & 2161 & 1104 & $51.09 \%$ & 488 & $22.58 \%$ & 0 & $0.00 \%$ & 475 & $21.98 \%$ & 94 & $4.35 \%$ \\
\hline 25 & MAC0113 & 1385 & 1090 & $78.70 \%$ & 176 & $12.71 \%$ & 0 & $0.00 \%$ & 93 & $6.71 \%$ & 26 & $1.88 \%$ \\
\hline 26 & MAC0115 & 2159 & 1027 & $47.57 \%$ & 398 & $18.43 \%$ & 1 & $0.05 \%$ & 499 & $23.11 \%$ & 234 & $10.84 \%$ \\
\hline 27 & MAC0119 & 85 & 65 & $76.47 \%$ & 18 & $21.18 \%$ & 0 & $0.00 \%$ & 2 & $2.35 \%$ & 0 & $0.00 \%$ \\
\hline 28 & MAC2166 & 4448 & 3779 & $84.96 \%$ & 464 & $10.43 \%$ & 0 & $0.00 \%$ & 184 & $4.14 \%$ & 21 & $0.47 \%$ \\
\hline \multirow[t]{2}{*}{29} & BIO0454 & 15 & 13 & $86.67 \%$ & 0 & $0.00 \%$ & 0 & $0.00 \%$ & 1 & $6.67 \%$ & 1 & $6.67 \%$ \\
\hline & & 19853 & 14034 & $70.69 \%$ & 3308 & $16.66 \%$ & 15 & $0.08 \%$ & 1977 & $9.96 \%$ & 519 & $2.61 \%$ \\
\hline
\end{tabular}

Tabela 3.6: Resultados por disciplina da Etapa 1.

SQP2-E1 - Qual é a evolução temporal deste percentual? - A dispersão temporal desses dados está representada na Figura 3.1.B. Estatisticamente, não é possível afirmar que há diferença significativa entre os anos analisados quanto às médias de reprovação, segundo o teste não-paramétrico de Kruskal-Wallis.

SQP3-E1 - Quantas vezes o aluno frequenta a disciplina de introdução à programação antes de obter aprovação? - Outra análise realizada foi a quantidade de vezes que um aluno precisou cursar a disciplina antes de obter aprovação. Para essa análise 
Resultados obtidos pelos alunos nas disciplinas de introdução à programação da USP cursadas entre 2010-1 e 2014-2

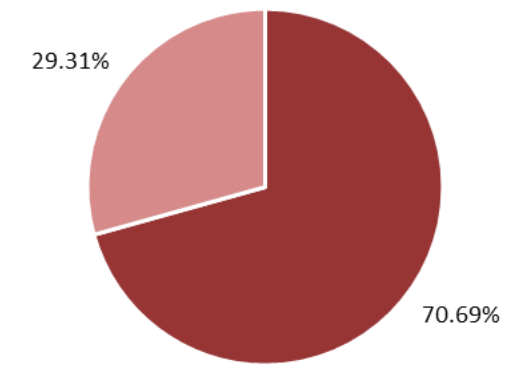

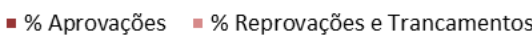

Dispersão temporal de 2010 a 2014 nas disciplinas de Introdução à Programação da USP

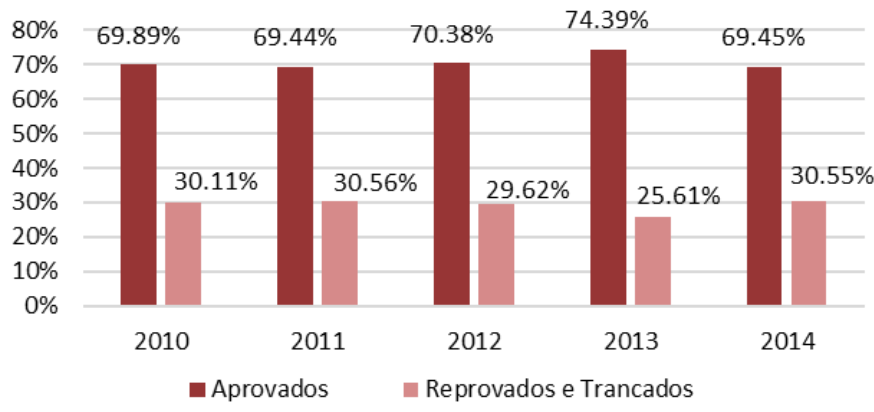

A

Figura 3.1: (A) Percentual geral e (B) Dispersão temporal dos resultados obtidos nas disciplinas de introdução à programação na USP, no período de 2010-1 a 2014-2.

foram considerados apenas os alunos que já possuíam aprovação no seu histórico escolar. Há alunos, por exemplo, que já se matricularam mais de 8 vezes na disciplina sem terem obtido aprovação até o momento em que os dados nos foram fornecidos e, por isso, não foram incluídos na análise. A Figura 3.2 mostra o percentual de vezes que um aluno se matricula na disciplina de introdução à programação antes de obter aprovação.

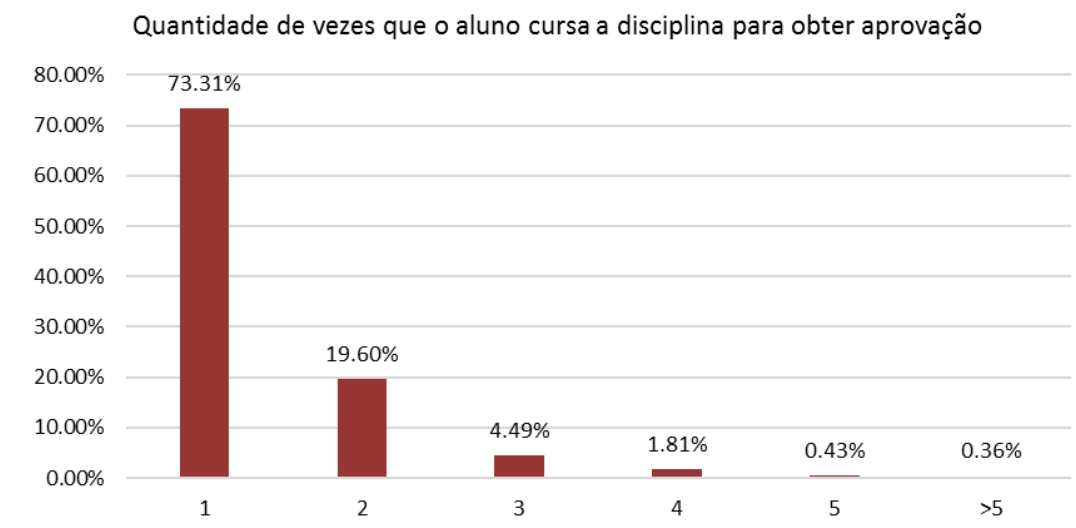

Figura 3.2: Percentual de vezes que alunos tiveram que cursar a disciplina de introdução à programação antes de obterem aprovação.

Quando selecionamos apenas alunos dos cursos da área de computação dos diversos campi da USP, obtivemos os percentuais apresentados na Figura 3.3. Esse resultado foi obtido desconsiderando-se as disciplinas exclusivamente de laboratório. Com os resultados apresentados, percebemos que não há uma homogeneidade nos resultados entre os cursos da área de computação. Essa diferença pode estar relacionada a vários fatores, como nível de cobrança feita pelos professores e tempo disponíveis de estudo.

SQP4-E1 - Como se compara este percentual com outra disciplina do mesmo semestre? - Fizemos também uma análise comparativa entre duas disciplinas em que normalmente os alunos apresentam dificuldades: a de introdução à programação e a 


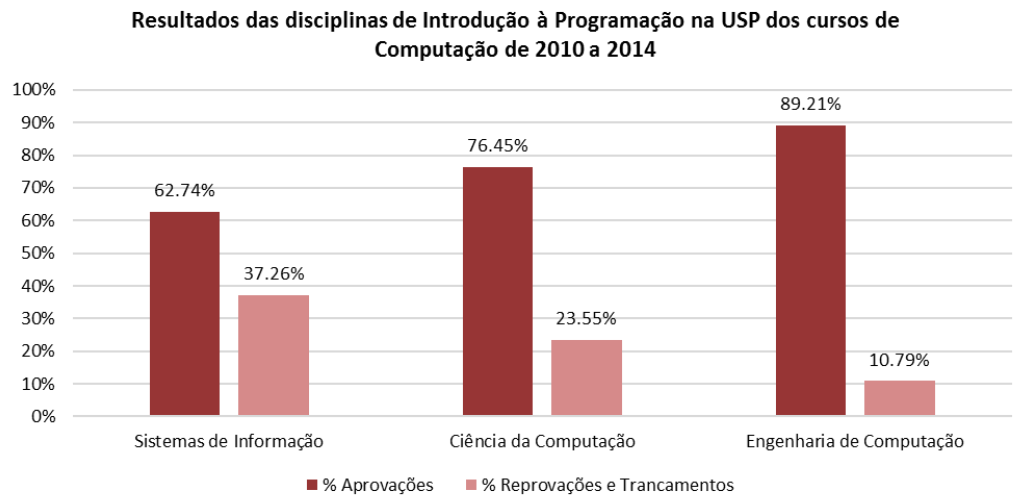

Figura 3.3: Percentual de aprovações e reprovações/trancamentos nas disciplinas de introdução à programação na USP, de 2010 a 2014, por curso da área de computação.

de cálculo. Pelo histórico, buscamos por alunos que cursaram pela primeira vez uma disciplina de introdução à programação (MAC110, MAC2166 e ACH2001) no mesmo ano e semestre em que também cursaram pela primeira vez uma de cálculo (MAT0111, MAT2453, ACH2011), nos campi da capital. Os dados mostram que existe uma relação bastante próxima nas médias e medianas das duas disciplinas (Tabela 3.7). Após analisarmos o gráfico de normalidade dos dados e os valores p obtidos pelo teste de normalidade ShapiroWilk com um nível de significância de $5 \%$, concluímos que não há evidência para afirmar que a amostra não foi retirada de uma população normalmente distribuída. Comparando as disciplinas de Cálculo e Introdução à Computação, não há indício para concluir, com $99 \%$ de confiança, que a média para ambas disciplinas são diferentes, ou seja, pode-se dizer que os alunos têm o mesmo rendimento em ambas disciplinas. Quanto as médias de 'ACH2001' e 'ACH2011' apresentadas na Tabela 3.7, esses valores se devem ao fato das notas finais alcançadas pelos alunos. Poucas notas usadas no cálculo são acima de 5,0 e, além disso, $42 \%$ das notas de 'ACH2001' e 34\% das de 'ACH2011' são 0,0 (zero), puxando assim a média para baixo.

\begin{tabular}{|c|c|c|c|c|c|c|c|c}
\hline & \multicolumn{2}{|c|}{ Introdução à Programação } & \multicolumn{4}{c|}{ Cálculo } \\
\cline { 2 - 9 } & $\begin{array}{c}\text { Sigla da } \\
\text { Disciplina }\end{array}$ & Média & Mediana & $\begin{array}{c}\text { Desvio } \\
\text { Padrão }\end{array}$ & $\begin{array}{c}\text { Sigla da } \\
\text { Disciplina }\end{array}$ & Média & Mediana & $\begin{array}{c}\text { Desvio } \\
\text { Padrão }\end{array}$ \\
\hline $\begin{array}{c}\text { Ciência da } \\
\text { Computação } \\
\text { (São Paulo) }\end{array}$ & MAC0110 & 5.41 & 6.80 & 3.50 & MAT0111 & 5.57 & 5.80 & 2.86 \\
\hline $\begin{array}{c}\text { Engenharia de } \\
\text { Computação } \\
\text { (São Paulo) }\end{array}$ & MAC2166 & 6.71 & 7.10 & 2.16 & MAT2453 & 5.68 & 5.70 & 1.80 \\
\hline $\begin{array}{c}\text { Sistemas de } \\
\text { Informação } \\
\text { (São Paulo) }\end{array}$ & ACH2001 & 1.46 & 0.50 & 1.97 & ACH2011 & 2.11 & 1.00 & 2.53 \\
\hline
\end{tabular}

Tabela 3.7: Comparação entre disciplina de introdução à programação e cálculo, cursadas pela primeira vez e no mesmo ano e semestre, nos cursos da área de computação da USP.

SQP5-E1 - Como se mostra tal percentual analisando-se isoladamente as diversas disciplinas de introdução à programação da USP? Foram computados os totais 
de aprovações e reprovações por nota das matrículas realizadas entre 2010 e 2014, nas disciplinas oferecidas nos primeiros semestres dos cursos de Ciência da Computação (no IME), Sistemas de Informação (na EACH) e Engenharia de Computação (na POLI), da USP na cidade de São Paulo - capital. Com isso, os gráficos da Figura 3.4 mostram os resultados alcançados por todos alunos que cursaram as disciplinas dos primeiros semestres, e que tiverem pelo menos $70 \%$ de frequência.

\subsection{Resultados da Etapa 2}

Os dados analisados na Etapa 2 também abrangem um período de 5 anos (2010-1 a 2014-2), porém a análise foi feita comparando os resultados dos alunos que não são da área de computação com os que são. Nessa etapa, foram consideradas 18.784 de 19.879 matrículas existentes em todas as 26 disciplinas juntas. As 1.095 matrículas desconsideradas são as que correspondem à situação "Não cadastrado", não sendo possível identificar se nesta situação o aluno foi ou não aprovado. Com esses dados, algumas análises foram feitas para buscar entender melhor o desempenho dos alunos que são da área de Computação e os das demais áreas.

Verificamos a quantidade de alunos que cursam a disciplina de introdução à programação por ano e obtivemos uma média de 3.756 matrículas. O total de matrículas e a média de alunos por turma pode ser visto na Tabela 3.8. Analisando os resultados obtidos por esses alunos e considerando cada matrícula com o mesmo peso, observamos que $70 \%$ resultaram em aprovação, $27 \%$ em reprovação por nota e/ou frequência e 3\% em trancamentos. Quando consideramos ano a ano, temos como resultado um percentual de $31 \%$ de reprovações e trancamentos juntos em 2010, 32\% - o maior índice - em 2011 e 2014, 30\% em 2012 e o menor índice em 2013, 26\%. Estatisticamente, não é possível afirmar que há diferença significativa entre os anos analisados quanto às médias de reprovação, segundo o teste não-paramétrico de Kruskal-Wallis.

\begin{tabular}{c|c|c|c}
\hline Ano & Total de Turmas & Total Matrículas por Ano & Média Matrículas por Turma \\
\hline $\mathbf{2 0 1 0}$ & $\mathbf{7 3}$ & $\mathbf{4 0 7 3}$ & 55,8 \\
\hline $\mathbf{2 0 1 1}$ & 66 & $\mathbf{3 7 8 7}$ & 57,4 \\
\hline $\mathbf{2 0 1 2}$ & 63 & 3679 & 58,4 \\
\hline $\mathbf{2 0 1 3}$ & 59 & 3643 & 61,7 \\
\hline $\mathbf{2 0 1 4}$ & 60 & 3602 & 60,0 \\
\hline Totais & $\mathbf{3 2 1}$ & $\mathbf{1 8 7 8 4}$ & $\mathbf{5 8 , 7}$ \\
\hline
\end{tabular}

Tabela 3.8: Total de turmas, matrículas e média de alunos por turma, por ano, referente às 26 disciplinas da Etapa 2.

SQP1-E2 - Quais são os resultados em termos de notas e reprovações/trancamentos das disciplinas de introdução à programação na USP? - Quando separamos os alunos da área de computação em um grupo e os demais em outro, verificamos que os alunos dos cursos da área de computação são reprovados com menos frequência (Figura 3.5), uma diferença estatisticamente significativa de $1,1 \%$, considerando todas as matrículas (Total). No caso de alunos cursando a disciplina pela primeira vez ( $1^{\mathrm{a}}$ vez), essa diferença percentual é maior $(8,2 \%)$. 


\section{Comparação entre 4 disciplinas oferecidas no primeiro semestre de Ciência da Computação da USP (IME)}

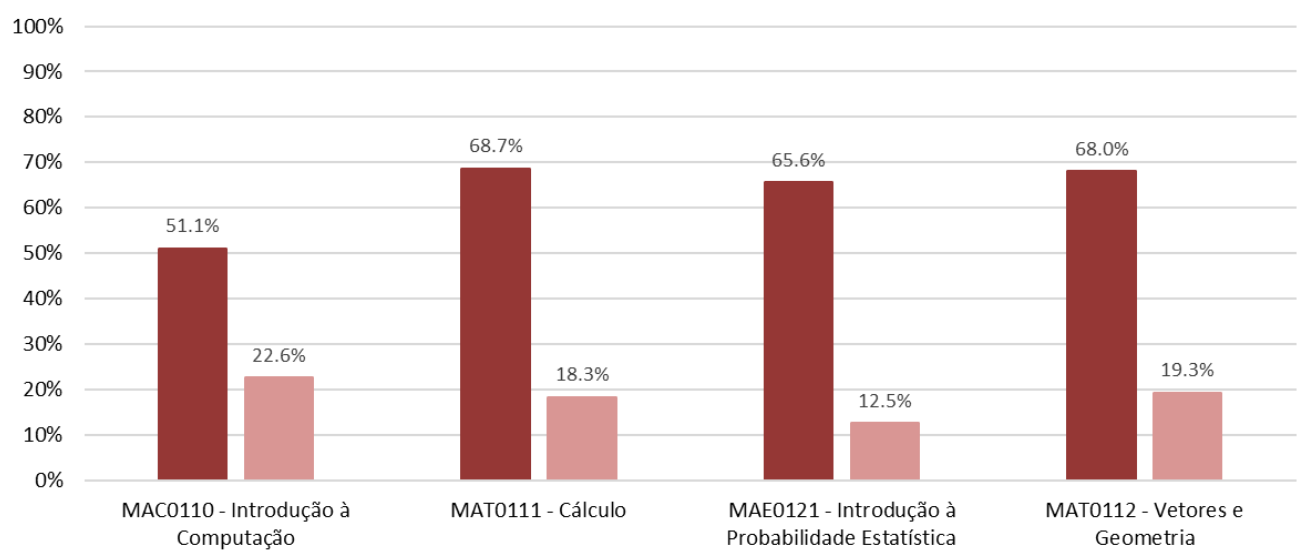

Comparação entre as disciplinas oferecidas no primeiro semestre de Sistemas de Informação da USP

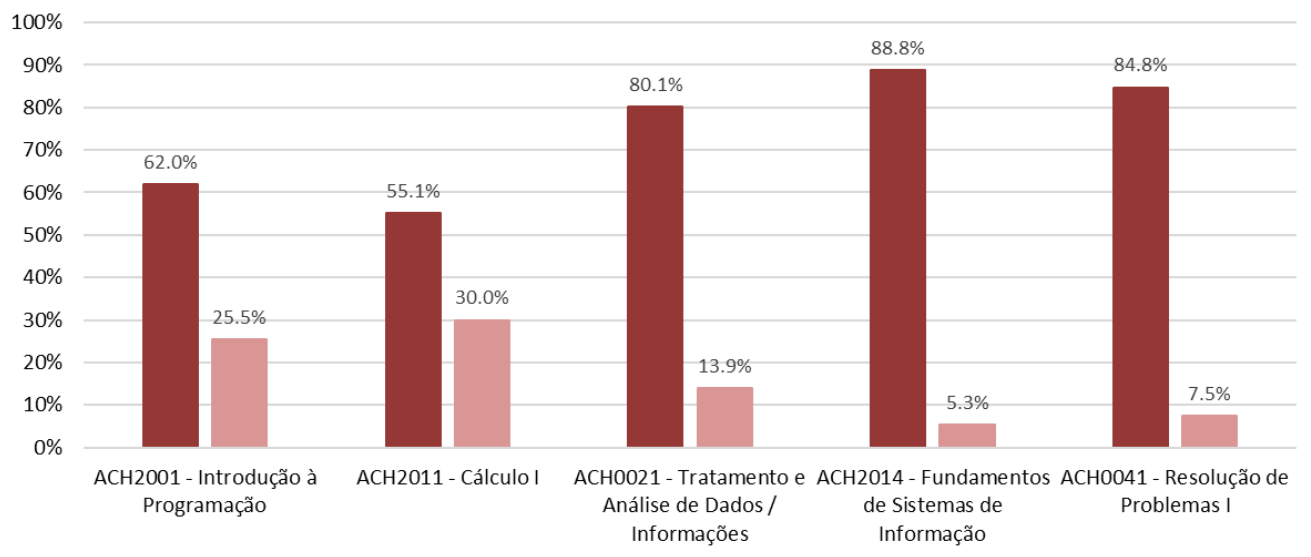

\section{Comparação entre as disciplinas oferecidas no primeiro} semestre de Engenharia de Computação da USP (Poli)

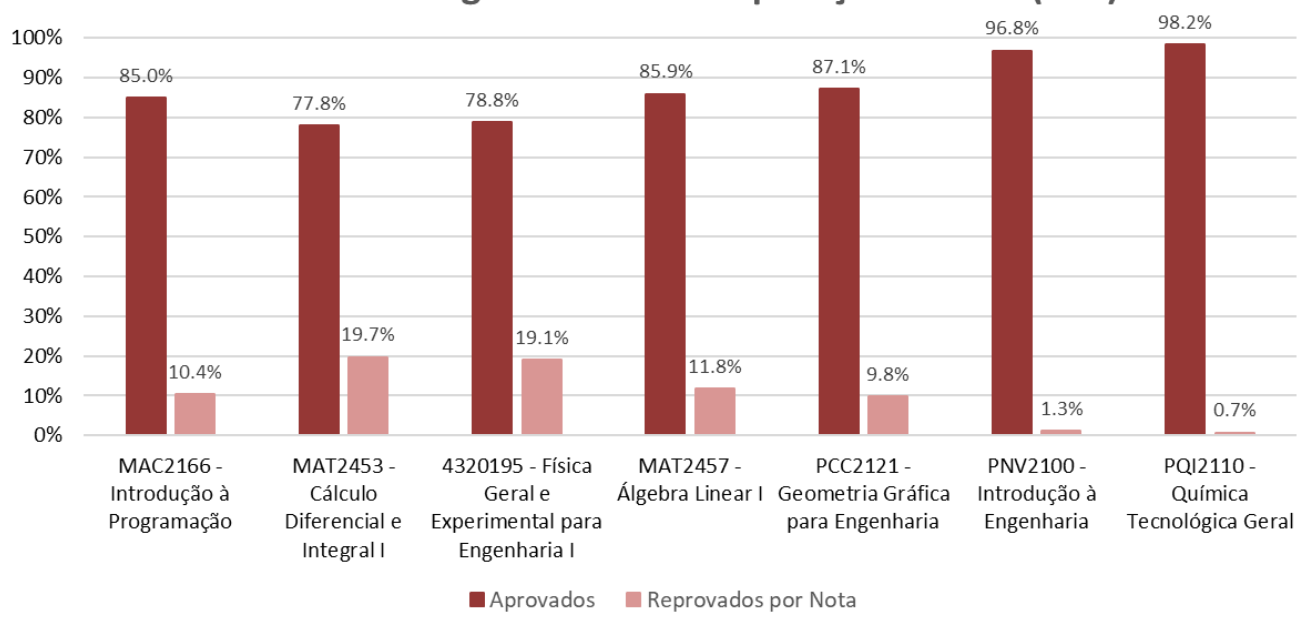

Figura 3.4: Percentual de aprovações e reprovações por nota dos alunos que frequentaram uma das disciplinas do primeiro semestre da grade curricular dos cursos da área de computação dos campi de São Paulo (capital) - USP. 


\section{Percentual de Reprovações e Trancamentos em Introdução à Computação}

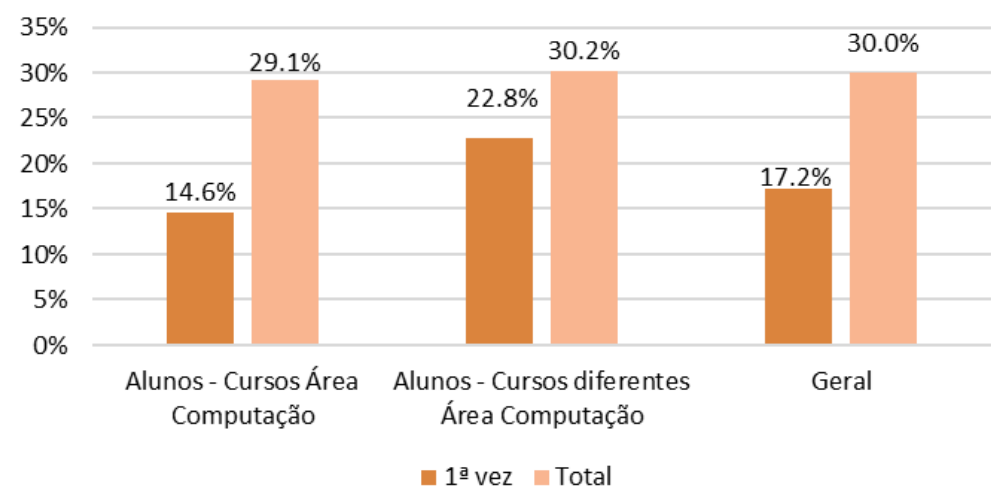

Figura 3.5: Percentual de Reprovações dos alunos que cursaram a disciplina pela primeira vez e geral, separados por cursos de Computação, dos demais cursos e visão completa da situação.

Analisamos também a quantidade de vezes que os alunos da área de computação e os demais cursaram a disciplina até obterem aprovação. Dos alunos dos cursos da área de computação, 24,5\% cursam duas ou mais vezes a disciplina para obterem aprovação. Já para os cursos de outras áreas, esse percentual cai para 14,8\% (Figura 3.6). É importante observar que, para essa análise, foram consideradas apenas as matrículas dos alunos que já obtiveram aprovação na disciplina, totalizando 12.722 matrículas: 10.821 dos alunos de cursos de outras áreas e 1.901 de alunos dos cursos da área de computação.

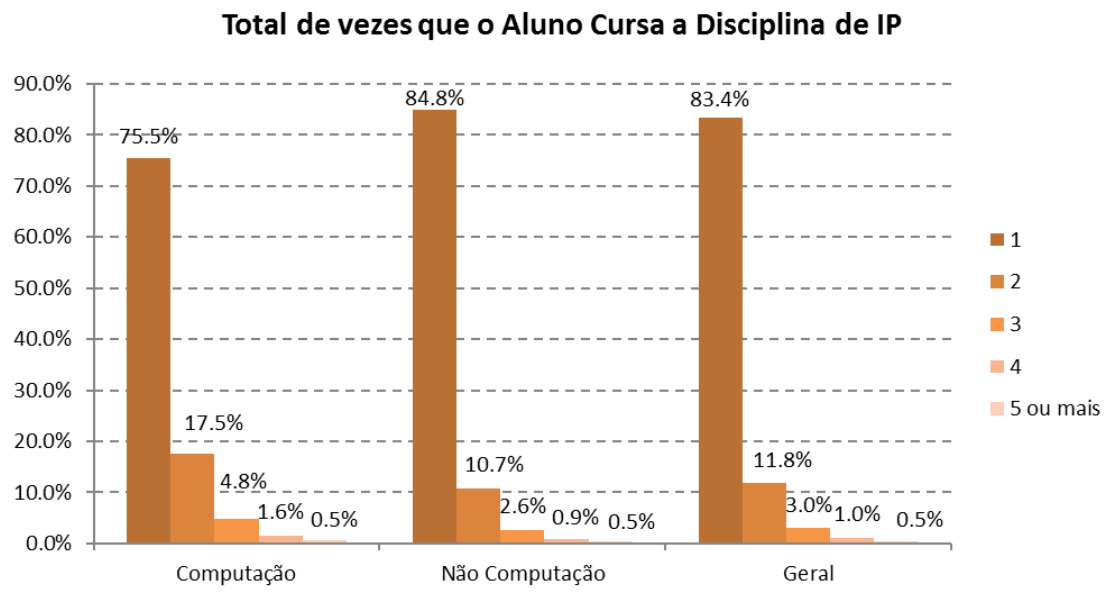

Figura 3.6: Percentual de vezes que os alunos de cursos de computação e demais áreas necessitam cursar a disciplina de introdução à programação para obterem aprovação na disciplina.

Há diversos fatores que podem influenciar o aprendizado dos alunos nessas disciplinas. Um deles é o conhecimento prévio do aluno em conteúdos considerados básicos para o desenvolvimento daquela habilidade. Outros podem ser os diferentes níveis de exigência, estratégias de ensino-aprendizagem, tecnologias adotadas, conteúdo didático, etc. dos professores que ministram a disciplina. Além disso, o nível de exigência também pode variar em função de a disciplina ser ou não de área afim ao curso. Outro fator a ser considerado neste contexto é a linguagem de programação adotada. 
Para analisar médias das turmas por professor e a linguagem de programação utilizada por eles, fizemos uma pesquisa com os professores vinculados ao Instituto de Matemática e Estatística - Departamento de Ciência da Computação da USP de São Paulo (IME-USP), Capital. Esses professores lecionam para turmas de diversos cursos/institutos. Foram feitas três perguntas por e-mail para 39 professores, dos quais obtivemos 36 réplicas, ou seja, uma participação de $92 \%$. Foram apresentadas, para cada professor, as turmas/ano que ele lecionou a disciplina e, com essa informação foi perguntado: (1) Qual a linguagem de programação que você adotou em cada uma delas?; (2) Qual foi a IDE (CodeBlocks, Dev C++, Eclipse, ...) ou outra ferramenta de apoio utilizada? e (3) Alguma metodologia diferenciada em alguma delas? Juntando as respostas obtidas e os dados que já possuíamos, fizemos análises complementares. Uma das constatações foi que as médias das notas por professor variaram de 3,0 a 7,1 no geral, sendo que 20 dos 36 professores obtiveram nota média nas turmas abaixo de 5,0, que é a média de aprovação da USP, conforme mostrado na Figura 3.7, ordenado por "1a vez".

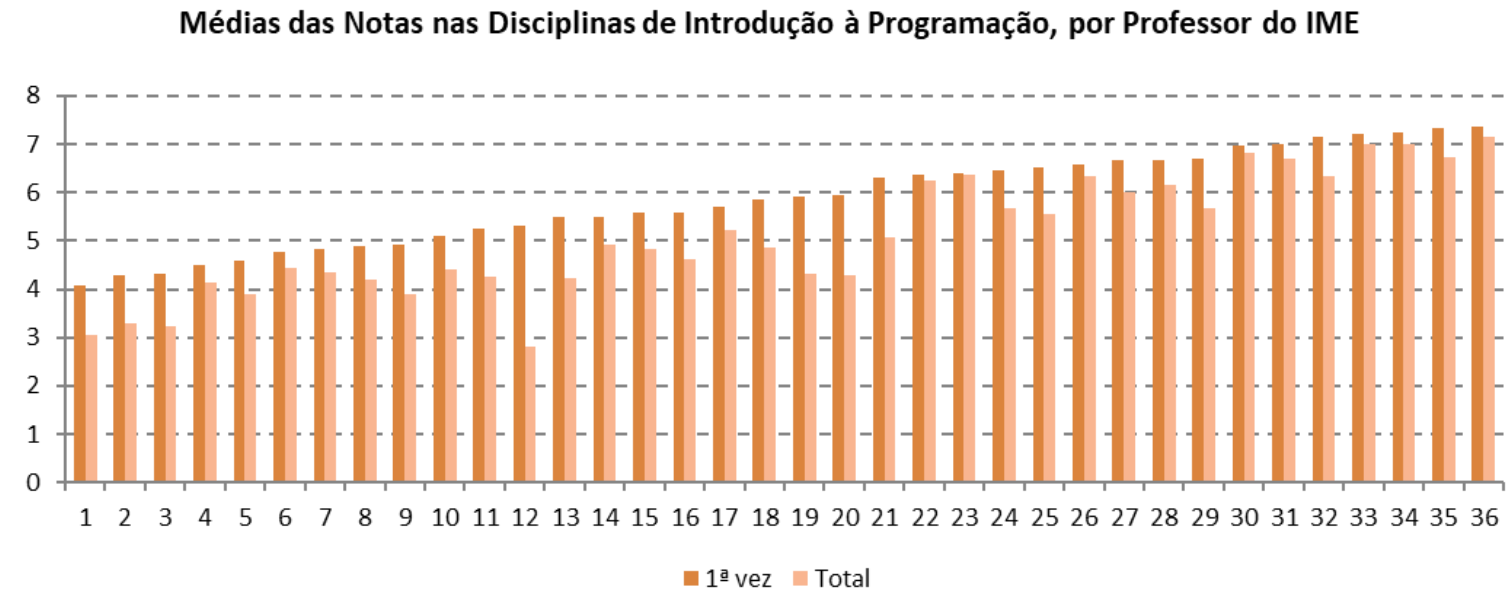

Figura 3.7: Médias das notas obtidas pelos alunos dos professores do IME-USP-SP, nas disciplinas de IP.

Quanto às linguagens, observamos que, ao longo dos cinco anos, a linguagem de programação C foi a mais utilizada, com exceção do ano 2013, no qual Python se sobressaiu (Figura 3.8). Python ficou como a segunda linguagem mais utilizada, seguida de VBA e, por último, Java. Cabe ressaltar que em algumas turmas o professor tem liberdade de escolher a linguagem, enquanto em outras ela é padronizada pelo curso, como é o caso do uso do VBA para as 4 turmas anuais na Faculdade de Economia, Administração e Contabilidade.

Os professores do IME-USP utilizaram, no período analisado, o Code::Blocks (mais popular), Eclipse, OpenGL e Dev-C++ para ensinar com C; DrJava (mais popular), BlueJ e Greenfoot para ensinar com Java; Excel quando utilizaram a linguagem VBA; e IDLE para Python.

\subsection{Limitações e Ameaças à Validade}

Alguns fatores levam à possibilidade de erros nos dados divulgados, como a possiblidade de erro na extração e compilação dos dados do sistema. Para evitar isso, foram 
Percentual de Turmas que Utilizaram cada Linguagem

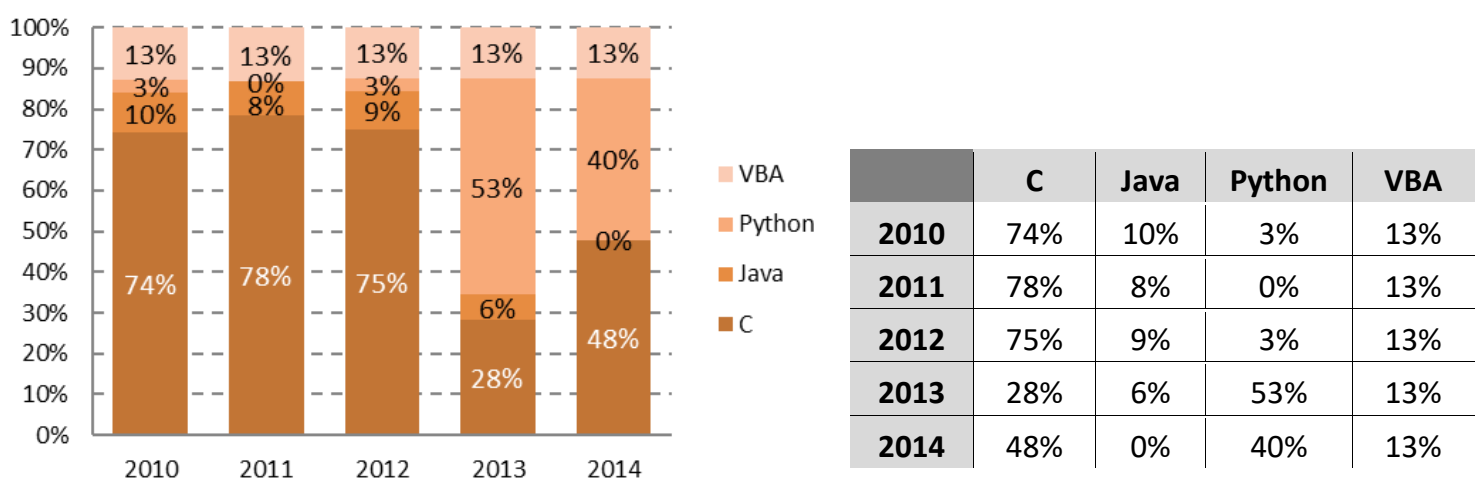

Figura 3.8: Percentuais de utilização das quatro linguagens citadas pelos professores do IME-USPSP, nas disciplinas de introdução à programação entre 2010 e 2014.

selecionados vários dados para checagem manual, comparando-os com outras fontes (planilha de professor, relatório do sistema, etc.).

Na separação por cursos da área de informática, o fato de, em alguns anos, os alunos da Escola Politécnica de Engenharia optarem após o ciclo básico pela habilitação em Engenharia da Computação pode fazer com que seus dados não tenham sido contabilizados. Além disso, ocorreram mudanças nos cursos de Engenharia de Computação, mudando seus códigos. Essas mudanças podem ter causado a não contabilização dos dados de alguns dos anos.

Outro fator relevante é o das matrículas que possuem situação final "Não Cadastrado". Essa situação refere-se ao fato da disciplina estar vinculada a uma outra e nesta outra estar a situação final. Esses casos foram desconsiderados neste estudo e isso poderia gerar alguma diferença quanto ao percentual de aprovações e reprovações/trancamentos.

\subsection{Conhecimentos Adquiridos}

Os resultados apresentados por estas análises dos bancos de dados disponibilizados pela USP corroboraram com os resultados de outros estudos, como o de BENNEDSEN e CASPERsen (2007). Considerando as disciplinas de introdução à programação lecionadas na USP e analisadas neste estudo, o percentual médio de reprovações e trancamentos é superior a $29 \%$ e, no decorrer dos cinco anos, este percentual manteve-se praticamente constante. Os alunos que frequentam cursos que não são da área de computação tiveram um índice de reprovação maior do que os alunos que são da área. Analisando-se as disciplinas individualmente, este percentual mostrou-se bastante variado, chegando a uma diferença de 56,27 pontos percentuais entre a com maior e a com menor índice de reprovação. Outro dado que foi levantado é que mais de $25 \%$ dos alunos que foram aprovados no período de 2010 a 2014 tiveram que cursar 2 ou mais vezes a disciplina de introdução à programação e que essa disciplina é uma das que mais reprova entre as do primeiro semestre dos cursos de computação. 
Os resultados apresentados mostram ainda que a linguagem $C$ é a linguagem mais utilizada pelos professores do IME-USP, com percentual médio de $62 \%$. Porém, ela vem perdendo espaço para a linguagem Python. Em 2010 a linguagem C era utilizada em 74\% das turmas e em 2014, esse número baixou para 48\%, enquanto que em Python foi de $3 \%$ em 2010 para $40 \%$ em 2014. Vale lembrar que as linguagens foram adotadas em diferentes cursos e por diferentes professores. Esses valores podem ter várias influências, como o nível de cobrança do professor que a leciona, visto que as médias por professor variam entre 3,0 e 7,1 . 


\section{Capítulo 4}

\section{Dificuldades para Aprender a Programar no Ponto de Vista de Alunos e Professores}

As análises do Estudo 3, da Fase 1 da metodologia dessa tese (Figura 1.1), que serão descritas neste capítulo foram realizadas com o intuito de conhecer mais e de forma mais aprofundada as dificuldades que os alunos enfrentam durante o aprendizado de programação. Para chegarmos nesse objetivo, foram coletados dados de alunos, através de preenchimento de diários, e de professores, através de entrevistas semi-estruturadas. Para nos guiar nessa tarefa, foram usadas as questões de pesquisa 2 e 3 desta tese, conforme apresentadas abaixo:

QP2 - Quais são as dificuldades referentes ao aprendizado de programação na perspectiva de alunos e professores?

\section{QP3 - Como as dificuldades mudam conforme a linguagem de programação usada?}

Primeiramente foram analisados os dados buscando por dificuldades que os alunos apresentavam para compreender o conteúdo abordado. Um conjunto de dificuldades por conteúdo foi catalogado, respondendo a QP2, conforme apresentado na Seção 4.2. Os resultados da primeira parte da análise foram divulgados com um artigo publicado na Revista IEEE da América Latina (Bosse e Gerosa, 2017). Além disso, durante as entrevistas com os professores, foram citadas muitas estratégias didáticas usadas para minimizar essas dificuldades. Essas estratégias são apresentadas e comentadas na Seção 4.2.1. Os resultados gerais - dificuldades e estratégias - foram apresentados na Conferência Anual sobre Inovação e Tecnologia no Ensino de Ciência da Computação (ITiCSE’19), na Escócia (Bosse, Redmiles et al., 2019b).

Durante as análises dos diários e entrevistas vimos que, em muitos casos, a dificuldade apresentada não era sobre o conteúdo que os alunos estavam estudando no momento ou que os professores estavam comentando nas entrevistas. Para entendermos melhor o que estava acontecendo e onde esse tipo de situação ocorria, realizamos uma nova análise sobre os dados dos diários e entrevistas. Os resultados obtidos mostram conexões 
entre os conteúdos que influenciam no aprendizado da programação, sendo que a falta de conhecimento apropriado em um determinado conteúdo pode gerar dificuldade no aprendizado de outro. Esses resultados são apresentados na Seção 4.3 e foram divulgados no artigo apresentado na Conferência Anual Fronteiras na Educação (IEEE FIE’19), nos Estados Unidos (Bosse, Redmiles et al., 2019a). Em seguida, buscamos responder a QP3 separando por linguagem as dificuldades apresentadas no aprendizado dos conteúdos (Seção 4.4). Nessa seção são apresentadas também dificuldades gerais citadas pelos alunos e uma análise das turmas envolvidas.

A seguir, apresentamos uma descrição geral da metodologia utilizada no Estudo 3 descrito acima.

\subsection{Metodologia Geral}

A metodologia utilizada nas três análises do Estudo 3 para os três estudos mencionados acima (das dificuldades, das conexões entre conteúdos e das dificuldades por linguagem de programação) difere em alguns pontos, principalmente no foco dado para a análise, visando chegar ao objetivo proposto para cada um deles. Porém, a coleta de dados e as etapas da análise são idênticas para todos. A Figura 4.1 mostra uma visão geral da metodologia utilizada, que é detalhada a seguir.

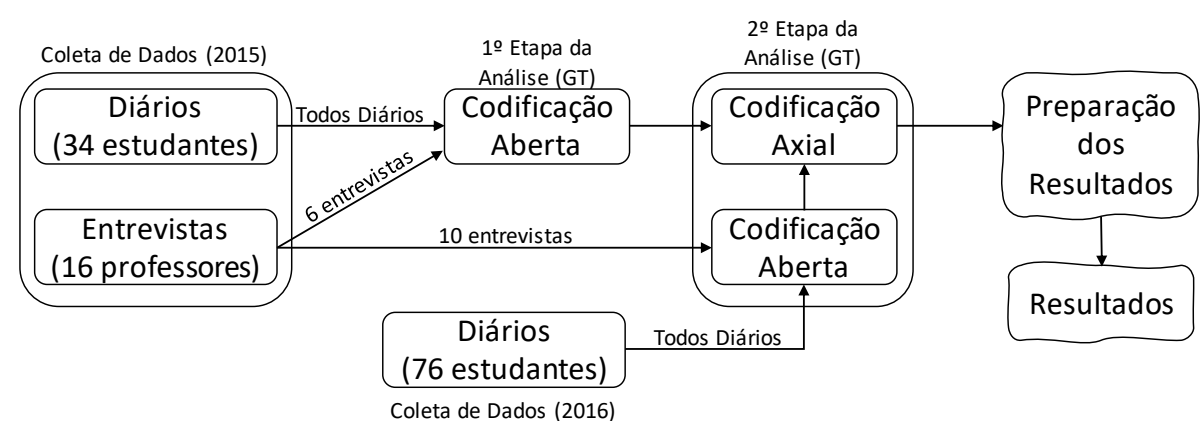

Figura 4.1: Visão geral da metodologia usada.

\subsubsection{Coleta de Dados}

Para o estudo das dificuldades com o conteúdo e das conexões entre tópicos brevemente descritos acima, foram utilizadas duas fontes de dados. A primeira fonte foram entrevistas semiestruturadas (J. W. Creswell e J. D. Creswell, 2017) com professores de introdução à programação. Focamos nos tópicos ministrados nas disciplinas de introdução à programação para obter uma perspectiva do professor quanto às dificuldades enfrentadas pelos alunos no aprendizado de programação e também das suas experiências de ensino. Dezesseis professores do Departamento de Ciência da Computação da USP foram selecionados para entrevistas. Cerca de 30 professores do departamento haviam ministrado esse curso pelo menos uma vez. Os seis primeiros professores entrevistados foram aqueles que ensinavam introdução à programação para as seis turmas do ano de 2015, cujos alunos mantinham diários sobre as dificuldades de aprender a programar. Os outros 10 foram selecionados aleatoriamente. Se necessário, mais professores seriam selecionados, porém 
a análise mostrou que os dados estavam se repetindo, indicando que esse número de entrevistas era suficiente. Cada professor foi identificado com um ID formado por um "P", seguido de um número de 1 a 16. A Tabela 4.1 mostra o número de anos de experiência como professor e o gênero de cada um deles.

\begin{tabular}{|c|c|c|}
\hline IDs & Tempo de Experiência & Gênero \\
\hline P1 - P3 & Mais de 40 anos & 1F e $2 \mathrm{M}$ \\
\hline P4-P5 & De 31 a 40 anos & 2M \\
\hline P6-P7 & De 21 a 30 anos & 2M \\
\hline P8-P12 & De 11 a 20 anos & 2F e 3M \\
\hline P13-P16 & De 1 a 10 anos & $4 M$ \\
\hline
\end{tabular}

Tabela 4.1: Tempo de Experiência e gênero dos 16 professores entrevistados.

As entrevistas começaram com uma pergunta muito geral: 'Na sua opinião, quais são as dificuldades enfrentadas pelos alunos nas disciplinas de introdução à programação?'. Durante a entrevista, o entrevistador ia orientando o professor a falar dos tópicos abordados em sala, conforme lista a seguir: variáveis, comando de atribuição, comandos de entrada e saída, expressões aritméticas , expressões relacionais $(<,>,=, \ldots)$ e lógicas (e, ou, não), estruturas de seleção (se ... senão), estruturas de repetição (enquanto, para ...), manipulação de strings, matrizes bidimensionais, dados estruturados, funções e ponteiros. Os tópicos foram selecionados através da análise do conteúdo programático das disciplinas de introdução à programação da universidade e, em seguida, comparados com o conteúdo abordado nos trabalhos publicados da área, confirmando nossa seleção. A maioria das entrevistas levou cerca de meia hora, mas algumas duraram até uma hora. Todas as entrevistas foram gravadas e transcritas para análise posterior.

A segunda fonte de coleta de dados foram diários preenchidos por alunos que estavam frequentando uma das disciplinas de introdução à programação. Coletamos dados de 6 turmas em 2015 (34 alunos) e de 6 turmas em 2016 (76 alunos), de pelo menos 7 departamentos distintos, gerando um total de 110 diários de alunos. Desses diários, 42 eram de alunos que estavam usando Python e 68 alunos estavam usando C. As turmas tinham em média 53 alunos, sendo que a menor tinha 29 e a maior 76 aprendizes. Todos os participantes assinaram um termo de consentimento nos dando permissão para ler e usar os dados dos diários, mantido o anonimato. Os diários foram organizados em documentos compartilhados no Google Docs especialmente para essa pesquisa e seu preenchimento não valeu nota para os alunos participantes. Pedimos aos alunos que incluíssem trechos de código, especialmente os com erros, além da abordagem usada para corrigir os erros e as dúvidas que eles tinham sobre o aprendizado dos tópicos. Para esclarecer possíveis mal-entendidos sobre o texto escrito pelos alunos e incentivá-los a manter seus diários, os pesquisadores colocavam perguntas nos diários quando necessário. Foi pedido também que os diários fossem mantidos durante toda a duração da disciplina. No entanto, alguns estudantes pararam de preencher o diário antes do término do curso. Cada aluno foi identificado com um ID, composto por um "S", seguido de um número de 1 a 110 . Quando necessário, foi acrescentado ao final um parênteses contendo um "C" ou um "P" para identicar a linguagem que o aluno estava usando. A Tabela 4.2 mostra o total e o percentual de alunos por faixa etária e pelo número de vezes que frequentaram o curso anteriormente (Tentativas Anteriores). 


\begin{tabular}{|c|r|r|c|r|r|}
\hline Idade & Total & $\%$ & Tentativas Anteriores & Total & $\%$ \\
\hline Não informado & 1 & 1 & 0 & 81 & 74 \\
\hline $15-24$ & 84 & 76 & 1 & 17 & 15 \\
\hline $25-34$ & 17 & 15 & 2 & 6 & 5 \\
\hline $35-44$ & 6 & 5 & 3 & 4 & 4 \\
\hline $45-54$ & 1 & 1 & 4 & 1 & 1 \\
\hline $55-64$ & 1 & 1 & 5 & 1 & 1 \\
\hline
\end{tabular}

Tabela 4.2: Faixa etária dos alunos e o número de vezes que frequentaram a disciplina.

\subsubsection{Análise dos Dados}

Para a análise dos dados, utilizamos técnicas da Teoria Fundamentada (Grounded Theory - GT), conforme descrito por J. Corbin e Strauss (2014). Durante a análise, surgiram conceitos, categorias e subcategorias. Segundo J. M. Corbin e Strauss (1990), os procedimentos da teoria fundamentada são projetados para desenvolver um conjunto bem integrado de conceitos que fornecem uma explicação teórica completa dos fenômenos sociais em estudo. Os agrupamentos desses conceitos em um grau mais alto de abstração são chamados de categorias (J. Corbin e Strauss, 2014). Para a análise, são utilizados três tipos básicos de codificação do GT: a codificação aberta, axial e a seletiva. A seletiva está representada na Figura 4.1 por "Preparação dos Resultados". A codificação aberta é o processo de decomposição dos dados; na codificação axial, as categorias são relacionadas às suas subcategorias e às relações testadas com os dados; e na codificação seletiva, as categorias são unificadas em torno de uma categoria principal (J. M. CoRbIN e STRAuss, 1990).

Os dados foram lidos e analisados e as informações relevantes foram marcadas com uma etiqueta, caracterizando um conceito. Agrupando esses conceitos, emergiram 8 categorias das entrevistas e 10 dos diários. Algumas delas aparecem em ambos, por exemplo, 'Dificuldades com os tópicos' e 'Estratégias Didáticas'. O próximo passo foi a codificação axial, quando todo texto marcado foi lido novamente para buscar as informações que se desejava, conforme a análise em andamento.

Na primeira análise (Seção 4.2), que buscava por dificuldades e estratégias, a releitura foi feita para identificar essas informações nos dados, além das ligações entre ambas (dificuldades e estratégias). Os resultados obtidos com essa análise foram validados por 6 professores experientes, confirmando a leitura das dificuldades encontradas nos dados. Em seguida, os dados foram apresentados para 6 professores inexperientes para verificar suas opiniões sobre a importância dos resultados obtidos na preparação das suas aulas. Esses professores haviam ministrado no máximo três vezes a disciplina de introdução à programação e trabalhavam em universidades de diferentes estados do Brasil.

A segunda análise (Seção 4.3) utilizou-se da releitura do texto marcado em entrevistas e diários para identificar conexões entre as subcategorias; As conexões foram criadas sempre que o conhecimento sobre um conteúdo era necessário para desenvolver o conhecimento em outro. As Figuras 4.3 a 4.15 mostram essas conexões de forma geral. Durante a codificação axial, as subcategorias foram reorganizadas para melhor atender o objetivo do estudo. O último passo foi analisar as conexões para entender o que elas revelavam, gerando assim os resultados.

Por fim, no terceiro estudo (Seção 4.4) a releitura abrangeu somente os diários. As 
entrevistas não foram usadas pelo fato dos professores terem feito os comentários basicamente sobre a linguagem $C$, sendo que ponderações referentes a Python são praticamente inexistentes. O objetivo foi buscar informações separadas por linguagem. Além disso, foi feita uma análise dos resultados gerados pelas 12 turmas participantes utilizando-se dos diários de classe com os resultados finais.

\subsection{Dificuldades Quanto ao Conteúdo}

O primeiro estudo buscou identificar, na visão de alunos e professores, as dificuldades enfrentadas pelos aprendizes durante o aprendizado de programação. As dificuldades apresentadas foram divididas por tópicos abordados nas disciplinas de introdução à programação. A Figura 4.2 apresenta um diagrama com conjuntos de dificuldades por tópicos. Essas dificuldades foram classificadas em três níveis. O nível 1, marcado com duas estrelas, compreende dificuldades consideradas mais impactantes para a aprendizagem da programação. O nível 2, com uma estrela, é o nível intermediário e o nível 3, sem estrelas, é o menos impactante. Após cada dificuldade aparece o número de vezes em que ela foi citada pelos 16 professores, seguido da letra de 'p', e o número de vezes em que ela foi citada pelos 110 alunos, seguido da letra 's': XpYs. Um exemplo é a dificuldade "Como usar" variáveis da Figura 4.2, onde o "3p9s" significa que 3 alunos e 9 professores citaram essa dificuldade.

Encontramos dificuldades relacionadas a 10 tópicos ensinados nas disciplinas de introdução à programação: Variáveis, Expressões, Funções de Entrada / Saída, Estruturas de Seleção e Repetição, Matrizes e Vetores, Funções, Ponteiros e Cadeia de Caracteres. Uma das dificuldades do primeiro nível de classificação é inicialização de variáveis, conforme mostrado no tópico VARIÁveIs do diagrama. Muitos alunos não sabem se é necessário inicializar e com que valor: "Ao compilar deu tudo certo, no entanto o resultado final (max) deu um número gigantesco. Problema arrumado, não havia colocado o valor inicial da variável max..." - S18. Além disso, a diferença no tratamento de variáveis na matemática e na programação pode gerar dúvidas, como explicado por P14: "Depois tem ' $x=x+1$ ' $e$ esses alunos com dificuldade não entendem que, se você lê como na matemática, 'x é igual a $x+1$ ', (o aluno retruca) 'mas é impossivel $x$ ser igual a $x+1$ '. Mas que na verdade não é igual, é uma atribuição".

Trabalhando com ExPREssõEs, os resultados mostram dificuldades relacionadas a detectar resultado errado devido a problemas de tipo de dados: "...quando é operação numérica, é difícil eles perceberem o erro. Então, por exemplo, um algoritmo que é pra calcular, fazer uma média, ... dá zero (como resultado) e eventualmente o aluno demora pra perceber que ele usou inteiro e não ponto flutuante" - P7. Outra fonte de dificuldade é escrever expressões lógicas. Segundo P14, “...tem uma coisa que existe em linguagem natural e que normalmente não existe em linguagem de programação, é você falar algo do tipo ' $x>3 e$ $<5$ ' e em computação eu não posso escrever assim, tem que escrever ' $x>3$ e $x<5$ ', então eles escrevem errado, eles escrevem ' $x>3 e<5$ ”'. Os alunos acham difícil escrever expressões lógicas na sintaxe da linguagem de programação, que geralmente é diferente daquela usada na matemática e na linguagem natural. E, como já citado por Hristova et al. (2003), há confusão entre ' =' and '=='. Segundo S34, isso é um erro cometido constantemente: "Escrevi o programa e notei algumas dificuldades que enfrento constantemente como ... se 


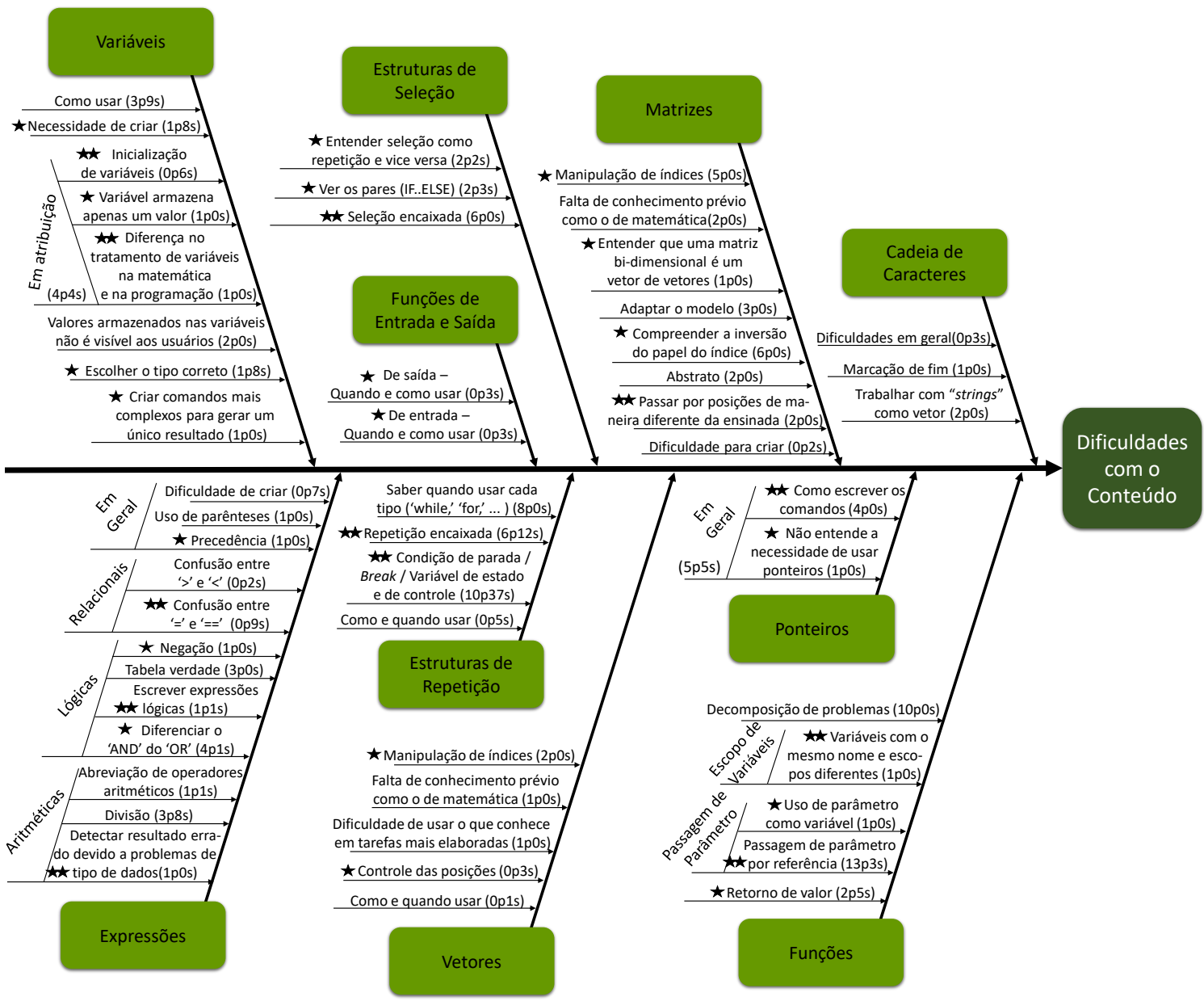

Figura 4.2: Diagrama apresentando uma lista de dificuldades por tópicos ensinados nas disciplinas de introdução à programação.

devo usar '=' ou '==' dentro dos condicionais ou laços'.

Em relação a Estruturas de SeleçÃo, a tarefa mais complicada é trabalhar com seleção encaixada, ou aninhada, com um conjunto de pares 'IF..ELSE': "Quando eu tinha um aninhamento, uma seleção dentro de outra, aí gerava uma grande confusão" - P15. Da mesma forma, o mais complicado de aprender em EsTRUTURAS DE REPETIÇÃo é a criação e uso de repetições encaixadas, ou aninhadas, ou seja, duas ou mais estruturas de repetição, uma dentro da outra, sendo a manipulação de matrizes um exemplo clássico de uso de repetições aninhadas. Outras dificuldades incluem a criação da condição de parada e manipulação da variável de controle. De acordo com P15, os alunos começam a usar a variável de controle sem sequer inicializá-la, “... trabalham uma variável numa condição de parada antes de atribuir um valor inicial a essa variável" e, em seguida, utilizam indevidamente os operadores de incremento ou decremento para que satisfaçam a condição de parada desejada: “... o desafio deles gerarem uma estrutura de repetição então era o que era uma condição de parada, como definir uma condição de parada e como, num primeiro momento, fazer um incremento de uma variável para que ela satisfaça uma condição de parada". Manipular variáveis também é uma tarefa necessária para trabalhar com MATRIZES, onde passar por posições de maneira diferente da ensinada é uma fonte de 
dificuldade, como exemplificado por P11: “... se a gente usa a matriz, por exemplo, para representar o tabuleiro de um jogo e pede pra percorrer na diagonal, ou de trás pra frente,... aí a coisa começa a ficar confusa. Principalmente se o ' $i$ ' e o ' $j$ ' (variáveis usadas para indicar a posição na linha e coluna) que estão ali começam a aparecer em ordem trocada".

Finalmente, para P4, ao ensinar Ponteiros, "a encrenca começa a ficar maior". Ponteiros são citados por muitos pesquisadores como um dos tópicos mais difíceis (MHASHI e Alakeel, 2013; Piteira e C. Costa, 2013; Sevella et al., 2013), e os resultados desse estudo confirmaram isso, como pode ser observado no comentário de P11: "Mas de conteúdo mesmo da disciplina eu acho que o mais difícil era mesmo para eles entenderem a questão de ponteiros". P13 relata que os alunos "acabam mais decorando" e acrescenta "eu acho que eles conseguem entender, mais pro final do segundo semestre", ou seja, somente na disciplina seguinte. Muitos até evitam ensinar ponteiros: "a gente tenta evitar também falar de ponteiros" - P10. Outros acabam mostrando apenas porque os ponteiros são necessários para passar parâmetros por referência, e a principal dificuldade é como escrever os comandos usando ponteiros. Trabalhando com FunçõEs, além da dificuldade com passagem de parâmetro por referência que usa Ponteiros, os alunos confundem variáveis com o mesmo nome e escopos diferentes.

\subsubsection{Estratégias Didáticas}

Durante as entrevistas, os professores mencionaram estratégias didáticas usadas para ensinar os tópicos e evitar dificuldades que os alunos enfrentam. A seguir são apresentadas as dez estratégias mais citadas por eles; a Tabela 4.3 apresenta um resumo contendo, na terceira coluna, os tópicos ou dificuldades vinculadas a cada uma delas. O termo 'Geral' usado nessa coluna indica que a estratégia foi citada pelo menos uma vez em cada um dos tópicos abordados.

\begin{tabular}{c|c|l|l}
\hline ID & $\begin{array}{c}N^{\circ} \\
\text { Cit. }\end{array}$ & \multicolumn{1}{|c}{ Nome da Estratégia } & \multicolumn{1}{|c}{ Ela pode auxiliar no ensino de quais conteúdos? } \\
\hline S1 & 16 & Uso de recursos visuais & $\begin{array}{l}\text { Variáveis. Repetições encaixadas. Funções. Vetores e matrizes. } \\
\text { Geral }\end{array}$ \\
\hline S2 & 10 & $\begin{array}{l}\text { Uso de 'pseudocódigo e linguagem de } \\
\text { programação' como um ciclo para ensinar cada } \\
\text { novo conceito }\end{array}$ & Geral \\
\hline S3 & 9 & Resolver junto com os alunos na sala de aula & Geral \\
\hline S4 & 8 & Explicar com problemas ou exercícios similares & Geral \\
\hline S5 & 8 & $\begin{array}{l}\text { Omitir alguns conceitos e detalhes da linguagem } \\
\text { de programação }\end{array}$ & $\begin{array}{l}\text { Ponteiros - como escrever os comandos. Funções - passagens } \\
\text { de parâmetro por referência. Linguagens de programação- } \\
\text { sintaxe. Geral }\end{array}$ \\
\hline S6 & 8 & Uso de "receitas" & $\begin{array}{l}\text { Linguagens de programação - sintaxe. Matrizes - manipulação } \\
\text { de índices e percorrer as posições de maneira diferente da } \\
\text { ensinada. Ponteiros - não entender a sua utilidade. Funções - } \\
\text { retorno de valor. Geral }\end{array}$ \\
\hline S7 & 7 & Execução passo a passo & $\begin{array}{l}\text { Funções - escopo de variáveis. Estruturas de repetição - } \\
\text { condição de parada e manipulação da variável de controle. } \\
\text { Geral }\end{array}$ \\
\hline S8 & 6 & $\begin{array}{l}\text { Fazer analogias com conceitos / objetos } \\
\text { conhecidos }\end{array}$ & Variáveis. Expressões. Funções. Estruturas de seleção. Geral \\
\hline S9 & 6 & Prática intensiva & Geral \\
\hline S10 & 5 & Programar no projetor & Geral \\
\hline
\end{tabular}

Tabela 4.3: Estratégias didáticas usadas para evitar ou minimizar as dificuldades enfrentadas pelos alunos ao estudarem programação.

Uso de recursos visuais (S1). A abstração é um dos principais problemas do curso. É difícil para o aluno iniciante visualizar onde estão os dados, como são processados ou como 
os comandos funcionam: “... há dificuldade em trabalhar com conceitos abstratos...” - P9; P15 lembrou que "... aulas que no primeiro momento não funcionavam, você tinha que ter algo visual também" e citou um exemplo "Declaração de variável precisa ser visual ... falar que declarar uma variável vai ocupar um espaço na memória, essa abstração é um pouco difícil". O 'visual' pode ser desenho: “...eu desenho a memória...” - P9 ou fazendo uso de recursos como setas que representam a entrada e a saída dos dados em uma função, por exemplo: "eu sempre faço de uma forma gráfica as entradas e saídas, com flechas" P8. Outra forma de apresentação visual é o uso de "... animações, se eu precisasse mostrar isso visualmente..." - P15, acrescentando que "... existem muitos recursos visuais na internet...".

Uso de 'pseudocódigo e linguagem de programação' como um ciclo para ensinar cada novo conceito (S2). Poucos professores começam a disciplina com pseudocódigo para mais tarde passar para uma linguagem de programação, "Com o algoritmo em pseudolinguagem eu não vi muito sucesso... ter duas linguagens simultâneas não ia ser tão efetivo" - P16. A maioria dos professores entrevistados usa o pseudocódigo apenas para ensinar o conceito e, logo em seguida, mostra esse mesmo conceito na linguagem de programação: "...eu passo o conceito algorítmico e depois eu vou para o programa ... eu faço assim, idas e voltas" - P9. Segundo P14, "A linguagem de programação é uma ferramenta pra ensinar os algoritmos e estruturas de dados" e o pseudocódigo ou pseudolinguagem é rapidamente usada, sem muitas regras, somente para explicar o conceito.

Resolver junto com os alunos na sala de aula (S3). Essa é uma técnica muito usada para "... deixar eles (os alunos) participarem e tentarem montar o programa junto. Muitas vezes eu mostro o programa mesmo sabendo que está errado e a gente tenta achar (o erro)" $\mathrm{P} 12$. Muitos professores relataram o uso dessa estratégia e afirmaram que ela funciona porque os alunos participam e porque eles podem ver o passo a passo de como o programa é desenvolvido.

Explicar com problemas ou exercícios similares (S4). Para introduzir e mostrar a utilidade dos conceitos que precisam ser ensinados na disciplina, uma estratégia é usar problemas: "Eu costumo começar a explicar um conteúdo através da descrição de um problema” - P16. Para P10, é uma forma de motivar os alunos, “... a gente tenta motivar usando alguns problemas", porque o aluno vê a utilidade do conceito na prática e aprende como ele deve ser usado. Entre a apresentação do primeiro problema ao aluno e de problemas mais complexos, P16 orienta "...trazer também pra aula exercícios que são parecidos mas que não resolvem exatamente aquele problema”. Dessa forma, o aluno pode praticar o conceito que foi ensinado e usá-lo em outras situações.

Omitir alguns conceitos e detalhes da linguagem de programação(S5). Detalhes da linguagem podem dificultar o desenvolvimento do código. Se o professor omitir alguns detalhes, eles podem melhorar o aprendizado inicial: " $A$ ideia era abstrair um pouco a sintaxe da linguagem" - P15. P5 acrescenta que “... se eu tiver que ensinar em C, não explico o comando de entrada de dados. Eu até brinco: 'olha Deus mandou fazer assim", pois se for explicar cada detalhe da sintaxe, o conteúdo não vai adiante. Além disso, conceitos também são omitidos quando são dispensáveis no momento. Um exemplo disso foi dado pelo P1, com a seguinte afirmação: "Passagem de parâmetros também é tudo por ponteiro, eu não preciso falar em ponteiro, eles fazem o exercício sem problemas... fica oculto pra eles esses 
conceitos, mas eles estão de fato usando".

Uso de 'receitas' (S6). Em conteúdos considerados mais complicados, como é o caso de passagem de referência que usa ponteiros, por exemplo: "Quando a gente dá em $C$ a gente faz a passagem por referência, mas a gente meio que dá uma 'receitinha', e fala assim, é usado o '\&' quando chamo a função e dentro da função é usado o '*”' - P12, ou seja, o professor fornece um passo-a-passo pronto de como deve ser feito. Essa estratégia evita explicações de sintaxe de linguagem muitas vezes desnecessárias para o momento, como é o caso da forma de escrita do 'scanf' e do 'printf' na linguagem de programação C.

Execução passo a passo (S7). Outra técnica usada com frequência é a execução passo a passo, para que os alunos vejam o que está acontecendo no programa, o que também os ajuda a encontrar erros existentes no código. Esta execução é feita no quadro ou mesmo usando o projetor. Tudo o que acontece, desde a alteração de valores nas variáveis até a saída de uma repetição ou alteração do escopo da variável, é mostrado linha por linha e analisado durante este exercício: "Usei slides que mostravam repetições acontecendo com a depuração do programa e passando por cada linha de instrução" - P15. No entanto, para estudantes mais avançados, esse exercício pode ser um pouco entediante.

Fazer analogias com conceitos / objetos conhecidos (S8). Isso envolve o uso de um exemplo cotidiano do mundo real, com situações familiares ao aluno, como sugeriu P5: "fazer uma associação com um problema do mundo real aonde você tem o mesmo tipo de situação. Acho que isso faz sentido, então isso ajuda bastante”. Em referência a expressões aritméticas, lógicas e relacionais, $\mathrm{P} 1$ disse que "eles (os alunos) confundem muito ... comecei com exemplos do dia a dia" e P14 reforça que ele considera "... isso uma coisa fundamental, exercícios que têm a ver com o universo do aluno".

Prática intensiva (S9). Cinco professores citaram prática intensiva durante as entrevistas, corroborando os resultados apresentados por Mhashi e Alakeel (2013). Segundo P13, "O aluno tem que chegar, sentar, estudar, ... resolver o maior número de exercícios possíveis eu acho. É bem estilo Kumon. É treinar, treinar, treinar”. O feedback também é importante, como disse o P14 - "Eu dou muito exercício pra eles fazerem em sala de aula, daí eles fazem no papel..., se tem três soluções, eu peço pros 3 alunos irem (no quadro) $e$ mostro as três soluções diferentes. Aí a gente discute as 3 soluções".

Programar no projetor (S10). Por fim, essa estratégia inclui o desenvolvimento do código durante a aula, projetando-o para que o aluno possa ver e participar, além de fazer alterações e mostrar os resultados de forma colaborativa: "eu uso lousa e projetor ... escrevendo um programa no ato e rodando" - P2; P11 disse que isso "...faz uma diferença significativa".

Conforme comentários feitos durante as entrevistas, as estratégias didáticas são usadas normalmente em conjunto, sendo raro o momento em que apenas uma técnica esteja sendo usada. Outro ponto importante de ser comentado é que o uso das estratégias didáticas deve ser algo pensado para que a técnica seja proveitosa para o ensino e aprendizagem de programação. Para verificar a importância da lista apresentada acima, uma validação foi realizada, conforme mostrado na subseção seguinte. 


\subsubsection{Validação}

Após a compilação dos resultados das dificuldades apresentadas na Figura 4.2 e das estratégias didáticas compiladas na Tabela 4.3, esses foram validados por 6 dos 16 professores experientes entrevistados na fase de coleta de dados. Nessas novas entrevistas, cada um deles foi questionado quanto à validade das dificuldades por tópico encontradas, assim como sobre as estratégias didáticas listadas. Durante essas entrevistas, uma nova ideia surgiu: uma sugestão para classificar as dificuldades por nível de impacto na aprendizagem da programação, conforme explicado na Seção 4.2.

Após a confirmação que os resultados das nossas análises estavam coerentes, seis professores inexperientes $(\mathrm{Pu})$ foram entrevistados. O pedido principal que norteou a entrevista foi que eles comentassem sua visão sobre a importância das dificuldades e estratégias apresentadas. As dificuldades foram mostradas a eles sem a classificação apresentada no diagrama da Figura 4.2. Mesmo desconhecendo a sugestão dada pelo professor experiente, dois deles comentaram a importância da classificação, como indicado no comentário a seguir, feito por $\mathrm{Pu} 4$ : “... a lista de dificuldades poderia me ajudar a organizar minhas aulas, mas acho que, se as dificuldades tivessem uma classificação, mostrando quais delas são as mais prejudiciais para os alunos que aprendem programação, seria mais fácil usar na prática...”.

Todos os seis professores inexperientes entrevistados disseram que as listas de dificuldades e estratégias poderiam ajudar a planejar o material usado com os alunos e a explicar os tópicos, conforme comentário feito por Pu6: “... conhecendo as dificuldades, eu poderia resolver os exercícios na sala de aula para que as dificuldades surgissem e assim eu ajudaria a esclarecer as dúvidas...". Três deles comentaram que a maioria das dificuldades poderia ser minimizada ou eliminada, dependendo da linguagem de programação usada, citando Python como exemplo. Eles acrescentaram que as dificuldades existem não apenas para a linguagem $\mathrm{C}$, mas também para muitas outras, como Java. Além disso, comentaram que um ponto importante dos resultados apresentados foi o vínculo das estratégias didáticas com os tópicos e/ou dificuldades. Embora a maioria das estratégias sejam conhecidas, essa conexão pode ajudar a determinar a mais adequada a ser usada em determinados momentos da aula.

\subsection{Conexões entre Tópicos}

O objetivo deste estudo foi identificar as conexões entre os tópicos necessários para programar, pois vimos que o aprendizado superficial de um tópico pode gerar consequências para outros. Segundo RoBins (2010), adquirir um conceito com sucesso torna o aprendizado de outro conceito estreitamente vinculado mais fácil, enquanto falhar torna mais difícil o aprendizado. Estudando a categoria 'Dificuldades com os tópicos', descobrimos conexões entre os tópicos (subcategorias). A Figura 4.3 mostra uma visão geral dessas conexões, as quais são detalhadas ao longo desta seção e apresentadas com diagramas menores. Cada conexão indica que um tópico requer outro para sua compreensão e uso. Todas as conexões são baseadas em comentários de dificuldades em aprender a programar, feitas nos diários ou entrevistas. A seguir, descrevemos essas conexões por tópico, ordenadas pelo tópico mais necessário para aprender outros para o menos necessário. 


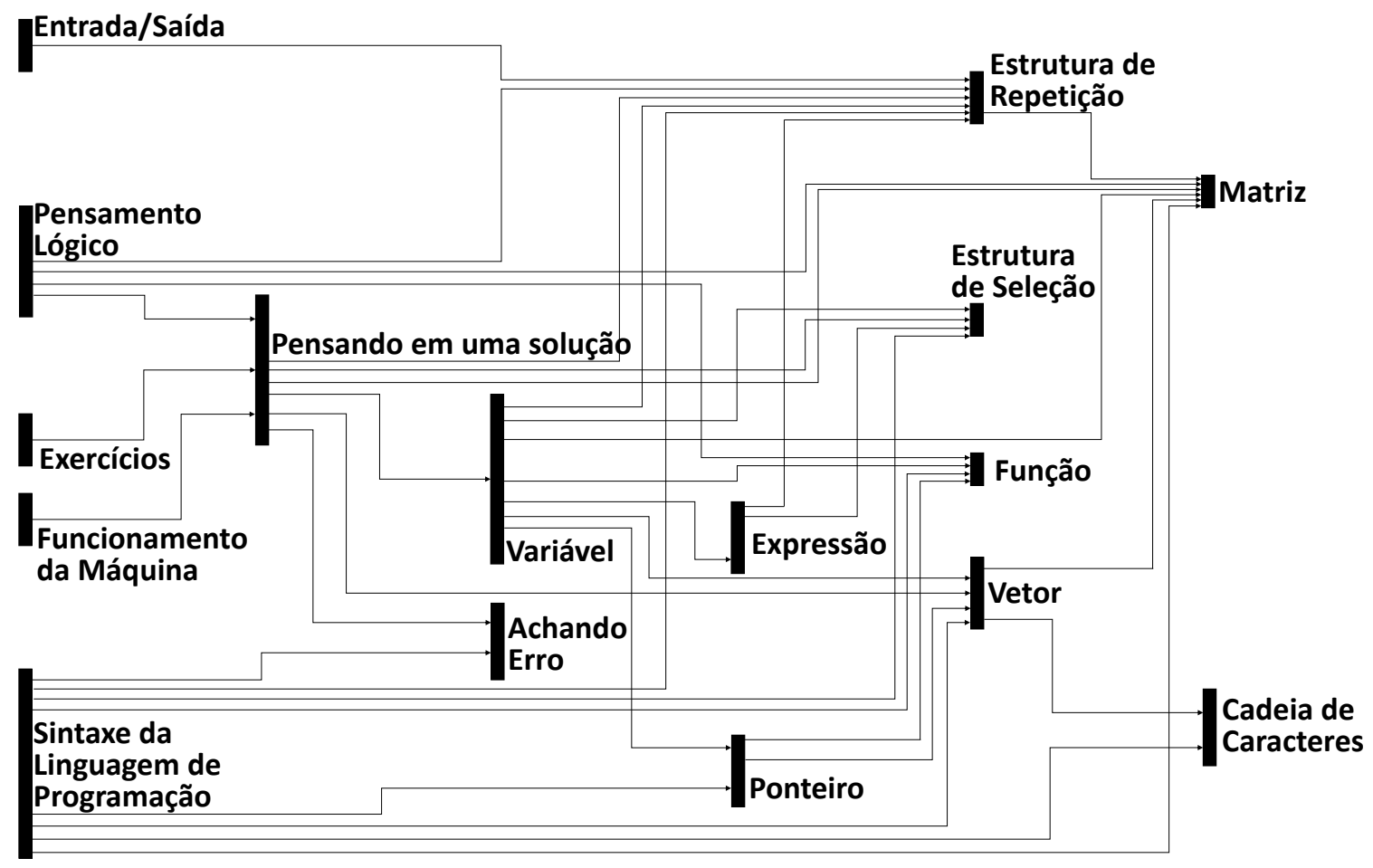

Figura 4.3: Visão geral das conexões encontradas entre os tópicos.

Sintaxe da linguagem de programação: $\mathrm{C}$ (usando Dev-C++ ou Code::Blocks como IDEs) e Python (usando IDLE) eram as linguagens de programação que estavam sendo usadas e várias referências à sintaxe foram feitas durante o estudo de outros tópicos, como apresentado na Figura 4.4. Isso pode indicar a importância de oferecer uma sólida formação em linguagem de programação. A dificuldade começa com o IDE usado, como disse P11: "Acostumar com a ferramenta que escolhemos para o semestre envolve muito trabalho e demanda muita energia" e S72 (C), enfatizando aspectos da sintaxe: "Eu gostaria de entender melhor por que eles colocam '\# include <stdio.h>', 'int main ()' com dois parênteses se precisamos então abrir chaves, por que eles escolheram 'In' como um comando para pular a linha e por que eles escolheram colocar a letra 'f' em 'printf' e 'scanf'". Problemas com erros de sintaxe foram frequentemente comentados por alunos e instrutores: "... as pessoas enfrentam problemas com a sintaxe..." - P7. Houve problemas com a sintaxe da linguagem de programação relacionadas a Estrutura de REPETição e Função, como a falta ou mau uso das chaves, "cometi um erro na posição das chaves em 'while'..., faz muita diferença..." - S41 (C). Outro erro comum é com indentação, “... a maior dificuldade está relacionada à indentação das instruções 'if' e 'else'..." - S22, trabalhando com EstrutuRA DE Seleção em Python. De acordo com o P10, trabalhar com Vetor em C "traz vários mal-entendidos relacionados à linguagem”, e para P12, trabalhar com MATRIz "começa a se transformar em uma confusão de índices e ter que pensar no que é uma linha, o que é uma coluna ... eles precisam entender que, na verdade, não é exatamente uma matriz como estamos acostumados, mas é um vetor de vetores (sobre como a matriz é representada nas linguagens)". Alguns professores evitam explicar Ponteiro e CAdeia DE CARACTERes ao ensinar programação com $\mathrm{C}$ porque a sintaxe da linguagem dificulta muito o aprendizado. Além disso, os alunos também têm dificuldade para AchAr Erros no código que 
desenvolveram e na maioria das vezes as mensagens que o compilador envia não ajudam a identificá-los.

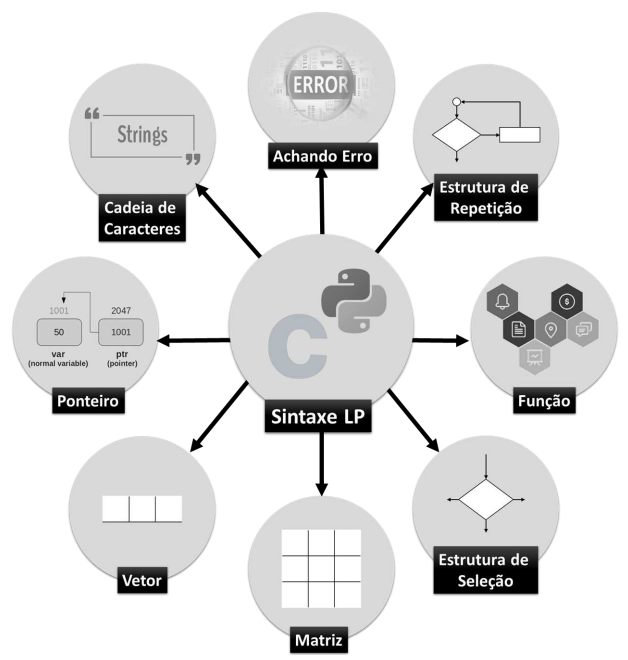

Figura 4.4: $O$ relacionamento entre o tópico Sintaxe da Linguagem de Programação (SLP) e os tópicos que precisam desse conhecimento.

Variável: Os alunos demonstram dificuldades para aprender sobre variáveis e aplicar o conhecimento na prática, como por exemplo, saber quando é necessário criar uma variável e como usá-la. Ou seja, eles confundem o nome da variável com o dado armazenado dentro dela e seu tipo; quantos dados a variável pode armazenar ao mesmo tempo, entre outras coisas. Questões sobre variáveis foram citadas em outros oito tópicos quando estavam sendo comentadas pelos participantes deste estudo, conforme pode ser verificado na Figura 4.5. Expressão é um deles. Os alunos mostraram que questões muito básicas sobre variáveis eram incompreendidas, como podemos ver no comentário feito por S3 - " 'count = count + 1' O que é isso? Qual é o objetivo disso? Isso está adicionando 1 ao valor total?". Além disso, as dúvidas sobre os tipos foram fortemente citadas quando estavam comentando sobre os resultados da divisão. Ao trabalhar com Estrutura DE RepetiÇÃo, eles destacaram principalmente questões sobre inicialização, quando e como alterar o valor por incremento ou decremento, além de dificuldade para entender qual valor foi salvo na variável. Trabalhando com Estrutura de Seleção, Vetor e Função, surgiram dúvidas sobre os tipos e seu uso, como no comentário feito por S34 - "...Eu tive algumas dificuldades principalmente porque envolvia caracteres e matrizes" e "A ideia [de que com uma] variável você está passando um valor e será usada dentro [da função] como uma variável" - P12. Tentando entender sobre Ponteiro, "eles [os alunos] sempre quiseram voltar a usar variáveis simples, manter tudo fixo, tudo constante...", mostrando-nos que há uma confusão entre os dois tópicos (Ponteiro e VAriável). Usando MATriz, para os alunos, as variáveis usadas para controlar as posições não podem mudar de função, ou seja, se a variável foi criada para indicar linhas, não poderia ser usada para indicar colunas e vice-versa, como ocorre na multiplicação de matrizes, por exemplo.

Pensando em uma solução: Muitos estudantes têm dificuldades para desenvolver uma solução para resolver tarefas, independentemente da linguagem. Eles frequentemente entendem a teoria ou acreditam que entenderam, mas não sabem como aplicar o conhecimento na prática (Figura 4.6). Um exemplo disso é o que o P4 explicou sobre VARIÁvel: 


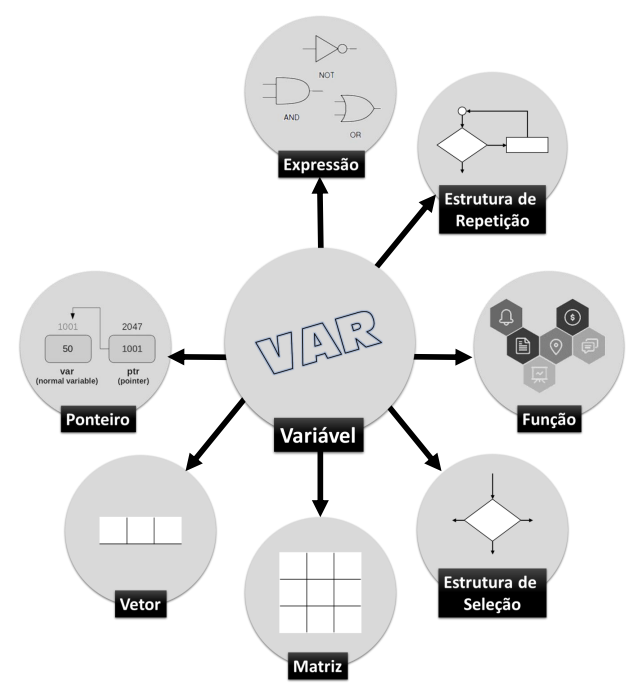

Figura 4.5: Diagrama mostrando em quais tópicos as dificuldades aparecem devido à falta de conhecimento de Variável.

"[o aluno] usa dez variáveis onde precisa de três. E há tantas variáveis desnecessárias que ele fica confuso". Trabalhando com Estrutura de Seleção, o S3 escreveu: "Tive dificuldade em entender o uso do 'if..else". Trabalhando com Vetor, S61 expôs que não tinha certeza "se é necessário usar o conceito de vetor". Às vezes, os alunos concluem os exercícios apenas com a ajuda de alguém, como S30 explicou ao trabalhar com EstruturA DE REPETIÇÃo: "[quando] o 'while' foi introduzido, tive dificuldade em trabalhar com a última lista [de exercícios], pude resolvê-la com a ajuda de um colega de classe, apesar que durante a aula senti que havia entendido perfeitamente como funcionava". Outra dificuldade enfrentada pelos alunos foi AchANDo Erro na solução, S34 afirmou que ele mudou a solução e que, mesmo assim, ainda não havia entendido o que estava errado. E por último, no tópico VETOR, P7 comenta que "Embora eu tenha desenhado, falado como eles deveriam enxergar a solução, haviam alguns [estudantes] que não conseguiam produzir os algoritmos utilizando Matriz".

Pensamento Lógico: Este tópico é considerado um dos mais importantes para aprender programação, como confirmado por P15 - "acredito que o primeiro ponto é o raciocínio lógico" e P12 - "raciocínio computacional talvez seja mais importante que cada tópico do curso". Muitos relatos mostram a falta dessa habilidade, como foi dito pelo professor P14 - "Qualquer algoritmo simples é muito difícil na cabeça deles porque eles não têm [pensamento lógico] [...] isso é uma maneira completamente diferente de pensar do que eles estão acostumados". Isso também foi confirmado por diversos alunos com muitos comentários feitos nos diários, como: "Eu tenho dificuldade em transformar um problema, geralmente simples de resolver com papel e caneta, em um programa" - S19 e "Eu tive dificuldades na lógica de montar o algoritmo..." - S1. Os professores trabalham nas aulas para melhorar essa habilidade: "O foco das aulas geralmente é o exercício de algoritmos, para desenvolver a capacidade dos alunos de pensar em soluções" - S71, mas mesmo assim os alunos continuam tendo dificuldade para PENSAR EM UMA SOLUÇÃo para desenvolver o código, "minha capacidade de aprender a teoria e aplicá-la sozinho(a) aos exercícios é insignificante”, mostrando a necessidade de trabalhar muito para melhorar o raciocínio lógico nos alunos (Figura 4.7). 


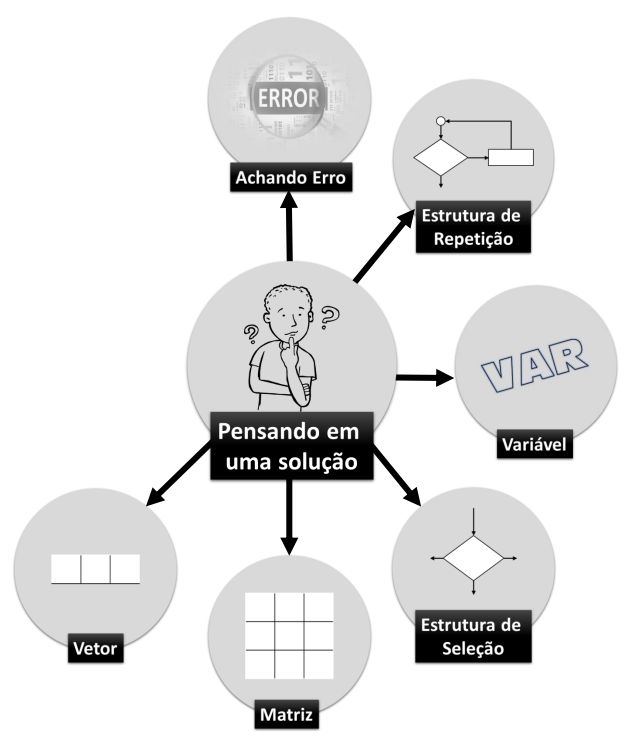

Figura 4.6: Diagrama mostrando em quais tópicos as dificuldades aparecem devido à falta de habilidade em Pensar em uma Solução.

Com os tópicos Estrutura de RepetiçÃo e FunçÃo, os alunos têm dificuldade em realizar a ordem correta de ações e comandos para atingir seus objetivos, "Uma dificuldade que sinto é como ordenar ações, por exemplo: devo terminar todas as funções e testar se deu certo ou é melhor testar antes? Mas como fazê-lo? Sendo que não sei como testar sem o programa já escrito" - S2. Outro tópico que exigiu raciocínio lógico é MATRIz, onde os alunos não sabiam o que fazer, como comentado por S50: "Passei o dia todo tentando fazer o terceiro EP (Exercício Programa) depois de estudar muito sobre Matrizes, mas só consegui passar mais de seis horas olhando para o monitor, sentindo meu cérebro fritar sem saber como começar a fazer o que o EP pedia".

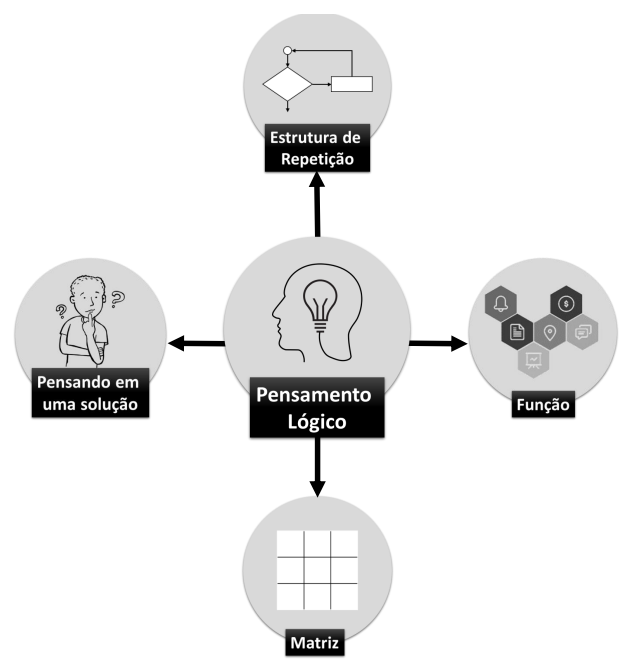

Figura 4.7: Diagrama mostrando as conexões existentes entre Pensamento Lógico e os demais tópicos.

Vetor: Algumas dificuldades enfrentadas pelos alunos no trabalho com vetores são a manipulação de índices e a falta de conhecimento prévio desse conceito, tratado na 
matemática, "Se a pessoa [aluno] não tiver o conceito de vetor e matriz, fica difícil entender..." - P5. Dois outros tópicos precisaram do conhecimento de vetor, conforme apresentado na Figura 4.8. O primeiro foi MATriz, "Matrizes começam a se transformar em um labirinto de índices e, tendo que pensar no que é uma linha, no que é uma coluna ... eles precisam entender que, na verdade, não é exatamente uma matriz como a que estamos acostumados, mas um vetor de vetores, que também é um pouco difícil" - P12, e o outro foi CADEIA DE CARACteres, como comentado por P15 - "Dificuldades no uso de string, ... quando olho para uma string, tenho os caracteres, cada um ocupando uma posição, vendo uma string como se fosse um vetor com um limite e um marcador final, no caso da linguagem C".

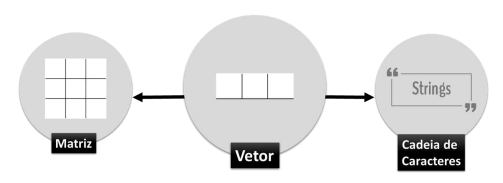

Figura 4.8: Diagrama mostrando em quais tópicos as dificuldades aparecem devido à falta de conhecimento de Vetor.

Ponteiro: Para o P4, ao ensinar ponteiros, "o problema começa a ficar maior" e alguns professores evitam explicar esse tópico devido à dificuldade que os alunos têm em entendêlo. Os alunos não gostam, como mostra o comentário feito por S42 ao trabalhar com FunçÃo: "Eu odeio funções ... passando parâmetros por referência ... bem-vindo ao inferno de ponteiros! ${ }^{* * * *} \& \&^{*} \&{ }^{*}$ !! Ugh”. E outro tópico que exigiu conhecimento de ponteiro foi Vetor (Figura 4.9). Entender um vetor como um ponteiro é importante ao passá-lo para uma função, por exemplo.

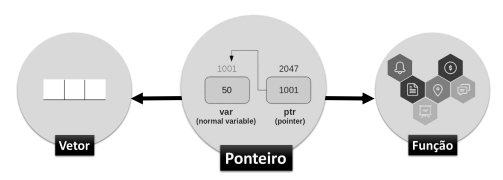

Figura 4.9: Diagrama mostrando em quais tópicos as dificuldades aparecem devido à falta de conhecimento de Ponteiro.

Expressão: Estrutura de Seleção e Estrutura de Repetição são os dois tópicos que precisavam que o conhecimento de Expressão fosse aprendido (Figura 4.10). Para Estrutura de SeleçÃo e Estrutura de Repetição, é necessário criar a condição que controla a estrutura. Nessa tarefa, é necessário o uso de expressões e, de acordo com P14, "... tem uma coisa que existe em linguagem natural e que normalmente não existe em linguagem de programação, é você falar algo do tipo ' $x>3 e<5$ ' e em computação eu não posso escrever assim, tenho que escrever ' $x>3$ e $x<5$ ', então eles escrevem errado, eles escrevem ' $x>3 e<5$ ”'.

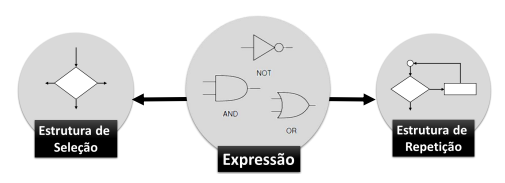

Figura 4.10: Diagrama mostrando em quais tópicos as dificuldades aparecem devido à falta de conhecimento sobre Expressões. 
Estrutura de Repetição: Criar a condição de parada, manipular a variável de controle e entender e criar repetições aninhadas são apenas alguns dos problemas enfrentados pelos alunos ao estudarem estruturas de repetição. Se os alunos não aprendem esse tópico corretamente, eles também poderão ter problemas com MATriz (Figura 4.11), que usa repetições aninhadas para controlar os dados dentro dela, conforme comentado por P13 - “...eu não vejo problemas de eles enxergarem ou entenderem a matriz ou vetor, eu vejo de eles conseguirem manipular isso. Usar um laço encadeado, por exemplo".

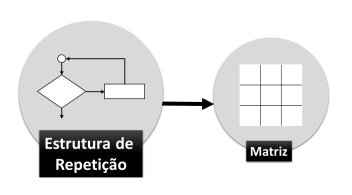

Figura 4.11: Diagrama mostrando em quais tópicos as dificuldades aparecem devido à falta de conhecimento de Estruturas de Repetição.

Entrada/Saída: Esse tópico é necessário para aprender a trabalhar com EsTRUTURA DE RePETiçÃo (Figura 4.12). Os alunos tiveram problemas para definir quais dados eram necessários para trabalhar no programa e como obtê-los. Para trabalhar com os dados, os alunos não sabiam se seria necessário usar o comando de entrada de dados. Outra questão sobre as funções de entrada/saída foi que alguns estudantes pensaram que os usuários podiam ver os resultados sem que para isso fosse necessário mostrar o resultado usando a função de saída de dados. Além disso, surgiu dificuldade em definir a posição correta da chamada das funções de entrada/saída no código: "Python está imprimindo a sequência inteira, em vez de apenas imprimir a saída final, o que você sugere para eu resolver isso? [perguntando no diário para o pesquisador]" - S22.

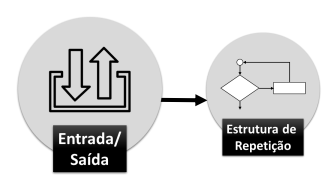

Figura 4.12: Diagrama mostrando em quais tópicos as dificuldades aparecem devido à falta de conhecimento sobre funcões de Entrada e Saída.

Exercício: A descrição dos exercícios precisa ser bem escrita. Esse tópico foi necessário para PENSAR EM UMA SOluÇão para os exercícios propostos (Figura 4.13). Para usar a teoria no desenvolvimento do código, é necessário que o aluno entenda perfeitamente qual é a tarefa, "Tentei ler o EP [trabalho], mas não consegui entender absolutamente nada do que estava sendo pedido" - S25.

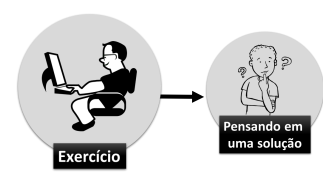

Figura 4.13: A conexão existente entre o tópico Exercício e Pensando em uma Solução.

Funcionamento da Máquina: P8 acredita que "a dificuldade está em entender como a máquina resolve os problemas que pra eles [alunos] são muito triviais e eles vêm com 
as maneiras de resolver que já conhecem, que estão habituados, e não conseguem pensar como a máquina pensa. Pensa não, resolve. Então, essa é a grande dificuldade”. Esse tópico foi necessário para PENSAR EM UMA SOLUÇÃo porque "saber como as coisas funcionam dentro do computador é muito útil, pois com isso você pode fazer esquemas que o ajudarão a pensar melhor sobre a situação e como proceder para alcançar um programa de resposta" S35 (Figura 4.14).

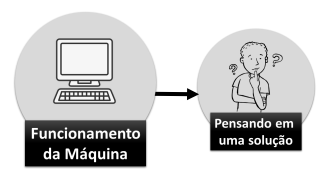

Figura 4.14: A conexão existente entre o tópico Funcionamento da Máquina e Pensando em uma Solução.

Matriz, Função, Achando Erro, Estrutura de Seleção, e Cadeia de Caracteres: Embora esses cinco tópicos não sejam necessários para ajudar no aprendizado de outros, são os que exigem muito conhecimento prévio para que o aluno possa aprendê-los. Por exemplo, os alunos podem ACHAR ERRO apenas se tiverem o conhecimento do tópico SINTAXE DA LINGUAGEM DE PROGRAMAÇão. Outro exemplo é aprender a desenvolver e usar FUNÇÕES, que usam conhecimento prévio de VARIÁvEIS, PONTEIROS, entre outros.

Os resultados mostraram as conexões entre os tópicos necessários para aprender a programar. Essas conexões mostram a existência de pré-requisitos entre os tópicos. A Figura 4.15 mostra destacados os tópicos necessários para um melhor aprendizado de Função, encontrados nos diários e entrevistas. Ao analisar os dados, constatamos que muitos dos relatos sobre as dificuldades não estavam relacionados ao tópico em estudo, mas à falta de conhecimento de outros tópicos. Isso ilustra a importância de conhecer bem essas conexões e saber qual conhecimento é necessário para que algo novo possa ser aprendido. Conforme a teoria do Momento de Aprendizagem (Learning Edge Momentum LEM) proposta por RoBINs (2010), os estágios iniciais da aprendizagem de programação são críticos para o resultado do processo pois, uma vez estabelecido um momento negativo, é difícil superá-lo. E, devido a isso, o autor acrescenta que se deve dar foco especial ao início do curso, pois o momento positivo deve ser estabelecido desde o início.

\subsection{Dificuldades Por Linguagem}

O terceiro estudo realizado com os dados dos diários foi quanto às dificuldades separadas por linguagem de programação: C e Python. As entrevistas realizadas com os professores não foram usadas nesse estudo, pois as dificuldades comentadas por eles foram na maioria das vezes referentes à linguagem $\mathrm{C}$. Com este estudo, verificamos que os três conteúdos que os alunos expressaram maiores dificuldades, nas duas linguagens, foram Estruturas de Repetição, Variáveis e Funções. Porém, a partir da quarta dificuldade, as diferenças começaram a aparecer, sendo que os alunos usando $\mathrm{C}$ sentiram dificuldades em mais conteúdos do que os que estavam usando Python. Conteúdos como Ponteiros, Matrizes e Expressões Lógicas, que não foram citados como sendo difíceis pelos alunos que utilizavam Python, foram citados pelos alunos usando C. Resumindo, todos os conteúdos que apresentaram 


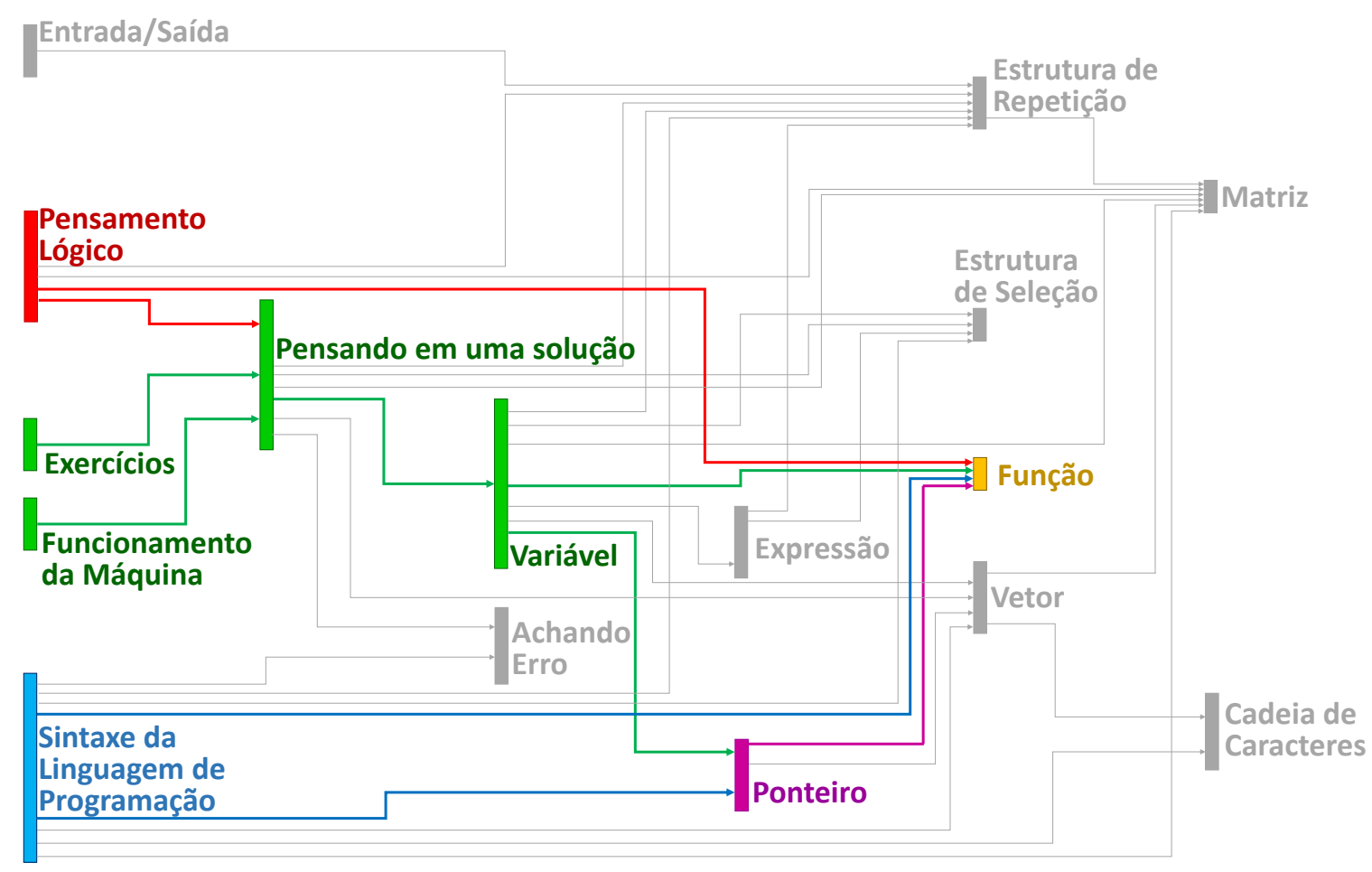

Figura 4.15: Conexões mostrando tópicos que influenciam o aprendizado de Funções.

dificuldades aos alunos usando Python também apresentaram dificuldades aos alunos usando C, porém não o inverso.

A Figura 4.16 mostra um quadro geral das dificuldades relatadas pelos alunos nos diários. O percentual foi calculado levando-se em consideração a quantidade de vezes que a dificuldade foi comentada por alunos trabalhando com uma determinada linguagem em relação à quantidade de alunos participantes no preenchimento dos diários dessa mesma linguagem. Por exemplo, houve mais comentários sobre dificuldades em Python com funções de E/S por aluno participante do que em C. A seguir, uma breve descrição sobre as circunstâncias nas quais as três dificuldades mais citadas foram relatadas pelos alunos.

Estruturas de Repetição - Os alunos, independentemente da linguagem, mostraram bastante dificuldade para aprender estruturas de repetição, como relatado por S21 (P) - "Estudei laços, muito difícil, consegui um algoritmo que funcionasse sim, mas está difícil demais...”. Também foi bastante comentado sobre dificuldades em aprender repetições encaixadas, "Hoje de manhã eu pensei na possibilidade de criar um laço 'while' duplo, mas não consegui formular um jeito de fazer isso" - S50 (C). Outro ponto que surgiu foi quanto à criação das condições de parada, “... entrou em loop (infinito). Percebi que a condição do laço estava errada" - S56 (C), e consequentemente em como manipular a variável usada para controlar a repetição. Os comentários relacionados com as Estruturas de Repetição foram encontrados durante os estudos tanto das próprias estruturas em si, como também durante estudos de vetores e matrizes, por exemplo.

Variáveis - Um dos tópicos que mostrou dificuldades com o uso de variáveis foi o de Estruturas de Repetição. Nesse tópico, a linguagem de programação apresentou problemas 


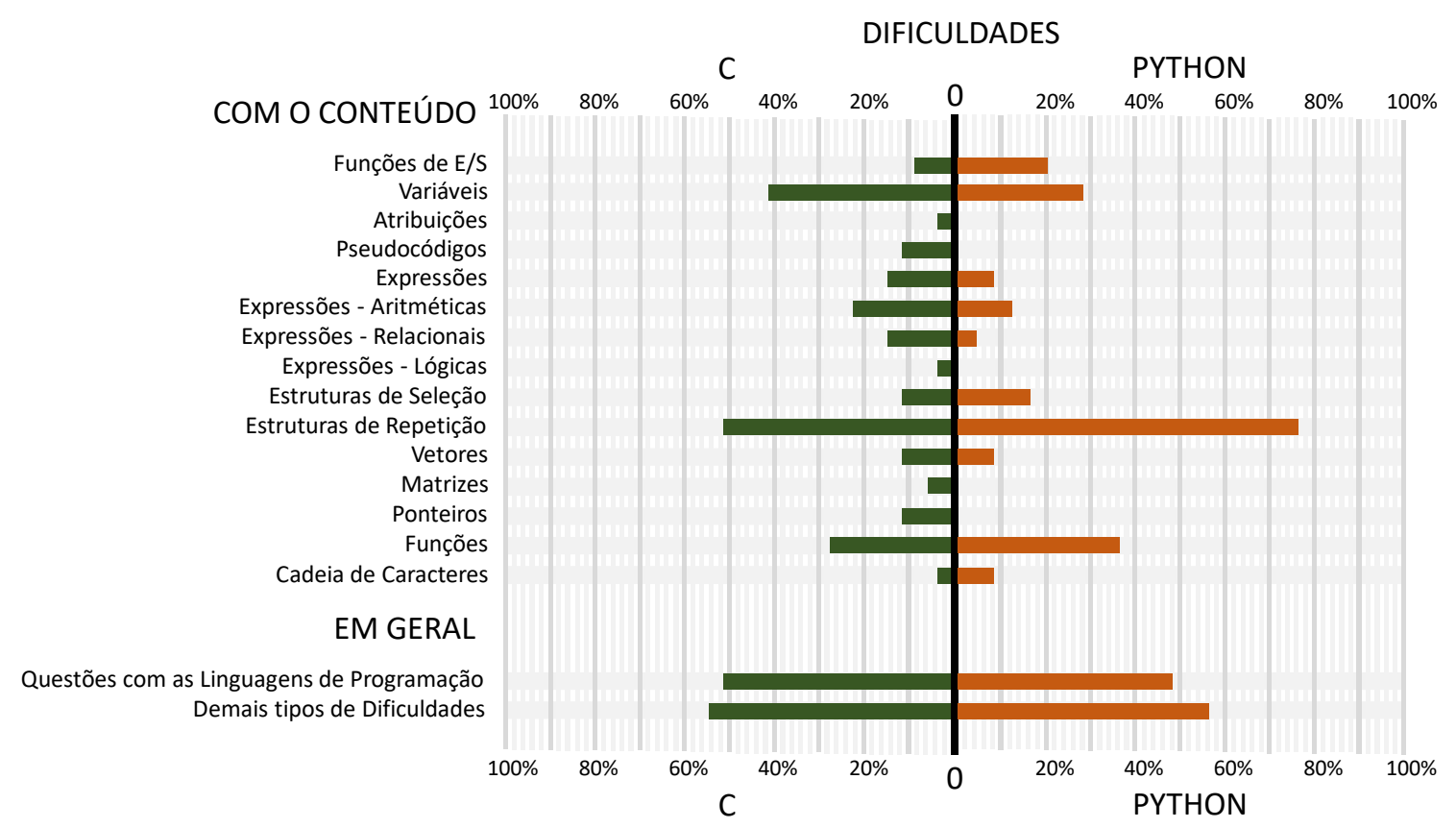

Figura 4.16: Dificuldades encontradas durante os estudos de programação.

diferentes. Enquanto em Python os alunos reportaram problemas na criação de variáveis no laço de repetição, conforme atestado pelo aluno S3 (P) - " 'count $=0$ ' - O que quer dizer esse 'count=0'? É o valor inicial que é igual a 0?", utilizando C, o problema foi maior em relação aos tipos 'char' e 'float', como relatou S41 (C) - “... ainda não sei programar esta parte :( principalmente quando o assunto é char". Na entrada de dados o problema foi definir o tipo correto para a variável, como aconteceu com alunos utilizando Python, pois muitas vezes se faz necessário converter o dado para o tipo correto. Os alunos também comentam sobre trabalhar com várias variáveis, "... fico um pouco frustrado quando tenho que usar muitas variáveis..." - S52 (C), porém a criação de muitas dessas variáveis é desnecessária e aos poucos os alunos começam a perceber isso, "... acredito que tenha utilizado muitas variáveis e que há alguma maneira mais simples" - S34 (C).

Funções - Surgiram dificuldades para entender funções, conforme apontado por S9 (P) - “...comecei a tentar realizá-lo com as funções e não está dando muito certo...". Independentemente da linguagem, houve dificuldade no uso de 'return' e em diferenciá-lo da função de saída ('print' ou 'printf'), ou seja, se o valor deve ser devolvido ou impresso pela função, S8 (P) - “... fiquei um pouco confusa com a ideia da diferença do return com o print...”. Na passagem de parâmetro, o aluno S42 (C) mostrou claramente que não gostava do conteúdo, onde a principal reclamação dele foi quanto à sintaxe do $\mathrm{C}$, reclamando da quantidade de detalhes que acabam dificultando o aprendizado. Ainda com a linguagem $\mathrm{C}$, a passagem por referência trouxe dificuldades pelo mal entendimento do funcionamento de ponteiros, conforme podemos verificar no comentário do aluno S38 (C), "A matéria está ficando mais complexa, sinto que não treinei funções o suficiente e o novo assunto (ponteiro e passagem por referência) já começou e parece um pouco complicado", além disso, passar valores do tipo 'string' e 'matrizes' também se mostrou complicado para os alunos. Com Python, a dificuldade foi, entre outras, saber da necessidade de passar o valor, "Estou tentando encontrar alguma maneira de utilizar o valor de uma variável que se encontra em 
uma função X e utilizá-lo em uma função Y” - S11 (P).

A Tabela 4.4 mostra um resumo da Figura 4.16 em ordem decrescente (das que mais apareceram para as que menos apareceram) das dificuldades por linguagem. Observa-se que os alunos que estavam usando $\mathrm{C}$ tiveram mais obstáculos para o aprendizado, pois apresentaram cinco tópicos a mais do que quando usado Python, sendo eles Atribuições, Pseudocódigos, Expressões Lógicas, Matrizes e Ponteiros. Pseudocódigo e ponteiros não foram citados pelos alunos usando Python pois o primeiro não foi usado nas aulas e o segundo fica escondido para o aprendiz, diferentemente de quando se utiliza C.

\begin{tabular}{ll|l}
\hline \multicolumn{1}{c|}{ Python } & \multicolumn{1}{c}{ C } \\
\hline $\mathbf{1}$ & Estruturas de Repetição & Estruturas de Repetição \\
\hline $\mathbf{2}$ & Variáveis & Funções \\
\hline $\mathbf{3}$ & Funções & Variáveis \\
\hline $\mathbf{4}$ & Funções de E/S & Expressões Aritméticas \\
\hline $\mathbf{5}$ & Estruturas de Seleção & Expressões / Expressões relacionais \\
\hline $\mathbf{6}$ & Expressões Aritméticas & Pseudocódigos / Estruturas de Seleção / Vetores / Ponteiros \\
\hline $\mathbf{7}$ & Expressões / Vetores / Cadeia de Caracteres & Funções de E/S \\
\hline $\mathbf{8}$ & Expressões relacionais & Matrizes \\
\hline $\mathbf{9}$ & & Atribuições / Expressões lógicas / Cadeia de Caracteres \\
\hline
\end{tabular}

Tabela 4.4: Dificuldades com o conteúdo, por linguagem, em ordem decrescente da mais para menos citada.

\subsubsection{Dificuldades Gerais por Linguagem}

Foram consideradas Dificuldades Gerais todas aquelas que não estão relacionadas diretamente com os conteúdos ministrados na disciplina de introdução à programação. Essas dificuldades aparecem na Figura 4.16 divididas em 'Questões com as Linguagens de Programação' e 'Demais Tipos de Dificuldades'. O item 'Questões com as Linguagens de Programação' foi aberto para mostrarmos algumas dificuldades sentidas pelos alunos quanto ao uso de cada linguagem, gerando assim as Figura 4.17 e Figura 4.18. Com a linguagem C, a maior reclamação foi quanto ao uso da IDE (Figura 4.17). As turmas utilizaram Code::Blocks Studio e Dev-CPP para programar e muitos estudantes reclamaram da dificuldade que tiveram para configurá-las nos seus computadores. Além disso, os maiores problemas que os alunos relataram foram com questões sintáticas, tais como a sintaxe do uso do 'scanf', das chaves e de ponto e vírgula.

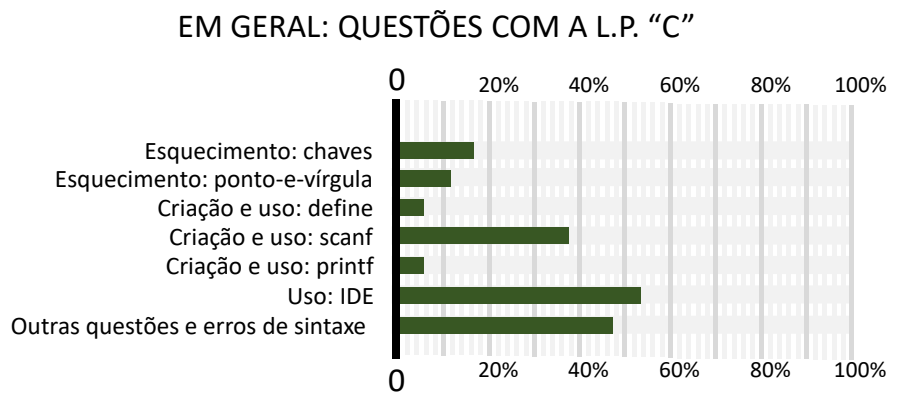

Figura 4.17: Dificuldades com $C$.

Com Python, foi constatada dificuldade com a indentação, mesmo que a IDE usada tenha sido o IDLE, que faz isso automaticamente. Além disso, mostraram problemas 
enfrentados com alguns comandos como o 'for', 'range' e 'is', e com o uso do depurador (Figura 4.18).

EM GERAL: QUESTÕES COM A L.P. “PYTHON”

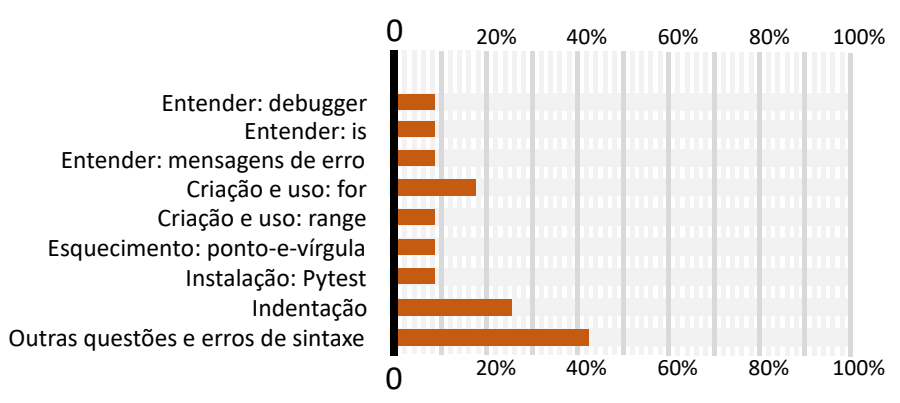

Figura 4.18: Dificuldades com Python.

Na Figura 4.19 são mostrados os tipos de dificuldades mais citados do item 'Demais Tipos de Dificuldades' da Figura 4.16. Essas dificuldades não são relacionadas com o conteúdo e nem exatamente com a linguagem de programação, porém dividimos por linguagem para mostrarmos com qual delas o aluno estava trabalhando ao fazer o relato do problema. O percentual foi calculado dividindo a quantidade de comentários pela quantidade de alunos participantes. Na Figura 4.19, separamos por linguagem para identificar qual linguagem estava sendo usada pelo aluno que relatou a dificuldade. As três mais citadas desse grupo foram: 'Encontrar erro no próprio código', 'Interpretação de texto' e 'Pensamento lógico'.

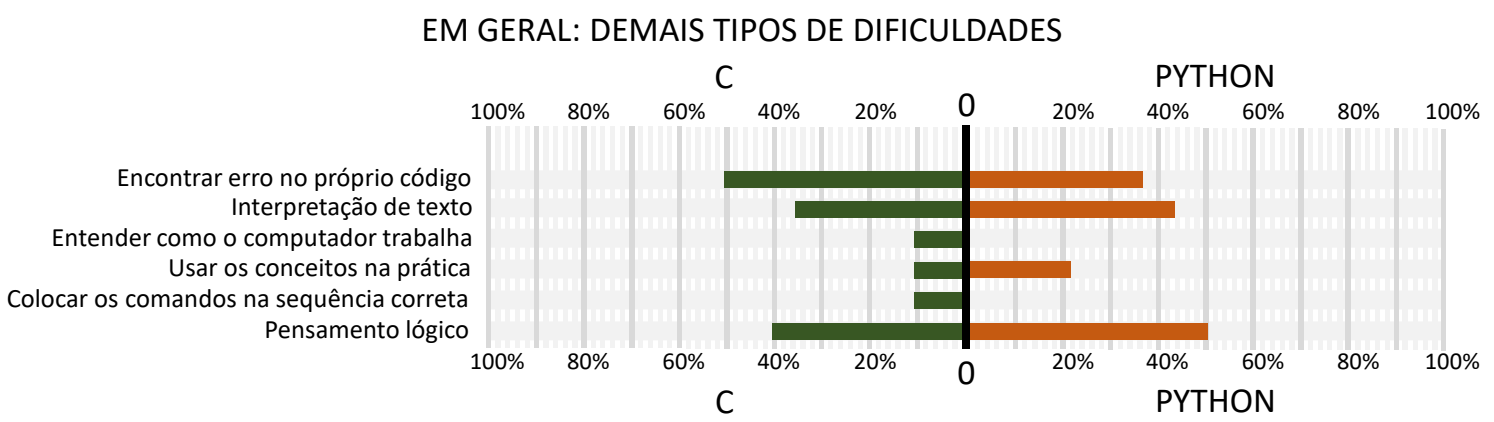

Figura 4.19: Dificuldades gerais.

Uma das primeiras coisas que o programador precisa fazer é entender exatamente o que está sendo pedido, porém, segundo RAUBER et al. (2003) é normal vermos nas universidades estudantes com dificuldades em interpretar textos. Essa dificuldade foi encontrada também pelos alunos participantes dos diários. Segundo o aluno S105 (C) “... senti muita dificuldade em entender o que o exercício pedia ... está complicado entender... Mas com a ajuda de outras pessoas consegui entender...". Em alguns momentos, exemplos de entrada e saída podem auxiliar no entendimento do enunciado. Após a etapa de entender o que se deseja, é necessário que o aluno consiga organizar as ideias para criar uma sequência lógica que possa resolver o problema proposto. Foram vários os comentários feitos pelos alunos relatando dificuldades com isso, "A minha maior dificuldade com a programação é justamente pensar em uma maneira de resolver problemas” - S93 (P). Considerando as 
etapas de desenvolvimento de software - (1) Fase de Diagnóstico, (2) Levantamento e Análise de Requisitos, (3) Fase de Desenvolvimento e (4) Etapa de Implantação - a terceira dificuldade, 'encontrar erros no próprio código', surge na terceira etapa do desenvolvimento, "Mas não estava entendo o que estava acontecendo de errado" - S25 (P). Isso pode ocorrer por várias razões, como pelo mal entendimento das mensagens de erros do compilador, "Passei bastante tempo tentando corrigir os erros que faltavam, não consegui interpretar as mensagens que o programa mostrava" - S96 (P), ou por não entenderem exatamente o que os comandos executam, iniciando-se assim as tentativas de possíveis soluções, sem saber exatamente o que se está fazendo, conforme mostra o comentário de S58 (C) “...o problema é com o 'while', acredito que faltam parênteses nas expressões, os colocarei e tentarei rodar novamente. Apareceu a mesma mensagem". Com isso os alunos acabam gastando bastante tempo na tentativa de fazer o código funcionar, "Estou a 30 minutos tentando resolver esse erro e não consigo" - S60 (C), podendo levá-los a desistir de tentar, "desisti de achar os erros" - S64 (C).

Surpreendentemente, os alunos que estavam utilizando Python relataram mais problemas de pensamento lógico e usar os conceitos na prática do que os que estavam usavam C. O percentual maior no $\mathrm{C}$ para o item 'encontrar erro no próprio código' pode estar relacionado à sintaxe do $\mathrm{C}$ que é mais complexa e cheia de detalhes se comparada com o Python. A seguir, uma análise das turmas cujos alunos participaram no preenchimento dos diários.

\subsection{Turmas Envolvidas: Uma Análise Quanto ao Rendimento}

Para entender se as diferentes linguagens impactavam a aprovação dos alunos, foram comparados os resultados das turmas usando C e Python. A média obtida pelas turmas que utilizaram Python foi superior à média obtida pelas turmas que usaram C. Na Tabela 4.5 são apresentados os dados referentes às 12 turmas cujos alunos participantes dos diários faziam parte. Para diferenciar os professores dessas 12 turmas dos professores entrevistados, citados anteriormente nos estudos apresentados nesse capítulo, foi acrescentado "_T" ao final dos seus respectivos códigos, conforme pode ser visto na coluna "Professor" da Tabela 4.5 .

\begin{tabular}{|c|c|c|c|c|c|c|c|c|c|c|}
\hline Turma & Professor & Curso* & Turno & $\begin{array}{c}\text { Ano/ } \\
\text { Semestre }\end{array}$ & $\begin{array}{l}\text { Linguagem } \\
\text { Usada }\end{array}$ & $\begin{array}{l}\text { Total } \\
\text { alunos }\end{array}$ & $\begin{array}{c}\text { Aprovados } \\
(\%)\end{array}$ & $\begin{array}{l}\text { Reprovados } \\
(\%)\end{array}$ & $\begin{array}{l}\text { Média } \\
\text { Geral }\end{array}$ & $\begin{array}{l}\text { Média } \\
\text { por LP }\end{array}$ \\
\hline $\mathrm{T} 1$ & $\mathrm{P} 1 \_\mathrm{T}$ & Física - Bacharelado & Diurno & \multirow{2}{*}{$2015 / 2$} & \multirow{4}{*}{ Python } & 45 & 80,0 & 20,0 & 7,0 & \multirow{4}{*}{5,4} \\
\hline $\mathrm{T} 2$ & P2_T & Oceanografia - Bacharelado & Diurno & & & 60 & 65,0 & 35,0 & 5,6 & \\
\hline T3 & P3_T & Matemática - Licenciatura & Diurno & \multirow{2}{*}{$2016 / 2$} & & 71 & 56,3 & 43,7 & 4,4 & \\
\hline $\mathrm{T} 4$ & P4_T & Matemática - Licenciatura & Noturno & & & 53 & 54,7 & 45,3 & 4,6 & \\
\hline T5 & P5_T & Matemática - Licenciatura & Noturno & \multirow{4}{*}{$2015 / 2$} & \multirow{8}{*}{ C } & 76 & 44,7 & 55,3 & 3,4 & \multirow{8}{*}{4,4} \\
\hline T6 & P6_T & Matemática - Licenciatura & Noturno & & & 68 & 41,2 & 58,8 & 3,6 & \\
\hline $\mathrm{T7}$ & P7_t & Geofísica - Bacharelado & Diurno & & & 36 & 33,3 & 66,7 & 3,1 & \\
\hline T8 & P8_T & Física - Bacharelado & Diurno & & & 50 & 52,0 & 48,0 & 4,7 & \\
\hline T9 & $\mathrm{P} 2 \_\mathrm{T}$ & Física - Bacharelado & Diurno & \multirow{4}{*}{$2016 / 2$} & & 65 & 70,8 & 29,2 & 6,1 & \\
\hline T10 & P6_T & Física - Bacharelado & Noturno & & & 29 & 62,1 & 37,9 & 4,6 & \\
\hline T11 & P9_T & Física - Bacharelado & Diurno & & & 33 & 57,6 & 42,4 & 4,7 & \\
\hline T12 & P10_T & Física - Bacharelado & Noturno & & & 53 & 56,6 & 43,4 & 4,6 & \\
\hline
\end{tabular}

Tabela 4.5: Resultados finais das 12 turmas de introdução à programação participantes. 
Analisando os dados apresentados na Tabela 4.5, observamos dois casos interessantes, um com as turmas T4 e T5 do curso de Matemática - Licenciatura, e o outro com as turmas cujo professor foi o P6_T. No primeiro caso, o das turmas T4 e T5, ambas do mesmo curso e turno, porém com linguagens distintas. A turma T4, que usou Python, teve rendimento $12 \%$ superior ao da turma T5 que usou C. No segundo caso, o professor P6_T lecionou para duas turmas, a turma T6, com alunos da área de computação e matemática e a turma T10, com alunos de outras áreas, ambas utilizando a linguagem $C$. Nesse caso, o que nos chamou a atenção é que a quantidade de alunos da turma T10 era menos da metade da turma T6, porém, o resultado da turma T10 não foi muito superior, não chegando nem a alcançar a média de aprovação da universidade $(5,0)$. Olhando as demais turmas quanto à quantidade de alunos, observamos que a turma com mais alunos (T5) não obteve a pior média, assim como a turma com menos alunos (T10) não obteve a melhor média. A literatura é inconclusiva sobre turmas menores serem melhores para o aprendizado (HANUSHEK, 1999); nosso estudo corrobora isso, pois não encontramos nenhuma relação significativa nesse sentido. Interessante citarmos também os resultados gerais obtidos por turmas de bacharelado vs licenciatura e turmas do período diurno vs noturno. Observa-se nos dados que a média geral das turmas de bacharelado e das turmas do turno diurno são melhores. Nesse último caso, provavelmente devido ao tempo de dedicação ao estudo ser maior para os alunos que estudam durante o dia e a nota de corte no vestibular.

\subsection{Limitações}

Os dados foram coletados de professores experientes do mesmo departamento que ensinam em diferentes faculdades em uma única universidade. Esse fator pode levantar algumas dúvidas quanto à precisão dos resultados em outros contextos. Uma pesquisa pode ser criada para confirmar os resultados obtidos e completar o conjunto de dificuldades e estratégias didáticas. Além disso, pesquisas confirmatórias futuras podem fornecer dados além das experiências desses professores, explorando o grau de desenvolvimento dos alunos nos cursos introdutórios de programação que usam as estratégias citadas na Seção 4.2.1. Vincular as descobertas às teorias pedagógicas existentes pode ser de grande valia para agregar conhecimento e aumentar a contribuição desses resultados.

\subsection{Conhecimentos Adquiridos}

Os alunos que estudam programação enfrentam muitas dificuldades para aprender, assim como seus professores para lecionar. Algumas dificuldades relacionadas ao conteúdo são geralmente leves; elas podem ser rapidamente esclarecidas com exemplos de aplicação e exercícios práticos, como é o caso na compreensão de uso de variáveis. Outras dificuldades são mais complicadas, exigindo que os professores usem vários recursos para melhorar o aprendizado, nem sempre com sucesso. Um desses casos é o tópico Ponteiro. Muitos professores compartilharam seu desejo de evitar lecionar esse tópico na disciplina de introdução à programação, porque o consideram muito difícil. No entanto, é necessário ensinar outros tópicos, como passar parâmetros por referência em Funções (C) que precisam desse conteúdo, mesmo que indiretamente. Para isso, os conceitos de ponteiro são frequentemente omitidos (S4) e usados na forma de 'receitas' (S8), evitando-se a necessidade 
de se aprofundar nele durante essa disciplina. Para os professores, os tópicos considerados mais difíceis foram estruturas de repetição (while, for, ...), vetores/matrizes e funções (Figura 4.2), sendo que na opinião dos estudantes, apenas um dos tópicos se difere, onde no lugar de vetores/matrizes, para os estudantes ficou o tópico variáveis (Tabela 4.4).

Algumas das dificuldades citadas nos estudos apresentados nesse capítulo podem ser vistas em resultados de outras pesquisas disponíveis na literatura. Variáveis e função, por exemplo, são tópicos também considerados difíceis por SEvella et al. (2013), estruturas de repetição, listas (matrizes), ponteiros e passagens de parâmetro (Funções), são citados por Mhashi e Alakeel (2013). Quando esses e outros tópicos precisam ser usados na prática, o Raciocínio Lógico torna-se muito importante para organizar as ideias sobre como proceder para atingir a meta desejada (GARNER et al., 2005). Para pensar em uma solução na prática, além do Raciocínio Lógico, foram necessários dois outros tópicos. O primeiro foi o Exercício, onde foi destacada a importância de um bom enunciado. Sem entender e saber qual é a tarefa, é improvável que ela seja resolvida, daí a importância de enunciados bem elaborados (Giraffa e Mora, 2013; A. Gomes e A. Mendes, 2014). O segundo foi o Funcionamento da Máquina, também citado por Milne e Rowe (2002), enfatizando a importância de saber como a máquina funciona em geral. Com isso, podemos ver que existem conexões entre os conteúdos.

Um dos motivos da existência de dificuldades é desconhecer essas conexões. Dificuldades existentes em um tópico podem existir pela falta de conhecimento de outro tópico, ou seja, uma espécie de pré requisitos entre eles. Um dos exemplos dados acima, onde se faz necessário ponteiro para aprender passagem de parâmetro por referência - função -, é uma prova disso. Apesar de que os professores já dispõem de recursos, como a estratégia de 'receita', para evitar se aprofundar em ponteiros num primeiro momento. Porém, em alguns casos isso não é possível e, para exemplificar isso, podemos pensar no uso de expressões para montar estruturas de repetições. Não existem receitas para isso. O aprendiz irá precisar ter aprendido de fato expressões para saber como criá-las nas condições de parada das estruturas de repetições. Sendo assim, podemos perceber a importância de manter a atenção na sequência de tópicos ensinados em sala de aula, pois um tópico mal ensinado ou aprendido pode gerar dificuldades em aprender outros. Um melhor conhecimento sobre essas conexões entre tópicos pode dar aos coordenadores e professores dos cursos a oportunidade de mudar a maneira de ensinar, evitando ou minimizando algumas dificuldades enfrentadas pelos alunos para aprender a programar. 


\section{Capítulo 5}

\section{Antipadrões no Aprendizado de Programação}

Neste capítulo é apresentado o estudo que buscou identificar e avaliar antipadrões nos códigos desenvolvidos por alunos durante atividades realizadas para a disciplina de introdução à programação. As linguagens de programação utilizadas foram $\mathrm{C}$ e Python.

Este estudo foi guiado de forma a responder as duas últimas questões de pesquisa da tese:

QP4 - Quais antipadrões aparecem nos códigos desenvolvidos por aprendizes de programação?

QP5 - Como professores/pesquisadores avaliam os resultados alcançados?

Como contribuições geradas com os resultados desse estudo têm-se catálogos de antipadrões em C, Python e que surgiram em ambas linguagens (Apêndices E, F e G). A identificação desses antipadrões pode ser útil para auxiliar instrutores e alunos no processo de ensino e aprendizagem de programação. Além disso, reconhecer os antipadrões pode desempenhar um papel fundamental em pesquisas que visam desenvolver sistemas de apoio ao ensino. Seria possível, por exemplo, elaborar material capaz de fornecer retornos aos alunos nos resultados obtidos no desenvolvimento dos seus códigos, considerando não apenas a sintaxe da linguagem, mas também a semântica e orientando-os quanto a estilos de programação que podem gerar hábitos indesejáveis.

Para melhor compreensão, este capítulo apresenta primeiro a metodologia e resultados do Estudo 4 e, em seguida, do Estudo 5 da Fase 2 desta tese (Figura 1.1).

\subsection{Estudo 4 - Coleta e Análise de Códigos de Aprendizes para Identificação de Antipadrões}

O objetivo do estudo 4 é identificar e catalogar os antipadrões identificados nos códigos dos aprendizes. Este estudo responde a QP4 desta tese e, para melhor nos orientar nessa 


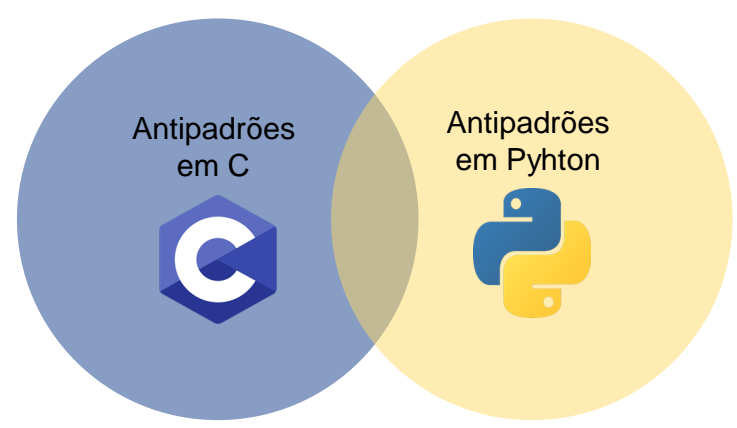

Figura 5.1: Antipadrões em C, em Python e sua intersecção.

tarefa, dividimos essa QP em duas:

QP4.1 - Quais equívocos encontrados nos códigos são recorrentes em cada uma das linguagens de programação analisadas?

QP4.2 - Quais dos equívocos identificados são comuns para ambas linguagens?

\subsubsection{Metodologia do Estudo 4}

Este estudo é dividido em duas etapas: coleta e análise dos códigos conforme detalhado a seguir. A Figura 5.2 mostra uma visão geral da metodologia aplicada.

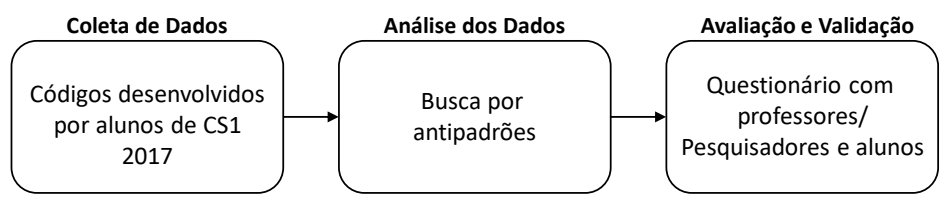

Figura 5.2: Visão Geral da metodologia de pesquisa usada nos E4 e E5.

\section{Coleta de Dados}

Os códigos analisados neste estudo vieram do curso reparador de introdução à programação (CS1) para estudantes de engenharia da Universidade de São Paulo, em 2017. O curso foi à distância, sem aulas presenciais; apenas os três exames ( 1 opcional) foram realizados na forma presencial. Para se inscreverem nesse curso, os alunos deviam ter feito o curso CS1 presencial obrigatório no ano anterior com pelo menos $70 \%$ de frequência sem terem sido aprovados. No curso à distância, os alunos usaram a mesmo linguagem de programação usada no curso presencial. Inicialmente haviam 166 alunos inscritos, 34 deles usando a linguagem C (os alunos de Engenharia Elétrica e Computacional) e 132 usando Python (outras engenharias, como Mecânica, Naval e Civil).

O curso teve 16 semanas de duração e, em cada uma delas, os alunos precisavam resolver um conjunto de exercícios práticos, com avaliação automática. Para a relização dessa avaliação automática, os alunos desenvolviam os códigos diretamente dentro do Laboratório Virtual de Programação (VPL) (RodRígueZ-DEL-PINo et al., 2012), que é um plugin para o Moodle. A Figura 5.2 mostra um esboço da coleta de dados realizada. Para receberem 
presença na semana, os alunos tinham que resolver os exercícios disponibilizados, tendo pelo menos uma resolução correta por semana. Além disso, os resultados das correções automáticas dos exercícios foram considerados na nota final. Foram disponibilizados um total de 62 exercícios, resultando em um média de cerca de 4 por semana. A resolução desses exercícios resultou num total aproximado de 55.000 submissões, ou seja, 55.000 compilações realizadas dentro do VPL. Vale ressaltar que os mesmos exercícios eram disponibilizados para alunos que estavam usando $\mathrm{C}$ e Python.

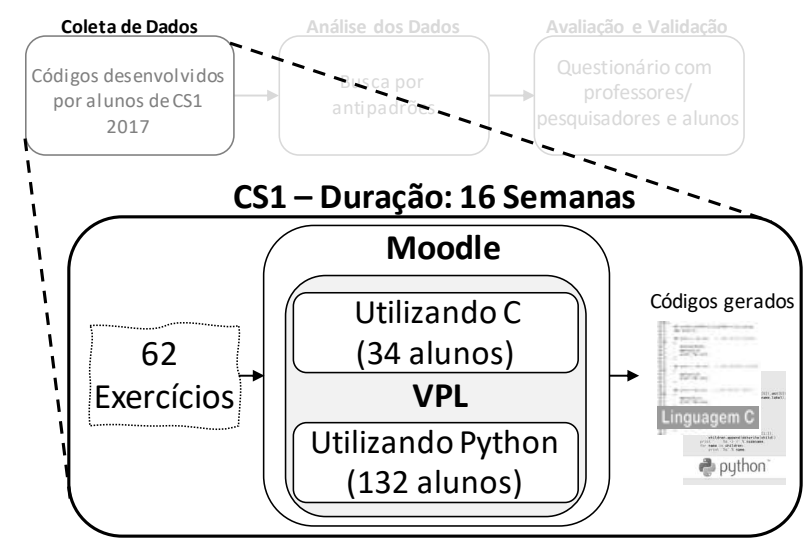

Figura 5.3: Esboço detalhado da coleta de dados.

Os exercícios da semana foram escolhidos pelo professor da disciplina com o objetivo de abordar conceitos de determinados conjuntos de tópicos. Para apresentar uma ideia do conteúdo que seria trabalhado, o professor intitulava cada semana, conforme apresentado a seguir:

1. <sem título>;

2. Introdução (variáveis, expressões e comandos de seleção);

3. Seleção e laços simples;

4. Funções e laços duplos;

5. Reposição/Revisão (Laços simples);

6. Avaliação 1;

7. Flutuante e caracteres;

8. Vetores e caracteres;
9. Vetores e caracteres;

10. Busca e ordenação;

11. Strings e troca de base decimal/binária;

12. Múltiplos e divisores comuns;

13. Matrizes;

14. Matrizes e indexadores indiretos;

15. Séries numéricas e recorrência; e

16. Variados para estudo e recuperação de nota.

Esses títulos nos ajudaram na escolha dos exercícios para análise, descrita a seguir.

\section{Análise dos Dados}

A análise dos dados coletados também foi realizada em etapas, conforme pode ser visto na Figura 5.4. A primeira tarefa executada foi organizar os dados para podermos iniciar a análise. O VPL separa em diversas pastas os códigos e resultados alcançados pelos alunos. Para facilitar acesso às submissões feitas, os códigos foram renomeados com o número do exercício, seguido do código de identificação do aluno, data e hora da submissão. As diversas submissões foram separadas por pastas. Em cada pasta foram colocados os códigos referentes a um determinado exercício. 


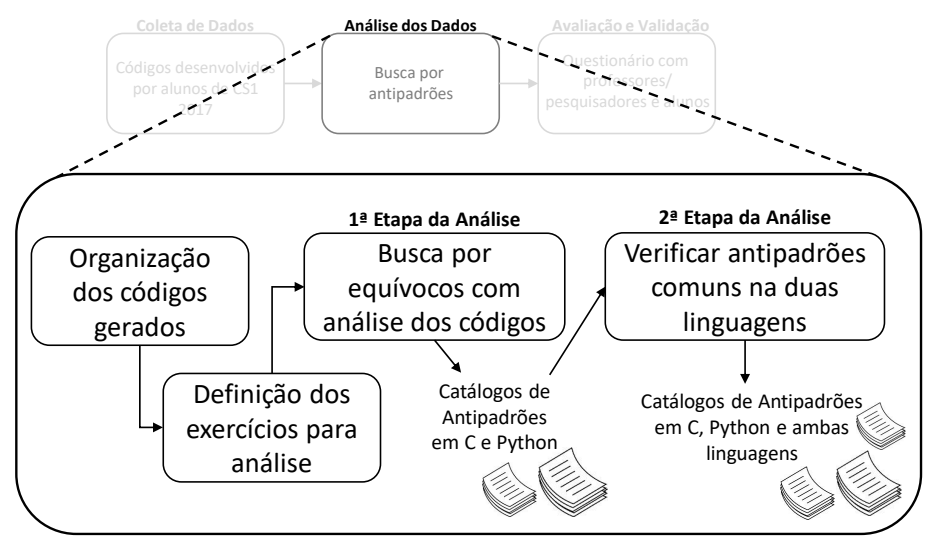

Figura 5.4: Esboço detalhado da análise dos dados.

A organização do curso em tópicos semanais nos ajudou na seleção dos exercícios que seriam usados para a análise. O critério para que um exercício fosse selecionado foi que ele exigisse do aluno conceitos usados pela primeira vez na disciplina ou que estivesse trabalhando os conceitos de forma mais básica. A escolha desse critério se deu pois é nessa situação que os equívocos normalmente aparecem com mais frequência. Os exercícios foram identificados pelo número da semana seguido de um ponto e o número do exercício. Por exemplo, o terceiro exercício da primeira semana foi numerado com ' 1.3 '. Foram selecionados 15 exercícios, cujos enunciados completos estão no Apêndice $C$ e um resumo na Tabela 5.1.

A primeira etapa da análise foi fazer a verificação visual dos códigos submetidos por exercício. Foram analisados um total de 2.233 submissões, sendo 1.253 desenvolvidas em C e 980 em Python. Para cada exercício, foram analisadas um mínimo de 50 submissões. Na pasta de cada exercício, foram abertas aleatoriamente as submissões de um determinado aluno e analisadas visualmente da primeira submissão à última, buscando por equívocos cometidos. Foram evitadas as submissões dos alunos que faziam mais de 20 submissões em um mesmo exercício. Esse critério foi criado durante a análise, visto que observamos, que nesses casos, existia uma contabilização de submissões analisadas muito alta, porém, poucos ou nenhum novo equívoco aparecia. Observamos que muitas dessas submissões não traziam alteração alguma ou alterações mínimas, sendo perceptível que o aluno estava trabalhando na forma 'tentativa e erro'.

Durante essa análise, vários equívocos foram encontrados. Cada novo equívoco encontrado era catalogado em uma nova ficha; os que já existiam foram adicionados como novo evento/ocorrência na ficha correspondente. Cada ficha é composta por três partes. A primeira parte serve para identificar o antipadrão de forma única. As informações que compõe essa parte podem ser vistas na Figura 5.5.

A segunda parte é destinada a mostrar em detalhes as ocorrências encontradas. São apresentados de três a quatro eventos para caracterizar um antipadrão. Informações como em qual submissão/compilação o equívoco ocorreu e em qual ele foi solucionado ajudam, por exemplo, a saber se o aluno resolveu o antipadrão e, se o fez, mostrar de que forma e quanto 'tempo' foi necessário para isso (Figura 5.6).

A última parte serve para sugerir um passo a passo de como o professor pode apresentar 


\title{
EXERCÍCIOS
}

\author{
1. Introdução
}

1.1 Introdução - ler um número inteiro (int) e imprimir este valor.

1.2 Introdução - ler número inteiro e imprimir seu quadrado 2. Introdução: variáveis, expressões e comando de seleção

2.1. Introdução - ler dois inteiros e imprimir o maior

2.2. Introdução - ler dois inteiros e imprimir resultado de expressão lógica 3. Seleção e laços simples

3.1. Seleção - Soma de inteiros representando ângulos internos de um triângulo 3.2. Seleção - Números Pitagóricos (verificar teorema de Pitágoras)

3.3. Laço - Somatório dos primeiros naturais até um limite

4. Funções e laços duplos

4.1 Funções: Introdução ao uso de funções: somar inteiros e média 4.2 Funções: Laço simples - Cálculo de fatorial (com entradas negativas)

4.7 Laço duplo - Obter a soma dos ímpares de cada subsequência

$$
\text { 7. Flutuante e Caracteres }
$$

7.1 Dado $\mathrm{n}$, computar a soma dos $\mathrm{n}$ primeiros termos da série harmônica

7.2 Dado $n$ inteiro e $x$ real, computar $x^{\wedge} n$

7.4 Introdução ao uso de caracteres: dado $n$ e $n$ caracteres, obter seu código ASCII

$$
\text { 8. Vetores e Caracteres }
$$

8.1 Determinar se um vetor está em ordem crescente

$$
\text { 13. Matrizes }
$$

13.1. Introdução às matrizes: imprimir linhas e soma da linha

Tabela 5.1: Enunciados reduzidos dos exercícios selecionados para análise.

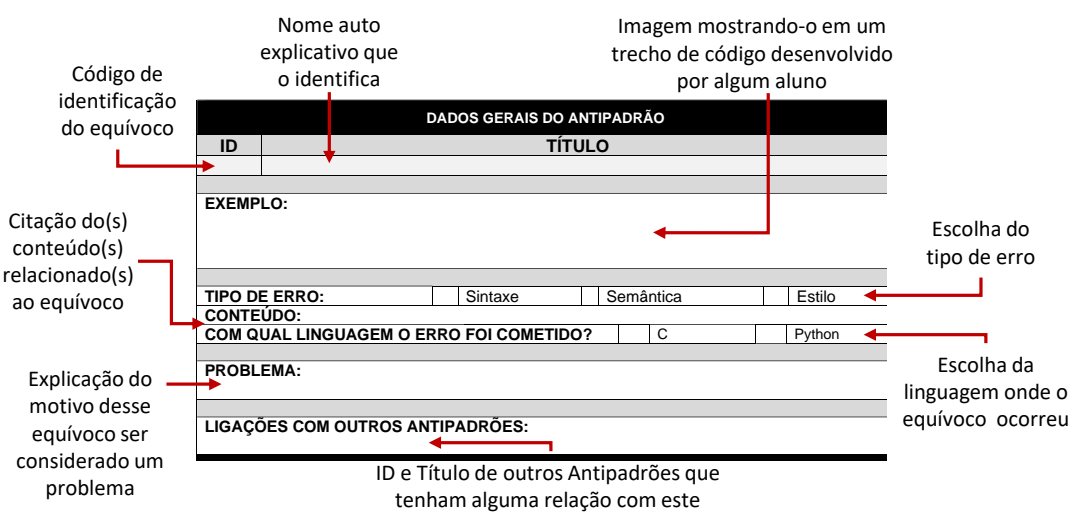

Figura 5.5: Explicação da primeira parte da ficha dos antipadrões.

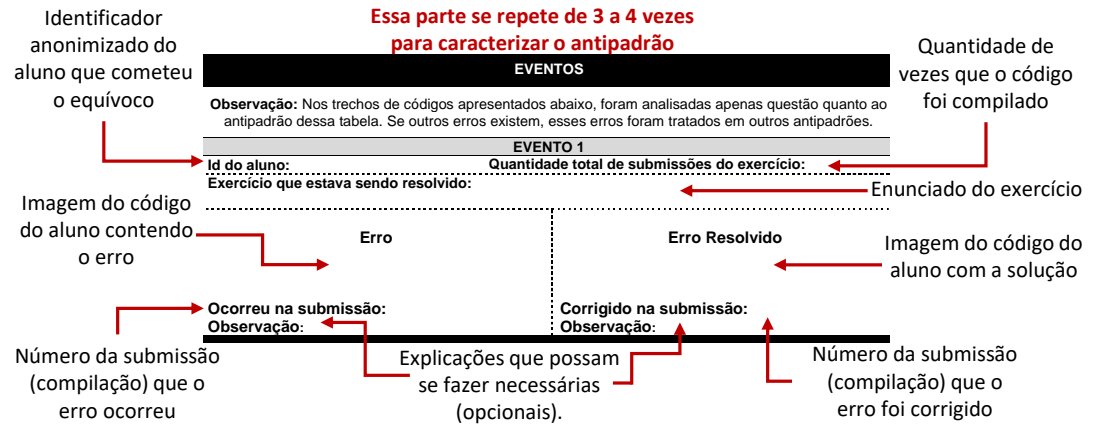

Figura 5.6: Explicação da segunda parte da ficha dos antipadrões. 
o antipadrão para seus alunos e também sugestão de um passo a passo de como o aluno pode estudá-lo (Figura 5.7).

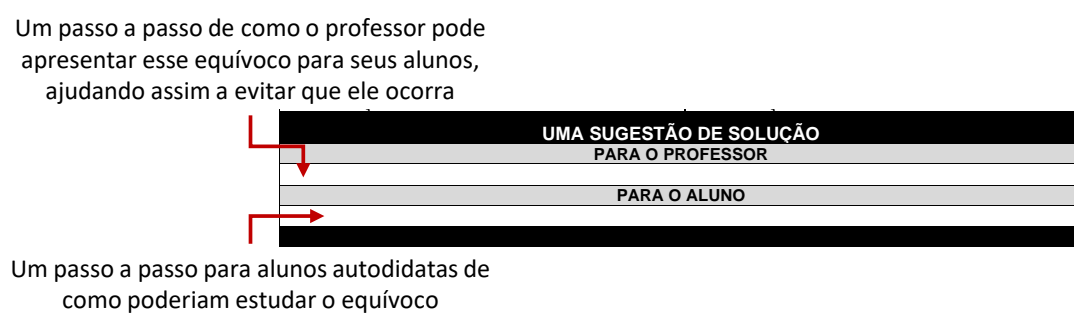

Figura 5.7: Explicação da terceira parte da ficha dos antipadrões.

Para a classificação do tipo de erro, levamos em consideração o sucesso ou não na compilação/interpretação e os resultados alcançados. Equívocos que causaram erros de compilação/interpretação foram considerados erros de sintaxe. Se o código pudesse ser executado mesmo com a presença do equívoco, mas gerando resultado ou comportamento diferente do esperado, esse equívoco era classificado como erro de semântica. Chamamos de erros de estilo os equívocos que não causaram erros de sintaxe ou de semântica, porém que podem gerar problemas futuros no desenvolvimento de códigos ou que podem ser considerados más práticas de programação.

Ao terminarmos a análise dos códigos com o fichamento dos equívocos, foram montados os catálogos de antipadrões de cada linguagem com os que apresentavam no mínimo três eventos de alunos distintos. Segundo W. H. Brown et al. (1998), o equívoco cometido três vezes em situações distintas torna-se um padrão (antipadrão). Em seguida, foram analisados os dois catálogos de antipadrões gerados (em C e Python) buscando por erros que apareceram em ambas as linguagens. Para cada par de antipadrões desses, foi criada uma única ficha, com um ID e um título em comum e juntando-se os demais dados. O conjunto dessas novas fichas gerou o terceiro catálogo de antipadrões.

\subsubsection{Resultados do Estudo 4: Antipadrões}

Os códigos coletados foram examinados e durante a análise do código, cada equívoco encontrado foi catalogado. Foram encontrados 95 equívocos em C e 44 em Python, cuja lista completa está disponível no Apêndice B. Os equívocos foram divididos de acordo com tópicos abordados na disciplina. A Figura 5.8 mostra o percentual deles, por tópico, em cada uma das duas linguagens.

Quando o equívoco apresentava mais de três eventos, sendo cada um cometido por um aluno diferente, ele passava a fazer parte do catálogo de antipadrões. Ao final da análise, três catálogos de antipadrões (Apêndice E, Apêndice F, Apêndice G) foram gerados, seguindo os passos mencionados na Seção 5.1.1. O primeiro catálogo apresenta os antipadrões encontrados nos códigos desenvolvidos com a linguagem de programação $C$, um total de 21; o segundo apresenta os antipadrões encontrados em Python, totalizando 11; e o terceiro apresenta os 9 que ocorreram em ambas as linguagens de programação. As fichas dos Catálogos dos Antipadrões fazem referência ao Apêndice C, onde são mostrados os enunciados completos dos exercícios que os alunos estavam resolvendo no momento em que o equívoco ocorreu, e também ao Apêndice $D$, onde são apresentadas descrições 


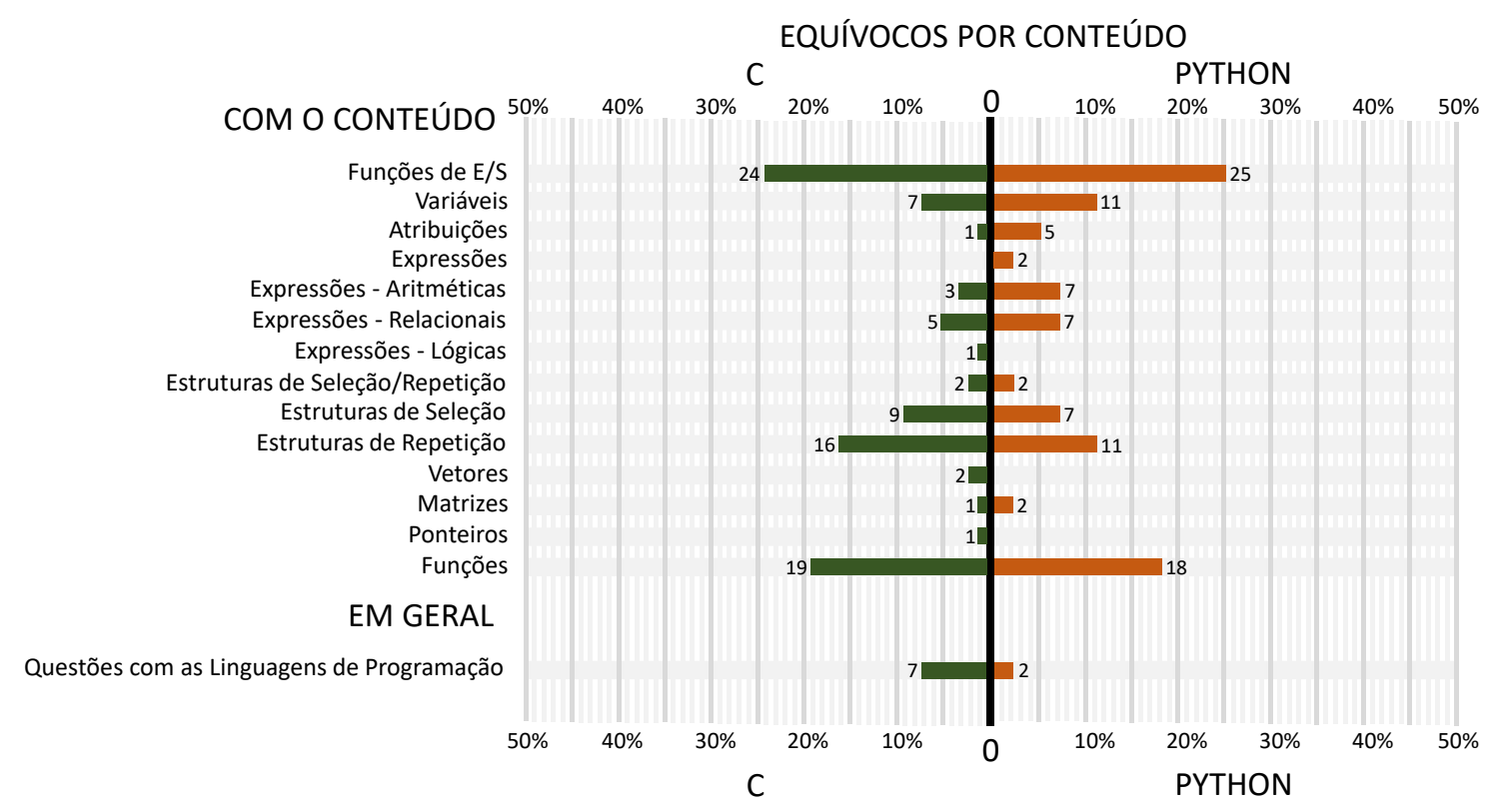

Figura 5.8: Percentual por tópico dos equívocos encontrados em códigos desenvolvidos em $C$ e Python.

completas das sugestões para professores de como evitar que o antipadrão surja nos códigos desenvolvidos pelos seus alunos, além de sugestões de soluções para alunos trabalharem esse conteúdo durante seus estudos fora da sala de aula. Além dessas informações, outras também compõem as fichas, conforme pode ser visto nas Figura 5.5, Figura 5.6 e Figura 5.7.

Cada antipadrão foi classificado como erro de sintaxe, semântica ou estilo. A Figura 5.9 apresenta o percentual de antipadrões classificados em cada tipo, separados por linguagem de programação. Nessa figura podemos observar que Python apresentou um percentual menor de antipadrões classificados como erros de semântica (30\%) e de estilo (5\%) se comparado com C, porém maior quanto à quantidade de erros de sintaxe, $25 \%$ maior que em C.

Comparando o número de submissões que os alunos precisaram para resolver os antipadrões do tipo sintático em C e Python (Figure 5.10), uma pequena diferença não estatisticamente significante foi identificada. O mesmo resultado foi obtido quando comparamos o número de eventos não resolvidos por tipo de erro por linguagem de programação (Figure 5.11).

A Figura 5.11 apresenta o percentual de eventos não resolvidos por tipo de erro e linguagem. Em C, o tipo de erro com menos equívocos não resolvidos é o de sintaxe, em que o próprio compilador aponta o erro, deixando-o mais visível ao aprendiz. Em seguida vêm os erros de semântica, em que o aluno pode perceber que há problemas pelo resultado ou comportamento não esperado que o código gera. Por último vêm os erros de estilo, com o maior número de eventos não resolvidos. Porém, na linguagem Python, o resultado foi o inverso, com mais eventos não resolvidos para os erros de sintaxe e menos para os de estilo. Resultado intrigante, pois os erros de sintaxe e de semântica são os mais percebidos, através de aviso dado pelo compilador/interpretador ou pelo resultado errado apresentado, 


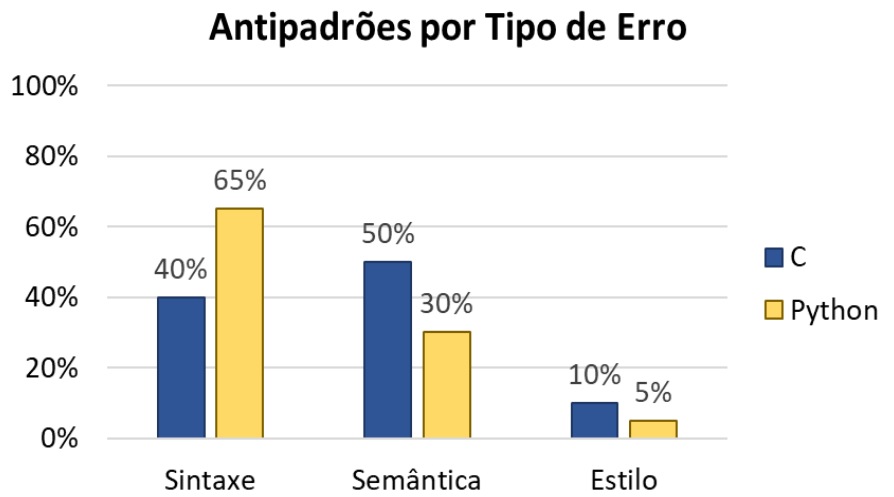

Figura 5.9: Percentual de antipadrões em cada tipo de erro, por linguagem.

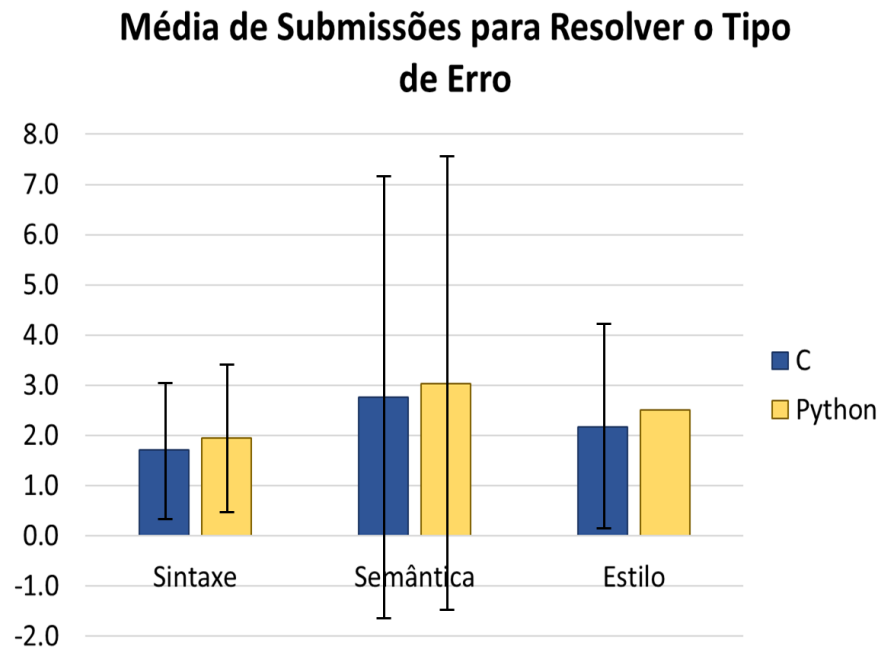

Figura 5.10: Média de submissões necessárias para resolver cada tipo de erro, por linguagem, mostrando o intervalo de confiança (95\%).

logo, os que considerávamos que seriam os erros mais resolvidos pelos alunos.

Nas três seções seguintes, são apresentadas as Tabelas 5.2, 5.4 e 5.6, com resumos dos catálogos de antipadrões. Nas cinco últimas colunas dessas tabelas estão registrados o total de eventos encontrados, em quantos desses eventos o aluno não conseguiu resolver o problema e a média, mediana e moda de submissões feitas do momento em que o equívoco se apresentou até momento em que ele foi corrigido.

A média foi calculada somando-se todas as submissões realizadas e dividido-se esse resultado pelo total de eventos, subtraídos os não resolvidos. Por exemplo, no segundo antipadrão da Tabela 5.2, C_GL1, foram encontrados 8 eventos, porém 2 sem correção.

Para a mediana, as quantidades de todas submissões até a correção foram ordenadas e o valor do meio selecionado. Em caso de quantidade par, foi feita a média dos dois valores do meio, como foi o caso do antipadrão 11, por exemplo. Para a moda, foi considerado o valor que mais aparece. Quando todos valores aparecem na mesma proporção, é considerado Amodal (exemplo: antipadrão 7); se houver dois valores iguais, o antipadrão foi considerado Bimodal (exemplo: antipadrão 16). 


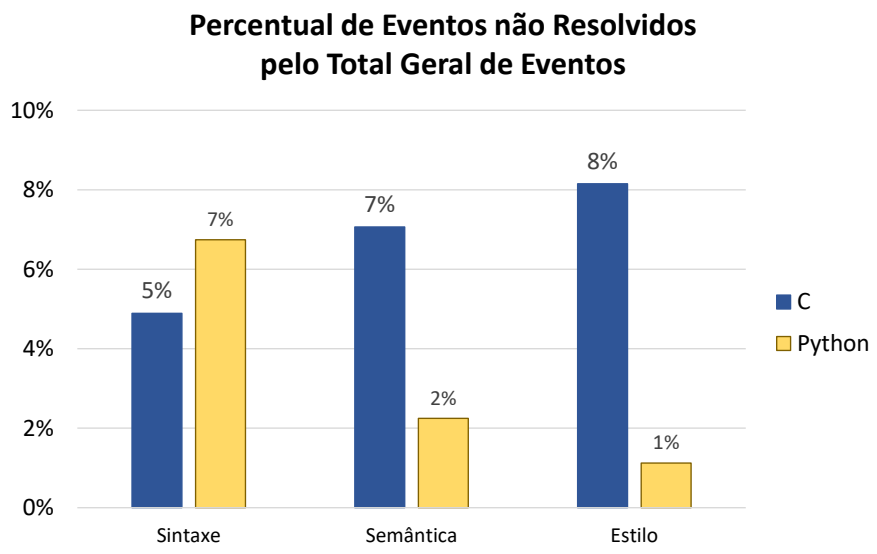

Figura 5.11: Percentual de eventos não resolvidos pelo total geral de eventos, por tipo de erro na linguagem

A seguir, continuando a explanação dos resultados encontrados neste estudo, apresentamos os catálogos de antipadrões encontrados em C e Python, separadamente, com o intuito de responder à "QP4.1 - Quais equívocos encontrados nos códigos são recorrentes em cada uma das linguagens de programação analisadas?”.

\section{Antipadrões em C}

Trinta dos 95 equívocos encontrados na linguagem $C$ são antipadrões, pois foram registrados 3 ou mais eventos para cada um deles. Desses 30, 21 ocorreram apenas na linguagem C. O catálogo completo com todas as fichas dos 21 antipadrões em $C$ pode ser visto no Apêndice E e um resumo na Tabela 5.2.

Para ilustrar, vamos usar três exemplos de cada um dos catálogos ilustrados nas Tabelas 5.3, 5.5 e 5.7. Eles foram escolhidos utilizando-se os seguintes critérios: o antipadrão com o maior número de eventos (E), outro com maior número de submissões até correção (S) e o com maior número de eventos não corrigidos, identificados com (?). Esses exemplos podem merecer atenção especial por causa dessas características: ocorrem muitas vezes nos códigos dos alunos, ou levam muito tempo para serem resolvidos ou por serem provavelmente desconsiderados por não causarem erros propriamente ditos no momento em que surgiram. Sendo assim, a Tabela 5.3 apresenta os antipadrões selecionados do catálogo de antipadrões de C: C_G2 (E), C_SS4 (S) e C_F1 (?). Uma imagem de cada um desses antipadrões é apresentada, sendo uma cópia do código desenvolvido por um aluno, mostrando como o erro apareceu.

Vale ressaltar que os três antipadrões mencionados foram encontrados respectivamente nos tópicos denominados de 'Geral', 'Estrutura de Seleção' e 'Função', abordados nas disciplinas de introdução à programação. Todos os tópicos que estavam sendo estudados e que apresentaram antipadrões no aprendizado de programação em C são: geral (2), função de entrada de dados (2), função de saída de dados (5), expressão aritmética (3), expressão relacional (1), estrutura de seleção (2), estrutura de repetição (1) e função (5). A seguir uma descrição desses três antipadrões.

C_G2 - Falta de “;” no final da linha: Este é um erro de sintaxe. Na maioria dos 


\begin{tabular}{|c|c|c|c|c|c|c|c|c|c|c|}
\hline \multirow{2}{*}{$\mathbf{N}$} & \multirow{2}{*}{ ID } & \multirow{2}{*}{ Nome do Antipadrão } & \multicolumn{2}{|c|}{ Linguagem } & \multirow{2}{*}{$\begin{array}{c}\text { Tipo do } \\
\text { Erro }\end{array}$} & \multirow{2}{*}{$\begin{array}{l}\text { Total de } \\
\text { Eventos }\end{array}$} & \multirow{2}{*}{$\begin{array}{c}\text { Total de } \\
\text { Eventos sem } \\
\text { Correção do } \\
\text { Equívoco (?) }\end{array}$} & \multicolumn{3}{|c|}{ Submissões até Correção } \\
\hline & & & C & Python & & & & Média & Mediana & Moda \\
\hline 1 & C_G2 & Falta de ";" no final da linha & $x$ & & Sintaxe & 15 & 0 & 1.5 & 1 & 1 \\
\hline 2 & C_GL1 & Falta chamada da biblioteca & $\mathrm{x}$ & & Sintaxe & 8 & 2 & 2.3 & 2 & 2 \\
\hline 3 & C_IF1 & $\begin{array}{l}\text { Falta do " } \& \text { " na frente da } \\
\text { variável no "scanf" }\end{array}$ & $x$ & & Semântica & 8 & 1 & 1.4 & 1 & 1 \\
\hline 4 & C_IF6 & $\begin{array}{l}\text { Falta vírgula para separar o } \\
\text { primeiro do segundo } \\
\text { parâmetro no "scanf" }\end{array}$ & $x$ & & Sintaxe & 3 & 0 & 2.3 & 1 & 1 \\
\hline 5 & C_OF1 & $\begin{array}{l}\text { Uso indevido do " } \& \text { " na frente } \\
\text { da variável no "printf" }\end{array}$ & $x$ & & Semântica & 5 & 0 & 1.0 & 1 & 1 \\
\hline 6 & C_OF3 & $\begin{array}{l}\text { Escrita incorreta do comando } \\
\text { "printf" }\end{array}$ & $x$ & & Sintaxe & 8 & 1 & 1.0 & 1 & 1 \\
\hline 7 & C_OF5 & $\begin{array}{l}\text { Parâmetro que identifica o } \\
\text { tipo de dado de saída } \\
\text { incorreto ou inexistente }\end{array}$ & $x$ & & Sintaxe & 4 & 1 & 3.0 & 2 & Amodal \\
\hline 8 & C_OF6 & $\begin{array}{l}\text { Uso do " } \& \text { " no lugar do "\%" na } \\
\text { função de saída de dados }\end{array}$ & $x$ & & Semântica & 3 & 0 & 3.7 & 3 & Amodal \\
\hline 9 & C_OF7 & $\begin{array}{l}\text { Não apresenta o resultado ao } \\
\text { usuário }\end{array}$ & $x$ & & Semântica & 4 & 0 & 1.3 & 1 & 1 \\
\hline 10 & C_AE1 & $\begin{array}{l}\text { Tipo do resultado float em } \\
\text { uma divisão de inteiros }\end{array}$ & $x$ & & Semântica & 9 & 1 & 3.3 & 3 & 3 \\
\hline 11 & C_AE2 & Fórmula aritmética errada & $x$ & & Semântica & 8 & 0 & 3.8 & 2.5 & 2 \\
\hline 12 & C_AE3 & $\begin{array}{l}\text { Realizar o cálculo antes de ter } \\
\text { valores nas variáveis utilizadas }\end{array}$ & $\mathrm{x}$ & & Semântica & 5 & 0 & 2.2 & 1 & 1 \\
\hline 13 & C_RE5 & $\begin{array}{l}\text { Realizar comparação antes de } \\
\text { ter valores nas variáveis } \\
\text { utilizadas }\end{array}$ & $\mathrm{x}$ & & Semântica & 3 & 0 & 1.7 & 1 & 1 \\
\hline 14 & C_SS1 & $\begin{array}{l}\text { Uso incorreto das chaves de } \\
\text { abertura ou de fechamento do } \\
\text { "if" ou do "else" }\end{array}$ & $x$ & & Sintaxe & 3 & 0 & 1.0 & 1 & 1 \\
\hline 15 & C_SS4 & $\begin{array}{l}\text { Colocar indevidamente ";" } \\
\text { após a condição do "if" e/ou } \\
\text { após o "else" }\end{array}$ & $x$ & & Semântica & 3 & 0 & 10.3 & 7 & Amodal \\
\hline 16 & $C_{-}$RS3 & $\begin{array}{l}\text { Imprimindo resultado em local } \\
\text { errado }\end{array}$ & $x$ & & Semântica & 7 & 1 & 3.2 & 2.5 & Bimodal $(1,3)$ \\
\hline 17 & C_F1 & Falta do return & $\mathrm{x}$ & & Semântica & 12 & 7 & 2.0 & 1 & $?$ \\
\hline 18 & C_F2 & $\begin{array}{l}\text { Falta de abertura "\{" e/ou } \\
\text { fechamento "\}" da função }\end{array}$ & $x$ & & Sintaxe & 5 & 0 & 2.6 & 1 & 1 \\
\hline 19 & C_F6 & $\begin{array}{l}\text { Chamada incorreta de uma } \\
\text { função tipada }\end{array}$ & $x$ & & Semântica & 5 & 0 & 2.0 & 2 & Bimodal $(1,2)$ \\
\hline 20 & C_F9 & $\begin{array}{l}\text { Declaração incorreta dos } \\
\text { parâmetros da função }\end{array}$ & $x$ & & Sintaxe & 6 & 4 & 1.5 & 1.5 & $?$ \\
\hline 21 & C_F10 & "return" x "printf" & $x$ & & Estilo & 7 & 3 & 2.5 & 2 & $?$ \\
\hline
\end{tabular}

Tabela 5.2: Resumo do Catálogo de Antipadrões em C.

casos, a linguagem $\mathrm{C}$ exige que a linha de comando seja finalizada com ponto e vírgula, caso contrário o programa não será compilado e, consequentemente, não será executado. No trecho de código mostrado na imagem da Tabela 5.3, as três linhas precisariam de um ponto e vírgula para finalizá-las. Esse antipadrão foi encontrado 15 vezes, ou seja, em 15 códigos de alunos distintos. Desses 15 eventos, dez tiveram o equívoco corrigido já na submissão seguinte, podendo ser caracterizado como falta de atenção, porém também ocorreram casos onde os alunos precisaram de 2 e 5 submissões para corrigir.

C_SS4 - Colocar indevidamente “;” após a condição do "if” e/ou após o "else”: Esta é uma exceção ao explicado para C_G2, pois essa linha não pode ter ponto e vírgula. A linha do 'if' ou do 'else' é onde um bloco de comandos é aberto e, por isso, não existe o ponto e vírgula. Esse equívoco foi classificado como erro de semântica pois, mesmo colocando o ponto e vírgula, se outros erros não existirem no código, o programa será compilado e executado. O problema estará no resultado gerado, que provavelmente estará errado. Com a presença do ponto e vírgula ao final da linha do 'if', o programa executará a linha do 'if', verificando a condição, porém, independentemente do resultado, o bloco de 


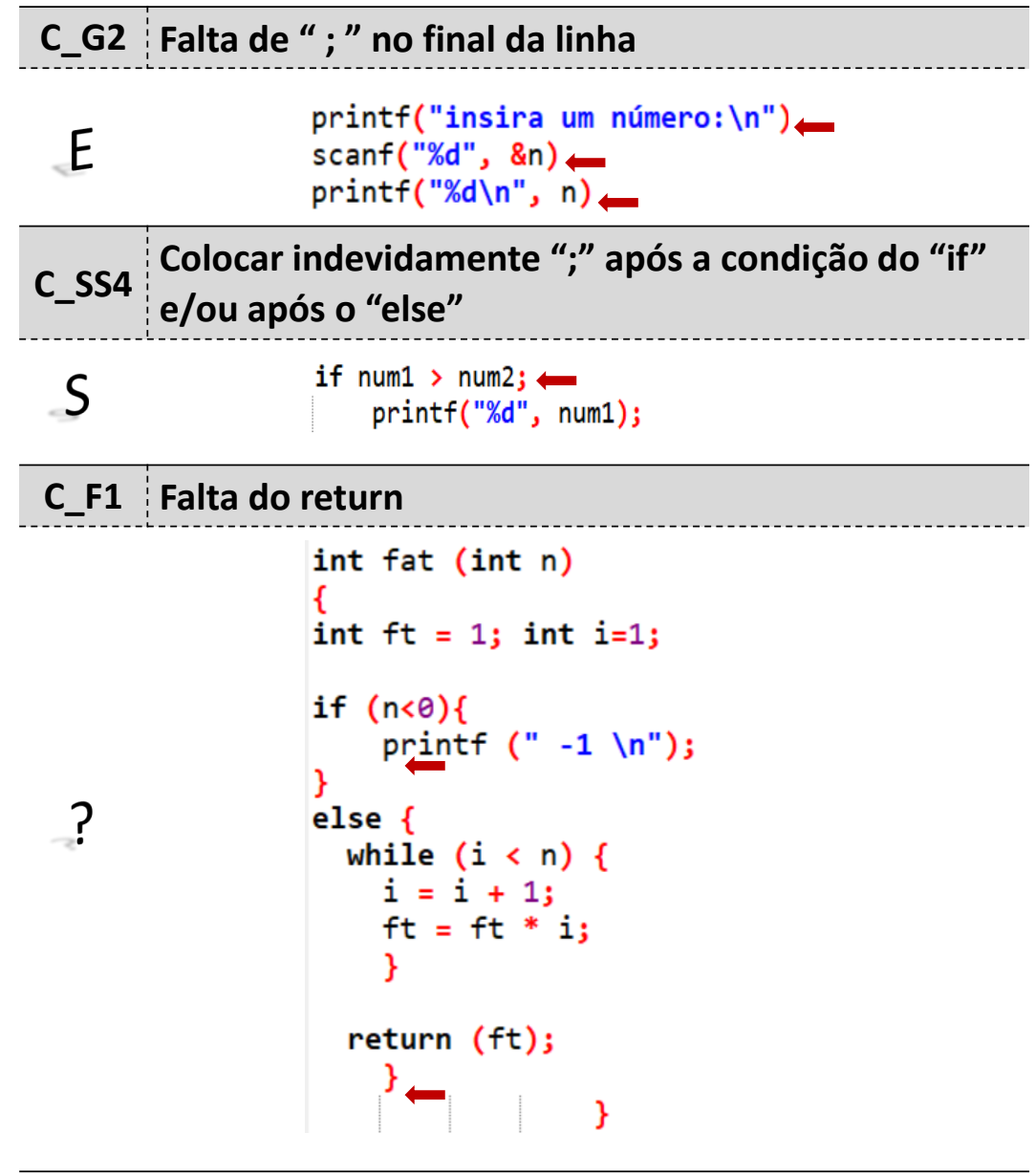

Tabela 5.3: Exemplos de códigos mostrando antipadrões que ocorreram somente ao ser usado o $C$.

comandos que deveria ser condicionado será executado, nesse caso o 'printf'. No trecho de código da Tabela 5.3, a presença indevida do ponto e vírgula não é o único erro: a condição da estrutura deveria estar entre parênteses, ou seja, ao invés de "if num1 > num2;" deveria ser "if (num1 > num2)". Para resolver esse antipadrão (C_SS4), o aluno demorou em cada uma das 3 ocorrências o equivalênte a 6, 7 e 18 submissões, resultando em uma média de mais de 10 submissões, caracterizando um desconhecimento de que esse ponto e vírgula não deveria existir.

C_F1 - Falta do return: A maioria das ocorrências desse equívoco foi encontrada na função 'main', não mostrando resultados errados ou erros de compilação para os alunos. No entanto, no exemplo apresentado na Tabela 5.3, o erro está em uma função que deveria retornar o fatorial do número 'n', o que não ocorre se o valor armazenado em ' $n$ ' for menor que 0 (zero). Nesse trecho de código, o aluno escolheu imprimir em vez de retornar. Essa escolha pode ser um problema, dependendo de como a devolução é tratada no local de recebimento. A moda desse antipadrão é ele não ser resolvido, ou seja, a reação mais comum vista para esse equívoco é o aprendiz desconsiderar o antipadrão ou abandonar o exercício. Isso ocorreu também para outros dois antipadrões, ambos também relacionados ao conteúdo 'Função': C_F9 - Declaração incorreta dos parâmetros da função e C_F10 - “return” x “printf”. 


\section{Antipadrões em Python}

Conforme explicado na Seção 5.1.1, uma parte dos alunos desenvolveu códigos utilizando a linguagem de programação Python. A análise desses códigos gerou um conjunto de 44 equívocos, sendo que 20 deles são antipadrões e, desses 20, onze foram vistos ocorrendo apenas com Python. O Catálogo desses 11 antipadrões é apresentado na íntegra no Apêndice F e um resumo na Tabela 5.4.

\begin{tabular}{|c|c|c|c|c|c|c|c|c|c|c|}
\hline \multirow{2}{*}{$\mathbf{N}$} & \multirow{2}{*}{ ID } & \multirow{2}{*}{ Nome do Antipadrão } & \multicolumn{2}{|c|}{ Linguagem } & \multirow{2}{*}{$\begin{array}{c}\text { Tipo do } \\
\text { Erro }\end{array}$} & \multirow{2}{*}{$\begin{array}{l}\text { Total de } \\
\text { Eventos }\end{array}$} & \multirow{2}{*}{$\begin{array}{c}\text { Total de } \\
\text { Eventos sem } \\
\text { Correção do } \\
\text { Equívoco (?) }\end{array}$} & \multicolumn{3}{|c|}{ Submissões até Correção } \\
\hline & & & C & Python & & & & Média & Mediana & Moda \\
\hline 1 & P_V2 & $\begin{array}{l}\text { Usar palavra reservada para } \\
\text { nome de variável }\end{array}$ & & $x$ & Sintaxe & 4 & 3 & 1.0 & 1 & $?$ \\
\hline 2 & P_V4 & $\begin{array}{l}\text { Conversão incorreta de tipo de } \\
\text { dado }\end{array}$ & & $x$ & Sintaxe & 3 & 0 & 3.3 & 3 & 3 \\
\hline 3 & P_V5 & Falta conversão de tipo & & $x$ & Semântica & 4 & 0 & 1.5 & 1.5 & Bimodal $(1,2)$ \\
\hline 4 & P_IF4 & Falta parênteses no "input" & & $x$ & Sintaxe & 3 & 0 & 2.3 & 2 & Amodal \\
\hline 5 & P_OF5 & $\begin{array}{l}\text { "print" seguido por "=" ou } \\
\text { outro parâmetro incorreto }\end{array}$ & & $x$ & Sintaxe & 3 & 1 & 2.0 & 2 & Amodal \\
\hline 6 & P_AE2 & Operador aritmético errado & & $x$ & Sintaxe & 4 & 0 & 1.0 & 1 & 1 \\
\hline 7 & P_SS1 & $\begin{array}{l}\text { Falta dos ":" no final da linha } \\
\text { do "if" ou do "else" }\end{array}$ & & $x$ & Sintaxe & 7 & 1 & 2.0 & 1.5 & 1 \\
\hline 8 & P_RS1 & $\begin{array}{l}\text { Ordem incorreta dos } \\
\text { comandos na estrutura }\end{array}$ & & $x$ & Semântica & 4 & 1 & 3.0 & 3 & Amodal \\
\hline 9 & P_SRS1 & $\begin{array}{l}\text { Uso de estrutura de repetição } \\
\text { onde deveria ser de seleção }\end{array}$ & & $x$ & Semântica & 3 & 1 & 1.5 & 1.5 & Amodal \\
\hline 10 & P_MDA1 & $\begin{array}{l}\text { Criação errada das linhas da } \\
\text { matriz }\end{array}$ & & $x$ & Semântica & 3 & 0 & 7.3 & 8 & Amodal \\
\hline 11 & P_F8 & $\begin{array}{l}\text { Função criada porém não } \\
\text { chamada }\end{array}$ & & $x$ & Semântica & 6 & 0 & 1.2 & 1 & 1 \\
\hline
\end{tabular}

Tabela 5.4: Resumo do Catálogo de Antipadrões em Python.

Seguindo o mesmo modelo apresentado anteriormente, três antipadrões desse catálogo foram escolhidos para terem seus resultados comentados, conforme apresentado na Tabela 5.5. Nessa Tabela, uma imagem de cada um desses três antipadrões é apresentada e, a seguir, uma descrição mais detalhada de cada um deles para reforçar a compreensão.

P_SS1 - Falta dos “:” no final do "if” ou do "else”: Este antipadrão foi o que apresentou maior número de eventos, sete no total, seguido de "P_F8 - Função criada porém não chamada", com seis. Nas regras da linguagem Python, a linha de comando que começa com 'if' ou 'else' deve terminar com dois pontos, porém, observando-se no trecho de código de P_SS1 da Tabela 5.5, vemos que isso não ocorre. A ausência desses dois pontos causará um erro de sintaxe e o código não será compilado/interpretado. Este antipadrão é bastante simples de ser corrigido, como podemos ver pela moda de 1 submissão utilizada para corrigí-lo. Mesmo assim, em alguns casos foram necessárias mais submissões, gerando uma média de 2 submissões. Em um dos casos, o aluno demorou 5 submissões e, em outro, o aprendiz desistiu do código, abandonando-o.

P_MDA1 - Criação errada das linhas da matriz : Em Python, as linhas de uma matriz são criadas conforme necessário e, portanto, devem ser criadas dentro da estrutura de repetição, pois o comando correspondente provavelmente será executado mais de uma vez. No entanto, foram encontradas três ocorrências em que os alunos criaram a linha antes de entrar na estrutura de repetição. Esse antipadrão se mostrou difícil de ser encontrado e corrigido, como podemos perceber pela mediana de 8 submissões para que a correção ocorresse. O fato de esse antipadrão ser apresentado como erro de semântica, ou seja, não 


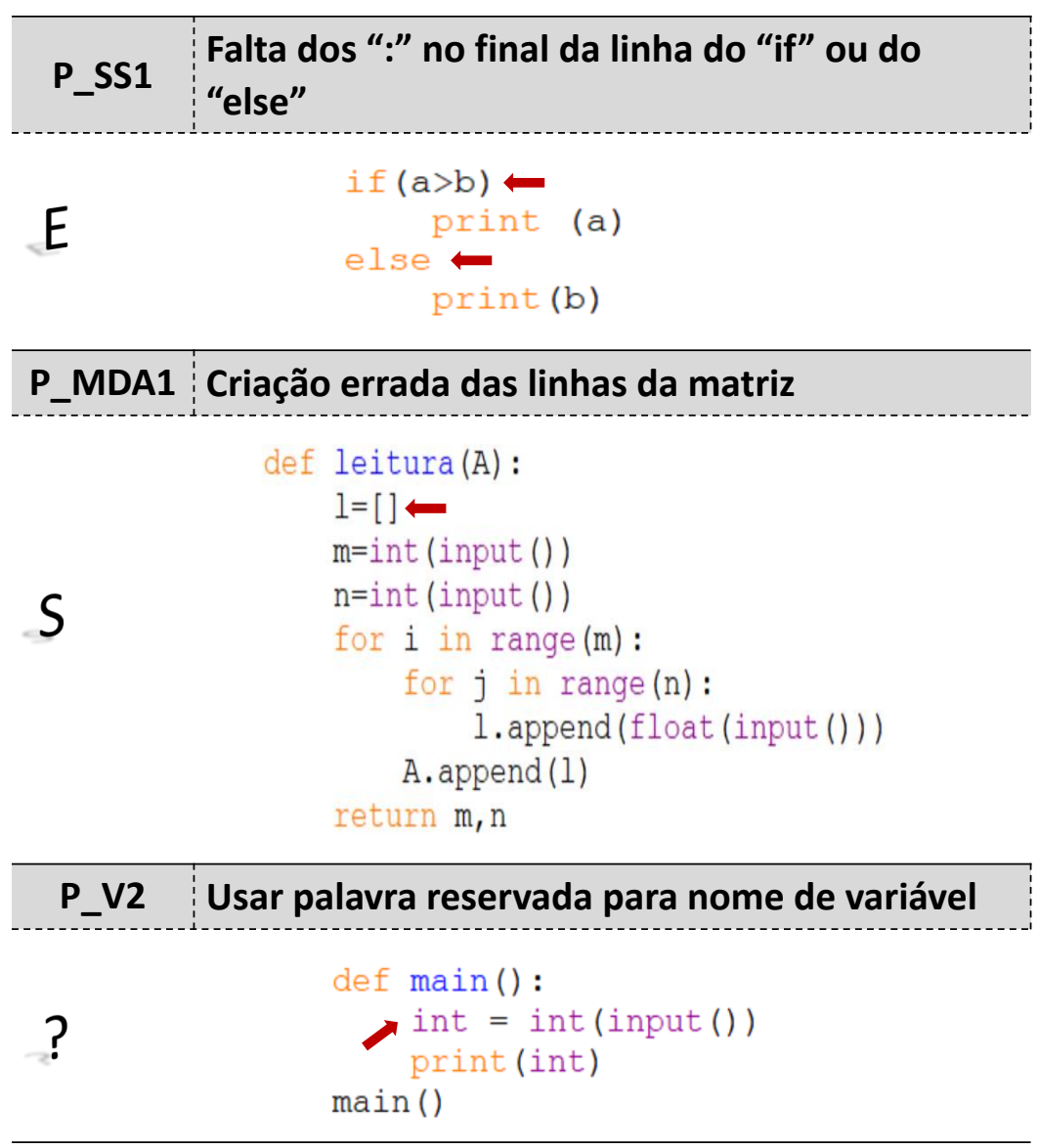

Tabela 5.5: Exemplos de códigos mostrando antipadrões que ocorreram somente com o uso da linguagem Python.

identificado pelo compilador/interpretador e sim pelo resultado errado gerado pelo código, sem que seja mostrado ao aprendiz onde o erro se encontra, dificulta a correção do mesmo (Figura 5.10).

P_V2 - Usar palavra reservada para nome de variável: a maioria das linguagens, como $\mathrm{C}$, Python, Java e $\mathrm{C}++$, tem como uma das regras que identificadores não podem ser criados com os mesmos nomes de palavras reservadas da linguagem. Observe na Tabela 5.4 que em três dos quatro eventos o antipadrão não foi corrigido e, como esse erro é de sintaxe, o aluno sequer viu o código executando. Apesar da média e mediana estarem mostrando que o aluno demora apenas uma submissão para resolver o problema, a moda está como '?', ou seja, o comum é o antipadrão não ser solucionado.

Os antipadrões em Python surgiram nos seguintes tópicos da disciplina de introdução à programação: variável (3), função de entrada de dados (1), função de saída de dados (1), expressão aritmética (1), estruturas de controle - seleção e repetição (1), estrutura de seleção (1), estrutura de repetição (1), matrizes (1) e função (1).

Na seção a seguir, são apresentados os antipadrões que ocorreram tanto em C quanto em Python, respondendo assim a "QP4.2 - Quais dos equívocos identificados são comuns para ambas linguagens?”. 


\section{Antipadrões Ocorridos em C e em Python}

Alguns antipadrões surgiram nas duas linguagens. A Tabela 5.6 mostra um resumo do catálogo completo apresentado no Apêndice G. A partir da sexta coluna, correspondente ao 'Tipo de Erro', as linhas são divididas para que os resultados possam ser apresentados por linguagem, exceto quando o resultado for o mesmo para ambas, como ocorreu no 'Tipo do Erro' do antipadrão V1, por exemplo.

\begin{tabular}{|c|c|c|c|c|c|c|c|c|c|c|}
\hline \multirow{2}{*}{$\mathbf{N}$} & \multirow{2}{*}{ ID } & \multirow{2}{*}{ Nome do Antipadrão } & \multicolumn{2}{|c|}{ Linguagem } & \multirow{2}{*}{$\begin{array}{l}\text { Tipo do } \\
\text { Erro }\end{array}$} & \multirow{2}{*}{$\begin{array}{l}\text { Total de } \\
\text { Eventos }\end{array}$} & \multirow{2}{*}{$\begin{array}{c}\text { Total de } \\
\text { Eventos sem } \\
\text { Correção do } \\
\text { Equívoco (?) }\end{array}$} & \multicolumn{3}{|c|}{ Submissões até Correção } \\
\hline & & & C & Python & & & & Média & Mediana & Moda \\
\hline \multirow{3}{*}{1} & \multirow[b]{2}{*}{ G1 } & \multirow{2}{*}{ Falta de indentação } & \multirow[b]{2}{*}{$\mathrm{x}$} & \multirow[b]{2}{*}{$\mathrm{x}$} & $P=$ Sintaxe & $P=9$ & $P=0$ & $P=2.2$ & 2 & 1 \\
\hline & & & & & $C=$ Estilo & $C=5$ & $C=4$ & $C=3.0$ & 3 & ? \\
\hline & \multirow{2}{*}{ V1 } & \multirow{2}{*}{ Uso de variável inexistente } & \multirow{2}{*}{$\mathrm{x}$} & \multirow{2}{*}{$\mathrm{x}$} & \multirow{2}{*}{ Sintaxe } & $P=4$ & $P=0$ & $P=1.8$ & 1.5 & 1 \\
\hline 2 & & & & & & $C=13$ & $C=0$ & $C=1.4$ & 1 & 1 \\
\hline \multirow{2}{*}{3} & \multirow{2}{*}{ V3 } & \multirow{2}{*}{$\begin{array}{l}\text { Atribuição usando "==" ao } \\
\text { invés de " }=\text { " }\end{array}$} & \multirow{2}{*}{$\mathrm{x}$} & \multirow{2}{*}{$\mathrm{x}$} & $P=$ Sintaxe & $P=3$ & $P=1$ & $P=3.0$ & 3 & Amodal \\
\hline & & & & & $\mathrm{C}=$ Semântica & $C=5$ & $C=2$ & $C=2.0$ & 1 & Bimodal $(1$, ?) \\
\hline \multirow{2}{*}{4} & \multirow{2}{*}{ IF2 } & \multirow{2}{*}{$\begin{array}{l}\text { Falta das aspas na chamada da } \\
\text { função de entrada de dados }\end{array}$} & \multirow{2}{*}{$\mathrm{x}$} & \multirow{2}{*}{$\mathrm{x}$} & \multirow{2}{*}{ Sintaxe } & $P=3$ & $P=0$ & $P=1.0$ & 1 & 1 \\
\hline & & & & & & $C=3$ & $C=1$ & $C=2.0$ & 2 & Amodal \\
\hline \multirow{3}{*}{5} & \multirow{2}{*}{ OF2 } & \multirow{2}{*}{$\begin{array}{l}\text { Falta das aspas na função de } \\
\text { saída de dados }\end{array}$} & \multirow{2}{*}{$\mathrm{x}$} & $x$ & Sintaxe & $P=5$ & $P=0$ & $P=1.8$ & 2 & Bimodal $(1,2)$ \\
\hline & & & & $x$ & Sintaxe & $C=4$ & $C=0$ & $C=1.0$ & 1 & 1 \\
\hline & & Falta da vírgula para separar o & & & & $P=3$ & $P=0$ & $P=1.3$ & 1 & 1 \\
\hline 6 & OF4 & $\begin{array}{l}\text { primeiro do segundo } \\
\text { parâmetro na função de saída } \\
\text { de dados }\end{array}$ & $x$ & $x$ & Sintaxe & $C=4$ & $C=0$ & $C=1.0$ & 1 & 1 \\
\hline 7 & RE1 & O uso do "=" ao invés de "==" & $\mathrm{x}$ & $\mathrm{x}$ & $\mathrm{P}=$ Sintaxe & $P=10$ & $P=0$ & $P=2.7$ & 1 & 1 \\
\hline & & & & & $C=$ Semântica & $C=5$ & $C=0$ & $C=1.8$ & 1 & 1 \\
\hline 8 & S\$2 & O não uso do "else" onde seria & $x$ & $x$ & Estilo & $P=5$ & $P=1$ & $P=2.5$ & 2 & 2 \\
\hline 8 & SSL & adequado & $x$ & $x$ & EStIIO & $C=9$ & $C=8$ & $C=1.0$ & 1 & $?$ \\
\hline 9 & RS2 & Variável de controle não está & $x$ & $\mathrm{x}$ & Semântica & $P=3$ & $P=0$ & $P=3.7$ & 2 & Amodal \\
\hline & & sendo alterada & & & & $C=5$ & $C=1$ & $C=1.8$ & 1.5 & 1 \\
\hline
\end{tabular}

Legenda: P e C correspondem respectivamente às linguagens de programação Python e $\mathrm{C}$.

Tabela 5.6: Resumo do Catálogo de Antipadrões em C e Python.

A Tabela 5.7 mostra seis dos nove antipadrões ocorridos em ambas linguagens. A seleção desses exemplos foi feita usando o mesmo critério explicado anteriormente. Nessa tabela podemos ver trechos de códigos de ambas linguagens para cada situação. Observe que os antipadrões para cada situação não são os mesmos para as duas linguagens, ou seja, o antipadrão que teve o maior número de eventos em $\mathrm{C}$ não foi o mesmo em Python, e assim por diante. Com isso, os seis antipadrões são: V1 em C e RE1 em Python os que apresentaram maior número de eventos (E); G1 em C e RS2 em Python os que apresentaram maior número de submissões até correção (S); e os que apresentaram maior número de eventos não corrigidos (?) foram SS2 em C e V3 em Python.

V1 - Uso de variável inexistente e RE1 - O uso do "=” ao invés de “==”: Em C, as variáveis precisam ser declaradas, informando o nome e o tipo de dados a serem usados. Em Python, na primeira vez em que a variável aparece no código, ela deve estar recebendo algum valor para que seu tipo fique definido. Treze ocorrências foram detectadas em $\mathrm{C}$ e 4 em Python, sendo esse um antipadrão com mais eventos encontrados em C. Embora os alunos de $\mathrm{C}$ tenham mais ocorrências, foram os de Python que demoraram mais tempo para identificar que a variável era inexistente e o porquê. Este erro é considerado um erro de sintaxe nas duas linguagens. $\mathrm{O}$ antipadrão com maior número de eventos em Python, RE1, com 10 eventos no total, também é de sintaxe para essa linguagem e de semântica para C. O uso do sinal de atribuição '=' no lugar de comparação '==' é um equívoco comum nas duas linguagens, porém, além de existirem mais ocorrências em Python, foi também nessa linguagem que os alunos demoraram mais para resolver o problema. 


\begin{tabular}{|c|c|c|c|}
\hline V1 & Uso de variável inexistente & RE1 & $\begin{array}{l}\text { O uso do "=" ao invés de } \\
\text { "==" }\end{array}$ \\
\hline \multicolumn{2}{|r|}{ C } & \multicolumn{2}{|r|}{ Python } \\
\hline$E$ & $\begin{array}{l}\text { \#include <stdio.h〉 } \\
\text { int main(void) }\{ \\
\text { int } n ; \\
\text { scanf("\%d", \&n); } \\
\Rightarrow m=n ;\end{array}$ & \multicolumn{2}{|r|}{ 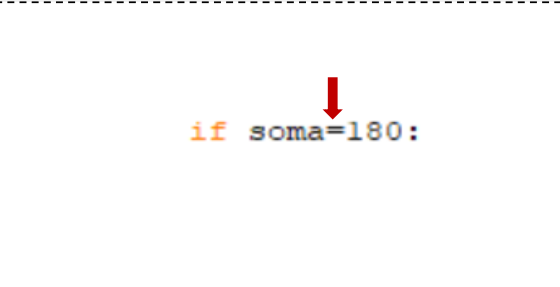 } \\
\hline G1 & Falta de indentação & RS2 & $\begin{array}{l}\text { Variável de controle não } \\
\text { está sendo alterada }\end{array}$ \\
\hline & C & \multicolumn{2}{|r|}{ Python } \\
\hline$S$ & $\begin{aligned} & \# \text { include <stdio.h> } \\
& \text { int main()\{ } \\
\Rightarrow & \text { int } a ; \\
\Rightarrow & \text { scanf( } \% \text { ("d", \&a); } \\
\Rightarrow & \text { printf("\%d", \&a); } \\
\Rightarrow & \text { return } \theta ; \\
& \}\end{aligned}$ & \multicolumn{2}{|r|}{$\begin{array}{l}\mathrm{i}=1 \\
\text { while }(\mathrm{i}<\mathrm{n}): \\
\quad \text { print ord }(\mathrm{c}[\mathrm{i}])\end{array}$} \\
\hline SS2 & $\begin{array}{l}\text { O não uso do "else" onde } \\
\text { seria adequado }\end{array}$ & V3 & $\begin{array}{l}\text { Atribuição usando "==" ao } \\
\text { invés de "=" }\end{array}$ \\
\hline & C & \multicolumn{2}{|r|}{ Python } \\
\hline$?=$ & 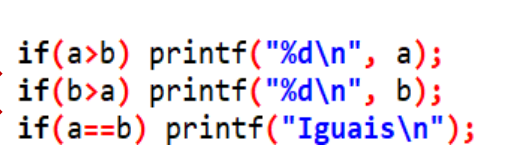 & \multicolumn{2}{|r|}{ soma $=a+b$} \\
\hline
\end{tabular}

Tabela 5.7: Exemplos de códigos mostrando antipadrões que ocorreram em ambas linguagens: $C e$ Python.

G1 - Falta de indentação e RS2 - Variável de controle não está sendo alterada: A falta de indentação é um equívoco recorrente nas duas linguagens, porém classificado como erro de estilo em $\mathrm{C}$ e de sintaxe em Python. Um código não indentado dificulta a análise visual, tanto que algumas linguagens obrigam que a indentação seja feita, como é o caso de Python. Como em C isso não é obrigatório, a moda (Tabela 5.6) mostra que muitos aprendizes acabam não corrigindo esse equívoco, pois o programa irá ser executado e o resultado não será influenciado por essa falta de indentação. Porém, entre os que arrumaram o equívoco, uma média de 3 submissões foi necessária. Para os que trabalharam com Python, RS2 é o antipadrão que teve uma média de submissões maior até que o equívoco tivesse sido solucionado. Ele é considerado um erro de semântica para ambas linguagens e sua presença faz com que o código tenha um comportamento diferente do esperado. Se a variável de controle não for alterada, é comum que o programa gere repetições infinitas. Embora esse comportamento do programa torne o erro mais claro, os alunos gastaram mais compilações/submissões para corrigí-lo. Essa dificuldade em trabalhar com a variável de controle já apareceu também em outro estudo realizado durante o período do doutorado, 
conforme descrito nas Seções 4.2 e 4.3 e publicado em dois artigos (Bosse, Redmiles et al., 2019b; Bosse, Redmiles et al., 2019a).

SS2 - O não uso do "else" onde seria adequado e V3 - Atribuição usando "==" ao invés de "=": o SS2 classificado como erro de estilo é também o equívoco que mais apresentou casos não resolvidos em ambas linguagens, sendo que em Python empatou com V3. Em SS2, os alunos substituem 'else' pelo uso de vários 'ifs', apresentando a dificuldade de visualizar os pares 'if'..'else', equívoco visto em estudo realizado por nós (Bosse, Redmiles et al., 2019b) e confirmado pela análise de código deste estudo. Essa prática de programação pode causar perda de desempenho do programa, já que mais comparações serão realizadas. Para Python, além de SS2, V3 se apresentou com a mesma quantidade de casos não corrigidos. Assim como os aprendizes fazem comparação usando sinal de atribuição '=', também fazem atribuição com sinal de comparação de igualdade '==' e, para Python, existiu evento não resolvido.

Os antipadrões encontrados em ambas linguagens surgiram nos seguintes tópicos: geral (1), variável (2), função de entrada de dados (1), função de saída de dados (2), expressão relacional (1), estrutura de seleção (1), estrutura de repetição (1). Com isso, foram apresentados os três catálogos de antipadrões, em C, Python e em ambas linguagens. Para avaliar esses resultados, foi desenvolvida uma pesquisa de questionário com professores de introdução à programação, cuja metodologia e resultados são apresentados a seguir.

\subsection{Estudo 5 - Estudo de Avaliação dos Antipadrões Identificados no E4}

Com o intuito de responder a "QP5 - Como professores e pesquisadores avaliam os resultados alcançados?" da tese, desenvolvemos o estudo 5, conforme metodologia apresentada abaixo.

\subsubsection{Metodologia do Estudo 5}

Para avaliar os catálogos de antipadrões obtidos no E4 (Apêndice E, F e Apêndice G), foi feita uma pesquisa de questionário junto a professores de disciplinas de introdução à programação. A pesquisa foi enviada via e-mail para uma lista de pesquisadores de educação em computação, para listas de professores de universidades conhecidas e para alguns outros professores da área. Também solicitamos a divulgação do e-mail para colegas e outras listas relevantes.

O questionário foi dividido em três partes. A primeira parte teve como objetivo obter um breve perfil dos respondentes: o país em que estão trabalhando, tempo de profissão como professor, tempo de experiência com disciplinas de introdução à programação e linguagens de programação que eles já usaram para ministrar esse curso. A segunda parte se destinava a avaliar os antipadrões. Foram apresentadas fichas resumidas de 3 antipadrões em C, outras 3 em Python e o catálogo completo dos 9 antipadrões que apareceram em ambas. Com base no Technology Acceptance Model (TAM) (DAVIS, 1989), a última parte buscava avaliar os catálogos em três níveis: quanto à utilidade, à facilidade de uso e à intenção de uso. O questionário na íntegra pode ser visto no Apêndice $\mathrm{H}$. 
Foram feitas análises quantitativas e qualitativas dos dados. Todos os resultados gerados com a análise das respostas dadas às três partes do questionário são apresentados a seguir, na Seção 5.2.2.

\subsubsection{Resultados do Estudo 5: Avaliação dos Catálogos de Antipadrões}

O questionário foi dividido e distribuído conforme explicado na Seção 5.2 .1 e ficou disponível para os possíveis respondentes por 25 dias. A seguir, apresentamos os resultados obtidos nas três partes do questionário.

\section{Parte 1: Perfil dos Respondentes}

Quarenta e três professores de introdução à programação participaram da pesquisa respondendo ao questionário. Na Figura 5.12, podemos ver que acima de $45 \%$ dos respondentes possuem mais de 15 anos de experiência com docência (A), porém, acima de $80 \%$ deles possuem menos de 15 anos de experiência em lecionar a disciplina de introdução à programação (B).

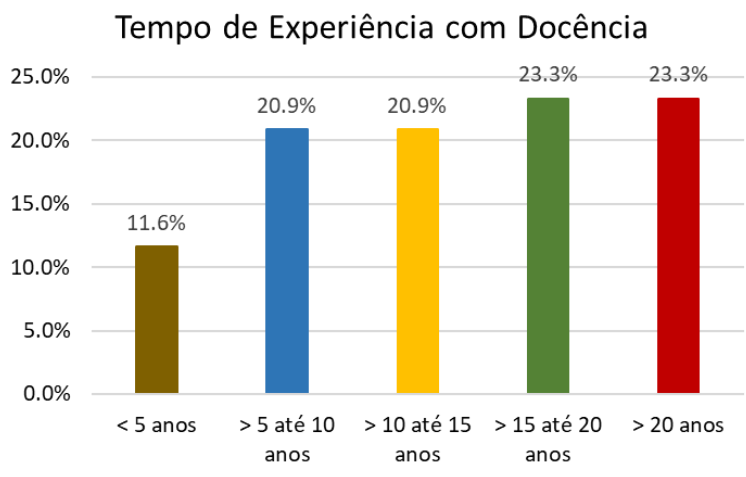

(A)

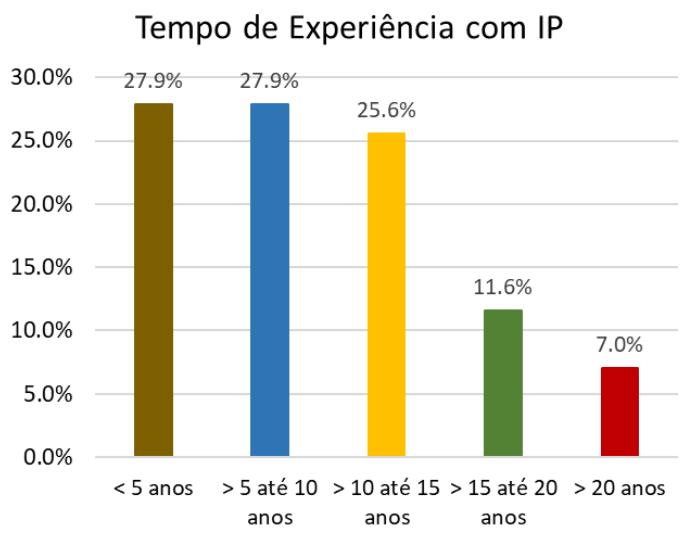

(B)

Figura 5.12: (A) Percentual de docentes por tempo de experiência e (B) Percentual de docentes por tempo de experiência em lecionar introdução à programação $(N=43$ docentes).

Entre os respondentes, apenas um deles trabalha fora do Brasil, na Finlândia, e mais de $85 \%$ deles trabalham em instituições públicas. Para ministrar aulas de introdução à programação, $83,7 \%$ já utilizaram alguma vez a linguagem de programação C, sendo ela a mais usada pelos respondentes. Em seguida vem Python, com 55,8\%, e depois Java, com 53,5\% (Figura 5.13). Considerando as linguagens de programação C e Python, 41,9\% dos respondentes já utilizaram ambas para ministrarem aulas de introdução à programação.

\section{Parte 2: Avaliação dos Antipadrões}

O objetivo dessa parte do questionário foi avaliar os antipadrões encontrados. Foram mostradas parte das fichas de 15 antipadrões: 3 do catálogo de C, 3 de Python e 9 de 
Linguagens de Programação já Usadas Pelos Respondentes da Pesquisa de Validação

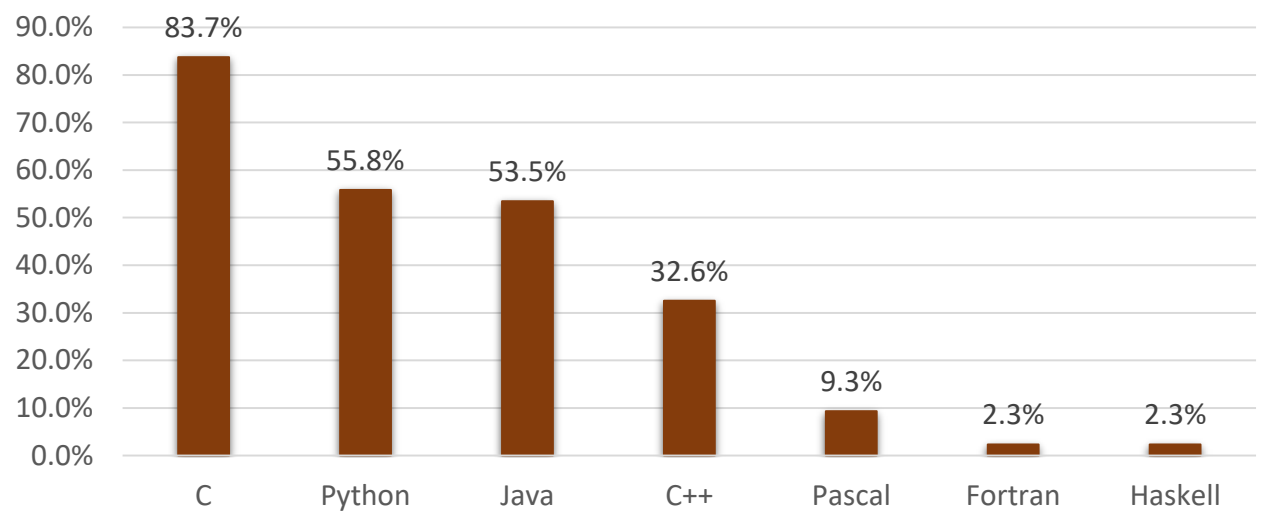

Figura 5.13: Percentual de respondentes que citou cada linguagem como sendo uma das utilizadas em suas aulas de introdução à programação ( $N=43$ respondentes).

ambas linguagens. A escolha pelos 6 primeiros, os de $\mathrm{C}$ e os de Python, se deu seguindo os mesmos critérios apresentados na Seção 5.1.2, ou seja, o antipadrão que teve maior número de eventos, o que teve maior média de submissões para ser resolvido e o que teve maior número de eventos não corrigidos. Os nove restantes são todos os antipadrões ocorridos em ambas linguagens.

Nessa parte, foram apresentadas 3 perguntas e uma área livre para qualquer comentário que o respondente considerasse importante fazer. A primeira era quanto ao respondente já ter visto o antipadrão apresentado em algum código. Levando-se em consideração que o equívoco foi visto pelo menos 3 vezes nos códigos, é desejado que os respondentes já tenham visto o antipadrão ocorrendo com seus alunos, confirmando assim a sua existência. A Tabela 5.8 apresenta todas respostas dadas para essa primeira pergunta. Colocando essas respostas num gráfico (Figura 5.14), tivemos a possibilidade de observar melhor que mais de 25\% de respondentes não conheciam 2 dos 15 antipadrões tiveram: antipadrões V3 Atribuição usando '==' ao invés de '=' e $P_{-} V 2$ - Usar palavra reservada para nome de variável. Se juntarmos as respostas negativas com as dos que não tinham certeza se já tinham visto, mais 3 antipadrões se juntam a esse grupo: P_SS1 - Falta dos ':' no final da linha do 'if' ou do 'else', P_MDA1 - Criação errada das linhas da matriz e OF4 Falta da vírgula para separar o primeiro do segundo parâmetro na função de saída de dados. Todos os 10 antipadrões restantes tiveram mais de $75 \%$ de respostas positivas, sendo que RE1 - O uso do “=” ao invés de “==”, teve $100 \%$ de confirmação.

As respostas para a segunda pergunta estão apresentadas na Tabela 5.9. Essa questão perguntava sobre o nível de dificuldade que o aprendiz tem para resolver o antipadrão. Analisando os resultados obtidos para essa pergunta e comparando com a média, mediana e moda obtidas experimentalmente, conforme apresentado na Tabela 5.10, podemos observar que na maioria dos casos os professores mostraram ter uma boa percepção quanto à dificuldade que o aluno tem para resolver determinado antipadrão.

Alguns casos merecem atenção, como por exemplo o do antipadrão P_V2, onde a média e mediana são baixas, porém a moda é o aluno não resolver o problema, ou seja, 


\begin{tabular}{|c|c|c|c|c|}
\hline \multirow[t]{2}{*}{ ? } & \multirow[t]{2}{*}{ ID } & \multicolumn{3}{|c|}{$\begin{array}{l}\text { A?.1 - Você já viu esse antipadrão em código } \\
\text { desenvolvido por algum aluno? }\end{array}$} \\
\hline & & Sim & Não & Eu não tenho certeza se vi \\
\hline 1 & C_G2 & 41 & 2 & $\begin{array}{c}0 \\
0\end{array}$ \\
\hline 2 & C_F1 & 39 & 1 & 3 \\
\hline 3 & C_SS4 & 33 & 5 & 5 \\
\hline 4 & P_V2 & 30 & 11 & 2 \\
\hline 5 & P_SS1 & 31 & 9 & 3 \\
\hline 6 & P_MDA1 & 28 & 9 & 6 \\
\hline 7 & G1 & 38 & 3 & 2 \\
\hline 8 & IF2 & 39 & 2 & 2 \\
\hline 9 & OF2 & 39 & 3 & 1 \\
\hline 10 & OF4 & 32 & 7 & 4 \\
\hline 11 & RE1 & 43 & 0 & 0 \\
\hline 12 & RS2 & 42 & 0 & 1 \\
\hline 13 & SS2 & 38 & 2 & 3 \\
\hline 14 & V1 & 36 & 4 & 3 \\
\hline 15 & V3 & 19 & 17 & 7 \\
\hline
\end{tabular}

Tabela 5.8: Respostas dadas à primeira pergunta feita sobre os antipadrões, investigando se o antipadrão já era conhecido pelo respondente ( $N=43$ respondentes).

\section{Você já viu o antipadrão em código desenvolvido} por algum aluno?

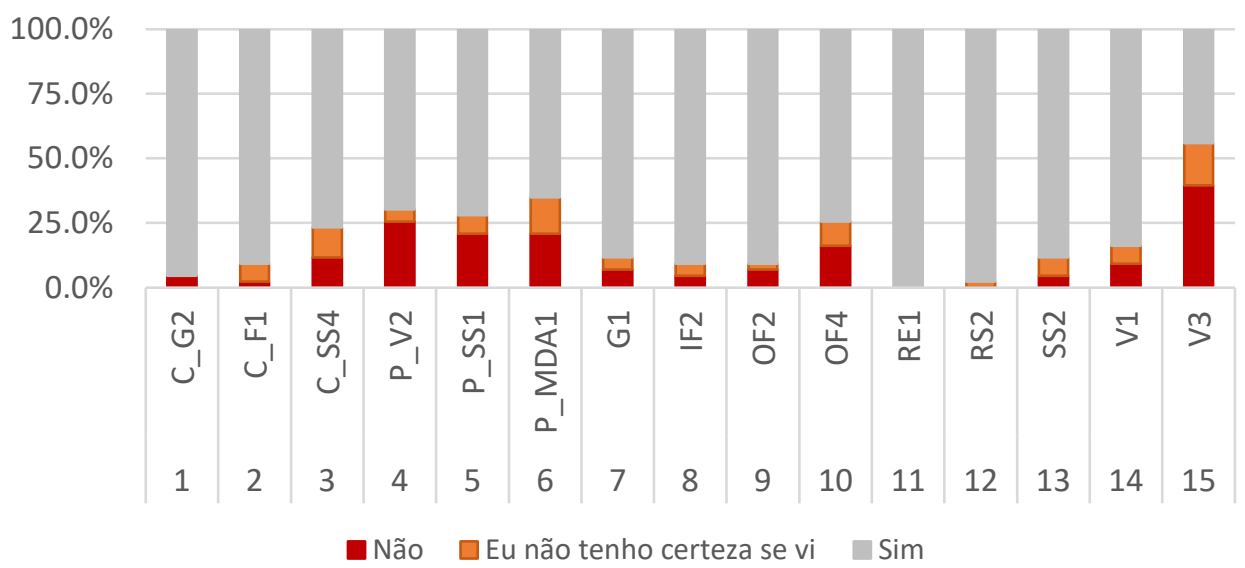

Figura 5.14: Percentuais das respostas dadas à primeira pergunta feita sobre os antipadrões, investigando se o antipadrão já era conhecido pelo respondente ( $N=43$ respondentes). 
o aluno que sabe, resolve rapidamente, porém a maioria desconhece o antipadrão e não consegue resolver o erro. O mesmo ocorre com G1, SS2 e V3, na linguagem C. Os dois primeiros são erros do tipo Estilo e não influenciam diretamente o resultado, fazendo com que o aluno não dê atenção a esse equívoco, deixando-o sem ser resolvido. O restante é um erro de semântica e gera resultado equivocado; mesmo assim, uma das modas é a não resolução.

Dois antipadrões, C_SS4 e P_MDA1, têm mediana 7 e 8, respectivamente, referente ao número de submissões para resolver o problema. Esses podem ser considerados valores altos, se comparados com os valores obtidos nos demais antipadrões. Apesar de a maioria dos professores ter considerado-os de "dificuldade moderada", a análise dos códigos mostrou que os alunos têm "grande dificuldade" para resolvê-los.

\begin{tabular}{|c|c|c|c|c|}
\hline \multirow[t]{2}{*}{$?$} & \multirow[t]{2}{*}{ ID } & \multicolumn{3}{|c|}{$\begin{array}{l}\text { A?.2 - Você acredita que o aluno pode resolver o antipadrão } \\
\text { acima: }\end{array}$} \\
\hline & & facilmente & com dificuldade moderada & com grande dificuldade \\
\hline 1 & C_G2 & 38 & 5 & 0 \\
\hline 2 & C_F1 & 22 & 21 & 0 \\
\hline 3 & C_SS4 & 18 & 23 & 2 \\
\hline 4 & P_V2 & 25 & 16 & 2 \\
\hline 5 & P_SS1 & 34 & 9 & 0 \\
\hline 6 & P_MDA1 & 4 & 23 & 16 \\
\hline 7 & G1 & 26 & 14 & 3 \\
\hline 8 & IF2 & 27 & 15 & 1 \\
\hline 9 & OF2 & 28 & 15 & 0 \\
\hline 10 & OF4 & 28 & 15 & 0 \\
\hline 11 & RE1 & 15 & 21 & 7 \\
\hline 12 & RS2 & 4 & 28 & 11 \\
\hline 13 & SS2 & 7 & 28 & 8 \\
\hline 14 & V1 & 27 & 15 & 1 \\
\hline 15 & V3 & 28 & 14 & 1 \\
\hline
\end{tabular}

Tabela 5.9: Respostas dadas à segunda pergunta feita sobre os antipadrões, investigando sobre o que o respondente entendia ser o nível de dificuldade do aluno para resolver o antipadrão ( $N=43$ respondentes).

A terceira pergunta da segunda parte do questionário indagava os professores quanto à melhor estratégia didática para minimizar os antipadrões nos códigos desenvolvidos pelos seus alunos. Para isso, foram apresentadas quatro estratégias para os professores, que podem ser verificadas na íntegra no Apêndice D. Eles podiam optar por uma delas ou apresentar uma nova estratégia usada por eles. As respostas dadas e apresentadas na Tabela 5.11 mostram que, para todos os antipadrões, a estratégia mais votada foi a de número 3, que propõe que o professor use um projetor para programar na frente dos alunos, fazendo o erro aparecer e assim podendo explicar e mostrar como resolvê-lo. Essa estratégia propõe que, após ser mostrado ao aluno, a prática da resolução seja reforçada através do desenvolvimento de novos códigos.

Por último, foi solicitado que os professores usassem o espaço extra da quarta questão para comentários e sugestões que considerassem importantes. A Tabela 5.12 apresenta os comentários feitos para cada um dos antipadrões apresentados.

Abaixo, considerações sobre alguns dos comentários realizados: 


\begin{tabular}{|c|c|c|c|c|c|}
\hline \multirow{2}{*}{ ID } & \multirow{2}{*}{ Nome do Antipadrão } & \multicolumn{3}{|c|}{ Submissões até Correção } & \multirow{2}{*}{$\begin{array}{l}\text { Opinião dos professore } \\
\text { quanto a dificuldade dos } \\
\text { alunos para resolvê-lo }\end{array}$} \\
\hline & & Média & Mediana & Moda & \\
\hline C_G2 & Falta de ";" no final da linha & 1.5 & 1 & 1 & 88,4\% - Fácil \\
\hline C_F1 & Falta do return & 2.0 & 1 & ? & 51,2\% - Fácil \\
\hline C_SS4 & $\begin{array}{l}\text { Colocar indevidamente ";" após a } \\
\text { condição do "if" e/ou após o "else" }\end{array}$ & 10.3 & 7 & Amodal & 53,5\% - Dificuldade Moderada \\
\hline P_V2 & $\begin{array}{l}\text { Usar palavra reservada para nome } \\
\text { de variável }\end{array}$ & 1.0 & 1 & ? & 58,1\% - Fácil \\
\hline P_SS1 & $\begin{array}{l}\text { Falta dos ":" no final da linha do "if" } \\
\text { ou do "else" }\end{array}$ & 2.0 & 1.5 & 1 & 79,1\% - Fácil \\
\hline P_MDA1 & Criação errada das linhas da matriz & 7.3 & 8 & Amodal & 53,5\% - Dificuldade Moderada \\
\hline G1 & Falta de indentação & $\begin{array}{l}P=2.2 \\
C=3.0\end{array}$ & $\begin{array}{l}2 \\
3\end{array}$ & $\begin{array}{l}1 \\
?\end{array}$ & 60,5\% - Fácil \\
\hline IF2 & $\begin{array}{l}\text { Falta das aspas na chamada da } \\
\text { função de entrada de dados }\end{array}$ & $\begin{array}{l}P=1.0 \\
C=2.0\end{array}$ & $\begin{array}{l}1 \\
2\end{array}$ & $\begin{array}{c}1 \\
\text { Amodal }\end{array}$ & 62,8\% - Fácil \\
\hline OF2 & $\begin{array}{l}\text { Falta das aspas na função de saída } \\
\text { de dados }\end{array}$ & $\begin{array}{l}P=1.8 \\
C=1.0\end{array}$ & $\begin{array}{l}2 \\
1\end{array}$ & $\begin{array}{l}\text { Bimodal }(1,2) \\
1\end{array}$ & 65,1\% - Fácil \\
\hline \multirow[b]{2}{*}{ OF4 } & \multirow{2}{*}{$\begin{array}{l}\text { Falta da vírgula para separar o } \\
\text { primeiro do segundo parâmetro na } \\
\text { função de saída de dados }\end{array}$} & $P=1.3$ & 1 & 1 & \multirow[b]{2}{*}{ 65,1\% - Fácil } \\
\hline & & $C=1.0$ & 1 & 1 & \\
\hline RE1 & O uso do " $=$ " ao invés de "==" & $\begin{array}{l}P=2.7 \\
C=1.8\end{array}$ & $\begin{array}{l}1 \\
1\end{array}$ & $\begin{array}{l}1 \\
1\end{array}$ & $48,8 \%$ - Dificuldade Moderada \\
\hline RS2 & $\begin{array}{l}\text { Variável de controle não está sendo } \\
\text { alterada }\end{array}$ & $\begin{array}{l}P=3.7 \\
C=1.8\end{array}$ & $\begin{array}{c}2 \\
1.5\end{array}$ & $\begin{array}{c}\text { Amodal } \\
1\end{array}$ & 65,1\% - Dificuldade Moderada \\
\hline SS2 & $\begin{array}{l}\text { O não uso do "else" onde seria } \\
\text { adequado }\end{array}$ & $\begin{array}{l}P=2.5 \\
C=1.0\end{array}$ & $\begin{array}{l}2 \\
1\end{array}$ & $\begin{array}{l}2 \\
?\end{array}$ & $65,1 \%$ - Dificuldade Moderada \\
\hline v1 & Uso de variável inexistente & $\begin{array}{l}P=1.8 \\
C=1.4\end{array}$ & $\begin{array}{c}1.5 \\
1\end{array}$ & $\begin{array}{l}1 \\
1\end{array}$ & 62,8\% - Fácil \\
\hline V3 & $\begin{array}{l}\text { Atribuição usando "==" ao invés de } \\
\text { "=" }\end{array}$ & $\begin{array}{l}P=3.0 \\
C=2.0\end{array}$ & $\begin{array}{l}3 \\
1\end{array}$ & $\begin{array}{c}\text { Amodal } \\
\text { Bimodal (1, ?) }\end{array}$ & 65,1\% - Fácil \\
\hline
\end{tabular}

Tabela 5.10: Média, mediana e moda da quantidade de submissões para resolver o antipadrão em comparação com a opinião dos professores em relação a dificuldade que o aluno tem nessa tarefa.

\begin{tabular}{|c|c|c|c|c|c|c|}
\hline \multirow{2}{*}{ ? } & \multirow{2}{*}{ ID } & \multicolumn{5}{|c|}{ A?.3 - Qual(is) estratégia(s) você considera mais apropriada(s) para tratar esse antipadrão nas aulas com seus alunos? } \\
\hline & & Estratégia 1 & Estratégia 2 & Estratégia 3 & |Estratégia 4 & Outras \\
\hline 1 & C_G2 & 13 & 11 & 30 & 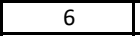 & Prática Individual em sala \\
\hline 2 & C_F1 & 15 & 16 & 29 & 14 & Prática Contextualizada \\
\hline 3 & C_SS4 & 17 & 22 & 27 & 11 & \\
\hline 4 & P_V2 & 25 & 12 & 27 & 9 & \\
\hline 5 & P_SS1 & 18 & 14 & 32 & 9 & Prática Individual em sala \\
\hline 6 & P_MDA1 & 18 & 21 & 24 & 23 & \\
\hline 7 & G1 & 19 & 12 & 33 & 10 & $\begin{array}{l}\text { Prática Individual em sala Somente a prática vai mostrar ao aluno... } \\
\end{array}$ \\
\hline 8 & IF2 & 17 & 11 & 33 & 8 & Prática Individual em sala \\
\hline 9 & OF2 & 19 & 13 & 35 & 6 & Prática Individual em sala \\
\hline 10 & OF4 & 19 & 14 & 34 & 4 & Prática Individual em sala \\
\hline 11 & RE1 & 26 & 23 & 31 & 16 & Prática Individual em sala \\
\hline 12 & RS2 & 22 & 24 & 30 & 26 & \\
\hline 13 & SS2 & 22 & 22 & 27 & 23 & \\
\hline 14 & V1 & 16 & 19 & 34 & 12 & Nunca tive essa experiência \\
\hline 15 & V3 & 19 & 17 & 36 & 12 & Prática Individual em sala \\
\hline
\end{tabular}

Tabela 5.11: Respostas dadas à terceira pergunta feita sobre os antipadrões, investigando qual estratégia didática o respondente considera melhor para evitar o antipadrão com seus alunos. 


\begin{tabular}{|c|c|c|}
\hline$?$ & ID & A?.4 - Se você tiver algo para acrescentar sobre esse antipadrão, estratégia, etc., use o espaço abaixo: \\
\hline 1 & C_G2 & na linguagem que mais ensinei (Python), esse antipadrão não ocorre =) \\
\hline 2 & C_F1 & não considero que isso seja um antipadrão - pode ser OU NÃO um erro, de acordo com a semântica deseja da função \\
\hline 3 & C_SS4 & Duas disciplinas de computação no mesmo semestre (python / java ou python / c) aumenta a confusão dos estudantes \\
\hline 4 & P_V2 & Pode ser que o aluno tenha esquecido de colocar uma variavel? \\
\hline 5 & P_SS1 & - \\
\hline \multirow{3}{*}{6} & \multirow{3}{*}{ P_MDA1 } & $\begin{array}{l}\text { O feedback apresentado na imagem não está claro. Foi apresentado apenas o passo necessário para solucionar o problema, mas não é } \\
\text { imediatamente claro qual é o problema inicialmente. Talvez apontar que a variável não se "limpa" sozinha, etc. }\end{array}$ \\
\hline & & o título desse antipadrão está um pouco genérico demais - existem várias outras formas erradas de criar as linhas de uma matriz \\
\hline & & A resposta correta ainda está errada. \\
\hline 7 & G1 & $\begin{array}{l}\text { Em C a mensagem de alerta não deveria ser classificada como erro mas sim alerta. O termo visualização também remete a uma estratégia } \\
\text { diferente do que deveria ser salientada. Seria mais claro se a mensagem remetesse ao conceito de "readability" ou compreensividade do } \\
\text { código }\end{array}$ \\
\hline 8 & IF2 & - \\
\hline 9 & OF2 & - \\
\hline 10 & OF4 & - \\
\hline 11 & RE1 & O erro é fácil de resolver, mas o conceito de programação envolvido é mais complexo do que a "simples" correção do erro. \\
\hline 12 & RS2 & - \\
\hline 13 & SS2 & - \\
\hline 14 & V1 & - \\
\hline \multirow[b]{2}{*}{15} & \multirow[b]{2}{*}{ V3 } & Erro fácil de corrigir, mas envolve conceito de programação mais complexo. \\
\hline & & $\begin{array}{l}\text { Os antipadrões propostos são muito recorrentes realmente, mas, senti falta de outros, principalmente os que ocorrem na definição e } \\
\text { controle das estruturas de repetição: (1) não controlar adequadamente a qtdade de vezes a ser repetido o que se deseja (ou fazer uma } \\
\text { vez a menos ou uma vez a mais); (2) não saber como funciona a estrutura de repetição PARA/FOR (seus elementos de controle implícito); } \\
\text { (3) não contar com a posição } 0 \text { do verto em C/C++; atualizar variável de contagem (contador) antes ou depois do momento devido; } \\
\text { dentre outras. }\end{array}$ \\
\hline
\end{tabular}

Tabela 5.12: Comentários feitos sobre os antipadrões apresentados.

C_G2 - Esse antipadrão não foi encontrado em Python e o comentário do professor confirma isso.

C_F1 - Basicamente existem 4 tipos de funções em $C^{1}$ : (1) função sem parâmetros e sem retorno de valor; (2) função sem parâmetros e com retorno de valor; (3) função com parâmetros e sem retorno de valor; e, (4) função com parâmetros e com retorno de valor. Quando a função não precisa retornar valor (tipos 1 e 3), é usado 'void' na frente do nome da função, na sua definição. Por exemplo, uma função do tipo 1:

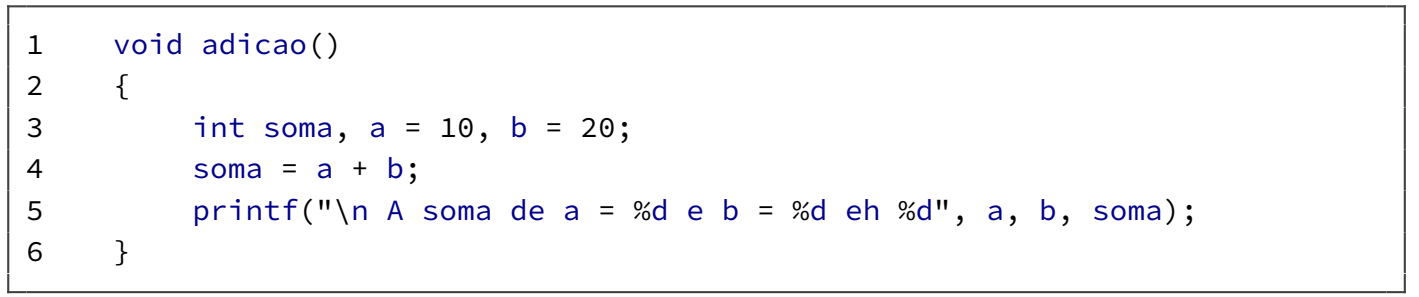

Caso a função precise retornar algum valor (tipos 2 e 4), é indicado o tipo do dado que será retornado na frente do nome da função durante sua definição, ou seja, no lugar do 'void'. Como exemplo podemos apresentar uma função do tipo 2:

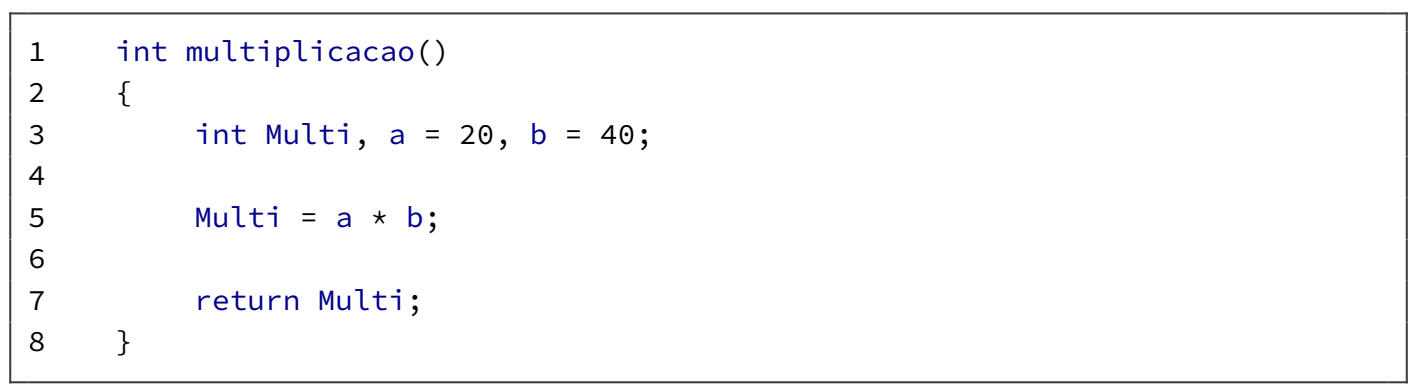

\footnotetext{
${ }^{1}$ www.tutorialgateway.org/types-of-functions-in-c/
} 
Por esse motivo, consideramos um erro a inexistência de 'return' em funções dos tipos 2 e 4.

C_SS4 - Os alunos que desenvolveram os códigos, já tinham cursado a disciplina anteriormente, utilizando $\mathrm{C}$ ou Python, e não tinham sido aprovados. Na disciplina onde os códigos foram gravados, alunos que tinham usado $\mathrm{C}$, continuaram usando $\mathrm{C}$ e os que usaram Python, permaneceram com essa linguagem. Sendo assim, esse comentário mostrou que não ficou claro ao respondente essa situação de divisão de linguagens.

P_V2 - consideramos que não tenha sido esquecimento, pois no lugar onde deveria estar o nome da variável, foi colocado o nome do tipo de dado.

P_MDA1 - Quanto ao feedback, foi melhorada a observação informando que a linha era criada apenas uma vez por estar fora da estrutura de repetição. O título foi mantido pois o antipadrão trata exatamente dessa questão de criação errada da linha da matriz. Na área do "Erro Resolvido" está apenas a parte do código que contém o antipadrão e não o código completo.

RE1 - Pelo comentário feito pelo professor, entendemos que ele quis mostrar a importância do reforço do conceito e não simplesmente mostrar a correção do equívoco.

V3 - Idem ao comentado para RE1.

Um professor sentiu falta de outros erros que ele considera recorrentes, porém, além do questionário não abordar todos os antipadrões encontrados, foram catalogados apenas os que foram vistos pelo menos três vezes nos códigos analisados.

\section{Parte 3: Avaliação dos Catálogos}

A terceira parte do questionário avalia os catálogos quanto à sua Utilidade, Facilidade e Inteção de Uso. A Figura 5.15 mostra os resultados obtidos e uma breve discussão é apresentada a seguir.

\section{Em Relação à Utilidade}

E1.1 - Melhoraria meu desempenho na prevenção desses equívocos

E1.2 - Melhoraria minha produtividade na prevenção desses equívocos

E1.3 - Aumentaria minha eficácia na prevenção desses erros

E1.4 - Útil em meu trabalho como professor/pesquisador

Em Relação à Facilidade de Uso

E2.1 - Fácil aprender a usar os catálogos

E2.2 - Fácil usar os catálogos

E2.3 - Fácil tomar conhecimento dos catálogos

E2.4 - Fácil aplicar os catálogos

Em Relação à Intenção de Uso

E3.1 - Usar regularmente no meu trabalho como professor/pesquisador

\begin{tabular}{|c|c|c|c|}
\hline 1 & 9 & 14 & 19 \\
\hline & 8 & 16 & 19 \\
\hline 2 & 6 & 17 & 18 \\
\hline 1 & 5 & 15 & 22 \\
\hline
\end{tabular}

\begin{tabular}{|c|c|c|c|}
\hline 1 & 8 & 10 & 24 \\
\hline 2 & 10 & 15 & 16 \\
\hline 2 & 5 & 13 & 23 \\
\hline 3 & 12 & 11 & 17 \\
\hline
\end{tabular}

\begin{tabular}{l|l|l|l}
8 & 12 & 9 & 14
\end{tabular}

Discordo fortemente Discordo Neutro Concordo

Concordo fortemente

Figura 5.15: Resultados da avaliação dos catálogos quanto à utilidade, facilidade e intenção de uso. 
Quanto à "Utilidade", os professores consideraram os catálogos úteis. As três primeiras questões (E1.1 à E1.3) afirmavam que os catálogos ajudariam na melhoraria do desempenho, da produtividade e da eficácia do professor na prevenção dos equívocos. A primeira questão (E1.1), quanto ao desempenho, se referia à execução, ao cumprimento de uma obrigação, questionando se o catálogo de antipadrões poderia ajudar o professor à melhorar sua tarefa de auxiliar os alunos à evitar os equívocos. A segunda questão (E1.2) tratava sobre a produtividade, sobre o fato dos catálogos poderem ajudar o professor a diminuir o surgimento dos equívocos em códigos de um número maior de alunos, em mais turmas. A terceira questão (E1.3) investigava se o conjunto de antipadrões poderia aumentar a segurança de um bom resultado, em outras palavras, a virtude ou o poder do professor em evitar os equívocos com mais segurança e qualidade junto à seus alunos. A questão E1.4 investigada se os catálogos poderiam ser úteis para os professores exercerem suas tarefas na docência ou como pesquisador. Todas as quatro afirmações tiveram entre $77 \%$ e $86 \%$ de concordância.

Quanto à "Facilidade de Uso", os índices de concordância foram de 79\% para 'facilidade de aprender a usar', $72 \%$ para 'facilidade de usar' e $84 \%$ quanto a 'facilidade de tomar conhecimento' dos catálogos. A 'facilidade de aplicar' os catálogos recebeu o menor índice de concordância (65\%).

Quanto à "Intenção de Uso", 53\% dos respondentes concordaram que pretendem usar regulamente os catálogos no trabalho como professor e pesquisador e $28 \%$ não tinham opinião formada quanto a isso, assinalando o 'Neutro', ou seja, não concordam, porém também não discordam dessa pretensão.

\subsection{Conhecimentos Adquiridos}

Foram muitos equívocos catalogados (Apêndice B) em ambas linguagens, C e Python, sendo que alguns deles foram identificados como sendo antipadrões nos códigos de estudantes de introdução à programação nessas duas linguagens (Apêndice $\mathrm{E}$, Apêndice $\mathrm{F}$, Apêndice G). Conhecer e estudar antipadrões na programação é tão importante quanto tomar conhecimento dos padrões "bons" (James Coplien (1994) apud W. H. Brown et al., 1998) e a aceitação disso perante a comunidade de professores e pesquisadores nessa área foi visível com os resultados obtidos na pesquisa de questionário realizada para avaliar os catálogos gerados.

Esses antipadrões, e até mesmo os equívocos que não foram identificados como antipadrões ainda, podem ser de alguma forma trabalhados ao se ministrar o conteúdo correspondente, evitando-se o tempo gasto em procurar e resolver o problema, principalmente dando-se especial atenção aos que demandam maior tempo para isso. Esses catálogos podem ser mais um passo de um movimento mais amplo de levantamento e categorização das dificuldades específicas enfrentadas pelos alunos que poderão ajudar professores e alunos no ensino-aprendizagem de programação, assim como pesquisadores no desenvolvimento de novas pesquisas e ferramentas que auxiliem estudantes nessa tarefa, como a automação de feedback . 


\section{Capítulo 6}

\section{Discussão}

Neste capítulo, buscamos avaliar os antipadrões apresentados no Capítulo 5 em relação ao entendimento subjetivo de alunos e professores, exposto no Capítulo 4, e discutir como os antipadrões podem ser utilizados tanto na prática do ensino quanto na pesquisa sobre o aprendizado da computação.

\subsection{Os Antipadrões e a Percepção Subjetiva das Dificuldades pelos Alunos}

Na Figura 4.17 vemos algumas dificuldades encontradas nos diários diretamente relacionadas à linguagem $\mathrm{C}$. Podemos observar, no gráfico apresentado, que problemas com as funções de entrada (scanf) e de saída (printf), esquecimento de chaves e ponto-e-vírgula, são alguns dos problemas mais citados. Essas dificuldades foram também recorrentes nos códigos. Foram encontrados 13 equívocos com funções de entrada, sendo 3 antipadrões (C_IF1, C_IF2 e C_IF6), e 10 com funções de saídas, sendo mais da metade considerados antipadrões, sete no total (C_OF1 ao C_OF7). Quanto às dificuldades apresentadas na linguagem Python (Figura 4.18), a indentação apareceu nos diários e também como antipadrão através da análise dos códigos.

Os antipadrões em $\mathrm{C}$ também foram encontrados em pelo menos outra fonte de dados. Por exemplo, o C_SS4 - Colocar indevidamente “;” após a condição do "if” e/ou após o "else" foi visto também durante o estudo com alunos com dificuldade apresentado no Apêndice A. Além disso, os alunos mostraram fazer confusão entre o "return" e o "printf” (c_F10) nos códigos e nos diários. E, como último exemplo, o antipadrão C_AE2 - Fórmula aritmética errada foi encontrado nos diários e durante o acompanhamento dos alunos com dificuldade. Entre outros exemplos que poderiam ser dados.

Dos 9 antipadrões comuns para as duas linguagens, 6 deles apareceram nos resultados das análises dos dados adquiridos por pelo menos mais alguma outra fonte de coleta de dados utilizada, como diários, entrevistas ou o estudo apresentado no Apêndice A, sendo: G1 - Falta de indentação, V1 - Uso de variável inexistente, V3 - Atribuição usando "==” ao invés de "=”, RE1 - O uso do “=” ao invés de "==”, SS2 - O não uso do "else" onde seria adequado e RS2 - Variável de controle não está sendo alterado. 
Após tomar conhecimento da existência dos antipadrões através dos catálogos, os professores podem tomar medidas nas suas aulas direcionadas a evitá-los. A forma mais escolhida para isso no questionário de avaliação que os professores responderam foi o uso do projetor para programar na frente do aluno fazendo o antipadrão aparecer. Com isso, o professor tem a oportunidade de explicar o motivo dele ser um problema, um erro, e como proceder para solucioná-lo. Porém, muitas outras atitudes poderiam ser tomadas, ou muitas outras formas de abordar o problema poderiam ser usadas pelos professores para evitá-los nos códigos dos seus alunos. O professor poderia, por exemplo, apresentar códigos com erros para que os alunos os encontrassem. Ou fazer com que duplas de alunos trabalhassem sobre códigos com antipadrões e depois apresentassem suas descobertas para os demais colegas. Essas abordagens ajudariam a desenvolver a habilidade de encontrar erros nos códigos, um problema que foi percebido através dos diários e na literatura (A. Gomes e A. J. Mendes, 2007).

Apesar dessas semelhanças, as dificuldades mais citadas nem sempre correspondem aos temas com mais antipadrões identificados. As três dificuldades mais comuns nos diários foram "Estruturas de Repetição", "Variáveis" e "Funções" (Figura 4.16), amplamente citadas nas entrevistas também. Se olharmos para a quantidade de antipadrões em cada linguagem, os 3 conteúdos com mais antipadrões em C são "Função de Saída de Dados" (printf) com 7, "Funções" com 5 e empatados com 3 antipadrões cada estão os conteúdos de "Função de Entrada de Dados" (scanf), "Expressão Aritmética", "Estrutura de Seleção" e "Geral". Em Python, são "Variável" com 5, seguido de "Função de Saída de Dados" (print) (3) e, por último, com 2 cada, os conteúdos de "Função de Entrada de Dados" (input), "Estrutura de Seleção" e "Estrutura de Repetição". Isso mostra que as dificuldades detectadas pelos diários se assemelharam com os conteúdos que apresentaram mais antipadrões em Python, enquanto apenas 'Funções' se assemelhou com os antipadrões em C.

\subsection{Os Antipadrões e a Percepção Subjetiva das Dificuldades pelos Professores}

Apesar de termos buscado a opinião de professores sobre as dificuldades de aprendizado dos alunos, algumas pesquisas indicam que professores podem não ser uma boa fonte de dados. Para Fisher e KeIL (2016), o conhecimento pode levar ao excesso de confiança, o que significa que os professores podem ignorar detalhes ao ensinar um tópico que conhecem bem. N. C. Brown e Altadmri (2014) chegaram à conclusão que o fato de os professores serem experientes não torna necessariamente confiável a definição de quais erros são mais frequentemente cometidos pelos aprendizes. Porém, Council et al. (2000) afirma que o conhecimento dos professores experientes pode ajudar outros instrutores na tarefa de como, por exemplo, organizar melhor o conteúdo dos alunos, sendo que esta afirmação foi confirmada com os resultados das entrevistas que fizemos com professores inexperientes perguntando sobre a utilidade das dificuldades apresentadas na Figura 4.2 e das estratégias didáticas listadas na Tabela 4.3, conforme descrito na Seção 4.2.2.

Analisando a Figura 4.2, os equívocos apresentados no Apêndice B e os catálogos de antipadrões (Apêndices E, F e G), vimos que algumas das dificuldades mencionadas pelos professores se confirmaram e outras não. Por exemplo, os dois problemas mais citados 
pelos professores foram quanto à 'condição de parada' em estruturas de repetição e a 'decomposição de problemas' para criação das funções. O primeiro, 'condição de parada', foi também a dificuldade mais recorrente nos diários e é um dos antipadrões ocorridos tanto em C como em Python, o 'RS2 - Variável de controle não está sendo alterada'. O segundo, 'decomposição de problemas', não foi detectado nem nos diários e nem pelos códigos. Porém, vale a pena ressaltar que alguns fatores podem ter influenciado no não aparecimento dessa dificuldade. Se analisarmos os enunciados dos exercícios analisados (Apêndice C), como o 8.1 por exemplo, poderemos observar que, quando o exercício pedia para o aluno desenvolver uma função, a tarefa a ser executada por ela, seus parâmetros e o valor a ser devolvido já eram detalhados pelo professor. Também é possível que boa parte do processo de decomposição do problema seja realizado pelo aluno antes de ele efetivamente tentar compilar algum código pela primeira vez.

Um conteúdo que gera muita dificuldade e cujos problemas foram vistos tanto nos diários quanto nos códigos, gerando muitos equívocos catalogados, foi o de 'Variáveis'. Porém, os professores neglicenciaram em parte esse conteúdo, praticamente não o considerando como fonte de dificuldades para os alunos (Figura 4.2). Através dos diários, vimos que os principais problemas que os alunos tiveram com variáveis foi em saber 'como usá-las', em saber quando há 'necessidade de criar', de 'inicializar' e quanto à 'escolha do tipo correto'.

Na Figura 4.2, podemos ver listados 8 pontos de dificuldades com variáveis encontrados em diários e entrevistas. Nos códigos, foram detectados 8 equívocos com variáveis usando $o$ C e 7 em Python (Apêndice B), sendo que, desse montante, 7 são antipadrões (3 em Python: P_V2, P_V4 e P_V5, e 2 que ocorreram nas duas linguagens: V1 e V3). A dificuldade em 'saber quando há necessidade de criá-las' foi confirmada com o antipadrão 'V1 - Uso de variável inexistente' em ambas linguagens. Um dos motivos que pode ter feito os professores não perceberem dificuldades nesse conteúdo é o fato de as variáveis serem normalmente trabalhadas dentro de outros tópicos, como em estruturas de repetição.

Os diários nos mostraram também vários eventos encontrados em duas dificuldades específicas quando os alunos estavam trabalhando com expressões, porém não citadas pelos professores durante as entrevistas. Uma delas é 'dificuldade em criar' as expressões. Esse problema apareceu também nos códigos através dos antipadrões 'C_AE2' e 'P_AE2' e do equívoco 'P_E1 - Mistura de comparações e operadores' que teve apenas um evento, logo não sendo considerado um antipadrão. O outro problema foi quanto à confusão no uso do '=' e '==', manifestando-se nos diários e através de dois antipadrões, o 'V3 Atribuição usando "==" ao invés de "=" e o 'RE1 - O uso de "=" ao invés de "==" em comparações.

Algumas dificuldades citadas pelos professores não se caracterizaram como antipadrões no nosso estudo. Um exemplo disso é a dificuldade de 'como escrever os comandos' usando Ponteiros. Essa dificuldade não foi vista nos diários (apenas uma reclamação feita num diário mostrando descontentamento) e, nos códigos, foi detectada como um equívoco com apenas 1 evento (C_P1 - Utilização incorreta do valor apontado por um ponteiro), logo não sendo catalogada como antipadrão. Porém, CAceffo, G. Gama et al. (2018) catalogou um equívoco, o 'F.1 - Usando \& em vez de * para desreferenciar o ponteiro' (F.1 - Using \& instead of * to dereference pointer) que mostra um problema que se refere a 
essa dificuldade.

Não podemos dizer que os professores falharam quanto às dificuldades mencionadas por eles durante as entrevistas. Algumas das que eles citaram foram detectadas como antipadrões, outras não foram visualizadas no nosso estudo ou foram apenas listadas como equívocos. Porém, os catálogos gerados tendem a serem alimentados com novos antipadrões e possivelmente, alguns equívocos mencionados pelos professores, até mesmo os não visualizados na análise de dados gerados por outras fontes de coleta, possam vir a ser antipadrões futuramente.

\subsection{Impacto dos Antipadrões no Aprendizado de Programação}

As fichas apresentam informações dos antipadrões que nos dão condições de analisar quais são os antipadrões que de alguma forma mais atrapalharam o aprendizado de programação. Nas fichas foram armazenadas informações sobre cada evento do antipadrão encontrado nos códigos. Foram registrados 3 ou 4 eventos por antipadrão. Registramos também informações de quando o erro ocorreu (em qual compilação) e quando foi resolvido (se foi). Essas informações nos ajudam a ver quanto tempo, medido por quantidade de compilações, o aluno levou para resolver ou desistir do equívoco. Através das Tabelas 5.3, 5.5 e 5.7, mostramos exemplos de antipadrões que se sobresaíram nessas três situações:

- (E) - Maior número de eventos: os antipadrões marcados com (E) nessas tabelas são os mais apareceram nos códigos, na linguagem correspondente.

- (S) - Maior número de submissões até correção: nesse caso, são apresentados os antipadrões que precisaram de mais compilações até que o aluno conseguiu chegar numa solução.

- (?) - Não resolvidos: são os antipadrões que apresentaram mais eventos em que os alunos não resolveram o equívoco.

Além dos exemplos mostrados nas tabelas citadas acima, é possível fazer essa análise com todos os antipadrões existentes nos catálogos. Com isso, ao serem acessados os antipadrões referentes a um determinado conteúdo, esse tipo de análise poderá nos dar condições de classificá-los por ordem de importância segundo o critério de interesse para a pessoa que irá utilizá-los.

Por exemplo, um professor irá explicar 'funções de saída de dados' em C (printf). Com a busca por antipadrões referentes a esse conteúdo nos catálogos de antipadrões, o resultado será um conjunto de 7 antipadrões, 5 só em $C$ e 2 ocorridos em ambas linguagens. Olhando para as tabelas de exemplos citadas acima, o professor não encontrará nenhum dos antipadrões retornados na busca. Porém, ele poderá fazer uma classificação dos antipadrões desse conjunto específico com base nos dados apresentados, tendo a possibilidade de escolher quais discutir com seus alunos em sala. 


\subsection{Utilidade dos Resultados}

Os resultados deste trabalho podem ser de interesse para três grupos: professores, aprendizes de programação e pesquisadores. A seguir são apresentadas algumas situações em que os resultados podem ser úteis para cada público.

\subsubsection{Para Professores e Aprendizes de Programação}

Os resultados apresentados na tese podem ser úteis aos professores, principalmente aos novatos, no planejamento da disciplina de introdução à programação. Conforme resultado da pesquisa apresentada por GIRAFFA e MoRA (2013), melhores materiais e professores mais preparados ajudariam a diminuir a evasão existente nesses cursos.

Um dos resultados desta tese são as conexões entre os tópicos, que mostram as principais dependências existentes entre eles para um melhor aprendizado de programação. As conexões identificadas, apresentadas nos diagramas da Seção 4.3, foram criadas a partir de comentários sobre dificuldades feitos nos diários e entrevistas. Muitas vezes, alunos e professores comentavam sobre dificuldades em um determinado tópico, mas indicavam que o problema estava no não aprendizado de outro. Apenas as conexões explicitamente mencionadas estão representadas nos diagramas; outras, mesmo óbvias, não foram incluídas, já que não estavam presentes no material estudado. Como exemplo de conexões não incluídas, podemos citar a conexão que existe entre vetor e estruturas de repetição. Para o aprendizado de vetor, é vital saber trabalhar com estruturas de repetição, necessárias para percorrer as posições. Porém, essa conexão não apareceu nos nossos dados. A preocupação com essas conexões e o levantamento parcial das conexões apresentado aqui podem ser uma valiosa fonte de apoio na decisão do que lecionar primeiro.

Segundo Robins (2010), adquirir um conceito com sucesso torna o aprendizado de outro conceito estreitamente vinculado mais fácil. Isso mostra a importância da decisão da ordem em que os conteúdos são apresentados aos aprendizes. Por exemplo, trabalhar primeiro com atividades que desenvolvam o pensamento lógico e em pensar em uma solução para a tarefa proposta para desenvolver habilidades importantes e necessárias para posteriormente evoluir no aprendizado de muitos outros tópicos. Em alguns casos, como o da Estrutura de Seleção e de Repetição, a ordem não tem influência. Alguns professores comentaram nas entrevistas que lecionavam primeiro estrutura de seleção e depois de repetição, outros diziam o inverso. Pelas conexões encontradas no nosso estudo, não encontramos dependência entre elas. Porém, encontramos que para o aprendizado desses dois tópicos, é fundamental que o aluno tenha aprendido sobre variáveis, expressões, sintaxe da linguagem utilizada, entre outros. Muitas dificuldades para aprender a programar podem ser minimizadas ou eliminadas tendo-se o cuidado de se garantir que conceitos necessários para a aquisição do novo conhecimento já tenham sido absorvidos pelos aprendizes.

Outro material que pode ser útil aos professores são as dificuldades por conteúdo apresentadas na Figura 4.2, as estratégias didáticas para minimizá-las (Tabela 4.3) e os catálogos de antipadrões. Esses conteúdos podem ajudar o professor a definir melhor como lecionar. Saber onde a dificuldade se encontra faz o professor poder se antecipar em ajudar o aluno onde ele normalmente precisa. O professor pode fazer as dificuldades aparecerem 
durante a explanação, tendo a oportunidade de discutir como evitá-las e/ou resolvê-las. Para ajudar na decisão de quais dificuldades abordar, o professor tem na Figura 4.2 a classificação das dificuldades das mais impactantes ao aprendizado para as menos.

Quanto aos antipadrões, na Seção 5.1.2 são apresentados três exemplos em cada linguagem, porém, as Tabelas 5.3, 5.5 e 5.7 mostram dados como média, mediana, modo e total de eventos encontrados e não solucionados, que podem auxiliar o professor nessa tarefa de escolha. Estudar os antipadrões nas salas de aula poderá trazer benefícios como a diminuição de ocorrências deles nos códigos dos alunos, além da diminuição do tempo para visualizá-los e corrigí-los quando ocorrerem.

Além desses dados, as fichas apresentam outras informações que podem ser usadas pelos professores, como o enunciado de cada exercício que estava sendo resolvido quando o equívoco ocorreu. O professor poderá usar o próprio exercício, ou algum parecido, para fazer o erro aparecer e assim poder explicar a situação ao aluno.

Acreditamos que, possivelmente, essas melhorias poderão trazer benefícios aos alunos. Além disso, os aprendizes poderão ter acesso aos catálogos de antipadrões e poderão se beneficiar com isso, estudando-os por conta própria. Para isso, as fichas contam com orientações de como esse estudo pode ser feito. Poder estudar o conteúdo dos antipadrões dará a oportunidade do aluno se preparar melhor para o aprendizado do conteúdo seguinte, tomando conhecimento dos equívocos recorrentes durante o estudo de programação.

\subsubsection{Para Pesquisadores}

O material resultante desta tese pode ser útil aos pesquisadores como fonte de inspiração e de dados para novas pesquisas. A Seção 7.1 dá algumas sugestões dessas pesquisas. Além destas, muitas outras possibilidades se abrem.

Uma possibilidade é a criação de uma nova linguagem de programação que evitasse dificuldades como as de sintaxe. Ela poderia ser voltada só para educação, levando para a sala de aula a possibilidade de se focar mais na lógica e menos na sintaxe. Os erros de semântica e de estilo também poderiam ser abordados explicitamente pela própria linguagem, com retorno adequado. Assim como o compilador acusa erros de sintaxe, a nova linguagem poderia detectar alguns de semântica e de estilo e dar explicações de quais poderiam ser os possíveis erros. Um exemplo disso é o não uso do 'else' onde seria adequado (SS2 - Erro de Estilo), ou a possibilidade de o aluno estar cometendo um equívoco que resultará em repetição infinita, como é o caso do antipadrão RS2, que é um erro de semântica.

Outra possibilidade seria criar mecanismos que pudessem detectar antipadrões automaticamente de códigos de aprendizes de programação, ou até mesmo, em outras áreas da computação. Esse mecanismo de detecção automática poderia se basear em um repositório de códigos e, usando conhecimento de 'Inteligência Artificial' e 'Aprendizado de Máquina', fazer uma busca por erros recorrentes para alimentar os católogos de antipadrões existentes, enriquecendo assim o conhecimento na área.

Com esse tipo de sistema, o pesquisador poderia inclusive extrapolar a ideia para outras áreas, como o aprendizado de línguas. Existem diversas possibilidades de pesquisa que 
poderiam surgir a partir dos dados gerados, podendo ser novos sistemas, sistemas de apoio ao ensino, novas metodologias, entre outras. 



\section{Capítulo 7}

\section{Conclusões}

O principal objetivo desse trabalho foi identificar padrões de dificuldades relacionados ao aprendizado de programação. Para isso utilizamos informações de diversas fontes, tais como entrevistas, diários, questionários e códigos.

Inicialmente, buscamos saber da situação das disciplinas de introdução à programação nos diversos cursos oferecidos na USP. Usamos para isso um banco de dados cedido pela universidade com os resultados alcançados pelos alunos regularmente matriculados em disciplinas de introdução à programação, entre 2010-1 e 2014-2. Vimos que 30\% dos alunos matriculados reprovam, uma média anual de 1.127 alunos que não obtiveram sucesso na disciplina nos anos analisados.

Em seguida, foi realizada a coleta de dados para detectar as dificuldades enfrentadas pelos alunos das disciplinas de introdução à programação oferecidas em diversos cursos de graduação. Utilizando dados coletados de entrevistas semiestruturadas e outras utilizando o método Think Aloud, além de diários, questionários, entre outras fontes, vimos dificuldades aparecendo em diversos conteúdos abordados na disciplina. Muitos dos conteúdos citados como difíceis já são conhecidos na literatura (M. Gomes et al., 2015; MHAshi e AlakeEL, 2013; Izu e Dinh, 2018; SEvella et al., 2013), porém buscamos detalhar mais, apresentando de maneira mais específica as situações às quais sua ocorrência está relacionada (Figura 4.2).

Esse detalhamento é um diferencial comparado com o que é apresentado na literatura. Na Figura 4.2, podemos ver os conteúdos, como variáveis, estruturas de repetição, expressões, entre outros e, ligados a cada um deles, um conjunto de dificuldades encontradas para aprendê-los. Além disso, um adicional às dificuldades é a sua classificação das mais prejudicam o aprendizado para as que menos prejudicam. Essa classificação pode ser usada pelo professor, por exemplo, na decisão de quais dificuldades dar mais atenção durante as aulas, devido ao tempo disponível. Dessa forma, torna-se possível não só apontar o conteúdo onde os alunos apresentam dificuldades mas também desenvolver ou aplicar estratégias que possam ser úteis para evitá-las.

Além dessas dificuldades, outros resultados foram alcançados com a análise desses dados, como uma lista de estratégias didáticas que poderiam ajudar a minimizar as dificuldades enfrentadas pelos alunos, conjuntos de dificuldades encontradas com o uso das 
linguagens $\mathrm{C}$ e Python, e conexões entre os conteúdos/tópicos necessários para aprender a programar. Essas conexões, encontradas a partir dos diários e entrevistas, apoiam o que diz a teoria Learning Edge Momentum de Robins (2010). Os dados nos mostraram o surgimento de dificuldades em determinados tópicos pela falha no aprendizado de outros, mostrando dependência entre eles. Esse achado nos mostra a importância de se definir com cuidado a sequência em que os tópicos são abordados pelos professores. Isso deve acontecer não somente no aprendizado de programação, mas em várias outras situações, como no aprendizado da matemática, onde determinados conteúdos também dependem de outros, exemplo: para aprender multiplicação, é necessário saber adição.

Como uma das principais contribuições deste trabalho temos os antipadrões levantados. Diferentemente do que foi apresentado na literatura (CACEFfo, FranÇA et al., 2017; SouzA et al., 2018; G. A. R. GAMA et al., 2018), este trabalho utilizou códigos gravados em cada compilação realizada pelo alunos durante resoluções dos exercícios apresentados na disciplina. Como existem equívocos que são cometidos no decorrer do desenvolvimento e corrigidos pelos alunos antes de gerar a última versão do código, esses equívocos apareceram e tivemos a oportunidade de catalogá-los. Fontes de dados que apresentam apenas a versão considerada final pelos alunos provavelmente perdem esse tipo de informação, como é o caso de análise de provas e trabalhos. Com a análise desses códigos, mais de 130 equívocos foram detectados nas linguagens $\mathrm{C}$ e Python, porém, adotando a regra citada por W. $\mathrm{H}$. BRown et al. (1998), consideramos antipadrões apenas os equívocos encontrados três vezes em situações distintas. Isso fez surgir catálogos com 21 antipadrões em C (Apêndice E), 11 em Python (Apêndice F) e 9 que ocorreram em ambas linguagens (Apêndice G). Usando os critérios anteriormente discutidos de coleta e análise, torna-se mais fácil aumentar os catálogos aqui definidos e replicar essa busca por antipadrões em outras linguagens de programação.

Os dados registrados em cada ficha de antipadrão, assim como os demais resultados gerados nessa tese, abrem inúmeras possibilidades para pesquisadores, professores e coordenadores de cursos trabalharem no aprimoramento da área. Professores e coordenadores recebem subsídios para estudar uma forma melhor de organizar e lecionar a disciplina de introdução à programação. Pesquisadores podem utilizar os resultados apresentados para criar formas de desenvolver sistemas de correções automáticas com orientações para alunos, não somente em erros de sintaxe, apontados pelos compiladores, mas também nos de semântica e de estilo. Outra possibilidade seria usar esses resultados para programar agentes inteligentes que guiem alunos em sistemas de autoaprendizado, sistemas que mostrem conceitos, apresentem exercícios, corrijam as soluções apresentadas e guiem o aluno para uma próxima etapa ou para o retorno a algum tópico mal compreendido. Conhecer antipadrões, dificuldades e conexões dos tópicos abrem essas possibilidades e muitas outras. Por outro lado, tanto os antipadrões que foram solucionados pelos alunos durante o desenvolvimento, quanto os que não foram selecionados e que aparecem na última versão compilada pelo aluno fizeram o aprendiz despender tempo para buscar a solução. Como esse tempo foi utilizado, analisando como o aluno fez até chegar na solução, é outro dado de interesse, mas que não foi tratado nesta tese e que pode enriquecer os resultados obtidos aqui.

Dificuldades sempre estarão presentes nas aulas de programação, porém a sua frequência e intensidade poderão ser diminuídas se buscarmos aprender com elas. Aprender com os 
erros é uma prática já citada na literatura (ELLSTröm, 2001; HARTEIs et al., 2008; STREumer e KHo, 2006), estudando/conhecendo os equívocos cometidos para evitar que outros alunos os cometam. Essa prática pode ser benéfica para o aprendizado. As contribuições desta tese podem ajudar nessa prática, além de dar subsídios aos pesquisadores no desenvolvimento de novas pesquisas para a melhoria do ensino-aprendizagem de programação.

\subsection{Sugestões de Trabalhos Futuros}

Algumas sugestões de trabalhos futuros que surgiram com o desenvolvimento desta tese:

Formas de tratar os antipadrões do tipo semântico: erros de sintaxe são mais fáceis de serem detectados por sistemas de correção automática de códigos, por serem detectados por compiladores/interpretadores, o que não acontece com erros semânticos. Desenvolver um estudo para detalhar mais os antipadrões do tipo semântico, mostrando suas características e comportamentos, poderia ser fonte importante para pesquisadores/desenvolvedores de sistemas de apoio à aprendizagem, e poderia ser utilizado como fonte também para professores da disciplina de introdução à programação.

Verificação dos efeitos que a troca da linguagem $C$ pelo Python teve na Escola Politécnica da USP (POLI-USP): a linguagem de programação usada nas aulas de introdução à programação das faculdades de Engenharia da POLI-USP (Capital) foi trocada gradativamente do C para o Python. Quais os resultados obtidos com tal troca?

Nesse mesmo trabalho, outras questões poderiam ser investigadas, como:

- Quantas turmas de introdução à programação foram oferecidas e quantos alunos as cursaram?

- Taxas de sucesso (aprovações) e insucesso (reprovações/trancamentos/desistências)?

- Há correlação do desempenho na disciplina com as notas no vestibular?

- Os professores influenciam no resultado?

- A linguagem influencia no índice de reprovações?

- Como a disciplina de introdução à programação se compara às demais lecionadas nos mesmos semestres?

Além da divulgação dos resultados por artigos, os resultados dessa análise poderiam ser divulgados dentro da USP, dando subsídios para decisões futuras.

Conexões entre tópicos necessários para aprender a programar: conforme pesquisa de Robins (2010) e resultados desta tese (Seção 4.3), adquirir um conceito com sucesso torna o aprendizado de outro conceito vinculado mais fácil. Pensando nisso, poderia ser desenvolvido um estudo para comprovar e completar as conexões entre tópicos apresentadas neste trabalho (Seção 4.3). Dessa forma, os coordenadores e professores teriam 
mais subsídios no planejamento da sequência em que o conteúdo poderia ser abordado para diminuir as dificuldades e melhorar o desempenho dos alunos.

Criação de um banco de questões onde as dificuldades pudessem ser trabalhadas: segundo A. Gomes e A. Mendes (2014), uma forma de ajudar os alunos é com exercícios bem elaborados, cuidadosamente pensados, refletindo como, qual, quando e por que cada exercício seria apresentado. Um banco de questões poderia ajudar o professor na hora da escolha e variação dos exercícios utilizados em cada situação.

Automação de feedback: segundo MHASHI e AlAKeEl (2013), um dos fatores relacionados com as dificuldades enfrentadas pelos alunos é a falta de feedback sobre as resoluções dos exercícios. Automatizar os feedbacks poderia trazer um ganho ao desenvolvimento dos alunos. Uma sugestão de trabalho futuro seria uma pesquisa quanto ao desenvolvimento dessa automação usando os antipadrões levantados nesta tese. Essa automação poderia dar uma orientação mais detalhada aos alunos de como proceder no momento que os antipadrões aparecessem nos códigos. 


\section{Apêndice A}

\section{Acompanhamento de Alunos com Dificuldade}

Numa exploração inicial dentro desta pesquisa de doutorado, realizamos um estudo prévio trabalhando diretamente com alguns alunos que haviam sido reprovados em uma disciplina de introdução à programação. O período de acompanhamento desses alunos, entre o resultado final da disciplina e a realização da prova de recuperação para os alunos que não tinham sido aprovados, serviu para buscarmos compreender um pouco mais sobre as dificuldades que esses alunos enfrentaram ou estavam enfrentando. A seguir, a descrição da metodologia usada e os resultados alcançados.

\section{A.1 Metodologia}

Para participarem desse estudo, foram convidados os alunos que tinham cursado uma das disciplinas de introdução à programação do segundo semestre de 2015 e que, não tendo sido aprovados, precisavam fazer a prova de recuperação. A intenção era a realização de um pequeno curso de 8 semanas, com assistência aos estudos de programação. A participação era opcional, não havendo nenhum ônus para o aluno que não aceitasse participar. A Figura A.1 mostra a metodologia utilizada.

Antes de iniciarmos o curso, alunos que não tinham tido sucesso na disciplina foram convidados a participar de um pesquisa. A primeira fase dessa pesquisa consistia em um encontro antes da prova de recuperação que eles iriam fazer com o intuito de obter nota o suficiente para aprovação. Nessa fase foi utilizado o protocolo Think Aloud. A técnica consiste em observar usuários que realizam tarefas específicas dentro de um ambiente controlado (RENZI et al., 2012). Nesse caso, as tarefas eram resoluções de quatro exercícios de programação resolvidos no computador, dentro do Virtual Programming Lab (VPL), que é um plugin para o Moodle. Durante a resolução dos exercícios, os alunos descreveram em voz alta, em tempo real, o que eles estavam pensando. Para capturar esses pensamentos expressados em voz alta, podíamos ter usado duas técnicas diferentes: (1) gravação em vídeo ou (2) transcrição por um moderador, essa segunda usada na nossa pesquisa. Embora a gravação de vídeo ou áudio tenha a vantagem de documentar tudo o que é feito e dito, a 


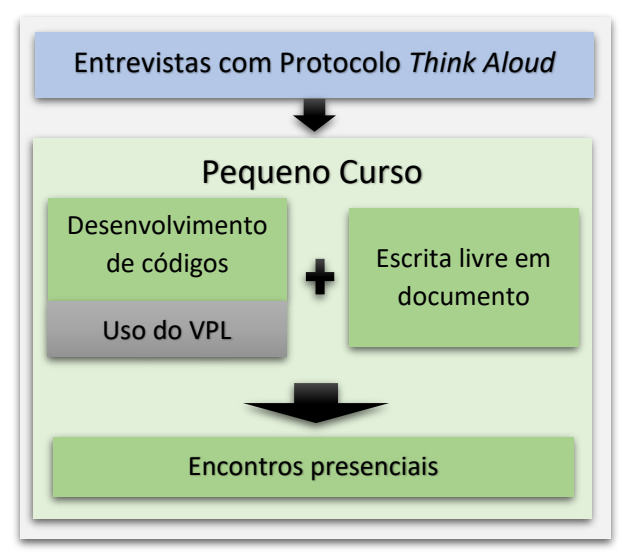

Figura A.1: Metodologia usada no acompanhamento de alunos com dificuldades.

desvantagem é que o usuário pode não se sentir à vontade e acabar não verbalizando tudo o que está experimentando. No caso da anotação em tempo real, o moderador escreve tudo o que acontece e o que os entrevistados dizem. A vantagem é que o ambiente se torna mais relaxado, levando os usuários a se sentirem mais à vontade, expondo tudo o que pensam. A desvantagem é que se corre o risco da velocidade necessária para a tomada de notas levar à perda de importantes informações de pesquisa (REnzI et al., 2012).

Genise (apud Renzi et al. (2012)) descreveu o procedimento de aplicação do protocolo em cinco etapas, onde o pesquisador:

1. organiza um pequeno grupo de usuários, cerca de 4;

2. atende os usuários;

3. decide quais tarefas devem ser realizadas e em que ambiente;

4. explica o método aos usuários, direcionando-os para verbalizar seus pensamentos;

5. notifica as mudanças necessárias na ferramenta.

Como nosso objetivo não é avaliar a ferramenta, mas as dificuldades de programação, o passo 5 não se aplica ao nosso estudo.

Seis alunos se candidataram a participar da entrevista, identificados na Apêndice A.2 com números de 1 a 6 para preservar sua identidade. As sessões foram realizadas com o processo de gravação, incluindo a tela do computador e gravações de áudio, para futuras análises, e pedimos aos alunos que resolvessem quatro exercícios com diferentes níveis de dificuldade.

O primeiro exercício pedia para o aluno desenvolver um código que tinha como entrada três valores inteiros e que gerasse como resultado a sua média aritmética. O segundo era praticamente o mesmo que o anterior, porém foi solicitado que a média fosse calculada dentro de uma função. O terceiro pedia para ler e armazenar valores em uma matriz e em seguida, exibir a matriz em ordem inversa. Por fim, no quarto exercício, era solicitado que o aluno desenvolvesse uma função, dentro de um modelo disponibilizado para eles, que ordenasse um vetor de nomes. Uma observação importante é que os alunos desconheciam o comando de comparação de strings e a explicação dele foi dada no próprio exercício; 
Queríamos observar como o aluno agiria perante tal dificuldade. Outra observação importante é que um exemplo de entrada e saída sempre foi fornecido para os alunos, em cada exercício, para evitar dúvidas de interpretação.

As ferramentas utilizadas foram o Moodle com o plugin VPL e a linguagem de programação foi o C. Como eles já tinham trabalhado com essas ferramentas durante o semestre letivo, a forma de utilização delas seria conhecida por todos. Cada entrevista durou cerca de uma hora, e os alunos foram encorajados a falar constantemente sobre o que estavam fazendo e pensando. Durante o processo, o moderador fez algumas poucas perguntas, como "O que você pensa sobre o uso da VPL na sala de aula?", para buscar informações além do que os alunos espontaneamente expuseram.

A segunda fase foi um pequeno curso que usou o mesmo ambiente das classes semestrais e da primeira fase da pesquisa (Moodle + VPL). Para esse curso, a cada duas semanas era disponibilizado um conjunto de exercícios para os alunos resolverem, foram 38 no total. O nível de dificuldade dos exercícios aumentava a cada novo conjunto disponibilizado. Foi solicitado que os alunos resolvessem os exercícios e, paralelamente, fizessem um registro livre desse processo em um documento de texto. Toda vez que o aluno compilava o programa, uma cópia era guardada para análise. A cada 15 dias e ao término do tempo de resolução de cada conjunto de exercícios, tínhamos um encontro presencial para esclarecimento de dúvidas e resolução passo a passo de alguns dos exercícios que eles tiveram mais dúvidas.

\section{A.2 Resultados}

Foram usadas duas formas para coletar dados para a pesquisa: através do método Think Aloud (Fase 1) e do mini curso (Fase 2), ambas com resoluções de exercícios no computador, usando o VPL no Moodle.

Na Fase 1, uma das atitudes observadas, adotada por 2 aluno, foi tomar notas enquanto liam os enunciados dos exercícios (aluno 1 e 3). Esses 2 alunos não apresentaram melhores resultados do que os demais, porém, um deles, quando solicitado pelo moderador da atividade, fez o seguinte comentário: "anotar ajuda a lembrar o que precisa ser feito, porque, de outra forma, não consigo lembrar". Uma diferença entre esses dois alunos e os outros foi que eles tinham menos erros ao declarar as variáveis e definir seus tipos. Eles praticamente não precisaram retornar ao código para mudar o que escreveram.

O moderador fez anotações sobre reações de alguns estudantes que mostraram instantaneamente não gostarem de um determinado conteúdo. O primeiro foi o estudante 6: ele não havia lido a questão inteira quando parou para fazer o seguinte comentário: "Fico nervoso quando vejo a palavra matriz". O estudante 1, ao começar a ler a segunda questão, falou instantaneamente "Não gosto de função" e "Tenho dificuldade com os parâmetros da função". Na pergunta 4, o estudante 1 disse: "À primeira vista, não gosto desse exercício, eu gosto de exercícios que têm números". Nessas três situações, os aprendizes não conseguiram resolver o exercício. Isso pode ser um sinal de que os alunos criam um bloqueio para os conteúdos frente aos quais eles enfrentam maiores dificuldades.

Também percebemos insegurança nos alunos e algum grau de ausência de raciocínio 
lógico. Quando confrontados com erros de compilação no exercício com matriz, eles fizeram comentários como "Vamos ver agora. Deve ter algo errado. Há sempre algo errado". O moderador observou que os comandos aos quais se referiam estavam corretamente escritos, mas com as variáveis não declaradas. Além disso, em alguns casos, os alunos enfrentaram problemas de executar o que eles pretendiam fazer: Eles verbalizaram algo mas escreveram (código) algo diferente. Esta situação foi detectada durante as entrevistas e observada pelo comentário do aluno 1, "Não sei se é assim ler uma matriz, mas está bem", e do aluno 6, "Eu acho que falta algo nesta impressão".

Foram muitos erros cometidos durante o desenvolvimento de códigos, tais como: (A) tentando ler os dados na matriz; (B) criando uma função sem nome, além da declaração incorreta dos parâmetros, e (C) pontos e vírgulas que encerram uma estrutura de repetição e seleção que nem mesmo começou (Figura A.2). Os erros de semântica deixavam os alunos mais desapontados do que os erros de sintaxe; Com erros de sintaxe, eles parecem mais acostumados. Erros de semântica fizeram com que os alunos abandonassem os exercícios mais rapidamente, por serem mais difíceis de serem resolvidos e por levarem mais tempo para serem consertados.

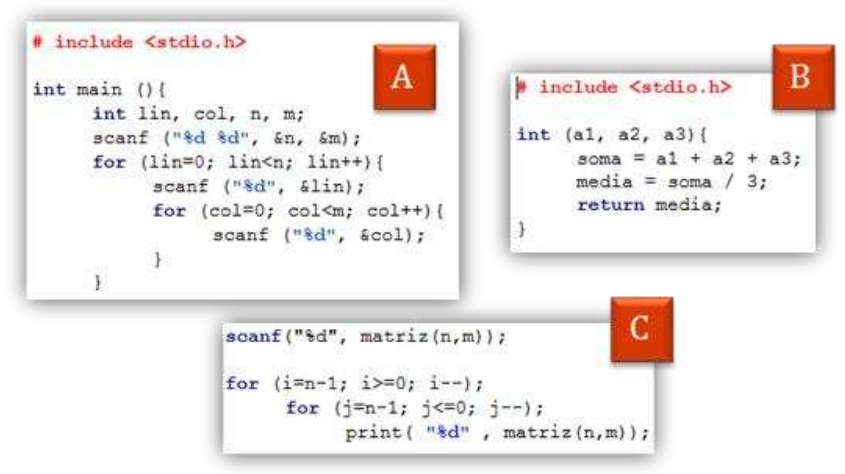

Figura A.2: Trechos de códigos com erros, desenvolvidos pelos alunos nas entrevistas.

No mini curso, os exercícios também foram resolvidos no VPL e, a cada compilação, o código era gravado. Em média, foram 7 compilações por exercício e, ao final, $84 \%$ dos alunos tiveram $100 \%$ de sucesso nos casos de teste analisados pelo sistema. Além disso, vale ressaltar que o aluno compilou, em média, 2 vezes até que o código estivesse sem erros de sintaxe, ou seja, até que o compilador não detectasse mais erros, e 3 vezes até que os resultados começassem a se aproximar do esperado. Durante a análise manual do código, foram detectados alguns erros de sintaxe (Tabela A.1) e semântica (Tabela A.2). Nessas Tabelas, mostramos os erros que ocorreram mais de uma vez, em códigos distintos.

Existem problemas que não impedem que o programa seja compilado e forneça o resultado correto, mas de forma pouco eficaz. Um exemplo é não usar 'else' nas estruturas de seleção 'if', optando por realizar múltiplos testes com 'ifs' seguidos. Este problema foi notado 11 vezes, ou seja, um número elevado em comparação com outros problemas. Outros erros incluíram o carregamento de bibliotecas desnecessárias e a falta de indentação. 


\begin{tabular}{c|l} 
Qde & \multicolumn{1}{c}{ Descrição } \\
\hline 7 & Não abriu com "\{" ou fechou com "\}" alguma estrutura ou função \\
\hline 3 & Erro na formatação da quantidade de casas decimais em um tipo float \\
\hline 3 & Uso de variáveis não declaradas \\
\hline 2 & Esqueceu ";" em algumas linhas \\
\hline 2 & Na declaração de variáveis do tipo float, separou os nomes com ";" e não "," \\
\hline 2 & Não separou as variáveis com "," dentro do parênteses do scanf \\
\hline 2 & Usou "," ao invés de "." em números reais: "if $($ s $>2000,00)$ " \\
\hline
\end{tabular}

Tabela A.1: Erros de sintaxe encontrados nos códigos dos alunos do mini curso.

\begin{tabular}{c|l} 
Qde & \multicolumn{1}{c}{ Descrição } \\
\hline 9 & Não cuidou de divisão por 0 (zero) \\
\hline 5 & Variável de controle do while não inicializada \\
\hline 2 & $\begin{array}{l}\text { A hora foi multiplicada por 360 e não } 3600 \\
\text { A hora foi multiplicada por 86400 e não } 3600\end{array}$ \\
\hline 2 & Errou a fórmula da raiz quadrática, esquecendo de dividir por 4 \\
\hline 2 & Estrutura de if..else montada de forma errada \\
\hline 2 & Para imprimir -1 usou 'return "-1" ' ao invés do comando printf \\
\hline
\end{tabular}

Tabela A.2: Erros de semântica encontrados nos códigos dos alunos do mini curso.

\section{A.3 Conhecimentos Adquiridos}

As dificuldades detectadas mostram que erros de sintaxe são os mais comuns. Esse resultado confirma a pesquisa de DenNy et al. (2011), que afirmam que muitas submissões são realizadas antes que o código esteja livre de erros de sintaxe (DENNy et al., 2011). Além disso, os alunos mostraram maior dificuldade com a manipulação de vetores e matrizes do que com estruturas de repetição e seleção. A falta de capacidade de interpretar os exercícios e a escolha da linguagem de programação também são fontes de dificuldades. 



\section{Apêndice B}

\section{Lista de Equívocos}

Lista com todos os equívocos encontrados com a análise dos códigos desenvolvidos em C e Python.

\section{EQUÍVOCOS EM C}

\begin{tabular}{|c|c|c|c|}
\hline No & ID & Nome do Equívoco & Antipadrão \\
\hline \multicolumn{4}{|c|}{ Tópico: Geral } \\
\hline 1 & C_G1 & Falta de indentação & $\mathrm{X}$ \\
\hline 2 & C_G2 & Falta de "; " no final da linha & $\mathrm{X}$ \\
\hline 3 & C_GL1 & Falta chamada da biblioteca) & $X$ \\
\hline 4 & C_GL2 & Chamada desnecessária de biblioteca & \\
\hline 5 & C_GL3 & Falta dos "<>" na chamada da biblioteca & \\
\hline 6 & C GL4 & Falta do "\#" na frente da chamada da biblioteca & \\
\hline 7 & C_GL5 & Escrita errada do nome da biblioteca ou falta da extensão ".h" & \\
\hline \multicolumn{4}{|c|}{ Tópico: Variável } \\
\hline 8 & C V1 & Uso de variável inexistente & $X$ \\
\hline 9 & C_V2 & Variáveis incorretamente colocadas dentro de parênteses na declaração & \\
\hline 10 & C_V3 & Atribuição usando "==" ao invés de "=" & $\mathrm{X}$ \\
\hline 11 & C_- V4 & Diferenciação entre letras maiúsculas e minúsculas no nome da variável & \\
\hline 12 & C_V5 & Declarar variáveis e não utilizá-las & \\
\hline 13 & C_V6 & Uso errado de aspas simples na atribuição & \\
\hline 14 & $\mathrm{C}^{-} \mathrm{V7}$ & Usar variável antes de inicializar & \\
\hline 15 & C_V8 & Impressão da variável que não tem o resultado final & \\
\hline \multicolumn{4}{|c|}{ Tópico: Função de Entrada de Dados } \\
\hline 16 & C_IF1 & Falta do "\&" na frente da variável no "scanf" & $\mathrm{X}$ \\
\hline 17 & C IF2 & Falta das aspas na chamada da função de entrada de dados & $\mathrm{X}$ \\
\hline 18 & C IF3 & Uso do "\&" no lugar do “\%” na função de entrada de dados & \\
\hline 19 & C_IF4 & Escrita incorreta do comando "scanf" & \\
\hline 20 & C_IF5 & $\begin{array}{l}\text { Uso indevido da vírgula “," no primeira argumento da função de entrada } \\
\text { de dados }\end{array}$ & \\
\hline 21 & C_IF6 & $\begin{array}{l}\text { Falta da vírgula para separar o primeiro do segundo parâmetro no } \\
\text { "scanf" }\end{array}$ & $\mathrm{X}$ \\
\hline 22 & C_IF7 & $\begin{array}{l}\text { Uso das aspas simples ao invés da dupla no primeiro parâmetro do } \\
\text { "scanf" }\end{array}$ & \\
\hline 23 & C_IF8 & Uso do pula linha, "In", no "scanf" & \\
\hline 24 & C_IF9 & Falta da vírgula para separar as variáveis no "scanf" & \\
\hline 25 & C IF10 & Parâmetro que identifica tipo do dado incompatível com a variável & \\
\hline 26 & C_IF11 & Uso do nome do tipo e não da variável & \\
\hline
\end{tabular}




\begin{tabular}{|c|c|c|c|}
\hline 27 & C_IF12 & \multirow{2}{*}{$\begin{array}{l}\text { Uso da configuração do tipo "float" no "scanf" } \\
\text { Uso do "\%" ao invés de "\&" na frente da variável na função de entrada } \\
\text { de dados }\end{array}$} & \\
\hline 28 & C_IF13 & & \\
\hline \multicolumn{4}{|c|}{ Tópico: Função de Saída de Dados } \\
\hline 29 & C_OF1 & Uso indevido do “\&” na frente da variável no "printf” & $\mathrm{X}$ \\
\hline 30 & C_OF2 & Falta das aspas na função de saída de dados & $\mathrm{X}$ \\
\hline 31 & C_OF3 & Escrita incorreta do comando "printf" & $\mathrm{X}$ \\
\hline 32 & C_OF4 & $\begin{array}{l}\text { Falta da vírgula para separar o primeiro do segundo parâmetro na } \\
\text { função de saída de dados }\end{array}$ & $\mathrm{X}$ \\
\hline 33 & C OF5 & Parâmetro que identifica o tipo de dado de saída incorreto ou inexistente & $\mathrm{X}$ \\
\hline 34 & C_OF6 & Uso do "\&" no lugar do "\%" na função de saída de dados & $\mathrm{X}$ \\
\hline 35 & C_OF7 & Não apresenta o resultado ao usuário & $\mathrm{X}$ \\
\hline 36 & C_OF8 & Falta da variável & \\
\hline 37 & C OF9 & Mau entendimento do que será impresso & \\
\hline 38 & C_OF10 & Colocar a variável dentro das aspas ao invés de fora dela & \\
\hline \multicolumn{4}{|c|}{ Tópico: Expressão Aritmética } \\
\hline 39 & C_AE1 & Tipo do resultado float em uma divisão de inteiros & $\mathrm{X}$ \\
\hline 40 & C AE2 & Fórmula aritmética errada & $\mathrm{x}$ \\
\hline 41 & C_AE3 & Realizar o cálculo antes de ter valores nas variáveis utilizadas & $\mathrm{x}$ \\
\hline \multicolumn{4}{|c|}{ Tópico: Expressão Relacional } \\
\hline 42 & C_RE1 & O uso do "=" ao invés de "==" & $\mathrm{X}$ \\
\hline 43 & C RE2 & O uso do ">>" ao invés de ">" & \\
\hline 44 & C_RE3 & Uso do "<" ao invés do ">" ou vice-versa & \\
\hline 45 & $\mathrm{C}^{-} \mathrm{RE} 4$ & O uso do "=<" ao invés de "<=" & \\
\hline 46 & C RE5 & Realizar comparação antes de ter valores nas variáveis utilizadas & $\mathrm{X}$ \\
\hline \multicolumn{4}{|c|}{ Tópico: Expressão Lógica } \\
\hline
\end{tabular}

\section{Tópico: Estrutura de Controle (Seleção/Repetição)}

48 C_SRS1 Ordem das estruturas invertida

49 C_SRS2 Uso de repetição no lugar de seleção e vice versa

\section{Tópico: Estrutura de Seleção}

\begin{tabular}{|c|c|c|c|}
\hline 50 & C_SS1 & $\begin{array}{l}\text { Uso incorreto das chaves de abertura ou de fechamento do "if" ou do } \\
\text { "else" }\end{array}$ & $\mathrm{X}$ \\
\hline 51 & C_SS2 & O não uso do "else" onde seria adequado & $\mathrm{X}$ \\
\hline 52 & C_ss3 & Apresentação do resultado equivocado & \\
\hline 53 & C SS4 & Colocar indevidamente ";" após a condição do "if" e/ou após o "else" & $\mathrm{X}$ \\
\hline 54 & C_ss5 & Condição fora de parênteses. & \\
\hline 55 & C_SS6 & $\begin{array}{l}\text { Uso do "else" sem a existência de um "if" pra compor a estrutura de } \\
\text { seleção }\end{array}$ & \\
\hline 56 & C_SS7 & O uso de ")" logo após o "if" & \\
\hline 57 & C_ss8 & Uso desnecessário de seleção encadeada & \\
\hline 58 & C_SS9 & O uso de ")" logo após o "if" & \\
\hline \multicolumn{4}{|c|}{ Tópico: Estrutura de Repetição } \\
\hline 59 & C_RS1 & Usar estrutura de repetição para imprimir 1 vez variáveis distintas & \\
\hline 60 & C RS2 & Variável de controle não está sendo alterada & $\mathrm{X}$ \\
\hline 61 & C RS3 & Imprimindo resultado em local errado & $\mathrm{X}$ \\
\hline 62 & $\mathrm{C}^{-} \mathrm{RS} 4$ & Condição fora de parênteses & \\
\hline 63 & C_RS5 & $\begin{array}{l}\text { Usar os parâmetros do "for" (inicialização;comparação,incremento) no } \\
\text { "while" }\end{array}$ & \\
\hline 64 & C_RS6 & Na estrutua "do..while", faltando o "while" no final & \\
\hline & C_RS7 & Uso de "," ao invés de ";" nos argumentos da estrutura "for" & \\
\hline 66 & C_RS8 & Variável de controle do "for" não sendo usada na comparação & \\
\hline
\end{tabular}


67 C_RS9 Uso do ";" após a condição do "while" (dentro dos parênteses)

68 C_RS10 Criar condição de parada e operações incorretas para gerar resultado

esperado

69 C_RS11 Variável de controle não inicializada

70 C_RS12 Variável de controle inicializada no local errado

71 C_RS13 Uso do "for" quando deveria ser usado o "while"

72 C_RS14 Terceiro argumento do "for" sendo usado para inicialização

73 C_RS15 Estrutura não inicializada ou finalizada com chaves, quando necessário

\section{Tópico: Vetor}

74 C ODA1 Uso de índice inexistente no vetor

75 C ODA2 Criação do vetor no tamanho errado

\section{Tópico: Matriz}

76 C_MDA1 Escrita incorreta da variável do tipo matriz

\section{Tópico: Ponteiro}

77 C_P1 Utilização incorreta do valor apontado por um ponteiro

\section{Tópico: Função}

78 C_F1 Falta do return

\section{Topico: Função}

79 C_F2 Falta de abertura "\{"e/ou fechamento "\}" da função

80 C_F3 Função criada porém não chamada

81 C_F4 Escrita errada do nome da função "main"

82 C_F5 Retorno de tipo incorreto

83 C_F6 Chamada incorreta de uma função tipada

84 C F7

85 C F8

Função posicionada depois de onde ela é chamada

86 C F9

$87 \quad C$ F10

$88 \quad \mathrm{C} F 11$

89 C F12

90 C F13

91 C F14

$92 \quad \mathrm{C} F 15$

Recebimento de um tipo diferente do retorno da função

Declaração incorreta dos parâmetros da função

"return" x "printf"

Erro na passagem de vetor por parâmetro

93 C_F16 valora ela

Colocar o "return" fora da função

Não considera parâmetro como variável

Uso de ";" no final da linha inicial da função

94 C_F17 Criação da função sem os parênteses após o nome

95 C_F18 Escopo de variável

\section{EQUÍVOCOS EM PYTHON}

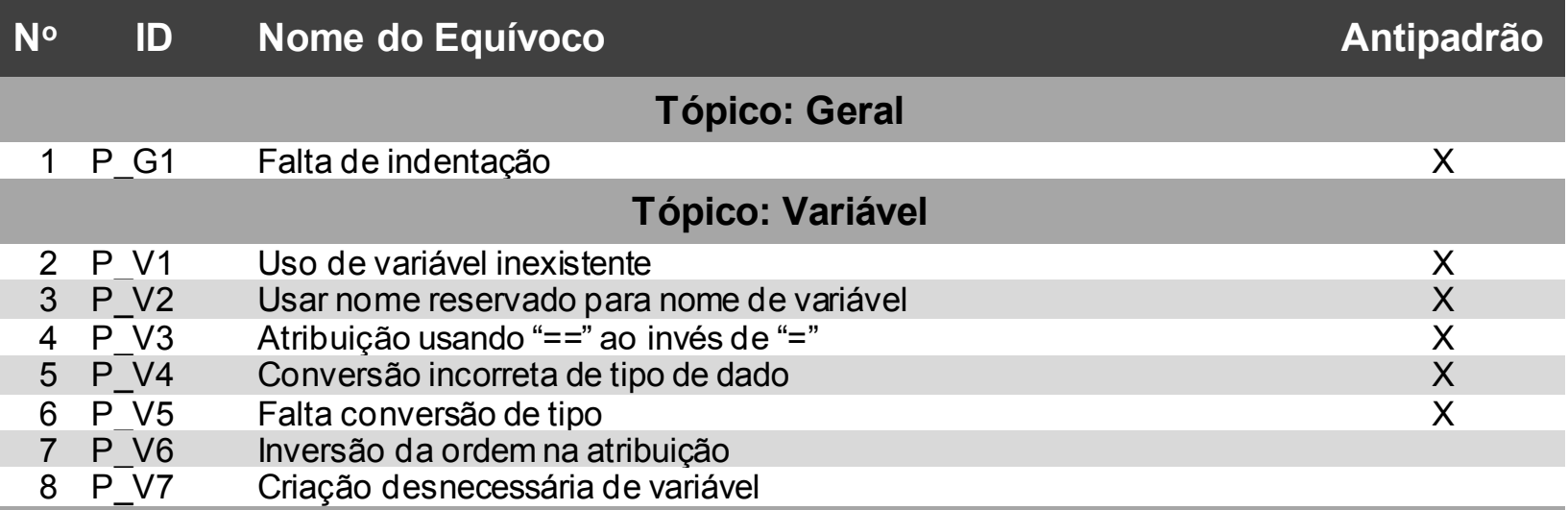


9 P_IF1 Escrita incorreta do comando "input"

$11 \mathrm{P}^{-} \mathrm{IF} 3$

Falta das aspas na chamada da função de entrada de dados

"Input" seguido de ":" ao invés de parênteses

12 P IF4 Falta dos parênteses no "input"

\section{Tópico: Função de Saída de Dados}

13 P_OF1 Não apresenta o resultado ao usuário

14 P_OF2 Falta das aspas na função de saída de dados

15 P_OF3 Falta parênteses no "print"

16 P_OF4

17 P_OF5

Falta da vírgula para separar o primeiro do segundo parâmetro na

função de saída de dados

18 P_OF6

"print" seguido por "=" ou outro parâmetro incorreto

19 P OF7

Escrita incorreta do nome da função de saída

Variável incorretamente entre aspas

\section{Tópico: Expressão}

20 P_E2 Mistura de comparações e operadores

\section{Tópico: Expressão Aritmética}

$21 \mathrm{P} \_$AE1 Tipo do resultado float em uma divisão de inteiro

22 P_AE2 Operador aritmético errado

23 P AE3 Realizar o cálculo antes de ter valores nas variáveis utilizadas

\section{Tópico: Expressão Relacional}

24 P_RE1 O uso do "=" ao invés de "=="

25 P_RE2 Uso de ">>" ou "<<" ao invés de ">" ou "<"

26 P_RE3 Uso de ">" ao invés de " $<$ " e vice versa

\section{Tópico: Estrutura de Controle (Seleção/Repetição)}

27 P_SRS1 Uso de estrutura de repetição onde deveria ser de seleção

Tópico: Estrutura de Seleção

28 P_SS1 Falta dos ":" no final da linha do "if" ou do "else" X

29 P_SS2 O não uso do "else" onde seria adequado

30 P_SS3 "if" sem condição ou com a condição em lugar errado

\section{Tópico: Estrutura de Repetição}

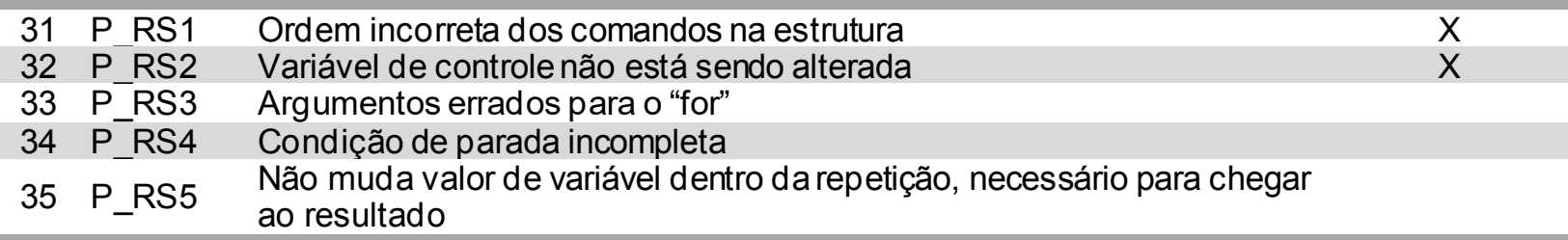

\section{ao resultado Tópico: Matriz \\ 36 P MDA1 Criação errada das linhas da matriz}

$\mathrm{X}$

\section{Tópico: Função}

$\begin{array}{lll}37 & \text { P_F1 } & \text { Falta parênteses na chamada da função } \\ 38 & \text { P_F2 } & \text { Declaração incorreta dos parâmetros da função } \\ 39 & \text { P_F3 } & \text { "return" x "print" } \\ 40 & \text { P_F4 } & \text { Chamada incorreta de uma função tipada } \\ 41 & \text { P_F5 } & \text { Função criada dentro de outra função } \\ 42 & \text { P_F6 } & \text { Declaração da função sem os parênteses dos parâmetros } \\ 43 & \text { P_F7 } & \text { Uso de palavra reservada para o nome da função }\end{array}$

44 P_F8 Função criada porém não chamada 


\section{Apêndice C}

\section{Enunciados dos Exercícios Selecionados}

Abaixo são apresentados os enunciados dos exercícios escolhidos para análise dos códigos gerados pelos alunos de introdução à programação.

\section{EXERCÍCIO 1.1}

Construa um algoritmo que recebe um número inteiro, a ser digitado pelo usuário, e imprime o valor digitado.

\section{EXERCÍCIO 1.2}

Construa um algoritmo que recebe um número inteiro (int), digitado pelo usuário, e imprime o quadrado desse número.

\section{EXERCÍCIO 2.1}

Construa um algoritmo que recebe dois números inteiros digitados pelo usuário e imprime o maior dentre os dois números.

\section{EXERCÍCIO 2.2}

Construa um algoritmo que recebe dois números inteiros como entradas (digamos na variáveis a e b) e imprima 1 se ocorrer "a<b" e 0 em caso contrário.

\section{EXERCÍCIO 3.1}

Construa um programa $\mathrm{C}$ ou Python que verifica se 3 números podem ou não representar os ângulos de um triângulo. Seu algoritmo deve solicitar que o usuário digite os 3 números naturais (representando ângulos em graus) e imprimir: "Sim" e os 3 números na sequência digitada, se somarem 180; e "NAO" e a soma dos 3 números em caso contrário.

\section{EXERCÍCIO 3.2}

Construa um algoritmo que lê três números naturais como entradas e verifica se esses números são pitagóricos. Três números são pitagóricos se o quadrado do maior deles (hipotenusa) é igual a soma do quadrado dos outros dois. Como saída de seu programa imprimir: se pitagóricos, o valor 1 e o valor da hipotenusa ao quadrado; se não pitagórico, apenas o valor 0.

Os números são denominados pitagóricos por corresponderem a comprimentos de lados de um triângulo retângulo, ou seja, $h^{2}=a^{2}+b^{2}$. 


\section{EXERCÍCIO 3.3}

Construa um programa C/Python que lê um natural (digamos na variável total) e computa a maior soma de naturais consecutivos, começando no 1, que seja menor ou igual ao valor digitado (<=total).

\section{EXERCÍCIO 4.1}

Construa um programa com funções de nome soma e media, ambas com 2 parâmetros formais do tipo int, que devolvem respectivamente, a soma dos parâmetros e sua média. As funções devem ter 2 parâmetros inteiros, como em soma $(a, b)$ e media $(a, b)$. Seu programa principal deverá receber do usuário 2 números inteiros, invocar com eles primeiro a funcão soma e imprimir sua soma, depois invocar media e imprimir sua média aritmética (invocando as funções).

\section{EXERCÍ́CIO 4.2}

Fazer um programa em C/Python implementando obrigatoriamente uma função de nome fat, com 1 parâmetro $\mathrm{n}$, que, dado um número inteiro $\mathrm{n}$, devolva o fatorial de $\mathrm{n}$ se $\mathrm{n}>=0$, caso contrário devolva -1 . Fazer um programa principal que solicite que o usuário digite um inteiro qualquer e usando a funcão fat imprima o fatorial do natural digitado.

Lembrando, a função fatorial fat(n) é definida apenas para os naturais (com o zero), da seguinte forma: fat $(0)=1$ e fat $(n)=n^{\star} f a t(n-1), n>0$. Assim, por exemplo, o fatorial de 4 é computado da seguinte forma: fat $(4)=$ $4 !=4 \cdot 3 \cdot 2 \cdot 1=24$.

Dessa forma, é preciso convencionar o que fazer se o usuário digitar um número inteiro negativo, neste caso seu programa deverá imprimir -1 (e.g., se a entrada for: $n=-10$ => saída $-1 ; n=-21$ => saída -1 ).

\section{EXERCÍCIO 4.7}

Construa um algoritmo que receba um número natural positivo $n(n>=1)$ e a seguir uma lista de $n$ valores inteiros não-nulos, cada qual seguida por um 0 (finalizador da subsequência), calcular a soma dos números ímpares de cada subsequência e imprimi-los (assim que ler o finalizador 0 ).

Exemplos: Para as subsequências abaixo, todas com $n=3$

Ex. 1. Entradas (incluindo o $n$ ): 3000 => saídas: 0

Ex. 2. Entradas (incluindo o $n$ ): $3202020=>$ saídas:0

Ex. 3. Entradas (incluindo o n): $3103050=>$ saídas:1 35

\section{EXERCÍCIO 7.1}

Construa um algoritmo que receba um natural positivo $n(n>0)$ e imprime a soma dos $n$ primeiros termos da série harmônica abaixo definida.

$H=1 / 1+1 / 2+1 / 3+1 / 4+\ldots+1 / k+\ldots$

\section{EXERCÍCIO 7.2}

Construa um algoritmo que receba um número natural positivo e valor real ( $\mathrm{n}$ e $\mathrm{x}$ ), calcule e imprima o valor de $x$. (potência de xelevado a n). Utilize apenas os operadores de soma e de produto de 2 inteiros.

\section{EXERCÍ́CIO 7.4}

Construa um programa que receba como entrada um número inteiro $\mathrm{n}$ e depois $\mathrm{n}$ caracteres, imprimindo os códigos ASCII (American Standard Code for Information Interchange) de cada um dos caracteres. 


\section{EXERCÍCIO 8.1}

1. Implementar uma função de nome determineSeOrdenado que recebe como parâmetros um inteiro $\mathrm{n}$ e vetor de inteiros vet e que devolve 1 se os elementos em vet[] estão em ordem crescente e 0 em caso contrário (ou seja, se vet[0] < vet[1] < ..< vet[n-1], devolve 1 e em qualquer outra configuração devolve 0$)$. 2. Fazer um programa principal no qual o usuário digita $n>0$, seguido de $n$ valores inteiros que são armazenados em um vetor (que poderá ter até 40 elementos). Usando a função do item 1, seu programa deve imprimir 1 se o vetor está em ordem crescente e 0 em caso contrário.

\section{EXERCÍCIO 13.1}

Fazer um programa no qual o usuário digita inteiros positivos $m$ e $n(m>0, n>0)$, seguido de $m \times n$ valores reais (float), que deverão ser armazenados em uma matriz de ordem $\mathrm{m} \times \mathrm{n}$. Depois seu programa deve imprimir cada linha, seguido do sinal de "=" e a soma da linha, começando pela linha 0 , depois linha 1 e assim por diante. Assim, deve-se primeiro imprimir o valor de $\mathrm{M}[0][0]$, seguido por $\mathrm{M}[0][1]$ e assim por diante até o último da linha (M[0][n-1]) e então o sinal de igual e a soma da linha zero. Depois seguem as linhas 2, 3 até m-1. 



\section{Apêndice D}

\section{Sugestões de Soluções para Professores e Alunos}

Abaixo são apresentadas as descrições detalhadas das soluções para professores e alunos mencionadas nos catálogos dos antipadrões.

\section{PARA PROFESSORES}

\section{Explicação usando quadro negro e projetor - reforço dos conceitos usando Kahoot $^{1}$ (plataforma de aprendizado baseada em jogos)}

Uma sugestão de como o professor poderia proceder em sala para tratar esse erro, evitando que ele seja uma dificuldades com seus alunos seria:

1. leve para a sala de aula códigos com antipadrões dos conteúdos abordados até o momento, tendo no máximo um erro por linha;

2. projete para os alunos;

3. peça que apontem um dos erros;

4. peça se alguém da sala poderia explicar quais as consequências da existência desse erro no programa;

5. reforce a explicação, se possível, dando mais exemplos do mesmo erro apontado;

6. explique a forma correta daquela linha/comando, sem o erro;

7. reescreva a linha no quadro, sem o erro, ou faça que a correção apareça no slide;

8. repita os passos 3 ao 7 enquanto houver erro no código; Em seguida:

9. projete a senha do quiz preparado no "kahoot" e peça que cada aluno se conecte com seu celular;

10. comece a "brincadeira" apresentando códigos com ou sem erros e os alunos tendo que escolher a opção correta;

11. divirtam-se com os resultados;

12. ao terminar, apresente os resultados e retome os exercícios que os alunos mais tiveram dificuldade.

P.S: O professor terá um rico material pois saberá onde os alunos ainda têm dificuldades, podendo

\footnotetext{
${ }^{1}$ Kahoot! é uma plataforma de aprendizado baseada em jogos, usada como tecnologia educacional em escolas e outras instituições de ensino. Os jogos são testes de múltipla escolha que permitem a geração de usuários e podem ser acessados por meio de um navegador da Web ou do aplicativo Kahoot.
} 
assim trabalhar melhor esses pontos em sala.

\section{Grupos trabalhando com execução passa a passo para entender os erros - reforço com exercícios}

Uma sugestão de como o professor poderia proceder em sala para tratar esse erro, evitando que ele seja uma dificuldades com seus alunos seria:

1. monte equipes de 2 ou 3 alunos;

2. entregue para as equipes códigos com o erro. Não necessariamente o mesmo código para todas as equipes;

3. peça para fazerem uma execução passo a passo do código apresentado;

4. em seguida, chame uma equipe para mostrar aos colegas o que eles encontraram e mostrarem também como chegaram no resultado;

5. peça aos demais se os que tem o mesmo exercício tiveram resultados diferentes. Se sim, peça que apresentem para a turma;

6. agora você (professor), usando de recursos visuais, simulando memória, por exemplo, mostre, corrija ou reforce o que foi apresentado;

7. repita os passos 3 a 6 caso tenha mais de um tipo de exercício;

8. dê exercícios para eles resolverem no qual eles pudessem cometer os erros comentados anteriormente;

9. peça que resolvam no quadro, assim você poderá corrigir caso ainda cometam.

\section{Programar na frente dos alunos, fazendo o erro aparecer - reforço pedindo que os alunos desenvolvam novos códigos}

Uma sugestão de como o professor poderia proceder em sala para tratar esse erro, evitando que ele seja uma dificuldades com seus alunos seria:

1. escolha um exercício em que o erro que você quer tratar pudesse acontecer;

2. vá para o quadro e faça um esboço superficial do que o código precisa fazer e em qual sequência;

3. use o projetor para então começar a programar na frente dos alunos;

4. faça o erro aparecer;

5. compile e peça que dêem sugestões de como o código poderia ser corrigido;

6. teste cada sugestão e explique se necessário os motivos que o fizeram não funcionar;

7. termine com o código funcionando projetado para os alunos verem;

8. dê mais um exercício para eles resolverem;

9. chame um aluno para desenvolver seu código direto no projetor;

10. vá explicando o que está acontencendo no momento em que o aluno está digitando;

11. repita os passos 8 ao 10 quantas vezes desejar, usando assim a prática intensiva para o aprendizado.

\section{Aplicar teste de mesa em um Código com o erro e outro sem, comparar os resultados - reforço pedindo que os alunos resolvam alguns exercícios}

Uma sugestão de como o professor poderia proceder em sala para tratar esse erro, evitando que ele seja uma dificuldades com seus alunos seria:

1. mostre um exemplo do erro ao aprendiz. Certifique-se de que o único problema no seu exemplo é aquele que você deseja tratar;

2. deixe bem claro, sinalizando o problema com círculo colorido ou seta; 
3. explique porque está errado;

4. faça um teste de bancada (teste de mesa) mostrando o que acontece;

5. arrume o código, e refaça o teste de bancada (teste de mesa);

6. compare o resultado;

7. certifique-se que o aprendiz entendeu pedindo que ele faça um ou dois exercícios iguais a esse, porém com outros trechos de códigos;

8. corrija na sala de aula, na presença dos aprendizes.

\section{PARA ALUNOS}

\section{Resolver exercícios, acrescentar erros nos códigos e pedir que o colega de sala os encontrem}

Uma forma de estudar esse antipadrão para evitá-lo no desenvolvimento dos seus códigos seria: Observação: É importante que esteja estudando com pelo menos um amigo e que tenham computador para desenvolver o exercício.

1. estudem alguns antipadrões de um determinado conteúdo;

2. escolham exercícios parecidos, que será necessáro usar o que se está estudando, para cada um resolver;

3. após os exercícios estarem prontos, resolvidos sem erros e dando os resultados esperados, cada um vai copiar seus códigos para o papel, atribuindo erros, sendo que cada um defini a quantidade de erros que quer colocar;

4. troquem os papéis;

5. corrijam o exercício do colega marcando os erros encontrados;

6. ao terminarem, confira com o colega que resolveu o exercício se algo passou despercebido ou se todos os erros foram encontrados;

7. cada um explica a resolução do exercício que fez para o outro, mostrando onde teve dificuldade e como resolveu.

\section{Estude um ou mais antipadrões, apresente ao colega de sala e reforce com exercício}

Uma forma de estudar esse antipadrão para evitá-lo no desenvolvimento dos seus códigos seria: Observação: É importante que esteja estudando com pelo menos um colega.

1. escolha um assunto estudado em sala, e defina uma parte desse assunto para cada um explicar;

2. cada um vai estudar esse conteúdo, montar uma rápida apresentação e procurar exemplos que ilustrem suas explicações;

3. busque pelo menos 1 exercício para ser resolvido após você ter feito a apresentação;

4. escolham de quem é a vez de apresentar;

5. começa a apresentação. A explicação deverá sanar as dúvidas de todos. Apresente o(s) possíveis equívocos (antipadrões) que possam ocorrer. Caso fiquem dúvidas, todos podem ajudar a buscar respostas que as solucione, caso o apresentador não saiba;

6. dê o enunciado do exercício escolhido e peçam que o(s) colega(s) resolva(m);

7. corrijam juntos fazendo o teste de mesa das soluções encontradas;

8. analisem o que aconteceria se o antipadrão existisse no código;

9. repita os passos 4 ao 9 quantas vezes forem necessárias para que todos apresentem suas 
partes.

\section{Introduzir o erro em um código e entender as consequências que ele gera.}

Uma forma de estudar esse antipadrão para evitá-lo no desenvolvimento dos seus códigos seria:

Observação: É importante que tenha computador para desenvolver o exercício.

1. copie para o ambiente de desenvolvimento o código de algum exercício resolvido em sala ou copiado de livros ou internet, onde o erro (antipadrão) possa ser inserido;

2. execute o programa e entenda o que ele está fazendo;

3. insira o erro (antipadrão) no código e tente executá-lo novamente;

4. em caso de erro de compilação, preste atenção em como o compilador apresenta esse erro, assim você terá mais facilidade de entender o que o compilador está apontando em eventual erro cometido;

5. caso o programa execute, preste atenção em como os resultados são apresentados, procurando entender onde o erro se encontra e como ele se comportou;

6. faça isso com vários exercícios até ter certeza que entendeu o antipadrão. 


\section{Apêndice E}

\section{Catálogo de Antipadrões em C}

A seguir é apresentado o catálogo de Antipadrões encontrados em C.

\section{CATÁLOGO DE ANTIPADRÕES EM C}

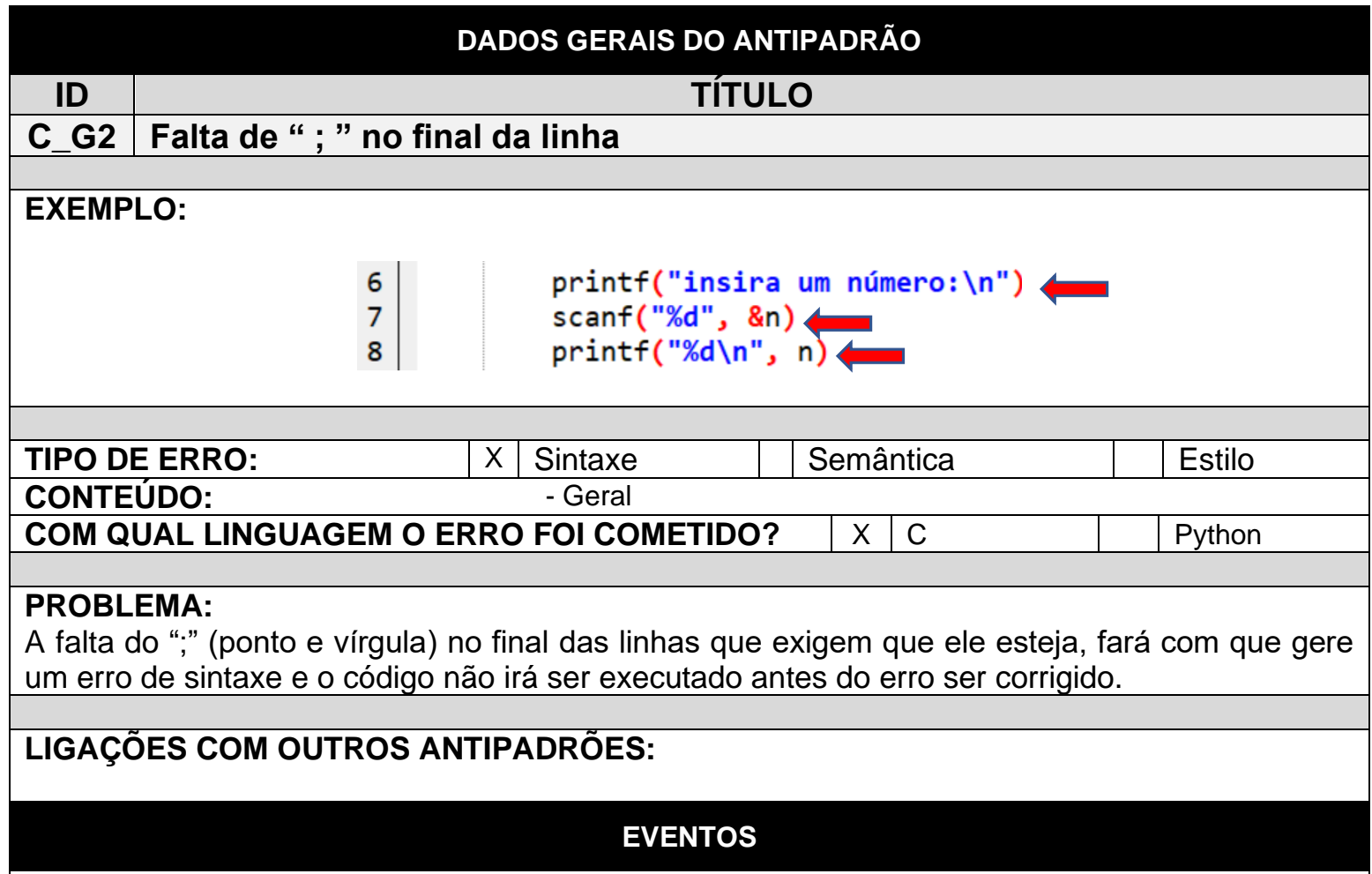

Observação: Nos trechos de códigos apresentados abaixo, foram analisadas apenas questão quanto ao antipadrão dessa tabela. Se outros erros existem, esses erros foram tratados em outros antipadrões. 
EVENTO 1

Id do aluno: 2558

Quantidade total de submissões do exercício:

3

Exercício que estava sendo resolvido:

Exercício 1.1

\section{Erro}

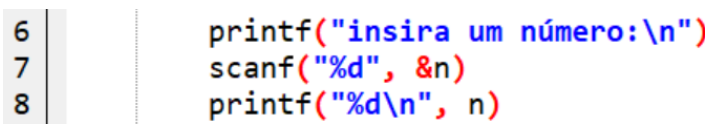

Ocorreu na submissão: 1

Observação:

Id do aluno: 2719
Exercício que estava sendo resol
Exercício 1.1
\[ 5 \mid \text { int num } \]

Ocorreu na submissão: 1

Observação:

Id do aluno: 4738
Exercício que estava sendo resolvido:
Exercício 1.1
Erro
$7 \mid \quad$ printf("Digite um numero inteiro: ")

Ocorreu na submissão: 2

Observação:

Id do aluno: 5242
Exercício que estava sendo resolvido:
Exercício 7.2
\[ \begin{array}{l}\mathrm{x}=\mathrm{h}^{*} \mathrm{x} \\ \mathrm{h}=\mathrm{x}\end{array} \]
11
12

Ocorreu na submissão: 9

Observação:

(1)

\section{Erro Resolvido}

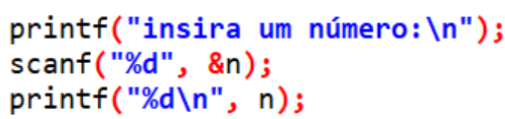

Corrigido na submissão: 2

Observação:

\section{EVENTO 2}

Quantidade total de submissões do exercício:

3

-

\section{Erro Resolvido}

5 int num;

Corrigido na submissão: 2

Observação:

\section{EVENTO 3}

Quantidade total de submissões do exercício:

3




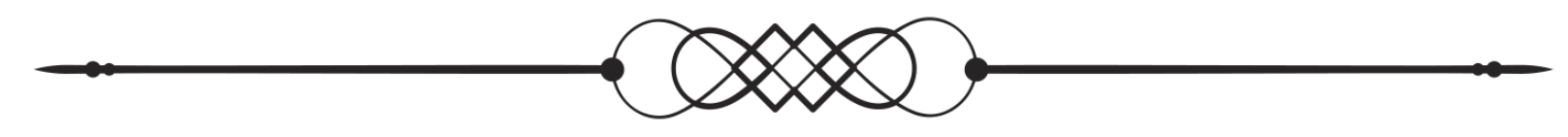

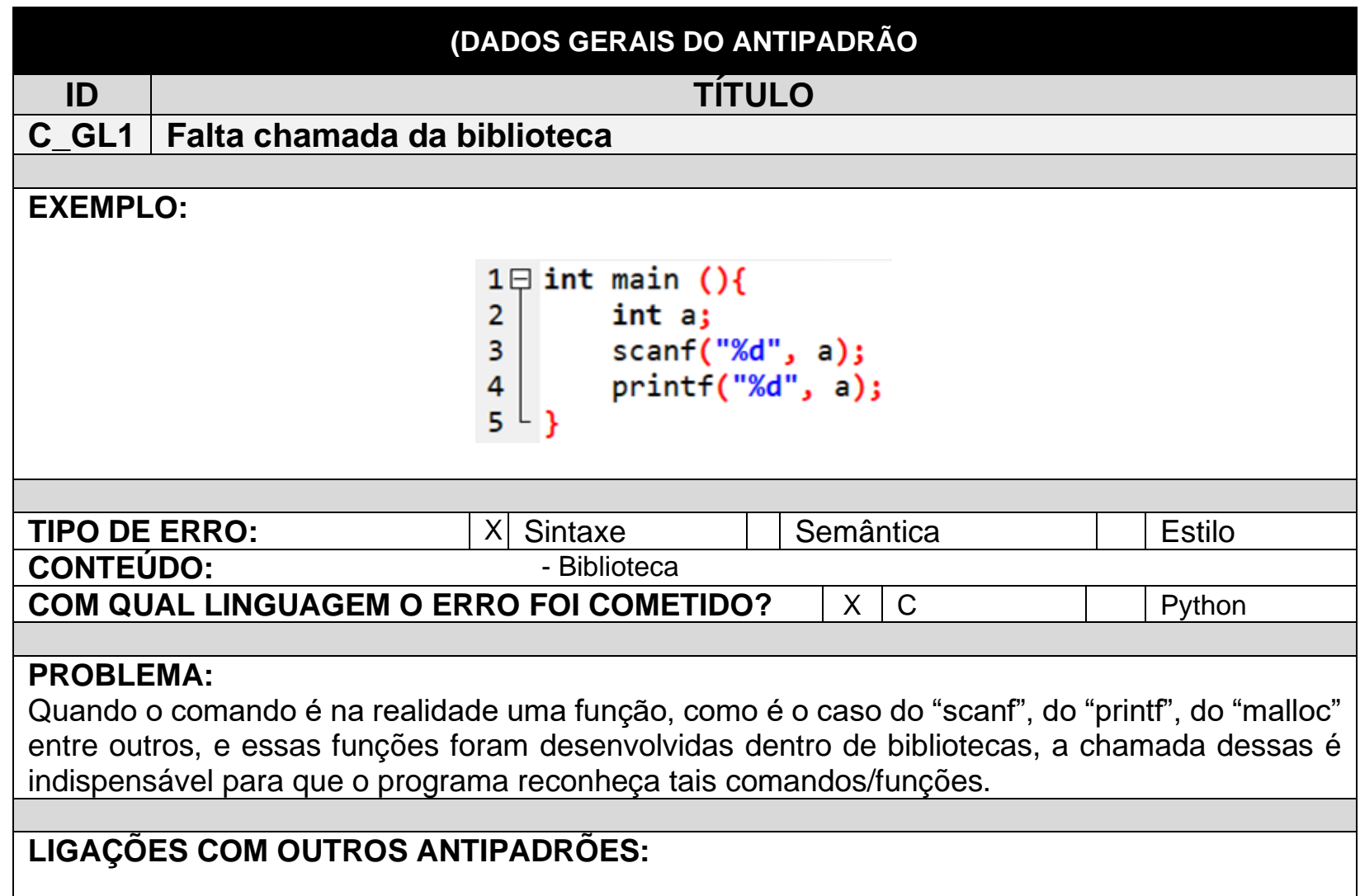

\section{EVENTOS}

Observação: Nos trechos de códigos apresentados abaixo, foram analisadas apenas questão quanto ao antipadrão dessa tabela. Se outros erros existem, esses erros foram tratados em outros antipadrões.

Id do aluno: 2670

EVENTO 1

Exercício que estava sendo resolvido:

Exercício 1.1

\section{Erro \\ 1甲 int main () \{}

\section{Ocorreu na submissão: 1}

Observação: $O$ código não compila. Falta a chamada da biblioteca que contem as funções de Entrada e Saída.

\section{Quantidade total de submissões do exercício: 4}

\section{Erro Resolvido}

1 \# include 〈stdio.h〉

$2 \boxminus$ int main () \{

Corrigido na submissão: 3

Observação: 
EVENTO 2

Id do aluno: $3167 \quad$ Quantidade total de submissões do exercício: 8

Exercício que estava sendo resolvido:

Exercício 1.1

\section{Erro}

1 \#include int main () \{

2 int $b=a$;

$3 \quad \operatorname{sacnf}(" \% d ", b)$;

Ocorreu na submissão: 1

Observação:

Id do aluno: 2040

Exercício que estava sendo resolvido:

Exercício 2.1

\section{Erro}

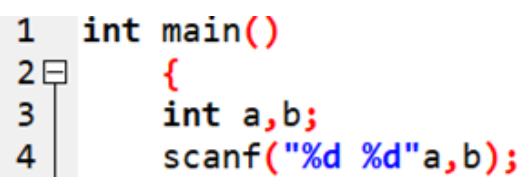

Ocorreu na submissão: 1

Observação:

Id do aluno: 5226

Exercício que estava sendo resolvido

Exercício 3.3

\section{Erro}

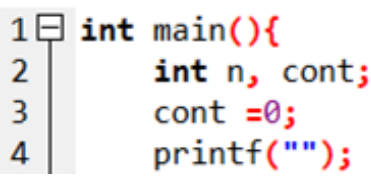

Ocorreu na submissão: 1

Observação:

\section{Erro Resolvido}

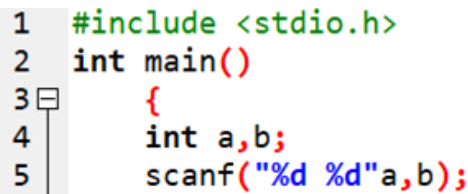

Corrigido na submissão: 3

Observação:

\section{EVENTO 4}

Quantidade total de submissões do exercício: 11

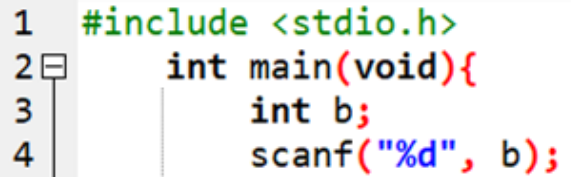

Corrigido na submissão: 6 Observação:

\section{EVENTO 3}

Quantidade total de submissões do exercício:

8

\section{Erro Resolvido}

UMA SUGESTÃO DE SOLUÇÃO

PARA O PROFESSOR

Explicação usando quadro negro e projetor - fixar os conceitos usando Kahoot (plataforma de aprendizado baseada em jogos)

\section{PARA O ALUNO}

Resolver exercícios, acrescentar erros nos códigos e pedir que o colega de sala os encontrem 


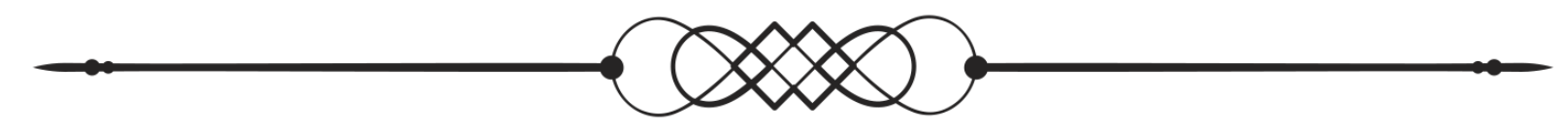

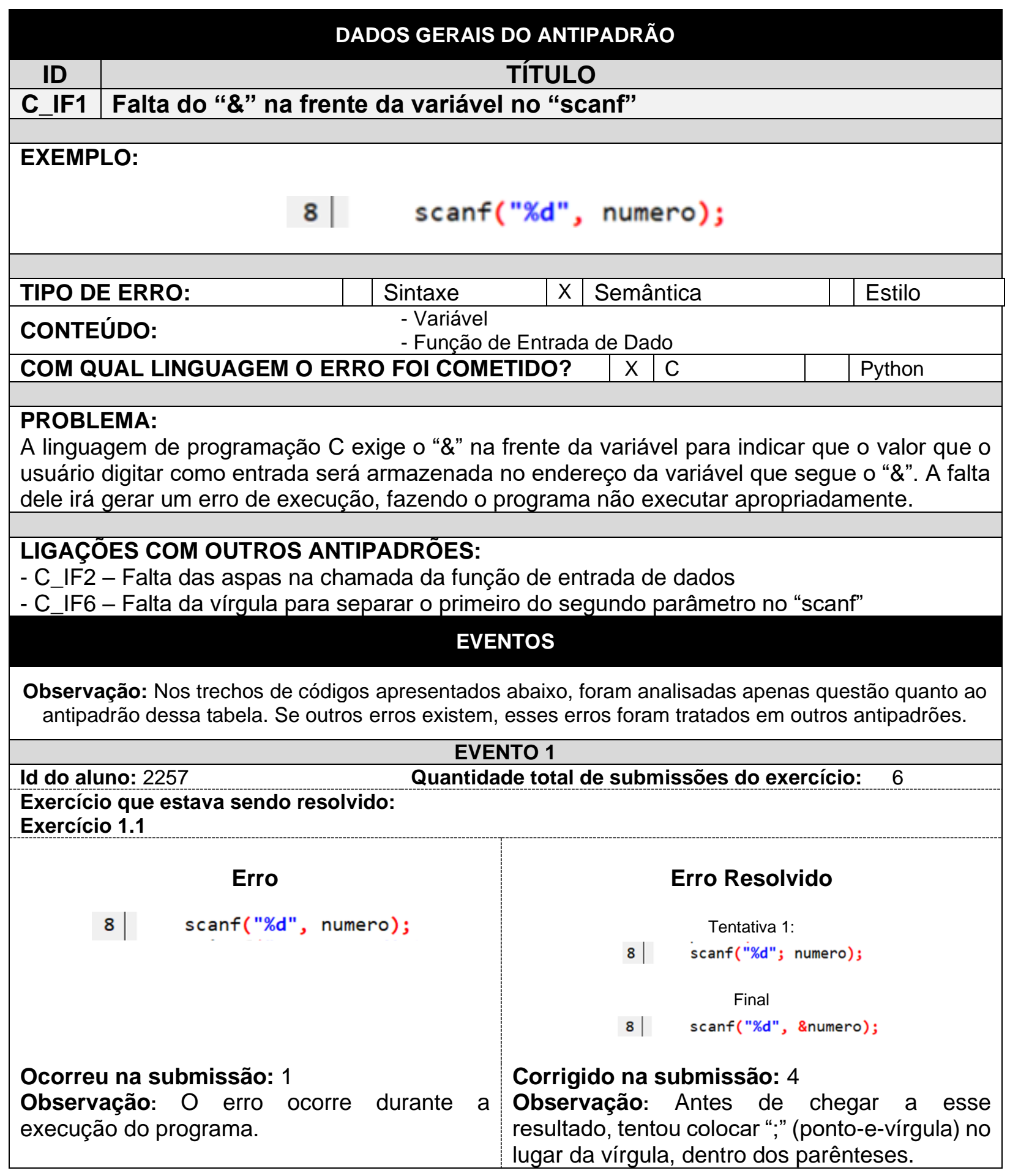


EVENTO 2

Id do aluno: 2670

Quantidade total de submissões do exercício:

Exercício que estava sendo resolvido:

Exercício 1.1

\section{Erro}

$$
3 \text { | scanf("\%d", a); }
$$

Ocorreu na submissão: 1

Observação:

Id do aluno: 2719

Exercício que estava sendo resolvido:

Exercício 1.1

$$
\begin{aligned}
& \text { Erro } \\
& 7 \text { scanf("\%d", num); }
\end{aligned}
$$

Ocorreu na submissão: 1

Observação:

Id do aluno: 1781

Exercício que estava sendo resolvido:

Exercício 2.1

$$
\begin{gathered}
\text { Erro } \\
5 \text { scanf( }(" \% d, \% d ", a, b) \text {; }
\end{gathered}
$$

Ocorreu na submissão: 1 Observação:

\section{Erro Resolvido}

3 scanf("\%d", \&a);

Corrigido na submissão: 2 Observação:

\section{EVENTO 3}

Quantidade total de submissões do exercício: 3

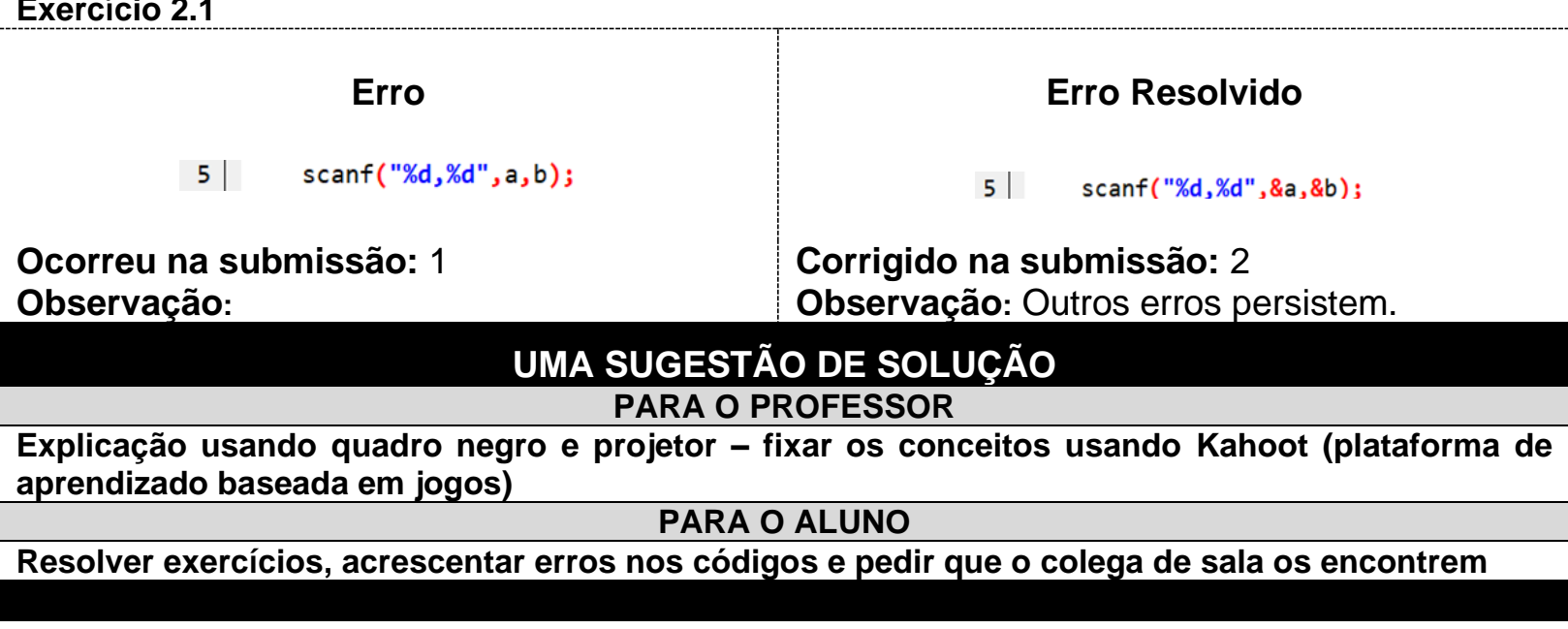

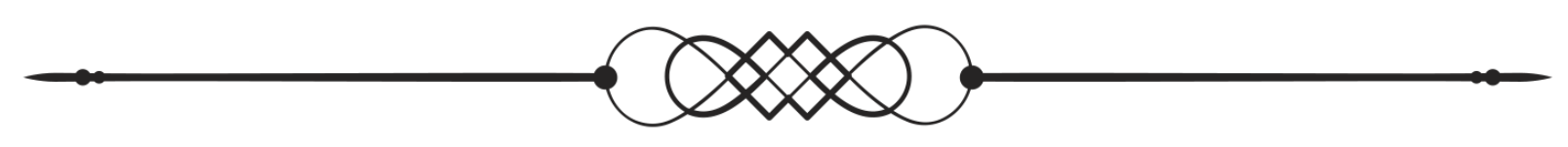

\section{PARA O PROFESSOR}

Explicação usando quadro negro e projetor - fixar os conceitos usando Kahoot (plataforma de aprendizado baseada em jogos)

Resolver exercícios, acrescentar erros nos códigos e pedir que o colega de sala os encontrem

\section{EVENTO 4}

Quantidade total de submissões do exercício: 3

\section{Erro Resolvido}

$7 \mid \quad \operatorname{scanf}(" \% d "$, \&num);

Corrigido na submissão: 3

Observação:

Observação: Outros erros persistem. 


\begin{tabular}{|c|c|c|c|}
\hline \multicolumn{4}{|c|}{ DADOS GERAIS DO ANTIPADRÃO } \\
\hline ID & \multicolumn{3}{|c|}{ TITULO } \\
\hline C_IF6 & \multicolumn{3}{|c|}{ Falta vírgula para separar o primeiro do segundo parâmetro no "scanf" } \\
\hline \multicolumn{4}{|c|}{ EXEMPLO: } \\
\hline \multicolumn{4}{|c|}{$4 \quad \operatorname{scanf}(" \% d \% d " a, b)$; } \\
\hline \multicolumn{2}{|c|}{ TIPO DE ERRO: } & Semântica & Estilo \\
\hline \multicolumn{4}{|c|}{$\begin{array}{l}\text { - Função de Entrada de Dado } \\
\text { - Função: declaração dos parâmetros }\end{array}$} \\
\hline \multicolumn{2}{|c|}{ COM QUAL LINGUAGEM O ERRO FOI COMETIDO? } & \begin{tabular}{|l|l|l|} 
& $X$ & $C$ \\
\end{tabular} & Python \\
\hline \multicolumn{4}{|c|}{$\begin{array}{l}\text { PROBLEMA: } \\
\text { Esse erro impede que o programa seja executado pois pela regra de escrita, os parâmetro } \\
\text { precisam ser separados por uma vírgula. }\end{array}$} \\
\hline \multicolumn{4}{|c|}{$\begin{array}{l}\text { LIGAÇÕES COM OUTROS ANTIPADRÕES: } \\
\text { - C_IF1 - Falta do "\&" na frente da variável no "scanf" } \\
\text { - C_IF2 - Falta das aspas na chamada da função de entrada de dados } \\
\text { - C_F9 - Declaração incorreta dos parâmetros da função }\end{array}$} \\
\hline
\end{tabular}

Observação: Nos trechos de códigos apresentados abaixo, foram analisadas apenas questão quanto ao antipadrão dessa tabela. Se outros erros existem, esses erros foram tratados em outros antipadrões.

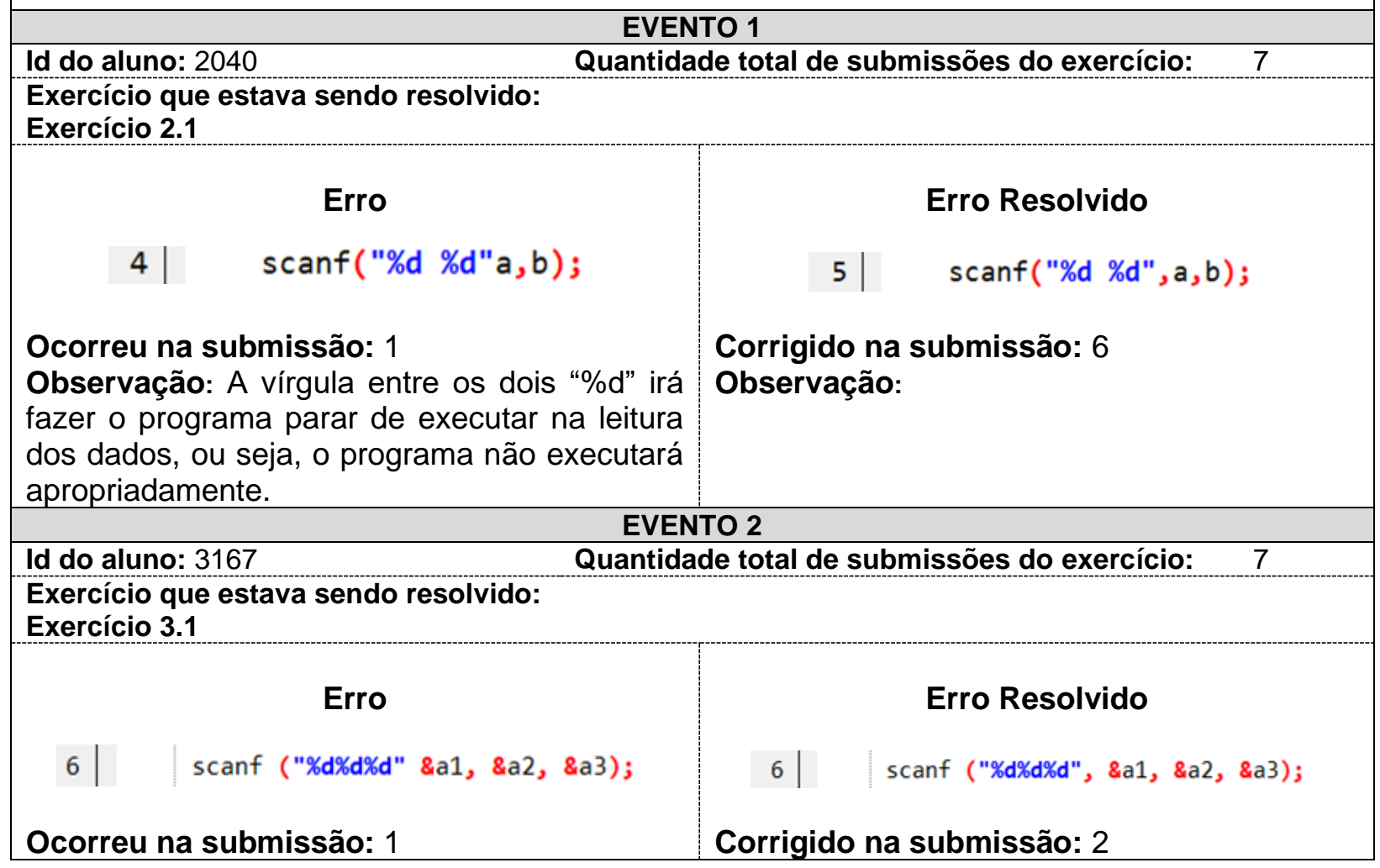


Observação:

\begin{tabular}{l} 
Id do aluno: 2810 \\
$\begin{array}{l}\text { Exercício que estava sendo resolvido: } \\
\text { Exercício 3.1 }\end{array}$ \\
\hline \multicolumn{2}{c}{ Euanto } \\
$7 \mid \quad$ scanf( "\%d \%d \%d" \&x, \&y, \&z);
\end{tabular}

Ocorreu na submissão: 1

Observação:

\section{Observação: \\ EVENTO 3}

uantidade total de submissões do exercício: 2

.

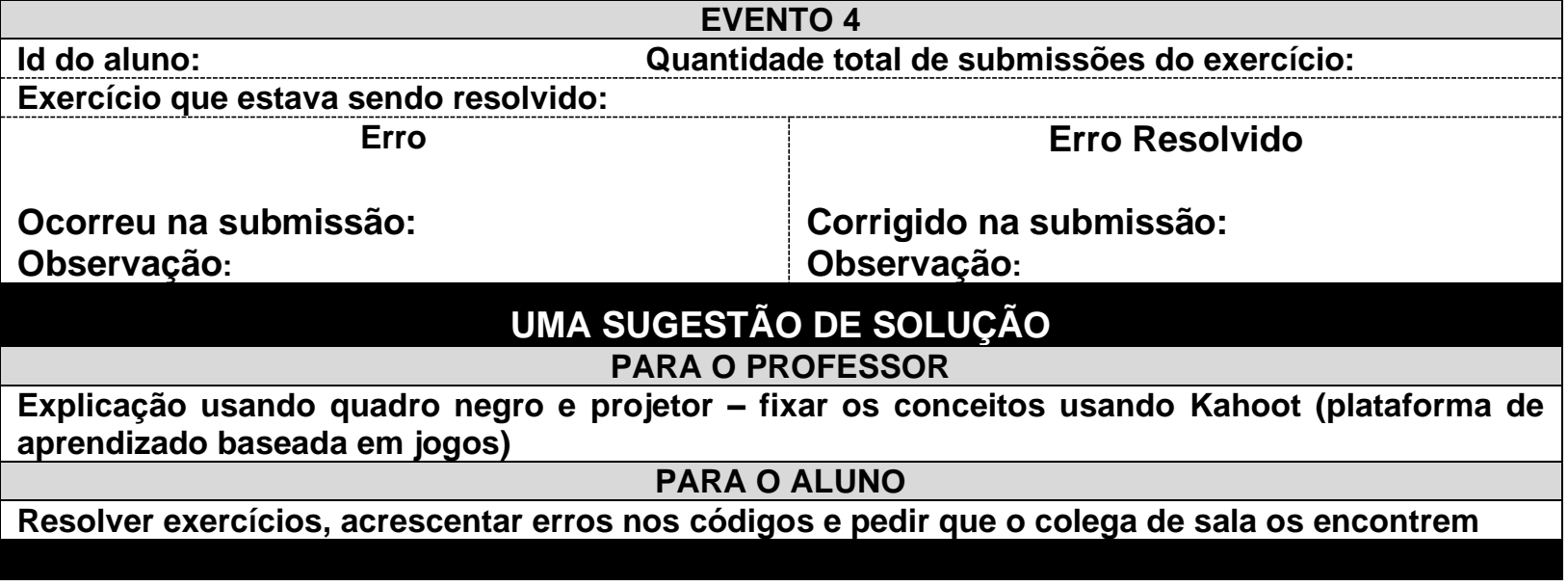

\section{Erro Resolvido}

7 | $\quad \operatorname{scanf}(" \% d \% d \% d ", 8 x, 8 y, 8 z)$;

Corrigido na submissão: 2

Observação:

\section{EVENTO 4}

\section{Quantidade total de submissões do exercício:}

\section{sendo resolvido:}

\section{E}




\section{PROBLEMA:}

O programa será executado, porém o resultado não será o esperado pois será impresso o endereço da variável que segue o \& e não o valor armazenado dentro dela.

\section{LIGAÇÕES COM OUTROS ANTIPADRÕES:}

- C_OF2 - Escrita incorreta do comando "printf"

- C_OF3 - Falta das aspas na função de saída de dados

- C_OF4 - Uso do "\&" no lugar do "\%" na função de saída de dados

- C_OF5 - Parâmetro que identifica o tipo de dado de saída incorreto ou inexistente

- C_OF6 - Falta da vírgula para separar o primeiro do segundo parâmetro na função de saída de dados

\section{EVENTOS}

Observação: Nos trechos de códigos apresentados abaixo, foram analisadas apenas questão quanto ao antipadrão dessa tabela. Se outros erros existem, esses erros foram tratados em outros antipadrões.

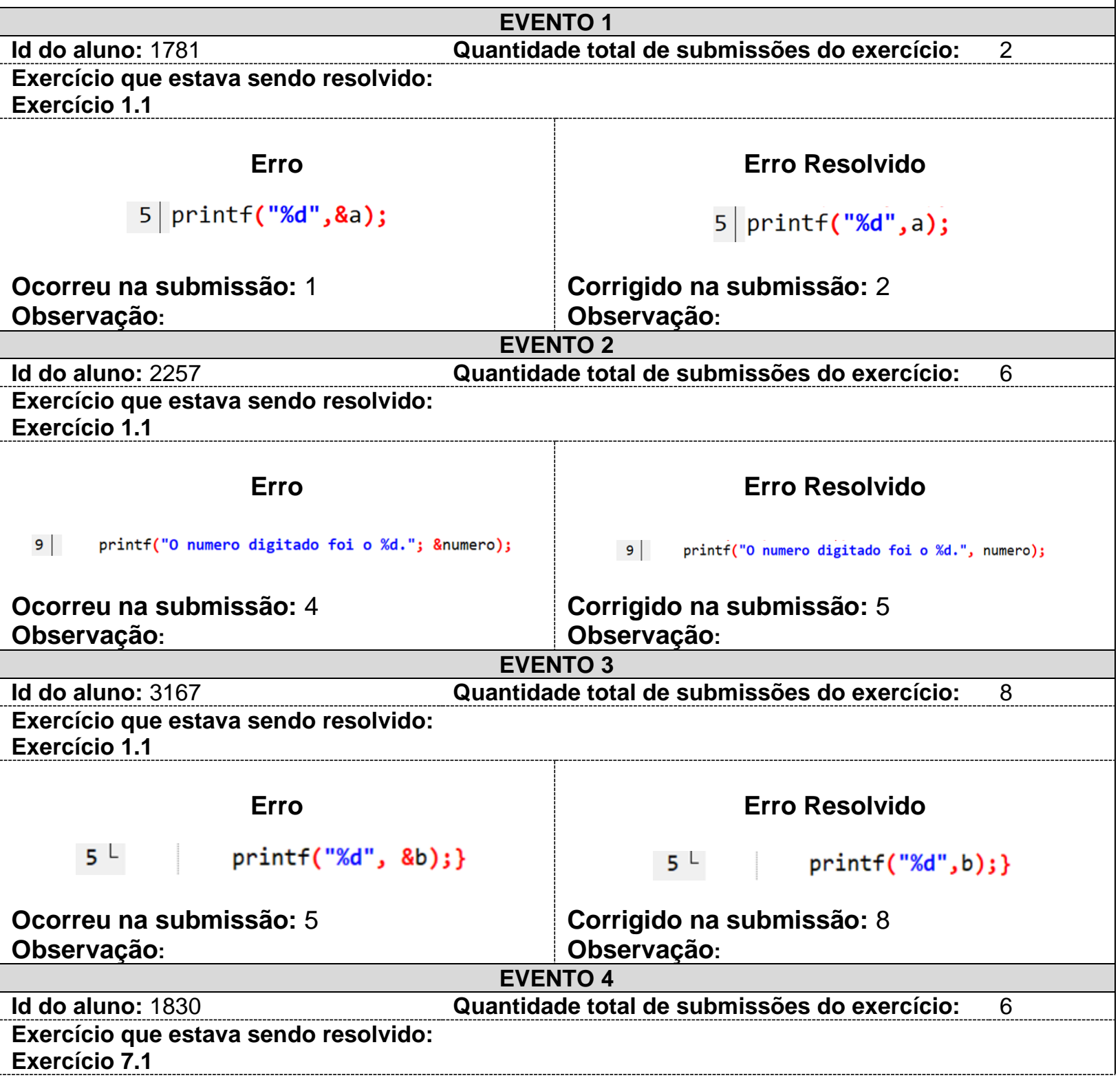




\section{Erro}

9 printf("\%f", \&soma);

Ocorreu na submissão: 3 Observação:

\section{Erro Resolvido}

9 | $\quad \operatorname{printf("\% f",~soma);~}$

Corrigido na submissão: 4

Observação:

\section{UMA SUGESTÃO DE SOLUÇÃO} PARA O PROFESSOR

Explicação usando quadro negro e projetor - fixar os conceitos usando Kahoot (plataforma de aprendizado baseada em jogos)

PARA O ALUNO
Resolver exercícios, acrescentar erros nos códigos e pedir que o colega de sala os encontrem

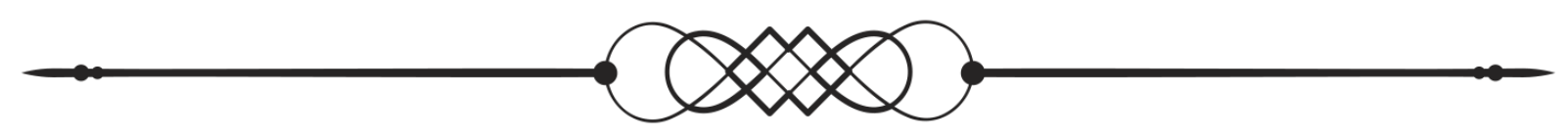

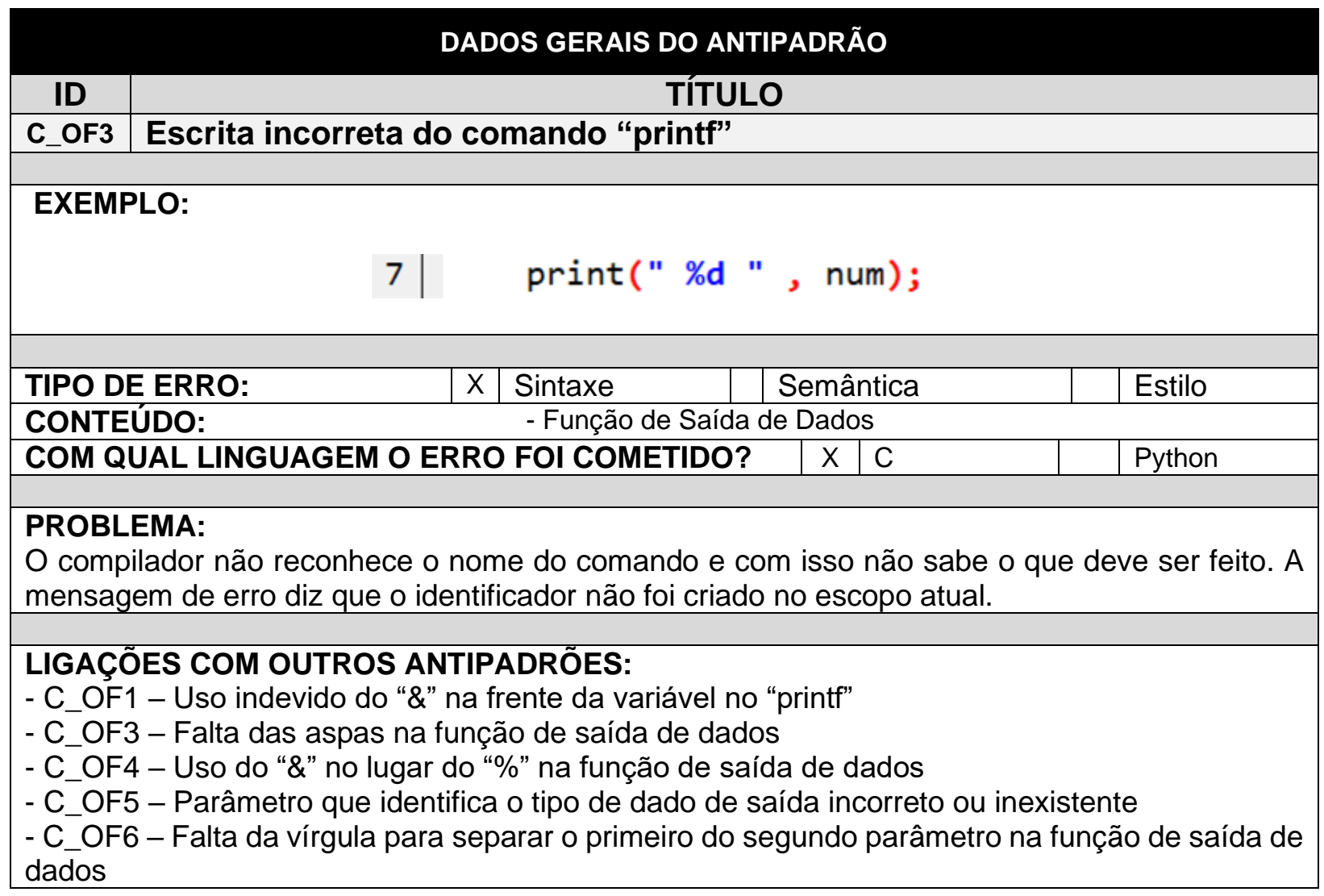




\section{EVENTOS}

Observação: Nos trechos de códigos apresentados abaixo, foram analisadas apenas questão quanto ao antipadrão dessa tabela. Se outros erros existem, esses erros foram tratados em outros antipadrões.

\begin{tabular}{|c|c|}
\hline \multicolumn{2}{|c|}{ EVENTO 1} \\
\hline Id do aluno: 2243 & de total de submissões do exercício: \\
\hline \multicolumn{2}{|l|}{$\begin{array}{l}\text { Exercício que estava sendo resolvido: } \\
\text { Exercício } 1.1\end{array}$} \\
\hline Erro & Erro Resolvido \\
\hline $7 \mid \quad \operatorname{print}(" \% d "$, num); & " \%d ", num); \\
\hline $\begin{array}{l}\text { Ocorreu na submissão: } 2 \\
\text { Observação: }\end{array}$ & $\begin{array}{l}\text { Corrigido na submissão: } 3 \\
\text { Observação: }\end{array}$ \\
\hline \multicolumn{2}{|c|}{ EVENTO 2} \\
\hline \multirow{2}{*}{\multicolumn{2}{|c|}{$\begin{array}{l}\text { Id do aluno: } 3430 \\
\text { Exercício que estava sendo resolvido: }\end{array}$}} \\
\hline & \\
\hline Erro & Erro Resolvido \\
\hline $7 \mid \quad \operatorname{prinft}(" \% d ", \& n) ;$ & $7 \mid \quad$ printf("\%d", \&n); \\
\hline $\begin{array}{l}\text { Ocorreu na submissão: } 1 \\
\text { Observação: }\end{array}$ & $\begin{array}{l}\text { Corrigido na submissão: } 2 \\
\text { Observacão: }\end{array}$ \\
\hline \multicolumn{2}{|c|}{ EVENTO 3} \\
\hline Id do aluno: 3300 & ide total de submissões do exercício: \\
\hline \multicolumn{2}{|l|}{$\begin{array}{l}\text { Exercício que estava sendo resolvido: } \\
\text { Exercício } 3.1\end{array}$} \\
\hline Erro & Erro Resolvido \\
\hline $15 \mid \quad \operatorname{print}(" S I M \% d \% d \% d ", a, b, c)$; & printf("SIM \%d \%d \%d", a, b, c); \\
\hline $\begin{array}{l}\text { Ocorreu na submissão: } 1 \\
\text { Observação: }\end{array}$ & $\begin{array}{l}\text { Corrigido na submissão: } 2 \\
\text { Observação: }\end{array}$ \\
\hline \multicolumn{2}{|c|}{ EVENTO 4} \\
\hline Id do aluno: 5242 & de total de submissões do exercício: \\
\hline \multicolumn{2}{|l|}{$\begin{array}{l}\text { Exercício que estava sendo resolvido: } \\
\text { Exercício } 3.3\end{array}$} \\
\hline Erro & Erro Resolvido \\
\hline print ( soma ) & \\
\hline $\begin{array}{l}\text { Ocorreu na submissão: } 8 \\
\text { Observação: }\end{array}$ & $\begin{array}{l}\text { Corrigido na submissão: } \\
\text { Observação: Erro não foi corrigido. }\end{array}$ \\
\hline
\end{tabular}




\section{UMA SUGESTÃO DE SOLUÇÃO PARA O PROFESSOR}

Explicação usando quadro negro e projetor - fixar os conceitos usando Kahoot (plataforma de aprendizado baseada em jogos)

\begin{tabular}{|c|}
\hline PARA O ALUNO \\
\hline Resolver exercícios, acrescentar erros nos códigos e pedir que o colega de sala os encontrem \\
\hline
\end{tabular}

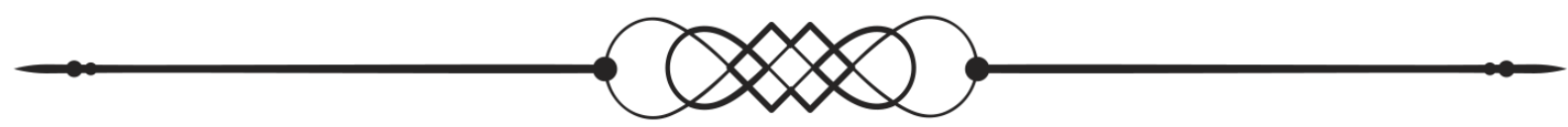

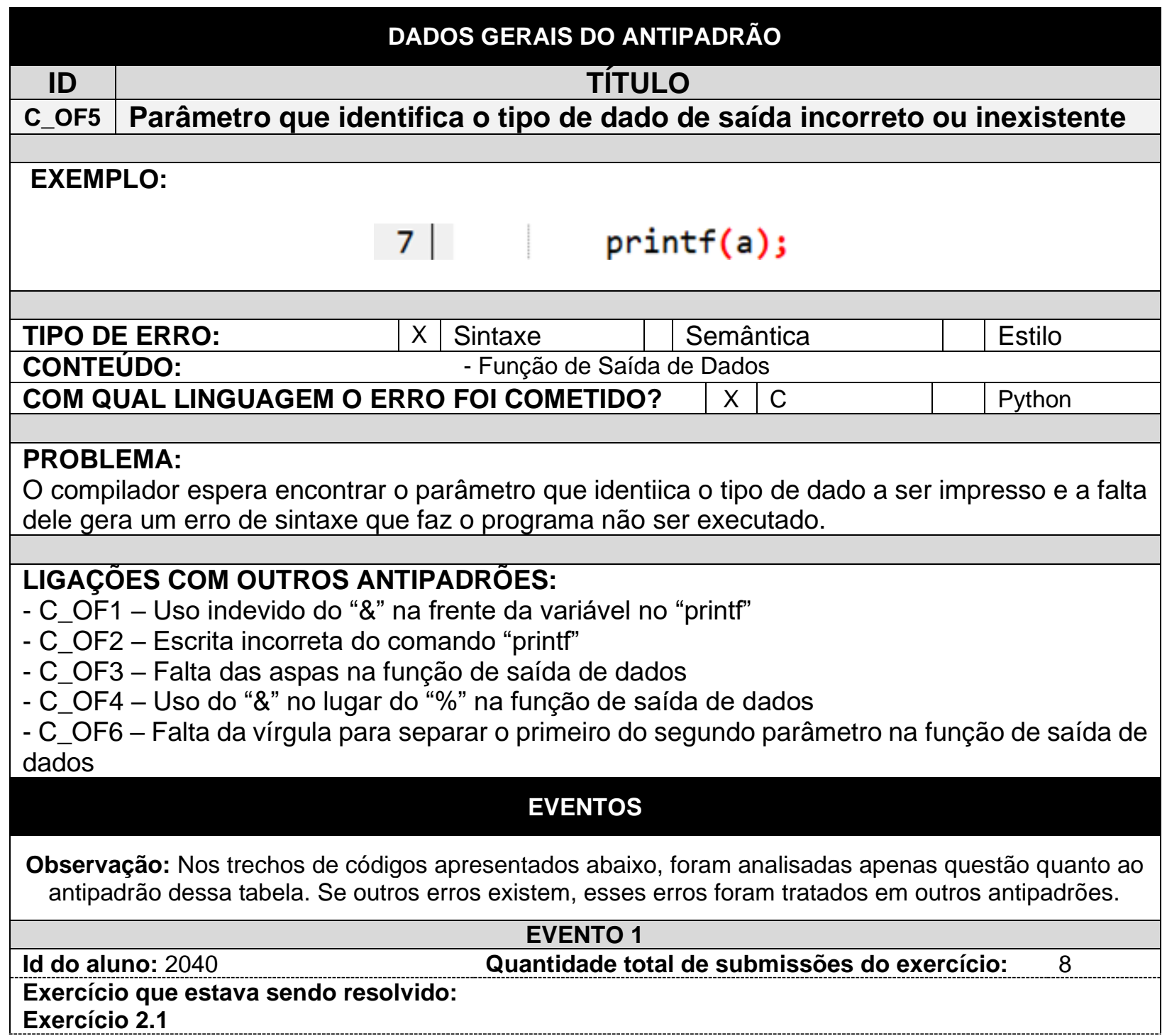




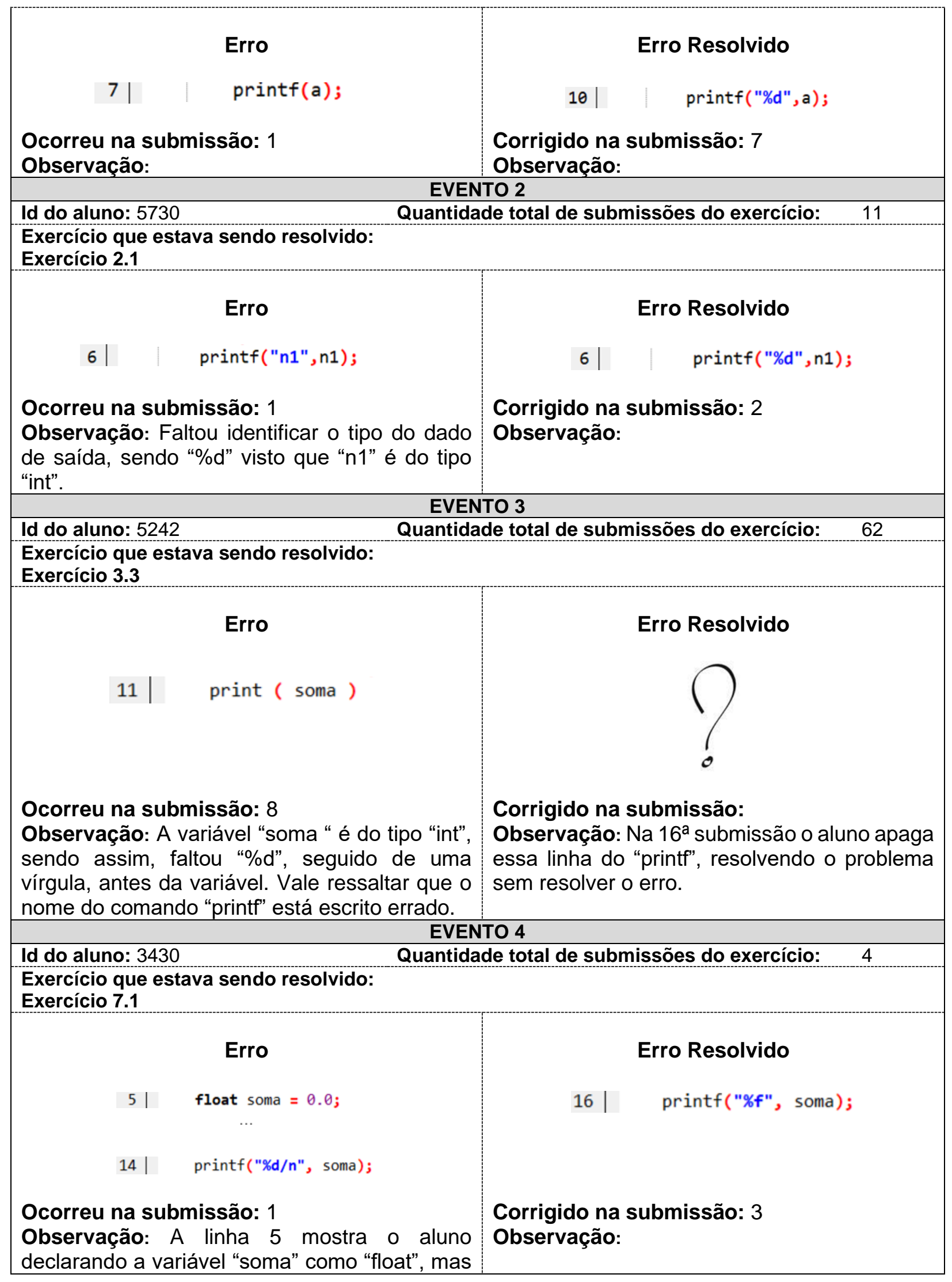




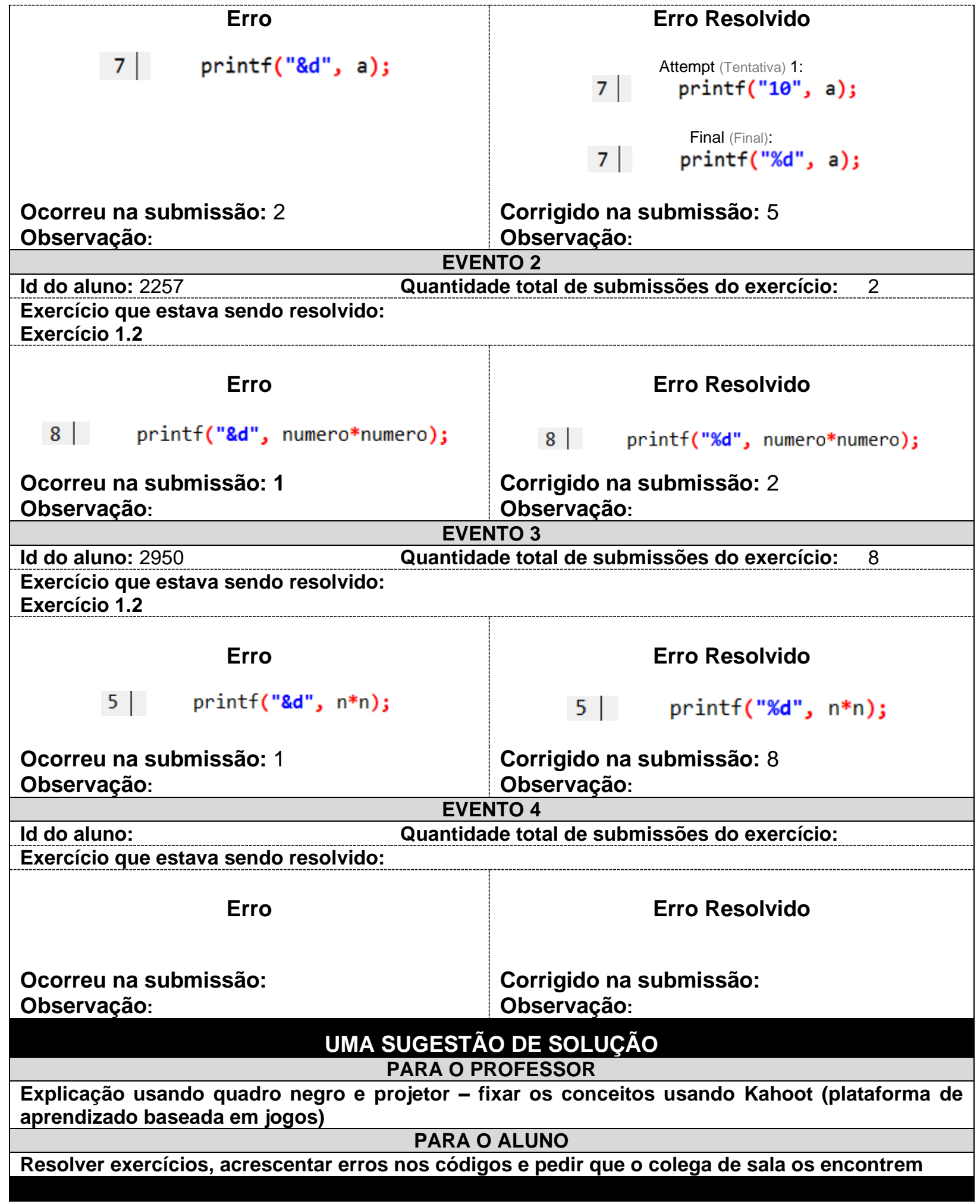




\section{DADOS GERAIS DO ANTIPADRÃO}

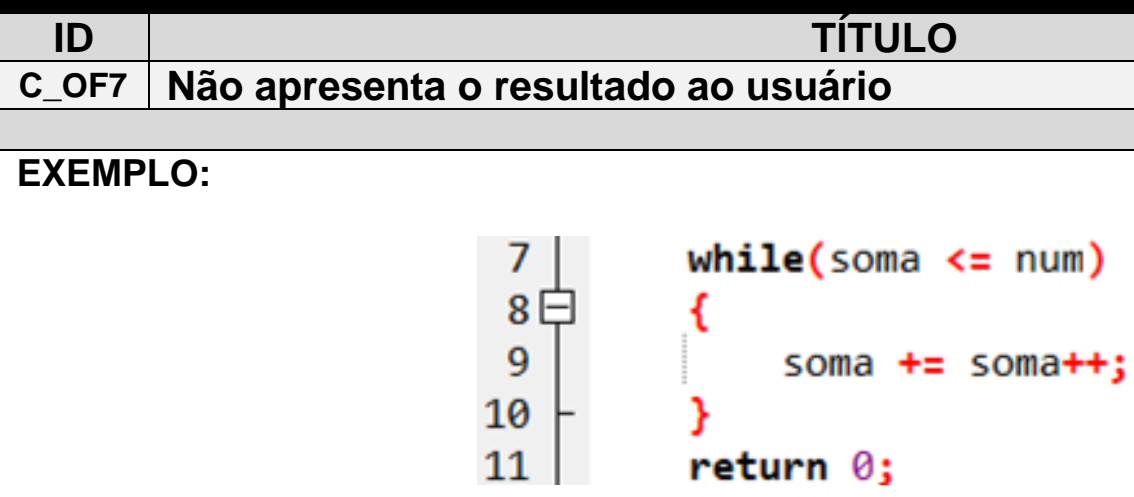

\begin{tabular}{|l|l|l|l|l|}
\hline TIPO DE ERRO: & Sintaxe & $\mathrm{X}$ & Semântica & Estilo \\
\hline CONTEÚDO: & - Geral \\
& - Função de Saída de Dados
\end{tabular}

\begin{tabular}{|c|c|c|c|}
\hline COM QUAL LINGUAGEM O ERRO FOI COMETIDO? & & $\mathrm{C}$ & Python \\
\hline
\end{tabular}

PROBLEMA:

O programa irá executar, porém o resultado não será apresentado ao usuário.

\section{LIGAÇÕES COM OUTROS ANTIPADRÕES:}

\section{EVENTOS}

Observação: Nos trechos de códigos apresentados abaixo, foram analisadas apenas questão quanto ao antipadrão dessa tabela. Se outros erros existem, esses erros foram tratados em outros antipadrões.

\section{EVENTO 1}

Id do aluno: 2243

Quantidade total de submissões do exercício: 11

Exercício que estava sendo resolvido:

Exercício 3.3

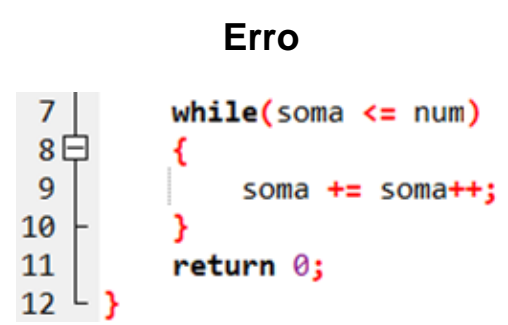

Ocorreu na submissão: 2 Observação:

\section{Erro Resolvido}

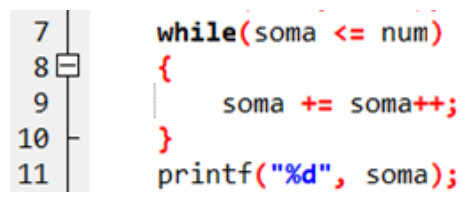

Corrigido na submissão: 11 Observação: 
EVENTO 2

Id do aluno: 1963

Quantidade total de submissões do exercício:

12

Exercício que estava sendo resolvido:

Exercício 4.1

\section{Erro}

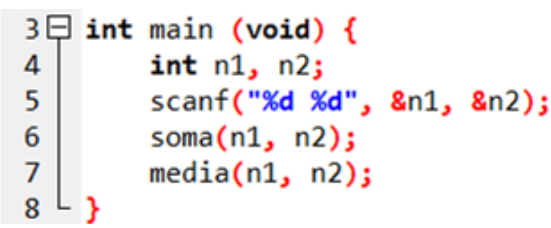

Ocorreu na submissão: 1 Observação:

Id do aluno: 1781

Exercício que estava sendo resolvido:

Exercício 7.2

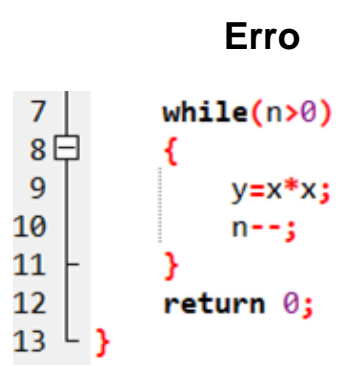

Ocorreu na submissão: 1

Observação: O resultado calculado dentro da repetição não foi apresentado ao usuário. P.S.:

A fórmula nesse código está errada.

Id do aluno: 2061

Quantidade total de submissões do exercício:

Exercício que estava sendo resolvido:

Exercício 8.1

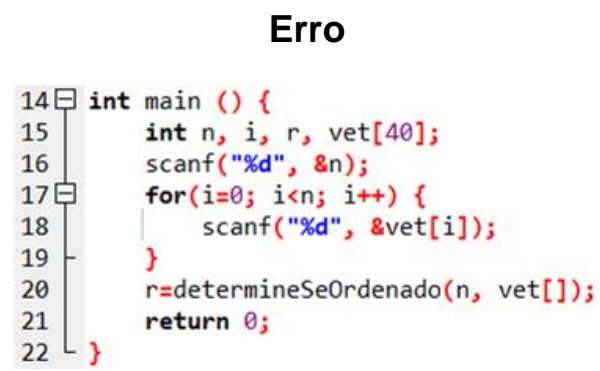

Ocorreu na submissão: 1 Observação:

\section{Erro Resolvido}

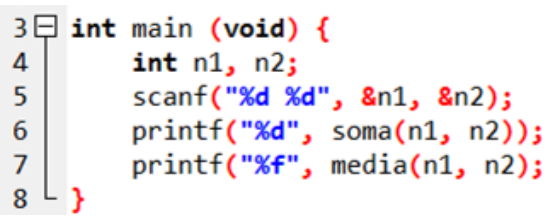

Corrigido na submissão: 2 Observação:

\section{EVENTO 3}

Quantidade total de submissões do exercício: 6

Corrigido na submissão: 3

Observação:
Corrigido na submissão: 2 Observação:
22 L

\section{Erro Resolvido}

$r=\operatorname{determineSeOrdenado}(n, \operatorname{vet}[])$; printf("\%d", r)

return $\theta$;

\section{UMA SUGESTÃO DE SOLUÇÃO}

PARA O PROFESSOR

Programar na frente dos alunos, fazendo o erro aparecer - reforço pedindo que os alunos 


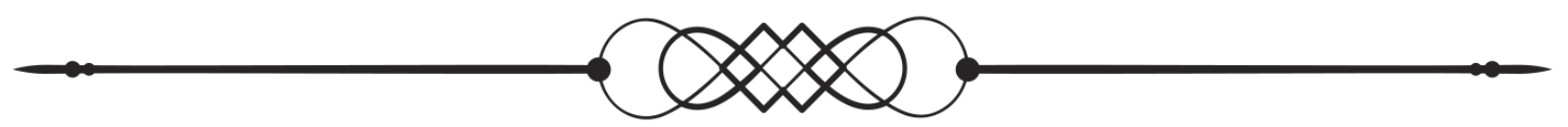

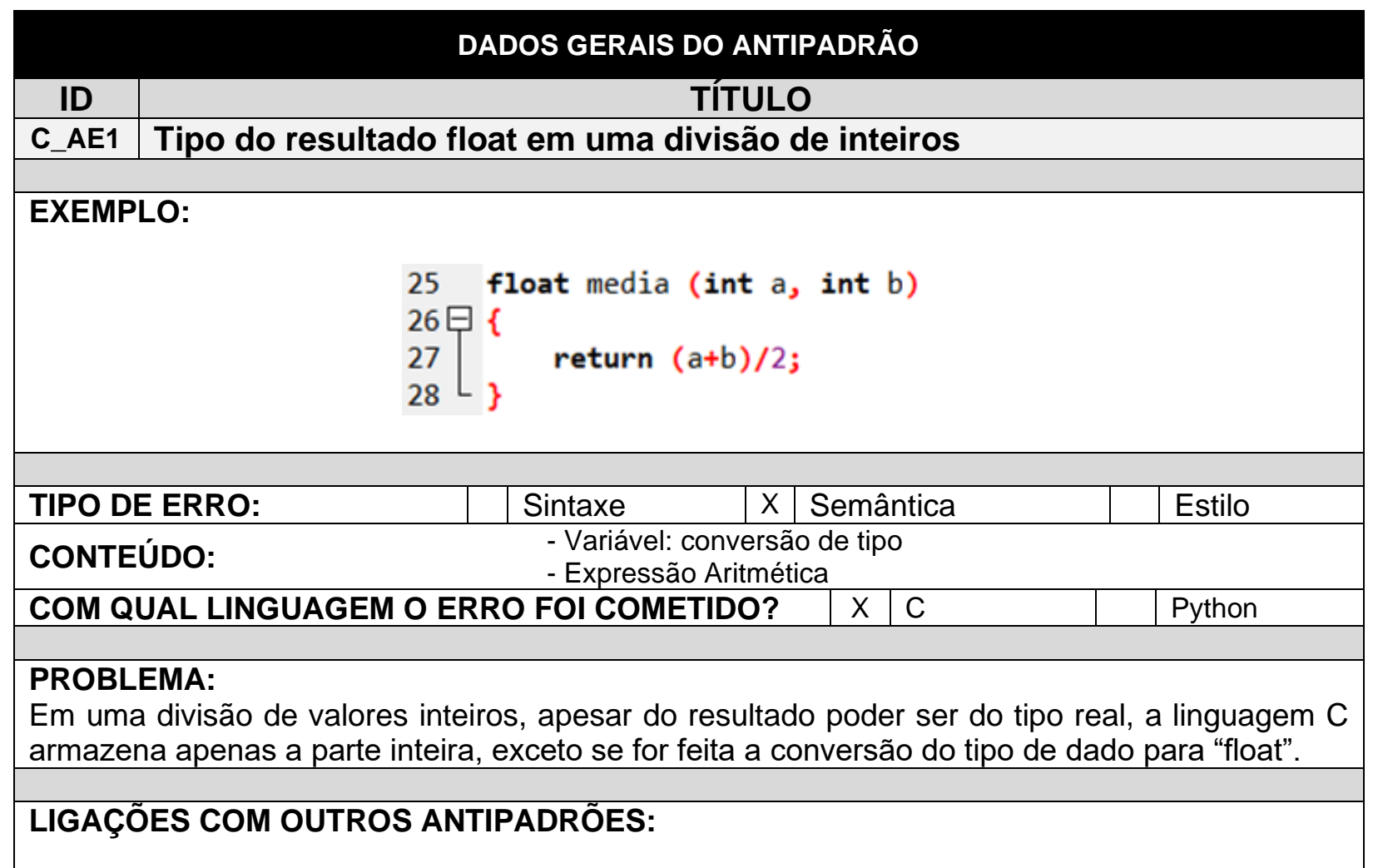

\section{EVENTOS}

Observação: Nos trechos de códigos apresentados abaixo, foram analisadas apenas questão quanto ao antipadrão dessa tabela. Se outros erros existem, esses erros foram tratados em outros antipadrões.

\begin{tabular}{|l|l|}
\hline & \multicolumn{1}{c|}{ EVENTO 1} \\
\hline Id do aluno: 1858 & Quantidade total de submissões do exercício: 10 \\
\hline $\begin{array}{l}\text { Exercício que estava sendo resolvido: } \\
\text { Exercício 4.1 }\end{array}$ & \\
\hline & \\
\hline
\end{tabular}




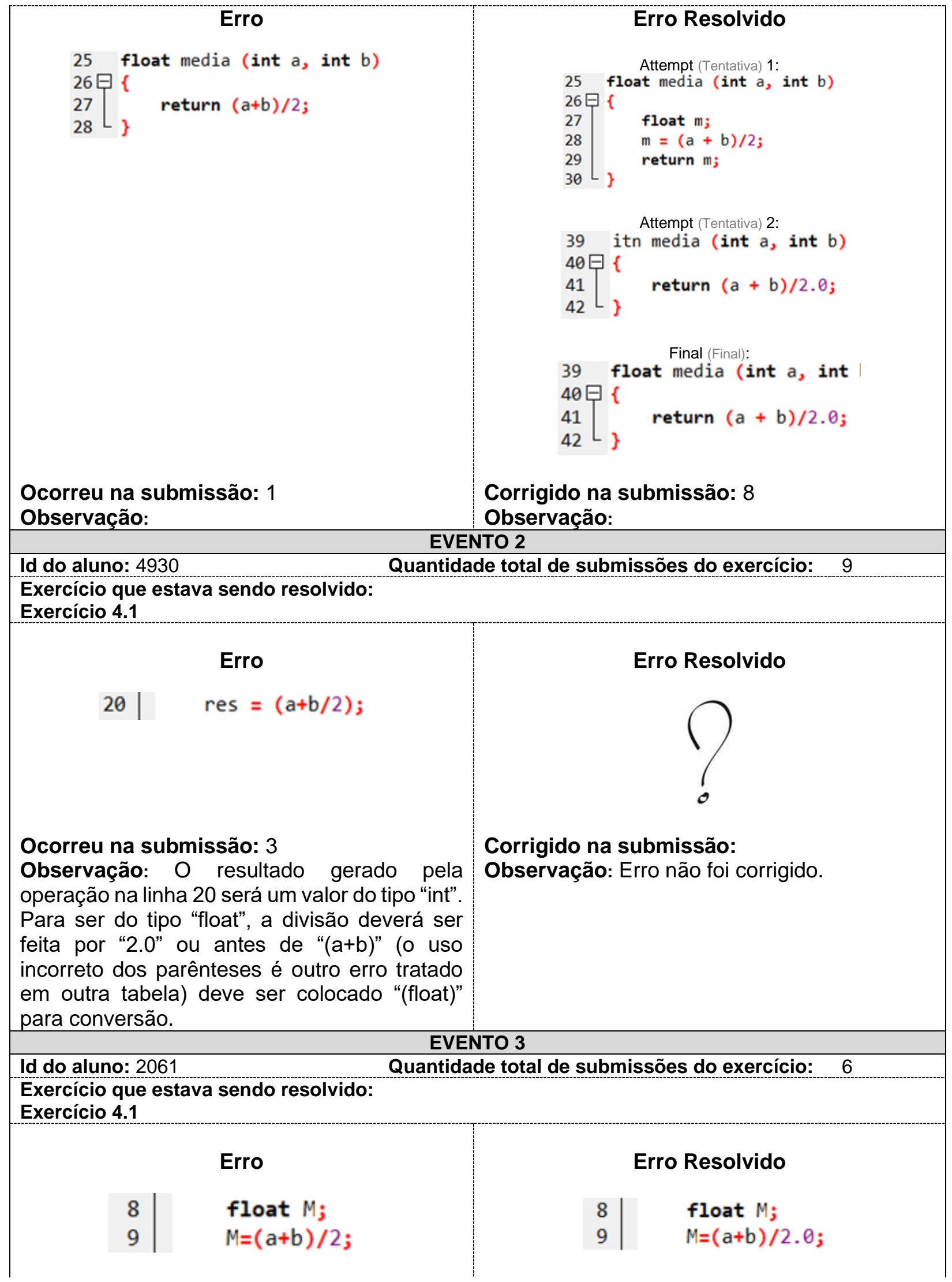


Ocorreu na submissão: 3

Observação: Essa divisão gera um resultado do tipo "int" e não "float".

\begin{tabular}{|c|c|}
\hline \multicolumn{2}{|c|}{$\begin{array}{lr}\text { Id do aluno: } 3139 & \text { EVEN } \\
& \text { Quantidac }\end{array}$} \\
\hline \multicolumn{2}{|c|}{$\begin{array}{l}\text { Exercício que estava sendo resolvido: } \\
\text { Exercício } 7.1\end{array}$} \\
\hline & Erro \\
\hline \begin{tabular}{r|}
5 \\
6 \\
7 \\
8 \\
9 \\
10 \\
11 \\
12
\end{tabular} & $\begin{array}{l}\text { int } n \text {, soma }=0 ; \\
\text { scanf }(" \% d ", 8 n) ; \\
\text { while }(n>=1)\{ \\
\quad \text { soma = soma }+1 / n ; \\
\quad n--; \\
\text { printf("\%d", soma); }\end{array}$ \\
\hline \multicolumn{2}{|c|}{$\begin{array}{l}\text { Ocorreu na submissão: } 3 \\
\text { Observação: Na linha } 8 \text {, as variáveis "soma" e } \\
\text { "n" foram declaradas como "int", porém, o } \\
\text { resultado armazenado em soma deveria ser do } \\
\text { tipo "float". Além de errar na declaração, } \\
\text { simplesmente fazer essa divisão não geraria } \\
\text { um valor "float" na variável soma. }\end{array}$} \\
\hline
\end{tabular}

Exercício que estava sendo resolvido:
Corrigido na submissão: 6 Observação:

\section{EVENTO 4}

ade total de submissões do exercício: 6

UMA SUGESTÃO DE SOLUÇÃO
PARA O PROFESSOR

Programar na frente dos alunos, fazendo o erro aparecer - reforço pedindo que os alunos desenvolvam novos códigos

Estude um ou mais antipadrões, apresente ao colega de sala e reforce com exercício

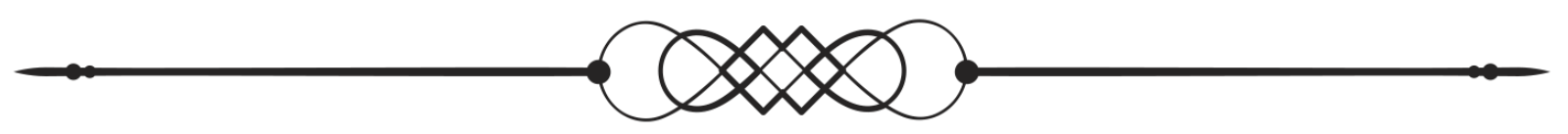

\begin{tabular}{|l|c|}
\hline \multicolumn{2}{|c|}{ DADOS GERAIS DO ANTIPADRÃO } \\
\hline ID & TÍTULO \\
\hline C_AE2 & Fórmula aritmética errada \\
\hline \multicolumn{2}{|c|}{} \\
\hline EXEMPLO: \\
\\
\\
\end{tabular}




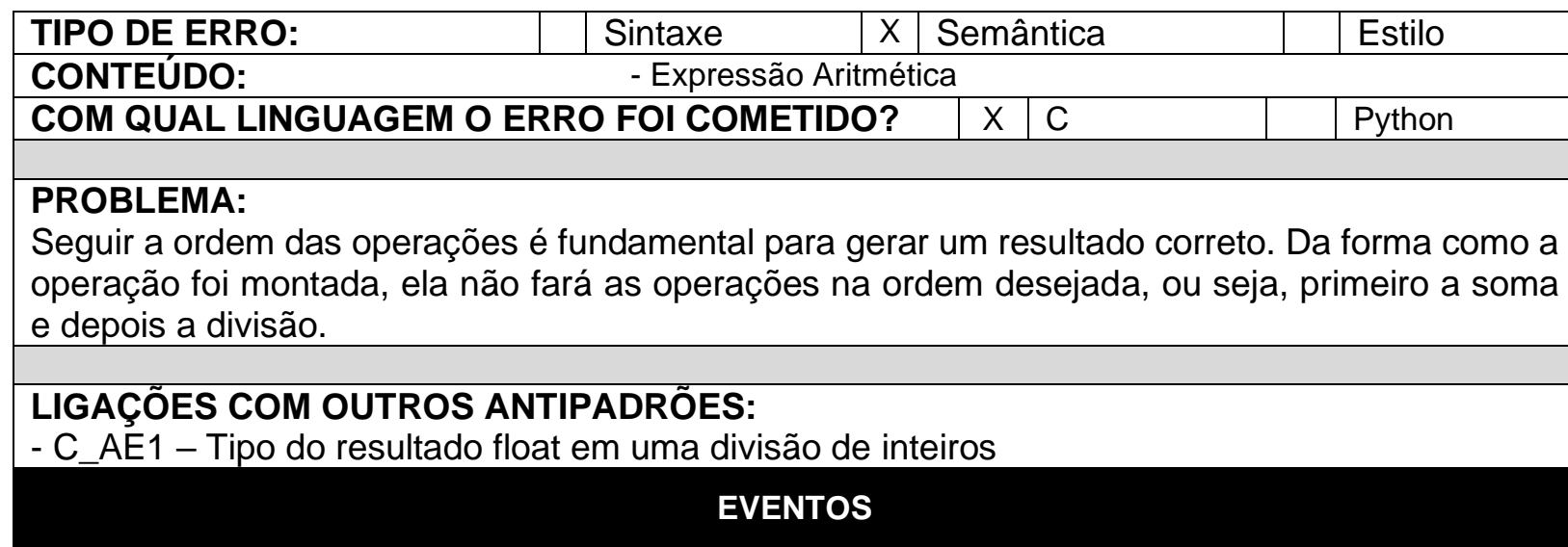

Observação: Nos trechos de códigos apresentados abaixo, foram analisadas apenas questão quanto ao antipadrão dessa tabela. Se outros erros existem, esses erros foram tratados em outros antipadrões.

\begin{tabular}{ll}
\hline & \multicolumn{1}{c|}{ EVENTO 1 } \\
\hline Id do aluno: 4770 & Quantidade total de submissões do exercício: \\
\hline $\begin{array}{l}\text { Exercício que estava sendo resolvido: } \\
\text { Exercício 4.1 }\end{array}$ &
\end{tabular}

$$
\begin{gathered}
\text { Erro } \\
19 \\
18
\end{gathered}\left[\begin{array}{r}
\text { double media(int } a \text {, int } b)\{ \\
\text { return }(a+b / 2) ;
\end{array}\right.
$$

Ocorreu na submissão: 1

Observação: Para calcular a média, a soma deveria estar entre parênteses, caso contrário, a divisão é feita primeiro.

Id do aluno: 4930

\section{EVENTO 2}

Quantidade total de submissões do exercício:

\section{Erro Resolvido}

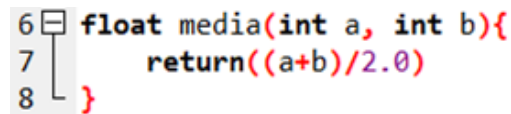

Corrigido na submissão: 12 Observação:

Exercício que estava sendo resolvido:

Exercício 4.1

\section{Erro}

20

$$
\text { res }=(a+b / 2) \text {; }
$$

Ocorreu na submissão: 3

Observação:

Id do aluno: 2243

Exercício que estava sendo resolvido:

Exercício 4.1

$$
\text { Erro }
$$

10

$$
\text { return } a+b / 2.0 \text {; }
$$

Ocorreu na submissão: 2 Observação:

\section{Erro Resolvido}

$21 \quad$ res $=(a+b) / 2$;

Corrigido na submissão: 5 Observação:

\section{EVENTO 3}

Quantidade total de submissões do exercício: 5 
EVENTO 4

Id do aluno: 1781

Quantidade total de submissões do exercício:

6

Exercício que estava sendo resolvido:

Exercício 7.2

\section{Erro}

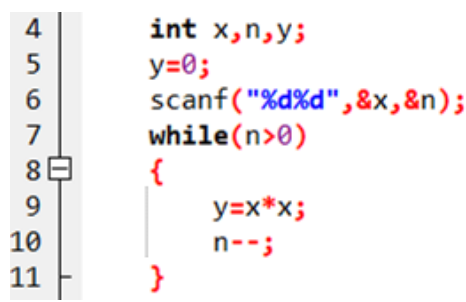

Ocorreu na submissão: 1

Observação: O objetivo era fazer $x^{n}$, logo o "y" iria acumular os resultados das multiplicações, porém isso não está acontecendo.

\section{Erro Resolvido}

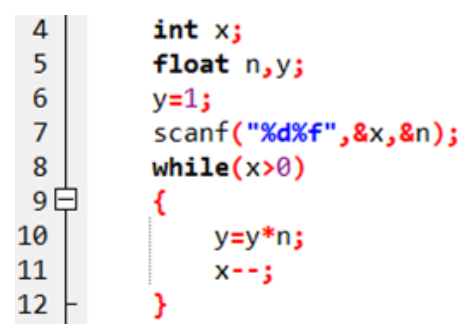

Corrigido na submissão: 6

Observação:

\section{UMA SUGESTÃO DE SOLUÇÃO}

\section{PARA O PROFESSOR}

Programar na frente dos alunos, fazendo o erro aparecer - reforço pedindo que os alunos desenvolvam novos códigos

Estude um ou mais antipadrões, apresente ao colega de sala e reforce com exercício

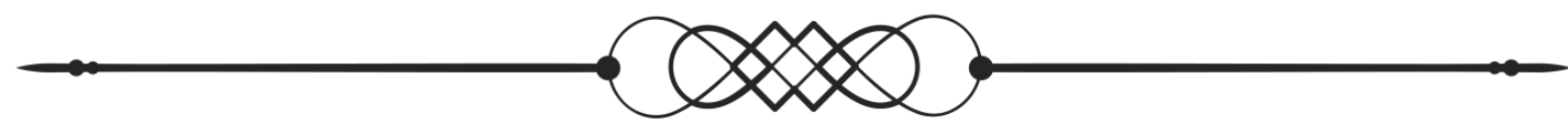

\section{DADOS GERAIS DO ANTIPADRÃO}

\section{ID TÍTULO \\ C_AE3 Realizar o cálculo antes de ter valores nas variáveis utilizadas}

\section{EXEMPLO:}

$$
\begin{array}{l|l}
3 & \text { int } a, b, c, d ; \\
4 & d=a+b+c ; \\
5 & \text { scanf ("\%d\%d\%d", \&a, \&b, \&c); }
\end{array}
$$

\begin{tabular}{|c|c|c|c|}
\hline TIPO DE ERRO: & Sintaxe & \begin{tabular}{l|l}
$\mathrm{X}$ & Semântica \\
\end{tabular} & Estilo \\
\hline CONTEÚDO: & $\begin{array}{l}\text { - Geral } \\
\text { - Variáa } \\
\text { - Funçã } \\
\text { - Expre }\end{array}$ & $\begin{array}{l}\text { le execução } \\
\text { rada de Dado } \\
\text { mética }\end{array}$ & \\
\hline
\end{tabular}




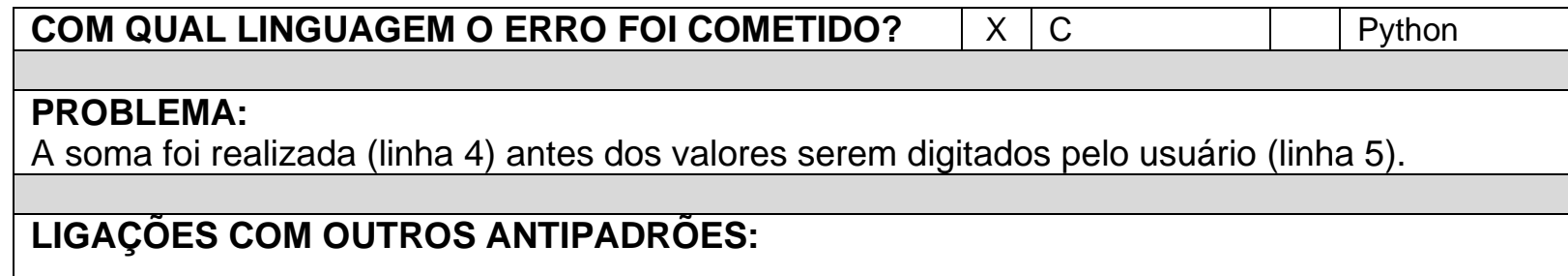

\section{EVENTOS}

Observação: Nos trechos de códigos apresentados abaixo, foram analisadas apenas questão quanto ao antipadrão dessa tabela. Se outros erros existem, esses erros foram tratados em outros antipadrões.

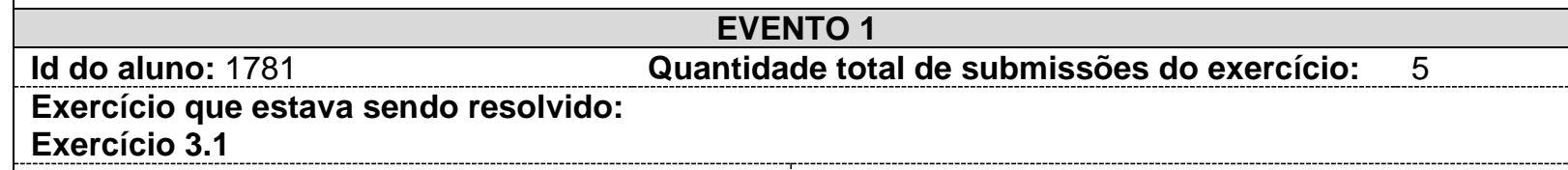

Exercício 3.1

Erro
\begin{tabular}{l|l}
4 & $d=a+b+c ;$ \\
5 & scanf $(" \% d \% d \% d ", \& a, \& b, \& c) ;$
\end{tabular}

Ocorreu na submissão: 1

Observação: As linhas 4 e 5 deveriam ser invertidas.

Id do aluno: 5098

Exercício que estava sendo resolvido:

Exercício 3.1

\section{Erro}

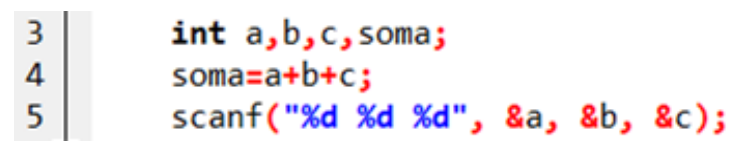

Ocorreu na submissão: 5

Observação:

Id do aluno: 5226

Exercício que estava sendo resolvido:

Exercício 3.3

\section{Erro}

\section{EVENTO 2}

Quantidade total de submissões do exercício: 12
Corrigido na submissão: 2 Observação:

\section{Erro Resolvido}

scanf ( $\% d \% d \% d ", \& a, \& b, \& c)$;

if $(a+b+c==180)\{$ 


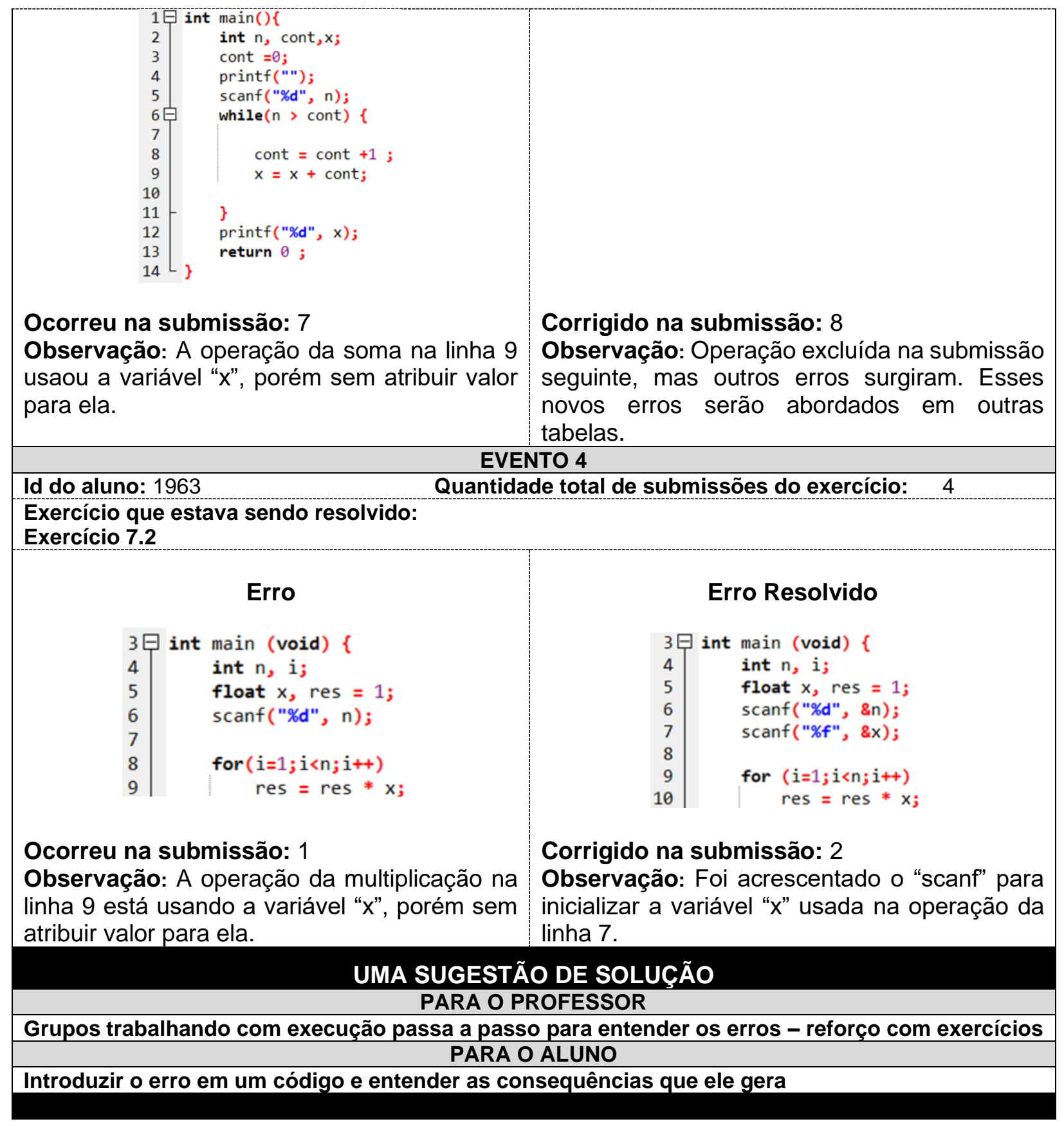

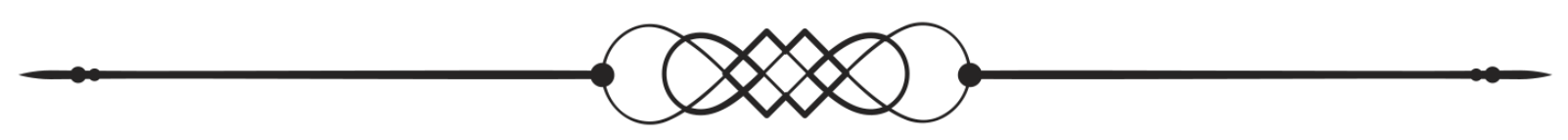




\section{DADOS GERAIS DO ANTIPADRÃO}

\begin{tabular}{|c|c}
\hline ID & TíTULO \\
\hline C_RE5 & Realizar comparação antes de ter valores nas variáveis utilizadas \\
\hline
\end{tabular}

EXEMPLO:

$$
\begin{array}{l|l}
3 & \text { int } a, b ; \\
4 \text { if }(a<b)\{
\end{array}
$$

\begin{tabular}{|l|l|l|l|l|}
\hline TIPO DE ERRO: & Sintaxe & $\mathrm{X}$ & Semântica & Estilo \\
\hline $\begin{array}{l}\text { CONTEÚDO: } \\
\text { - Variável } \\
\text { - Expressão Relacional }\end{array}$ \\
\hline COM QUAL LINGUAGEM O ERRO FOI COMETIDO? & $\mathrm{X}$ & $\mathrm{C}$ & & Python \\
\hline
\end{tabular}

\section{PROBLEMA:}

A comparação será feita com valores que chamamos de "lixo da memória", ou seja, valores desconhecidos e não controlados.

\section{LIGAÇÕES COM OUTROS ANTIPADRÕES:}

\section{EVENTOS}

Observação: Nos trechos de códigos apresentados abaixo, foram analisadas apenas questão quanto ao antipadrão dessa tabela. Se outros erros existem, esses erros foram tratados em outros antipadrões.

Id do aluno: $1781 \quad$ Quantidade total de submissões do exercício: 5

Exercício que estava sendo resolvido:

Exercício 2.2

\section{Erro$$
\text { 3曰 } \quad \text { int } a, b \text {; }
$$

Ocorreu na submissão: 2

Observação: Na linha 3 as variáveis "a" e "b" são declaradas, sem atribuição de valores e, na linha seguinte já são comparadas.

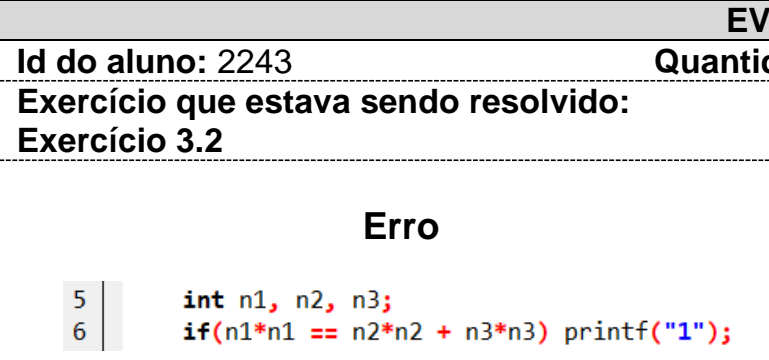

Ocorreu na submissão: 1

\section{EVENTO 2}

Corrigido na submissão: 3 Observação:

\section{Erro Resolvido}

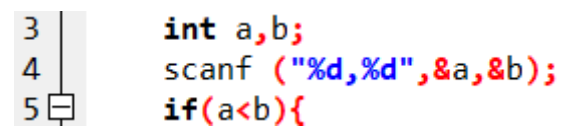

if $(a<b)\{$

dade total de submissões do exercício: 
Observação:

\begin{tabular}{l} 
Id do aluno: 1830 \\
Exercício que estava sendo resolvido: \\
Exercício 3.1 \\
\hline
\end{tabular}

Ocorreu na submissão: 3 Observação:

\section{Id do aluno:}

Exercício que estava sendo resolvido:

\section{Erro}

Ocorreu na submissão:

Observação:
Observação:

\section{EVENTO 3}

Quantidade total de submissões do exercício: :

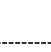




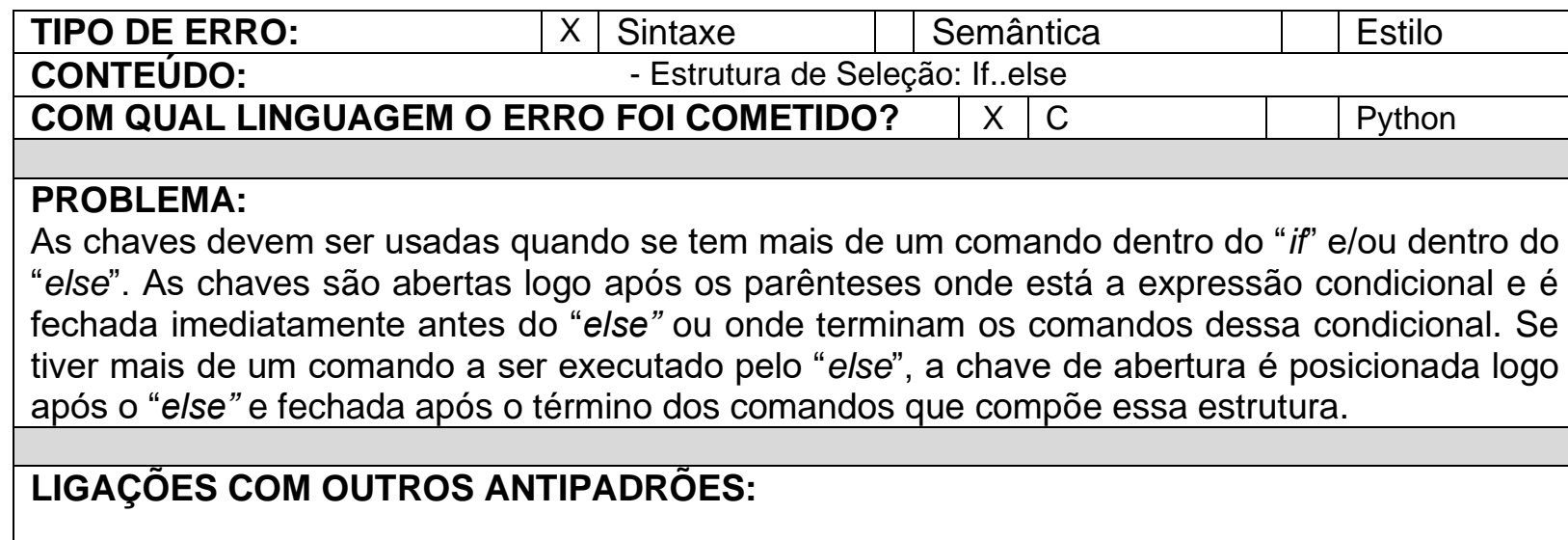

\section{EVENTOS}

Observação: Nos trechos de códigos apresentados abaixo, foram analisadas apenas questão quanto ao antipadrão dessa tabela. Se outros erros existem, esses erros foram tratados em outros antipadrões.

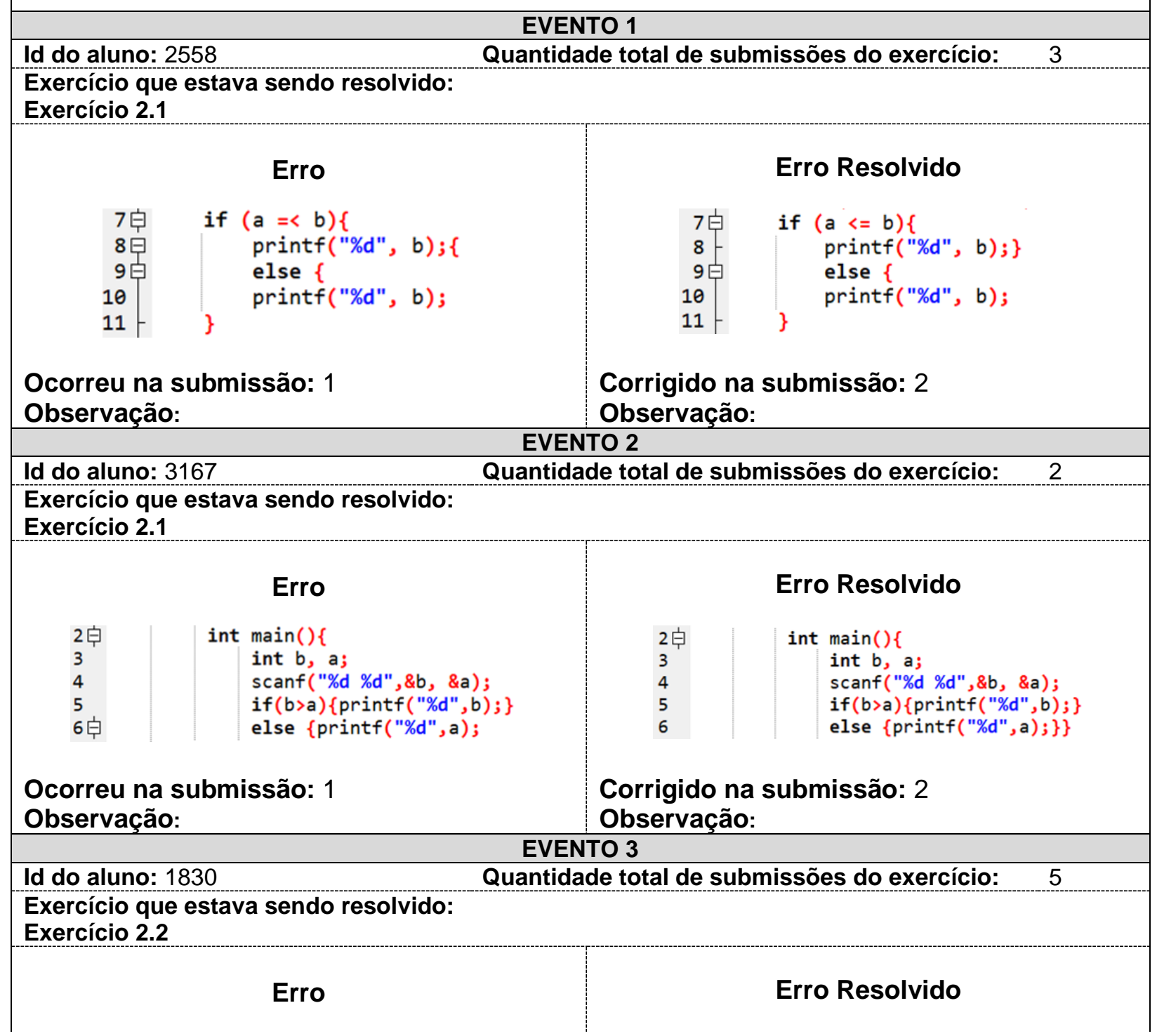




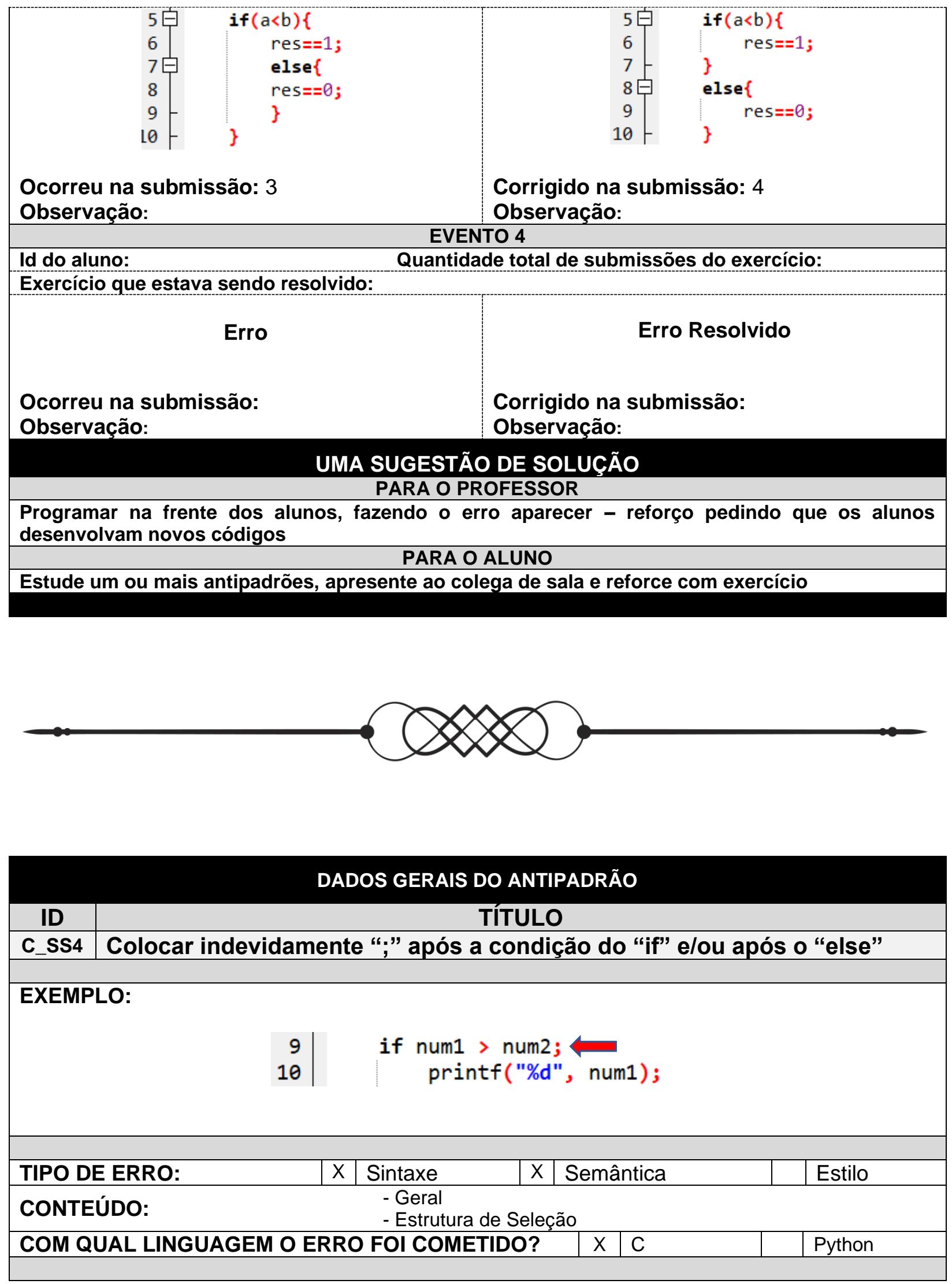




\section{PROBLEMA:}

O ponto e vírgula logo após a condição do "if' fará com que ele seja finalizado exatamente nesse ponto e os comandos que deveriam ser executados somente se a condição fosse verdadeira, irão executar independente da resposta. O mesmo vale para o "else". Porém, se for colocado o ponto e vírgula após a condição do "if" e esse tiver um "else" associado a ele, ocorrerá um erro de compilação, ou seja, o código não será executado.

\section{LIGAÇÕES COM OUTROS ANTIPADRÕES:}

- C_G2 - Falta de "; " no final da linha

\section{EVENTOS}

Observação: Nos trechos de códigos apresentados abaixo, foram analisadas apenas questão quanto ao antipadrão dessa tabela. Se outros erros existem, esses erros foram tratados em outros antipadrões.

EVENTO 1

Exercício que estava sendo resolvido:

Exercício 2.1

Quantidade total de submissões do exercício:

20

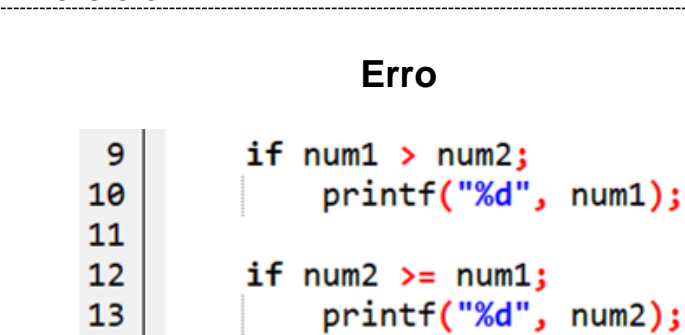

Ocorreu na submissão: 1

Observação:

\section{EVENTO 2}

Corrigido na submissão: 19

\section{Observação:}

Id do aluno: 5730 Quantidade total de submissões do exercício:

Exercício que estava sendo resolvido:

Exercício 2.1

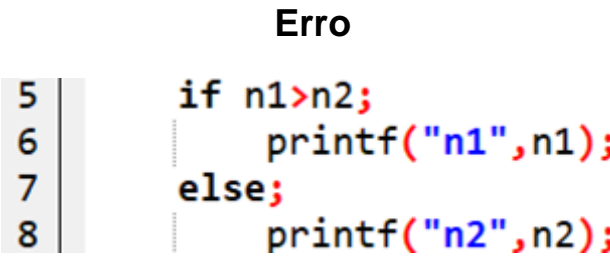

Ocorreu na submissão: 1

Observação:

Id do aluno: 2901

Exercício que estava sendo resolvido:

Exercício 3.1

\section{Erro Resolvido}

if (num $1>=$ num 2 ) \{ \} else\{

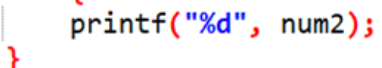

0




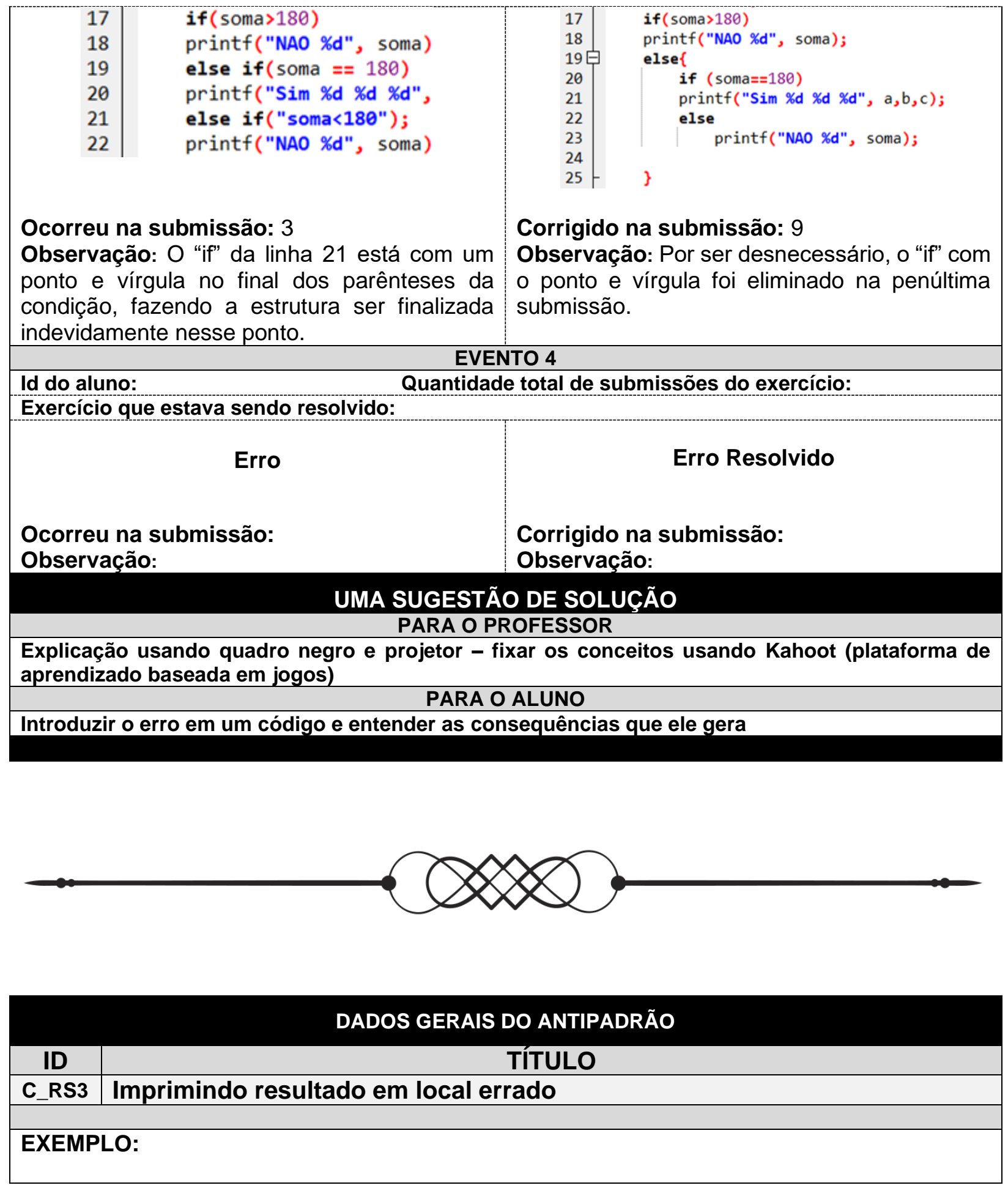




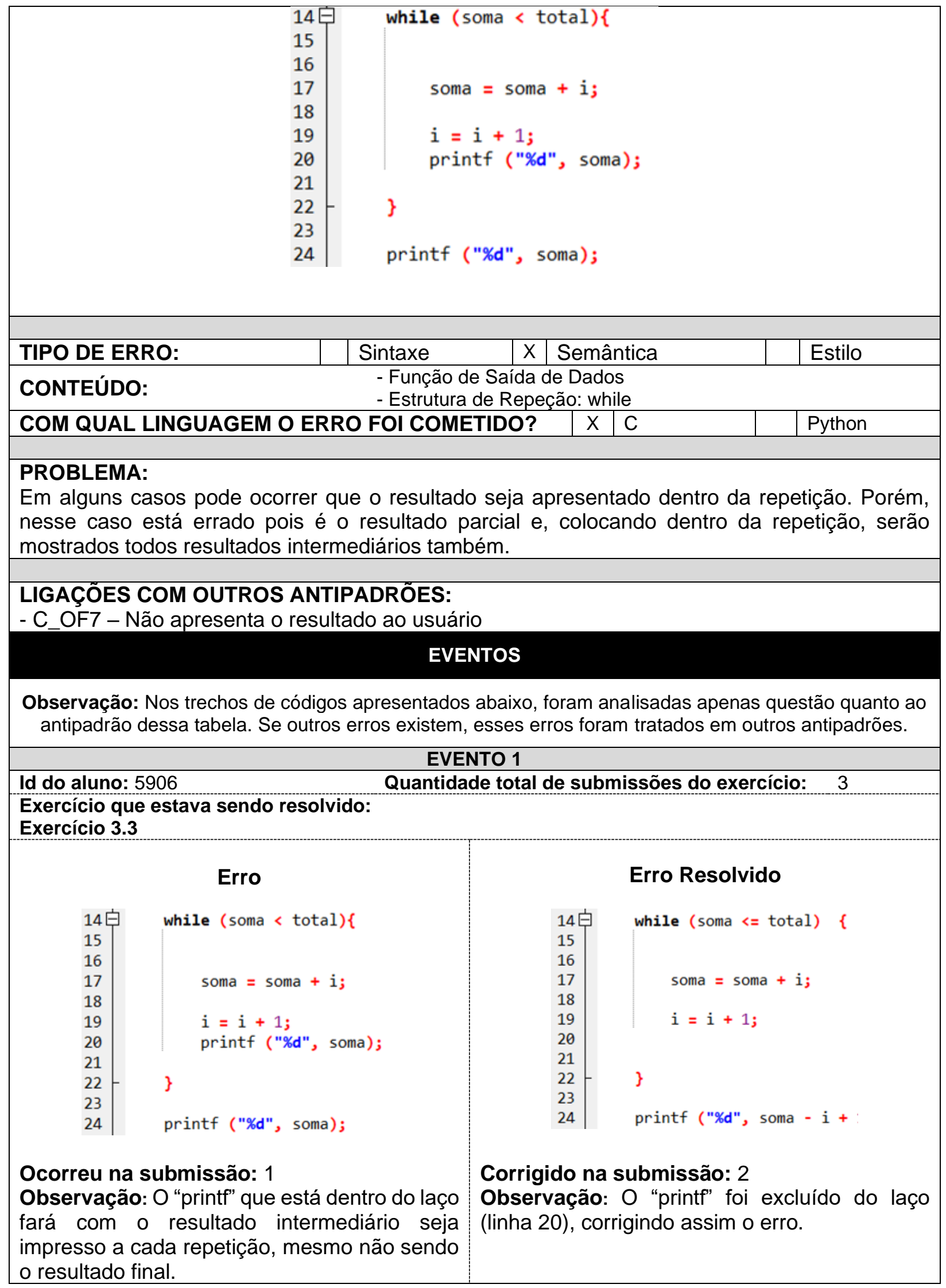


EVENTO 2

Id do aluno: $5730 \quad$ Quantidade total de submissões do exercício:

59

Exercício que estava sendo resolvido:

Exercício 3.3

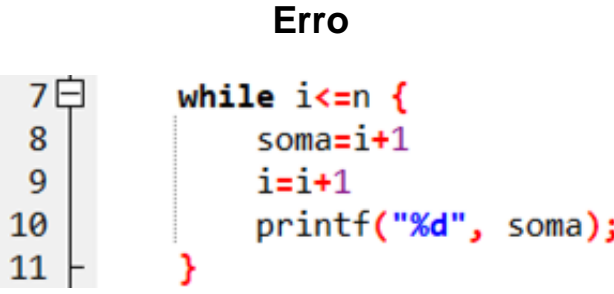

Ocorreu na submissão: 1

Observação: Com o "printf" na linha 10, o resultado era impresso em cada repetição ao invés de ser apresentado apenas no final.

\section{EVENTO 3}

Quantidade total de submissões do exercício: 62
Corrigido na submissão: 10

Observação: O "printf" foi retirado de dentro do laço e colocado fora, na linha 15.

Id do aluno: 5242

Exercício 3.3

\section{Ocorreu na submissão: 8}

Observação:

\section{Erro}

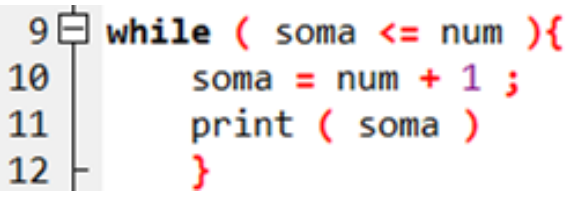

Id do aluno: 1830

Exercício que estava sendo resolvido:

Exercício 4.7

\section{Erro}
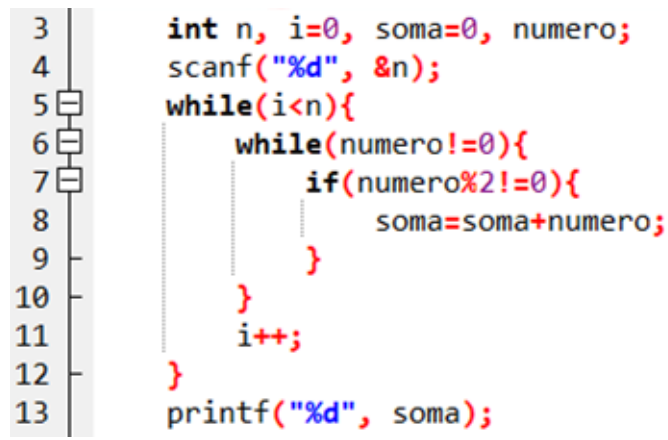

Ocorreu na submissão: 3

Observação: O exercício pede para mostrar a soma dos ímpares de cada uma das $\mathrm{n}$ subsequências, ou seja, o "printf" deveria estar

\section{Erro Resolvido}

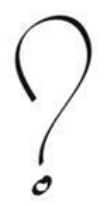

Corrigido na submissão:

Observação:

\section{EVENTO 4}

Quantidade total de submissões do exercício: 12

\section{Erro Resolvido}

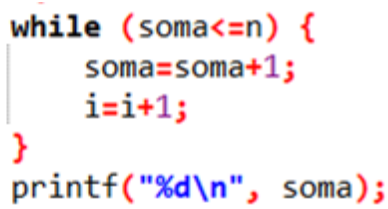

soma $=$ soma +1 ;

$i=i+1$;

printf("\%d\n", soma); 
logo após o fechamento da estrutura de repetição interna.

\section{UMA SUGESTÃO DE SOLUÇÃO}

PARA O PROFESSOR

Aplicar teste de mesa em um Código com o erro e outro sem, comparar os resultados - reforço pedindo que os alunos resolvam alguns exercícios

\section{PARA O ALUNO}

Resolver exercícios, acrescentar erros nos códigos e pedir que o colega de sala os encontrem

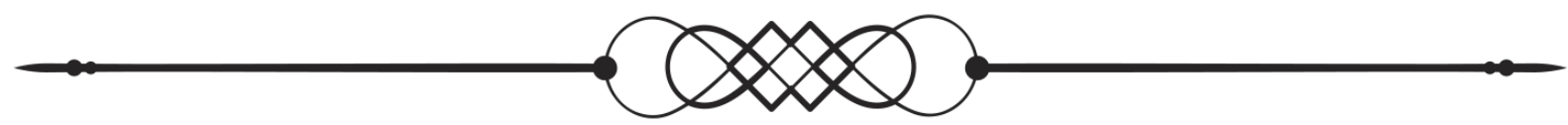

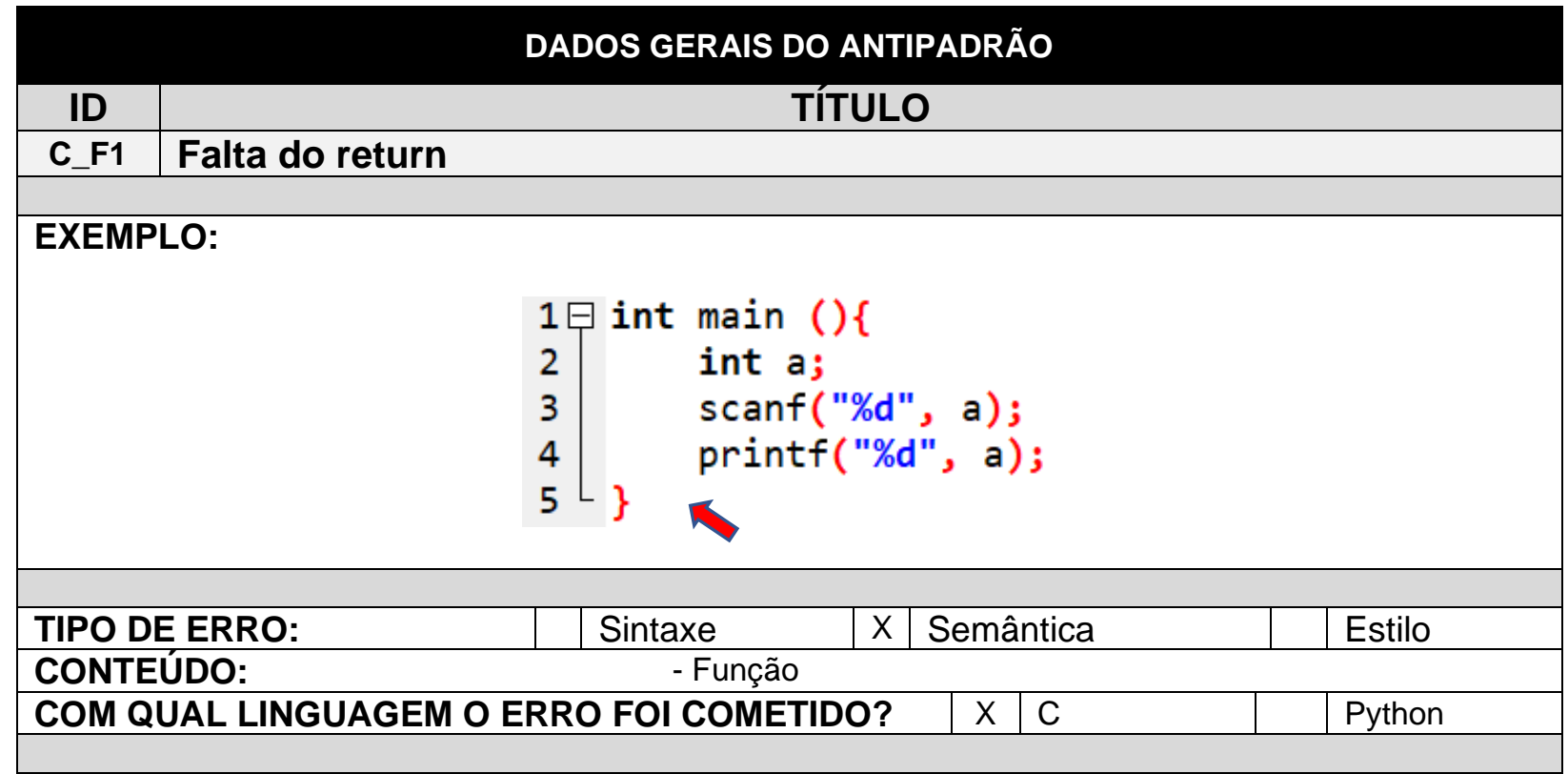

PROBLEMA:

A falta do return poderá passar despercebida quando o valor não é necessário no programa, como é muitas vezes o caso do return na função "main". Porém, as funções desenvolvidas servem para processar algo e quando programadas para retornar o valor, o resultado é necessário para a continuidade do programa, sendo que sua falta causará uma falha nos resultados. Por esse motivo, funções tipadas precisam executar o return na sua finalização.

\section{LIGAÇÕES COM OUTROS ANTIPADRÕES:}

- C_F2 - Falta de abertura "\{" e/ou fechamento "\}" da função

- C_F9 - Declaração incorreta dos parâmetros da função

- C F10 - "return" x "printf"

\section{EVENTOS}

Observação: Nos trechos de códigos apresentados abaixo, foram analisadas apenas questão quanto ao 
antipadrão dessa tabela. Se outros erros existem, esses erros foram tratados em outros antipadrões.

EVENTO 1

Id do aluno: 2670

Quantidade total de submissões do exercício:

4

Exercício que estava sendo resolvido:

Exercício 1.1

\section{Erro}

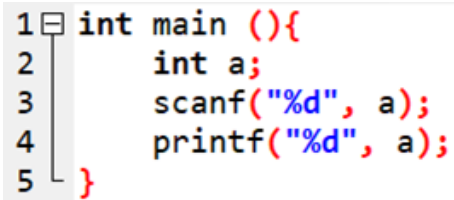

Ocorreu na submissão: 1 Observação:

Id do aluno: 2950

Exercício que estava sendo resolvido:

Exercício 1.1

\section{Erro}

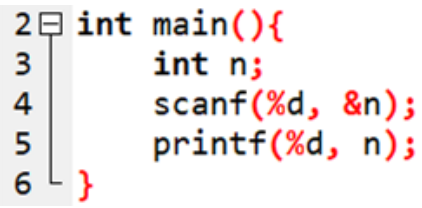

Ocorreu na submissão: 1

Observação:

Id do aluno: 5226

Exercício que estava sendo resolvido:

Exercício 1.1

\section{Erro}

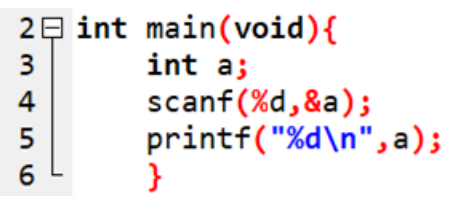

Ocorreu na submissão: 1

Observação:

Id do aluno: 5554

Exercício que estava sendo resolvido:

Exercício 4.2

\section{Erro Resolvido}

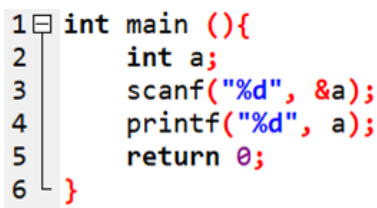

Corrigido na submissão: 2 Observação:

\section{EVENTO 2}

Quantidade total de submissões do exercício: 2

Erro

Corrigido na submissão:

Observação: Erro não foi corrigido.

\section{EVENTO 3}

Quantidade total de submissões do exercício: 2

\section{Erro Resolvido}

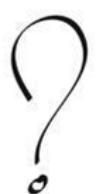

0 


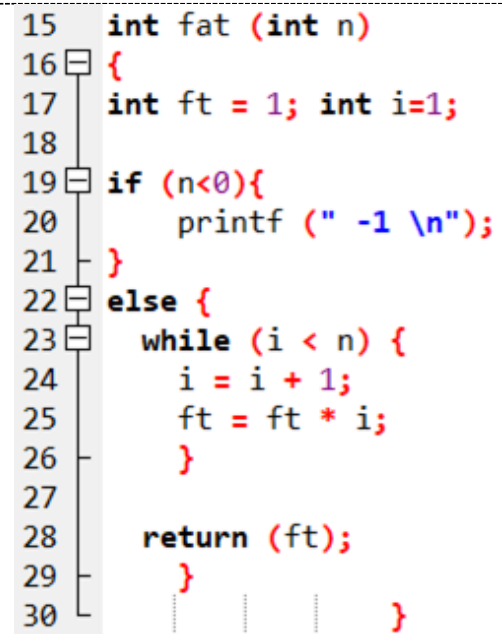

\section{Ocorreu na submissão: 3}

Observação: A função fat não retorna valor caso o valor de "n", recebido por parâmetro, seja menor que "0". O aluno não percebeu que nesse caso a função do tipo "int" fica sem "return".

\section{UMA SUGESTÃO DE SOLUÇÃO}

\section{PARA O PROFESSOR}

Programar na frente dos alunos, fazendo o erro aparecer - reforço pedindo que os alunos desenvolvam novos códigos

Estude um ou mais antipadrões, apresente ao colega de sala e reforce com exercício

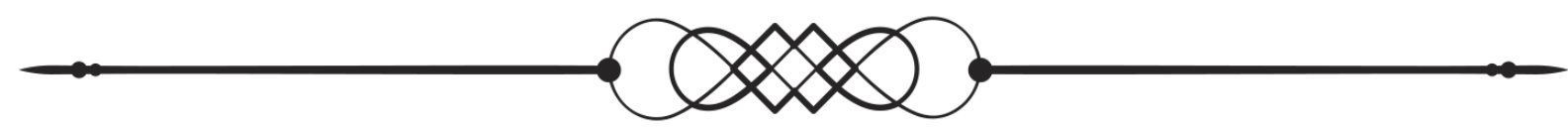

\begin{tabular}{|c|c|c|}
\hline \multicolumn{3}{|c|}{ DADOS GERAIS DO ANTIPADRÃO } \\
\hline ID & \multicolumn{2}{|c|}{$\begin{array}{c}\text { TÍTULO } \\
\end{array}$} \\
\hline C_F2 & \multicolumn{2}{|c|}{ Falta de abertura "\{" e/ou fechamento "\}" da função } \\
\hline \multicolumn{3}{|c|}{ EXEMPLO: } \\
\hline & 1 & \#include 〈stdio.h〉 \\
\hline & & int main() \\
\hline & 3 & int $n$; \\
\hline & & $\operatorname{scanf}(" \% d ", \& n)$; \\
\hline & 5 & printf("\%d",n); \\
\hline
\end{tabular}




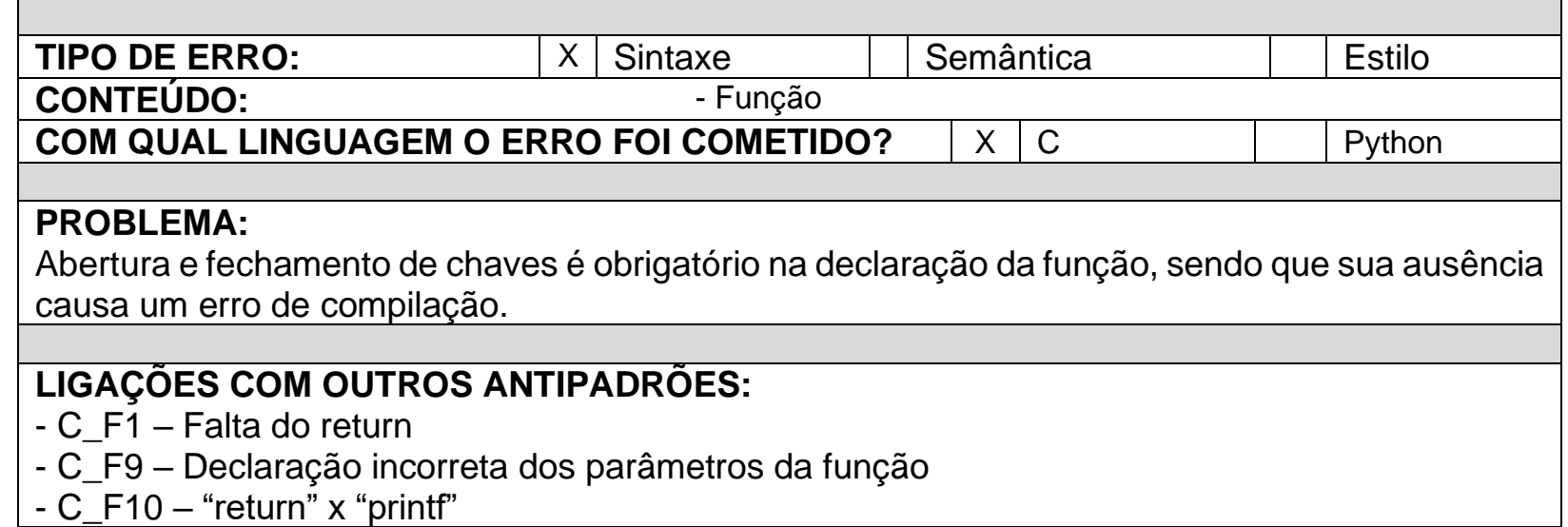

\section{EVENTOS}

Observação: Nos trechos de códigos apresentados abaixo, foram analisadas apenas questão quanto ao antipadrão dessa tabela. Se outros erros existem, esses erros foram tratados em outros antipadrões.

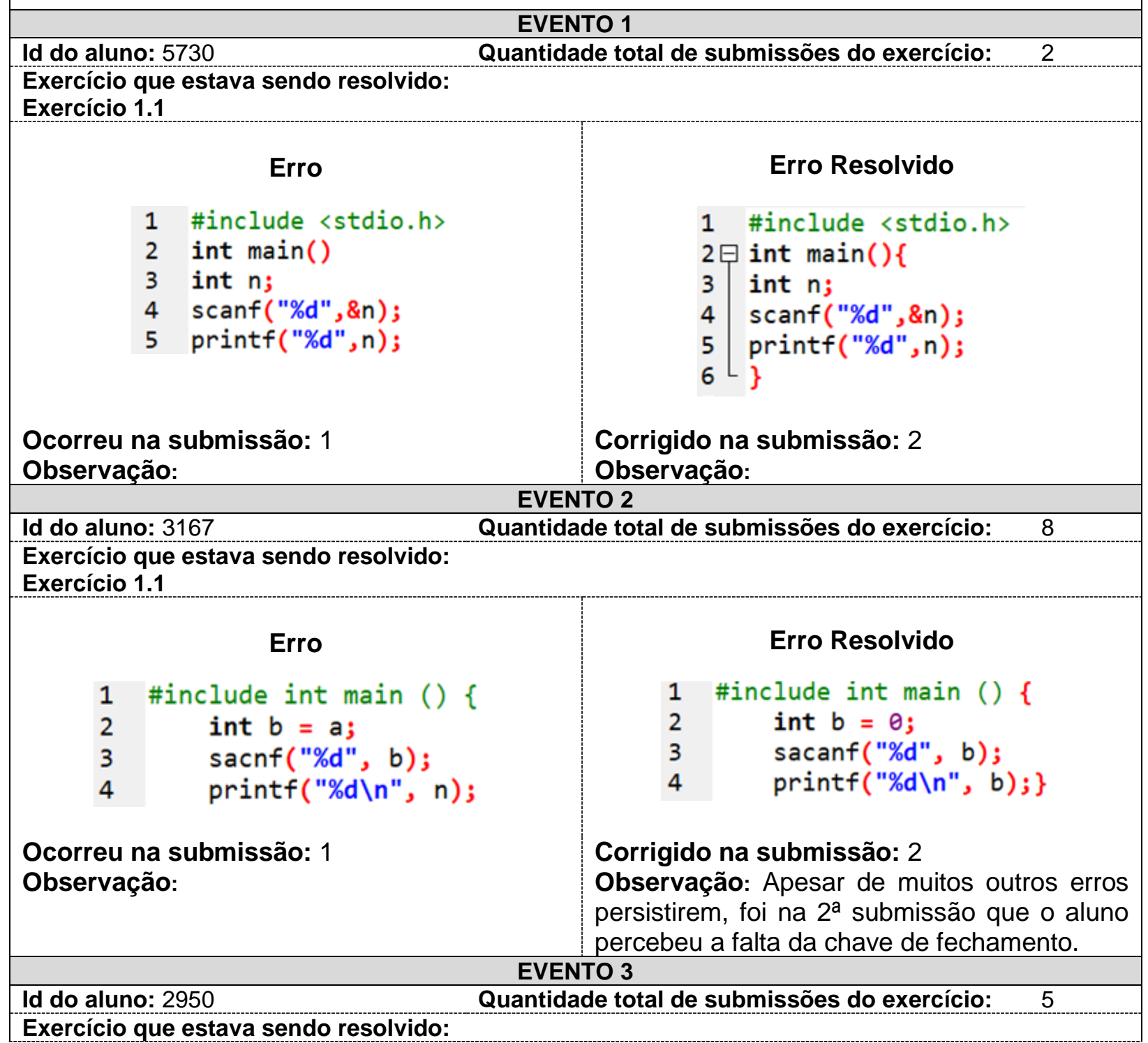


Exercício 3.1

\section{Erro}

1 \#include 〈stdio.h〉

2白 int main(void) \{

3 int $a, b, c$;

4 scanf("\%d \%d \%d", \&a, \&b, \&c);

5 if $(a+b+c==180)$

6 printf("Sim \%d \%d \%d", a, b, c);

7 else

\begin{tabular}{l|l}
8 & $\operatorname{printf}(" \mathrm{NAO} ")$;
\end{tabular}

Ocorreu na submissão: 1

Observação:

\section{EVENTO 4}

Id do aluno: 2243

Quantidade total de submissões do exercício:

\section{Erro Resolvido}

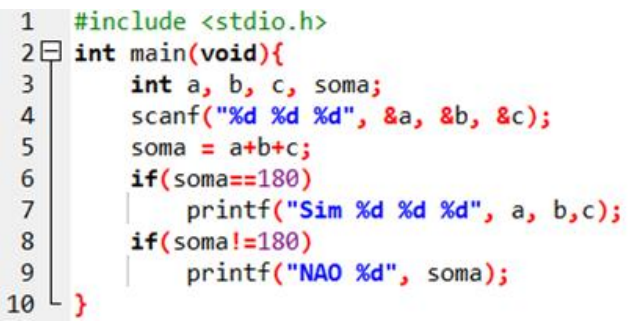

\section{Corrigido na submissão: 5}

Observação: $O$ aluno insistiu em alterar a estrutura de seleção da $2^{\mathrm{a}}$ a $4^{\mathrm{a}}$ submissão e só na $5^{\text {a }}$ submissão ele conseguiu compilar 0 código por ter fechada a função. Inclusive a estrutura de seleção da primeira submissão estava melhor elaborada por usar o "else".

Exercício que estava sendo resolvido:

Exercício 2.2

\section{Erro}

3 int main(void)

4 追

5 int $a, b$;

6 scanf ("\%d\%d", \&a, \&b);

7 if $(\mathrm{a}<\mathrm{b}) \operatorname{printf}(" 1 ")$;

8 else printf("0");

9 return 0 ;

\section{Ocorreu na submissão: 1}

Observação:

\section{Erro Resolvido}

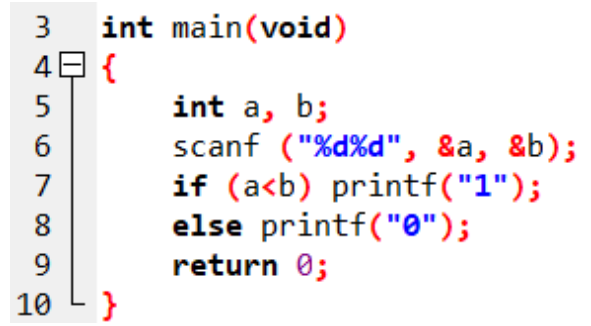

Corrigido na submissão: 2

Observação:

\section{UMA SUGESTÃO DE SOLUÇÃO}

\section{PARA O PROFESSOR}

Explicação usando quadro negro e projetor - fixar os conceitos usando Kahoot (plataforma de aprendizado baseada em jogos)

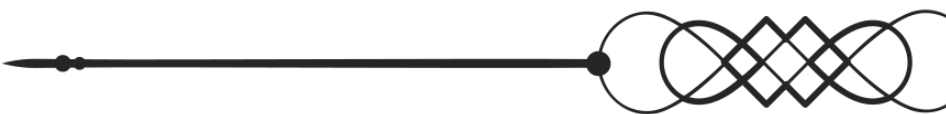




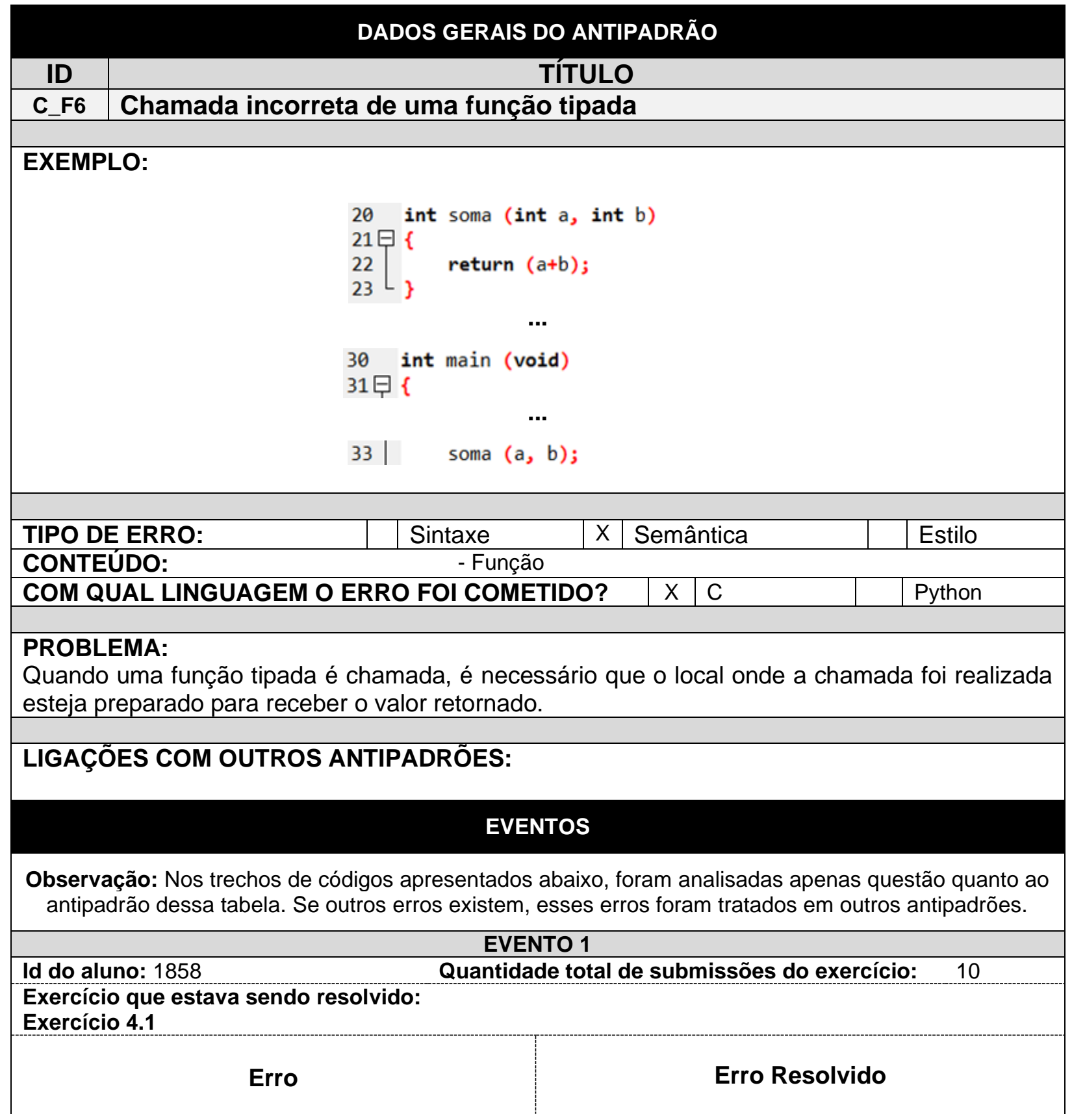




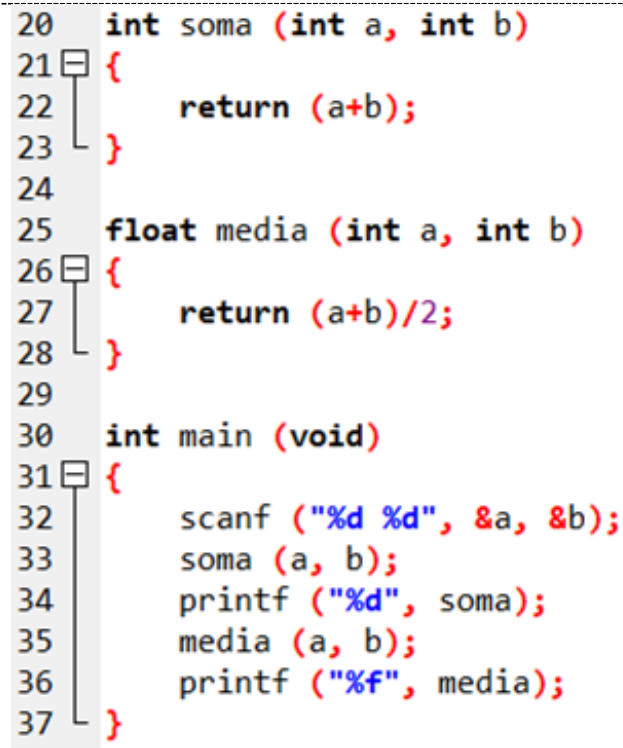

Ocorreu na submissão: 1

Observação: A linha 33, exceto o ponto-evírgula, deveriam subtituir "soma" na linha 34. O mesmo paras as linhas 35 / 36. Outra opção seria a atribuição do retorno para um variável.

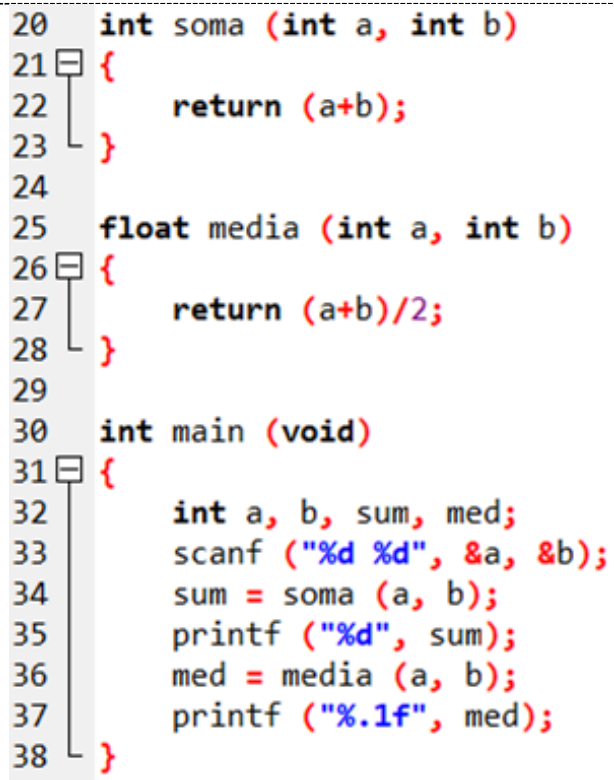

Corrigido na submissão: 3

Observação: $O$ erro foi resolvido nas linhas 34 e 36.

\begin{tabular}{l} 
EVENTO 2 \\
Id do aluno: $1963 \quad$ Quantidade total de submissões do exercício: 12 \\
\hline Exercício que estava sendo resolvido: \\
Exercício 4.1
\end{tabular}

\section{Erro}

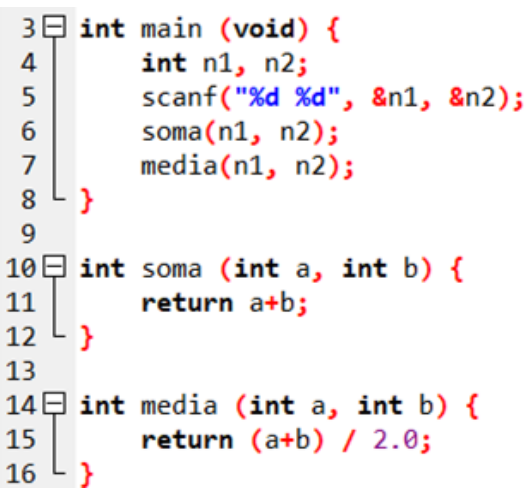

Ocorreu na submissão: 1

Observação: Chamada incorreta nas linhas 6 e 7 .

\section{Erro Resolvido}

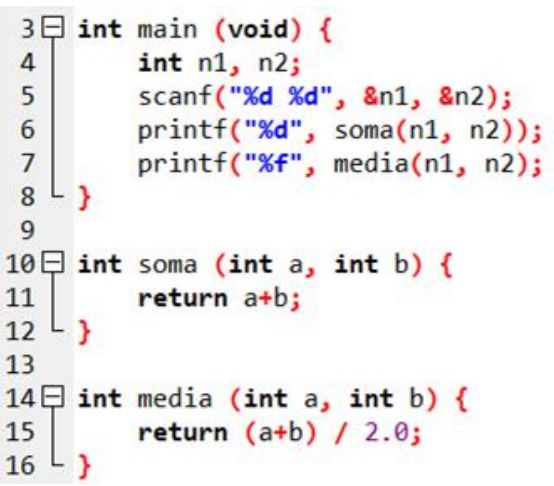

Corrigido na submissão: 2

Observação: Nas linhas 6 e 7, a chamada da função foi colocada dentro do "printf", resolvendo o problema.

Id do aluno: 5906

Quantidade total de submissões do exercício:

4 


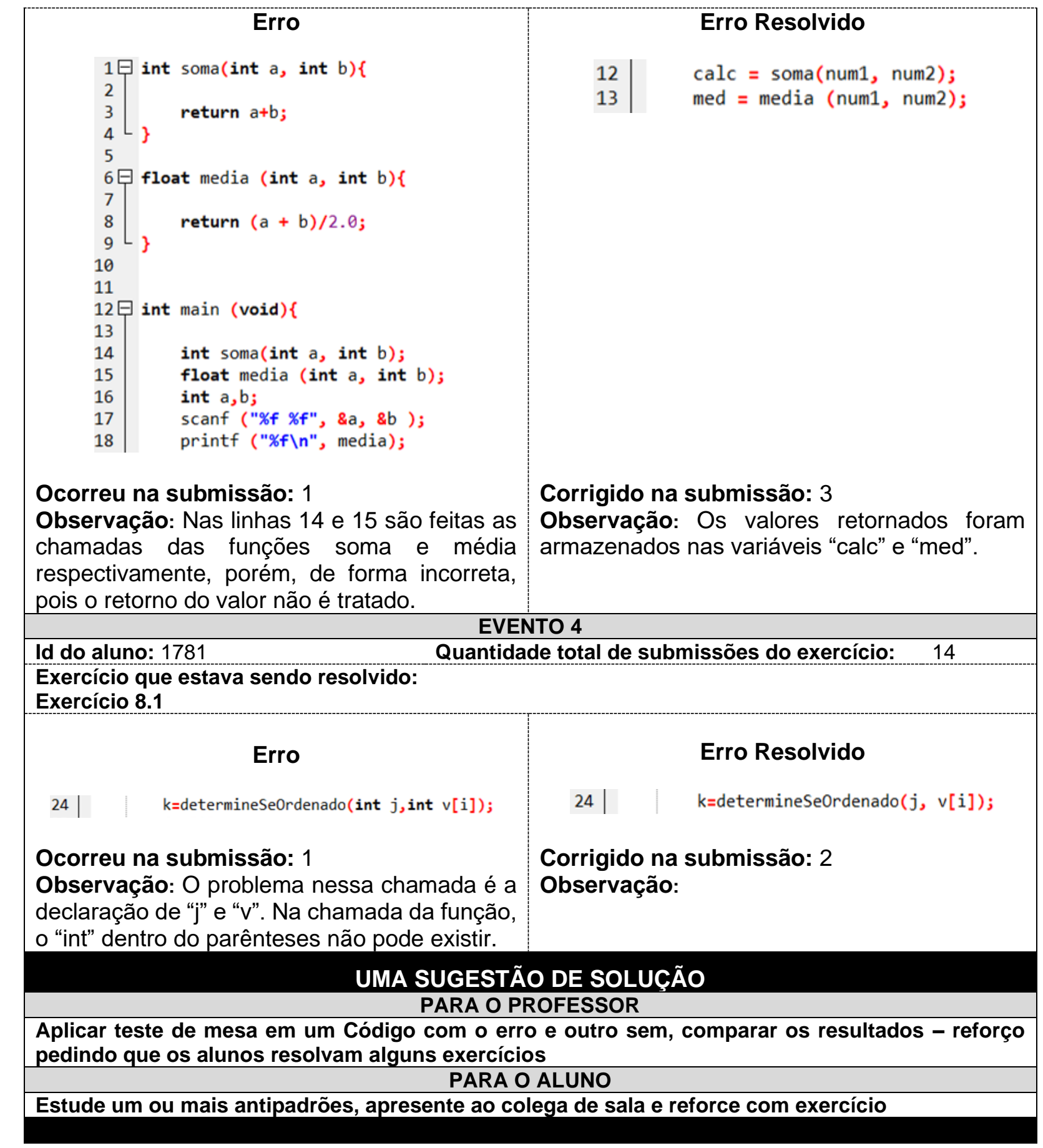

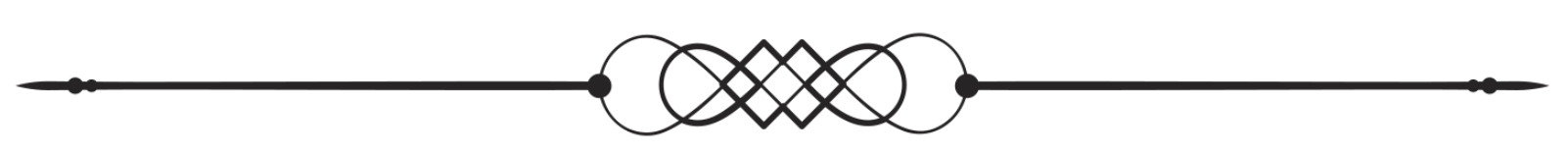




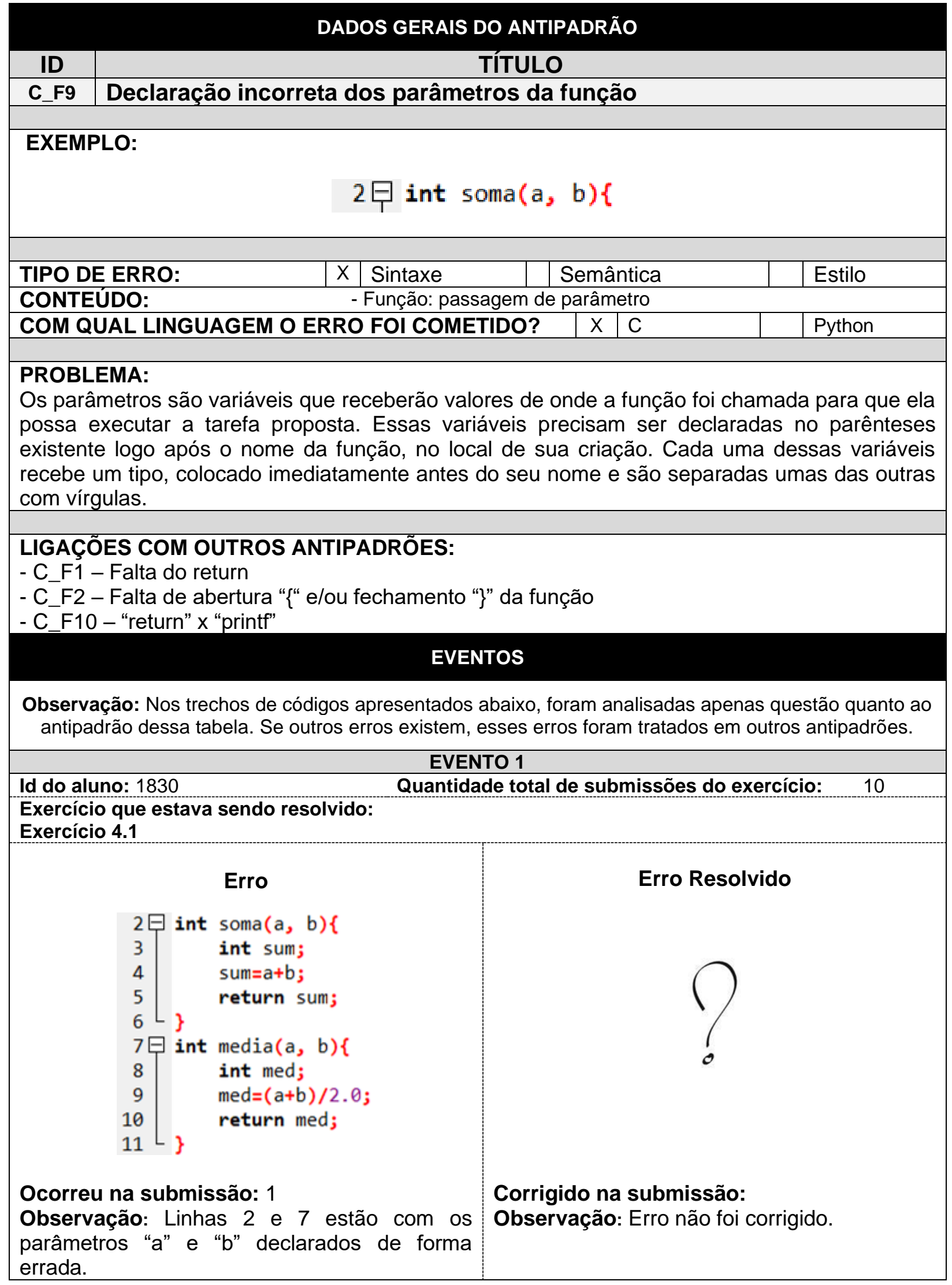


EVENTO 2

Id do aluno: 2040

Quantidade total de submissões do exercício:

Exercício que estava sendo resolvido:

Exercício 4.1

\section{Erro}

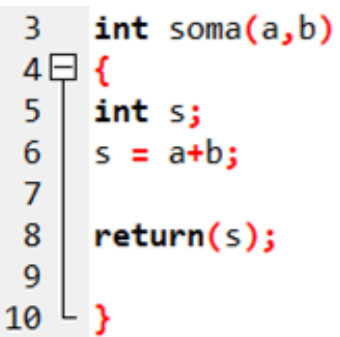

Ocorreu na submissão: 1

Observação: Linha 3 está com os parâmetros "a" e "b" declarados de forma incorreta.

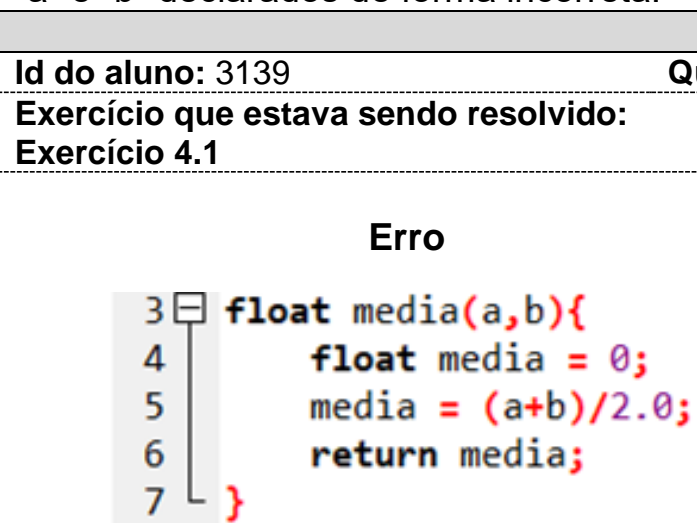

Ocorreu na submissão: 2

Observação: Linha 3 está com os parâmetros "a" e "b" declarados de forma incorreta.

\section{EVENTO 3}

Quantidade total de submissões do exercício:

\section{Erro Resolvido}

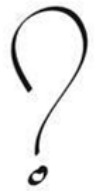

Corrigido na submissão:

Observação: Erro não foi corrigido. 
"a" e "b" declarados de forma incorreta.

\section{UMA SUGESTÃO DE SOLUÇÃO}

\section{PARA O PROFESSOR}

Programar na frente dos alunos, fazendo o erro aparecer - reforço pedindo que os alunos desenvolvam novos códigos

\section{Estude um ou mais antipadrões, apresente ao colega de sala e reforce com exercício}

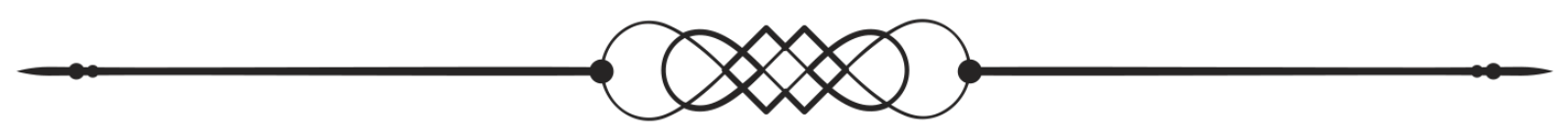

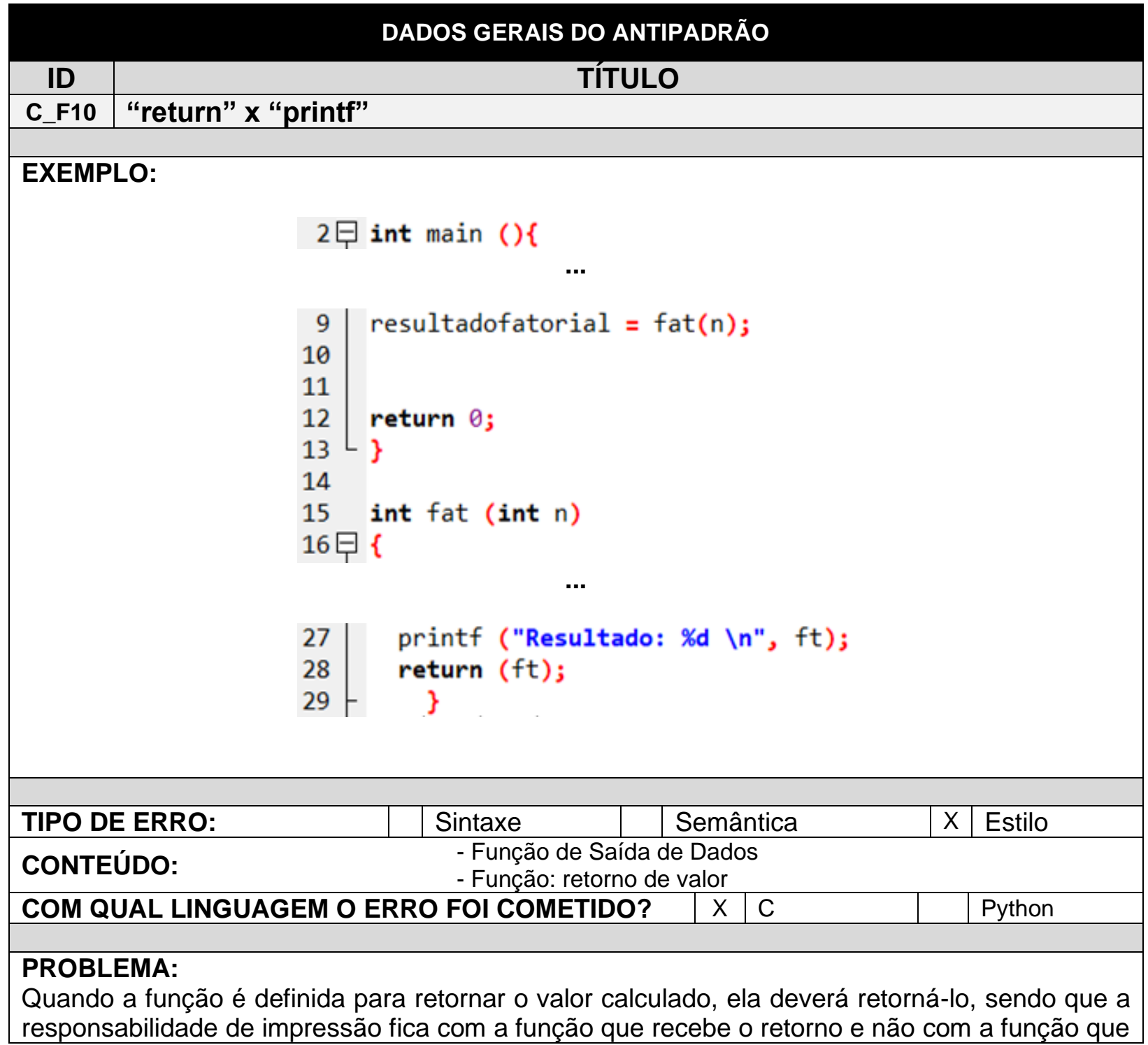


gerou o resultado.

LIGAÇÕES COM OUTROS ANTIPADRÕES:

- C_F1 - Falta do return

- C_F2 - Falta de abertura "\{" e/ou fechamento "\}" da função

- C F9 - Declaração incorreta dos parâmetros da função

\section{EVENTOS}

Observação: Nos trechos de códigos apresentados abaixo, foram analisadas apenas questão quanto ao antipadrão dessa tabela. Se outros erros existem, esses erros foram tratados em outros antipadrões.

\begin{tabular}{ll} 
& EVENTO 1 \\
\hline Id do aluno: 5226 & Quantidade total de submissões do exercício: \\
Exercício que estava sendo resolvido: & \\
Exercício 7.2 &
\end{tabular}

Exercício 7.2

\section{Erro}

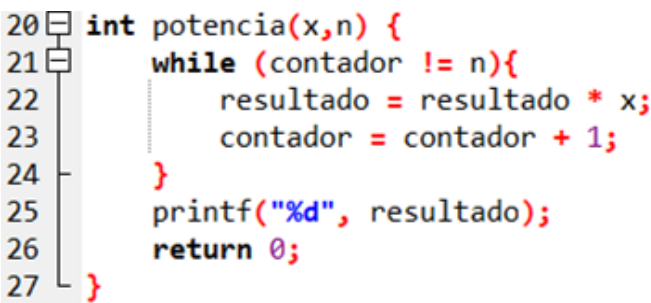

Ocorreu na submissão: 1

Observação: A função deveria retornar o "resultado" na linha 26 e o "printf" da linha 25 deveria estar na função onde esta foi chamada.

Id do aluno: 2950

EVENTO 2

Exercício que estava sendo resolvido:

Exercício 2.2

\section{Erro}

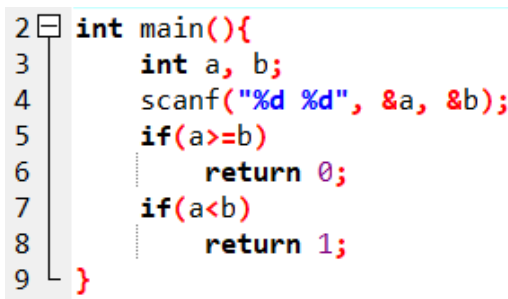

Ocorreu na submissão: 1

Observação: $O$ resultado deveria ser impresso e não retornado, como foi feito nas linhas 6 e 8.

Id do aluno: 5098 EVENTO 3

Exercício que estava sendo resolvido:

\section{Erro Resolvido}

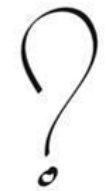

Corrigido na submissão:

Observação: Erro não foi corrigido.

Quantidade total de submissões do exercício:

3

\section{Erro Resolvido}

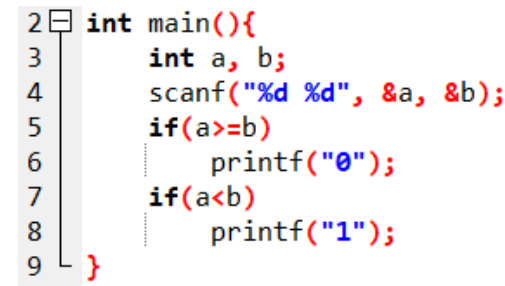

Corrigido na submissão: 2 Observação:

Quantidade total de submissões do exercício: 5 


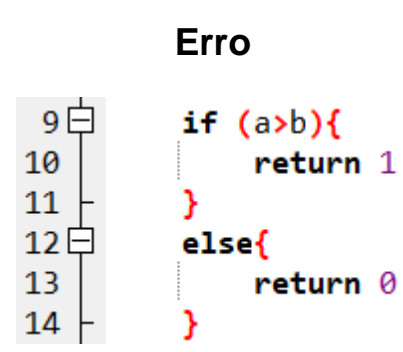

Ocorreu na submissão: 1

Observação: Os valores "1" e "0" deveriam ser impressos e não retornado, como foi feito nas linhas 10 e 13.

\section{Erro Resolvido}

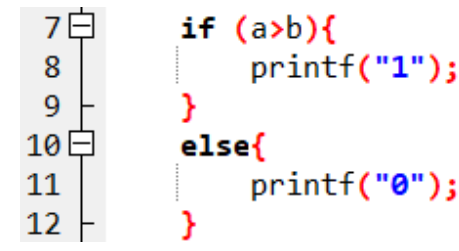

Corrigido na submissão: 4 Observação:

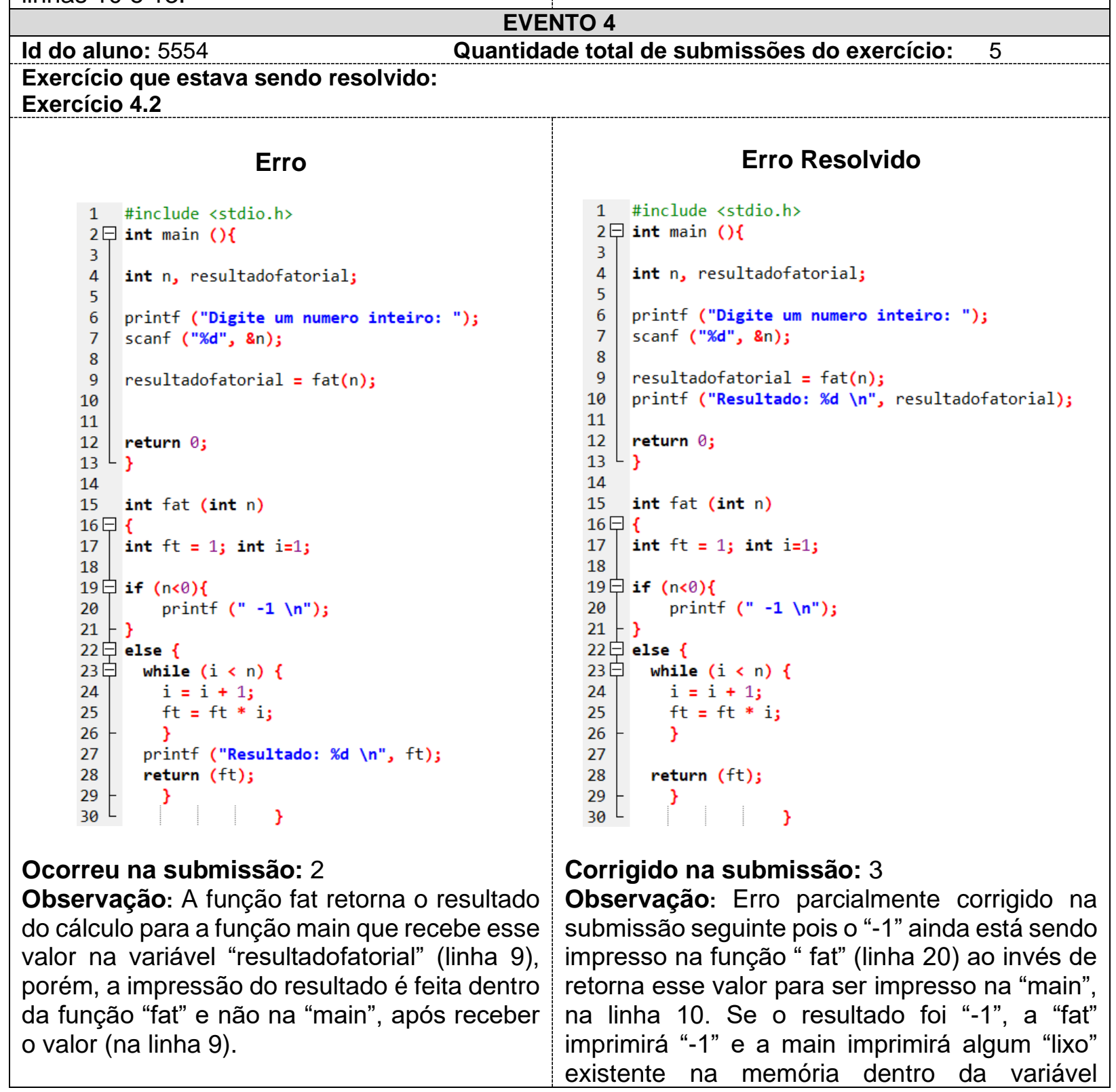


"resultadofatarial, normalmente o valor "0".

\section{UMA SUGESTÃO DE SOLUÇÃO}

PARA O PROFESSOR

Aplicar teste de mesa em um Código com o erro e outro sem, comparar os resultados - reforço pedindo que os alunos resolvam alguns exercícios

\section{PARA O ALUNO}

Estude um ou mais antipadrões, apresente ao colega de sala e reforce com exercício 


\section{Apêndice F}

\section{Catálogo de Antipadrões em Python}

A seguir é apresentado o catálogo de Antipadrões encontrados em Python.

\section{CATÁLOGO DE ANTIPADRÕES EM PYTHON}

\begin{tabular}{|c|c|c|c|c|}
\hline \multicolumn{5}{|c|}{ DADOS GERAIS DO ANTIPADRÃO } \\
\hline ID & \multicolumn{4}{|c|}{$\begin{array}{cc}\text { TÍTULO } \\
\end{array}$} \\
\hline P_V2 & \multicolumn{4}{|c|}{ Usar palavra reservada para nome de variável } \\
\hline \multirow{3}{*}{\multicolumn{5}{|c|}{$\begin{array}{l}\text { def } \operatorname{main}() \text { : } \\
\quad \text { int }=\text { int (input ()) } \\
\text { print (int) }\end{array}$}} \\
\hline & & & & \\
\hline & & & & \\
\hline \multirow{2}{*}{\multicolumn{5}{|c|}{ 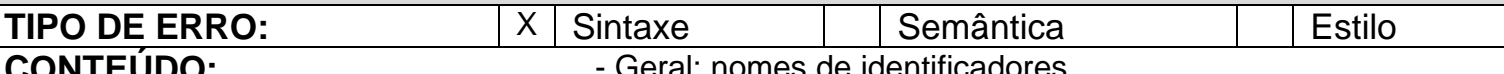 }} \\
\hline & & & & \\
\hline \multicolumn{3}{|c|}{$\begin{array}{l}\text { CONTEÚDO: } \\
\text { - Geral: nomes de identificadores } \\
\text { COM QUAL LINGUAGEM O ERRO FOI COMETIDO? }\end{array}$} & $x$ & Python \\
\hline \multicolumn{5}{|c|}{$\begin{array}{l}\text { PROBLEMA: } \\
\text { Palavras reservadas como "print", "int", "input", entre outras, não podem ser usadas para } \\
\text { identificadores, como é o caso dos nomes das variáveis. }\end{array}$} \\
\hline \multicolumn{5}{|c|}{$\begin{array}{l}\text { LIGAÇÕES COM OUTROS ANTIPADRÕES: } \\
\text { - V1 - Uso de variável inexistente } \\
\text { - V3 - Atribuição usando "==" ao invés de "=" }\end{array}$} \\
\hline
\end{tabular}




\section{EVENTOS}

Observação: Nos trechos de códigos apresentados abaixo, foram analisadas apenas questão quanto ao antipadrão dessa tabela. Se outros erros existem, esses erros foram tratados em outros antipadrões.

Id do aluno: 3237
Exercício que estava sendo resolvido:
Exercício 1.1
\[ \begin{array}{l}\text { Erro } \\ \text { int }=\text { int }(\text { input ()) } \\ \text { print (int) }\end{array} \]

Ocorreu na submissão: 1

Observação: Usou a palavra reservada "int" para nomear a variável.

\section{EVENTO 1}

Quantidade total de submissões do exercício:

2

\begin{tabular}{|ll|}
\hline & EVENTO 2 \\
\hline Id do aluno: 4730 & Quantidade total de submissões do exercício: 16 \\
\hline Exercício que estava sendo resolvido: & \\
Exercício 1.1 &
\end{tabular}

Erro

int = input ("Digite um numero inteiro: ")

print ("O numero inteiro dado foi: ", int)

Ocorreu na submissão: 1

Observação: Usou a palavra reservada "int" para nomear a variável.

Id do aluno: 3498

EVENTO 3

Exercício que estava sendo resolvido:

Exercício 3.3

\section{Erro}

soma $=$ int

\section{Ocorreu na submissão: 1}

Observação: No lugar desse "int" deveria ter um valor ou uma variável.

\section{Erro Resolvido}

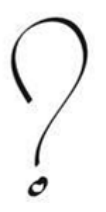

Corrigido na submissão:

Observação: Erro não foi corrigido.

\section{EVENTO 4}

Id do aluno: 2068

Quantidade total de submissões do exercício:

\section{Erro Resolvido}

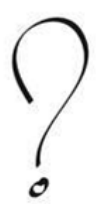

Corrigido na submissão:

Observação: Erro não foi corrigido.

Exercício que estava sendo resolvido:

Exercício 7.2 


\section{Erro \\ pot $=$ float}

Ocorreu na submissão: 2

Observação: No lugar do "float" deveria ter um valor ou uma variável.

\section{Erro Resolvido}

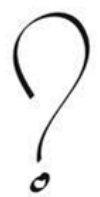

Corrigido na submissão:

Observação: Erro não foi corrigido.

\section{UMA SUGESTÃO DE SOLUÇÃO}

\section{PARA O PROFESSOR}

Grupos trabalhando com execucão passa a passo para entender os erros - reforco com exercícios

$$
\text { PARA O ALUNO }
$$

Estude um ou mais antipadrões, apresente ao colega de sala e reforce com exercício

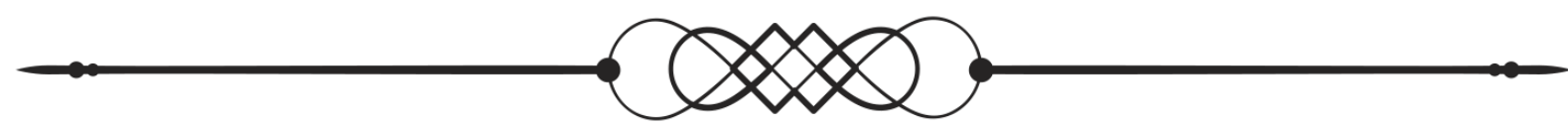

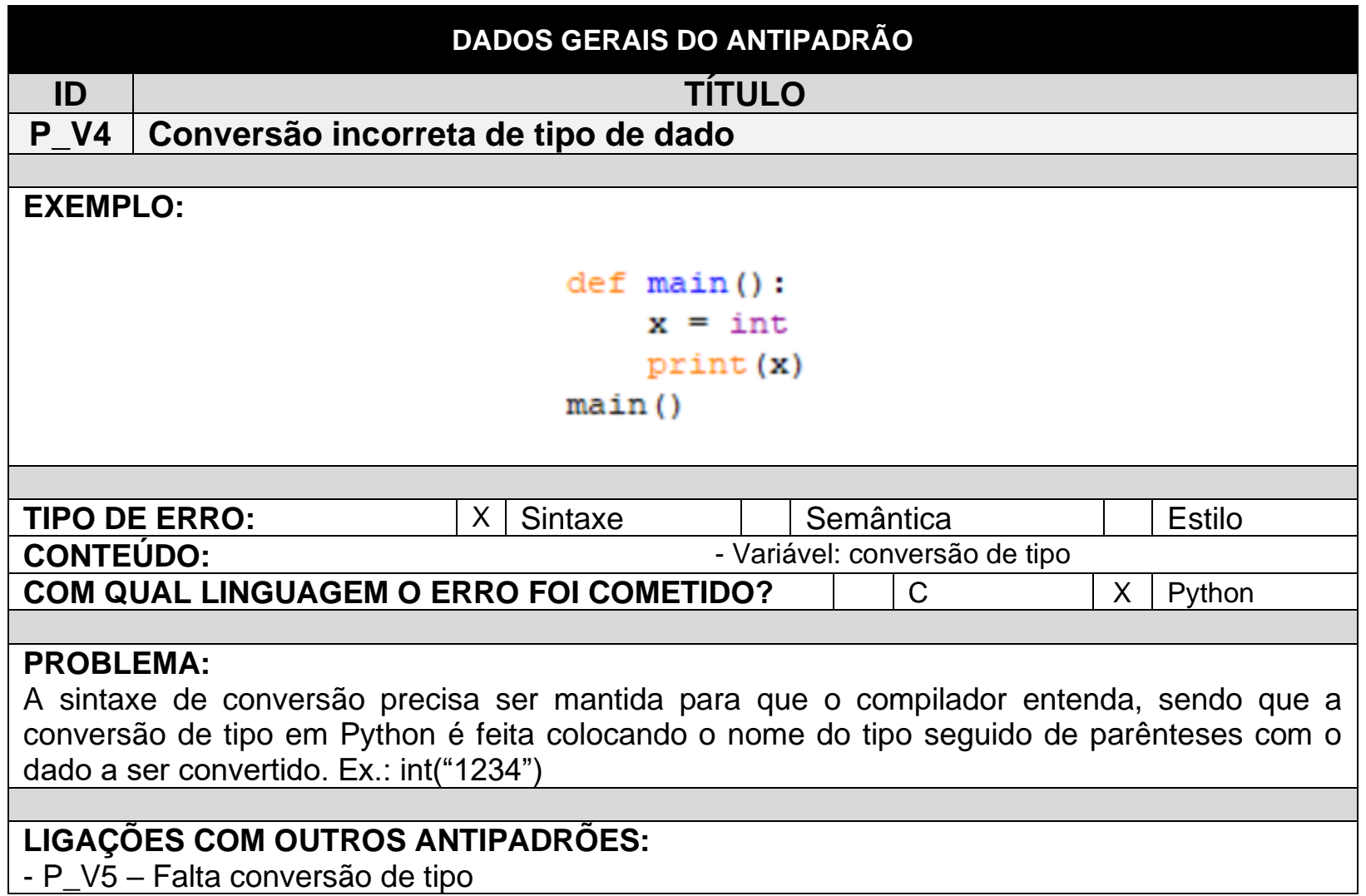




\section{EVENTOS}

Observação: Nos trechos de códigos apresentados abaixo, foram analisadas apenas questão quanto ao antipadrão dessa tabela. Se outros erros existem, esses erros foram tratados em outros antipadrões.

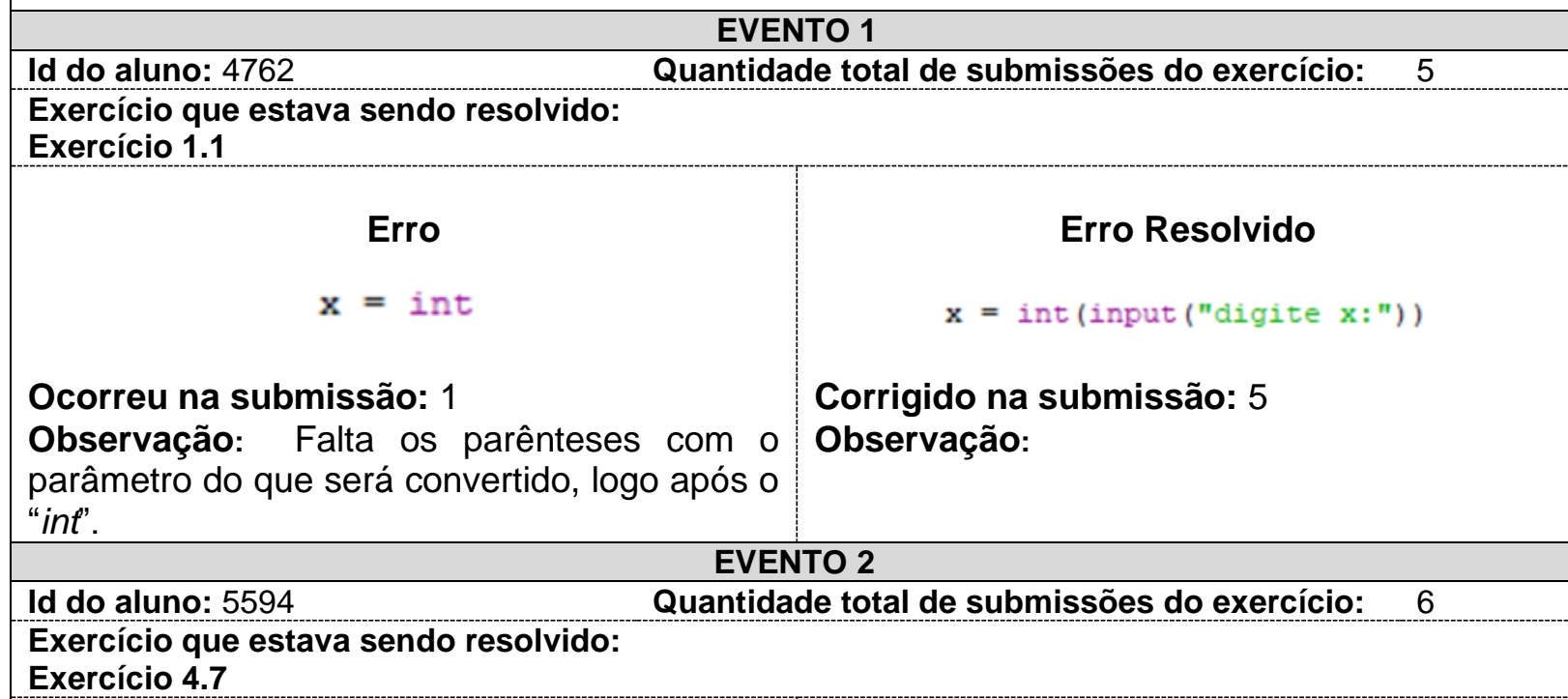

Erro num=input (int ("num: "))

Ocorreu na submissão: 1

Observação: $O$ "int" e o "input" estão em ordem inversa.

Id do aluno: 4842

EVENTO 3

Exercício que estava sendo resolvido:

Exercício 1.1

Observação: Após o "int" deveria ter

\section{Quantidade total de submissões do exercício: 4}

\section{Erro Resolvido}

num=int (input ())

Corrigido na submissão: 4

Observação:
Ocorreu na submissão: 1 parênteses.

Id do aluno:

Exercício que estava sendo resolvido:

\section{Erro}

Ocorreu na submissão:

Observação:

\section{EVENTO 4}

Quantidade total de submissões do exercício:

\section{Erro Resolvido}

n=int (input ())

Corrigido na submissão: 4 Observação: 


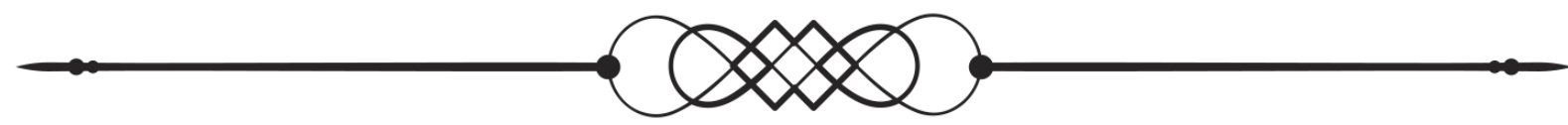

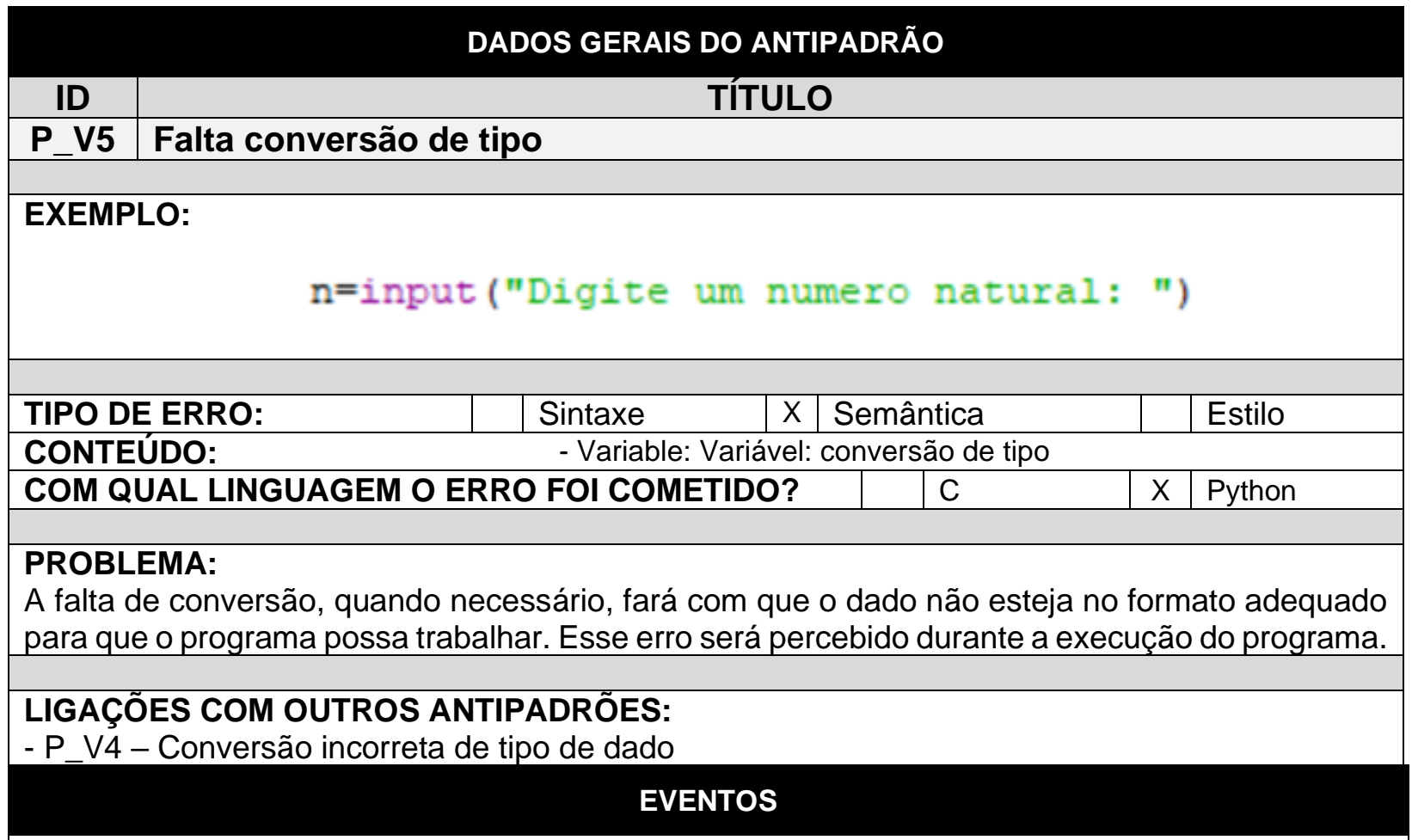

Observação: Nos trechos de códigos apresentados abaixo, foram analisadas apenas questão quanto ao antipadrão dessa tabela. Se outros erros existem, esses erros foram tratados em outros antipadrões.

Id do aluno: 5594

\section{EVENTO 1}

Exercício que estava sendo resolvido:

Exercício 4.7

Quantidade total de submissões do exercício: 6

$$
\begin{gathered}
\text { Erro } \\
\text { n=input ("Digite um numero natural: ") }
\end{gathered}
$$

Ocorreu na submissão: 1

Observação: Falta a conversão do dado de entrada para tipo numérico.

\section{Erro Resolvido}

$\mathrm{n}=$ int (input ())

Corrigido na submissão: 3

Observação: 
EVENTO 2

Id do aluno: $4730 \quad$ Quantidade total de submissões do exercício: 3
Exercício que estava sendo resolvido:

Exercício 1.2

\section{Erro}

num = input ("Digite um numero inteiro: ")

Ocorreu na submissão: 1

Observação:

Id do aluno: 4762

Exercício que estava sendo resolvido:

Exercício 1.2

$$
\begin{gathered}
\text { Erro } \\
\mathrm{x} \text { = input ("digite } \mathrm{x}: \text { ") }
\end{gathered}
$$

Ocorreu na submissão: 1

Observação:

Id do aluno: 4842

Exercício que estava sendo resolvido:

Exercício 2.1

$$
\begin{gathered}
\text { Erro } \\
\mathrm{n}=\text { input () }
\end{gathered}
$$

Ocorreu na submissão: 1

Observação:

\section{Erro Resolvido}

$\mathrm{n}=$ input ("Digite um numero inteiro: ")

num $=$ int $(n)$

Corrigido na submissão: 2 Observação:

\section{EVENTO 3}

Quantidade total de submissões do exercício: 3 


\section{DADOS GERAIS DO ANTIPADRÃO}

\begin{tabular}{|c|c|c|c|c|c|}
\hline \multirow{2}{*}{$\frac{\text { ID }}{P \text { IF4 }}$} & \multicolumn{5}{|c|}{ TITULO } \\
\hline & \multicolumn{5}{|c|}{ Falta parênteses no "input” } \\
\hline \multirow{3}{*}{\multicolumn{6}{|c|}{$\begin{array}{l}a=\text { input } \\
\text { print (a) }\end{array}$}} \\
\hline & & & & & \\
\hline & & & & & \\
\hline \multicolumn{2}{|c|}{\begin{tabular}{l|l} 
TIPO DE ERRO: & \rangle \\
\end{tabular}} & \begin{tabular}{l|l} 
Sintaxe & \\
\end{tabular} & Semântica & & Estilo \\
\hline \multicolumn{6}{|c|}{$\begin{array}{ll}\text { CONTEÚDO: } & \text { - Função de Entrada de Dados } \\
& \text { - Função }\end{array}$} \\
\hline \multicolumn{3}{|c|}{ COM QUAL LINGUAGEM O ERRO FOI COMETIDO? } & \begin{tabular}{l|l|l|} 
& & $C$ \\
\end{tabular} & $\mathrm{X}$ & Python \\
\hline \multicolumn{6}{|c|}{$\begin{array}{l}\text { PROBLEMA: } \\
\text { Toda nome de função é seguido de parênteses usados para colocar os parâmetros, mesmo que } \\
\text { eles não existem. Como "input" é uma função, ela precisa estar seguida de parênteses. }\end{array}$} \\
\hline
\end{tabular}

Observação: Nos trechos de códigos apresentados abaixo, foram analisadas apenas questão quanto ao antipadrão dessa tabela. Se outros erros existem, esses erros foram tratados em outros antipadrões.

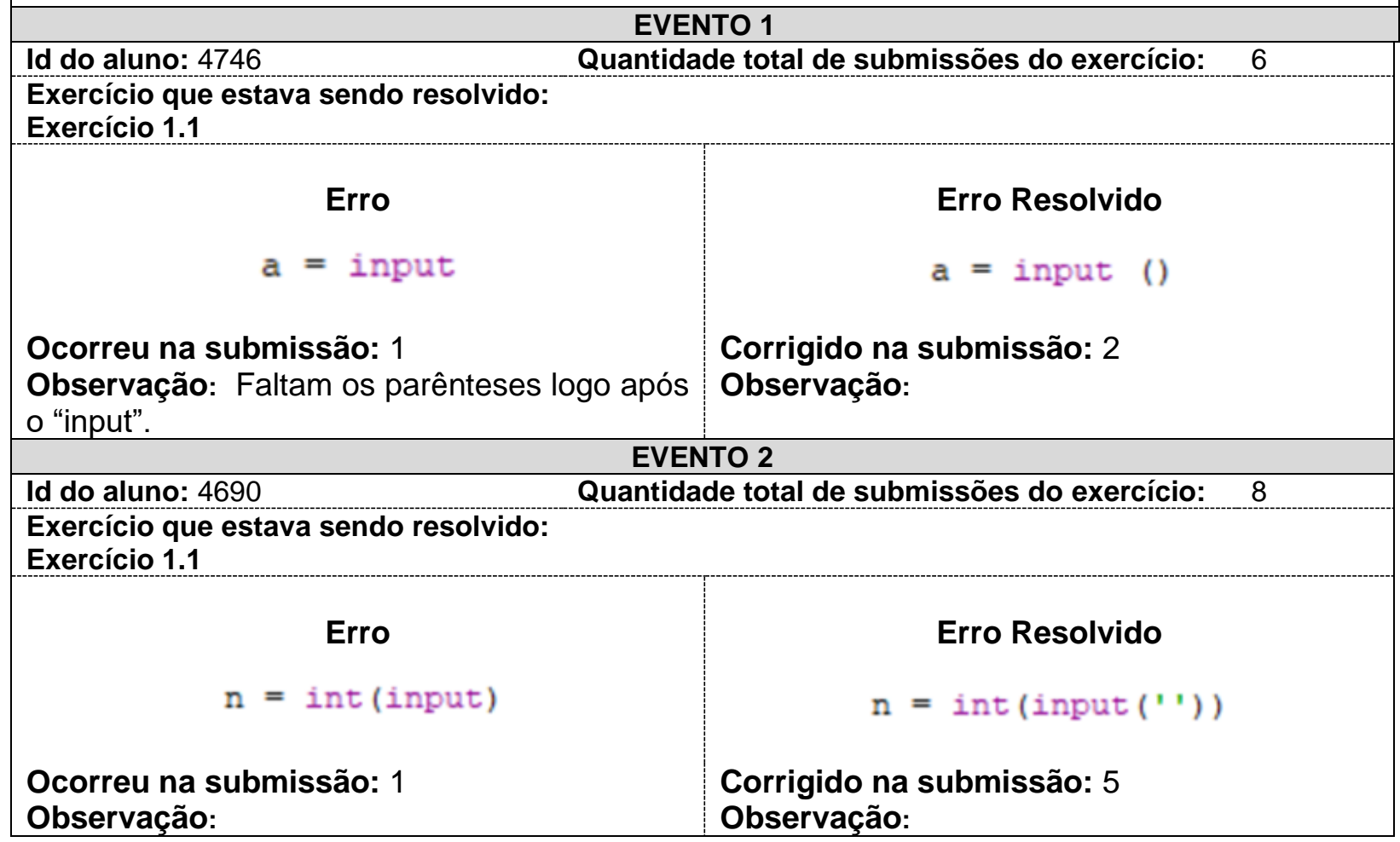


EVENTO 3

Id do aluno: 4962

Quantidade total de submissões do exercício:

4

Exercício que estava sendo resolvido:

Exercício 1.1

Erro

\section{$a=i n t$ (input)}

Ocorreu na submissão: 1

Observação:

Id do aluno:

Exercício que estava sendo resolvido:

\section{Erro}

Ocorreu na submissão:

Observação:

\section{Erro Resolvido}

a=int (input ())

Corrigido na submissão: 3 Observação:

\section{EVENTO 4}

Quantidade total de submissões do exercício:

\section{Erro Resolvido}

Corrigido na submissão:

Observação:

\section{UMA SUGESTÃO DE SOLUÇÃO}

PARA O PROFESSOR

Explicação usando quadro negro e projetor - fixar os conceitos usando Kahoot (plataforma de aprendizado baseada em jogos)

Resolver exercícios, acrescentar erros nos códigos e pedir que o colega de sala os encontrem

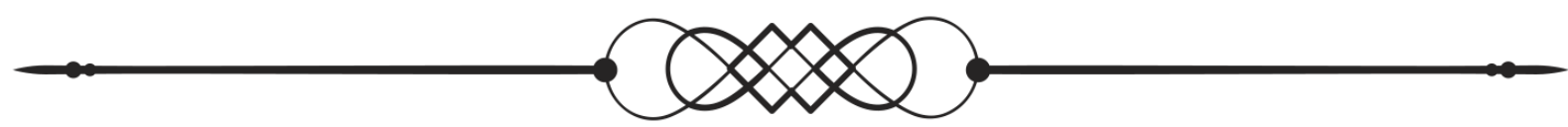

\section{DADOS GERAIS DO ANTIPADRÃO}

\begin{tabular}{c|c} 
ID & TÍTULO \\
\hline P_OF5 & "print" seguido por "=" ou outro parâmetro incorreto
\end{tabular}

EXEMPLO:

$$
\text { print }=(" n ")
$$

TIPO DE ERRO:

CONTEÚDO:

COM QUAL LINGUAGEM O ERRO FOI COMETIDO?
Semântica

C
Estilo

$\mathrm{X}$ Python




\section{PROBLEMA:}

O sinal de "=" é usado para atribuição e como o "print" não é uma variável, não poderá estar seguido desse sinal.

\section{LIGAÇÕES COM OUTROS ANTIPADRÕES:}

- P_OF2 - Falta das aspas na função de saída de dados

- P OF4 - Falta da vírgula para separar os parâmetros no "print"

\section{EVENTOS}

Observação: Nos trechos de códigos apresentados abaixo, foram analisadas apenas questão quanto ao antipadrão dessa tabela. Se outros erros existem, esses erros foram tratados em outros antipadrões.

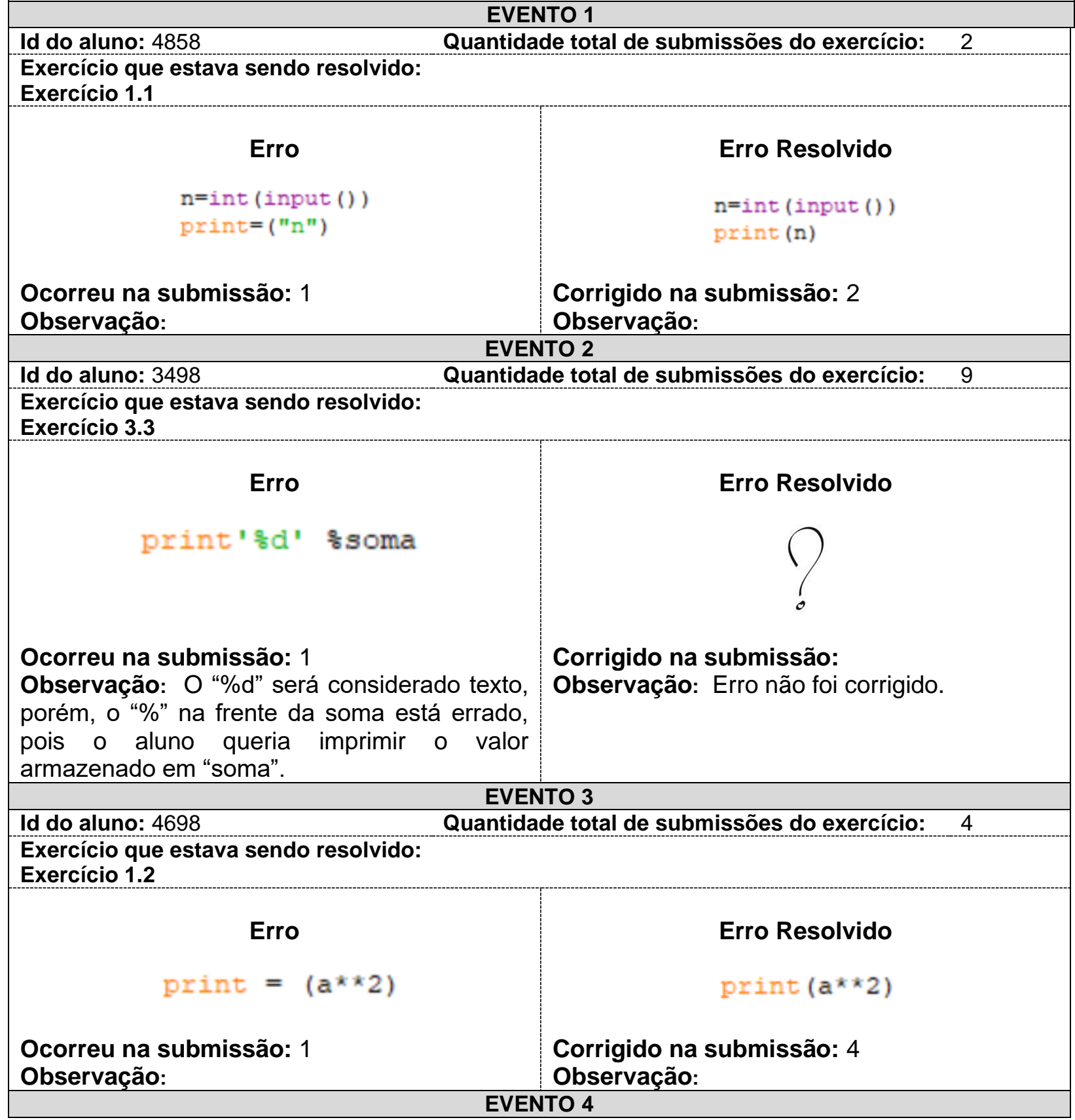


Id do aluno:

Quantidade total de submissões do exercício:

Exercício que estava sendo resolvido:

Erro

\section{Erro Resolvido}

Ocorreu na submissão:

Observação:

Corrigido na submissão:

Observação:

\section{UMA SUGESTÃO DE SOLUÇÃO}

PARA O PROFESSOR

Explicação usando quadro negro e projetor - fixar os conceitos usando Kahoot (plataforma de aprendizado baseada em jogos)

Resolver exercícios, acrescentar erros nos códigos e pedir que o colega de sala os encontrem

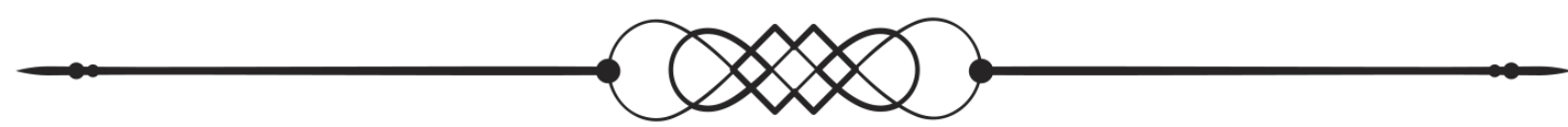

DADOS GERAIS DO ANTIPADRÃO

\begin{tabular}{c|lc} 
ID & TÍTULO \\
\hline P_AE2 & Operador aritmético errado
\end{tabular}

EXEMPLO:

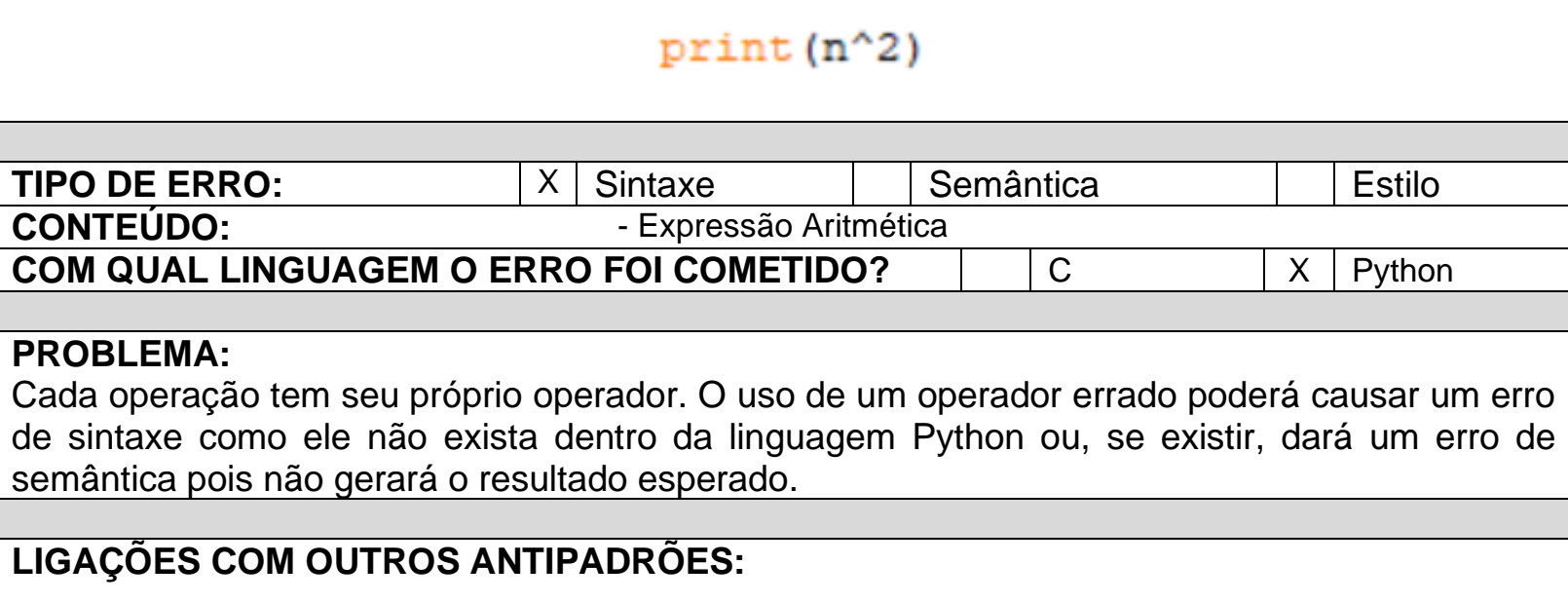

\section{EVENTOS}

Observação: Nos trechos de códigos apresentados abaixo, foram analisadas apenas questão quanto ao antipadrão dessa tabela. Se outros erros existem, esses erros foram tratados em outros antipadrões. 


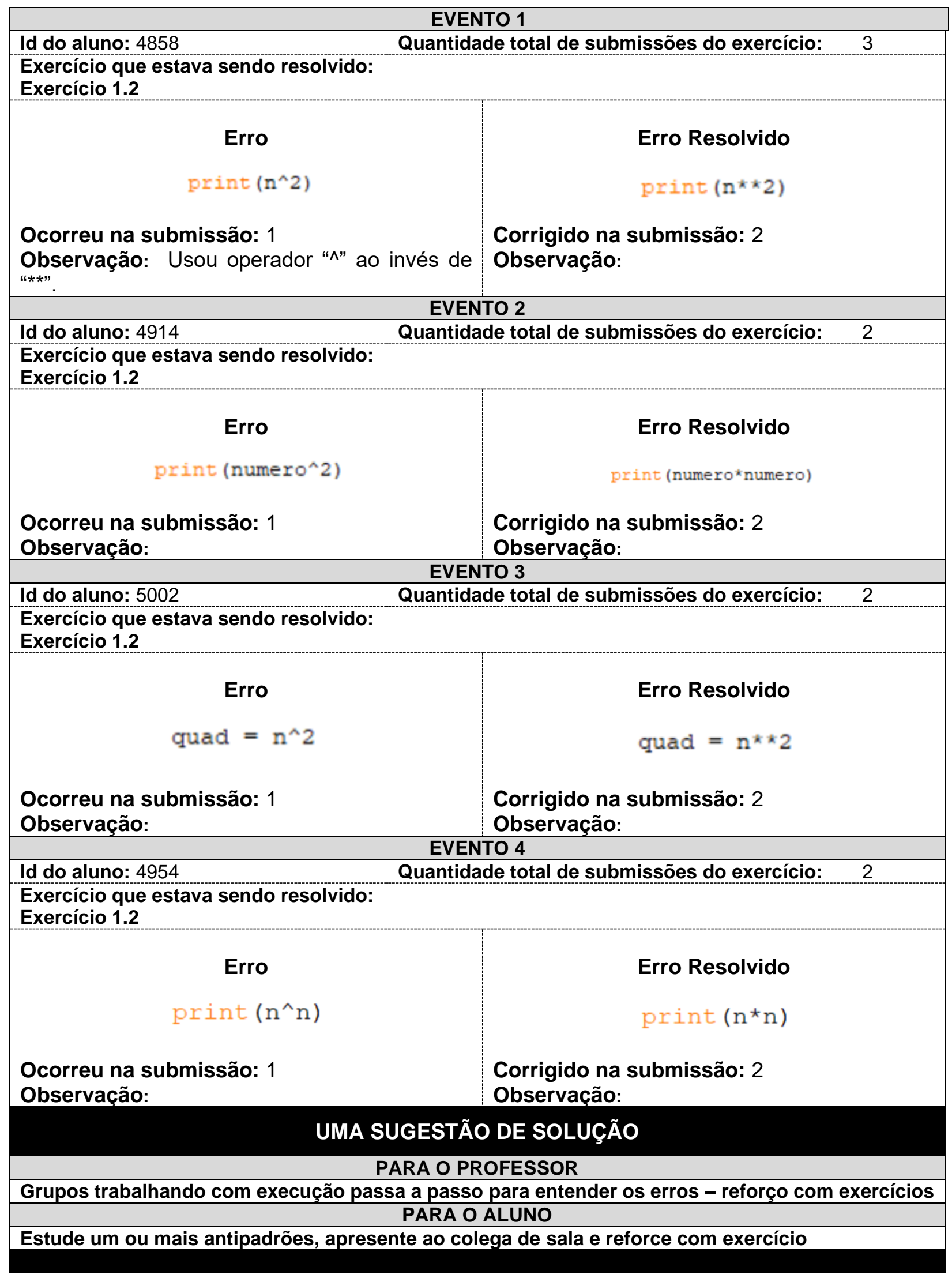




\section{DADOS GERAIS DO ANTIPADRÃO}

\begin{tabular}{c|c} 
ID & TÍTULO \\
\hline P_SS1 & Falta dos ":" no final da linha do "if" ou do "else"
\end{tabular}

\section{EXEMPLO:}

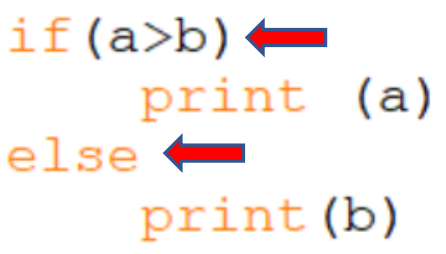

\begin{tabular}{l|l|l|l|l|l|}
\hline TIPO DE ERRO: & $\mathrm{X}$ & Sintaxe & Semântica & & Estilo \\
\hline CONTEÚDO: & - Estrutura de Seleção & $\mathrm{C}$ & Python \\
\hline COM QUAL LINGUAGEM O ERRO FOI COMETIDO? & $\mathrm{C}$ & $\mathrm{X}$
\end{tabular}

\section{PROBLEMA:}

Os dois pontos ":" indicam início de um bloco, logo, após a condição do "if" ou após o "else" é necessário que ele seja inserido no código.

\section{LIGAÇÕES COM OUTROS ANTIPADRÕES:}

- SS2 - O não uso do "else" onde seria adequado

\section{EVENTOS}

Observação: Nos trechos de códigos apresentados abaixo, foram analisadas apenas questão quanto ao antipadrão dessa tabela. Se outros erros existem, esses erros foram tratados em outros antipadrões.

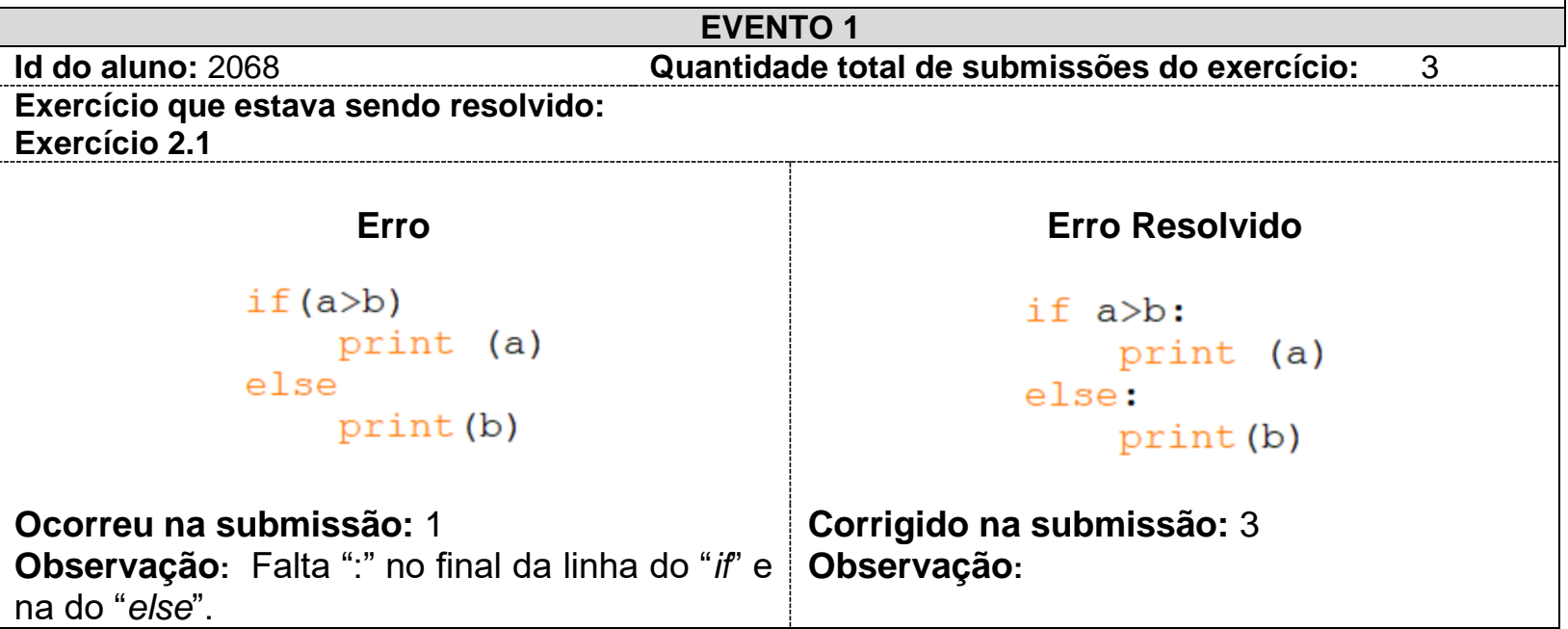




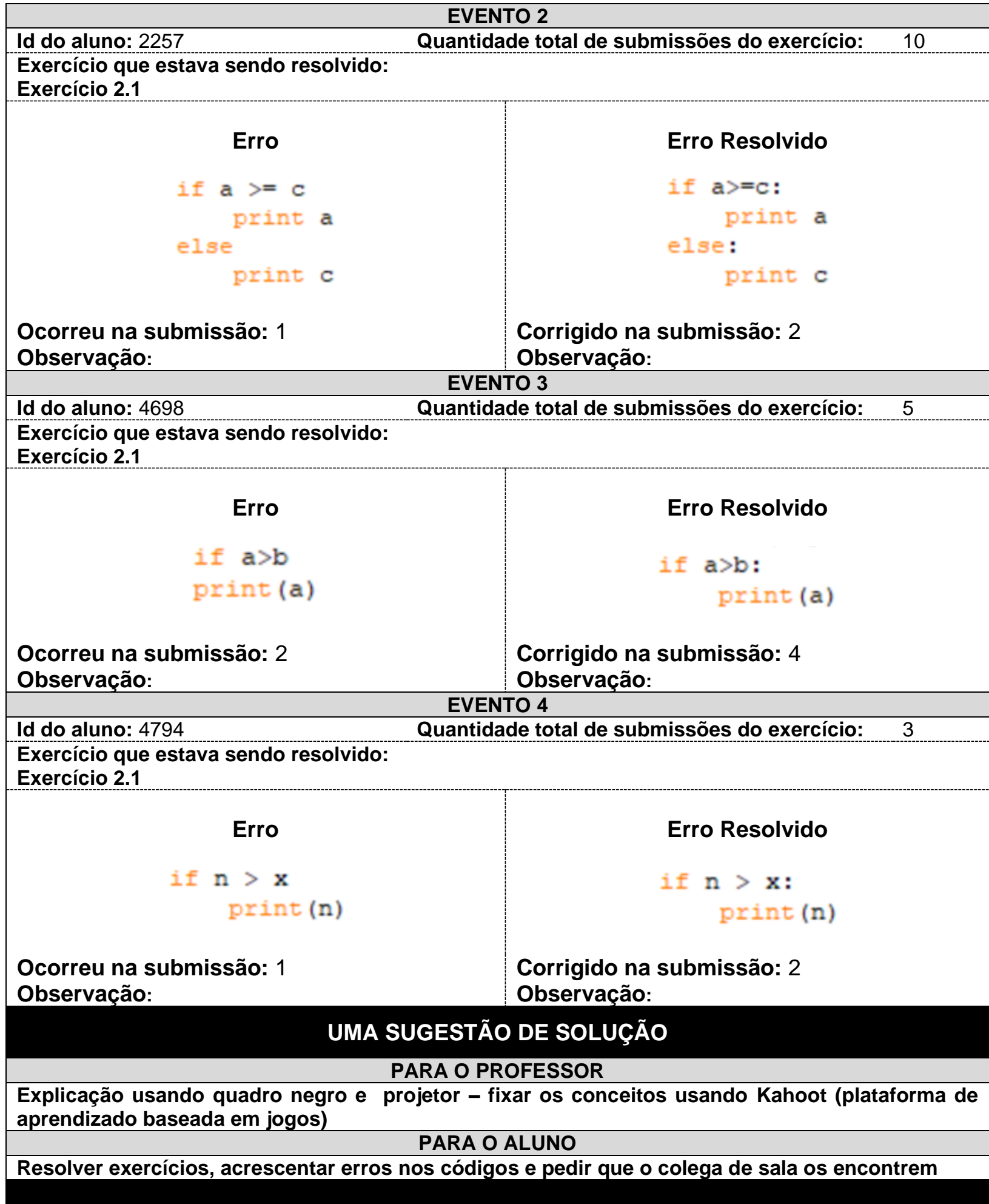

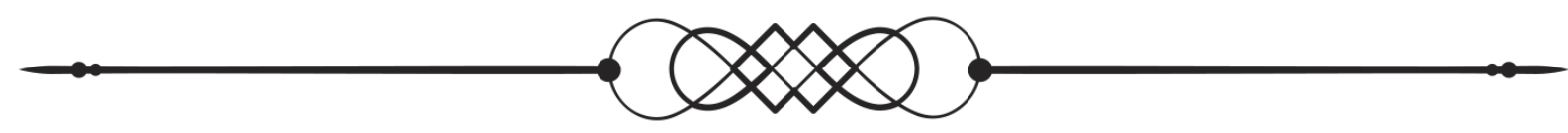




\section{DADOS GERAIS DO ANTIPADRÃO}

\begin{tabular}{|c|c|}
\hline ID & TíTULO \\
\hline P_RS1 & Ordem incorreta dos comandos na estrutura \\
\hline
\end{tabular}

\section{EXEMPLO:}

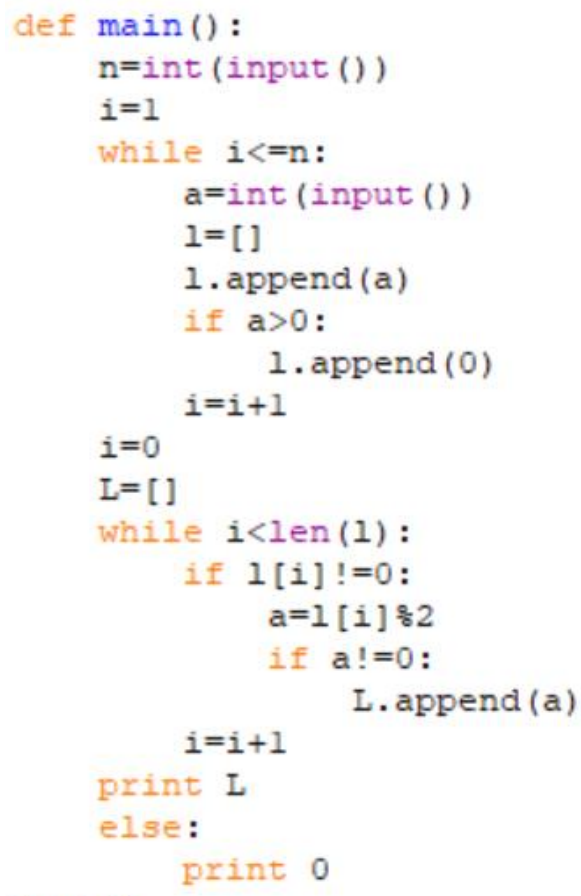

\section{PROBLEMA:}

A ordem dos comandos influencia no resultado do programa, logo, é fundamental o cuidado na ordem estipulada para os comandos usados.

\section{LIGAÇÕES COM OUTROS ANTIPADRÕES:}

\section{EVENTOS}

Observação: Nos trechos de códigos apresentados abaixo, foram analisadas apenas questão quanto ao antipadrão dessa tabela. Se outros erros existem, esses erros foram tratados em outros antipadrões.

Id do aluno: 4962

EVENTO 1

Exercício que estava sendo resolvido:

Exercício 4.7 


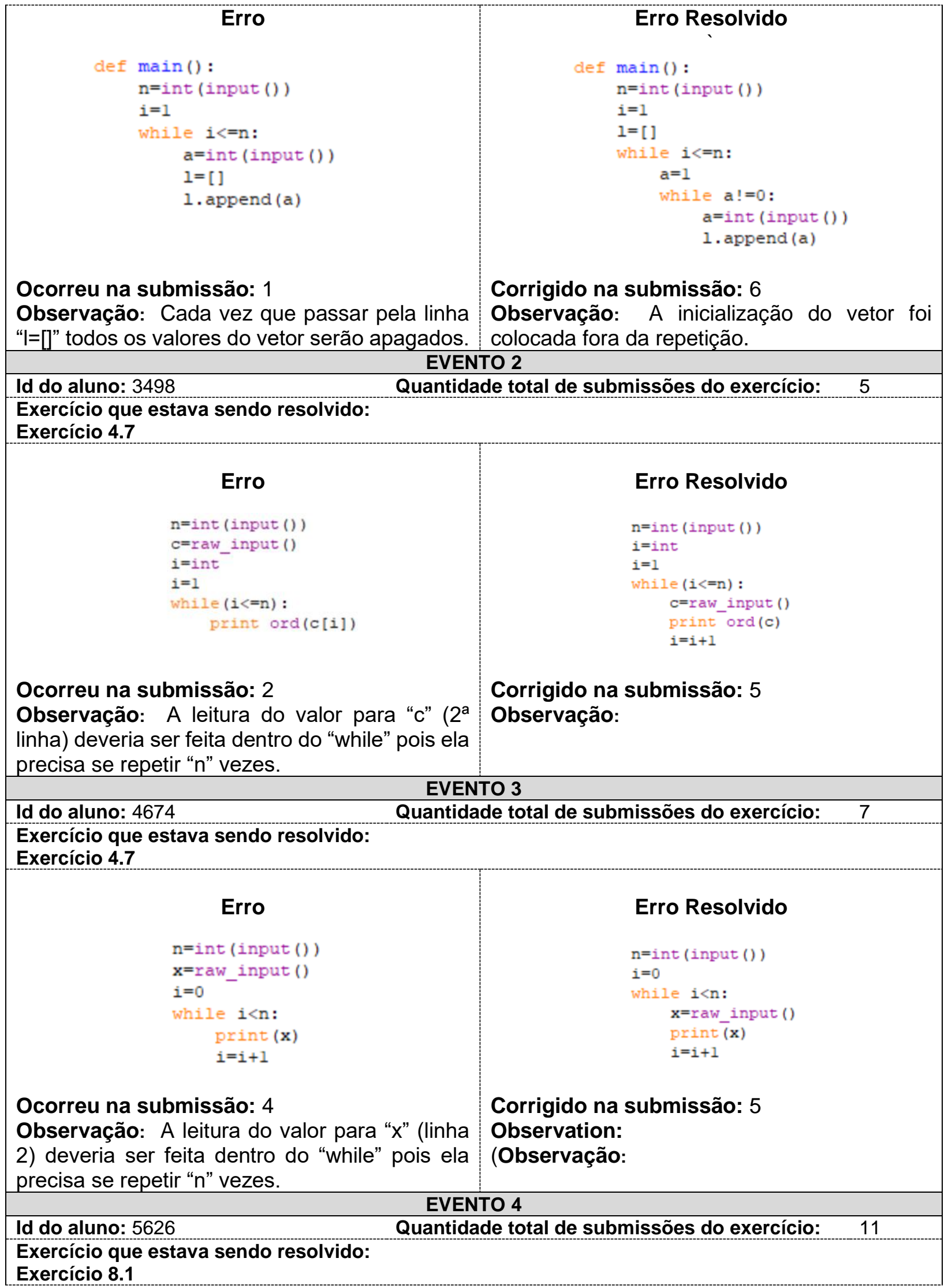




\section{Erro}

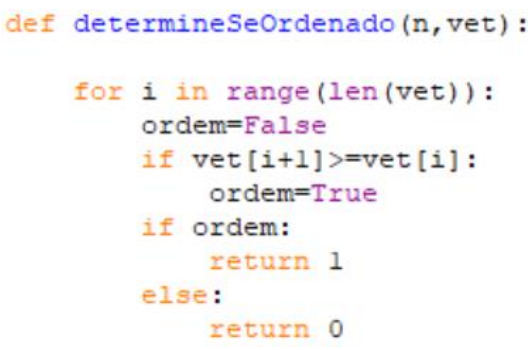

\section{Ocorreu na submissão: 1}

Observação: O commando "ordem=False" deveria estar antes do "for" e a estrutura "if ordem:" depois.

\section{Erro Resolvido}

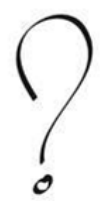

Corrigido na submissão:

Observação: Erro não foi corrigido.

\section{UMA SUGESTÃO DE SOLUÇÃO}

PARA O PROFESSOR

Programar na frente dos alunos, fazendo o erro aparecer - reforço pedindo que os alunos desenvolvam novos códigos

\section{PARA O ALUNO}

Introduzir o erro em um código e entender as consequências que ele gera

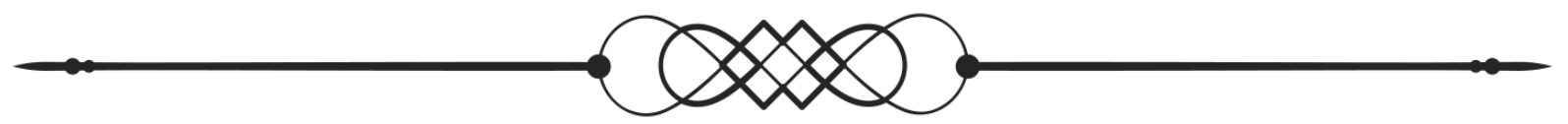

\section{DADOS GERAIS DO ANTIPADRÃO}

ID TÍTULO

P_SRS1 Uso de estrutura de repetição onde deveria ser de seleção

\section{EXEMPLO:}

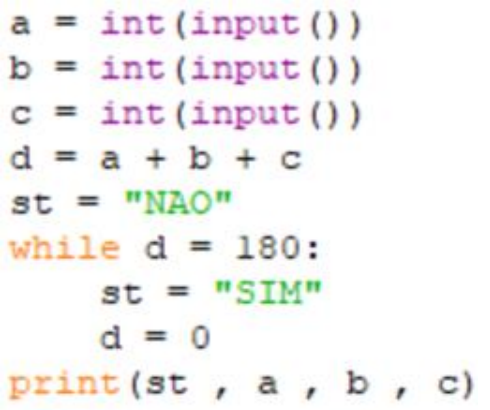




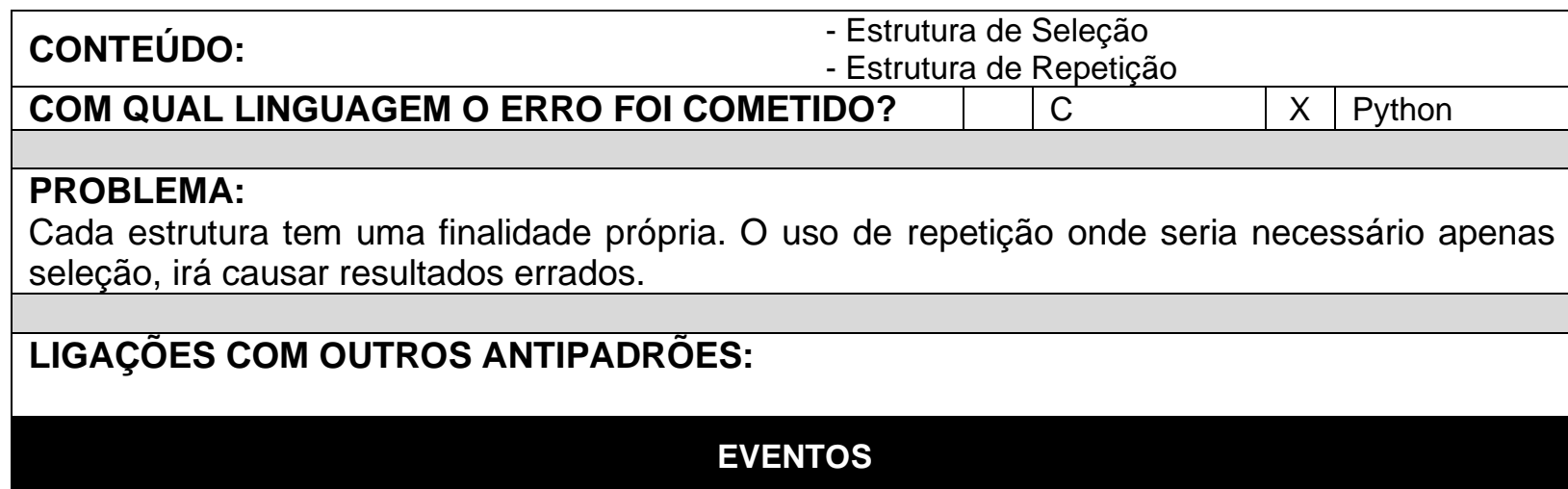

Observação: Nos trechos de códigos apresentados abaixo, foram analisadas apenas questão quanto ao antipadrão dessa tabela. Se outros erros existem, esses erros foram tratados em outros antipadrões.

\begin{tabular}{|c|c|}
\hline \multicolumn{2}{|c|}{ EVENTO 1} \\
\hline Id do aluno: 4890 & Quantidade total de submissões do exercício: \\
\hline \multicolumn{2}{|l|}{$\begin{array}{l}\text { Exercício que estava sendo resolvido: } \\
\text { Exercício } 3.1\end{array}$} \\
\hline Erro & \multirow[b]{3}{*}{$\begin{array}{l}\text { Corrigido na submissão: } \\
\text { Observação: Erro não foi corrigido. }\end{array}$} \\
\hline $\begin{array}{c}\mathrm{a}=\operatorname{int}(\text { input }()) \\
\mathrm{b}=\operatorname{int}(\text { input }()) \\
\mathrm{c}=\operatorname{int}(\text { input }()) \\
\mathrm{d}=\mathrm{a}+\mathrm{b}+\mathrm{c} \\
\text { st }=\text { "NAO" } \\
\text { while } \mathrm{d}=180: \\
\text { st }=\text { "SIM" } \\
\mathrm{d}=0 \\
\text { print }(\text { st }, \mathrm{a}, \mathrm{b}, \mathrm{c})\end{array}$ & \\
\hline $\begin{array}{l}\text { Ocorreu na submissão: } 1 \\
\text { Observação: No lugar do "while" deferia ser um } \\
\text { "if". }\end{array}$ & \\
\hline \multicolumn{2}{|c|}{ EVENTO 2} \\
\hline \multicolumn{2}{|c|}{ Quantidade total de submissões do exercício: } \\
\hline \multicolumn{2}{|l|}{$\begin{array}{l}\text { Exercício que estava sendo resolvido: } \\
\text { Exercício } 3.1\end{array}$} \\
\hline Erro & Erro Resolvido \\
\hline $\begin{array}{l}\text { while } a+b+c: \\
\text { print ("Sim" a, b, c) }\end{array}$ & $\begin{array}{l}\text { if } a+b+c==180: \\
\text { print ("Sim", } a, b, c)\end{array}$ \\
\hline print ("NAO" $a+b+c)$ & $\begin{array}{l}\text { else: } \\
\text { print ("NAO", } a+b+c)\end{array}$ \\
\hline $\begin{array}{l}\text { Ocorreu na submissão: } 5 \\
\text { Observação: No lugar do "while" deveria ser } \\
\text { um "if". }\end{array}$ & $\begin{array}{l}\text { Corrigido na submissão: } 7 \\
\text { Observação: }\end{array}$ \\
\hline \multicolumn{2}{|c|}{ EVENTO 3} \\
\hline Id do aluno: 4970 & Quantidade total de submissões do exercício: \\
\hline $\begin{array}{l}\text { Exercício que estava sendo resolvido: } \\
\text { Exercício } 3.1\end{array}$ & \\
\hline
\end{tabular}




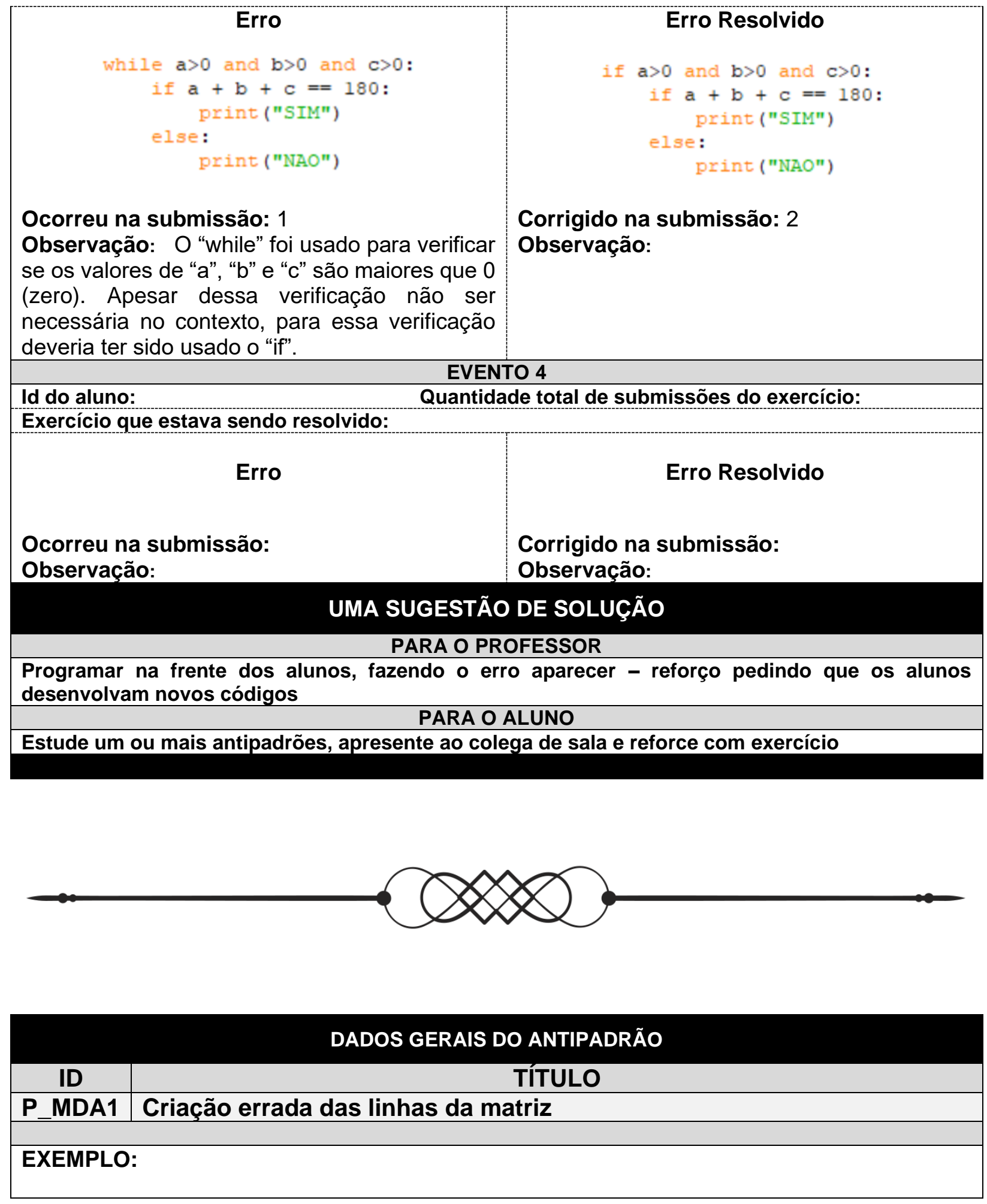




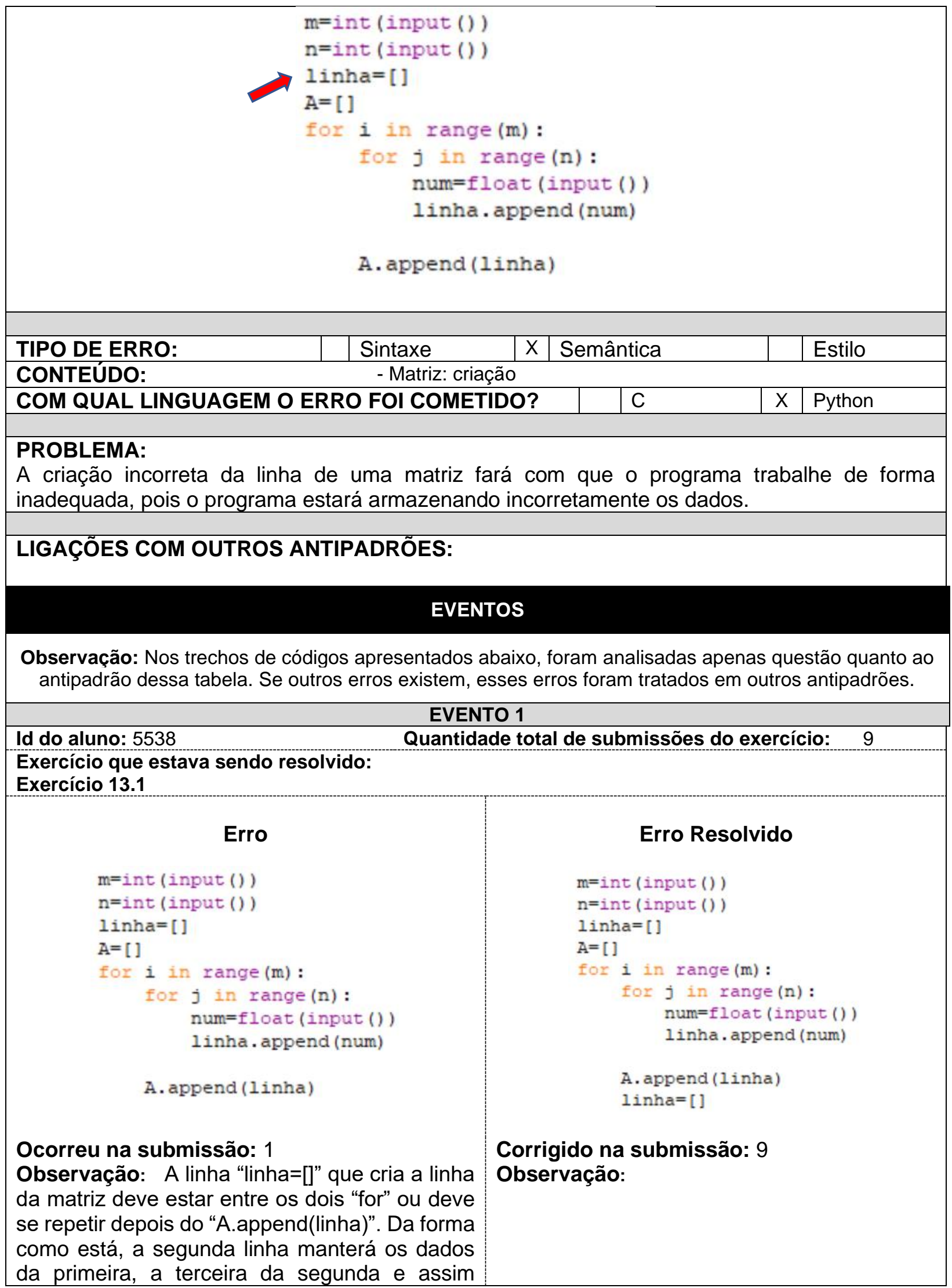




\begin{tabular}{|c|c|}
\hline \multicolumn{2}{|c|}{ EVENTO 2} \\
\hline Id do aluno: 5714 & Quantidade total de submissões do exercício: \\
\hline \multicolumn{2}{|l|}{$\begin{array}{l}\text { Exercício que estava sendo resolvido: } \\
\text { Exercício } 13.1\end{array}$} \\
\hline Erro & Erro Resolvido \\
\hline 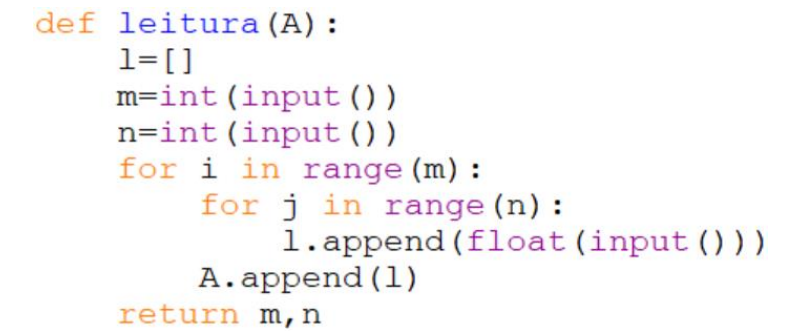 & 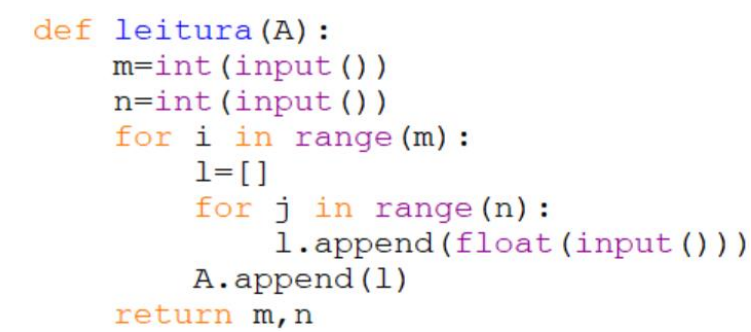 \\
\hline $\begin{array}{l}\text { Ocorreu na submissão: } 1 \\
\text { Observação: A linha "I=[]" que cria a linha da } \\
\text { matriz deve estar entre os dois "for" ou deve se } \\
\text { repetir depois do "A.append(I)". }\end{array}$ & $\begin{array}{l}\text { Corrigido na submissão: } 6 \\
\text { Observação: }\end{array}$ \\
\hline
\end{tabular}

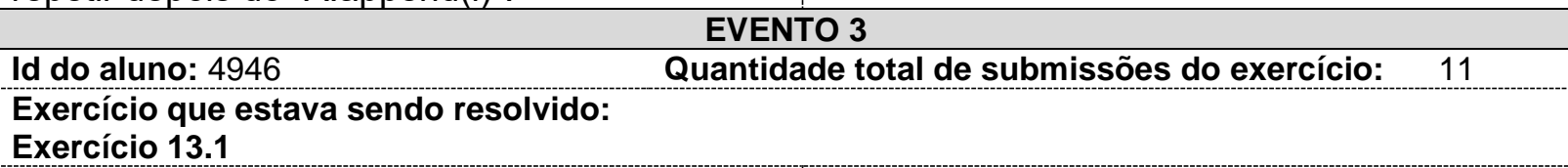

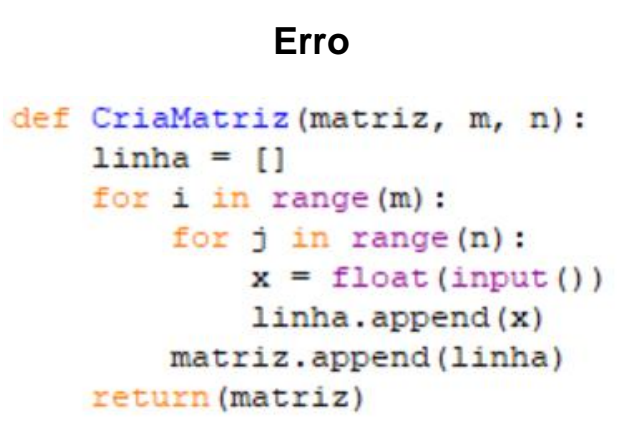

Ocorreu na submissão: 1

Observação: A linha "linha = []" que cria a linha da matriz deve estar entre os dois "for" ou deve se repetir depois do "matriz.append(linha)".

\begin{tabular}{|l|c|}
\hline \multicolumn{1}{|c|}{} & \multicolumn{1}{c|}{ EVENTO 4} \\
\hline \multicolumn{1}{|c|}{ Erro do aluno: } & Quantidade total de submissões do exercício: \\
\hline Exercício que estava sendo resolvido: & \multicolumn{1}{c}{ Erro Resolvido } \\
$\begin{array}{l}\text { Ocorreu na submissão: } \\
\text { Observação: }\end{array}$ & $\begin{array}{l}\text { Corrigido na submissão: } \\
\text { Observação: }\end{array}$ \\
& UMA SUGESTÃO DE SOLUÇÃO
\end{tabular}

Corrigido na submissão: 10 Observação:

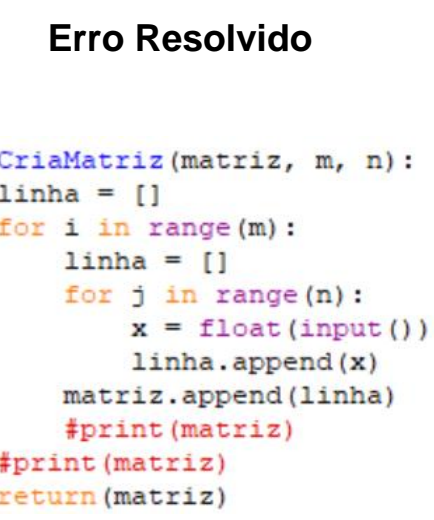

linha = []

in range (m):

$j$ in range $(n)$ :

$\mathrm{x}=$ float (input ())

matriz,append (linha)

\#print (matriz)

\#print (matriz)

$$
10
$$


Aplicar teste de mesa em um Código com o erro e outro sem, comparar os resultados - reforço pedindo que os alunos resolvam alguns exercícios

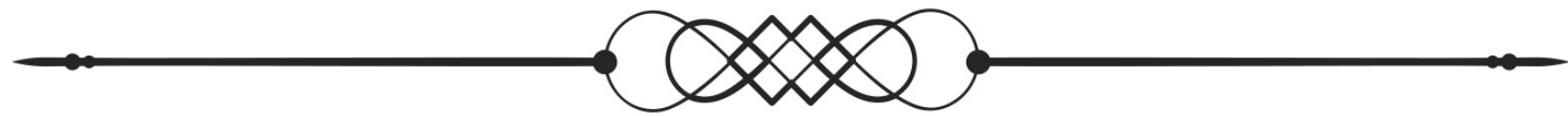

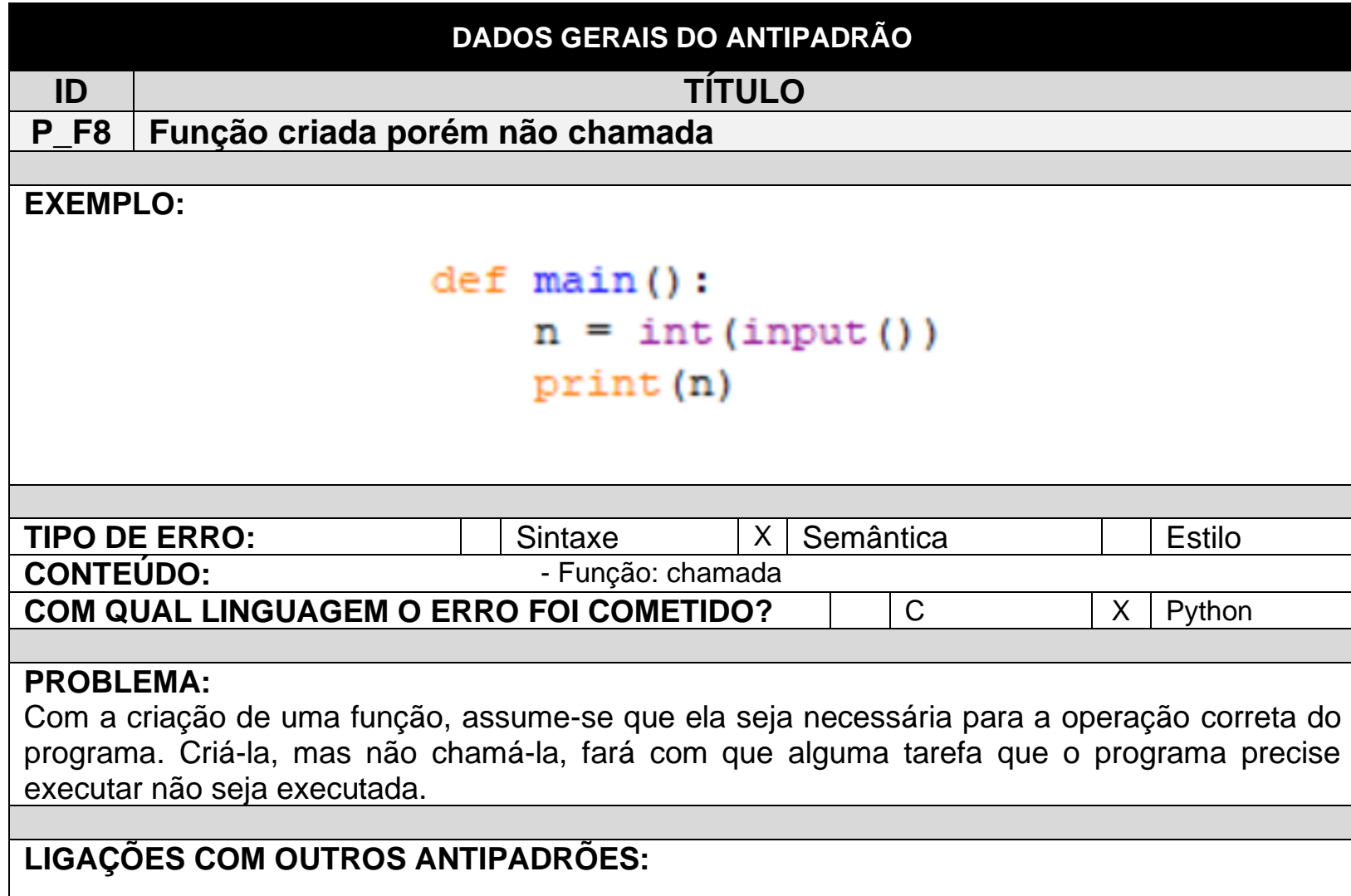

\section{EVENTOS}

Observação: Nos trechos de códigos apresentados abaixo, foram analisadas apenas questão quanto ao antipadrão dessa tabela. Se outros erros existem, esses erros foram tratados em outros antipadrões.

Id do aluno: 4826

\section{EVENTO 1}

Exercício que estava sendo resolvido:

Exercício 1.1

Quantidade total de submissões do exercício: 4




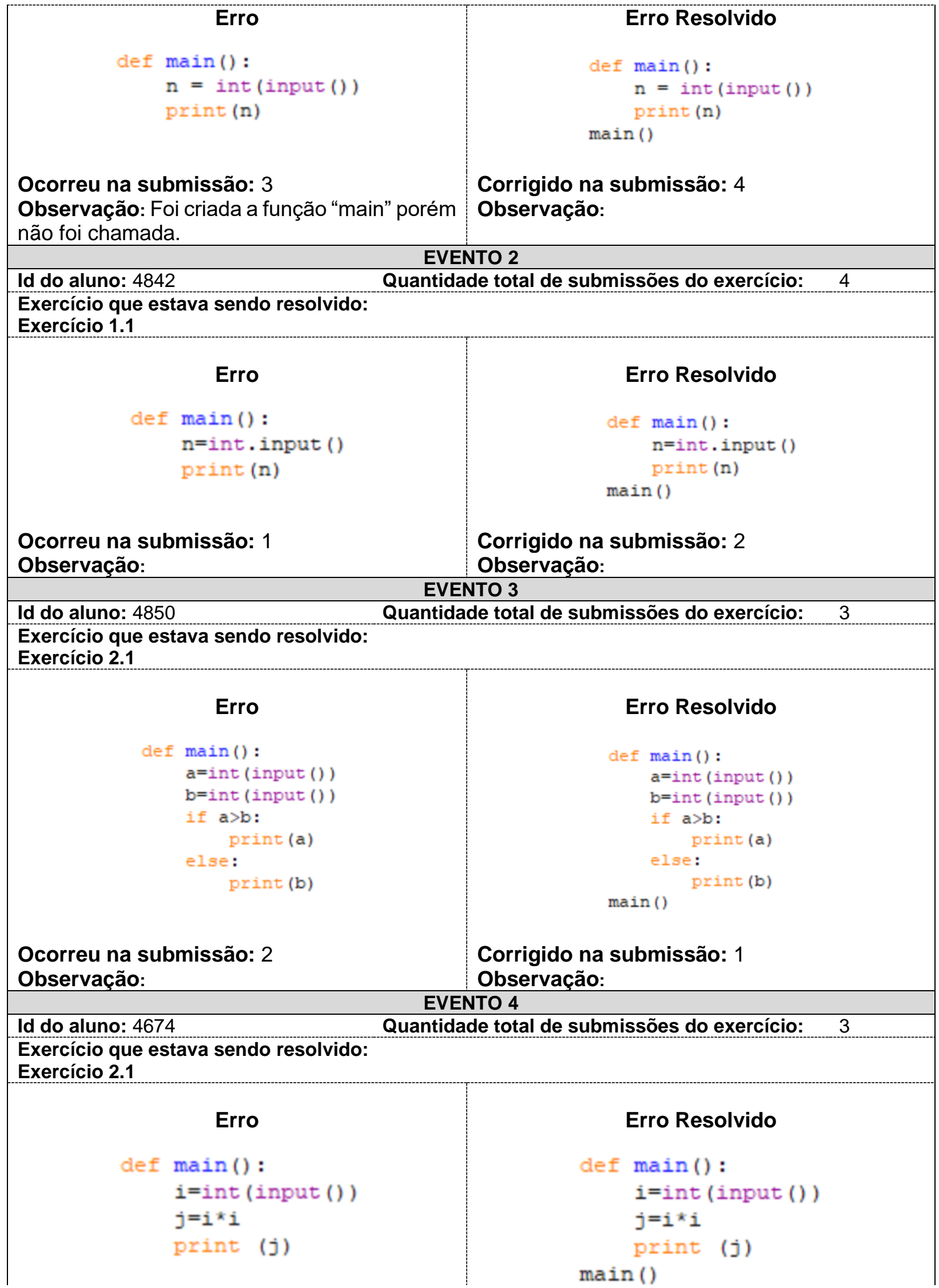


Ocorreu na submissão: 1

Observação:
Corrigido na submissão: 2

Observação:

\section{UMA SUGESTÃO DE SOLUÇÃO}

PARA O PROFESSOR

Programar na frente dos alunos, fazendo o erro aparecer - reforço pedindo que os alunos desenvolvam novos códigos

PARA O ALUNO

Estude um ou mais antipadrões, apresente ao colega de sala e reforce com exercício 



\section{Apêndice G}

\section{Catálogo de Antipadrões em C e Python}

A seguir é apresentado o catálogo de Antipadrões encontrados em C e em Python.

\section{CATÁLOGO DE ANTIPADRÕES EM C E PYTHON}

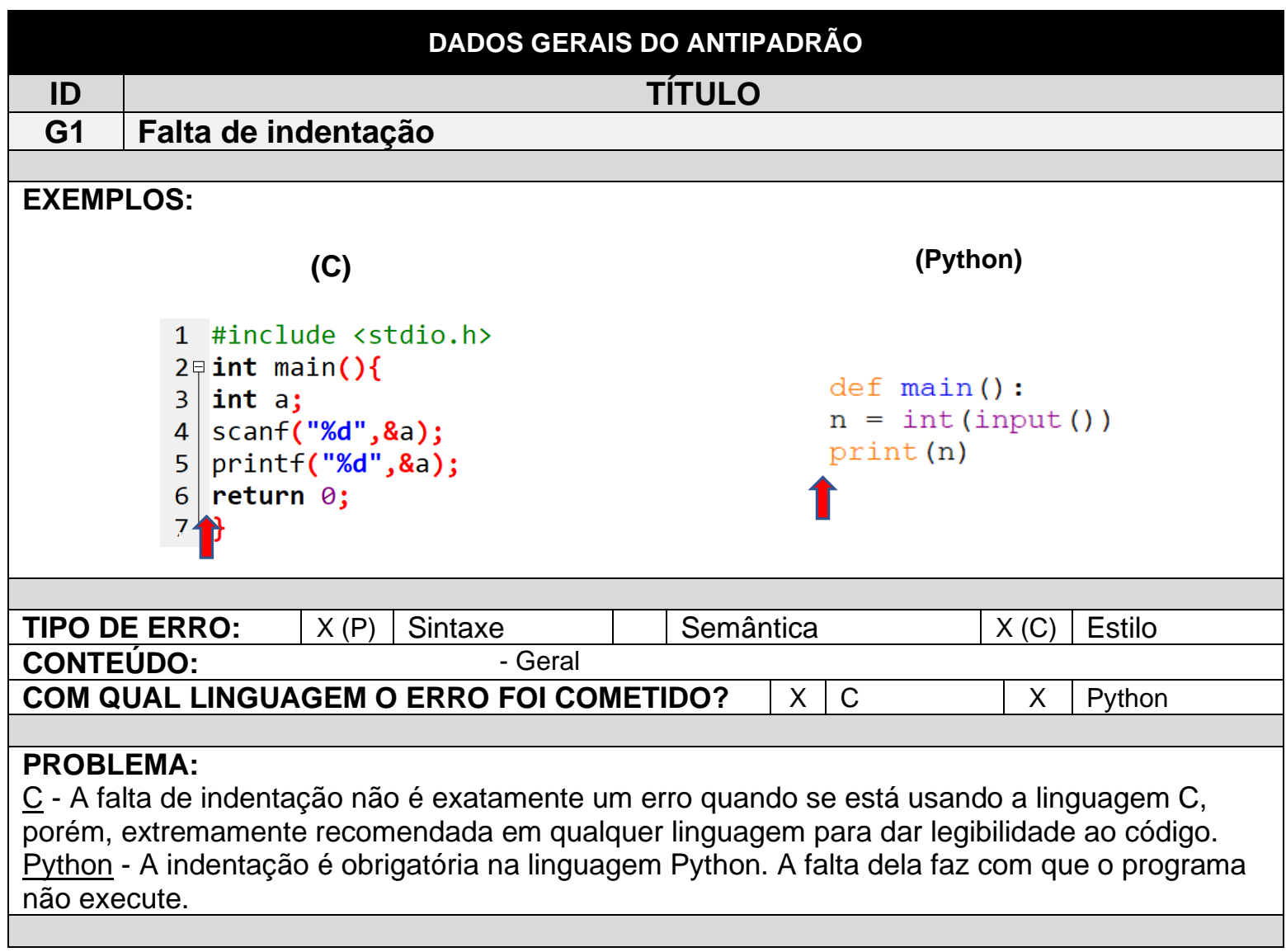




\section{LIGAÇÕES COM OUTROS ANTIPADRÕES:}

\section{EVENTOS}

Observação: Nos trechos de códigos apresentados abaixo, foram analisadas apenas questão quanto ao antipadrão dessa tabela. Se outros erros existem, esses erros foram tratados em outros antipadrões.

\begin{tabular}{ll}
\hline & EVENTO 1 - C \\
\hline Id do aluno: 1781 & Quantidade total de submissões do exercício: \\
\hline $\begin{array}{l}\text { Exercício que estava sendo resolvido: } \\
\text { Exercício 1.1 }\end{array}$ &
\end{tabular}

\section{Erro}

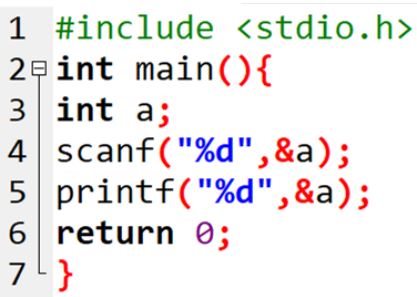

Ocorreu na submissão: 1

Observação: A falta de indentação é uma má prática de programação que fará com que a visualização do código seja comprometida.

\begin{tabular}{|c|c|}
\hline \multirow{2}{*}{\multicolumn{2}{|c|}{$\begin{array}{l}\text { Id do aluno: } 5554 \quad \text { Quantidade total de submissões do exercício: } \\
\text { Exercício que estava sendo resolvido: } \\
\text { Exercício } 1.1\end{array}$}} \\
\hline & \\
\hline Erro & Erro Resolvido \\
\hline 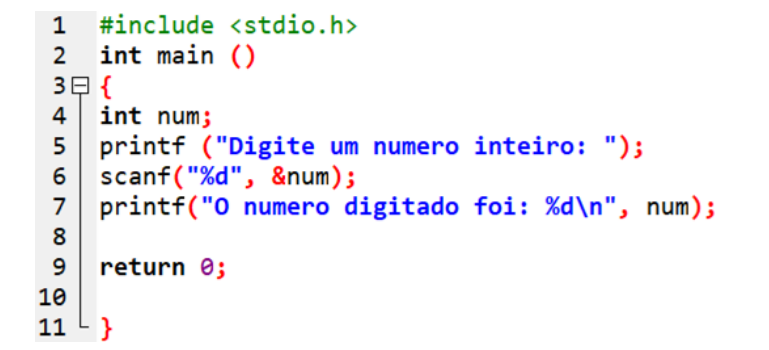 & $\dot{0}$ \\
\hline $\begin{array}{l}\text { Ocorreu na submissão: } 1 \\
\text { Observação: A falta de indentação é uma má } \\
\text { prática de programação que fará com que a } \\
\text { visualização do código seja comprometida. }\end{array}$ & $\begin{array}{l}\text { Corrigido na submissão: } \\
\text { Observação: } A \text { indentação não foi corrigida. }\end{array}$ \\
\hline \multicolumn{2}{|c|}{ EVENTO $3-\mathrm{C}$} \\
\hline \multirow{2}{*}{$\begin{array}{l}\text { Id do aluno: } 4930 \\
\text { Exercício que estava sendo resolvido: } \\
\text { Exercício } 2.1\end{array}$} & ade total de submissões do exercício: \\
\hline & \\
\hline
\end{tabular}

\section{Erro Resolvido}

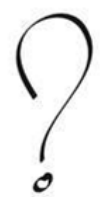

Corrigido na submissão:

Observação: A indentação não foi corrigida.

\section{EVENTO 2 - C}

\section{Id do aluno: 5554 \\ Exercício que estava sendo resolvido:} Quantidade total de submissões do exercício:

Exercício 1.1

\section{Erro}

\section{Erro Resolvido}




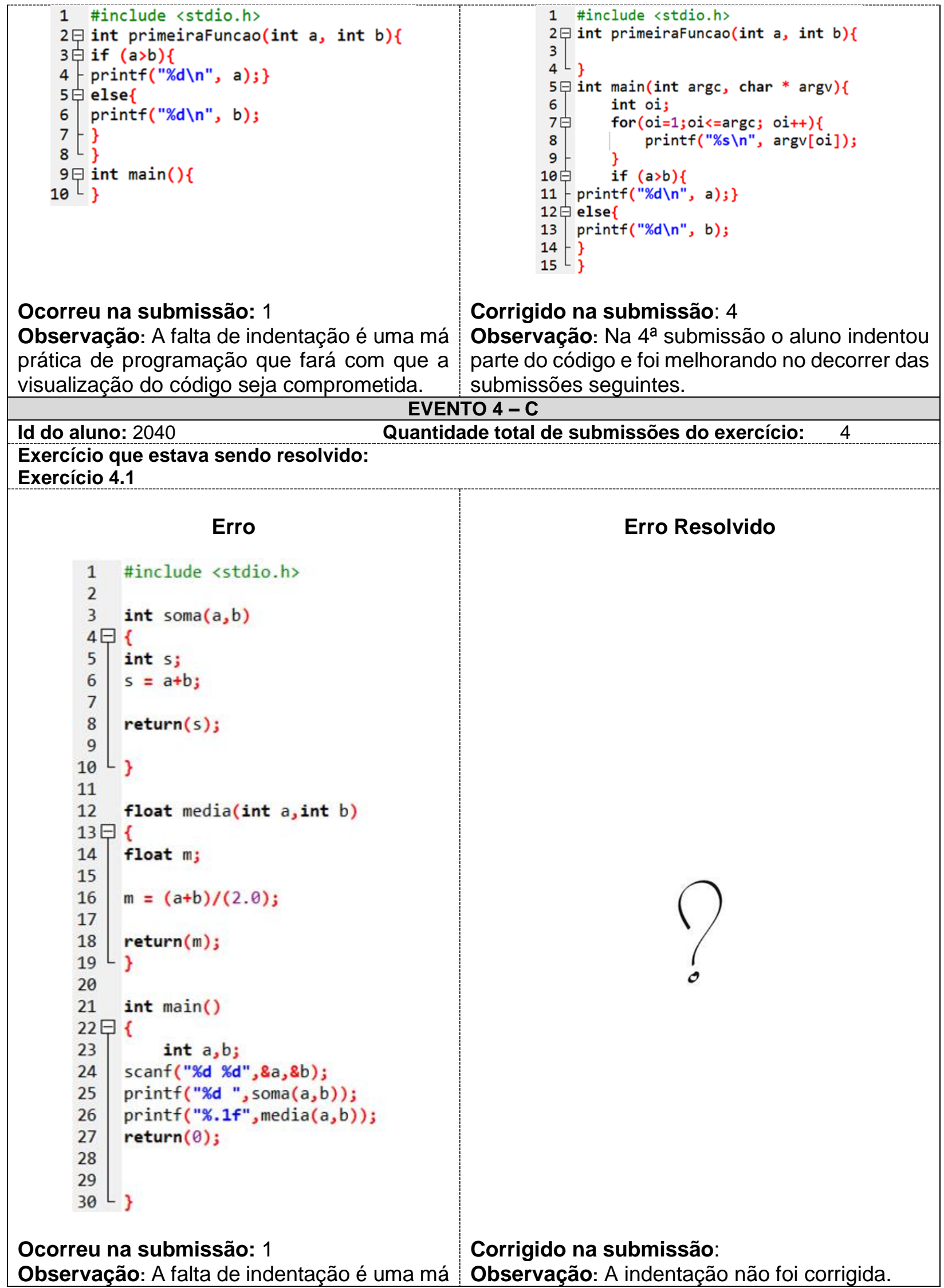


prática de programação que fará com que a visualização do código seja comprometida.

Id do aluno: 4666
Exercício que estava sendo resolv
Exercício 1.1
\[ \begin{array}{c}\text { Erro } \\ \text { def main (): } \\ \mathrm{n}=\operatorname{int}(\text { input () }) \\ \operatorname{print}(\mathrm{n}) \\ \operatorname{main}()\end{array} \]

Ocorreu na submissão: 11 Observação:

\section{EVENTO 1 - Python}

Quantidade total de submissões do exercício: 12

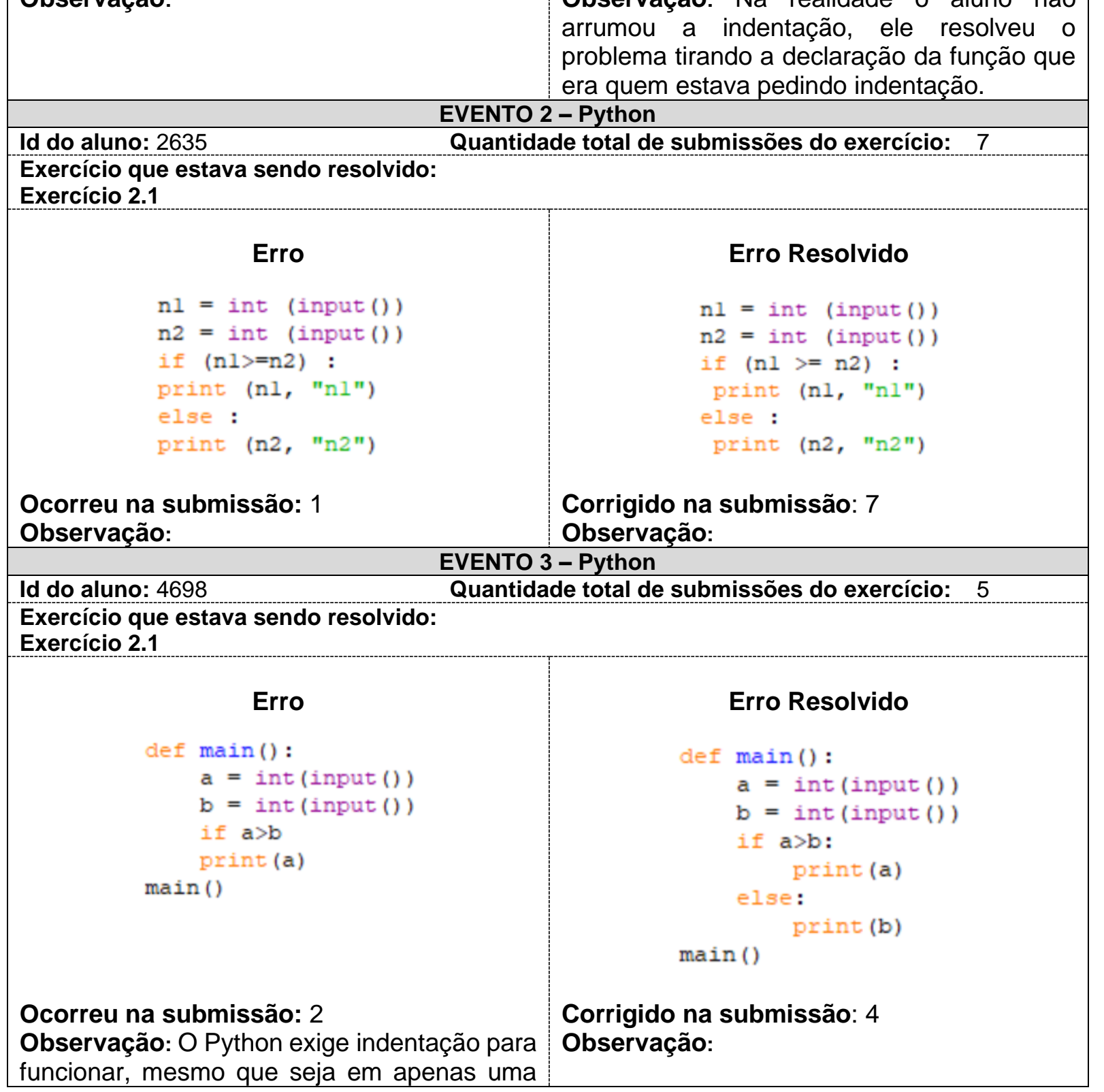


linha, como é o caso da linha "print", não funcionará.

Id do aluno: 4826

EVENTO 4 - Python

Exercício que estava sendo resolvido:

Exercício 4.1

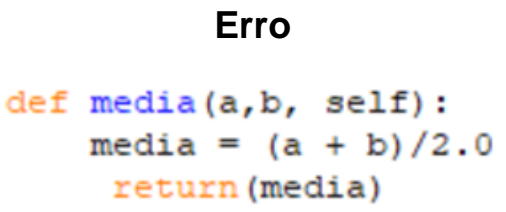

Erro

def media ( $a, b$, self) :

media $=(a+b) / 2.0$

return (media)

Ocorreu na submissão: 3

Observação: $O$ "return" não está indentado corretamente.
Quantidade total de submissões do exercício: 4

\section{UMA SUGESTÃO DE SOLUÇÃO}

PARA O PROFESSOR

Explicação usando quadro negro e projetor - fixar os conceitos usando Kahoot (plataforma de aprendizado baseada em jogos)

Resolver exercícios, acrescentar erros nos códigos e pedir que o colega de sala os encontrem

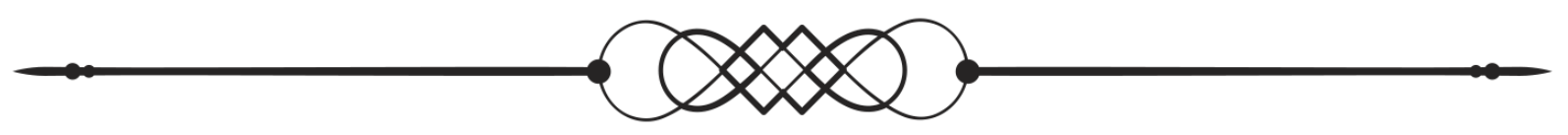

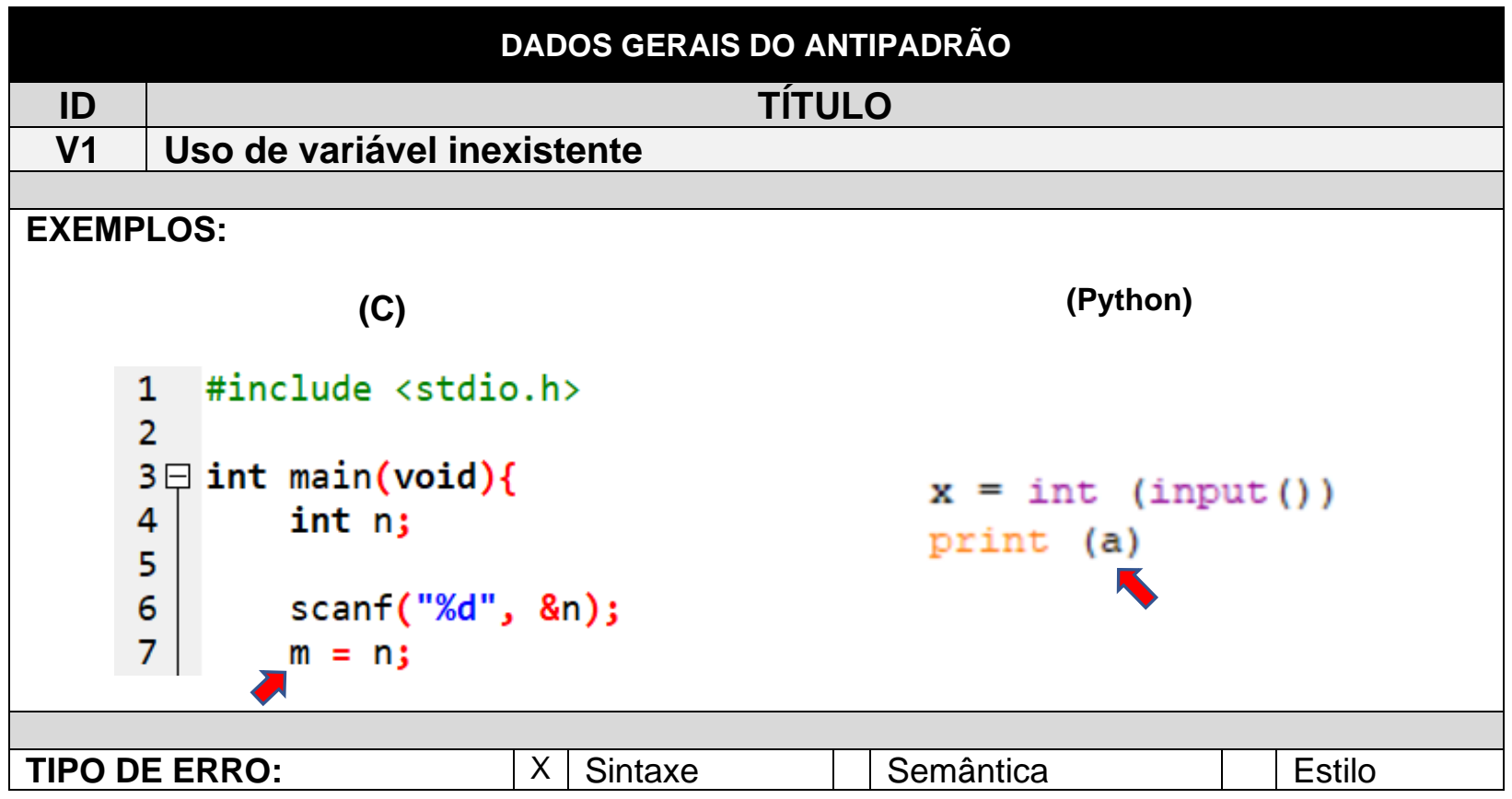




\begin{tabular}{|c|c|c|c|}
\hline \multicolumn{4}{|l|}{ CONTEÚDO: $\quad$ - Variável: declaração } \\
\hline COM QUAL LINGUAGEM O ERRO FOI COMETIDO? & C & & Python \\
\hline \multicolumn{4}{|c|}{$\begin{array}{l}\text { PROBLEMA: } \\
\text { C - Ao usarmos um identificador, como nomes de variáveis, constantes, estruturas (structs), etc, } \\
\text { é necessário informar ao programa na linguagem } C \text { ao que o identificador se refere. No caso de } \\
\text { variáveis não declaradas, o compilador não conseguirá identificar do que se trata aquele nome } \\
\text { nesse escopo. } \\
\text { Python - A declaração de variáveis em Python se dá através de uma atribuição, que definirá o } \\
\text { seu tipo de dado. Utilizá-la antes disso gerará um erro. }\end{array}$} \\
\hline $\begin{array}{l}\text { LIGAÇÕES COM OUTROS ANTIPADRÕES: } \\
\text { - Usar palavra reservada para nome de variável } \\
\text { - Atribuição usando "==" ao invés de "=" }\end{array}$ & & & \\
\hline
\end{tabular}

\section{EVENTOS}

Observação: Nos trechos de códigos apresentados abaixo, foram analisadas apenas questão quanto ao antipadrão dessa tabela. Se outros erros existem, esses erros foram tratados em outros antipadrões.

\begin{tabular}{l} 
EVENTO 1 - C \\
\hline Id do aluno: $3430 \quad$ Quantidade total de submissões do exercício: \\
\hline Exercício que estava sendo resolvido: \\
Exercício 1.1
\end{tabular}

\section{Erro}

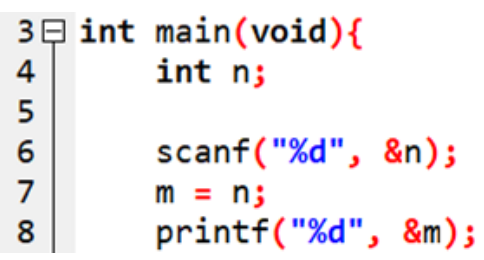

Ocorreu na submissão: 5

Observação: Esse erro foi cometido quando o aluno estava tentando resolver outro (C_OF1).

\section{Erro Resolvido}

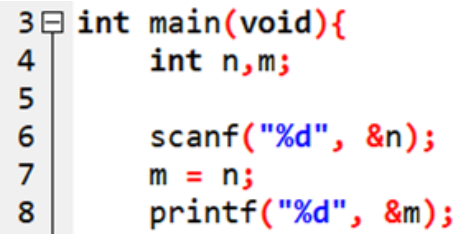

Corrigido na submissão: 6

Observação:

Id do aluno: 4930

\section{EVENTO 2 - C}

Exercício que estava sendo resolvido:

Exercício 2.1

\section{Erro}

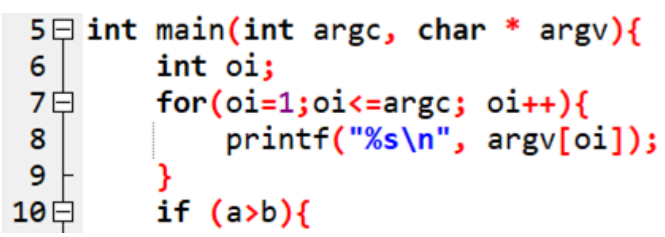

\section{Ocorreu na submissão: 4}

Observação: Variáveis "a" e "b" foram usadas a partir da linha 10, porém não foram declaradas.

\section{Erro Resolvido}

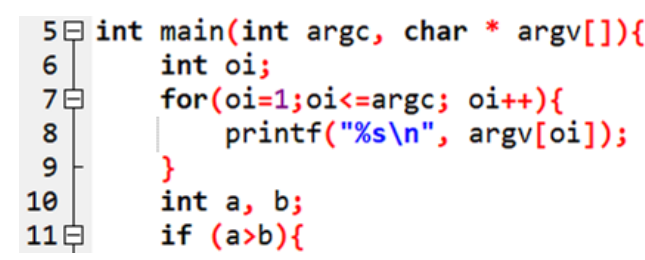

Corrigido na submissão: 5

Observação: 


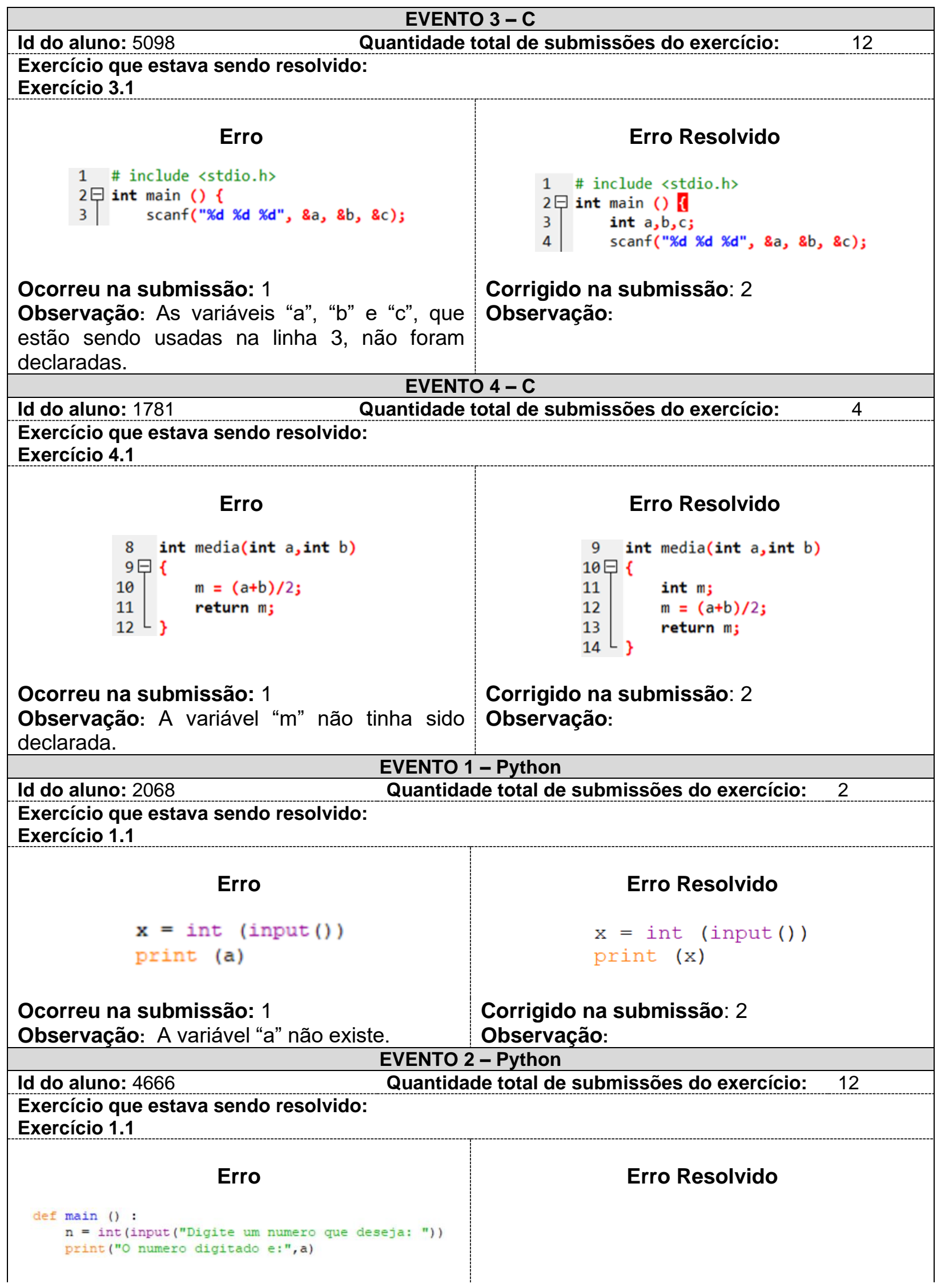


Ocorreu na submissão: 5

Observação: A variável "a" não existe.

dé main ()

$\mathrm{n}=$ int (input ("Digite um numero que deseja: "))

print ("O numero digitado e: ",n)

$\operatorname{main}()$

Corrigido na submissão: 7

Observação:

EVENTO 3 - Python

Id do aluno: 5650

Quantidade total de submissões do exercício:

10

Exercício que estava sendo resolvido:

Exercício 8.1

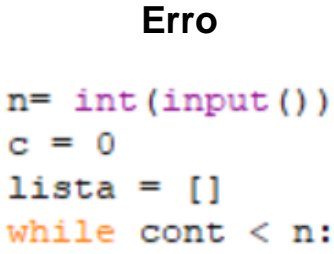

Ocorreu na submissão: 1

Observação: A variável "cont" usada na condição do "while" é inexistente.

\section{Id do aluno:}

Exercício que estava sendo resolvido:

\section{Erro}

Ocorreu na submissão:

Observação:

\section{EVENTO 4 - Python}

Quantidade total de submissões do exercício:
Corrigido na submissão: 4 Observação:

\section{Erro Resolvido \\ $\mathrm{n}=$ int (input ()) \\ $c=0$ \\ lista $=[1]$ \\ while $\mathrm{c}<\mathrm{n}$ :}

Erro Resolvido

Corrigido na submissão:

Observação:

\section{UMA SUGESTÃO DE SOLUÇÃO}

PARA O PROFESSOR

Grupos trabalhando com execução passa a passo para entender os erros - reforco com exercícios PARA O ALUNO

Estude um ou mais antipadrões, apresente ao colega de sala e reforce com exercício

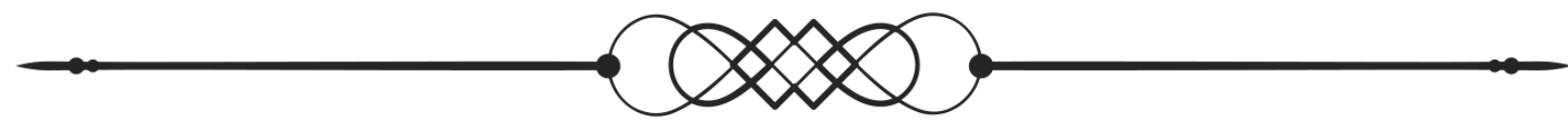




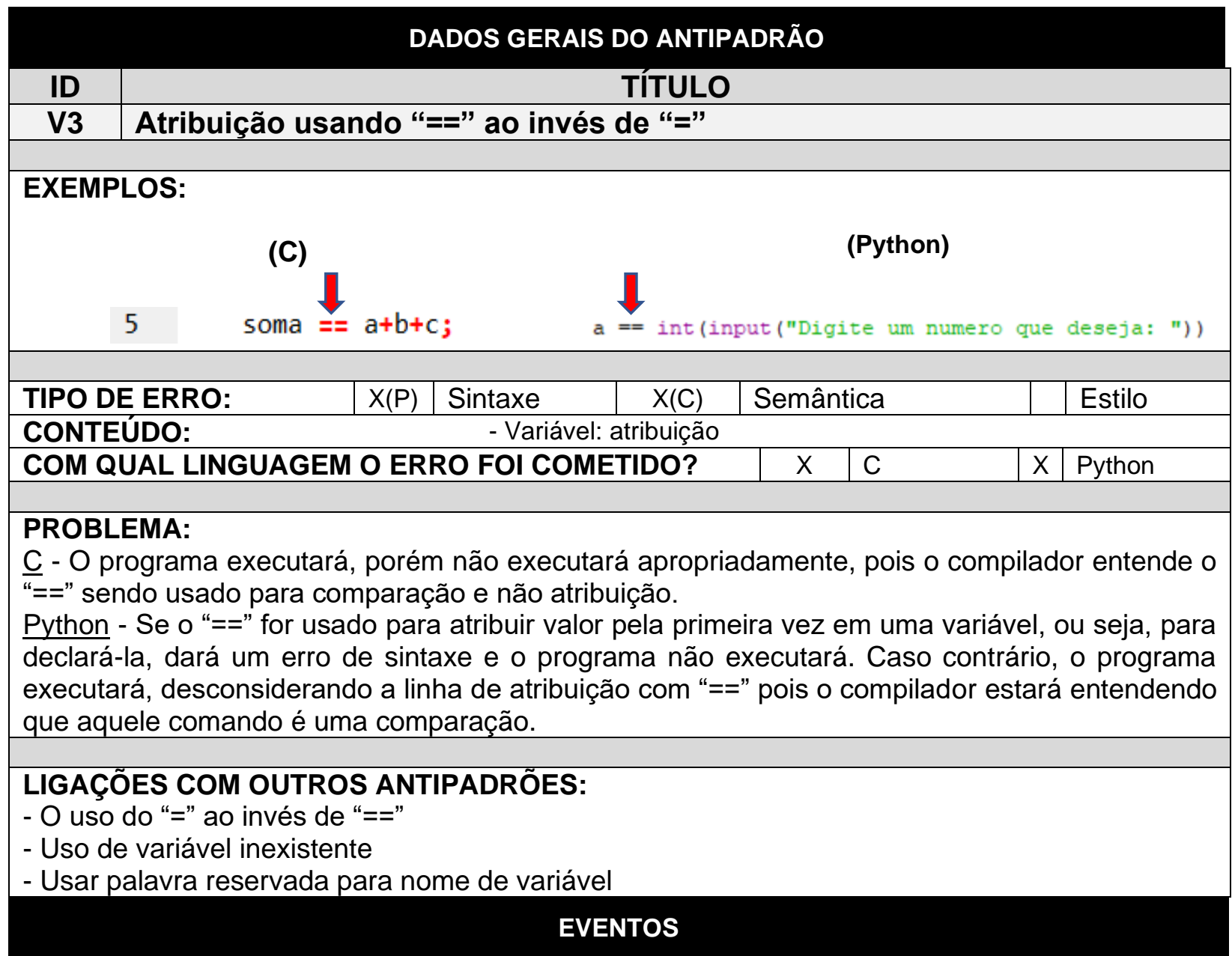

Observação: Nos trechos de códigos apresentados abaixo, foram analisadas apenas questão quanto ao antipadrão dessa tabela. Se outros erros existem, esses erros foram tratados em outros antipadrões.

\begin{tabular}{|c|c|c|}
\hline \multicolumn{3}{|c|}{ EVENTO 1 - C } \\
\hline Id do aluno: 2950 & dade total de submissões do exercício: & 5 \\
\hline \multicolumn{3}{|c|}{$\begin{array}{l}\text { Exercício que estava sendo resolvido: } \\
\text { Exercício } 3.1\end{array}$} \\
\hline Erro & \multicolumn{2}{|l|}{ Erro Resolvido } \\
\hline soma $=a+b+c$; & soma $=a+b+c ;$ & \\
\hline $\begin{array}{l}\text { Ocorreu na submissão: } 3 \\
\text { Observação: A atribuição é feita com "=" e } \\
\text { não "==" que é usado em comparacões. }\end{array}$ & \multicolumn{2}{|l|}{$\begin{array}{l}\text { Corrigido na submissão: } 4 \\
\text { Observação: }\end{array}$} \\
\hline \multicolumn{3}{|c|}{ EVENTO 2 - C } \\
\hline Id do aluno: $2936 \quad$ Quant & dade total de submissões do exercício: & 7 \\
\hline \multicolumn{3}{|c|}{$\begin{array}{l}\text { Exercício que estava sendo resolvido: } \\
\text { Exercício } 7.4\end{array}$} \\
\hline
\end{tabular}




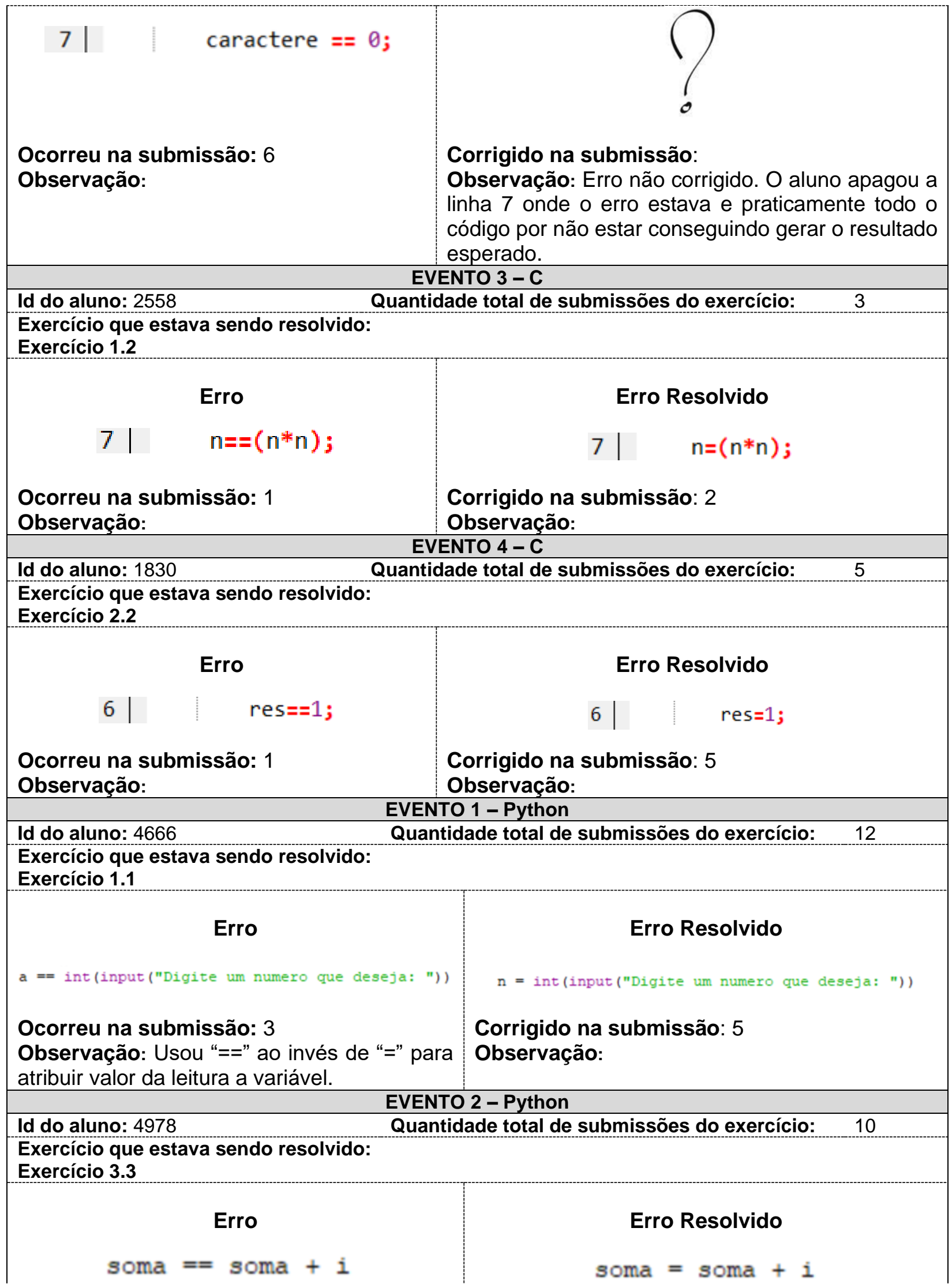


Ocorreu na submissão: 1

Observação:

Id do aluno: 4914

Exercício que estava sendo resolvido:

Exercício 4.1

Exercício que estava sendo resolvido:
Corrigido na submissão: 5

Observação:

EVENTO 3 - Python

Quantidade total de submissões do exercício: 2

$$
\begin{gathered}
\text { Erro } \\
\text { soma }==a+b
\end{gathered}
$$

Ocorreu na submissão: 1

Observação:

Id do aluno:

Erro

Ocorreu na submissão:

Observação:

\section{Erro Resolvido}

$\mathrm{s}=\mathrm{a}+\mathrm{b}$

Corrigido na submissão: 2

Observação:

Quantidade total de submissões do exercício:

\section{UMA SUGESTÃO DE SOLUÇÃO \\ Observação:}

PARA O PROFESSOR

Explicação usando quadro negro e projetor - fixar os conceitos usando Kahoot (plataforma de aprendizado baseada em jogos)

PARA O ALUNO

\section{Erro Resolvido}

Corrigido na submissão:

\section{Introduzir o erro em um código e entender as consequências que ele gera}

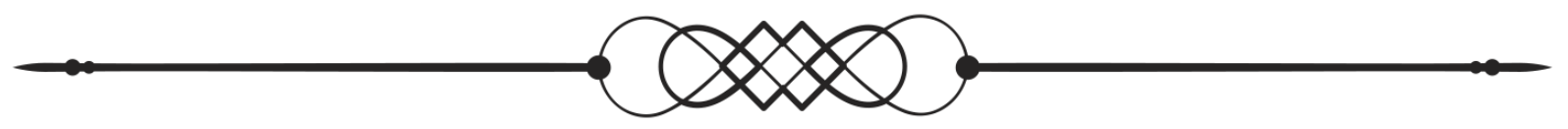

\section{DADOS GERAIS DO ANTIPADRÃO}

\section{ID $\quad$ TÍTULO \\ IF2 $\quad$ Falta das aspas na chamada da função de entrada de dados}

\section{EXEMPLOS:}

(C)

(Python) 


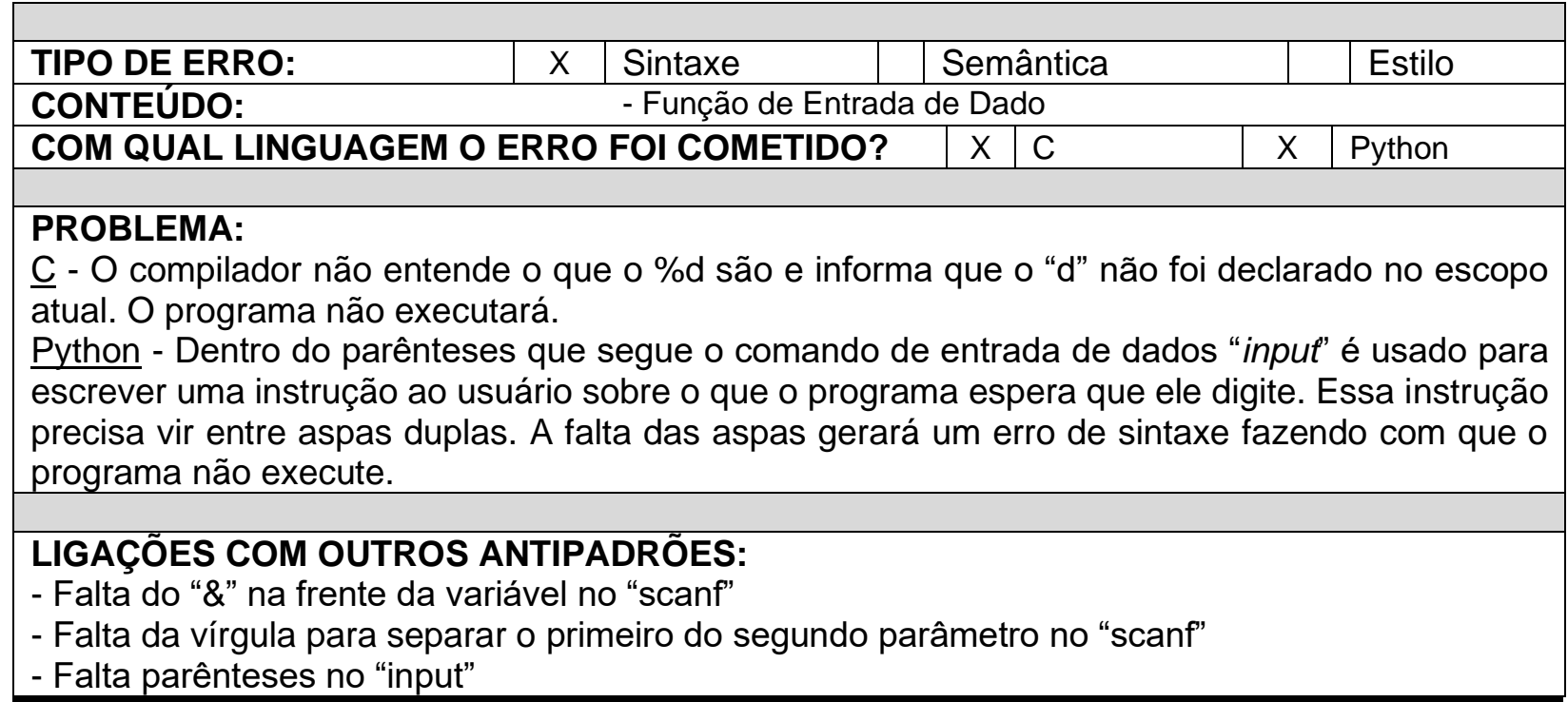

\section{EVENTOS}

Observação: Nos trechos de códigos apresentados abaixo, foram analisadas apenas questão quanto ao antipadrão dessa tabela. Se outros erros existem, esses erros foram tratados em outros antipadrões.

\begin{tabular}{|c|c|c|}
\hline \multicolumn{3}{|c|}{ EVENTO 1 - C } \\
\hline Id do aluno: 2950 & \multicolumn{2}{|c|}{ Quantidade total de submissões do exercício: } \\
\hline \multicolumn{3}{|c|}{$\begin{array}{l}\text { Exercício que estava sendo resolvido: } \\
\text { Exercício } 1.1\end{array}$} \\
\hline \multicolumn{2}{|r|}{ Erro } & Erro Resolvido \\
\hline 4 & $\operatorname{scanf}(\% d, \& n)$ & $\operatorname{scanf}(" \% d ", \& n)$ \\
\hline \multicolumn{2}{|c|}{$\begin{array}{l}\text { Ocorreu na submissão: } 1 \\
\text { Observação: }\end{array}$} & $\begin{array}{l}\text { Corrigido na submissão: } 2 \\
\text { Observação: }\end{array}$ \\
\hline \multicolumn{3}{|c|}{ EVENTO 2 - C } \\
\hline Id do aluno: 3529 & \multicolumn{2}{|c|}{ Quantidade total de submissões do exercício: } \\
\hline \multicolumn{3}{|c|}{$\begin{array}{l}\text { Exercício que estava sendo resolvido: } \\
\text { Exercício } 1.1\end{array}$} \\
\hline \multicolumn{2}{|r|}{ Erro } & Erro Resolvido \\
\hline \multirow{3}{*}{\multicolumn{2}{|c|}{$5 \quad \operatorname{scanf}(\% d, \& n) ;$}} & Attempt (Tentativa) 1: \\
\hline & & $\operatorname{scanf}(\% d, n)$ \\
\hline & & \begin{tabular}{l|l} 
& Final $($ Final): \\
& scanf $(" \% d ", \& n) ;$
\end{tabular} \\
\hline \multicolumn{2}{|c|}{$\begin{array}{l}\text { Ocorreu na submissão: } 1 \\
\text { Observação: }\end{array}$} & $\begin{array}{l}\text { Corrigido na submissão: } 4 \\
\text { Observação: }\end{array}$ \\
\hline \multicolumn{3}{|c|}{ EVENTO 3-C } \\
\hline Id do aluno: 5226 & \multicolumn{2}{|c|}{ Quantidade total de submissões do exercício: } \\
\hline \multicolumn{3}{|c|}{$\begin{array}{l}\text { Exercício que estava sendo resolvido: } \\
\text { Exercício } 1.1\end{array}$} \\
\hline
\end{tabular}




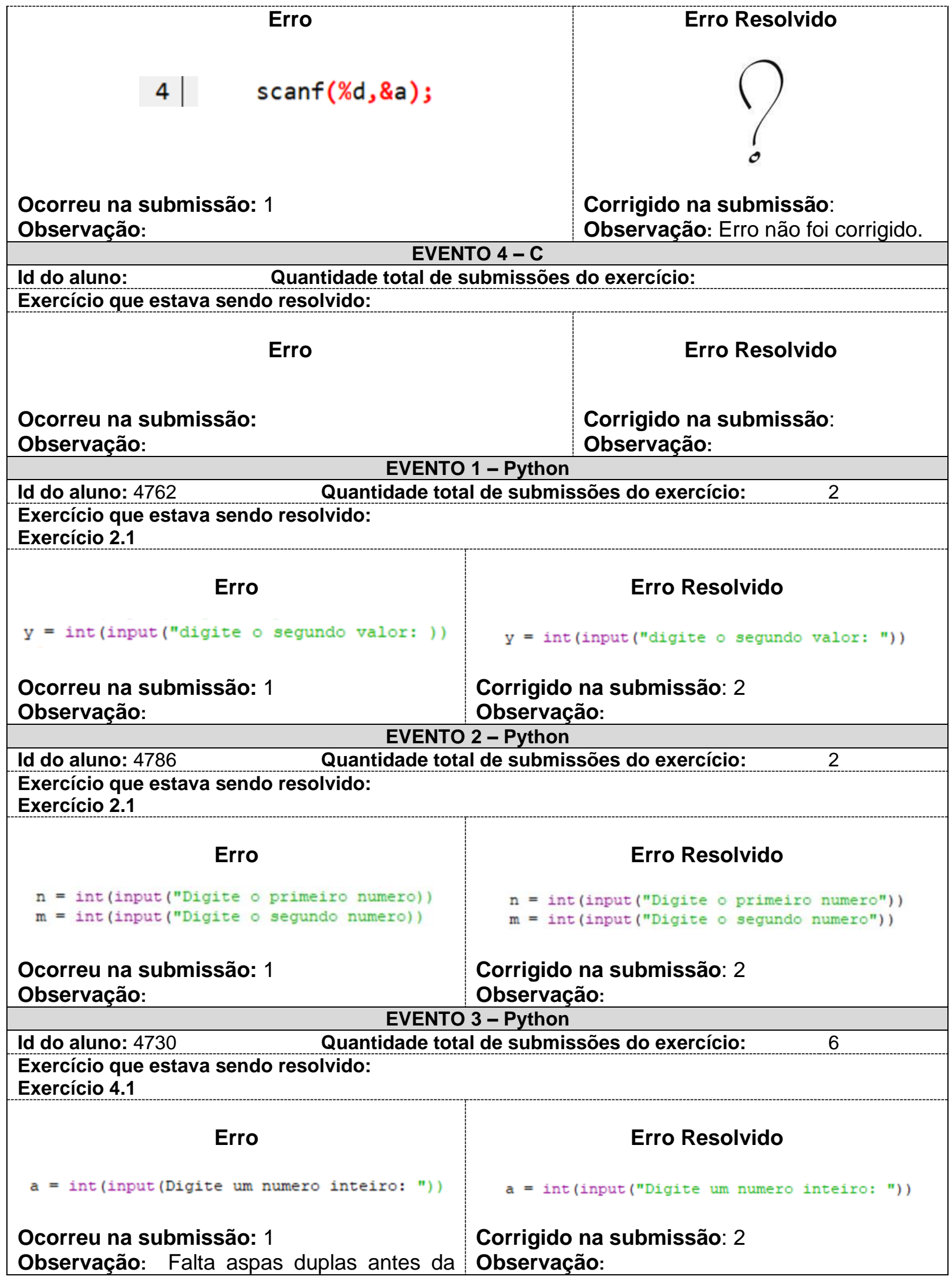




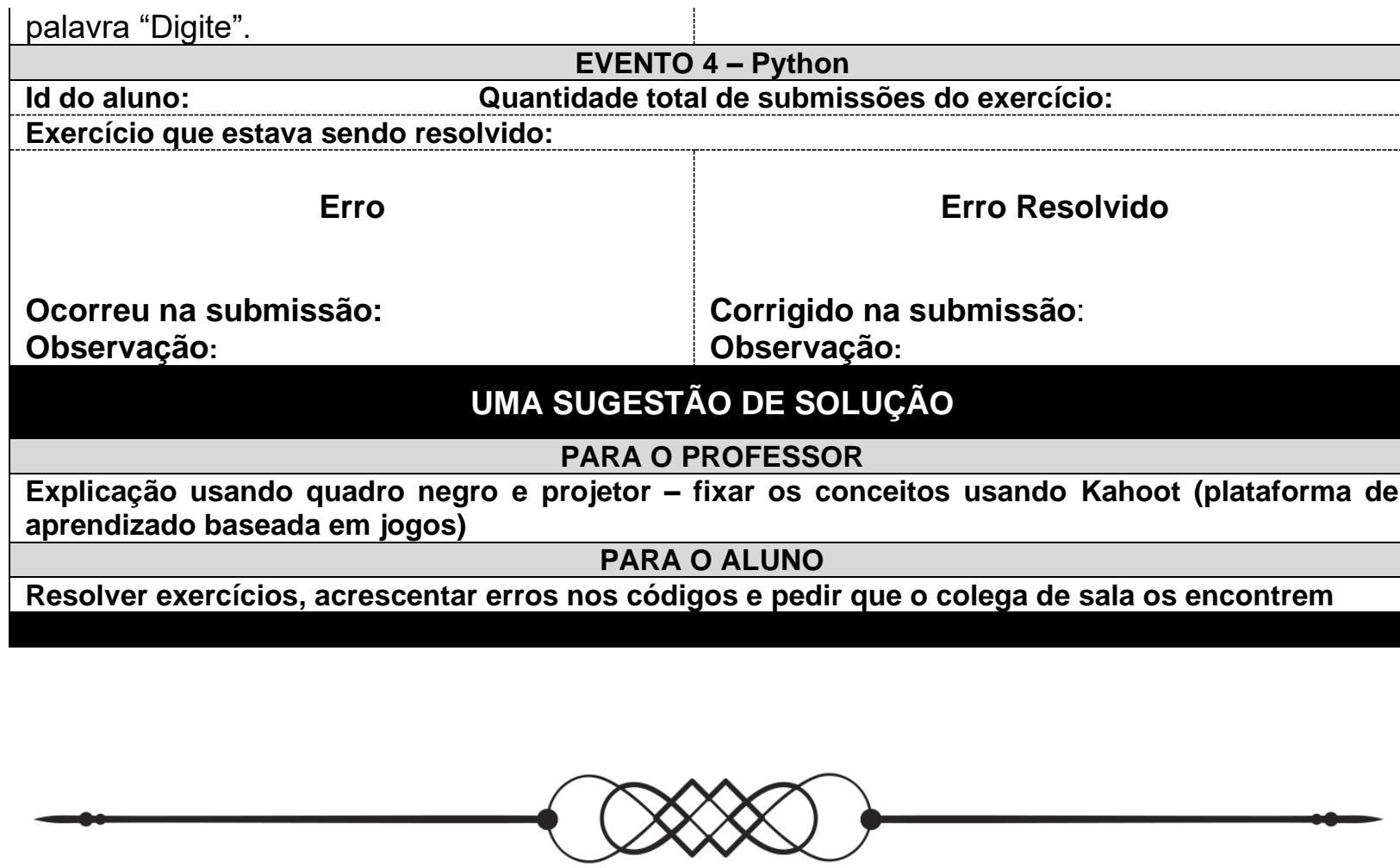

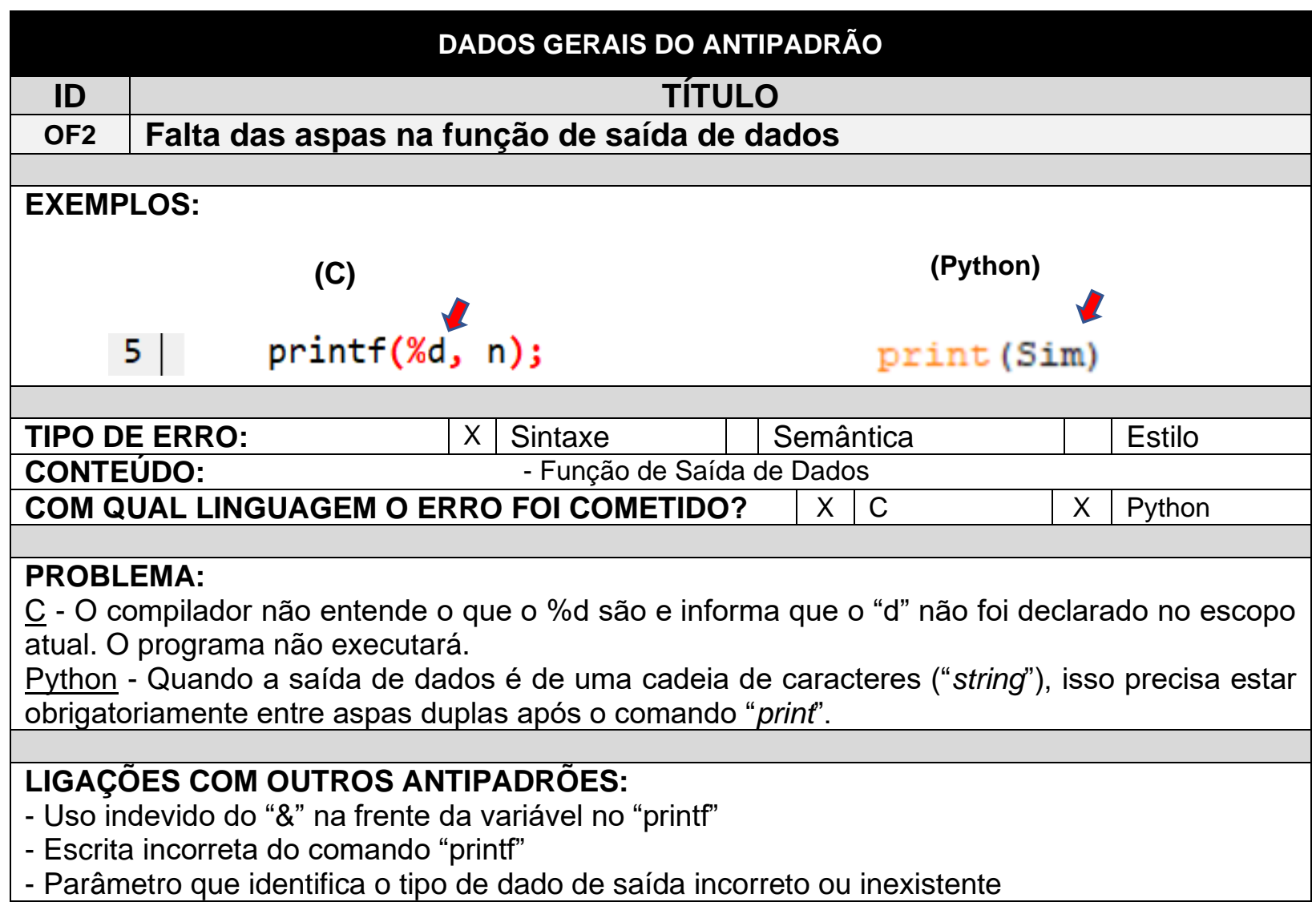


- Uso do "\&" no lugar do "\%" na função de saída de dados

- Falta da vírgula para separar o primeiro do segundo parâmetro na função de saída de dados - "print" seguido por "=" ou outro parâmetro incorreto

\section{EVENTOS}

Observação: Nos trechos de códigos apresentados abaixo, foram analisadas apenas questão quanto ao antipadrão dessa tabela. Se outros erros existem, esses erros foram tratados em outros antipadrões.

Id do aluno: 2950

EVENTO 1 - C

Exercício que estava sendo resolvido:

Exercício 1.1

Quantidade total de submissões do exercício: 2

\section{Exercicio 1.1}

\section{Erro}

$5 \quad \operatorname{printf}(\% d, n)$;

Ocorreu na submissão: 1

Observação:

\section{Erro Resolvido}

5 | $\quad$ printf("\%d", n);

Corrigido na submissão: 2 Observação:

Id do aluno: 1963

EVENTO 2 - C

Exercício que estava sendo resolvido:

Exercício 2.1

Quantidade total de submissões do exercício:

2

\section{Erro}

10

pritnf("\%d \n, n2);

\section{Ocorreu na submissão: 1}

Observação:

\section{Erro Resolvido}

10

$$
\text { printf("\%d \n", n2); }
$$

Corrigido na submissão: 2

\section{Observação:}

\begin{tabular}{lll} 
& EVENTO 3 - C \\
\hline Id do aluno: 1830 & Quantidade total de submissões do exercício: 10 \\
\hline Exercício que estava sendo resolvido: &
\end{tabular}

\section{Exercício 4.1}

\section{Erro}

18

printf(\%f)

\section{Ocorreu na submissão: 1}

Observação: Falta a variável para saber o valor a ser impresso, além de outros erros.

\section{Erro Resolvido}

18

$$
\text { printf("\%d\n", s); }
$$

Corrigido na submissão: 2

Observação:

EVENTO 4 - C

Id do aluno: 4922 Quantidade total de submissões do exercício:

Exercício que estava sendo resolvido:

Exercício 2.2

\section{Erro Resolvido}




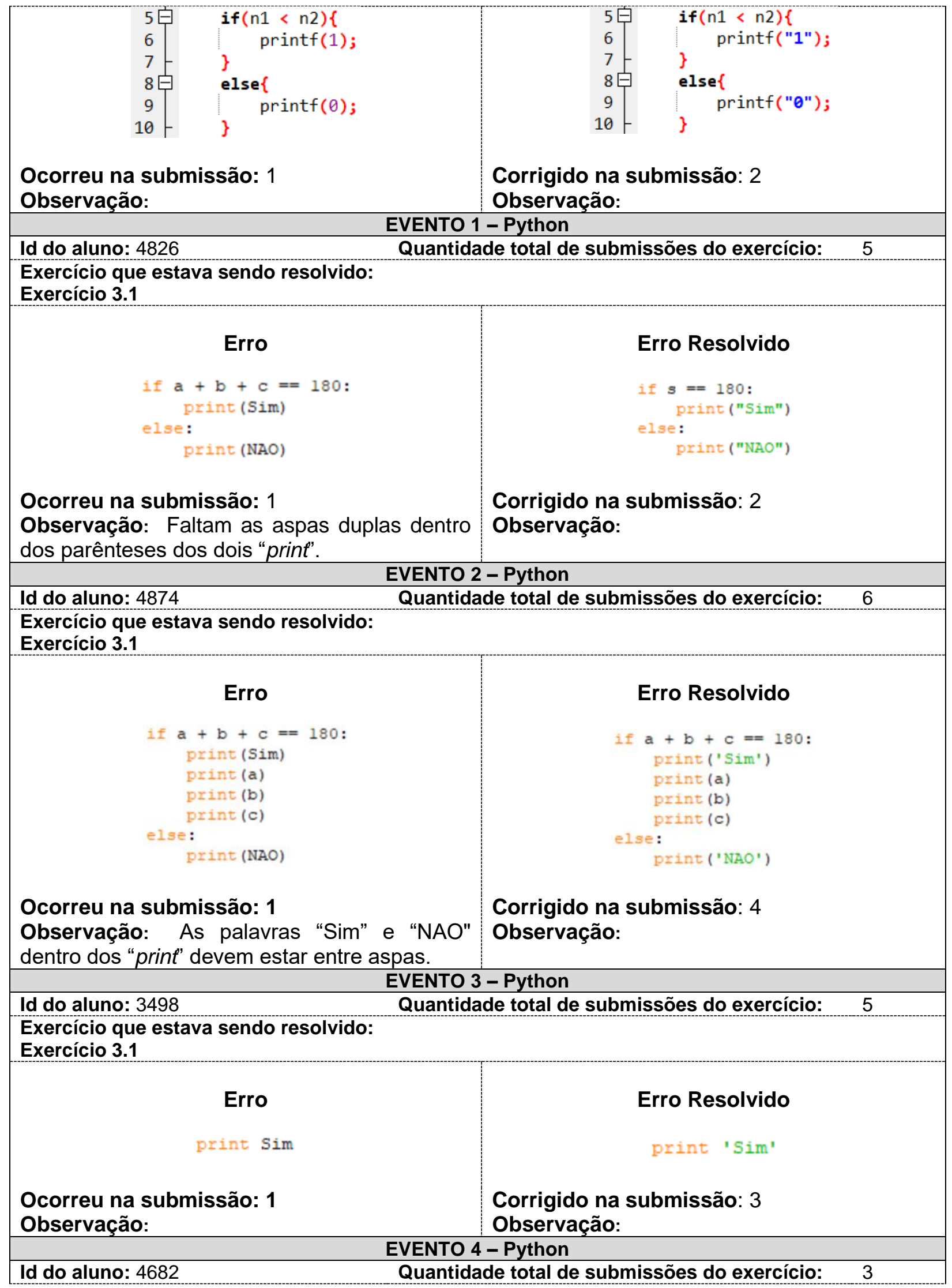


Exercício que estava sendo resolvido:

Exercício 3.1

\section{Erro}

print (NAO)

Ocorreu na submissão: 1

Observação:

\section{Erro Resolvido}

print ("NAO")

Corrigido na submissão: 3

Observação:

\section{UMA SUGESTÃO DE SOLUÇÃO}

PARA O PROFESSOR

Explicação usando quadro negro e projetor - fixar os conceitos usando Kahoot (plataforma de aprendizado baseada em jogos)

Resolver exercícios, acrescentar erros nos códigos e pedir que o colega de sala os encontrem

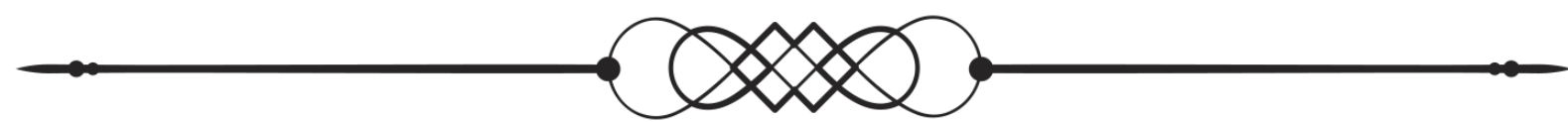

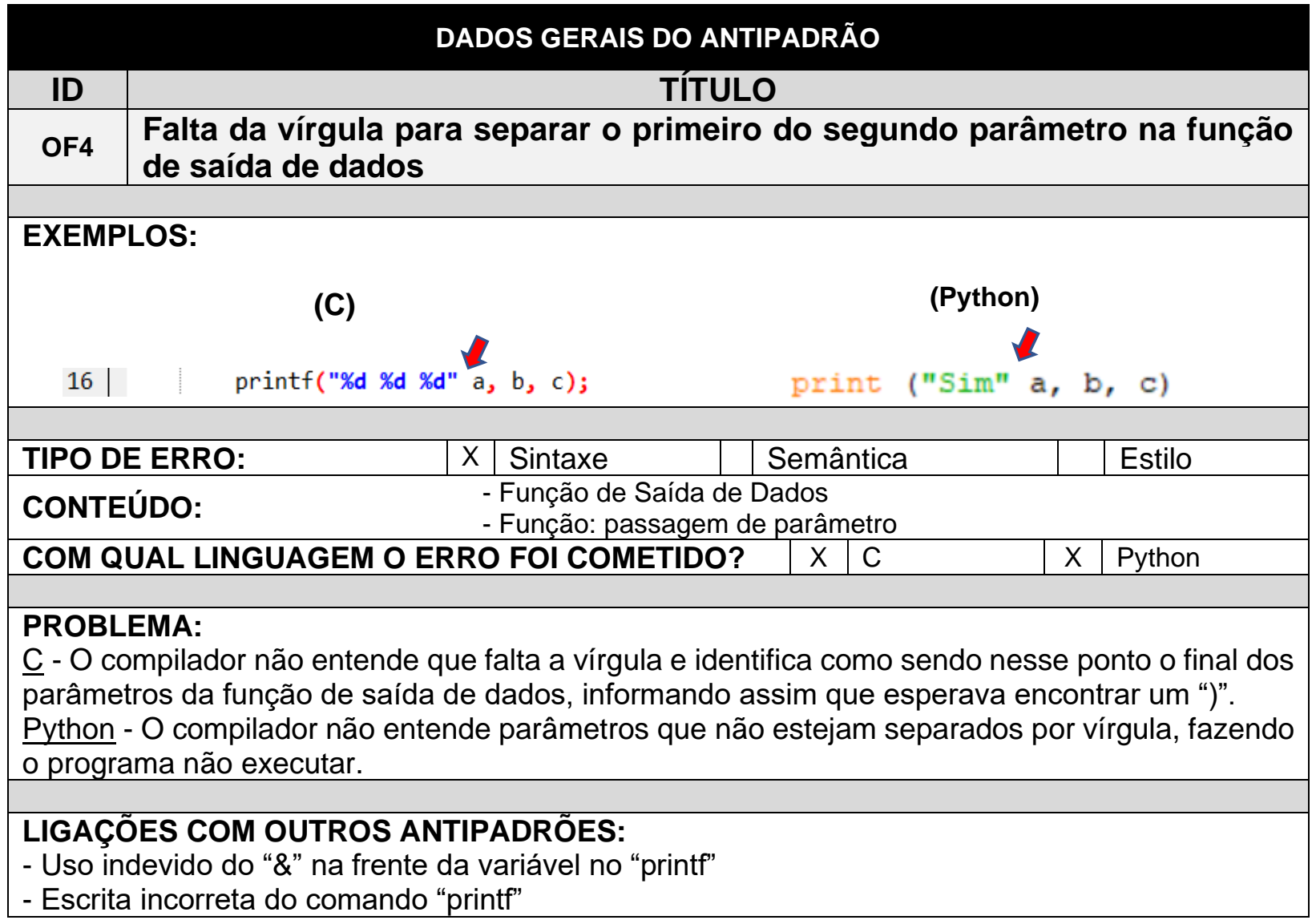


- Falta das aspas na função de saída de dados

- Uso do "\&" no lugar do "\%" na função de saída de dados

- Parâmetro que identifica o tipo de dado de saída incorreto ou inexistente

- "print" seguido por "=" ou outro parâmetro incorreto

\section{EVENTOS}

Observação: Nos trechos de códigos apresentados abaixo, foram analisadas apenas questão quanto ao antipadrão dessa tabela. Se outros erros existem, esses erros foram tratados em outros antipadrões.

\begin{tabular}{|c|c|}
\hline \multicolumn{2}{|c|}{$\begin{array}{ll}\text { EVENTO 1 - C } \\
\end{array}$} \\
\hline \multirow{2}{*}{\multicolumn{2}{|c|}{$\begin{array}{l}\text { Id do aluno: } 2810 \quad \text { Quantidade total de submissões do exercício: } 7 \\
\text { Exercício que estava sendo resolvido: }\end{array}$}} \\
\hline & \\
\hline \multirow[b]{3}{*}{$\begin{array}{l}\text { Ocorreu na submissãc } \\
\text { Observação: }\end{array}$} & Erro Resolvido \\
\hline & \multirow{2}{*}{$\begin{array}{l}\quad 16 \mid \quad \operatorname{printf("\% d~\% d~\% d",~a,~b,~c)~} \\
\text { Corrigido na submissão: } 5 \\
\text { Observacão: }\end{array}$} \\
\hline & \\
\hline \multicolumn{2}{|c|}{ EVENTO $2-\mathrm{C}$} \\
\hline \multicolumn{2}{|c|}{ Quantidade total de submissões do exercício: 7} \\
\hline \multicolumn{2}{|l|}{$\begin{array}{l}\text { Exercício que estava sendo resolvido: } \\
\text { Exercício } 3.1\end{array}$} \\
\hline Frro & Erro Resolvido \\
\hline $7 \mid \quad$ printf ("\%d\%d\%d" a1, a2, a3); & 7| $\mid$ printf ("\%d\%d\%d", a1, a2, a3); \\
\hline $\begin{array}{l}\text { Ocorreu na submissão: } 1 \\
\text { Observação: }\end{array}$ & $\begin{array}{l}\text { Corrigido na submissão: } 2 \\
\text { Observação: }\end{array}$ \\
\hline \multicolumn{2}{|c|}{ EVENTO $3-\mathrm{C}$} \\
\hline \multicolumn{2}{|c|}{ Quantidade total de submissões do exercício: 4} \\
\hline \multicolumn{2}{|l|}{$\begin{array}{l}\text { Exercício que estava sendo resolvido: } \\
\text { Exercício } 7.4\end{array}$} \\
\hline Erro & Erro Resolvido \\
\hline 13 printf ("\%d\n" (int)c); & $13 \mid \quad$ printf $(" \% d \backslash n ", c)$; \\
\hline $\begin{array}{l}\text { Ocorreu na submissão: } 1 \\
\text { Observação: }\end{array}$ & $\begin{array}{l}\text { Corrigido na submissão: } 2 \\
\text { Observacão: }\end{array}$ \\
\hline \multicolumn{2}{|c|}{ EVENTO $4-\mathrm{C}$} \\
\hline \multicolumn{2}{|c|}{ Quantidade total de submissões do exercício: 2} \\
\hline \multicolumn{2}{|l|}{$\begin{array}{l}\text { Exercício que estava sendo resolvido: } \\
\text { Exercício } 7.1\end{array}$} \\
\hline Erro & Erro Resolvido \\
\hline $10 \mid \operatorname{printf("\% f"~soma);~}$ & printf("\%f", soma); \\
\hline $\begin{array}{l}\text { Ocorreu na submissão: } 1 \\
\text { Observação: }\end{array}$ & $\begin{array}{l}\text { Corrigido na submissão: } 2 \\
\text { Observação: }\end{array}$ \\
\hline
\end{tabular}




\begin{tabular}{|c|c|}
\hline \multicolumn{2}{|c|}{$\begin{array}{l}\text { EVENTO 1 - Python } \\
\end{array}$} \\
\hline \multirow{2}{*}{\multicolumn{2}{|c|}{$\begin{array}{l}\text { Id do aluno: } 4914 \quad \text { Quantidade total de submissões do exercício: } \\
\text { Exercício que estava sendo resolvido: } \\
\text { Exercício } 3.1\end{array}$}} \\
\hline & \\
\hline $\begin{array}{l}\text { Erro } \\
\text { print ("Sim" a, b, c) } \\
\text { print ("NAO" } a+b+c) \\
\text { Ocorreu na submissão: } 5 \\
\text { Observação: Nos dois "print" falta vírgula para } \\
\text { separar o primeiro do segundo parâmetro. }\end{array}$ & $\begin{array}{l}\text { Erro Resolvido } \\
\text { print ("Sim", a, b, c) } \\
\text { print ("NAO", a + b + c) } \\
\text { Corrigido na submissão: } 6 \\
\text { Observação: }\end{array}$ \\
\hline \multicolumn{2}{|c|}{ EVENTO 2 - Python } \\
\hline \multicolumn{2}{|c|}{$\begin{array}{l}\text { Exercício que estava sendo resolvido: } \\
\text { Exercício } 3.1\end{array}$} \\
\hline $\begin{array}{l}\text { Ocorreu na submissão: } 1 \\
\text { Observação: Falta vírgula para separar os } \\
\text { parâmetros do "print" (Obs.: os "/n" deveriam ser } \\
\text { "In" e precisariam estar entre aspas duplas } \\
\text { (antipadrão P_OF2)) }\end{array}$ & $\begin{array}{l}\text { Erro Resolvido } \\
\qquad \begin{array}{l}\text { print (a) } \\
\text { print (b) } \\
\text { print (c) }\end{array} \\
\text { Corrigido na submissão: } 2 \\
\text { Observação: Ao invés de acrescentar vírdula } \\
\text { para separar as variáveis, foi separado em } \\
\text { mais "print". }\end{array}$ \\
\hline \multicolumn{2}{|c|}{ EVENTO 3 - Python } \\
\hline \multicolumn{2}{|l|}{$\begin{array}{l}\text { Exercício que estava sendo resolvido: } \\
\text { Exercício 3.1 }\end{array}$} \\
\hline 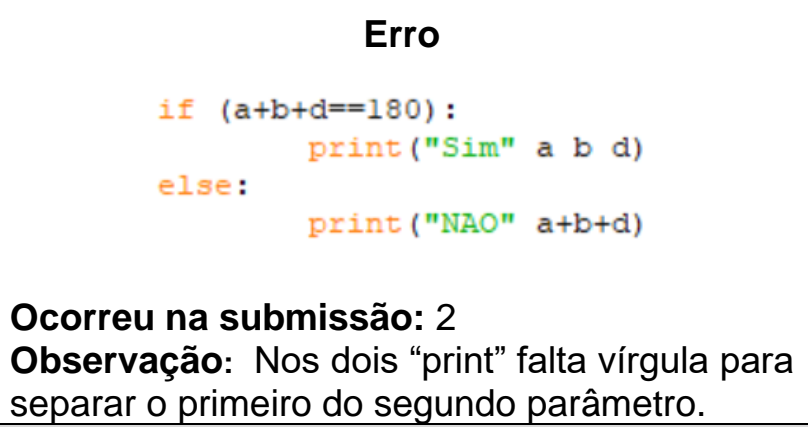 & 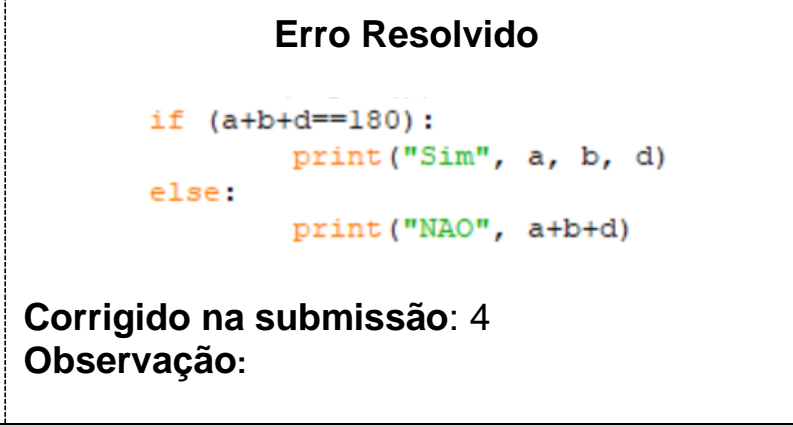 \\
\hline \multicolumn{2}{|c|}{ EVENTO 4 - Python } \\
\hline \multicolumn{2}{|c|}{ Quantidade total de submissões do exercício: } \\
\hline Ocorreu na submissão: & Corrigido na submissão: \\
\hline
\end{tabular}


Observação:

Observação:

\section{UMA SUGESTÃO DE SOLUÇÃO}

PARA O PROFESSOR

Explicação usando quadro negro e projetor - fixar os conceitos usando Kahoot (plataforma de aprendizado baseada em jogos)

Resolver exercícios, acrescentar erros nos códigos e pedir que o colega de sala os encontrem

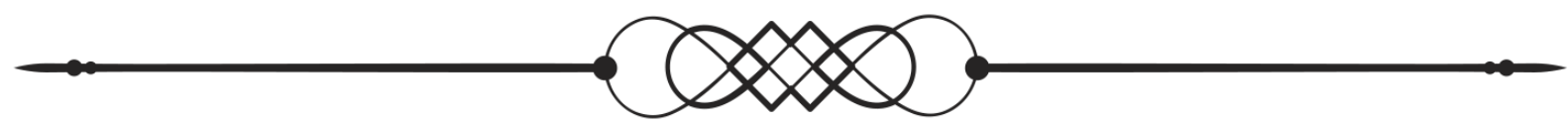

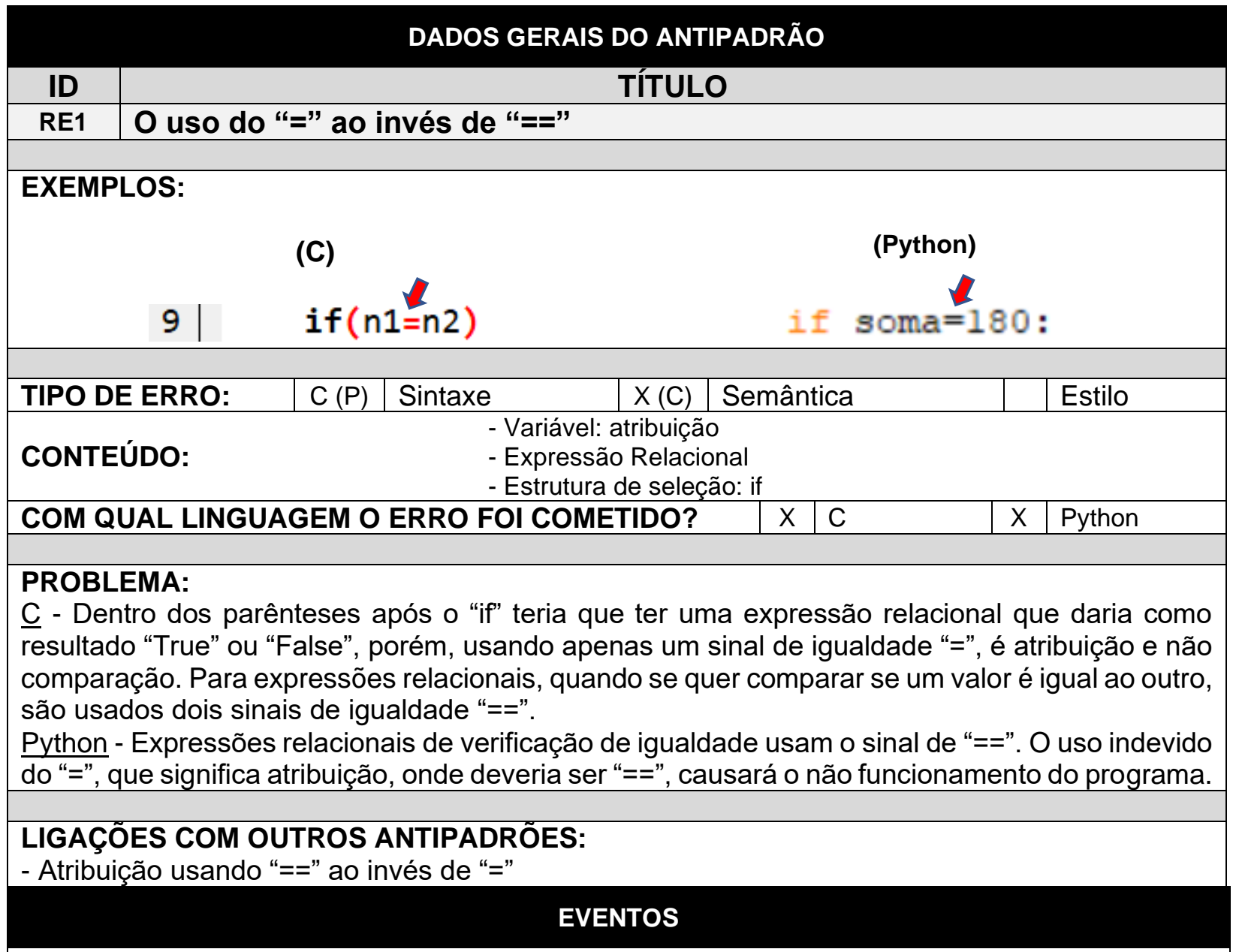

Observação: Nos trechos de códigos apresentados abaixo, foram analisadas apenas questão quanto ao antipadrão dessa tabela. Se outros erros existem, esses erros foram tratados em outros antipadrões. 
EVENTO 1-C

Id do aluno: $1781 \quad$ Quantidade total de submissões do exercício

Exercício que estava sendo resolvido:

Exercício 2.1

\section{Erro}

$$
\text { 13追 if) (a=b) }\{
$$

Ocorreu na submissão: 4 Observação:

Id do aluno: 2950

Exercício que estava sendo resolvido:

Exercício 2.1

\section{Erro}

$$
9 \quad \text { if }(\mathrm{n} 1=\mathrm{n} 2)
$$

Ocorreu na submissão: 2

Observação:

Id do aluno: 1830

Exercício que estava sendo resolvido:

Exercício 3.1

\section{Erro}

$$
\text { 5帛 if }(a+b+c=180)\{
$$

Ocorreu na submissão: 1

Observação:

Id do aluno: 3300

Exercício que estava sendo resolvido:

Exercício 3.1

\section{Erro}

$$
\text { 13占 if (soma = 180) }\{
$$

Ocorreu na submissão: 1

Observação:

Id do aluno: 4850

Exercício que estava sendo resolvido:

Exercício 3.1

\section{Erro}

Erro Resolvido

$$
\text { 13帛 if }(a==b)\{
$$

Corrigido na submissão: 5 Observação:

Quantidade total de submissões do exercício: EVENTO 2 - C Quat 
Ocorreu na submissão: 2

Observação: Para comparação é usado "==" e não "=".
Corrigido na submissão: 14

Observação:

\begin{tabular}{ll|}
\hline & EVENTO 2 - Python \\
\hline Id do aluno: 4890 & Quantidade total de submissões do exercício: \\
\hline Exercício que estava sendo resolvido: & 6 \\
Exercício 3.1 &
\end{tabular}

Exercício 3.1

$$
\begin{gathered}
\text { Erro } \\
\text { while } \mathrm{d}=180 \text { : }
\end{gathered}
$$

Ocorreu na submissão: 1

Observação:

\begin{tabular}{l} 
EVENTO 3 - Python \\
\hline Id do aluno: $4914 \quad$ Quantidade total de submissões do exercício: \\
$\begin{array}{l}\text { Exercício que estava sendo resolvido: } \\
\text { Exercício 3.1 }\end{array}$
\end{tabular}

\section{Erro Resolvido}

while $\mathrm{d}==180$ :

Corrigido na submissão: 2 Observação:

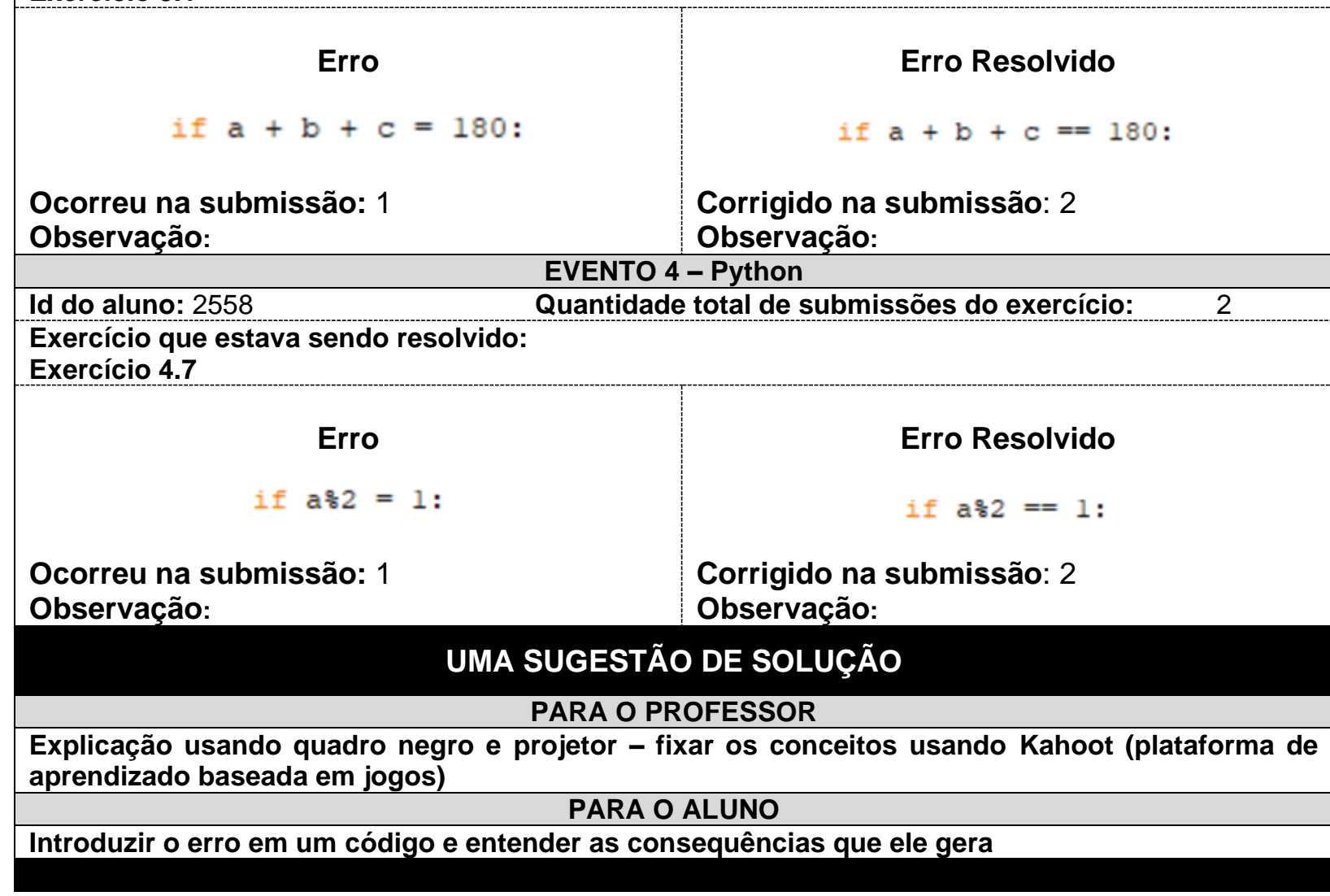

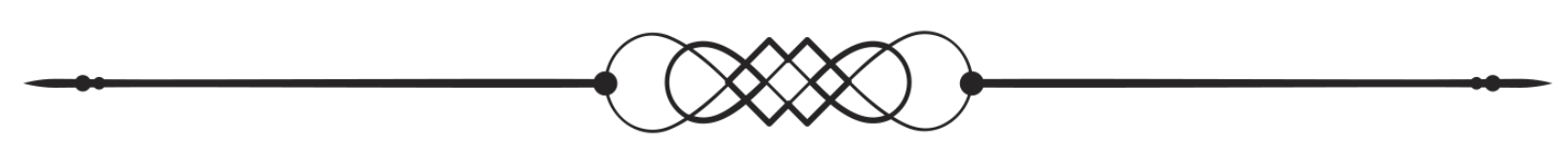




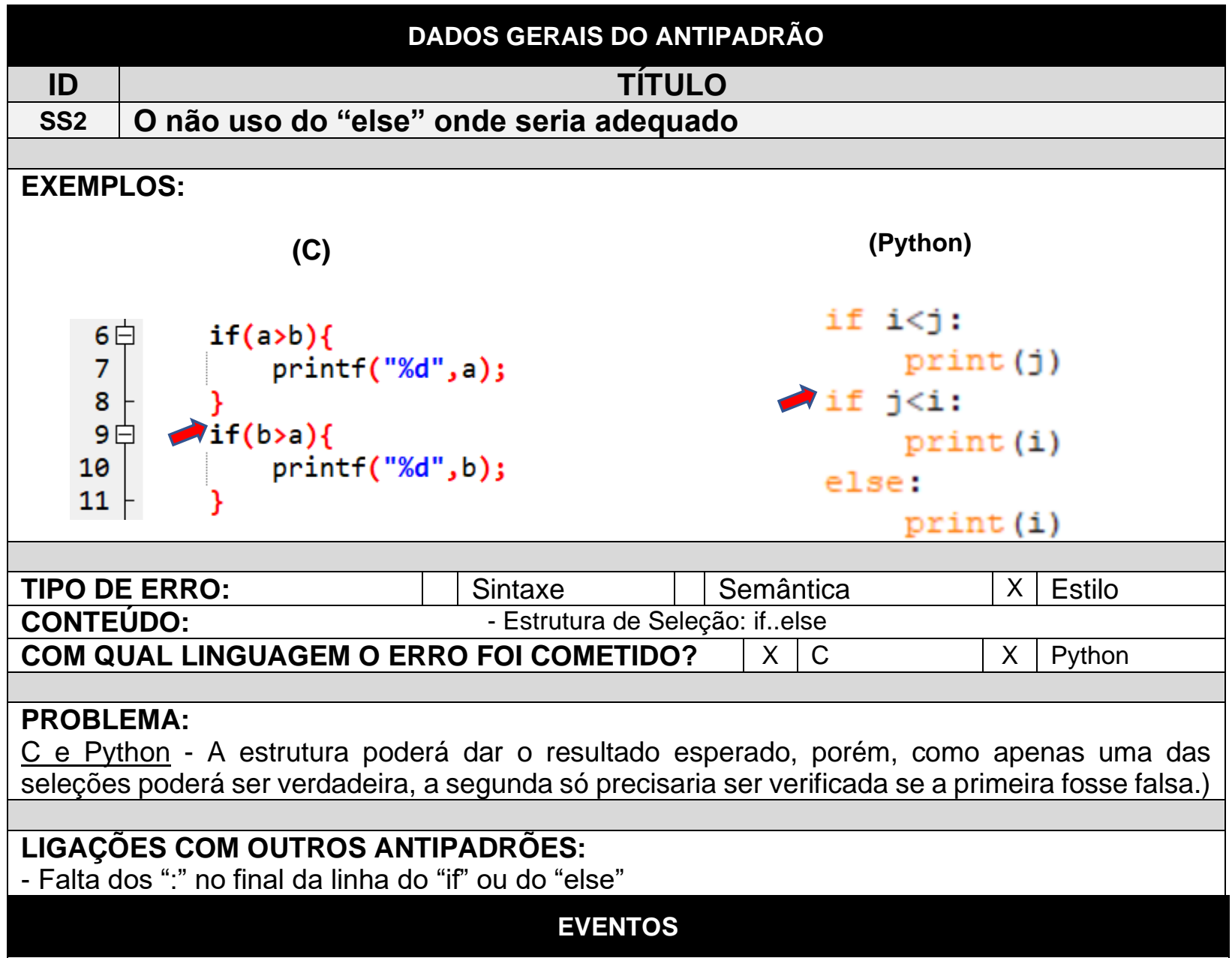

Observação: Nos trechos de códigos apresentados abaixo, foram analisadas apenas questão quanto ao antipadrão dessa tabela. Se outros erros existem, esses erros foram tratados em outros antipadrões.

Id do aluno: $1781 \quad$ Quantidade total de submissões do exercício:

Exercício que estava sendo resolvido:

Exercício 2.1

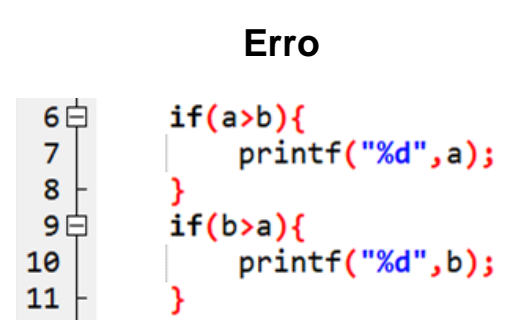

Ocorreu na submissão: 2

Observação:

Id do aluno: 2040

Exercício que estava sendo resolvido:

Exercício 2.1

\section{Erro Resolvido}

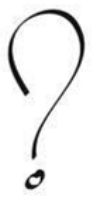

Corrigido na submissão:

Observação: Erro não foi corrigido. 


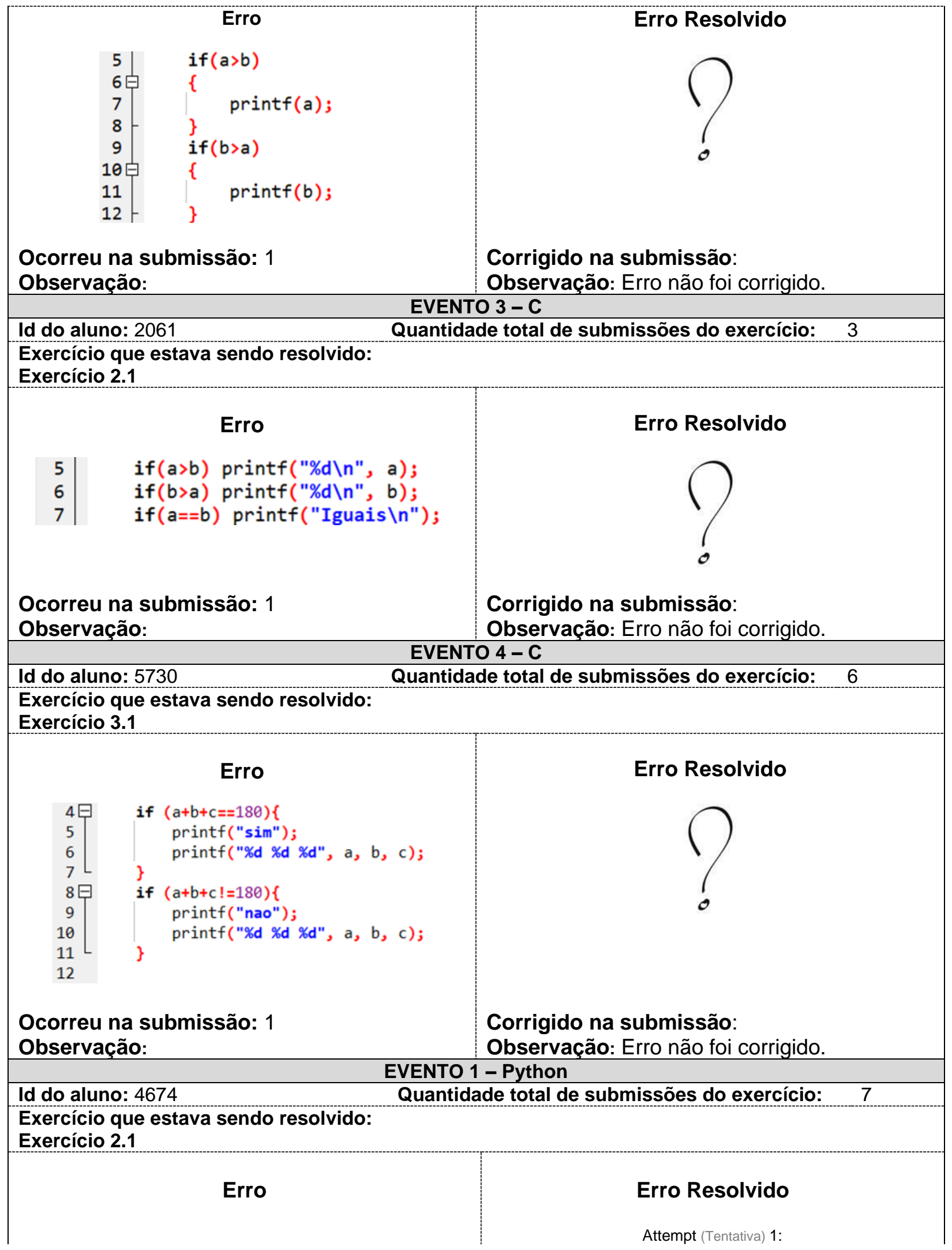




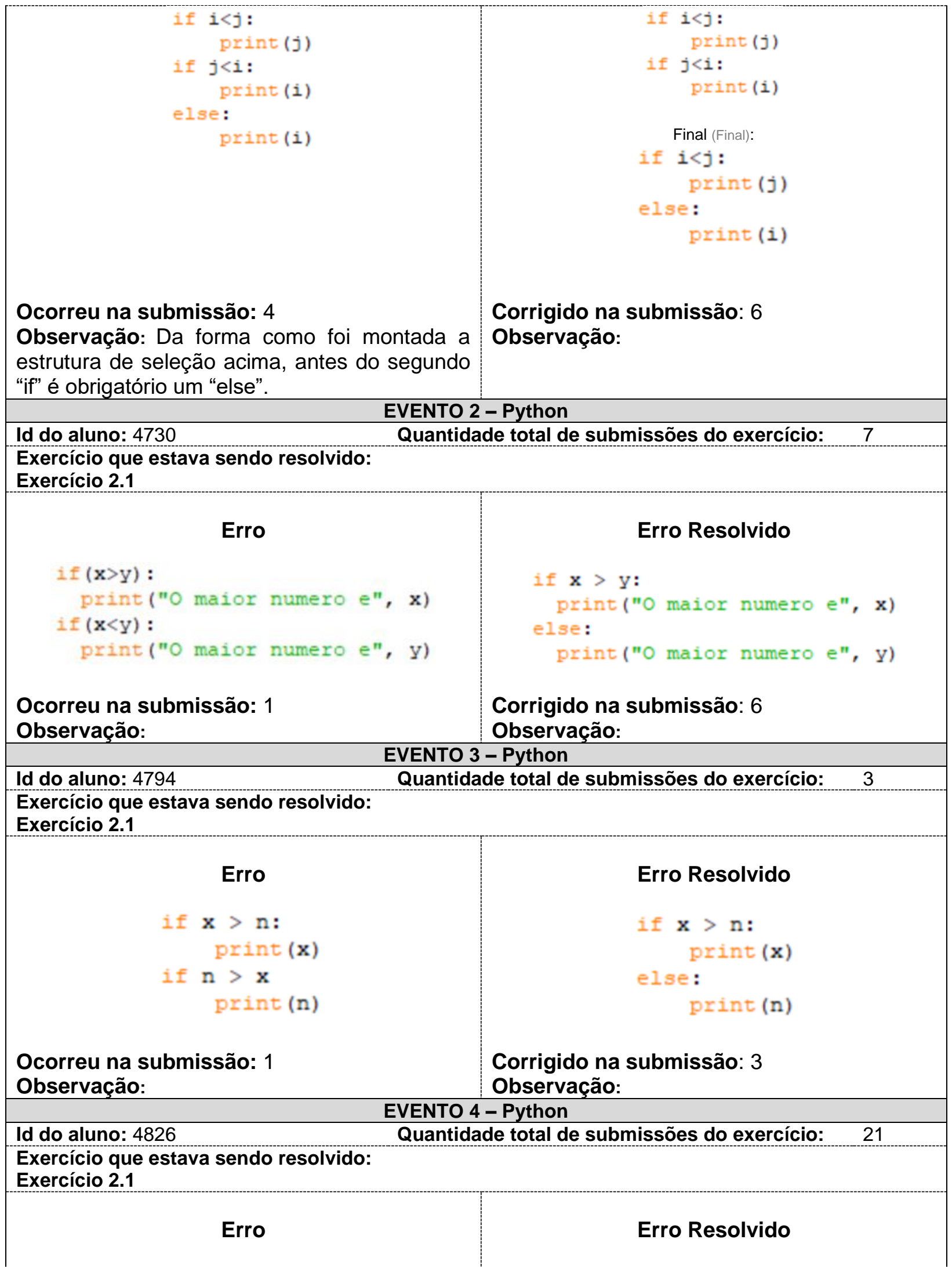




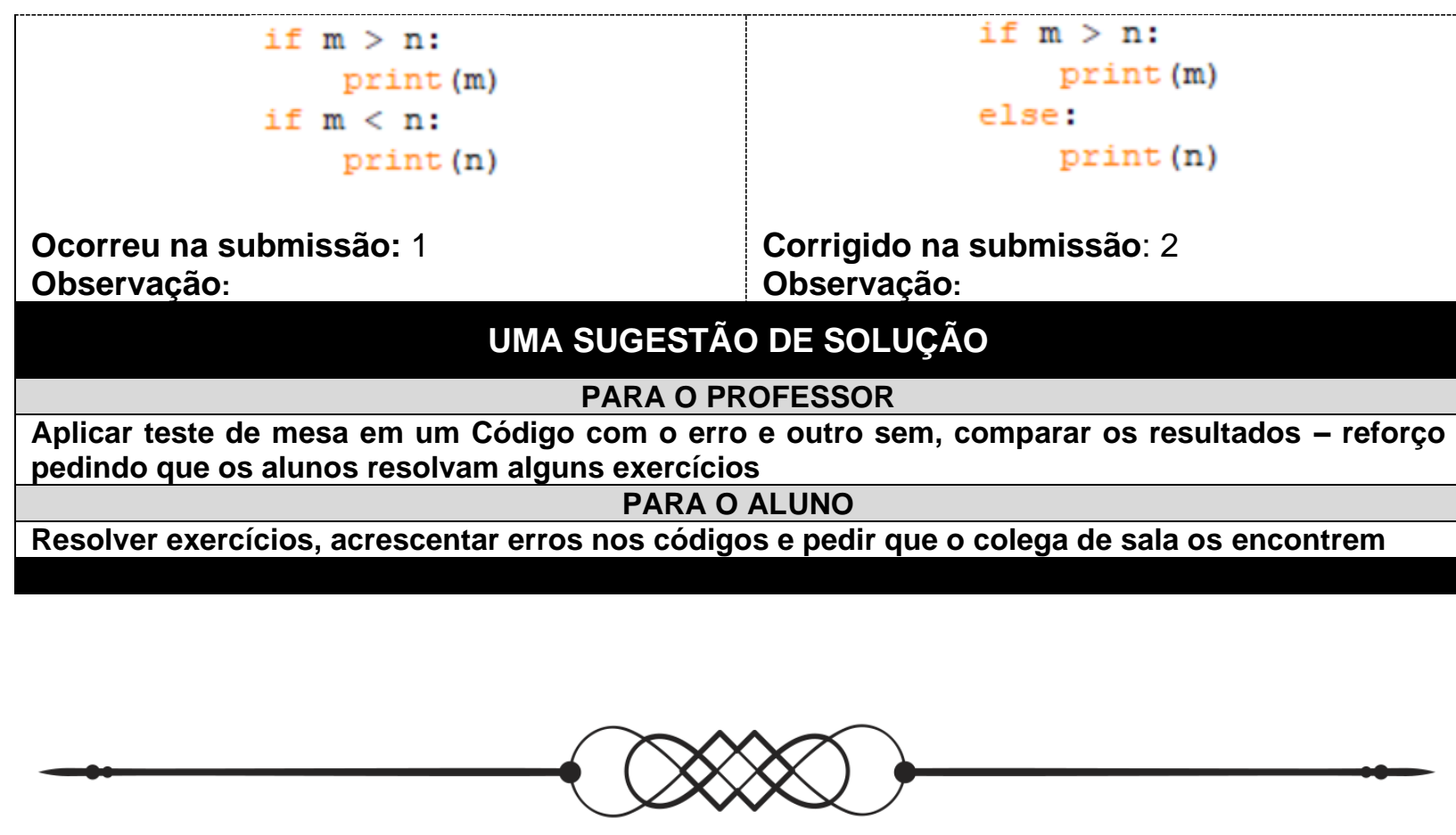

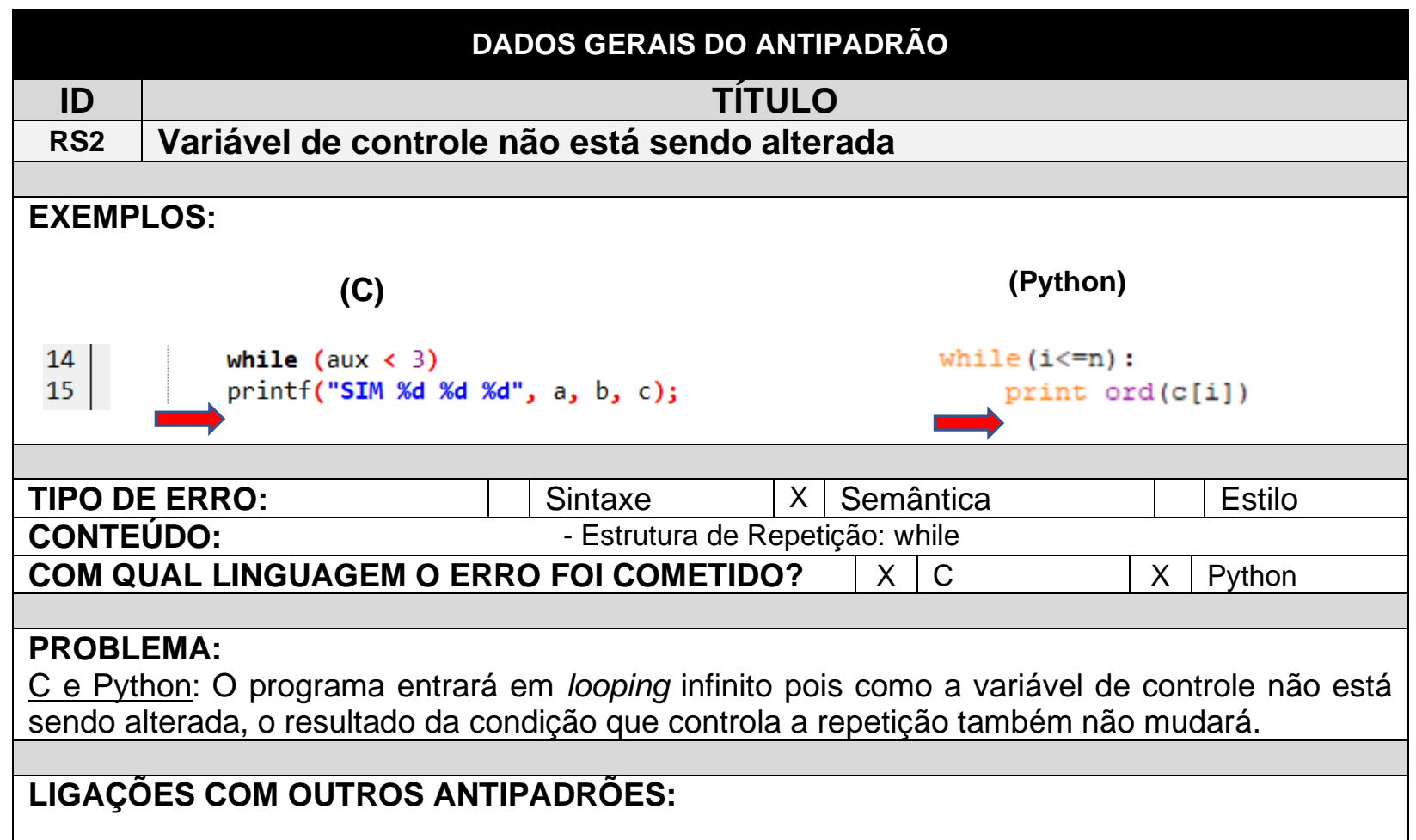

\section{EVENTOS}

Observação: Nos trechos de códigos apresentados abaixo, foram analisadas apenas questão quanto ao antipadrão dessa tabela. Se outros erros existem, esses erros foram tratados em outros antipadrões. 


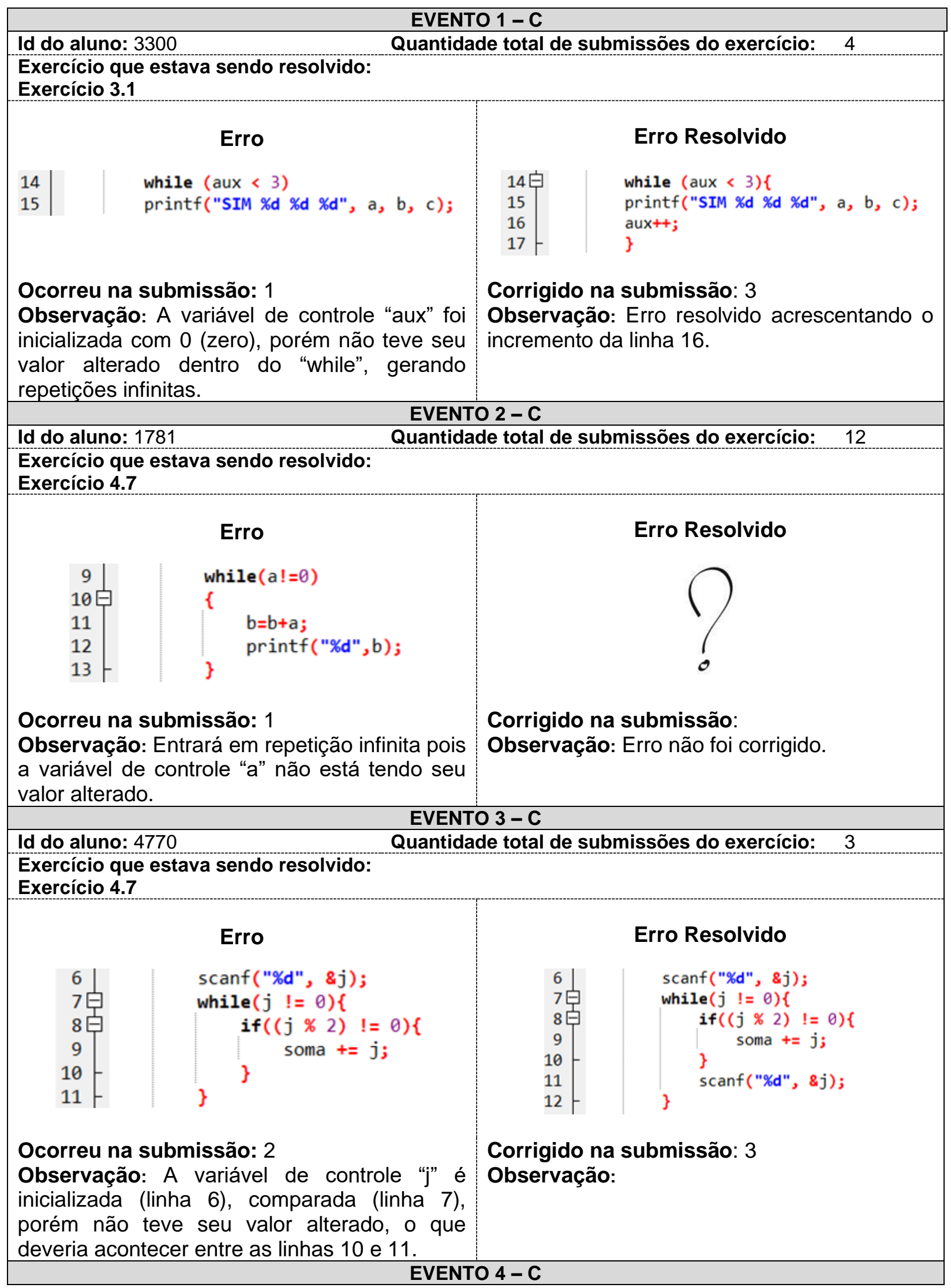


Id do aluno: 1963

Quantidade total de submissões do exercício:

21

Exercício que estava sendo resolvido:

Exercício 8.1

\section{Erro}

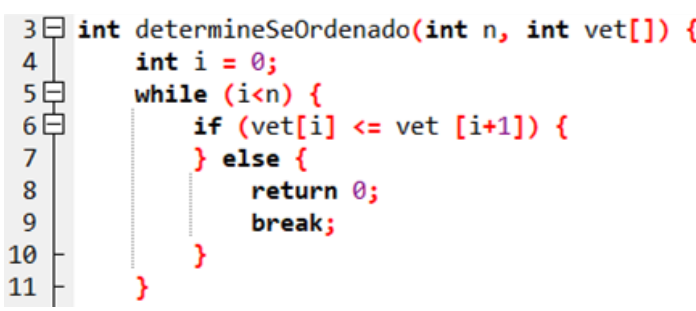

Ocorreu na submissão: 1

Observação: Variável de controle "i" do "while" não teve seu valor alterado dentro da repetição.

\section{Id do aluno: 3498 \\ Exercício que estava sendo resolvido: \\ Exercício 7.4

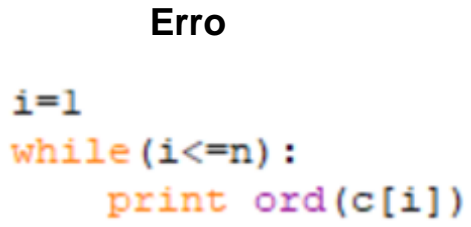

Erro

$i=1$

while $(i<=n)$ :

print ord(c[i])

Ocorreu na submissão: 2

Observação: A variável de controle "i" não está sendo alterada dentro do "while", causando repetições infinitas.

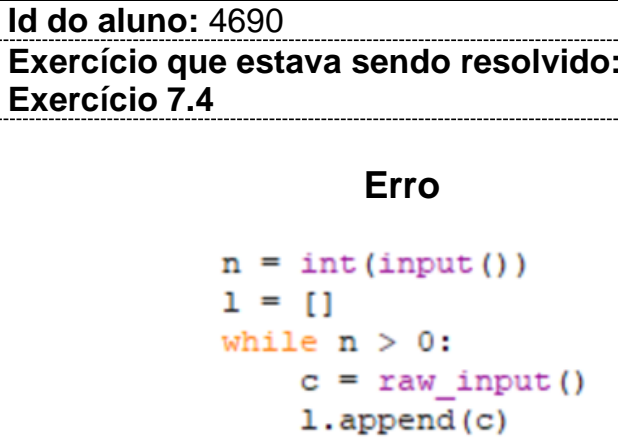

Id do aluno: 4690

Exercício que estava sendo resolvido:

Exercício 7.4

\section{Erro}

Ocorreu na submissão: 1

Observação: A variável de controle "n" não está sendo alterada dentro do "while", causando repetição infinita.

Id do aluno: 4730

\section{EVENTO 1 - Python}

Quantidade total de submissões do exercício:

\section{Erro Resolvido \\ $i=1$ \\ while $(i<=n)$ : \\ print ord(c[i]) \\ $i=i+1$}

Corrigido na submissão: 3

Observação:

\section{EVENTO 2 - Python}

Quantidade total de submissões do exercício:

16

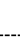

\section{Erro Resolvido}

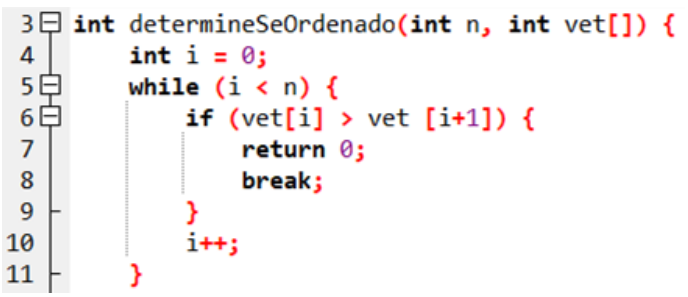

Corrigido na submissão: 4

\section{Observação:}


Exercício que estava sendo resolvido:

Exercício 7.4

\section{Erro}

$\mathrm{n}=$ int (input ("Digite um numero: "))

$c=$ raw input ("Digite uma palavra com", $n$, " caracteres")

$\mathrm{x}=0$

while $\mathrm{n} !=0$ :

print $(\mathrm{c} \cdot \operatorname{chr}(\mathrm{x}))$
pris

$\mathrm{x}=\mathrm{x}-1$

Ocorreu na submissão: 1

Observação: Desconsiderando outros erros e olhando para a estrutura de repetição "while", a variável de controle "n" não está sendo alterada, causando repetição infinita.

\begin{tabular}{|l|c|}
\hline \multicolumn{2}{|c|}{ EVENTO 4 - Python } \\
\hline \multicolumn{1}{|c|}{ Quantidade total de submissões do exercício: } \\
\hline \multicolumn{1}{|c|}{ Erro } & \multicolumn{1}{c|}{$\begin{array}{c}\text { Erro Resolvido } \\
\text { Exercício que estava sendo resolvido: }\end{array}$} \\
$\begin{array}{l}\text { Ocorreu na submissão: } \\
\text { Observação: }\end{array}$ & $\begin{array}{l}\text { Corrigido na submissão: } \\
\text { Observação: }\end{array}$ \\
\hline
\end{tabular}

\section{UMA SUGESTÃO DE SOLUÇÃO}

PARA O PROFESSOR

Aplicar teste de mesa em um Código com o erro e outro sem, comparar os resultados - reforço pedindo que os alunos resolvam alguns exercícios

\section{PARA O ALUNO}

Introduzir o erro em um código e entender as consequências que ele gera 



\section{Apêndice $\mathbf{H}$}

\section{Questionário de Validação dos Catálogos de Antipadrões}

A seguir é apresentado o questionário de validação dos Catálogos de Antipadrões, preparado e distribuído utilizando-se o Google Forms.

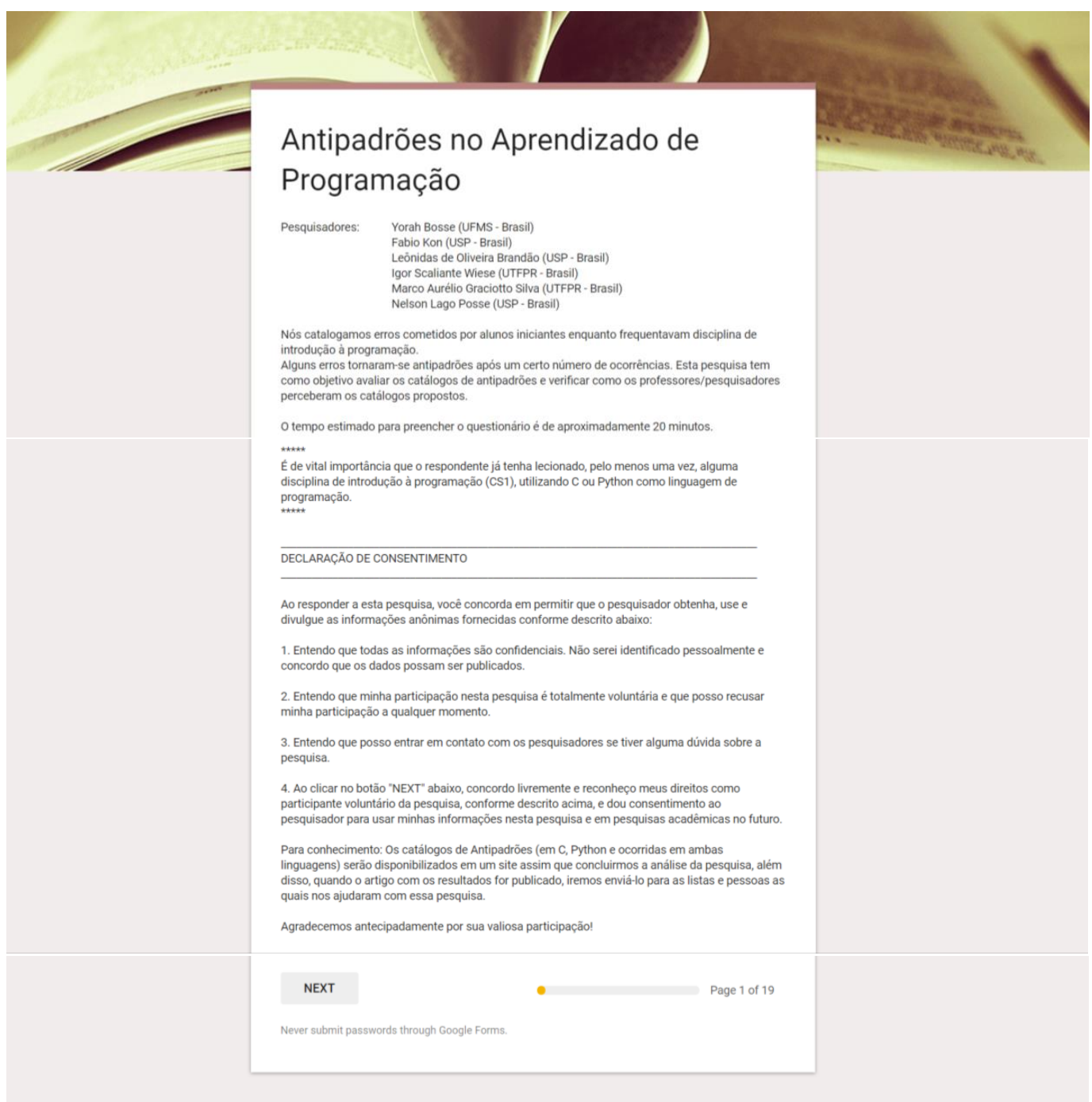




\section{Antipadrões no Aprendizado de Programação}

* Required

\section{Primeiro bloco de questões: Perfil}

P1. Em qual país você está trabalhando atualmente?

Brasil

Estados Unidos

Canadá

Austrália

Other:

P2. Marque abaixo as linguagens que você já usou para ensinar programação (CS1): *

$\square c$

$\mathrm{C}++$

Python

Java

Other:

P3. Há quantos anos você trabalha como professor? *
$0<5$ anos
> $>5$ até 10 anos
$>10$ até 15 anos
$>15$ até 20 anos
$>20$ anos

P4. Quantos anos de experiência você tem com cursos introdutórios de programação (CS1)? *
$\mathrm{O}<5$ anos
$>5$ até 10 anos
$>10$ até 15 anos
$>15$ até 20 anos
$\mathrm{O}>20$ anos

P5. Qual é a classificação da principal instituição em que você trabalha atualmente? *
Pública
Privada
Other:

\section{Antipadrões no Aprendizado de Programação}

\section{Segundo bloco de questōes: Catálogos de Antipadrōes}

\section{Importante}

Nas próximas 15 páginas, apresentaremos tabelas que descrevem os antipadrões, e vocé será solicitado a responder algumas perguntas sobre eles. Vocé encontrará em cada tabela o ID e o título do antipadrão, uma imagem do equivoco mostrado em um código de aluno, uma classificaçāo do equivoco e uma explicaçăo do motivo pelo qual ele é considerado um problema, além de um evento do equivoco encontrado.

Serão 15 tabelas, cada uma apresentando um antipadrão. Apesar de estarmos apresentando somente 15 antipadrōes, gostariamos de informar que não são somente esses que catalogamos, temos um total de 50 .

Esse bloco de questões será iniciado apresentando um conjunto de estratégias didáticas que os professores poderiam utilizar para minimizar a ocorrência dos antipadrões nos códigos dos seus alunos. Você será questionado sobre essas estratégias durante a perguntas sobre os antipadrōes.

Em seguida serão apresentados 3 antipadrōes em C, depois três em Python e, finalmente, nove que apareceram nas duas linguagens.

\section{Estratégias Didáticas}

Por favor, leia com atenção as quatro estratégias que podem ser usadas nas aulas para evitar erros de programação. Essas estratégias serão usadas em algumas perguntas feitas durante a apresentação dos 15 antipadrōes a seguir.

1. Explicação usando quadro negro e projector - reforçar usando Kahoot

Uma sugestão de como o professor poderia proceder em sala para tratar esse erro. evitando que ele seja uma dificuldades com seus alunos seria:

leve para a sala de aula códigos com antipadrões dos conteúdos abordados até 0 momento, tendo no máximo um erro por linha

2 projete para os alunos

3. peca que apontem un dos erros

peça se alguém da sala poderia explicar quais as consequências da existência desse erro no programa

5. reforce a explicação, se possivel, dando mais exemplos do mesmo erro apontado 6. explique a forma correta do comando, sem o erro

7. reescreva a linha de comando no quadro, sem o erro, ou faça que a correção apareça no slide

8. repita os passos 3 ao 7 enquanto houver erro no código

Em seguida:

9. projete a senha do quiz preparado no "kahoot" e peça que cada aluno se conecte com seu celular ou notebook

10. comece a "brincadeira" apresentando códigos com ou sem erros e os alunos tendo que escolher a opção correta

11. divirtam-se com os resultados

12. ao terminar, apresente os resultados e retome os exercícios que os alunos mais tiveram dificuldade, explicando-os.

P.S: O professor terá um rico material pois saberá onde os alunos ainda têm dificuldades, podendo assim trabalhar melhor esses pontos em sala.

2 Grupos trabalhando com execução passa a passo para entender os erros - reforça com exercícios

Uma sugestão de como o professor poderia proceder em sala para tratar esse erro. evitando que ele seja uma dificuldades com seus alunos seria:

1. monte equipes de 2 ou 3 alunos:

2. entregue para as equipes códigos com o erro. Não necessariamente o mesmo código

para todas as equipes;

3. peça para fazerem uma execução passo a passo do código apresentado;

4. em seguida, chame uma equipe para mostrar aos colegas o que eles encontraram e

mostrarem também como chegaram no resultado;

5. peça aos demais se os que tem o mesmo exercicio tiveram resultados diferentes. Se sim, peça que apresentem para a turma;

6. agora você (professor), usando de recursos visuais, simulando memória, por exemplo, mostre, corrija ou reforce o que foi apresentado:

7. repita os passos 3 a 6 caso tenha mais de um tipo de exercicio: 
8. dê exercicios para eles resolverem no qual eles pudessem cometer os erros comentados anteriormente;

9. peça que resolvam no quadro, assim você poderá corrigir caso ainda cometam.

\section{Programar na frente dos alunos, fazendo o erro aparecer - reforçar pedindo que os alunos desenvolvam novos códigos}

Uma sugestão de como o professor poderia proceder em sala para tratar esse erro evitando que ele seja uma dificuldades com seus alunos seria:

. escolha um exercício em que o erro que você quer tratar pudesse acontecer

2. vá para o quadro e faça um esboço superficial do que o código precisa fazer e em qual sequência;

faça o erro aparecer:

compile e peça que dêem sugestōes de como o código poderia ser corrigido 6. teste cada sugestão e explique se necessário os motivos que o fizeram funcionar ou

7. termine com o código funcionando projetado para os alunos verem

8. dê mais um exercicio para eles resolverem:

. chame um aluno para desenvolver seu código direto no projetor

10. vá explicando o que está acontencendo no momento em que o aluno está digitando:

11. repita os passos 8 ao 10 quantas vezes desejar, usando assim a prática intensiva para o aprendizado.

4. Aplicar teste de mesa em um código com o erro e outro sem, comparar os resultados reforçar pedindo que os alunos resolvam alguns exercicios

Uma sugestão de como o professor poderia proceder em sala para tratar esse erro. evitando que ele seja uma dificuldades com seus alunos seria:

1. mostre um exemplo do erro ao aprendiz. Certifique-se de que o único problema no seu exemplo é aquele que você deseja tratar

2. deixe bem claro, sinalizando o problema com circulo colorido ou seta;

3. explique porque está errado:

4. faça um teste de bancada (teste de mesa) mostrando o que acontece;

5. arrume o código, e refaça o teste de bancada (teste de mesa)

6. compare o resultado,

. certifique-se que o aprendiz entendeu pedindo que ele faça um ou dois exercicios

parecidos com esse;

8. corrija na sala de aula, na presença dos aprendizes.
3. use o projetor para então começar a programar na frente dos alunos;

A falta do " (ponto e virgula) no final das linhas que exigem que ele esteja, fard com que gere

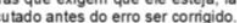
EVENTOS

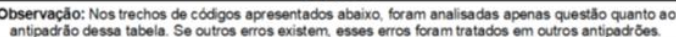
antipadrảo dessa tabela. Se outros erros existem, esses erros foram tratados em outros antipadröes. EVENTO 1
If do aluno: $2558 \quad$ Quantidade total de submissóes do exercicio 3 Id do aluno: 2558
Exercidio que estava sendo resolvido:
Exercicio 1.1

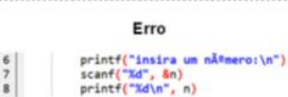
Observaçào:
Ocorreu na submissà o: 1

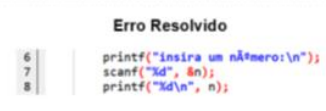

Corrigido na submissăo: 2
A1.1 Você já viu esse antipadrão em código desenvolvido por algum aluno? *

Sim

Não

Eu nåo tenho certeza se vi

A1.2 Você acredita que o aluno pode resolver o antipadrão acima: *

facilmente

com dificuldade moderada

com grande dificuldade

A1.3 Qual(is) estratégia(s) você considera mais apropriada(s) para tratar esse antipadrão nas aulas com seus alunos? *

Estratégia 1 - Explicação usando quadro negro e projector - reforço dos conceitos usando Kahoot

Estratégia 2 - Grupos trabalhando com execução passa a passo para entender os erros - reforço com exercícios

Estratégia 3 - Programar na frente dos alunos, fazendo o erro aparecer reforço pedindo que os alunos desenvolvam novos códigos

Estratégia 4 - Aplicar teste de mesa em um Código com o erro e outro sem, comparar os resultados - reforço pedindo que os alunos resolvam alguns exercicios

\section{Antipadrões no Aprendizado de Programação}

* Required

\section{Segundo bloco de questões: Catálogos de Antipadrões}

Olhe o antipadrão abaixo e responda às perguntas.

Antipadrão 1 - em C

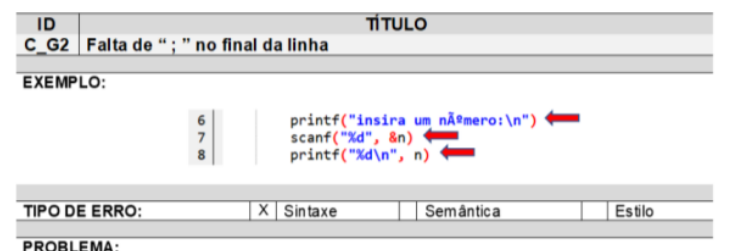

$\square$ Other:

A1.4 Se você tiver algo para acrescentar sobre esse antipadrão, estratégia, etc., use o espaço abaixo:

Your answer 


\section{Antipadrões no Aprendizado de Programação}

* Required

\section{Segundo bloco de questões: Catálogos de Antipadrões}

Olhe $\mathrm{o}$ antipadrão abaixo e responda às perguntas.

Antipadrão 2 - em C

\begin{tabular}{l|l}
\hline ID & TITULO \\
\hline C.F1 & Falta do return \\
\hline EXEMPLO:
\end{tabular}

EXEMPLO:

$$
\begin{aligned}
& \text { int main }() f \\
& \text { int as } \\
& \text { scanf( "qd", a ); } \\
& \text { printf(" "qd", a); }
\end{aligned}
$$

, 1

\begin{tabular}{l|l|l|l|l|}
\hline TIPO DE ERRO: & Sintaxe & $\mathrm{X}$ & Semántica & Estlo \\
\hline
\end{tabular}

PROBLEMA:

A falta do return poderá passar despercebida quando o valor năo é necessário no programa como e multas vezes o caso do return na função "main". Porém, as funçōes desenvolvidas necessário para a continuidade do programa, sendo que sua falta causará uma falha nos sultados. Por esse motivo, funcŏes tipags precisam executar o return na sua finalizacăo. EVENTOS

Observação: Nos trechos de códigos apresentados abaixo, foram analisadas apenas questão quanto ac antipadråo dessa tabeli. Se outros erros existem, esses erros foram tratados em outros antipadrōes. $\begin{array}{cc}\text { EVENTO 1 } & \text { Id do aluno: } 2670 \quad \text { Quantidade total de submissōes do exercício } \quad 4\end{array}$ Exercicio que estava sendo resolvido:

\section{Erro}

$$
\begin{aligned}
& 19 \text { int } \operatorname{main}(x) \\
& 2 \\
& 3 \\
& 3 \\
& 4 \\
& 4 \\
& 5
\end{aligned}
$$

Ocorreu na submissão: 1 Observação:

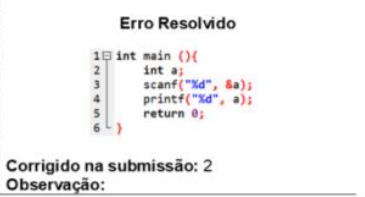

A2.1 Você já viu esse antipadrão em código desenvolvido por algum aluno? *

Sim

Não

Eu não tenho certeza se vi
A2.2 Você acredita que o aluno pode resolver o antipadrão acima: *

facilmente

com dificuldade moderada

com grande dificuldade

A2.3 Qual(is) estratégia(s) você considera mais apropriada(s) para tratar esse antipadrão nas aulas com seus alunos? *

Estratégia 1 - Explicação usando quadro negro e projector - reforço dos conceitos usando Kahoot

Estratégia 2 - Grupos trabalhando com execução passa a passo para entender os erros - reforço com exercícios

Estratégia 3 - Programar na frente dos alunos, fazendo o erro aparecer reforço pedindo que os alunos desenvolvam novos códigos

Estratégia 4 - Aplicar teste de mesa em um Código com o erro e outro sem, comparar os resultados - reforço pedindo que os alunos resolvam alguns exercícios

$\square$ Other:

A2.4 Se você tiver algo para acrescentar sobre esse antipadrão, estratégia, etc., use o espaço abaixo:

Your answer

BACK

NEXT

Page 5 of 19 


\section{Antipadrões no Aprendizado de Programação}

* Required

\section{Segundo bloco de questões: Catálogos de Antipadrões}

Olhe $\mathrm{o}$ antipadrão abaixo e responda às perguntas.

Antipadrão 3 - em C

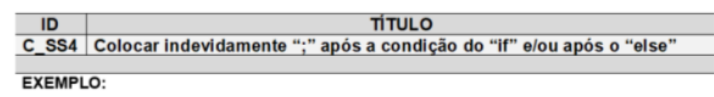

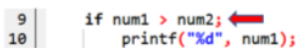

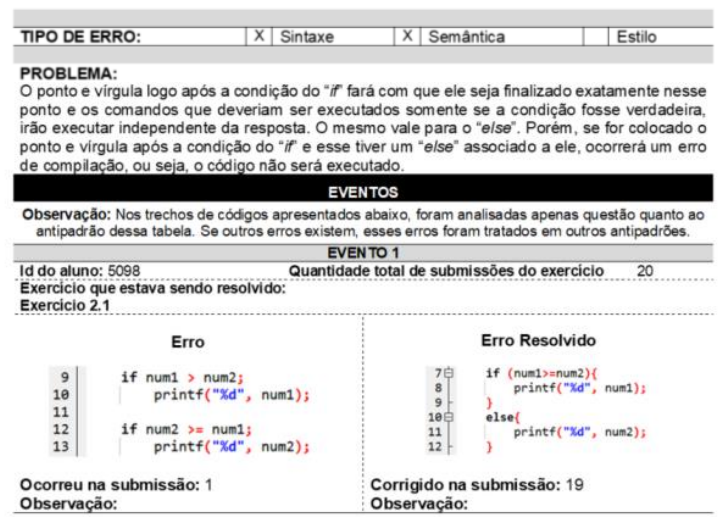

A3.1 Você já viu esse antipadrão em código desenvolvido por algum aluno?*
Sim
$\bigcirc$ Não
Eu não tenho certeza se vi

A3.2 Você acredita que o aluno pode resolver o antipadrão acima: *
facilmente
com dificuldade moderada
com grande dificuldade

A3.3 Qual(is) estratégia(s) você considera mais apropriada(s) para tratar esse antipadrão nas aulas com seus alunos? *

Estratégia 1 - Explicação usando quadro negro e projector - reforço dos conceitos usando Kahoot

Estratégia 2 - Grupos trabalhando com execução passa a passo para entender os erros - reforço com exercícios

$\square$ Estratégia 3 - Programar na frente dos alunos, fazendo o erro aparecer reforço pedindo que os alunos desenvolvam novos códigos

Estratégia 4 - Aplicar teste de mesa em um Código com o erro e outro sem comparar os resultados - reforço pedindo que os alunos resolvam alguns exercicios

Other:

A3.4 Se você tiver algo para acrescentar sobre esse antipadrão, estratégia, etc., use o espaço abaixo:

Your answer

BACK

NEXT

Page 6 of 19 


\section{Antipadrões no Aprendizado de Programação}

* Required

Segundo bloco de questões: Catálogos de Antipadrões

Olhe $\mathrm{o}$ antipadrão abaixo e responda às perguntas.

Antipadrão 1 - em Python

\begin{tabular}{|c|c|c|}
\hline $\begin{array}{l}\text { ID } \\
\text { P V2 }\end{array}$ & \multicolumn{2}{|c|}{$\begin{array}{c}\text { TíTULO } \\
\text { Usar palavra reservada para nome de variável }\end{array}$} \\
\hline \multicolumn{3}{|c|}{ EXEMPLO: } \\
\hline \multicolumn{3}{|c|}{$\begin{array}{l}\text { def main (): } \\
\text { int }=\text { int (input ()) } \\
\text { print (int) } \\
\operatorname{main}()\end{array}$} \\
\hline \multicolumn{3}{|c|}{ TIPO DE ERRO: } \\
\hline \multicolumn{3}{|c|}{$\begin{array}{l}\text { PROBLEMA: } \\
\text { Palavras reservadas como "prine, "inf, "inpur,, entre outras, não podem ser usadas para } \\
\text { identificadores, como é o caso dos nomes das variáveis. }\end{array}$} \\
\hline \multicolumn{3}{|c|}{ EVENTOS } \\
\hline \multicolumn{3}{|c|}{ 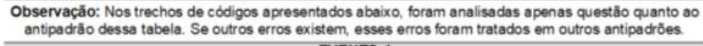 } \\
\hline \multicolumn{3}{|c|}{$\begin{array}{l}\text { EVENTO 1 } \\
\text { Id do aluno: } 3237 \\
\begin{array}{l}\text { Exercicio que estava sendo resolvido: } \\
\text { Exercicio 1.1 }\end{array}\end{array}$} \\
\hline & Erro & Erro Resolvido \\
\hline & $\begin{array}{l}\text { int }=\text { int (input ()) } \\
\text { print (int) }\end{array}$ & $\begin{array}{l}\text { inteiro }- \text { int (input ()) } \\
\text { print (1nte1ro) }\end{array}$ \\
\hline $\begin{array}{l}\text { Ocorre } \\
\text { Observ } \\
\text { para no }\end{array}$ & $\begin{array}{l}\text { Ina submissäo: } 1 \\
\text { çăo: Usou a palavra reservada "int } \\
\text { near a variável. }\end{array}$ & $\begin{array}{l}\text { Corrigido na submissão: } 2 \\
\text { Observaçāo: }\end{array}$ \\
\hline
\end{tabular}

A4.1 Você já viu esse antipadrão em código desenvolvido por algum aluno? *

Sim

Não

Eu não tenho certeza se vi
A4.2 Você acredita que o aluno pode resolver o antipadrão acima: *

facilmente

com dificuldade moderada

com grande dificuldade

A4.3 Qual(is) estratégia(s) você considera mais apropriada(s) para tratar esse antipadrão nas aulas com seus alunos? *

Estratégia 1 - Explicação usando quadro negro e projector - reforço dos conceitos usando Kahoot

Estratégia 2 - Grupos trabalhando com execução passa a passo para entender os erros - reforço com exercícios

Estratégia 3 - Programar na frente dos alunos, fazendo o erro aparecer reforço pedindo que os alunos desenvolvam novos códigos

Estratégia 4 - Aplicar teste de mesa em um Código com o erro e outro sem, comparar os resultados - reforço pedindo que os alunos resolvam alguns exercicios

Other:

A4.4 Se você tiver algo para acrescentar sobre esse antipadrão, estratégia, etc., use o espaço abaixo:

Your answer 


\section{Antipadrões no Aprendizado de Programação}

* Required

Segundo bloco de questões: Catálogos de Antipadrões

Olhe o antipadrão abaixo e responda às perguntas.

Antipadrão 2 - em Python

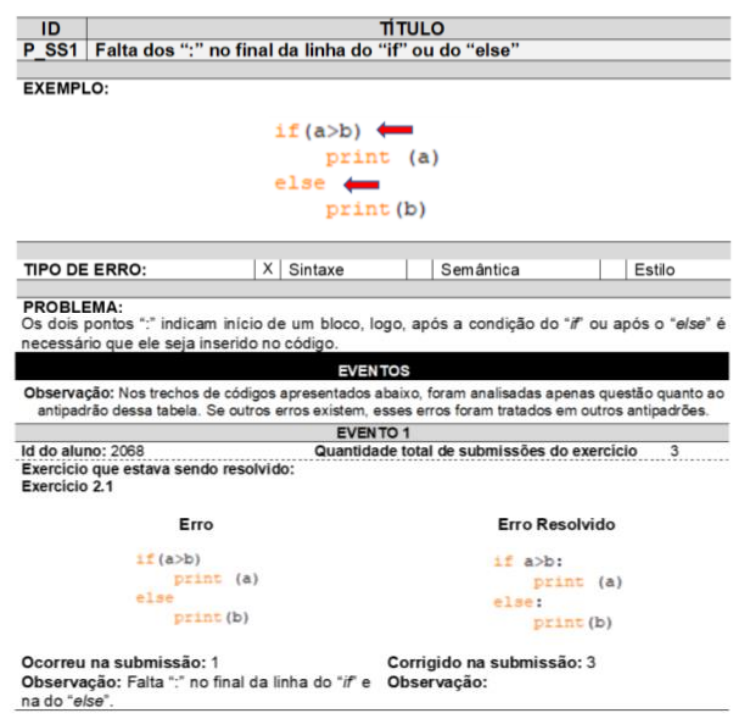

A5.1 Você já viu esse antipadrão em código desenvolvido por algum aluno? *
Sim
Não
Eu não tenho certeza se vi

A5.2 Você acredita que o aluno pode resolver o antipadrão acima: *
facilmente
com dificuldade moderada
com grande dificuldade

A5.3 Qual(is) estratégia(s) você considera mais apropriada(s) para tratar esse antipadrão nas aulas com seus alunos? *

Estratégia 1 - Explicação usando quadro negro e projector - reforço dos conceitos usando Kahoot

Estratégia 2 - Grupos trabalhando com execução passa a passo para entender os erros - reforço com exercicios

Estratégia 3 - Programar na frente dos alunos, fazendo o erro aparecer reforço pedindo que os alunos desenvolvam novos códigos

Estratégia 4 - Aplicar teste de mesa em um Código com o erro e outro sem comparar os resultados - reforço pedindo que os alunos resolvam alguns exercícios

Other:

A5.4 Se você tiver algo para acrescentar sobre esse antipadrão, estratégia, etc., use o espaço abaixo:

Your answer 


\section{Antipadrões no Aprendizado de Programação}

*Required

Segundo bloco de questões: Catálogos de Antipadrões

Olhe $\mathrm{o}$ antipadrão abaixo e responda às perguntas.

Antipadrão 3 - em Python

\begin{tabular}{l|l}
\multicolumn{1}{c}{ TíTULO } \\
\hline ID & \\
\hline P_MDA1 & Criação errada das linhas da matriz \\
\hline EXEMPLO:
\end{tabular}

EXEMPLO:

$$
m=\text { int (input ()) }
$$$$
\text { linha }=[1
$$

1 in range $(\mathrm{m})$ :

$y$ in range (n):

A. append (11nha)

\begin{tabular}{|c|c|}
\hline TIPO DE ERRO: & X Semântica \\
\hline \multicolumn{2}{|c|}{$\begin{array}{l}\text { PROBLEMA: } \\
\text { A criaçáa incorreta da linha de uma matriz fará com que o programa trabalhe de forma } \\
\text { inadequada, pois o programa estará armazenando incorretamente os dados. }\end{array}$} \\
\hline \multicolumn{2}{|c|}{ EVENTOS } \\
\hline \multicolumn{2}{|c|}{ 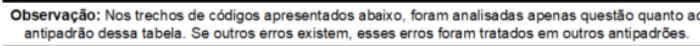 } \\
\hline \multicolumn{2}{|l|}{$\begin{array}{l}\text { Id do aluno: } 5538 \\
\text { Exercicio que estava sendo resolvido: } \\
\text { Exercicio 13.1 }\end{array}$} \\
\hline Erro & Erro Resolvido \\
\hline 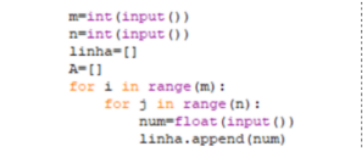 & 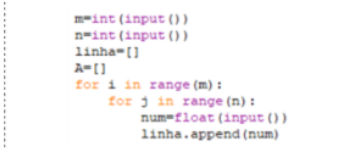 \\
\hline A. append (11nha) & $\begin{array}{l}\text { A. append (11inha) } \\
\text { 1inna }=11\end{array}$ \\
\hline $\begin{array}{l}\text { Ocorreu na submissão: } 1 \\
\text { Observaçäo: A linha "linha=[l" que cria a linha } \\
\text { da matriz deve estar entre os dois "for" ou deve } \\
\text { se repetir depois do "A.append (linha)". }\end{array}$ & $\begin{array}{l}\text { Corrigido na submissão: } 9 \\
\text { Observação: }\end{array}$ \\
\hline
\end{tabular}

A6.1 Você já viu esse antipadrão em código desenvolvido por algum aluno? *

Sim

Não

Eu não tenho certeza se vi

A6.2 Você acredita que o aluno pode resolver o antipadrão acima: *

facilmente

com dificuldade moderada

com grande dificuldade

A6.3 Qual(is) estratégia(s) você considera mais apropriada(s) para tratar esse antipadrão nas aulas com seus alunos? *

Estratégia 1 - Explicação usando quadro negro e projector - reforço dos conceitos usando Kahoot

Estratégia 2 - Grupos trabalhando com execução passa a passo para entender os erros - reforço com exercícios

Estratégia 3 - Programar na frente dos alunos, fazendo o erro aparecer reforço pedindo que os alunos desenvolvam novos códigos

Estratégia 4 - Aplicar teste de mesa em um Código com o erro e outro sem, comparar os resultados - reforço pedindo que os alunos resolvam alguns exercicios

Other:

A6.4 Se você tiver algo para acrescentar sobre esse antipadrão, estratégia, etc., use o espaço abaixo:

Your answer

BACK

NEXT

Page 9 of 19 


\section{Antipadrões no Aprendizado de Programação}

• Required

\section{Segundo bloco de questōes: Catálogos de Antipadrões}

Olhe o antipadrāo abaixo e responda às perguntas

Antipadrão 1 - em C e Python

\begin{tabular}{l|l}
\hline ID & TITULO \\
\hline G1 & Falta de indentação \\
\hline EXEMPLO:
\end{tabular}

(c)

(Python)

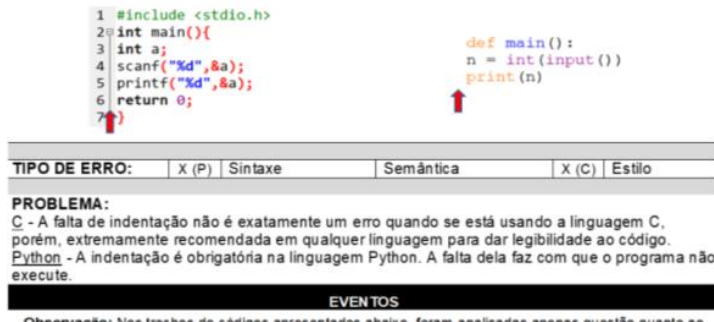

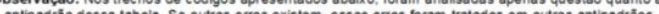

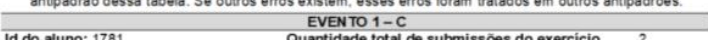

Id do aluno: 1781 Exercicio que esta
Exercicio 1.1

\begin{tabular}{|c|c|}
\hline Erro & Erro Resolvido \\
\hline 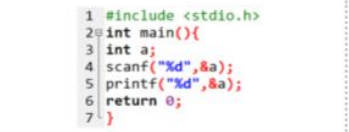 & \\
\hline 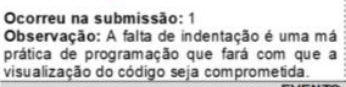 & $\begin{array}{l}\text { Corrigido na submissão: } \\
\text { Observação: A indentaçẵo não foi corrigida. }\end{array}$ \\
\hline $\begin{array}{ll}\text { EVENTO } \\
\text { Id do aluno: } 4666 & \text { Total of } \\
\text { cQuantidd }\end{array}$ & $\begin{array}{l}\text { 1-PYTHON } \\
\text { submissions of the exercise: } \\
\text { ade total de submissóps do exercicio) } \quad 12\end{array}$ \\
\hline \multicolumn{2}{|c|}{ 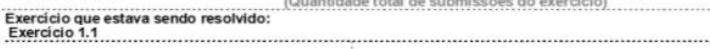 } \\
\hline Erro & Erro Resolvido \\
\hline $\begin{array}{l}\operatorname{def} \operatorname{main}(): \\
\mathrm{n}=\text { int (input ()) } \\
\text { print (n) } \\
\text { main () }\end{array}$ & $\begin{array}{l}n-1 \text { int (input (1) } \\
\text { print (n) }\end{array}$ \\
\hline $\begin{array}{l}\text { Ocorreu na submissão: } 11 \\
\text { Observação: }\end{array}$ & 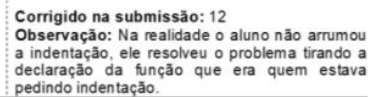 \\
\hline
\end{tabular}

A7.1 Você já viu esse antipadrão em código desenvolvido por algum aluno? *

Sim

Não

Eu não tenho certeza se vi

A7.2 Você acredita que o aluno pode resolver o antipadrão acima: *

facilmente

com dificuldade moderada

com grande dificuldade

A7.3 Qual(is) estratégia(s) você considera mais apropriada(s) para tratar esse antipadrão nas aulas com seus alunos? *

$\square$ Estratégia 1 - Explicaçăo usando quadro negro e projector - reforço dos conceitos usando Kahoot

Estratégia 2 - Grupos trabalhando com execução passa a passo para entender os erros - reforço com exercícios

Estratégia 3 - Programar na frente dos alunos, fazendo o erro aparecer reforço pedindo que os alunos desenvolvam novos códigos

Estratégia 4 - Aplicar teste de mesa em um Código com o erro e outro sem. comparar os resultados - reforço pedindo que os alunos resolvam alguns exercícios

$\square$ Other:

A7.4 Se você tiver algo para acrescentar sobre esse antipadrão, estratégia, etc., use o espaço abaixo:

Your answer

BACK

NEXT

Page 10 of 19 


\section{Antipadrões no Aprendizado de Programação}

* Required

\section{Segundo bloco de questões: Catálogos de Antipadrões}

Olhe $\mathrm{o}$ antipadrão abaixo e responda às perguntas.

Antipadrão 2 - em C e Python

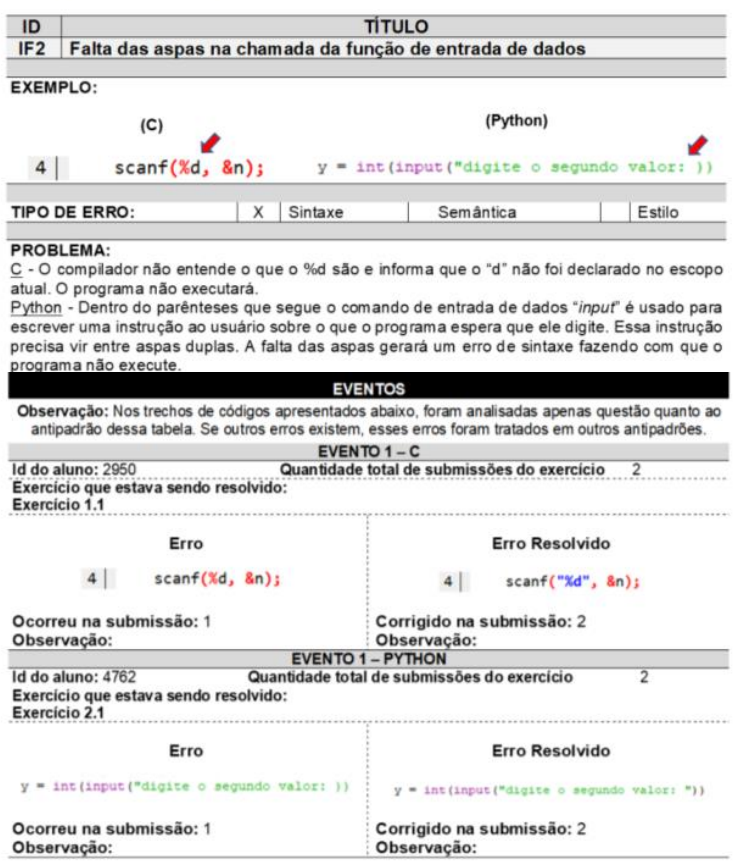

A8.1 Você já viu esse antipadrão em código desenvolvido por algum aluno? *

Sim

$\bigcirc$ Não

Eu não tenho certeza se vi

A8.2 Você acredita que o aluno pode resolver o antipadrão acima: *

facilmente

com dificuldade moderada

com grande dificuldade

A8.3 Qual(is) estratégia(s) você considera mais apropriada(s) para tratar esse antipadrão nas aulas com seus alunos? *

Estratégia 1 - Explicação usando quadro negro e projector - reforço dos conceitos usando Kahoot

Estratégia 2 - Grupos trabalhando com execução passa a passo para entender os erros - reforço com exercicios

Estratégia 3 - Programar na frente dos alunos, fazendo o erro aparecer reforço pedindo que os alunos desenvolvam novos códigos

Estratégia 4 - Aplicar teste de mesa em um Código com o erro e outro sem comparar os resultados - reforço pedindo que os alunos resolvam alguns exercicios

Other:

A8.4 Se você tiver algo para acrescentar sobre esse antipadrão, estratégia, etc., use o espaço abaixo:

Your answer

BACK

NEXT

Page 11 of 19 


\section{Antipadrões no Aprendizado de Programação}

\section{* Required}

\section{Segundo bloco de questōes: Catálogos de Antipadrões}

Olhe o antipadrão abaixo e responda às perguntas.

Antipadrão 3 - em C e Python

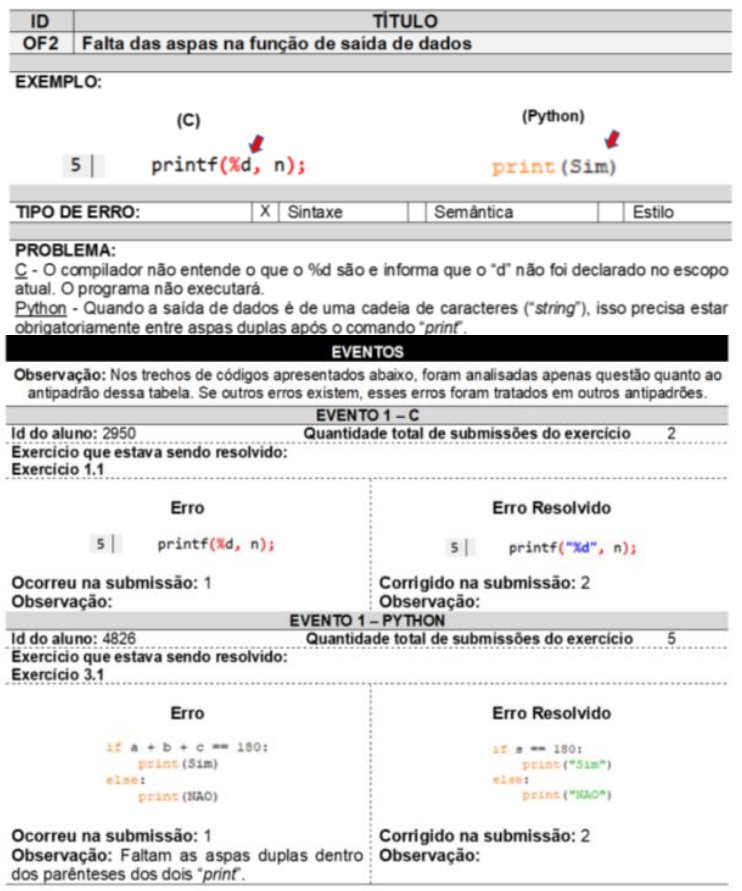

A9.1 Você já viu esse antipadrão em código desenvolvido por algum aluno?*
Sim
Não
Eu não tenho certeza se vi

A9.2 Você acredita que o aluno pode resolver o antipadrão acima: *
facilmente
com dificuldade moderada
com grande dificuldade

A9.3 Qual(is) estratégia(s) você considera mais apropriada(s) para tratar esse antipadrão nas aulas com seus alunos? *
Estratégia 1 - Explicação usando quadro negro e projector - reforço dos onceitos usando Kahoot
Estratégia 2 - Grupos trabalhando com execução passa a passo para
entender os erros - reforço com exercícios
Estratégia 3 - Programar na frente dos alunos, fazendo o erro aparecer - reforço pedindo que os alunos desenvolvam novos códigos
Estratégia 4 - Aplicar teste de mesa em um Código com o erro e outro sem. comparar os resultados - reforço pedindo que os alunos resolvam alguns exercicios
$\square$ Other:

A9.4 Se você tiver algo para acrescentar sobre esse antipadrão, estratégia, etc., use o espaço abaixo:

Your answer

NEXT

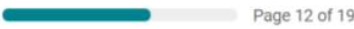




\section{Antipadrões no Aprendizado de Programação}

* Required

\section{Segundo bloco de questões: Catálogos de Antipadrões}

Olhe o antipadrão abaixo e responda às perguntas

Antipadrão 4 - em C e Python

\begin{tabular}{|c|c|c|}
\hline ID & \multicolumn{2}{|c|}{ TITULO } \\
\hline OF 4 & \multicolumn{2}{|c|}{$\begin{array}{l}\text { Falta da virgula para separar o primeiro do segundo parâmetro na função } \\
\text { de saida de dados }\end{array}$} \\
\hline \multicolumn{3}{|c|}{ EXEMPLO: } \\
\hline & (C) & (Python) \\
\hline 16। & printf("Xd $\left.x d x d d^{-} a, b, c\right) ;$ & print ("Sim" a, b, c) \\
\hline TIPOD & \begin{tabular}{l|l}
$\mathrm{X}$ & Sintaxe \\
\end{tabular} & | Semântica \\
\hline \multicolumn{3}{|c|}{ 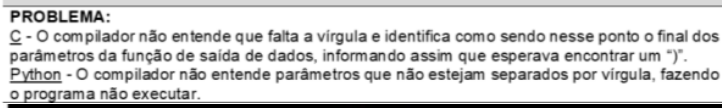 } \\
\hline \multicolumn{3}{|c|}{ EVENTOS } \\
\hline \multicolumn{3}{|c|}{$\begin{array}{l}\text { Observaçăo: Nos trechos de códigos apresentados abaixo, foram analisadas apenas questão quanto ac } \\
\text { antipadráo dessa tabela. Se outros erros existem, esses erros foram tratados em outros antipadróes. }\end{array}$} \\
\hline \multicolumn{3}{|c|}{$\begin{array}{ll}\text { Id do aluno: } 2810 & \begin{array}{l}\text { EVENTO 1-C } \\
\text { Quantidade total de submissōes do exercicio }\end{array}\end{array}$} \\
\hline & Erro & Erro Resolvido \\
\hline 16 & $\operatorname{printf}\left(-x d x d x a^{-} a, b, c\right)$; & 16| printf( $\left(x d \times x \times 0^{-}, 0, b, c\right)$; \\
\hline \multicolumn{2}{|c|}{$\begin{array}{l}\text { Ocorreu na submissão: } 4 \\
\text { Observação: }\end{array}$} & $\begin{array}{l}\text { Corrigido na submissāo: } 5 \\
\text { Observação: }\end{array}$ \\
\hline \multirow{2}{*}{\multicolumn{3}{|c|}{$\begin{array}{l}\text { Id do aluno: } 4914 \\
\text { Exercicio que estava sendo resolvido: }\end{array}$}} \\
\hline & & \\
\hline & Erro & Erro Resolvido \\
\hline & $\begin{array}{l}\text { print }(" 5 i m " a, b, c) \\
\text { print ("Mao" } a+b+c)\end{array}$ & $\begin{array}{l}\text { prine }(" S i m ", a, b, c) \\
\text { print ("wao", } \mathbf{a}+\mathbf{b}+\mathbf{c})\end{array}$ \\
\hline $\begin{array}{l}\text { Ocorre } \\
\text { Obser } \\
\text { separa }\end{array}$ & $\begin{array}{l}\text { u na submissão: } 5 \\
\text { ração: Nos dois "print falta virgula para } \\
\text { ro primeiro do segundo parâmetro. }\end{array}$ & $\begin{array}{l}\text { Corrigido na submissão: } 6 \\
\text { Observação: }\end{array}$ \\
\hline
\end{tabular}

A10.1 Você já viu esse antipadrão em código desenvolvido por algum aluno?*

$\bigcirc \operatorname{sim}$

○ão

Eu não tenho certeza se vi

A10.2 Você acredita que o aluno pode resolver o antipadrão acima: *

facilmente

com dificuldade moderada

com grande dificuldade

A10.3 Qual(is) estratégia(s) você considera mais apropriada(s) para tratar esse antipadrão nas aulas com seus alunos? *

$\square$ Estratégia 1 - Explicação usando quadro negro e projector - reforço dos conceitos usando Kahoot

Estratégia 2 - Grupos trabalhando com execução passa a passo para entender os erros - reforço com exercicios

Estratégia 3 - Programar na frente dos alunos, fazendo o erro aparecer reforço pedindo que os alunos desenvolvam novos códigos

Estratégia 4 - Aplicar teste de mesa em um Código com o erro e outro sem comparar os resultados - reforço pedindo que os alunos resolvam alguns exercicios

Other:

A10.4 Se você tiver algo para acrescentar sobre esse antipadrão, estratégia, etc., use o espaço abaixo:

Your answer

BACK

NEXT

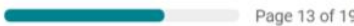




\section{Antipadrões no Aprendizado de Programação}

* Required

\section{Segundo bloco de questões: Catálogos de Antipadrões}

Olhe o antipadrão abaixo e responda às perguntas.

Antipadrão 5 - em C e Python

\begin{tabular}{|c|c|c|}
\hline ID & \multirow{2}{*}{\multicolumn{2}{|c|}{ O uso do "=" ao invés de "=z" }} \\
\hline RE1 & & \\
\hline \multicolumn{3}{|c|}{ EXEMPLO: } \\
\hline & (C) & (Python) \\
\hline & if $(n 1=n 2)$ & if soma $=180$ : \\
\hline TIPOD & $|C(P)|$ Sintaxe & \begin{tabular}{|l|l|}
$x(C)$ & Semântica \\
\end{tabular} \\
\hline \multicolumn{3}{|c|}{ 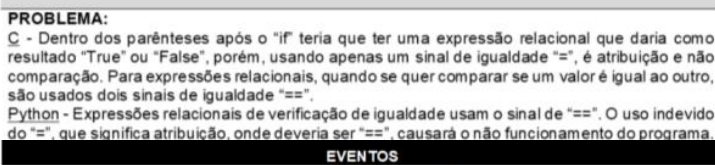 } \\
\hline \multicolumn{3}{|c|}{$\begin{array}{l}\text { Observacão: Nos trechos de códgos apresentados abaixo, foram analisadas apenas questăo quanto ao } \\
\text { antipadrăo dessa tabela. Se outros erros existem, esses erros foram tratados em outros antipadröes. }\end{array}$} \\
\hline \multicolumn{3}{|c|}{$\begin{array}{l}\text { Id do aluno: } 1781 \\
\text { Exercicio que estava sendo resolvido: } \\
\text { Exercicio } 21\end{array}$} \\
\hline \multicolumn{2}{|r|}{ Erro } & Erro Resolvido \\
\hline & if) $(a=b)\{$ & if $(a==b)\{$ \\
\hline \multicolumn{2}{|c|}{$\begin{array}{l}\text { Ocorreu na submissão: } 4 \\
\text { Observaçăo: }\end{array}$} & $\begin{array}{l}\text { Corrigido na submissão: } 5 \\
\text { Observação: }\end{array}$ \\
\hline \multicolumn{3}{|c|}{$\begin{array}{l}\text { Id do aluno: } 4850 \\
\text { Exercicicio que estava sendo resolvido: }\end{array}$} \\
\hline & Erro & Erro Resolvido \\
\hline & if soma=180: & if soma $=180$ : \\
\hline $\begin{array}{l}\text { Ocorre } \\
\text { Obsery } \\
\text { nâo }="\end{array}$ & $\begin{array}{l}\text { u na submissão: } 2 \\
\text { açăo: Para comparaçắo è usado "=" e }\end{array}$ & $\begin{array}{l}\text { Corrigido na submissão: } 14 \\
\text { Observação: }\end{array}$ \\
\hline
\end{tabular}

A11.1 Você já viu esse antipadrão em código desenvolvido por algum aluno? *

○ sim

○ Não

Eu não tenho certeza se vi

A11.2 Você acredita que o aluno pode resolver o antipadrão acima: *

$\bigcirc$ facilmente

com dificuldade moderada

com grande dificuldade

A11.3 Qual(is) estratégia(s) você considera mais apropriada(s) para tratar esse antipadrão nas aulas com seus alunos? *
Estratégia 1 - Explicação usando quadro negro e projector - reforço dos conceitos usando Kahoot
Estratégia 2 - Grupos trabalhando com execução passa a passo para entender os erros - reforço com exercícios
Estratégia 3 - Programar na frente dos alunos, fazendo o erro aparecer - reforço pedindo que os alunos desenvolvam novos códigos
Estratégia 4 - Aplicar teste de mesa em um Código com o erro e outro sem, comparar os resultados - reforço pedindo que os alunos resolvam alguns exercícios
$\square$ Other:

A11.4 Se você tiver algo para acrescentar sobre esse antipadrão, estratégia, etc., use o espaço abaixo:

Your answer NEXT Page 14 of 19 
APÊNDICE H

\section{Antipadrões no Aprendizado de Programação}

* Required

\section{Segundo bloco de questões: Catálogos de Antipadrões}

Olhe o antipadrão abaixo e responda às perguntas.

Antipadrão 6 - em C e Python

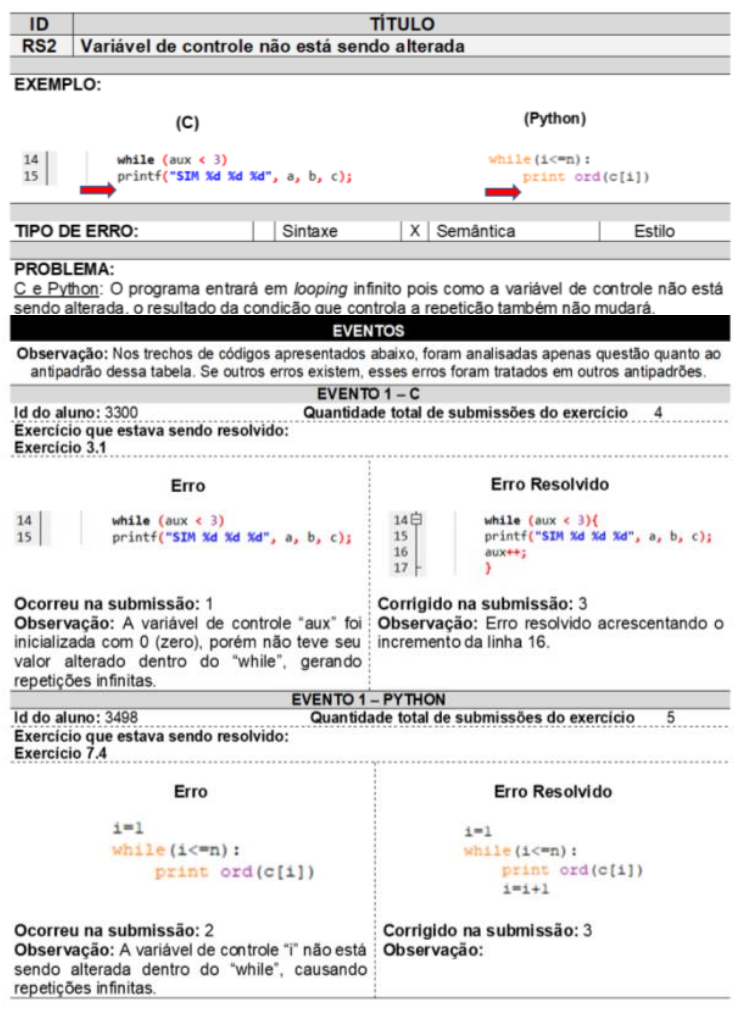

A12.1 Você já viu esse antipadrão em código desenvolvido por algum aluno? *

$\bigcirc \operatorname{sim}$

Não

Eu não tenho certeza se vi

A12.2 Você acredita que o aluno pode resolver o antipadrão acima: *

facilmente

com dificuldade moderada

com grande dificuldade

A12.3 Qual(is) estratégia(s) você considera mais apropriada(s) para tratar esse antipadrão nas aulas com seus alunos? *
Estratégia 1 - Explicação usando quadro negro e projector - reforço dos conceitos usando Kahoot
Estratégia 2 - Grupos trabalhando com execução passa a passo para entender os erros - reforço com exercicios
Estratégia 3 - Programar na frente dos alunos, fazendo o erro aparecer - reforço pedindo que os alunos desenvolvam novos códigos
Estratégia 4 - Aplicar teste de mesa em um Código com o erro e outro sem, comparar os resultados - reforço pedindo que os alunos resolvam alguns exercicios
Other:

A12.4 Se você tiver algo para acrescentar sobre esse antipadrão, estratégia, etc., use o espaço abaixo:

Your answer 


\section{Antipadrões no Aprendizado de Programação}

* Required

\section{Segundo bloco de questões: Catálogos de Antipadrões}

Olhe o antipadrão abaixo e responda às perguntas.

Antipadrão 7 - em C e Python

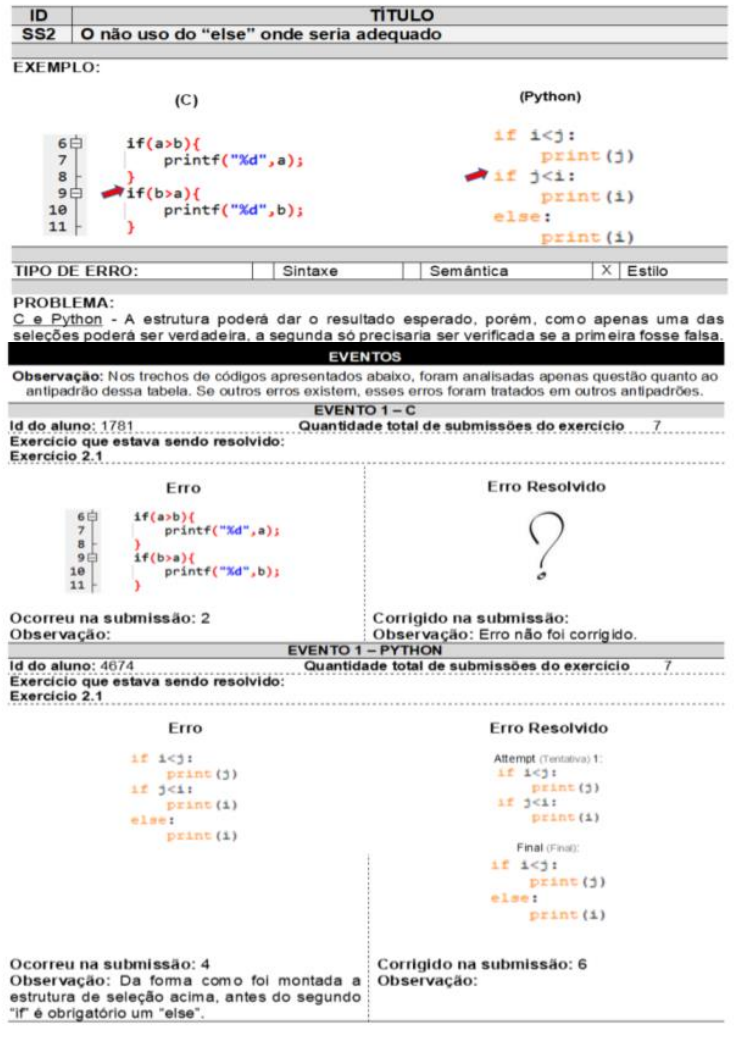

A13.1 Você já viu esse antipadrão em código desenvolvido por algum aluno? *

$\bigcirc \operatorname{sim}$

○ão

Eu não tenho certeza se vi

A13.2 Você acredita que o aluno pode resolver o antipadrão acima: *

$\bigcirc$ facilmente

$\bigcirc$ com dificuldade moderada

com grande dificuldade

A13.3 Qual(is) estratégia(s) você considera mais apropriada(s) para tratar esse antipadrão nas aulas com seus alunos? *

$\square$ Estratégia 1 - Explicação usando quadro negro e projector - reforço dos conceitos usando Kahoot

Estratégia 2 - Grupos trabalhando com execução passa a passo para entender os erros - reforço com exercícios

Estratégia 3 - Programar na frente dos alunos, fazendo o erro aparecer reforço pedindo que os alunos desenvolvam novos códigos

Estratégia 4 - Aplicar teste de mesa em um Código com o erro e outro sem, comparar os resultados - reforço pedindo que os alunos resolvam alguns exercicios

$\square$ Other:

A13.4 Se você tiver algo para acrescentar sobre esse antipadrão, estratégia, etc., use o espaço abaixo:

Your answer

BACK NEXT

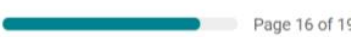




\section{Antipadrões no Aprendizado de Programação}

\section{* Required}

\section{Segundo bloco de questões: Catálogos de Antipadrões}

Olhe $\circ$ antipadrão abaixo e responda às perguntas.

Antipadrão 8 - em C e Python

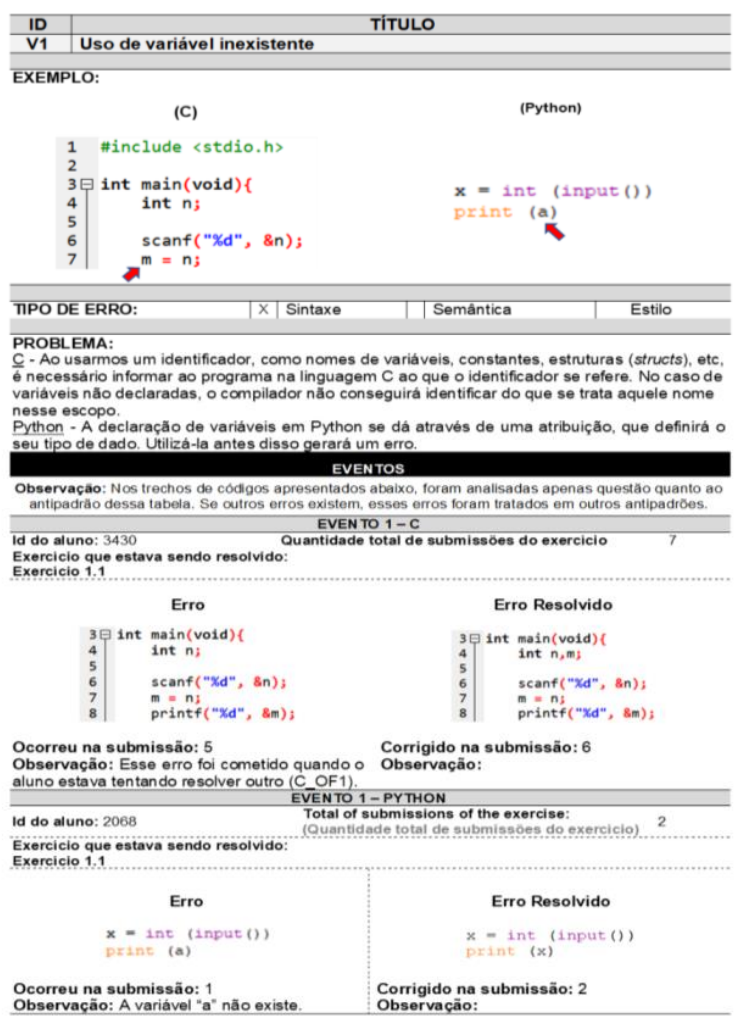

A14.1 Você já viu esse antipadrão em código desenvolvido por algum aluno?

Sim

Năo

Eu não tenho certeza se vi

A14.2 Você acredita que o aluno pode resolver o antipadrão acima: *

facilmente

com dificuldade moderada

com grande dificuldade

A14.3 Qual(is) estratégia(s) você considera mais apropriada(s) para tratar esse antipadrão nas aulas com seus alunos? *

Estratégia 1 - Explicação usando quadro negro e projector - reforço do conceitos usando Kahoot

Estratégia 2 - Grupos trabalhando com execução passa a passo para entender os erros - reforço com exercícios

Estratégia 3 - Programar na frente dos alunos, fazendo o erro aparecer reforço pedindo que os alunos desenvolvam novos códigos

Estratégia 4 - Aplicar teste de mesa em um Código com o erro e outro sem comparar os resultados - reforço pedindo que os alunos resolvam alguns exercícios

$\square$ Other:

A14.4 Se você tiver algo para acrescentar sobre esse antipadrão, estratégia, etc., use o espaço abaixo:

Your answer 


\section{Antipadrões no Aprendizado de Programação}

\section{* Required}

\section{Segundo bloco de questões: Catálogos de Antipadrões}

Olhe $\mathrm{o}$ antipadrão abaixo e responda às perguntas.

Antipadrão 9 - em C e Python

\begin{tabular}{|c|c|c|}
\hline ID & \multirow{2}{*}{\multicolumn{2}{|c|}{$\begin{array}{r}\text { TitULLO } \\
\text { Atribuição usando "=" ao invés de "=" }\end{array}$}} \\
\hline V3 & & \\
\hline \multicolumn{3}{|c|}{ EXEMPLO: } \\
\hline & (C) & (Python) \\
\hline & soma $=a+b+c ;$ & I ine (1nput/"oigite un numero gue desera: \\
\hline TIPOD & $X(P) \mid$ Sintaxe & \begin{tabular}{l|l}
$X(C)$ & Semântica \\
\end{tabular} \\
\hline \multirow{2}{*}{\multicolumn{3}{|c|}{ 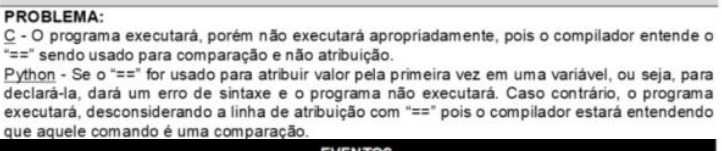 }} \\
\hline & & \\
\hline \multicolumn{3}{|c|}{ 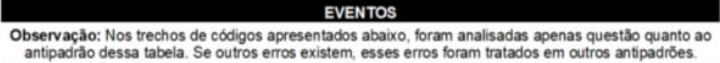 } \\
\hline \multicolumn{3}{|c|}{ 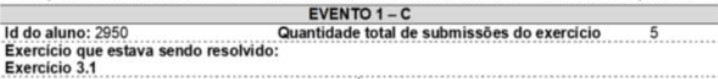 } \\
\hline & Erro & Erro Resolvido \\
\hline & soma $=a+b+c ;$ & soma $=a+b+c ;$ \\
\hline \multicolumn{2}{|c|}{ 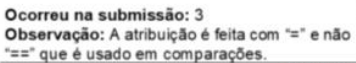 } & $\begin{array}{l}\text { Corrigido na submissão: } 4 \\
\text { Observaçấ: }\end{array}$ \\
\hline \multicolumn{3}{|c|}{$\begin{array}{l}\text { Id do aluno: } 4666 \quad \text { EVENTO 1-PYTHON } \\
\text { Exercicio que estava sendo resolvido: } \\
\text { Exercicio } 11 \text {. }\end{array}$} \\
\hline & Erro & Erro Resolvido \\
\hline - $\cdots$ in & 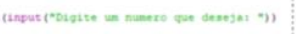 & 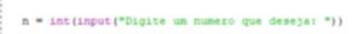 \\
\hline $\begin{array}{l}\text { Ocorre } \\
\text { Observ } \\
\text { atribuir }\end{array}$ & $\begin{array}{l}\text { na submissãa: } 3 \\
\text { açä:: Usou "=" ao invés de "=" para } \\
\text { falor da lettura a variável. }\end{array}$ & $\begin{array}{l}\text { Corrigido na submissão: } 5 \\
\text { Observaçấ: }\end{array}$ \\
\hline
\end{tabular}

A15.1 Você já viu esse antipadrão em código desenvolvido por algum aluno? *
$\bigcirc \operatorname{sim}$
ก Não
Eu não tenho certeza se vi

A15.2 Você acredita que $o$ aluno pode resolver $o$ antipadrão acima: *
facilmente
com dificuldade moderada
com grande dificuldade

A15.3 Qual(is) estratégia(s) você considera mais apropriada(s) para tratar esse antipadrão nas aulas com seus alunos? *
Estratégia 1 - Explicação usando quadro negro e projector - reforço dos conceitos usando Kahoot
Estratégia 2 - Grupos trabalhando com execuçăo passa a passo para entender os erros - reforço com exercicios
Estratégia 3 - Programar na frente dos alunos, fazendo o erro aparecer - reforço pedindo que os alunos desenvolvam novos códigos
Estratégia 4 - Aplicar teste de mesa em um Código com o erro e outro sem comparar os resultados - reforço pedindo que os alunos resolvam alguns
exercicios
$\square$ Other:

A15.4 Se você tiver algo para acrescentar sobre esse antipadrão, estratégia, etc., use o espaço abaixo:

Your answer

BACK

NEXT 


\section{Antipadrões no Aprendizado de Programação}

* Required

\section{Terceiro bloco de questões: Avaliação}

A seguir são apresentadas questões para que os catálogos de antipadrōes no aprendizado de programação sejam avaliados quanto sua utilidade, facilidade de uso e intenção de uso:

\section{E1. Em relação à Utilidade}

E1.1) Estar ciente dos antipadrões no aprendizado de programação melhoraria meu desempenho na prevenção desses equívocos no desenvolvimento do código na sala de aula. (ou seja, impedindo mais rapidamente que ocorra) *

$\begin{array}{lllll}1 & 2 & 3 & 4 & 5\end{array}$

Discordo fortemente $\bigcirc \bigcirc \bigcirc \bigcirc \bigcirc$ concordo fortemente

E1.2) Estar ciente dos antipadrões no aprendizado de programação melhoraria minha produtividade na prevenção desses equívocos no desenvolvimento do código da sala de aula. (ou seja, impedindo mais e mais rapidamente que ocorra) *

$$
\begin{array}{llllllll} 
& 1 & 2 & 3 & 4 & 5 & \\
\text { Discordo fortemente } & \bigcirc & \bigcirc & \bigcirc & \bigcirc & \bigcirc & \text { concordo fortemente }
\end{array}
$$

E1.3) Estar ciente dos antipadrões no aprendizado de programação aumentaria minha eficácia na prevenção desses erros no desenvolvimento do código da sala de aula. (ou seja, impedindo mais) *

$$
\begin{array}{lllll}
1 & 2 & 3 & 4 & 5
\end{array}
$$

Discordo fortemente $\bigcirc \bigcirc \bigcirc \bigcirc$ concordo fortemente

E1.4) Eu consideraria os catálogos proposto de antipadrões no aprendizado de programação (em C, Python e ambas linguagens) útil em meu trabalho como professor/pesquisador.

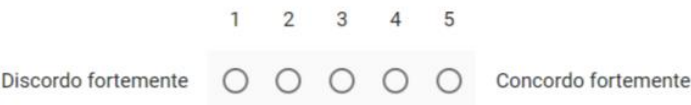

\section{E2. Em relação à Facilidade de Uso}

E2.1) Eu acharia fácil aprender a usar os catálogos propostos de antipadrões no aprendizado de programação. *

$$
\begin{array}{lllll}
1 & 2 & 3 & 4 & 5
\end{array}
$$

Discordo fortemente $\mathrm{O} O \mathrm{O}$ concordo fortemente

E2.2) Eu acharia fácil usar os catálogos propostos de antipadrões no aprendizado de programação para impedir que os alunos cometessem esses equívocos no desenvolvimento de códigos. *

\section{Discordo fortemente $\bigcirc \bigcirc \bigcirc \bigcirc \bigcirc$ concordo fortemente}

E2.3) Eu acharia fácil tomar conhecimento dos catálogos propostos de antipadrões no aprendizado de programação. *

$$
\begin{array}{llllllll} 
& 1 & 2 & 3 & 4 & 5 & \\
\text { Discordo fortemente } & \bigcirc & \bigcirc & \bigcirc & \bigcirc & \bigcirc & \text { concordo fortemente }
\end{array}
$$

E2.4) Eu acharia fácil aplicar os catálogos propostos de antipadrões no aprendizado de programação. *

$\begin{array}{lllll}1 & 2 & 3 & 4 & 5\end{array}$

Discordo fortemente $\bigcirc \bigcirc \bigcirc \bigcirc \bigcirc$ concordo fortemente

\section{E3. Em relação à Intenção de Uso}

E3.1) Pretendo usar regularmente no meu trabalho como professor/pesquisador os catálogos propostos de antipadrões no aprendizado de programação. *

$$
\begin{array}{llllllll} 
& 1 & 2 & 3 & 4 & 5 & \\
\text { Discordo fortemente } & \bigcirc & \bigcirc & \bigcirc & \bigcirc & \bigcirc & \text { concordo fortemente }
\end{array}
$$

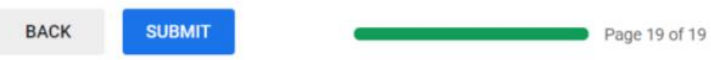




\section{Referências}

[AвIDI et al. 2019] Mouna ABId, Foutse Кномн e Yann-Gaël GuÉHÉneuc. "Antipatterns for multi-language systems”. Em: Proceedings of the 24th European Conference on Pattern Languages of Programs. 2019, pgs. 1-14 (citado na pg. 16).

[Alexander et al. 1977] Christopher Alexander et al. A pattern language. 1977 (citado na pg. 15).

[Alonso et al. 2010] Fernando Alonso, Genoveva Lopez, José María Font e Daniel MANRIQUE. "Learner satisfaction when applying an instructional model in elearning”. Em: Proceedings of the 2nd International Conference on Computer Supported Education (CSEDU), Spain. 2010 (citado na pg. 25).

[Beaubouef e Mason 2005] Theresa Beaubouef e John Mason. "Why the high attrition rate for Computer Science students: Some thoughts and observations". Em: ACM SIGCSE Bulletin 37.2 (2005), pgs. 103-106 (citado na pg. 1).

[BECKER 2019] Brett A BECKER. "A survey of introductory programming courses in Ireland". Em: Proceedings of the 2019 ACM Conference on Innovation and Technology in Computer Science Education. 2019, pgs. 58-64 (citado nas pgs. 2, 14, 18, 21).

[Becker e Quille 2019] Brett A Becker e Keith Quille. "50 years of CS1 at SIGCSE: A review of the evolution of introductory programming Education Research". Em: Proceedings of the 50th acm technical symposium on computer science education. ACM. 2019, pgs. 338-344 (citado na pg. 18).

[Bennedsen e Caspersen 2007] Jens Bennedsen e Michael E Caspersen. "Failure rates in introductory programming”. Em: ACM SIGCSE Bulletin 39.2 (2007), pgs. 3236 (citado nas pgs. $4,14,16,25,30,41$ ).

[Bennedsen e Caspersen 2019] Jens Bennedsen e Michael E Caspersen. "Failure rates in introductory programming: 12 years later”. Em: ACM Inroads 10.2 (2019), pgs. 30-36 (citado nas pgs. 1, 16).

[Bergström e Blackwell 2016] Ilias Bergström e Alan F Blackwell. "The practices of programming". Em: 2016 IEEE Symposium on Visual Languages and HumanCentric Computing (VL/HCC). IEEE. 2016, pgs. 190-198 (citado na pg. 13). 
[Bogdanchikov et al. 2013] A Bogdanchikov, M Zhaparov e R Suliyev. "Python to learn programming”. Em: Journal of Physics: Conference Series. Vol. 423. 1. IOP Publishing. 2013, pg. 012027 (citado na pg. 21).

[Bolger et al. 2003] Niall Bolger, Angelina Davis e Eshkol RAFAeli. "Diary methods: Capturing life as it is lived”. Em: Annual review of psychology 54.1 (2003), pgs. 579616 (citado na pg. 5).

[Bosse e Gerosa 2015a] Yorah Bosse e Marco Aurelio Gerosa. "As disciplinas de introdução à programação na USP: um estudo preliminar”. Em: WAlgProg '15 Workshop de Ensino em Pensamento Computacional, Algoritmos e Programação Em: Anais dos Workshops do IV Congresso Brasileiro de Informática na Educação CBIE) (out. de 2015), pgs. 1389-1397. DOI: 10.5753/cbie.wcbie.2015.1389 (citado na pg. 29).

[Bosse e Gerosa 2015b] Yorah Bosse e Marco Aurelio Gerosa. "Reprovações e trancamentos nas disciplinas de introdução à programação da Universidade de São Paulo: Um estudo preliminar”. Em: XXIII WEI - Workshop sobre Educação em Computação - Em: Anais do XXXV Congresso da Sociedade Brasileira de Computação (jul. de 2015), pgs. 1-10 (citado na pg. 29).

[Bosse e Gerosa 2017] Yorah Bosse e Marco Aurelio Gerosa. "Difficulties of programming learning from the point of view of students and instructors". Em: IEEE Latin America Transactions 15.11 (2017), pgs. 2191-2199 (citado na pg. 43).

[Bosse, Redmiles et al. 2019a] Yorah Bosse, David Redmiles e Marco A Gerosa. "Connections and influences among topics of learning how to program". Em: 2019 IEEE Frontiers in Education Conference (FIE). IEEE. 2019, pgs. 1-8 (citado nas pgs. 44, 82).

[Bosse, Redmiles et al. 2019b] Yorah Bosse, David Redmiles e Marco A Gerosa. "Pedagogical content for professors of introductory programming courses”. Em: (2019) (citado nas pgs. 43, 82).

[Bradbury e Jalbert 2009] Jeremy S Bradbury e Kevin Jalbert. "Defining a catalog of programming anti-patterns for concurrent Java". Em: Proc. of the 3rd International Workshop on Software Patterns and Quality (SPAQu'09). Citeseer. 2009, pgs. 6-11 (citado na pg. 16).

[N. C. Brown e Altadmri 2014] Neil CC Brown e Amjad Altadmri. "Investigating novice programming mistakes: educator beliefs vs. student data". Em: Proceedings of the tenth annual conference on International computing education research. ACM. 2014, pgs. 43-50 (citado nas pgs. 1, 4, 18, 21, 92).

[W. H. Brown et al. 1998] William H Brown, Raphael C Malveau, Hays W McCorMICK e Thomas J Mowbray. AntiPatterns: refactoring software, architectures, and projects in crisis. John Wiley \& Sons, Inc., 1998 (citado nas pgs. 2, 6, 7, 15, 16, 28, $72,90,100)$. 
REFERÊNCIAS

[Byckling e SajAniemi 2006] Pauli Byckling e Jorma Sajaniemi. "Roles of variables and programming skills improvement”. Em: ACM SIGCSE Bulletin 38.1 (2006), pgs. 413-417 (citado na pg. 14).

[CAceffo, França et al. 2017] Ricardo Caceffo, Breno de França et al. "An Antipattern documentation about misconceptions related to an introductory programming course in C". Em: Technical Report 17-15. Institute of Computing, University of Campinas, 2017, pg. 42 (citado nas pgs. 19, 100).

[Caceffo, Frank-Bolton et al. 2019a] Ricardo Caceffo, Pablo Frank-Bolton, Renan Souza e Rodolfo Azevedo. "Identifying and validating Java misconceptions toward a CS1 concept inventory". Em: Proceedings of the 2019 ACM Conference on Innovation and Technology in Computer Science Education. 2019, pgs. 23-29 (citado na pg. 19).

[Caceffo, Frank-Bolton et al. 2019b] Ricardo Caceffo, Pablo Frank-Bolton, Renan Souza e Rodolfo Azevedo. Identifying and validating fava misconceptionscomplementary material. Rel. técn. Technical Report IC-19-05. Institute of Computing, University of Campinas ..., 2019 (citado na pg. 19).

[CAceffo, G. Gama et al. 2018] Ricardo Caceffo, Guilherme Gama et al. A concept inventory for CS1 introductory programming courses in C. Rel. técn. Tech. rep., University of Campinas, SP, Brasil, 2018 (citado na pg. 93).

[Caceffo, Wolfman et al. 2016] Ricardo Caceffo, Steve Wolfman, Kellogg S Booth e Rodolfo AzEvedo. "Developing a Computer Science concept inventory for introductory programming". Em: Proceedings of the 47th ACM Technical Symposium on Computing Science Education. ACM. 2016, pgs. 364-369 (citado nas pgs. 1, 4, 18, 19).

[Cooper et al. 2003] Stephen Cooper, Wanda Dann, Randy Pausch e Randy Pausch. "Teaching objects-first in introductory Computer Science". Em: ACM SIGCSE Bulletin 35.1 (2003), pgs. 191-195 (citado na pg. 1).

[J. M. Corbin e Strauss 1990] Juliet M Corbin e Anselm Strauss. "Grounded theory research: Procedures, canons, and evaluative criteria”. Em: Qualitative sociology 13.1 (1990), pgs. 3-21 (citado na pg. 46).

[J. Corbin e Strauss 2014] Juliet Corbin e Anselm Strauss. Basics of qualitative research: Techniques and procedures for developing grounded theory. Sage publications, 2014 (citado nas pgs. 5, 46).

[Council et al. 2000] National Research Council et al. How people learn: Brain, mind, experience, and school: Expanded edition. National Academies Press, 2000 (citado nas pgs. 9, 92). 
[J. W. Creswell e J. D. Creswell 2017] John W Creswell e J David Creswell. Research design: Qualitative, quantitative, and mixed methods approaches. Sage publications, 2017 (citado nas pgs. 5, 6, 31, 44).

[D’Souza et al. 2019] Rachel D’Souza, Mahima Bhayana, Marzieh Ahmadzadeh e Brian HARRINGTON. "A Mixed-methods study of novice programmer interaction with Python error messages". Em: Proceedings of the Western Canadian Conference on Computing Education. ACM. 2019, pg. 15 (citado na pg. 20).

[DAvis 1989] Fred D Davis. "Perceived usefulness, perceived ease of use, and user acceptance of information technology". Em: MIS quarterly (1989), pgs. 319-340 (citado na pg. 82).

[Deek et al. 1998] FadiP Deek, Howard Kimmel e James A McHugh. "Pedagogical changes in the delivery of the first-course in computer science: Problem solving, then programming”. Em: Journal of Engineering Education 87.3 (1998), pgs. 313-320 (citado na pg. 27).

[P. Deitel e H. Deitel 2016] Paul Deitel e Harvey Deitel. C - How to program, Global edition. Pearson Education UK, 2016 (citado na pg. 14).

[Dellos 2015] Ryan Dellos. "Kahoot! A digital game resource for learning”. Em: International Journal of Instructional technology and distance learning 12.4 (2015), pgs. 49-52 (citado na pg. 10).

[Denny et al. 2011] Paul Denny, Andrew Luxton-Reilly, Ewan Tempero e Jacob HenDRICKX. "Understanding the syntax barrier for novices". Em: Proceedings of the 16th annual joint conference on Innovation and technology in computer science education. 2011, pgs. 208-212 (citado na pg. 107).

[DijKstra et al. 1989] Edsger W Dijkstra et al. "On the cruelty of really teaching Computing Science”. Em: Communications of the ACM 32.12 (1989), pgs. 13981404 (citado na pg. 17).

[Drosos et al. 2017] Ian Drosos, Philip J Guo e Chris Parnin. "HappyFace: Identifying and predicting frustrating obstacles for learning programming at scale”. Em: 2017 IEEE Symposium on Visual Languages and Human-Centric Computing (VL/HCC). IEEE. 2017, pgs. 171-179 (citado na pg. 13).

[Elenbogen et al. 2000] Bruce S Elenbogen, Bruce R Maxim e Chris McDonald. "Yet, more WEB exercises for learning C++". Em: Proceedings of the thirty-first SIGCSE technical symposium on Computer science education. 2000, pgs. 290-294 (citado na pg. 27).

[Ellström 2001] Per-Erik Ellström. "Integrating learning and work: Problems and prospects”. Em: Human resource development quarterly 12.4 (2001), pgs. 421-435 (citado na pg. 101). 
REFERÊNCIAS

[Fischer e Giaccardi 2006] Gerhard Fischer e Elisa Giaccardi. "Meta-design: A framework for the future of end-user development". Em: End user development. Springer, 2006, pgs. 427-457 (citado na pg. 13).

[Fisher e Keil 2016] Matthew Fisher e Frank C KeIl. "The curse of expertise: When more knowledge leads to miscalibrated explanatory insight”. Em: Cognitive science 40.5 (2016), pgs. 1251-1269 (citado na pg. 92).

[G. A. R. Gama et al. 2018] Guilherme Augusto Ramos Gama et al. "Why do students make mistakes? an antipattern documentation about misconceptions related to CS1 introductory programming courses in Python”. Em: Revista dos Trabalhos de Iniciação Científica da UNICAMP 26 (2018) (citado nas pgs. 19, 100).

[GARner et al. 2005] Sandy Garner, Patricia HAden e Anthony Robins. "My program is correct but it doesn't run: a preliminary investigation of novice programmers' problems". Em: Proceedings of the 7th Australasian conference on Computing education-Volume 42. Australian Computer Society, Inc. 2005, pgs. 173-180 (citado nas pgs. $4,13,16-18,24,25,66)$.

[Giraffa e Mora 2013] Maria Martins Giraffa e Michael da costa Mora. "Evasão na disciplina de algoritmo e programação: um estudo a partir dos fatores intervenientes na perspectiva do aluno”. Em: Congresos CLABES. 2013 (citado nas pgs. 17, $24,25,66,95)$.

[A. Gomes e A. Mendes 2014] Anabela Gomes e Antonio Mendes. "A teacher's view about introductory programming teaching and learning: Difficulties, strategies and motivations”. Em: 2014 IEEE Frontiers in Education Conference (FIE) Proceedings. IEEE. 2014, pgs. 1-8. DOI: 10.1109/FIE.2014.7044086 (citado nas pgs. 1, 4, 16-18, $24-26,66,102)$.

[A. Gomes e A. J. Mendes 2007] Anabela Gomes e António José Mendes. "Learning to program-difficulties and solutions”. Em: International Conference on Engineering Education-ICEE. Vol. 2007. 2007 (citado nas pgs. 4, 18, 20, 24-27, 92).

[M. Gomes et al. 2015] Marina Gomes, Liliane Becker, Lucas Gestaro, Erico Amaral e Liane Margarida Rockenbach TAROUCO. "Um estudo sobre erros em programaçãoReconhecendo as dificuldades de programadores iniciantes." Em: Anais dos Workshops do Congresso Brasileiro de Informática na Educação. Vol. 4. 1. 2015, pg. 1398 (citado nas pgs. 1, 17, 19-21, 99).

[HAmer et al. 2008] John Hamer et al. "Contributing student pedagogy". Em: ACM SIGCSE Bulletin 40.4 (2008), pgs. 194-212 (citado na pg. 26).

[HANushek 1999] Eric A Hanushek. "Some findings from an independent investigation of the Tennessee STAR experiment and from other investigations of class size effects". Em: Educational Evaluation and Policy Analysis 21.2 (1999), pgs. 143-163 (citado na pg. 65). 
[Harteis et al. 2008] Christian Harteis, Johannes Bauer e Hans Gruber. "The culture of learning from mistakes: How employees handle mistakes in everyday work". Em: International fournal of Educational Research 47.4 (2008), pgs. 223-231 (citado na pg. 101).

[HARVEY et al. 2002] M DEITEL HARVEY, PAUL J DEITEL, BEN WIEDERMANN e P LIPERI JONATHAN. Python - How to Program. 2002 (citado na pg. 14).

[Helminen e Malmi 2010] Juha Helminen e Lauri Malmi. "Jype-a program visualization and programming exercise tool for Python”. Em: Proceedings of the 5th international symposium on Software visualization. ACM. 2010, pgs. 153-162 (citado na pg. 1).

[Hertz 2010] Matthew Hertz. "What do CS1 and CS2 mean?: investigating differences in the early courses". Em: Proceedings of the 41st ACM technical symposium on Computer science education. ACM. 2010, pgs. 199-203 (citado nas pgs. 7, 14).

[Hristova et al. 2003] Maria Hristova, Ananya Misra, Megan Rutter e Rebecca MERCURI. "Identifying and correcting Java programming errors for introductory computer science students”. Em: ACM SIGCSE Bulletin 35.1 (2003), pgs. 153-156 (citado nas pgs. 1, 4, 18, 47).

[Ichinco et al. 2014] Michelle Ichinco, Yoanna Dosouto e Caitlin Kelleher. "A tool for authoring programs that automatically distribute feedback to novice programmers”. Em: 2014 IEEE Symposium on Visual Languages and Human-Centric Computing (VL/HCC). IEEE. 2014, pgs. 207-208 (citado na pg. 13).

[Izu e Dinh 2018] Cruz Izu e Peter Dinh. "Can novice programmers write C functions?" Em: 2018 IEEE International Conference on Teaching, Assessment, and Learning for Engineering (TALE). IEEE. 2018, pgs. 965-970 (citado nas pgs. 20, 99).

[JEnkins 2002] Tony Jenkins. "On the difficulty of learning to program". Em: Proceedings of the 3rd Annual Conference of the LTSN Centre for Information and Computer Sciences. Vol. 4. 2002. Citeseer. 2002, pgs. 53-58 (citado nas pgs. 4, 13, 16-18, $24,26)$.

[Jiménez e Villalobos 2010] Camilo Jiménez e Jorge Villalobos. "Learning/teaching a computer programming course". Em: Analysis of State-ofthe-Art Solutions for Personalised Learning Support (2010), pg. 3 (citado na pg. 25).

[Koscianski e Bini 2009] A Koscianski e E Bini. "Tackling barriers in the learning of computer programming”. Em: 9th IFIP World Conference on Computers in Education. 2009 (citado na pg. 1).

[Kristi 2003] AM Kristi. "Problems in learning and teaching programming-a literature study for developing visualizations in the Codewitz-Minerva Project". Em: Codewitz Need Analysis, Institute of Software System, Tampere University of Technology, Finland (2003), pgs. 1-12 (citado nas pgs. 4, 13, 16, 18, 24). 
REFERÊNCIAS

[Kuittinen e Sajaniemi 2004] Marja Kuittinen e Jorma Sajaniemi. "Teaching roles of variables in elementary programming courses". Em: Proceedings of the 9th annual SIGCSE conference on Innovation and technology in computer science education. 2004, pgs. 57-61 (citado na pg. 14).

[Lahtinen et al. 2005] Essi Lahtinen, Kirsti Ala-Mutka e Hannu-Matti Järvinen. "A study of the difficulties of novice programmers". Em: ACM SIGCSE Bulletin 37.3 (2005), pgs. 14-18 (citado nas pgs. 17, 26).

[Lang et al. 2006] Jeff Lang, Gwen C Nugent, Ashok Samal e L-K Soh. "Implementing CS1 with embedded instructional research design in laboratories”. Em: IEEE Transactions on Education 49.1 (2006), pgs. 157-165 (citado na pg. 26).

[LEE 2014] Michael J LeE. "Gidget: An online debugging game for learning and engagement in computing education". Em: 2014 IEEE Symposium on Visual Languages and Human-Centric Computing (VL/HCC). IEEE. 2014, pgs. 193-194 (citado na pg. 13).

[Licorish et al. 2018] Sherlock A Licorish, Helen E Owen, Ben Daniel e Jade Li GeORGE. "Students' perception of Kahoot!'s influence on teaching and learning". Em: Research and Practice in Technology Enhanced Learning 13.1 (2018), pg. 9 (citado na pg. 10).

[Lindstrom 2005] Greg Lindstrom. "Programming with Python". Em: IT professional 5 (2005), pgs. 10-16 (citado na pg. 21).

[Lister et al. 2006] Raymond Lister et al. "Research perspectives on the objects-early debate”. Em: ACM SIGCSE Bulletin 38.4 (2006), pgs. 146-165 (citado na pg. 27).

[Mannila et al. 2006] Linda Mannila, Mia Peltomäki e Tapio Salakoski. "What about a simple language? Analyzing the difficulties in learning to program". Em: Computer Science Education 16.3 (2006), pgs. 211-227 (citado na pg. 21).

[MAnolescu et al. 2006] Dragos-Anton Manolescu, Markus Voelter e James Noble. Pattern languages of program design 5. Vol. 5. Addison-Wesley Professional, 2006 (citado na pg. 15).

[Meerbaum-Salant et al. 2013] Orni Meerbaum-Salant, Michal Armoni e Mordechai Ben-ArI. "Learning Computer Science concepts with Scratch". Em: Computer Science Education 23.3 (2013), pgs. 239-264 (citado na pg. 1).

[Menezes e Nobre 2002] CS De Menezes e Isaura Alcina Martins Nobre. "Um ambiente cooperativo para apoio a cursos de introdução a programação”. Em: Congresso da Sociedade Brasileira de Computação. Vol. 22. 2002 (citado nas pgs. 1, 4, 25).

[Mhashi e Alakeel 2013] Mahmoud M Mhashi e Alim Alakeel. "Difficulties facing students in learning computer programming skills at Tabuk University". Em: Proceedings of the 12th International Conference on Education and Educational Te- 
chnology (EDU'13), Iwate, Japan. 2013, pgs. 15-24 (citado nas pgs. 1, 4, 16-18, 20, 24-27, 49, 51, 66, 99, 102).

[Milne e Rowe 2002] Iain Milne e Glenn Rowe. "Difficulties in learning and teaching programming-views of students and tutors". Em: Education and Information technologies 7.1 (2002), pgs. 55-66. DOI: 10.1023/A:1015362608943. URL: www. springerlink.com/index/h1u587b0r3e9eja3.pdf (citado nas pgs. 13, 17, 24, 66).

[Minayo 2006] MCS Minayo. "Técnicas de pesquisa: entrevista como técnica privilegiada de comunicação”. Em: MCS Minayo. O desafio do conhecimento: pesquisa qualitativa em saúde (2006), pgs. 261-297 (citado na pg. 5).

[Oliveira Brandẽo et al. 2012] Leônidas de Oliveira Brandẽo, Romenig da Silva Ribeiro e Anarosa AF Brandẽo. "A system to help teaching and learning algorithms”. Em: 2012 Frontiers in Education Conference Proceedings. IEEE. 2012, pgs. 1-6 (citado na pg. 24).

[Paul e Harvey 2012] Deitel Paul e Deitel Harvey. Java - How to program. 2012 (citado na pg. 14).

[Pears et al. 2007] Arnold Pears et al. "A survey of literature on the teaching of introductory programming”. Em: ACM SIGCSE Bulletin. Vol. 39. 4. ACM. 2007, pgs. 204223 (citado na pg. 1).

[Piteira e C. Costa 2013] Martinha Piteira e Carlos Costa. "Learning computer programming: Study of difficulties in learning programming”. Em: Proceedings of the 2013 International Conference on Information Systems and Design of Communication. ACM. 2013, pgs. 75-80 (citado nas pgs. 1, 17, 20, 21, 49).

[Piwek e Savage 2020] Paul Piwek e Simon Savage. "Challenges with learning to program and problem solve: An analysis of student online discussions”. Em: (2020) (citado na pg. 21).

[QIan e Lehman 2017] Yizhou Qian e James Lehman. "Students' misconceptions and other difficulties in introductory programming: A literature review”. Em: $A C M$ Transactions on Computing Education (TOCE) 18.1 (2017), pgs. 1-24 (citado na pg. 17).

[RAdenski 2006] Atanas Radenski. "Python first: A lab-based digital introduction to Computer Science”. Em: ACM SIGCSE Bulletin. Vol. 38. 3. ACM. 2006, pgs. 197-201 (citado na pg. 1).

[Rauber et al. 2003] J Rauber, M Rosseto, AM FÁvero, AA FÁvero e C Tonieto. "Que tal um pouco de lógica”. Em: Porto Alegre: Clio (2003) (citado na pg. 63).

[REIS 1994] Harry T REIs. "Domains of experience: Investigating relationship processes from three perspectives". Em: Theoretical frameworks for personal relationships (1994), pgs. 87-110 (citado na pg. 5). 
REFERÊNCIAS

[Renzi et al. 2012] AB Renzi, S Freitas, I Kuhn e S Köhler. "Use of Think-Aloud Protocol to verify usability problems and flow during use of entertainment and personal journal". Em: 12o Congresso Internacional de Ergonomia e Usabilidade de Interfaces Humano-Computador. 2012, pg. 7 (citado nas pgs. 103, 104).

[RISING 1998] Linda Rising. The patterns handbook: Techniques, strategies, and applications. Vol. 13. Cambridge University Press, 1998 (citado na pg. 15).

[Robins 2010] Anthony Robins. "Learning Edge Momentum: A new account of outcomes in CS1". Em: Computer Science Education 20.1 (2010), pgs. 37-71 (citado nas pgs. $1,25,52,59,95,100,101)$.

[Robins et al. 2003] Anthony Robins, Janet Rountree e Nathan Rountree. "Learning and teaching programming: A review and discussion”. Em: Computer science education 13.2 (2003), pgs. 137-172 (citado nas pgs. 1, 6, 16, 28).

[Rodríguez-del-Pino et al. 2012] Juan Carlos Rodríguez-Del-Pino, Enrique Rubio Royo e Zenón Hernández Figueroa. "A Virtual Programming Lab for Moodle with automatic assessment and anti-plagiarism features". Em: (2012) (citado nas pgs. 6,68$)$.

[Rufinus e Kortsarts 2006] Jeff Rufinus e Yana Kortsarts. "Teaching an introductory programming course for non-majors using Python”. Em: Director (2006), pg. 07 (citado na pg. 21).

[SAdler et al. 2013] Philip M SAdler, Gerhard Sonnert, Harold P Coyle, Nancy CookSMith e Jaimie L Miller. "The influence of teachers' knowledge on student learning in middle school physical science classrooms". Em: American Educational Research fournal 50.5 (2013), pgs. 1020-1049 (citado na pg. 18).

[Santos e H. A. X. Costa 2006] Rodrigo Pereira dos Santos e Heitor Augustus Xavier Costa. "Análise de metodologias e ambientes de ensino para algoritmos, estruturas de dados e programação aos iniciantes em computação e informática”. Em: INFOCOMP 5.1 (2006), pgs. 41-50 (citado na pg. 30).

[Sevella et al. 2013] Pranay Kumar Sevella, Young Lee e Jeong Yang. "Determining the barriers faced by novice programmers". Tese de dout. Texas A \& M UniversityKingsville, 2013 (citado nas pgs. 1, 2, 18, 20, 21, 49, 66, 99).

[Softex 2009] Observatório Softex. "Software e serviços de TI: a indústria brasileira em perspectiva”. Em: Campinas:[sn] (2009) (citado na pg. 1).

[Soloway e Spohrer 2013] Elliot Soloway e James C Spohrer. Studying the novice programmer. Psychology Press, 2013 (citado na pg. 25).

[Souza et al. 2018] Renan Souza, Ricardo Caceffo, Pablo Frank-Bolton e Rodolfo Azevedo. An antipattern documentation about possible misconceptions related to introductory programming courses (CS1) in JAVA. Rel. técn. Technical Report IC- 
18-20. Institute of Computing, University of Campinas ..., 2018 (citado nas pgs. 1, $19,100)$.

[Streumer e Kho 2006] JN Streumer e M Kho. "The world of work-related learning". Em: Work-related learning. Springer, 2006, pgs. 3-49 (citado na pg. 101).

[TAN et al. 2009] Phit-Huan TAN, Choo-Yee Ting e Siew-Woei Ling. "Learning difficulties in programming courses: undergraduates' perspective and perception”. Em: 2009 International Conference on Computer Technology and Development. Vol. 1. IEEE. 2009, pgs. 42-46 (citado nas pgs. 18, 20).

[VAn Gorp e Grissom 2001] Mark J VAN Gorp e Scott Grissom. “An empirical evaluation of using constructive classroom activities to teach introductory programming". Em: Computer Science Education 11.3 (2001), pgs. 247-260 (citado na pg. 25).

[Wainer e Xavier 2018] Jacques Wainer e Eduardo C Xavier. “A controlled experiment on Python vs C for an introductory programming course: Students' outcomes”. Em: ACM Transactions on Computing Education (TOCE) 18.3 (2018), pg. 12 (citado na pg. 21).

[Watson e Li 2014] Christopher Watson e Frederick WB Li. "Failure rates in introductory programming revisited". Em: Proceedings of the 2014 conference on Innovation \& technology in computer science education. ACM. 2014, pgs. 39-44 (citado na pg. 1).

[Webber e Possamai 2009] Carine G Webber e Rodrigo Possamai. “An immune-based approach to evaluate programming learning”. Em: 9th IFIP World Conference on Computers in Education. 2009 (citado na pg. 1).

[Weintrop 2015] David Weintrop. "Blocks, text, and the space between: The role of representations in novice programming environments". Em: 2015 IEEE Symposium on Visual Languages and Human-Centric Computing (VL/HCC). IEEE. 2015, pgs. 301-302 (citado na pg. 13).

[Wentworth et al. 2015] Peter Wentworth, Jeffrey Elkner, Allen B Downey e Chris Meyer. "How to think like a computer scientist: Learning with Python 3". Em: (2015) (citado na pg. 21).

[WheEler e Reis 1991] Ladd WheELER e Harry T Reis. "Self-recording of everyday life events: Origins, types, and uses”. Em: Fournal of personality 59.3 (1991), pgs. 339354 (citado na pg. 5).

[WINg 2006] Jeannette M Wing. "Computational thinking". Em: Communications of the ACM 49.3 (2006), pgs. 33-35 (citado na pg. 25). 